
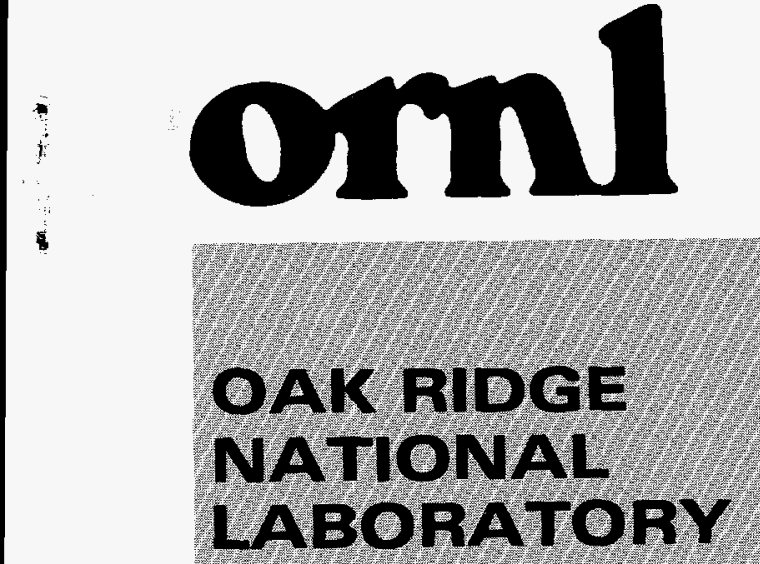

MARTIN MARUETRA
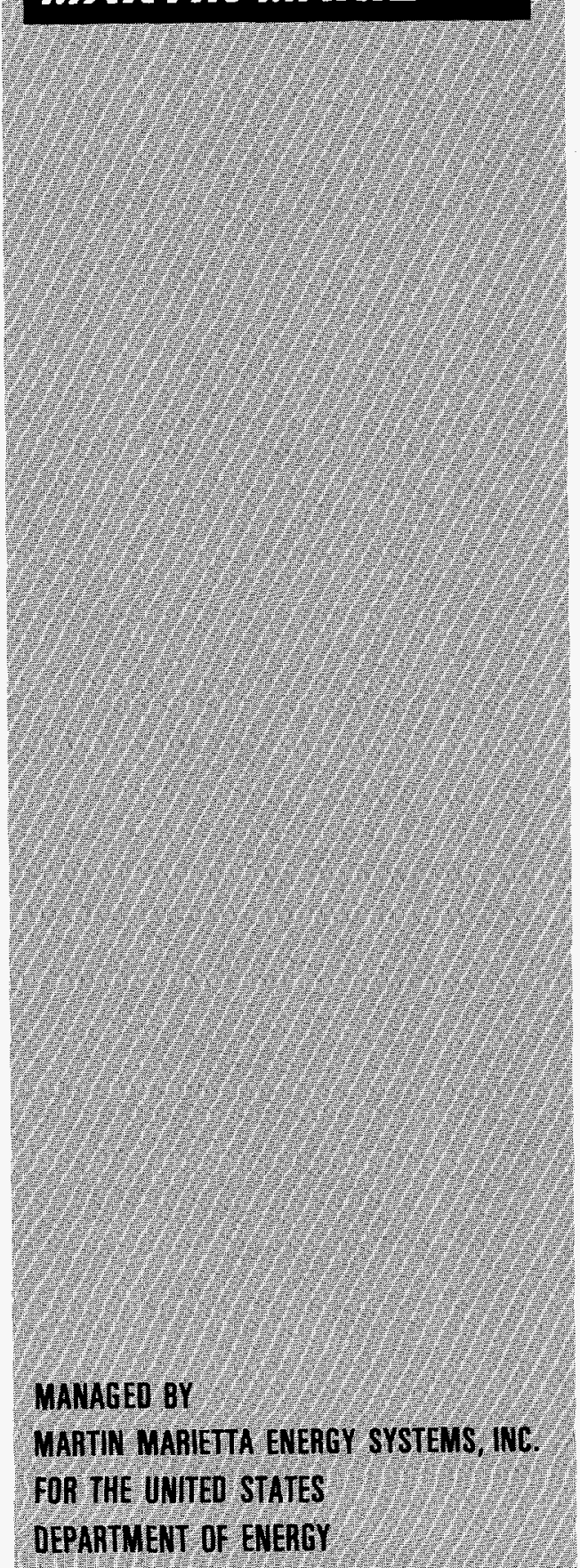

MANAGED BY

MARTIN MARIETTA ENERGY SYSTEMS, INC.

FOR THE UNITED STATES

DEPARTMENT OF ENERGY
AF FIVIED

ORNL/TM-11210
OCT 161995

OSTI

DISPOSAL OF CHEMICAL AGENTS AND MUNITIONS STORED AT PUEBLO DEPOT ACTIVITY, COLORADO

FINAL PHASE I ENVIRONMENTAL REPORT
J. W. Terry

T. J. Blasing

J. T. Ensminger

R. O. Johnson

S. M. Schexnayder
J. T. Shor

W. P. Staub

V. R. Tolbert

G. P. Zimmerman 
This report has been reproduced directly from the best available copy.

Available to DOE and DOE contractors from the Office of Scientific and Technical Information, P.O. Box 62, Oak Ridge, TN 37831; prices available from (615) 576-8401, FTS 626-8401.

Available to the public from the National Technical Information Service, U.S. Department of Commerce, 5285 Port Royal Rd., Springfield, VA 22161.

This report was prepared as an account of work sponsored by an agency of the United States Government. Neither the United States Government nor any agency thereof, nor any of their employees, makes any warranty, express or implied, or assumes any legal liability or responsibility for the accuracy, completeness, or usefulness of any information, apparatus, product, or process disclosed. or represents that its use would not infringe privately owned rights. Reference herein to any specific commercial product, process, or service by trade name, trademark, manufacturer, or otherwise, does not necessarily constitute or imply its endorsement, recommendation, or favoring by the United States Government or any agency thereof. The views and opinions of authors expressed herein do not necessarily state or reflect those of the United States Government or any agency thereof. 


\section{DISCLAIMER}

Portions of this document may be illegible in electronic image products. Images are produced from the best available original document. 


\section{DISPOSAL OF CHEMICAL AGENTS AND MUNITIONS STORED AT PUEBLO DEPOT ACTIVITY, COLORADO}

FINAL PHASE I ENVIRONMENTAL REPORT
J. W. Terry
J. T. Shor
T. J. Blasing
W. P. Staub
J. T. Ensminger
V. R. Tolbert
R. O. Johnson
G. P. Zimmerman
S. M. Schexnayder

Date Published: April 1995

Research supported by

Program Manager for Chemical Demilitarization Aberdeen Proving Ground, Maryland 31010-5401

Prepared by

OAK RIDGE NATIONAL LABORATORY

Oak Ridge, Tennessee 37831

Managed by

MARTIN MARIETTA ENERGY SYSTEMS, INC.

for the

U.S. DEPARTMENT OF ENERGY

under Contract No. DE-AC05-84OR21400 
TABLE OF CONTENTS

Page

LIST OF FIGURES $\ldots \ldots \ldots \ldots \ldots \ldots \ldots \ldots \ldots \ldots \ldots \ldots \ldots \ldots \ldots$

LIST OF TABLES $\ldots \ldots \ldots \ldots \ldots \ldots \ldots \ldots \ldots \ldots \ldots \ldots \ldots \ldots \ldots \ldots \ldots$

ABBREVIATIONS AND ACRONYMS $\ldots \ldots \ldots \ldots \ldots \ldots \ldots \ldots \ldots$

FOREWORD $\ldots \ldots \ldots \ldots \ldots \ldots \ldots \ldots \ldots \ldots \ldots \ldots \ldots \ldots \ldots \ldots \ldots$

PREFACE $\ldots \ldots \ldots \ldots \ldots \ldots \ldots \ldots \ldots \ldots \ldots \ldots \ldots \ldots \ldots \ldots \ldots \ldots$

EXECUTIVE SUMMARY $\ldots \ldots \ldots \ldots \ldots \ldots \ldots \ldots \ldots \ldots \ldots \ldots \ldots$

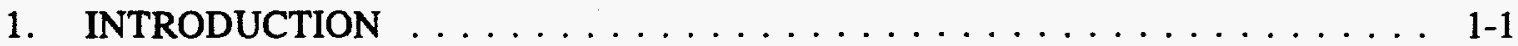

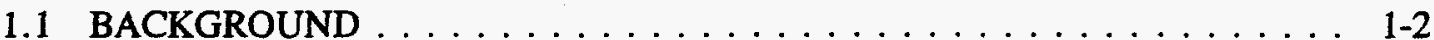

1.2 PUEBLO DEPOT ACTIVITY $\ldots \ldots \ldots \ldots \ldots \ldots \ldots \ldots \ldots$

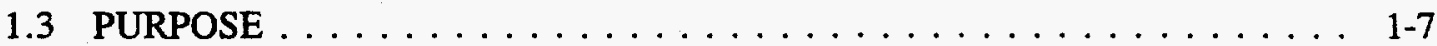

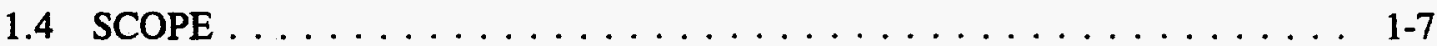

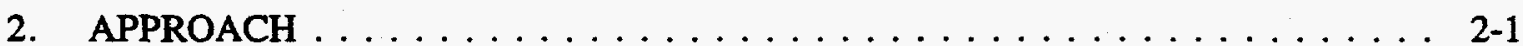

2.1 IDENTIFYING THE PROGRAMMATIC ENVIRONMENTALLY

PREFERRED ALTERNATIVE . . . . . . . . . . . . . . . . 2-1

2.2 PHASE I CONCEPTUAL FRAMEWORK $\ldots \ldots \ldots \ldots \ldots \ldots \ldots$

2.3 DATA COLLECTION AND AGENCIES CONTACTED . . . . . . . 2-7

3. DEVELOPMENTS IN DISPOSAL TECHNOLOGY SINCE THE FPEIS $\ldots \ldots$. . 3-1

3.1 ASSESSMENTS OF THE DISPOSAL PROCESS IN THE FPEIS . . . . . . 3-1

3.1 .1 Background . . . . . . . . . . . . . . . . 3-1

3.1.2 Technology-Related Assumptions and Commitments . . . . . . . . 3-2

3.2 RECENT DISPOSAL EXPERIENCE AT JACADS . . . . . . . . . . . . 3-4

3.2 .1 Plant Performance . . . . . . . . . . . . . . . . . 3-7

3.2.1.1 Processing efficiency . . . . . . . . . . . . 3-7

3.2.1.2 On-site movement of munitions . . . . . . . . . . . . . 3-9

3.2.1.3 Personnel training . . . . . . . . . . . . . . . . 3-10

3.2.2 Environmental Performance . . . . . . . . . . . . . . . 3-11

3.2.2.1 Stack emissions . . . . . . . . . . . . . . . . . . 3-11

3.2.2.2 Solid waste management $\ldots \ldots \ldots \ldots \ldots \ldots$. . . . . . . . . . . .

3.2.2.3 Environmental monitoring . . . . . . . . . . 3-18 
3.2.2.4 Worker exposure . . . . . . . . . . . . . . . . . . . 3-19

3.2.2.5 Environmental compliance . . . . . . . . . . . . . 3-21

3.2.3 Accidents and Other Nonroutine Events . . . . . . . . . . . . . 3-24

3.2.3.1 Stack release . . . . . . . . . . . . . . . . . 3-25

3.2.3.2 In-plant release . . . . . . . . . . . . . . . . 3-26

3.2.3.3 Nonroutine incidents not involving chemical agent . . . . . . 3-26

3.3 OTHER RECENT DEVELOPMENTS AND DISPOSAL

EXPERIENCE . . . . . . . . . . . . . . . . . . . . . . 3-27

3.3.1 Alternative Technologies . . . . . . . . . . . . . . . 3-30

3.3.1.1 Chemical neutralization . . . . . . . . . . . . 3-30

3.3.1.2 Plasma arc . . . . . . . . . . . . . 3-31

3.3.1.3 Enzyme-catalyzed hydrolysis . . . . . . . . . . . 3-31

3.3.1.4 Supercritical water oxidation . . . . . . . . . . . 3-32

3.3 .1 .5 Summary . . . . . . . . . . . . . . . . . 3-32

3.3 .2 Cryofracture . . . . . . . . . . . . . . . . . . . .

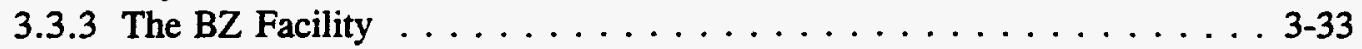

3.3.4 The Chemical Demilitarization Training Facility . . . . . . . . . 3-36

3.3.5 The Tooele Facility . . . . . . . . . . . . . . . 3-36

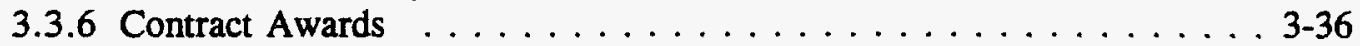

3.3.7 Individual Equipment Advances . . . . . . . . . . . . . . . 3-37

3.4 FUTURE PLANS FOR SITE-SPECIFIC OPERATIONAL TESTING . . . . 3-37

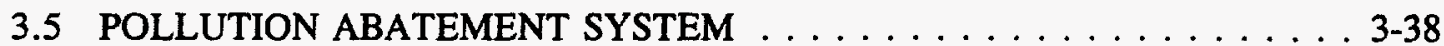

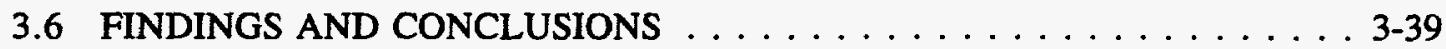

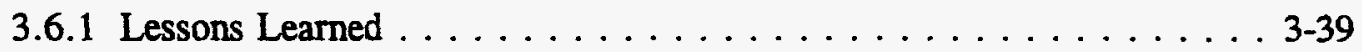

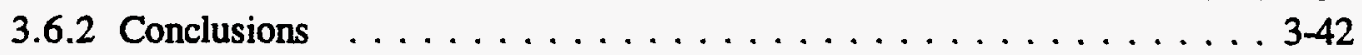

4. TRANSPORTATION DEVELOPMENTS SINCE THE FPEIS $\ldots \ldots \ldots \ldots \ldots$

4.1 TRANSPORTATION ANALYSES IN THE FPEIS . . . . . . . . . . . . 4-1

4.1.1 Recommendations of the Panel of Transportation Experts . . . . . . . 4-2

4.1 .2 Transport Containers . . . . . . . . . . . . . . . . 4 4-6

4.1 .3 Transport Vehicles $\ldots \ldots \ldots \ldots \ldots \ldots \ldots \ldots \ldots \ldots . \ldots \ldots$ 4-8

4.1.3.1 Trucks . . . . . . . . . . . . . . . 4-8

4.1.3.2 Trains and railcars $\ldots \ldots \ldots \ldots \ldots \ldots . \ldots . \ldots . . \ldots 4$

4.1 .4 Monitoring . . . . . . . . . . . . . . . . . . . 4-9

4.1.5 Safety and Security . . . . . . . . . . . . . . 4-9

4.1 .6 Public Response . . . . . . . . . . . . . . . . . . . . . . 4-10

4.1 .7 Institutional Factors . . . . . . . . . . . . . . . . . 4-11

4.1.8 Command, Control, and Security . . . . . . . . . . . . . 4-11

4.1 .9 Logistics . . . . . . . . . . . . . . . . . . . 4-12

4.1.10 Transportation Alternatives Eliminated

from Detailed Consideration in the FPEIS . . . . . . . . . . . . 4-13 
4.2 REMOVAL OF THE U.S. CHEMICAL STOCKPILE FROM EUROPE . . 4-14 4.2.1 Execution of Operation Retrograde . . . . . . . . . . . . . . 4-15

4.2.2 Differences and Similarities between the European Move and the Movement of the PUDA Stockpile . . . . . . . . . . . . . . . 4-19

4.2.3 Comparison of FPEIS Assumptions and Commitments

to the Recent Transportation Experience . . . . . . . . . . . . . . . 4-20

4.3 OTHER RELATED DEVELOPMENTS IN THE TRANSPORTATION

OF HAZARDOUS WASTES . . . . . . . . . . . . . . . . 4-20

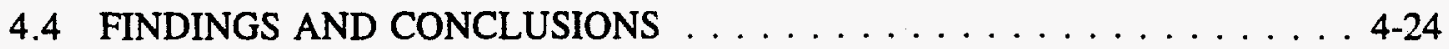

4.4 .1 Lessons Learned . . . . . . . . . . . . . . . . . . . . . 4-24

4.4 .2 Conclusions . . . . . . . . . . . . . . . . 4-25

5. NEW INFORMATION AFFECTING IMPLEMENTATION OF

ON-SITE DISPOSAL AT PUEBLO DEPOT ACTIVITY . . . . . . . . . . . 5-1

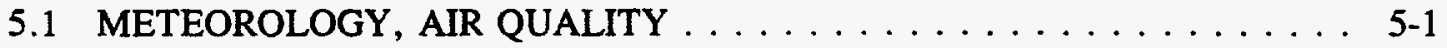

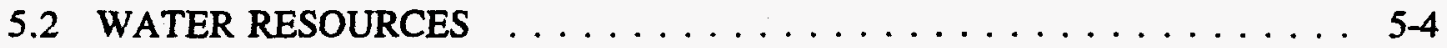

5.3 LAND USE . . . . . . . . . . . . . . . . . . . 5-7

5.4 ECOLOGICAL RESOURCES $\ldots \ldots \ldots \ldots \ldots \ldots \ldots \ldots \ldots \ldots \ldots$. . . . . . . . .

5.5 SOCIAL, ECONOMIC, AND CULTURAL RESOURCES . . . . . . . . 5-15

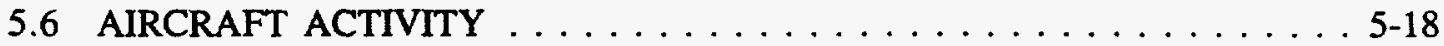

6. RE-EXAMINING ON-SITE DISPOSAL AS THE

ENVIRONMENTALLY PREFERRED ALTERNATIVE . . . . . . . . . 6-1

6.1 NEW VALUES FOR PROGRAMMATIC DATA AND

ASSUMPTIONS AND THEIR SIGNIFICANCE $\ldots \ldots \ldots \ldots \ldots \ldots$ 6-1

6.1.1 Accident Database . . . . . . . . . . . . . . . . . 6 6-1

6.1 .1 .1 On-site transportation $\ldots \ldots \ldots \ldots \ldots \ldots \ldots \ldots \ldots \ldots$ 6-1

6.1 .1 .2 Meteorology . . . . . . . . . . . . . . . . 6-2

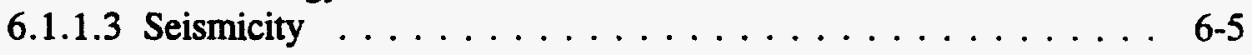

6.1 .1 .4 Aircraft activity . . . . . . . . . . . . . . . 6-7

6.1 .1 .5 Meteorites/tornadoes . . . . . . . . . . . . . 6 6-7

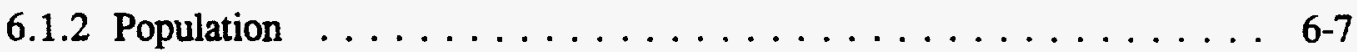

6.1 .3 Summary . . . . . . . . . . . . . . . . . . . 6-9

6.2 EVALUATING MEASURES OF RISK WITH DATA

COLLECTED DURING PHASE I . . . . . . . . . . . . . . . . . . 6-9

6.2 .1 Approach . . . . . . . . . . . . . . . . . . 6-10

6.2 .2 Results . . . . . . . . . . . . . . . . . . . . . . 6-12

6.2.3 Comparison of FPEIS and Phase I Risk Values . . . . . . . . . . . 6-12

6.2.4 Effect of Various Meteorological Conditions upon

Measures of Risk . . . . . . . . . . . . . . . . 6-15

6.3 DESIGN CHANGES REQUIRING RE-EXAMINATION OF RISK

AT THE PUEBLO DEPOT ACTIVITY . . . . . . . . . . . . 6-16

6.3.1 Container Handling Building (CHB) $\ldots \ldots \ldots \ldots$ 6-16 
6.3.2 Redesigned On-Site Container . . . . . . . . . . . . . . . . 6-17

6.3.3 Addition of a Mustard Thaw Capability . . . . . . . . . . . . . . 6-18

6.4 EXAMINATION OF RISKS FOR A CRYOFRACTURE DISPOSAL

FACILITY AT THE PUEBLO DEPOT ACTIVITY . . . . . . . . . . . 6-18

6.5 IDENTIFYING THE SITE-SPECIFIC ENVIRONMENTALLY

PREFERRED ALTERNATIVE . . . . . . . . . . . . . . . . 6-19

7. DEVELOPMENTS IN EMERGENCY PREPAREDNESS . . . . . . . . . 7-1

7.1 EMERGENCY PREPAREDNESS MITIGATION FOR FIXED

SITES IN THE FPEIS ENVIRONMENTALLY PREFERRED

ALTERNATIVE . . . . . . . . . . . . . . . . . . 7-1

7.2 DEVELOPMENTS IN ON-SITE EMERGENCY

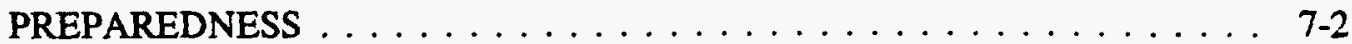

7.2.1 National CSEPP Activities . . . . . . . . . . . . . 7-4

7.2.2 PUDA Emergency Preparedness Enhancements . . . . . . . . . 7-4

7.2.2.1 PUDA CSEPP Phase I activities . . . . . . . . . 7-5

7.2.2.2 PUDA CSEPP Phase II activities . . . . . . . . . 7-5

7.2.2.3 PUDA CSEPP Phase III activities . . . . . . . . 7-6

7.2.2.4 Summary of PUDA emergency preparedness

developments since the FPEIS ............ . . 7-7

7.3 EMERGENCY PREPAREDNESS MITIGATION FOR

RAIL TRANSPORT CORRIDORS IN THE FPEIS $\ldots \ldots \ldots \ldots \ldots \ldots$. . . . . .

7.4 EMERGENCY PREPAREDNESS FOR THE

EUROPEAN PORTION OF THE MOVEMENT OF

CHEMICAL MUNITIONS FROM THE FEDERAL

REPUBLIC OF GERMANY . . . . . . . . . . . . . . . . 7-9

7.4.1 Mobile Emergency Response Capabilities . . . . . . . . . . . . . . . . . 7-9

7.4.2 Prepositioned Emergency Response Capabilities . . . . . . . . . . . . 7-10

7.4 .3 Conclusions . . . . . . . . . . . . . . . . . . . . . . 7-10

7.5 COMPARISON OF FPEIS COMMITMENTS AND RECENT

DEVELOPMENTS IN EMERGENCY PREPAREDNESS . . . . . . . . . 7-10

7.5.1 Emergency Preparedness for Installations

and Surrounding Communities . . . . . . . . . . . 7-11

7.5.2 Emergency Preparedness for Rail Movement . . . . . . . . . . . 7-11

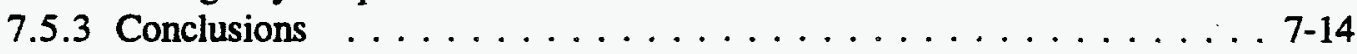

8. FINDINGS AND CONCLUSIONS $\ldots \ldots \ldots \ldots \ldots \ldots \ldots \ldots \ldots$

8.1 ENVIRONMENTALLY PREFERRED ALTERNATIVE . . . . . . . . 8-1

8.2 PROPOSED SCOPE FOR THE SITE-SPECIFIC EIS $\ldots \ldots \ldots \ldots \ldots \ldots$. 8 .3

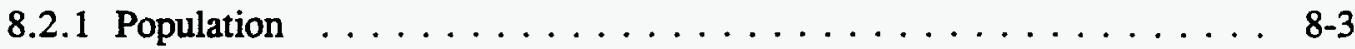

8.2.2 Meteorology and Air Quality . . . . . . . . . . . . . 8-4

8.2.3 Surface Water and Groundwater . . . . . . . . . . . . . . . 8-4

8.2 .4 Land Use $\ldots \ldots \ldots \ldots \ldots \ldots \ldots \ldots \ldots \ldots \ldots . \ldots \ldots \ldots$ 
8.2 .5 Ecological Resources . . . . . . . . . . . . . . . . . . . 8 8-4

8.2.6 Social, Economic, and Cultural Resources . . . . . . . . . . 8 8-5

8.2 .7 Aircraft Activity . . . . . . . . . . . . . . . 8-5

8.2.8 Emergency Preparedness $\ldots \ldots \ldots \ldots \ldots \ldots$ 8-5

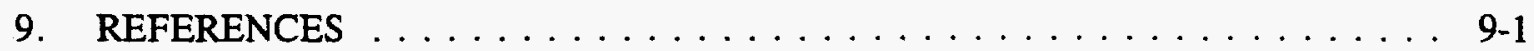

APPENDIX A. IMPACT ANALYSES IN THE FINAL PROGRAMMATIC ENVIRONMENTAL IMPACT STATEMENT (FPEIS) . . . . . . . . A A-1

APPENDIX B. DESCRIPTION OF SITE-SPECIFIC COMMUNITY RESOURCES .................... B-1

APPENDIX C. DESCRIPTION OF SITE-SPECIFIC SURFACE WATER AND GROUNDWATER RESOURCES . . . . . . . . . . . c C-1

APPENDIX D. DESCRIPTION OF SITE-SPECIFIC ECOLOGICAL

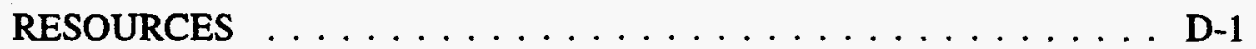

APPENDIX E. RESPONSES TO COMMENTS FROM STATE AND FEDERAL AGENCIES . . . . . . . . . . . . . . E-1

APPENDIX F. SEISMICITY $\ldots \ldots \ldots \ldots \ldots \ldots \ldots \ldots \ldots \ldots \ldots$

APPENDIX G. JACADS PROCESSING RATES $\ldots \ldots \ldots \ldots \ldots \ldots \ldots$

APPENDIX H. DETAILS REGARDING THE REMOVAL OF THE

U.S. CHEMICAL STOCKPILE FROM EUROPE . . . . . . . . . H-1

APPENDIX I. EXAMINATION OF ON-SITE METEOROLOGICAL DATA $\ldots \ldots$ I-1 



\section{LIST OF FIGURES}

Figure

1.1. Map of the vicinity of the Pueblo Depot Activity, Pueblo, Colorado . . . . . . 1-5

1.2. General layout of the Pueblo Depot Activity, Pueblo, Colorado . . . . . . . . . . 1-6

1.3. Potential impact region of Pueblo Depot Activity, Pueblo, Colorado . . . . . . . . 1-8

2.1. Flowchart illustrating selection of the Chemical Stockpile Disposal

Program environmentally preferred alternative $\ldots \ldots \ldots \ldots \ldots \ldots . \ldots . \ldots .2$

2.2. Conceptual overview of data types on which the programmatic

environmentally preferred alternative is based . . . . . . . . . $2-4$

2.3 Flowchart illustrating the Phase $\mathrm{I}$ concept $\ldots \ldots \ldots \ldots \ldots \ldots$

3.1. The Johnston Atoll Chemical Agent Disposal System incineration process ......................... 3-5

3.2. Cumulative Production-Scheduled Days . . . . . . . . . . . . . . 3-9

3.3. Schematic process diagram for a cryofracture facility $\ldots \ldots \ldots \ldots \ldots \ldots$

4.1. Movement of the chemical stockpile to the continental United States

regional disposal centers (located at Anniston, Alabama, and Tooele, Utah) . . . . 4-3

4.2. Movement of the chemical stockpile to a continental United States

National Disposal Center (located at Tooele, Utah). . . . . . . . . . . . . . . 4-4

4.3. Schematic diagram of the off-site transportation container (OFC) . . . . . . . 4-7

4.4. Activities associated with Operation Retrograde (the removal of the U.S.-owned chemical stockpile from Europe). . . . . . . . . . . . 4-16

4.5. Scheduling of the movement of the European stockpile of chemical munitions . . . 4-17

4.6. Ocean route for Operation Retrograde . . . . . . . . . . . . . . . . . . . 4-19

5.1. Wind roses for Pueblo Memorial Airport covering the periods from 1963-64 (a) and 1960-64 (b) 
5.2. Location of important ecological resources within $100-\mathrm{km}$ (62-mile) zone around Pueblo Depot Activity $\ldots \ldots \ldots \ldots \ldots \ldots \ldots$. . . . . . . . . . . . .

5.3. On-post work and residential populations at Pueblo Depot Activity (PUDA) . . . 5-17

6.1. Risk with mitigation in the vicinity of the Pueblo Depot Activity (PUDA) for programmatic alternatives $\ldots \ldots \ldots \ldots$ 6-14 


\section{LIST OF TABLES}

Table

3.1. Summary of U.S. Army's experience in industrial-scale chemical

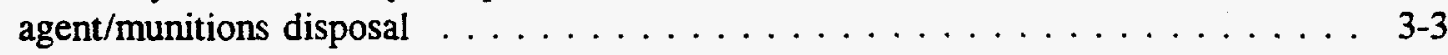

3.2. Emissions and annual average ground-level concentrations of industrial-type pollutants from disposal facilities . . . . . . . . . . . 3-12

3.3. Summary of Toxic Substances Control Act burn results at Johnston Atoll Chemical Agent Disposal System . . . . . . . . . . . . . 3-14

3.4. Comparison of polychlorinated biphenyl (PCB) emissions from Johnston Atoll Chemical Agent Disposal System (JACADS) with PCB emissions from three commercial PCB incinerators permitted by the U.S. Environmental

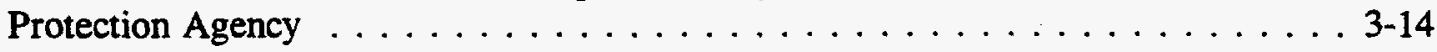

3.5. Solid wastes expected from on-site disposal facilities and acreage required for disposal of ash and salts $\ldots \ldots \ldots \ldots \ldots \ldots$ 3-16

3.6. Agent release values and maximum predicted ground level concentrations from routine operations of the proposed disposal facility $\ldots \ldots \ldots \ldots \ldots$. . . . 20

3.7. Summary of system test conditions and results $\ldots \ldots \ldots \ldots \ldots \ldots \ldots$

3.8. Alternate technologies for destruction of the chemical weapons stockpile

3.9. Projected chemical agent stockpile destruction schedule $\ldots \ldots \ldots \ldots \ldots$. . . . . 38

3.10. Comparison of Final Programmatic Environmental Impact Statement (FPEIS) assumptions and commitments with disposal technology experience at Johnston Atoll Chemical Agent Destruction System (JACADS) . . . . . . . . 3-39

4.1. Members of the expert panel on transportation concepts for chemical munitions . . . . . . . . . . . . . . . . . . . 4-5

4.2. Comparison of Final Programmatic Environmental Impact Statement (FPEIS) assumptions and commitments with actual experience in transporting chemical munitions from Europe to Johnston Island 
5.1. Number of protected ecological resources within the no-deaths distance for the most serious on-site accidents under worst case meteorological conditions at Pueblo Depot Activity

5.2. Ecological resources within the $100-\mathrm{km}$ (62-mile) impact zone around Pueblo Depot Activity (PUDA) as identified during the Phase I process

5.3 Threatened and Endangered Species identified within the $100-\mathrm{km}$ (62-mile) zone and Pueblo Depot Activity (PUDA) during preparation of the Final Programmatic Environmental Impact Statement (FPEIS) and Phase I Report . . . . . . . . . . . . . . . . . . . . . 5-13

5.4. Comparison of 1986 and 1988 air traffic activity at Pueblo

6.1. Joint frequency distribution (in percent) of stability and wind speed for the Pueblo Depot Activity $\ldots \ldots \ldots \ldots \ldots \ldots$. . . . . . . . .

6.2. Residential population distribution around the proposed disposal facility site at the Pueblo Depot Activity as given in the Final Programmatic Environmental Impact Statement

6.3. Residential population distribution around the proposed disposal facility site at the Pueblo Depot Activity using data collected during Phase I .

6.4. Comparison of Phase I and Final Programmatic Environmental Impact Statement (FPEIS) fatality estimates for an accidental release of mustard agent during on-site disposal at Pueblo Depot Activity . . . . . . . . . . . . . . . . . . . . 6-13

6.5. Results of comparing the recomputed measures of risk for alternatives at the Pueblo Depot Activity

7.1. Rail transport corridor emergency preparedness components in the Final Programmatic Environmental Impact Statement (FPEIS) and in the European movement

7.2. Population of cities along European rail transport route (1987) $7-13$ 


\section{ABBREVIATIONS AND ACRONYMS}

$\begin{array}{ll}\text { ACAMS } & \text { automatic continuous air monitoring system } \\ \text { agl } & \text { above ground level } \\ \text { ANAD } & \text { Anniston Army Depot } \\ \text { APG } & \text { Aberdeen Proving Ground } \\ \text { ASC } & \text { allowable stack concentration } \\ \text { ATC } & \text { Applied Technology Council } \\ \text { BZ } & \text { nonlethal but incapacitating agent } \\ \text { CAMDS } & \text { Chemical Agent Munitions Disposal System } \\ \text { CDTF } & \text { Chemical Demilitarization Training Facility } \\ \text { CEQ } & \text { Council on Environmental Quality } \\ \text { CHB } & \text { container handling building } \\ \text { CML } & \text { conservative most likely } \\ \text { CO } & \text { carbon monoxide } \\ \text { CONUS } & \text { continental United States } \\ \text { CSDP } & \text { Chemical Stockpile Disposal Program } \\ \text { CSEPP } & \text { Chemical Stockpile Emergency Preparedness Program } \\ \text { CY } & \text { calendar year } \\ \text { D2PC } & \text { a computer model for atmospheric dispersion } \\ \text { DAAMS } & \text { depot area air monitoring system } \\ \text { DATS } & \text { Drill and Transfer System } \\ \text { decon } & \text { decontaminating } \\ \text { DEHP } & \text { diethyl phosphite } \\ \text { DFS } & \text { deactivation furnace system } \\ \text { DHHS } & \text { U.S. Department of Health and Human Services } \\ \text { DOD } & \text { U.S. Department of Defense } \\ \text { DODES } & \text { Colorado Division of Disaster Emergency Services } \\ \text { DOE } & \text { U.S. Department of Energy } \\ \text { DOI } & \text { U.S. Department of the Interior } \\ \text { dscm } & \text { dry standard cubic meters } \\ \text { DOT } & \text { U.S. Department of Transportation } \\ \text { DRE } & \text { Destruction and Removal Efficiency } \\ \text { E } & \text { east } \\ \text { EIS } & \text { environmental impact statement } \\ \text { ENE } & \text { east-northeast } \\ \text { EOC } & \text { Emergency Operations Center } \\ \text { EPA } & \text { U.S. Environmental Protection Agency } \\ \text { EPCRA } & \text { Emergency Planning and Community Right-to-Know Act } \\ \text { EPGA } & \text { effective peak ground acceleration } \\ \text { EPRI } & \text { Electric Power Research Institute } \\ \text { ERCP } & \text { Emergency Response Concept Plan } \\ & \end{array}$




$\begin{array}{ll}\text { ESE } & \text { east-southeast } \\ \text { FEMA } & \text { Federal Emergency Management Agency } \\ \text { FPEIS } & \text { Final Programmatic Environmental Impact Statement } \\ \text { ft } & \text { feet } \\ \text { FTE } & \text { full-time equivalent } \\ \text { FWS } & \text { U.S. Fish and Wildife Service } \\ \text { g } & \text { (1) gram } \\ \text { GB } & \text { (2) acceleration due to gravity } \\ \text { gpm } & \text { chemical nerve agent, also called Sarin } \\ \text { H } & \text { gallons per minute } \\ \text { ha } & \text { chemical blister agent, also generally called mustard } \\ \text { HCl } & \text { hectare } \\ \text { HD } & \text { hydrogen chloride } \\ \text { HLW } & \text { chemical blister agent, also generally called mustard } \\ \text { hr } & \text { high-level radioactive wastes } \\ \text { HT } & \text { hour } \\ \text { I } & \text { chemical blister agent, also generally called mustard } \\ \text { ICBO } & \text { "importance factor" } \\ \text { I }_{\text {mm }} & \text { International Conference of Building Officials } \\ \text { INEL } & \text { modified Mercalli intensity } \\ \text { INF } & \text { Idaho National Engineering Laboratory } \\ \text { IRZ } & \text { Intermediate-Range Nuclear Forces } \\ \text { JACADS } & \text { immediate response zone } \\ \text { kg } & \text { Johnston Atoll Chemical Agent Disposal System } \\ \text { km } & \text { kilogram } \\ \text { L } & \text { kilometer } \\ \text { LBAD } & \text { liter } \\ \text { lb } & \text { Lexington-Blue Grass Army Depot } \\ \text { LEPC } & \text { pound } \\ \text { LIC } & \text { Local Emergency Planning Committees } \\ \text { m } & \text { liquid incinerator } \\ \text { M } & \text { meter } \\ \text { MCE } & \text { body-wave magnitude } \\ \text { MDB } & \text { Maximum Credible Event } \\ \text { mg } & \text { Munitions Demilitarization Building } \\ \text { Mgd } & \text { milligram } \\ \text { MHI } & \text { million gallons per day } \\ \text { MILVAN } & \text { munitions holding igloo } \\ \text { min } & \text { military ammunition shipping containers } \\ \text { mm } & \text { minute } \\ \text { MOU } & \text { millimeter } \\ \text { MPa } & \text { Memorandum of Understanding } \\ & \text { megapascal } \\ & \\ & \\ & \end{array}$




$\begin{array}{ll}\text { mph } & \text { miles per hour } \\ \text { MPF } & \text { metal parts furnace } \\ \text { N } & \text { north } \\ \text { NAAP } & \text { Newport Army Ammunition Plant } \\ \text { NaOCl } & \text { sodium hypochlorite } \\ \text { NE } & \text { northeast } \\ \text { NEPA } & \text { National Environmental Policy Act of 1969 } \\ \text { NF } & \text { national forest } \\ \text { NNE } & \text { north-northeast } \\ \text { NNW } & \text { north-northwest } \\ \text { NO } & \text { nitrogen dioxide } \\ \text { NOAA } & \text { National Oceanic and Atmospheric Administration } \\ \text { NO } & \text { nitrogen oxide } \\ \text { NP } & \text { national parks } \\ \text { NRC } & \text { Nuclear Regulatory Commission } \\ \text { NW } & \text { northwest } \\ \text { NWA } & \text { national wilderness area } \\ \text { NWR } & \text { national wildlife refuge } \\ \text { OFC } & \text { off-site transportation containers } \\ \text { OMC } & \text { operations and maintenance contractor } \\ \text { ONC } & \text { on-site container } \\ \text { ORNL } & \text { Oak Ridge National Laboratory } \\ \text { OVT } & \text { Operations Verification Test } \\ \text { PACOG } & \text { Pueblo Area Councils of Government } \\ \text { PAS } & \text { pollution abatement system } \\ \text { PAZ } & \text { protective action zone } \\ \text { PBA } & \text { Pine Bluff Arsenal } \\ \text { PCB } & \text { polychlorinated biphenyl } \\ \text { PGA } & \text { peak ground acceleration } \\ \text { PIC } & \text { products of incomplete combustion } \\ \text { PM } & \text { particulate matter less than 10 microns in diameter } \\ \text { PMCD } & \text { Program Manager for Chemical Demilitarization } \\ \text { ppm } & \text { parts per million } \\ \text { PSD } & \text { prevention of significant deterioration } \\ \text { psig } & \text { pounds per square inch, gage } \\ \text { Pt. } & \text { Part } \\ \text { Pub. L. } & \text { Public Law } \\ \text { PUDA } & \text { Pueblo Depot Activity } \\ \text { RCRA } & \text { Resource Conservation and Recovery Act of 1976 } \\ \text { R\&D } & \text { research and development } \\ \text { RMA } & \text { Rocky Mountain Arsenal } \\ \text { ROD } & \text { Record of Decision } \\ \text { RVD } & \text { recreation visitor days } \\ & \\ & \end{array}$




$\begin{array}{ll}\text { S } & \text { second } \\ \text { S } & \text { south } \\ \text { SAIC } & \text { Science Applications International Corporation } \\ \text { SE } & \text { southeast } \\ \text { SERC } & \text { State Emergency Response Commission } \\ \text { SO } & \text { sulfur dioxide } \\ \text { SOP } & \text { standing operating procedure } \\ \text { SP } & \text { state park } \\ \text { SSC } & \text { secondary steel container } \\ \text { SSE } & \text { (1) south-southeast } \\ & \text { (2) safe-shutdown earthquake } \\ \text { SSW } & \text { south-southwest } \\ \text { SW } & \text { southwest } \\ \text { SWMA } & \text { state wildlife management areas } \\ \text { TSCA } & \text { Toxic Substances Control Act } \\ \text { TEAD } & \text { Tooele Army Depot } \\ \text { TMI } & \text { Three Mile Island } \\ \text { TOX } & \text { toxic cubicle } \\ \text { TRU } & \text { transuranic } \\ \text { TSP } & \text { total suspended particulates } \\ \text { TWA } & \text { time weighted average } \\ \text { UAPB } & \text { University of Arkansas at Pine Bluff } \\ \text { UBC } & \text { Uniform Building Code } \\ \text { UMDA } & \text { Umatilla Depot Activity } \\ \text { VX } & \text { chemical nerve agent } \\ \text { W } & \text { west } \\ \text { WC } & \text { worst case } \\ \text { WIPP } & \text { Waste Isolation Pilot Plant } \\ \text { WMA } & \text { wildlife management areas } \\ \text { WNW } & \text { west-northwest } \\ \text { WSW } & \text { west-southwest } \\ & \\ & \end{array}$




\section{FOREWORD}

Under the Chemical Stockpile Disposal Program (CSDP), the U.S. Army proposes to dispose of lethal chemical agents and munitions stored at eight existing Army installations in the continental United States. In compliance with the National Environmental Policy Act (NEPA), the Army initiated a site-specific NEPA review of this proposed action at the Pueblo Depot Activity (PUDA) near Pueblo, Colorado. The environmental compliance documentation is to be prepared in two phases.

In Phase I, the overall CSDP decision to dispose of the PUDA stockpile by an on-site reverse-assembly and incineration process was further considered, and its validity at PUDA was reviewed with newer, more detailed data than those providing the basis for the final programmatic environmental impact statement (FPEIS) (completed in January 1988) for the CSDP. A Phase I Environmental Report was prepared to present the findings of the Phase I review.

Phase II [the preparation of a site-specific environmental impact statement (EIS)] will focus on the site-specific implementation (plant construction and disposal operations) of onsite disposal at PUDA. It should be emphasized that the Phase I Environmental Report is the starting point for the site-specific decision-making process, and it provides the environmental information by which the impacts of the proposed action can be assessed in the site-specific EIS.

A final Phase I Environmental Report for PUDA was issued by the Army in September 1993 (Disposal of Chemical Agents and Munitions Stored at Pueblo Depot Activity, Colorado: Final Phase I Environmental Report, Program Manager for Chemical Demilitarization, Aberdeen Proving Ground, Md.) The report concluded that the FPEIS environmentally preferred alternative (on-site disposal), which is also the Army's preferred alternative, is indeed valid for PUDA. No new or unique site-specific information was found that would change or contradict the conclusions of the FPEIS with respect to PUDA. The report recommended that preparation of the site-specific EIS should proceed and should focus on implementation of the on-site incineration program and should not consider other alternatives for disposing of the PUDA stockpile.

The PUDA Phase I report was independently reviewed by Argonne National Laboratory (ANL) and the review summarized in a report (Chemical Stockpile Disposal Program: Review and Comment on the Phase I Environmental Report for the Pueblo Depot Activity, Pueblo, Colorado, ANL/EA/TM-14, Argonne, Ill., March 1994). Additional recommendations for the content of the site-specific EIS are included in the ANL review. On September 22, 1994, the findings and conclusions of the PUDA Phase I report and the independent ANL review, were transmitted via a letter of concurrence to Congress by the Hon. Robert M. Walker, Assistant Secretary of the Army. Preparation of the site-specific EIS for PUDA was initiated following the Phase I certification.

This Oak Ridge National Laboratory Technical Memorandum consists of the September 1993 Final Phase I report. It was prepared to document the Phase I process for disposal of chemical agents and munitions stored at PUDA. 


\section{PREFACE}

Under the Chemical Stockpile Disposal Program (CSDP), the U.S. Army proposes to dispose of lethal chemical agents and munitions stored at eight existing Army installations in the continental United States. In 1988, the U.S. Army issued the final programmatic environmental impact statement (FPEIS) for the CSDP. The FPEIS and the subsequent Record of Decision (ROD) identified an on-site disposal process as the preferred method for destruction of the stockpile. That is, the FPEIS determined the environmentally preferred alternative to be on-site disposal in high-temperature incinerators, while the ROD selected this alternative for implementation as the preferred method for destruction of the stockpile.

In this Phase I report, the overall CSDP decision regarding disposal of the PUDA stockpile is subjected to further analyses, and its validity at PUDA is reviewed with newer, more detailed data than those providing the basis for the conclusions in the FPEIS. The findings of this Phase $\Gamma$ report will be factored into the scope of a site-specific environmental impact statement to be prepared for the destruction of the PUDA stockpile.

The focus of this Phase I report is on those data identified as having the potential to alter the Army's previous decision regarding disposal of the PUDA stockpile; however, several other factors beyond the scope of this Phase I report must also be acknowledged to have the potential to change or modify the Army's decisions regarding PUDA. These factors include:

- The Army's on-going program to test a prototype disposal system. Operational verification testing of the Johnston Atoll Chemical Agent Disposal System (JACADS) began in 1990. JACADS is a prototype of the disposal technology proposed for use at all eight storage locations. Through four test campaigns, JACADS has destroyed over $1.75 \times 10^{5} \mathrm{~kg}$ (190 tons) of chemical agent and over 57,000 munitions. The results of these "proof-of-principle" tests will assist the Army with the verification of reverseassembly or "baseline" as the preferred disposal technology. In the reverse-assembly process, the munitions would first be taken apart, and the lethal agent would be drained. The chemical agent, as well as the munition components, would then be incinerated.

- The potential for cryofracture technology to augment or replace reverse-assembly. One alternative to the baseline disposal technology is "cryofracture" in which the reverseassembly process of disassembling the munitions is replaced by immersing the munitions in liquid nitrogen thereby embrittling the metal and freezing the chemical agent inside. The frozen munitions would then be shattered in a mechanical press and the fractured pieces incinerated. The Army has pursued the development of cryofracture technology via testing at various facilities across the country and is now ready to begin full-scale tests.

- The National Research Council's study on alternate disposal technologies for the chemical stockpile. The Army requested a study of alternative technologies from the National 
Research Council (NRC) and Congress subsequently required the Army to prepare a report on alternative technologies. The NRC study began in 1992 and is scheduled for publication in early 1994. It will focus on the feasibility of alternatives to the Army's proposed incineration disposal technology (i.e., reverse-assembly). The Army will incorporate the findings of the study into its own technology summary prior to reporting the results, as well as its recommendations, to Congress. 


\section{EXECUTIVE SUMMARY}

The Pueblo Depot Activity (PUDA) near Pueblo, Colorado, is one of eight continental United States (CONUS) Army installations where lethal unitary chemical agents and munitions are stored and where destruction of agents and munitions is proposed under the Chemical Stockpile Disposal Program (CSDP). Unitary agents are so named because they can produce their desired toxic effect on human health in their form as stored; they do not require mixing with another component to become toxic, as is the case with binary chemical agents. The chemical agent inventory at PUDA consists of approximately $10 \%$, by weight, of the total U.S. stockpile of lethal unitary chemical agents. The PUDA inventory consists of only mustard agent (agents HD and HT) in explosively configured munitions: 155-mm projectiles (HD), 4.2-in mortar rounds (HD and HT), and 105-mm projectiles (HD).

In January 1988, the U.S. Army issued a Final Programmatic Environmental Impact Statement (FPEIS) for the CSDP that identified on-site disposal of agents and munitions as the environmentally preferred alternative (i.e., the alternative with the least potential to cause significant adverse impacts). In some instances, the FPEIS included generic data and assumptions that were developed to allow a consistent comparison of potential impacts among programmatic alternatives and did not include detailed conditions at each of the eight installations. In the FPEIS, the environmentally preferred alternative was identified using a method based on five measures of risk directed at potential human health and ecosystem or environmental effects; the adequacy of emergency response also played a key role in the selection process. In the Record of Decision (ROD) following the FPEIS, on-site disposal was selected for implementation of the program.

Following the issuance of the ROD for the FPEIS, the Army began site-specific National Environmental Policy Act (NEPA) reviews for the installations involved in the CSDP. The Army has developed a two-phase process for conducting the site-specific NEPA studies. Phase I is a continuation of the site-specific scoping process for the PUDA disposal facility that began with a public meeting held at Pueblo, Colorado, on June 4, 1990. In Phase I, the programmatic decision of on-site disposal is given further consideration by a review of its validity at PUDA using more detailed and more recent data than those used in the FPEIS. Phase II [the preparation of a site-specific environmental impact statement (EIS)] is to address potential impacts from implementation of the FPEIS preferred alternative for disposal of the PUDA stockpile.

The purpose of this Phase I report is to examine the proposed implementation of onsite disposal at PUDA in light of more recent and more detailed data than those on which the FPEIS is based. The following two principal issues are addressed: (1) whether or not the new data would result in rejection of on-site disposal at PUDA as the environmentally preferred alternative (using the same selection method and data analysis tools as in the FPEIS) and (2) whether or not the new data indicate the presence of significant environmental resources that could be affected by on-site disposal at PUDA. Discussions are presented on new developments related to disposal technology, off-site transportation, and emergency preparedness and how they could affect the FPEIS conclusions concerning disposal at PUDA. 
Completion of the Phase I process allows the preparation of the site-specific EIS to begin in Phase II. If Phase I supports on-site disposal, then the EIS would be limited to on-site disposal at PUDA. If on-site disposal is not supported by the results of Phase I, then the scope of the EIS would be expanded to include off-site shipment of the stockpile for disposal.

In this Phase I report, the Army's recent experience in destroying chemical agents and munitions is examined for the purpose of identifying any recent developments in the disposal technology that could have affected the conclusions reached in the FPEIS, had the information been available prior to its publication. The Army's prototype disposal facility, the Johnston Atoll Chemical Agent Disposal System (JACADS), located in the south Pacific, employs a design that contains the basic concepts of reverse assembly and incineration as presented in the FPEIS. In July 1990, operational verification testing (OVT) of JACADS began. From July 1990 through February 1991 (the period of the GB campaign), approximately

7,490 GB-filled rockets and about 75,000 lb of agent had been destroyed with no findings or developments that would indicate either the safety or environmental acceptability of the technology are questionable. There were a few, small releases of agent within the JACADS facility. Even during the agent release events, emissions from the JACADS facility were under all applicable federal and state standards. In particular, no releases escaped the facility with concentrations greater than $8 \%$ of the $1-\mathrm{hr}$ allowable stack concentration (ASC). The containment and filtration systems worked as designed.

JACADS downtime because of mechanical problems has been higher than expected. Problem areas included the rocket shear machine, clogging of demisters, and jamming of the heated conveyor system that carries the decontaminated rocket body scrap away from the deactivation furnace. However, corrections were made during the scheduled maintenance shutdown in December and January, 1991, and downtime decreased substantially. No new information has resulted from the Army's recent experience with the chemical munitions disposal technology that suggests the FPEIS conclusions would have been different if this experience had been gained prior to publication of the FPEIS.

The current status of potential alternative disposal technologies is also examined in this report (e.g., chemical neutralization and enzyme catalyzed hydrolysis). To date, none of the alternative technologies have been demonstrated to efficiently and completely destroy chemical agent and energetic materials and to decontaminate metal munitions components, as has the JACADS technology. Substantial investments of time and resources would be required to determine whether any of the alternative technologies have potential utility for chemical munitions destruction. Among the alternatives to the proposed JACADS technology is cryofracture, a process in which the munitions are frozen in a liquid nitrogen bath [at about $\left.-210^{\circ} \mathrm{C}\left(-350^{\circ} \mathrm{F}\right)\right]$ and then shattered prior to being fed into an incinerator. Cryofracture differs from the proposed JACADS technology primarily in the manner by which the munitions are handled prior to incineration. The Army is actively developing the cryofracture process as an alternative to the JACADS technology. While projectiles, mortars, mines, and rockets appear to be ideal candidates for cryofracture, it offers no advantage to the baseline process for bulk items. For bulk items, the cryofracture methodology drains the liquid from the container, incinerates the liquid, and shears the room temperature containers in the press for feed to the rotary kiln. Because the entire PUDA inventory consists of projectiles and 
mortar rounds, PUDA is a potential candidate for the demonstration of the cryofracture process.

The Army's recent experience in the movement of the U.S.-owned chemical munitions stockpile from West Germany to Johnston Island in the Pacific Ocean (Operation Retrograde) has been addressed in order to provide perspective on the success of the operation and to review recent developments in munitions transportation that could have affected the conclusions of the FPEIS if the new information had been available prior to its publication. Because the transportation of the U.S.-owned stockpile involved agents and munitions types different from those stored at PUDA, there is limited applicability of this experience to the off-site alternative for the PUDA inventory. There are, however, several broader aspects of Operation Retrograde that relate to the FPEIS analysis methods for off-site transport at the CONUS facilities. The safety and operational procedures and other details employed during Operation Retrograde were very similar to the assumptions and concepts incorporated into the FPEIS assessment.

Operation Retrograde experienced no chemical accident, incident, or event that could have contributed to the release of chemical agent into the environment. Additionally, there were no incidents that threatened the security of the munitions during transport. In fact, the safety and feasibility of conducting Operation Retrograde could have been predicted using the FPEIS transportation and data analysis methods. The FPEIS concluded that off-site movement of chemical agents and munitions could be performed in a safe and environmentally acceptable manner. However, the on-site alternative presented less risk and offered the promise of a more manageable emergency preparedness program. No new information resulted from the Army's recent transportation experience that suggests the FPEIS conclusions would have been different if this new experience had been gained prior to its publication.

During the Phase I process, data on resources that could be affected by on-site disposal at PUDA were gathered to determine if any significant new or site-specific resources are present that could prevent or delay construction and operation of the on-site disposal facility (including incident-free operations and accident scenarios). The resources that were considered included meteorology and air quality, surface and groundwater, land use, ecology, socioeconomics, and aircraft activity. Some of these resources were examined in the FPEIS in assessing potential impacts of the programmatic alternatives, whereas others represent issues that were not appropriate for detailed examination on the programmatic level. No assessment of potential environmental impacts was done during the Phase I process. Rather, the data were examined to help identify potential issues to be analyzed under Phase II. No unique resources with the potential to prevent or delay implementation of on-site disposal at PUDA have been identified. However, the new data will add to the understanding of potential impacts to be evaluated in the site-specific EIS.

More recent and more detailed site-specific data of the same types used in the FPEIS risk calculations were gathered during the Phase I process for PUDA. These new data were then examined and compared with the FPEIS data to determine if they have changed enough to warrant recomputation of the five measures of risk used to select the programmatic environmentally preferred alternative. Of all of the data types examined, only residential 
population was identified as having changed enough to warrant recomputation of risk. The changes in residential population are due primarily to population growth and to a change in the location of the residents in relation to the current preferred site of the proposed disposal facility. For meteorite frequency, meteorology, seismicity, aircraft activity, and agent on-site transport distance, either no new data were identified during the Phase I process or, if identified, were not sufficiently different from data used in the FPEIS risk assessment to warrant reevaluation of risk.

New population data were used to compute potential fatalities from accidental releases of chemical agents using the same computation methods and values for all other parameters as in the FPEIS. The revised fatality estimates were then used to compute the five measures of risk for on-site disposal, continued storage, and on-site activities associated with the off-site disposal alternative. The alternatives were then evaluated with the FPEIS method for identifying the environmentally preferred alternative, using the Phase I risk values as input. The FPEIS method is a three-tiered approach: the first involves human health considerations; the second involves the risks to the environment; and the third involves emergency preparedness.

There have been recent changes in both design and operating procedures for the PUDA facility that were not assessed in the FPEIS. Among these is the addition of a container handling building (CHB) to provide a buffer storage area during nighttime disposal operations. An examination in this Phase I report of the risks added from the CHB indicates that substantially higher levels of risk would exist as compared to those presented in the FPEIS for PUDA. Even with these increased levels of risk, there is no reason to reject onsite disposal in favor of the off-site disposal alternatives. Nevertheless, the Army is currently developing and evaluating design modifications for the PUDA facility to reduce risk values to levels that are equal to or less than those in the FPEIS.

Based on the above evaluation, on-site disposal was identified as the environmentally preferred alternative for PUDA at the first tier of analysis (human health). For PUDA, it was not necessary to proceed to the second tier since on-site disposal was found to be a clear winner at the first tier. If the off-site transportation risks (not addressed in this document because they were addressed in the FPEIS) are added, the on-site alternative is clearly preferable given the opportunity for accident impact reductions associated with on-site emergency planning and preparedness. The conclusion is that on-site disposal remains valid as the environmentally preferred alternative for PUDA.

The analysis to reach the FPEIS programmatic decision resulted in ties at the first and second tiers. The programmatic decision in favor of on-site disposal was made at the third tier (emergency preparedness). Because emergency preparedness played an important role in the FPEIS programmatic selection of on-site disposal as the environmentally preferred alternative, new developments in that area are presented in the Phase I report. The Army recommended that enhancements to emergency preparedness should be made, whichever disposal alternative was selected. Subsequently, emergency preparedness improvements have been initiated at each of the CONUS chemical munitions storage facilities, independent of the CSDP. The potential of these improvements to reduce the impacts of an accidental release of chemical agent differs for each programmatic alternative, including continued storage. This 
difference was a major factor in identifying on-site disposal as the preferred alternative. The Phase I report (1) summarizes emergency preparedness mitigation measures for the proposed disposal sites as discussed in the FPEIS; (2) describes and summarizes the status of emergency preparedness enhancements made at the storage and proposed disposal sites since the FPEIS, including those for PUDA; (3) summarizes the emergency preparedness mitigation measures for rail transport corridors; and (4) identifies relevant new information regarding emergency preparedness for rail transport, specifically those measures implemented during the European portion of Operation Retrograde. None of the information presented would have affected the selection of on-site disposal as the environmentally preferred alternative for destruction of the PUDA stockpile.

In summary, the above information supports the FPEIS conclusion that on-site incineration, with the well developed state of the technology, logistically simpler concept, and more effective emergency response capability, is still valid for PUDA. 
- 


\section{INTRODUCTION}

The U.S. Army is under Congressional mandate to dispose of the U.S. stockpile of lethal unitary chemical agents and munitions. In 1988, following a detailed programmatic environmental study that included the comparison of the potential environmental impacts of various disposal alternatives, the Army selected on-site incineration as the environmentally preferred alternative. This report examines the proposed implementation of on-site disposal at Pueblo Depot Activity (PUDA) in light of more recent and more detailed data than those on which the original decision was based. PUDA, which is located near Pueblo, Colorado, is one of eight continental United States (CONUS) Army installations where lethal unitary chemical agents and munitions are stored, and where destruction of agents and munitions is proposed.

The following two principal issues are addressed in this report: (1) whether or not the new data would result in the rejection of on-site disposal at PUDA as the environmentally preferred alternative (using the same methods and data analysis tools as in the Final Programmatic Environmental Impact Statement (FPEIS) (U.S. Army 1988a) and (2) whether or not the new data indicate the presence of significant environmental resources that could be affected by implementation of on-site disposal at PUDA.

Assessment of the first issue will be based upon new information related to the following recent, major developments, which have implications for the current disposal plans.

- The recent experience of Operational Verification Testing (OVT) of the Army's prototype incinerator, the Johnston Atoll Chemical Disposal System (JACADS), has resulted in significant new information concerning the incineration technology. Section 3 of this report summarizes the JACADS OVT results (both positive and negative) along with other chemical agent incineration experience to date, and whenever possible draws comparisons with the FPEIS assumptions and commitments related to the technology. It also addresses lessons learned from the problems experienced at JACADS.

- $\quad$ Reverse assembly and cryofracture are viable materials handling processes to prepare chemical warfare agents for incineration. Facility and process designs are under way for both options. However, other technologies have been investigated. Section 3 addresses the current status of alternative disposal technologies and, to the extent possible, compares them to the experience with the JACADS incineration technology to date.

- The successful movement of the U.S.-owned chemical munition stockpile from the Federal Republic of Germany (FRG) to Johnston Atoll (under Operation Retrograde, also known as Operation Steel Box) has provided new information concerning the transport of chemical agents and munitions. Section 4 of this report addresses the relevant details of Operation Retrograde and, whenever possible, compares them to the assumptions and commitments related to off-site transport in the FPEIS. 
- The FPEIS risk assessment methodology has been re-examined in light of new information about potential accidents and their possible effects on the environment (primarily human receptors). Section 2 of this report reviews the FPEIS risk assessment methodology. Section 6 presents a recalculation of risk factors using updated data.

- $\quad$ Emergency preparedness planning was a major factor in the FPEIS decision process for the CONUS sites, and a major planning concern for Operation Retrograde.

Section 7 of this report generally describes the emergency preparedness activities that are planned or underway at the CONUS facilities with reference to the experience gained during Operation Retrograde.

Assessment of the second issue, relating to potentially affected environmental resources, will be based on detailed information that has been collected about the PUDA site and its environs (Sect. 5). Since the purpose of the FPEIS was to perform a programmatic comparison of alternatives, detailed site-specific information on all environmental resources at the eight installations where chemical agents and munitions are stored was not used in most cases. Moreover, in some instances, the FPEIS uses generic information for the purpose of ascertaining significant differences among alternatives. Although such an approach is appropriate at the programmatic level, there is the perception that use of more detailed and more site-specific information may yield a different result.

\subsection{BACKGROUND}

In 1985, Congress directed the U.S. Department of Defense (DOD) to destroy the entire U.S. stockpile of unitary chemical agents and munitions in conjunction with the acquisition of binary chemical weapons (Pub. L. 99-145). DOD assigned the responsibility for the destruction of the stockpile to the U.S. Army, which subsequently established the Chemical Stockpile Disposal Program (CSDP).

Unitary chemical agents are so named because they can produce the desired toxic effect on human health in the form in which they are stored; they do not require mixing with another component to become toxic (as is the case with binary chemical agents). The unitary agent stored at PUDA accounts for $10 \%$ (by weight) of the total U.S. stockpile. Only one type of agent is stored at PUDA: mustard agent (including both agents HD and HT). Mustard agent is maintained at PUDA inside munitions (e.g., mortar rounds and projectiles) that also contain various explosive components (e.g., fuses, propellants, and bursters). All of these munitions are stored inside earth-covered concrete structures called igloos.

A federal program such as the CSDP requires a review in accordance with the National Environmental Policy Act (NEPA) of 1969 (Pub. L. 91-190, as amended) to ensure that environmental factors are given adequate consideration early in the decision-making process. For the CSDP, the NEPA review strategy has been structured to address two levels of decision making: the programmatic level and the site-specific level. Programmatic-level decision making focuses on alternative strategies-including disposal locations and the disposal technologies-for destroying the stockpiles. The programmatic decisions are national in scope and concern: (1) on-site destruction versus off-site transport for destruction at another 
installation and (2) the destruction technology. Site-level decision making focuses on implementation of the programmatic strategy at a particular site and is not national in scope. This two-level, tiered NEPA approach was acknowledged by the Council on Environmental Quality (CEQ) early in the NEPA process for the CSDP [A. A. Hill, chairman, CEQ, letter to A. M. Hoeber, Deputy Under Secretary of the Army, June 2, 1986]. Tiering is encouraged by CEQ (40 CFR Pt. 1502.20).

A Draft Programmatic Environmental Impact Statement (DPEIS) was issued in July 1986. In response to comments on the DPEIS and after numerous supporting studies were conducted during a 2-year period, the FPEIS was issued in January 1988 (U.S. Army 1988a). [Copies of the FPEIS may be obtained by contacting the U.S. Army at the following address: Chemical Materiel Destruction Agency, ATTN: SFIL-CME-N, Aberdeen Proving Ground, Maryland 21010-5401, phone (410) 671-3633.] More information on the FPEIS can be found in Appendix A.

The FPEIS identifies on-site incineration as the environmentally preferred alternative. Subsequently, the Army, in its record of decision (ROD) for the FPEIS, has selected on-site incineration as its preferred alternative [Fed. Regist. 53 (38), 5816-17 (Feb. 26, 1988)]. The Army's ROD also states,

The [eight] site-specific [NEPA] reviews will focus both on the implementation of the programmatic decision and on specific issues and concerns at each site. Additional study may uncover information that would warrant the reconsideration of the programmatic decision.

In light of this provision in the ROD, a decision was made to conduct the site-specific NEPA reviews in two phases. In Phase I, the programmatic decision in favor of on-site disposal is given further consideration by a review of its validity at each storage installation using newer, more detailed data than those used in the FPEIS. Specifically, new developments related to the incineration technology, agent transportation technology, emergency preparedness, and new environmental and population data are analyzed. The resulting Phase I Environmental Report is independently reviewed for adequacy and accuracy. The Army then certifies the Phase I process, either confirming or rejecting the programmatic decision of on-site disposal for the site in question.

In Phase II, a site-specific Environmental Impact Statement (EIS) is prepared. The scope of the EIS is limited to implementation of the on-site disposal decision if the programmatic decision is confirmed in Phase $I$. If the programmatic decision of on-site disposal is not confirmed in Phase I, then the scope of the EIS will be broadened to include off-site disposal alternatives (i.e., shipment of the inventory to another site for destruction) in addition to on-site disposal.

The site-specific NEPA reviews for CSDP began with Tooele Army Depot (TEAD) (U.S. Army 1988c; ANL 1989a; U.S. Army 1989a). The process has continued with Anniston Army Depot (ANAD) (U.S. Army 1989b; ANL 1989b; U.S. Army 1991d); Umatilla Depot Activity (UMDA) (U.S. Army 1990a; ANL 1990b), Pine Bluff Arsenal (PBA) (U.S. Army 1990b; ANL 1990c), and with this report for PUDA. This Phase I Environmental Report is part of the NEPA scoping process at PUDA, and it provides the 
environmental information by which the site-specific impacts of the proposed action are to be assessed in Phase II, the site-specific EIS.

\subsection{PUEBLO DEPOT ACTIVITY}

PUDA is located in Pueblo County, Colorado, about $160 \mathrm{~km}$ (100 miles) southeast of Denver and $23 \mathrm{~km}$ (14 miles) east of Pueblo (Fig. 1.1); the Arkansas River is about $1.6 \mathrm{~km}$ (1 mile) south of PUDA. The facility encompasses 9,168 ha $(22,654$ acres) and is situated on flat to gently sloping prairie. Surrounding land areas are mostly undeveloped ranchland used for grazing, with some light commercial and residential zoning to the south.

PUDA was established by the U.S. Army in 1942 as a storage and supply depot for ammunition and general supplies during World War II. After the war, PUDA became responsible for rebuilding and maintaining artillery fire control and optical materials and reconditioning transport and combat vehicles. Responsibilities for the distribution and storage of ammunition for a six-state area and various supplies for a nine-state area were added by 1951. By the early 1970s, PUDA had become a special weapons center with responsibility for distribution and training. It was also responsible for accountability of general supply stocks at three other reserve depots. Other functions included rebuilding and maintaining guided missiles and radio-controlled aerial targets, distributing U.S. Air Force ammunition over an eight-state area, storing strategic and critical materials, and calibrating and maintaining electronic test equipment. In 1974, PUDA was reduced to activity status and was assigned to TEAD. Activities, personnel, and missions were reduced.

The current missions at PUDA are (1) to operate a supply depot activity under the command of TEAD, providing for the receipt, storage, issue, maintenance, and disposal of assigned commodities; (2) to provide limited maintenance to prevent deterioration of activity facilities and retain limited shipping and receiving capabilities for assigned commodities; and (3) to manage the chemical munitions stockpile on-site and prepare for chemical munitions disposal under the CSDP. In 1989, PUDA had 5 military employees and 711 civilian employees. Tenants at the installation (the Occupational Health Clinic, Area Calibration and Repair Center, U.S. Army Information Systems Command, Martin Marietta Corp., Defense Reutilization Marketing Office, 1121st Signal Battalion, and the Pershing Project Office) employed 20 military personnel and 42 civilians in 1989.

The facilities at PUDA (Fig. 1.2) include about 270 buildings used for administration, housing, maintenance, and storage; about 920 igloos used for conventional and chemical munitions storage; active and inactive demolition grounds; and undeveloped perimeter zones. The installation does not manufacture, use, or test munitions, except to conduct surveillance testing for quality control of conventional munitions.

PUDA was recommended for realignment by the Defense Secretary's Commission on Base Realignment and Closure in its December 1988 report (DOD 1988). Through the Defense Authorization Amendments and Base Closure and Realignment Act (Pub. L. 100-526), Congress directed the Secretary of Defense to close or realign all military installations recommended for such action by the commission. The primary activities involved in the PUDA realignment are the transfer of the supply mission to TEAD, the transfer of the conventional ammunition mission to Red River Army Depot, Texas, and the 
ORNL.DWG 90M-10441

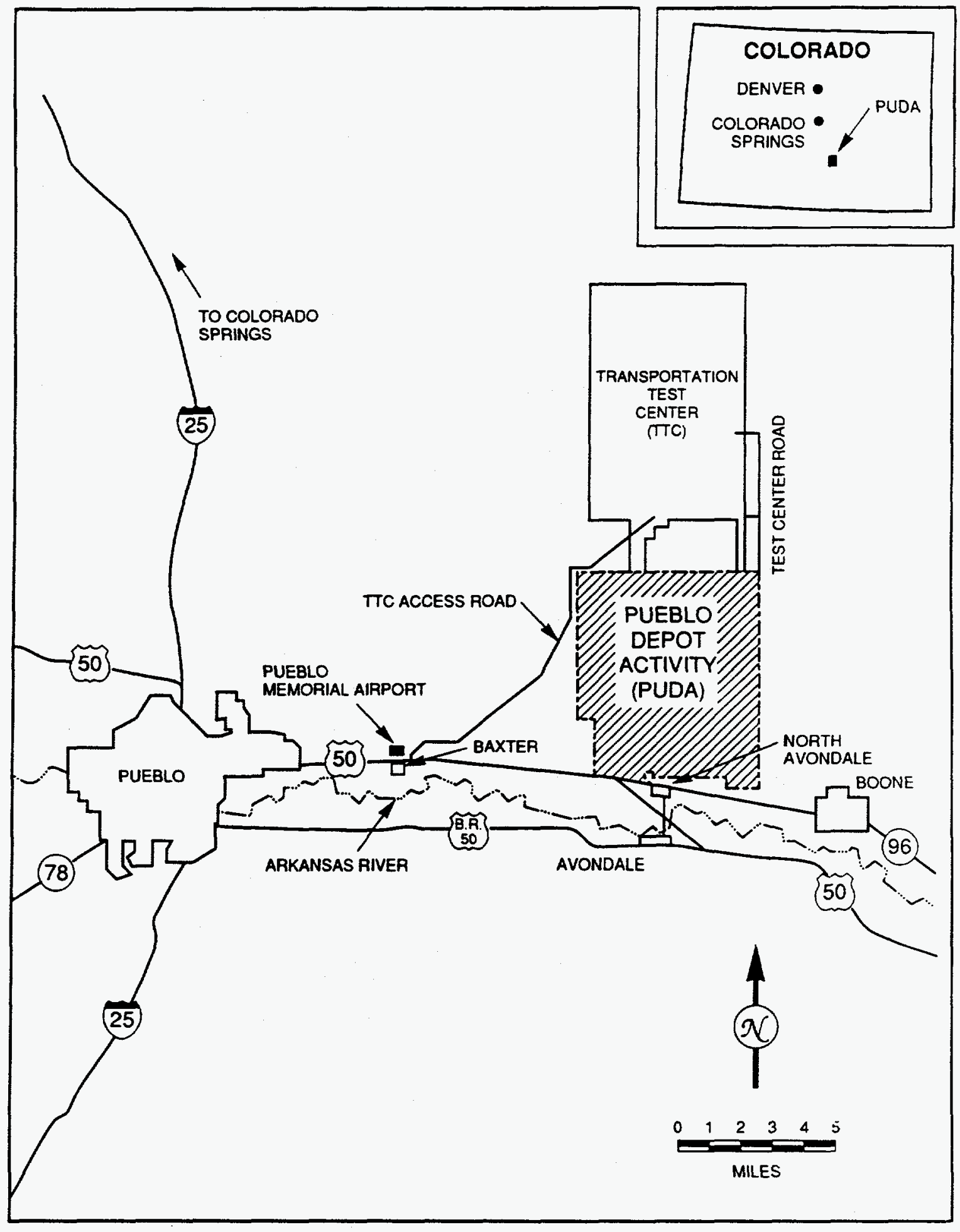

Fig. 1.1. Map of the vicinity of the Pueblo Depot Activity, Pueblo, Colorado. 


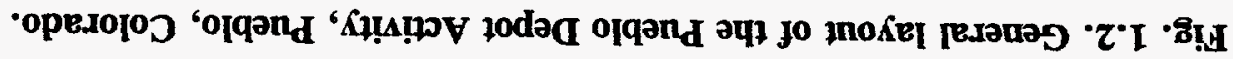

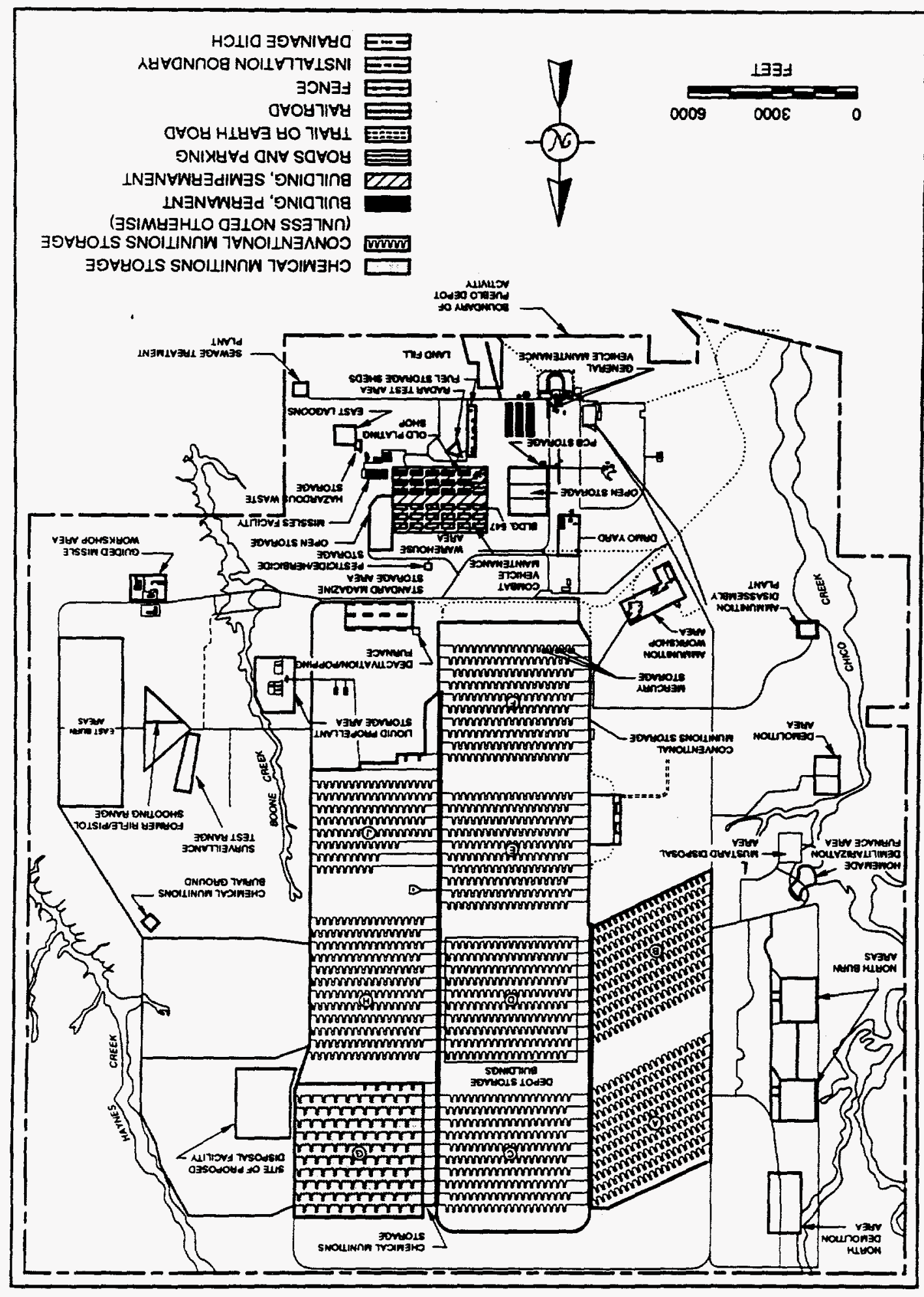

5mot-nos smo-indo 
elimination of obsolete conventional ammunition at PUDA. The potential impacts of these actions have been analyzed in a separate EIS (U.S. Army 1991a) and will be addressed in the site-specific EIS for the proposed CSDP action at PUDA.

The chemical agent inventory at PUDA consists of about $10 \%$, by weight, of the total U.S. lethal chemical stockpile. The PUDA inventory consists of only the blister agent mustard (chemical agents HD and HT) in explosively configured $105-\mathrm{mm}$ and $155-\mathrm{mm}$ projectiles (HD), and 4.2-in mortar rounds (HD and HT). The total PUDA chemical munitions inventory is stored inside earth-covered concrete igloos. The proposed disposal facility at PUDA is planned for construction in the northern part of the installation (Fig. 1.2).

\subsection{PURPOSE}

This Phase I Environmental Report has been prepared by the U.S. Department of the Army to assist in the development of site-specific NEPA compliance documentation for disposal of the lethal unitary chemical agents and munitions stored at PUDA. It is a continuation of the NEPA scoping process for destruction of the chemical weapons stored at PUDA. The process began during the preparation of the FPEIS and has continued on a sitespecific basis with a public meeting held at Pueblo, Colorado, on June 4, 1990. The report is not intended to validate the Army's programmatic ROD for the CSDP; rather it provides information for determining the validity of the FPEIS environmentally preferred alternative, on-site disposal, for PUDA.

\subsection{SCOPE}

NEPA provides an orderly process by which environmental considerations are incorporated into the decision-making process for major activities of federal agencies. Although technology-related issues may be discussed, this and other CSDP NEPA documents do not satisfy the environmental information needs of the facility-permitting process required by the Resource Conservation and Recovery Act (RCRA). The RCRA documentation must address more detailed technology information requirements and will also include public meetings to discuss RCRA-related technology issues.

Data gathered during the Phase I process include the following: (1) any new information that was not available for use in the FPEIS (e.g., threatened and endangered species, disposal technology developments), (2) more detailed information than was required for the programmatic purpose of comparing alternatives in the FPEIS (e.g., specific munition types, storage configurations, and transport distances), and (3) any information that may have been overlooked in the FPEIS.

The potential impact region addressed by this Phase I report is limited to the area within $100 \mathrm{~km}$ (62 miles) of the site of the proposed disposal facility at PUDA (Fig. 1.3). This area (also referred to as the 100-km [62-mile] zone) is the largest credible zone of potential human health impacts as identified in the FPEIS. At PUDA, the continued storage alternative was postulated in the FPEIS to have the potential for accidents causing human fatalities to a distance of $100 \mathrm{~km}$ (62 miles). In fact, this radius would apply to all 
ORNL-DWG 92-12607

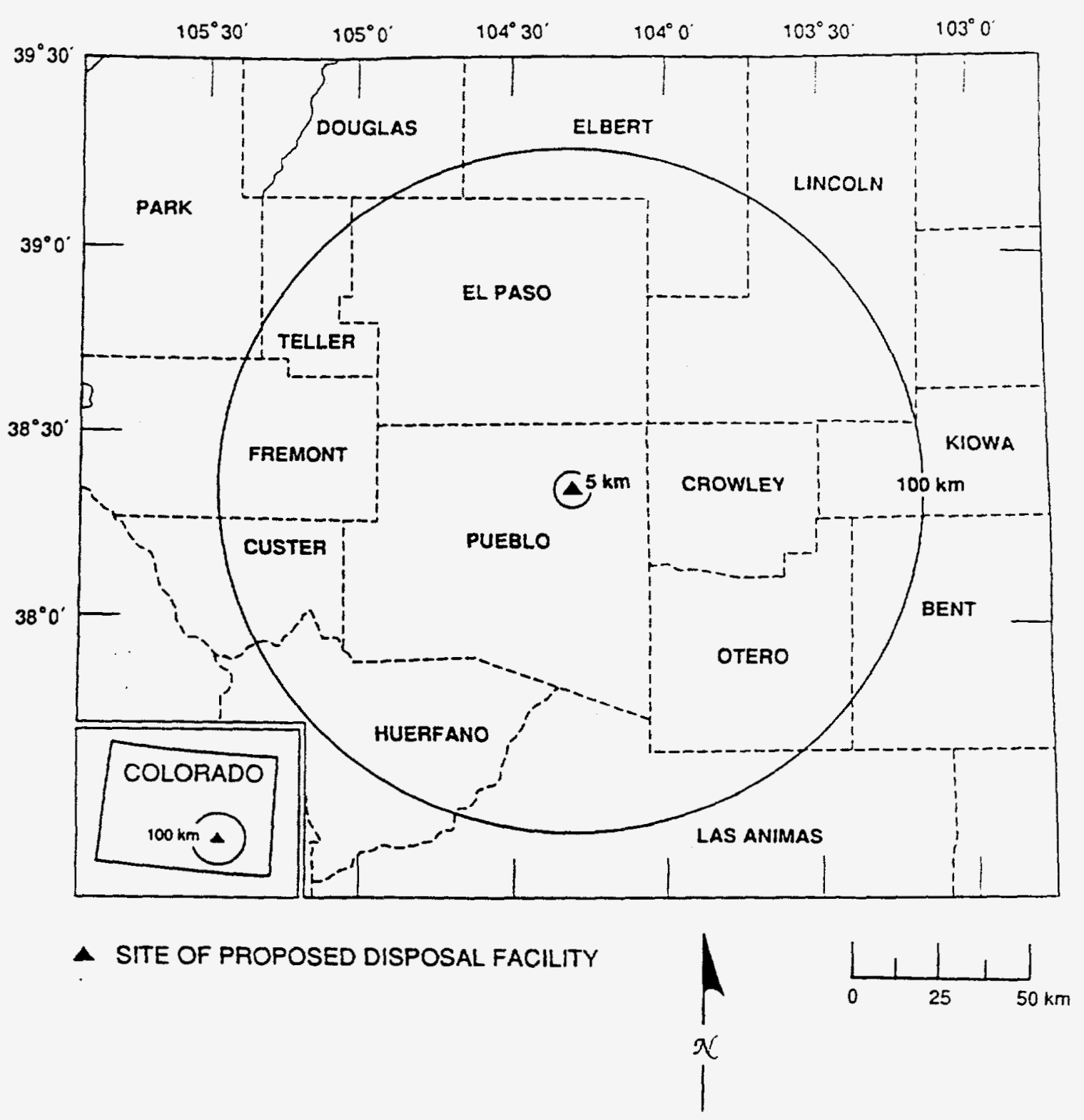

Fig. 1.3. Potential impact region of Pueblo Depot Activity, Pueblo, Colorado. 
alternatives because each would require storage until completion of disposal operations. However, for the purposes of analysis and comparison of the risks of the various alternatives, the nonstorage risks of each alternative are used here. The on-site disposal alternative at PUDA was estimated in the FPEIS to have the potential for accidents (e.g., handling accidents resulting in detonation or an aircraft crash into a storage igloo) causing human fatalities to a distance of $5 \mathrm{~km}$ ( 3 miles). The regional and national disposal alternatives were postulated to have the potential for accidents causing human fatalities to a distance of $100 \mathrm{~km}$ (62 miles). Thus, different impact zones are applicable to different alternatives.

In the FPEIS, information on some of the resources was collected for zones of different sizes. This Phase I report addresses resource information to the minimum distance applicable for the alternatives under consideration. Some resources are described for larger regions as appropriate (e.g., potential ecological impacts do not necessarily coincide with the zone for human fatalities; economic impacts are more appropriately described on a multicounty or regional basis).

Section 2 of this report briefly discusses the method employed in the FPEIS to identify the environmentally preferred alternative (more detail is given in Appendix A). It also describes the approach taken in this Phase I report to reassess the programmatic data for PUDA, and it defines and outlines the framework under which the re-examination of FPEIS data is to be performed.

Section 3 provides an assessment of the recent developments with the Army's disposal technology by summarizing lessons learned during JACADS operations and comparing JACADS results to the FPEIS data and assumptions. Major factors contributing to risk from disposal operations are identified and their potential to change the relative ranking of alternatives is addressed.

Section 4 provides perspective on the Army's recent success in moving chemical munitions from Europe to Johnston Island. This section also reviews those aspects of the FPEIS risk assessment and decision methodology that were associated with the movement of chemical agents and munitions in order to attempt a comparison to the European experience. The overall theme of this section is to state the relevance of the recent transportation experience in terms of the assumptions and commitments included in the FPEIS assessment.

Section 5 addresses data (population, meteorology, etc.) and resources that are relevant to site-specific implementation.

Section 6 re-examines the environmentally preferred alternative using data collected during Phase I. It first presents the types of information used to identify the programmatic environmentally preferred alternative; it then presents the recent and detailed data of this type collected for PUDA during Phase I. Data that have changed appreciably are used to reevaluate on-site disposal using the FPEIS approach; then, the new information is compared with that used in the FPEIS to identify the environmentally preferred alternative.

Section 7 provides an update of the emergency preparedness planning for the CSDP. The needs of the specific disposal sites may vary, so an emergency response concept plan has been developed for PUDA and for each one of the other storage/disposal sites.

A summary of Phase I findings is given in Sect. 8, along with conclusions regarding the subsequent preparation of the site-specific EIS for PUDA. Findings from each of the previous chapters are combined in a final discussion of their effects on the selection of on-site incineration as the environmentally preferred alternative and on its implementation at PUDA. 


\section{APPROACH}

The FPEIS concluded that on-site disposal of the U.S. stockpile of lethal unitary chemical agents and munitions is environmentally preferred over off-site disposal alternatives, both for the CSDP as a whole and for the environs and affected population in the vicinity of PUDA. This Phase I Environmental Report more closely examines the preference for on-site disposal of the PUDA inventory in light of newer or more site-specific information than was used in the FPEIS.

\subsection{IDENTIFYING THE PROGRAMMATIC ENVIRONMENTALLY PREFERRED ALTERNATIVE}

During preparation of the FPEIS, a method was developed to systematically compare the programmatic alternatives in order to identify the environmentally preferred alternative. Alternatives were compared with respect to potential impacts from implementing each of the alternatives under both normal operations and accident scenarios. A probabilistic risk assessment was conducted for accidents and their potential impacts to human health. The results of this risk assessment were presented in terms of five "measures of risk" which became the basis for comparing alternatives in the FPEIS.

Since the publication of the FPEIS, there have been no new risk technology developments that would bring the risk assessment method into serious question. The calculation of expected fatalities as a measure of risk is an accepted method for determining the risk associated with industrial operations. The inclusion of four other measures of risk provide additional insight into possible impacts of the on-site disposal operations. Furthermore, any modification of the risk methodology at this time would hamper the comparison of the more detailed and more recent site-specific data to the FPEIS results, a stated function of this Phase I report.

The FPEIS concludes that potential impacts from normal, incident-free operations would be minimal and mitigable and would not be significant in distinguishing among program alternatives. Consequently, potential effects from accident scenarios figure prominently in identifying the environmentally preferred alternative. The method consists of sequential examination and comparison of factors reflecting the programmatic goals of no fatalities and minimal environmental insult. The comparison involves three consecutive tiers of examination for each programmatic alternative: (1) human health impacts, (2) ecosystem and environmental impacts, and (3) feasibility and potential effectiveness of emergency planning and preparedness. Appendix A presents details on how the method was developed and used in the FPEIS. Fig. 2.1 provides an overview of how the method was used to identify on-site disposal as the programmatic environmentally preferred alternative (i.e., the alternative with the least potential for causing significant adverse impacts). 
ORNL.DWG 89M-8762R2

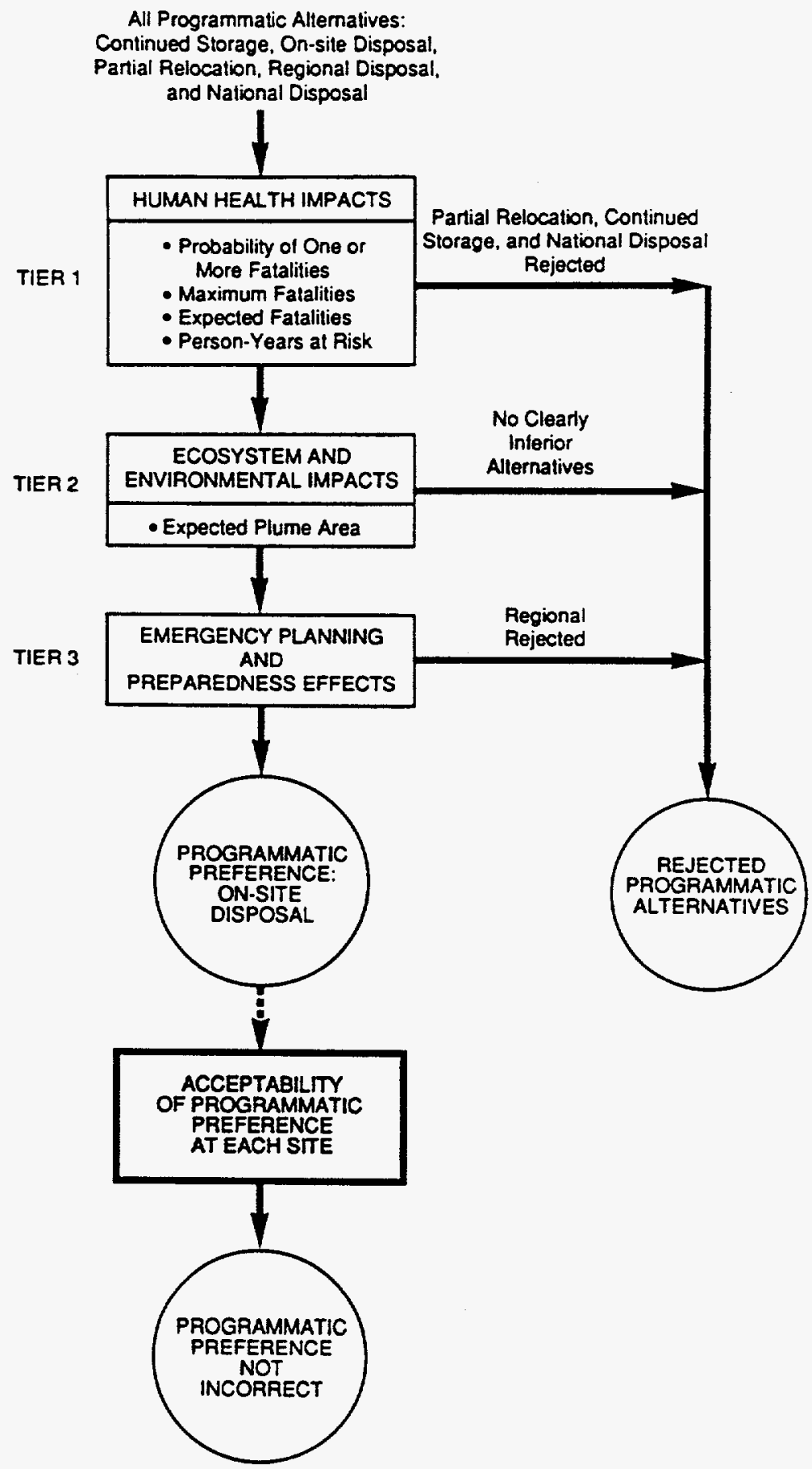

Fig. 21. Flowchart illustrating selection of the Chemical Stockpile Disposal Program environmentally preferred alternative. 
For the first tier, four measures of risk were developed to compare alternatives (see Appendix A for a detailed mathematical description of each measure of risk):

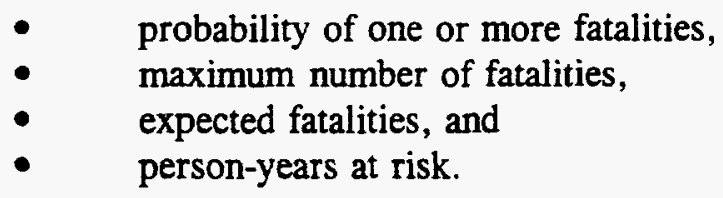

For the second tier, a fifth measure of risk was developed to serve as a surrogate measure of potential impact to the ecosystem:

- $\quad$ expected plume area.

Figure 2.2 presents a simplified generalization of the types of data used to formulate the five measures of risk. The risk measures comprise two types of data: (1) residential population and (2) accident probabilities-agent release quantities (the expected plume area risk measure is the only one of the five that does not reflect population estimates and is represented solely by the physical characteristics of the hypothetical accident). Within the population data category, the number of people around the depot and their location are of primary interest. Within the accident category, two types of data are of interest: internal and external. Internal data, those over which the Army has control, are the technology factors affecting the accident probabilities and agent release quantities: the types of equipment in the technology, the procedures by which the technology is used, and the transportation of agents and munitions on-site. The Army can control them through design changes, procedure changes, or location changes of the proposed disposal facility (or railhead loading facility in the case of national disposal). External data, those over which the Army has little (if any) control, are meteorological factors; the amount of aircraft activity (which can be controlled over an installation through the use of prohibited airspace but which cannot be controlled outside this airspace); the frequency and intensity of earthquakes (seismicity); and the frequency of meteorite strikes. The assumptions and information used for the external data are described in more detail in Appendix A, as are the mathematical processes used to analyze the data for the computation of measures of risk.

Of the five risk measures discussed above, the first four were used for the health effects tier, and the fifth risk measure was used for the ecosystem environment tier. No risk measures were deemed necessary for the third tier, which deals primarily with the adequacy of emergency planning and preparedness. Thus, the method used to prepare the FPEIS consists of comparing a particular risk measure for a given alternative with the same risk measures for the other alternatives. To avoid presenting classified data on the stockpile at any particular site, the exact numbers calculated for these risk measures were not used on a siteby-site basis. Site-specific numbers were translated into shading patterns in the form of graphical pictograms. (See examples in Appendix A.) 


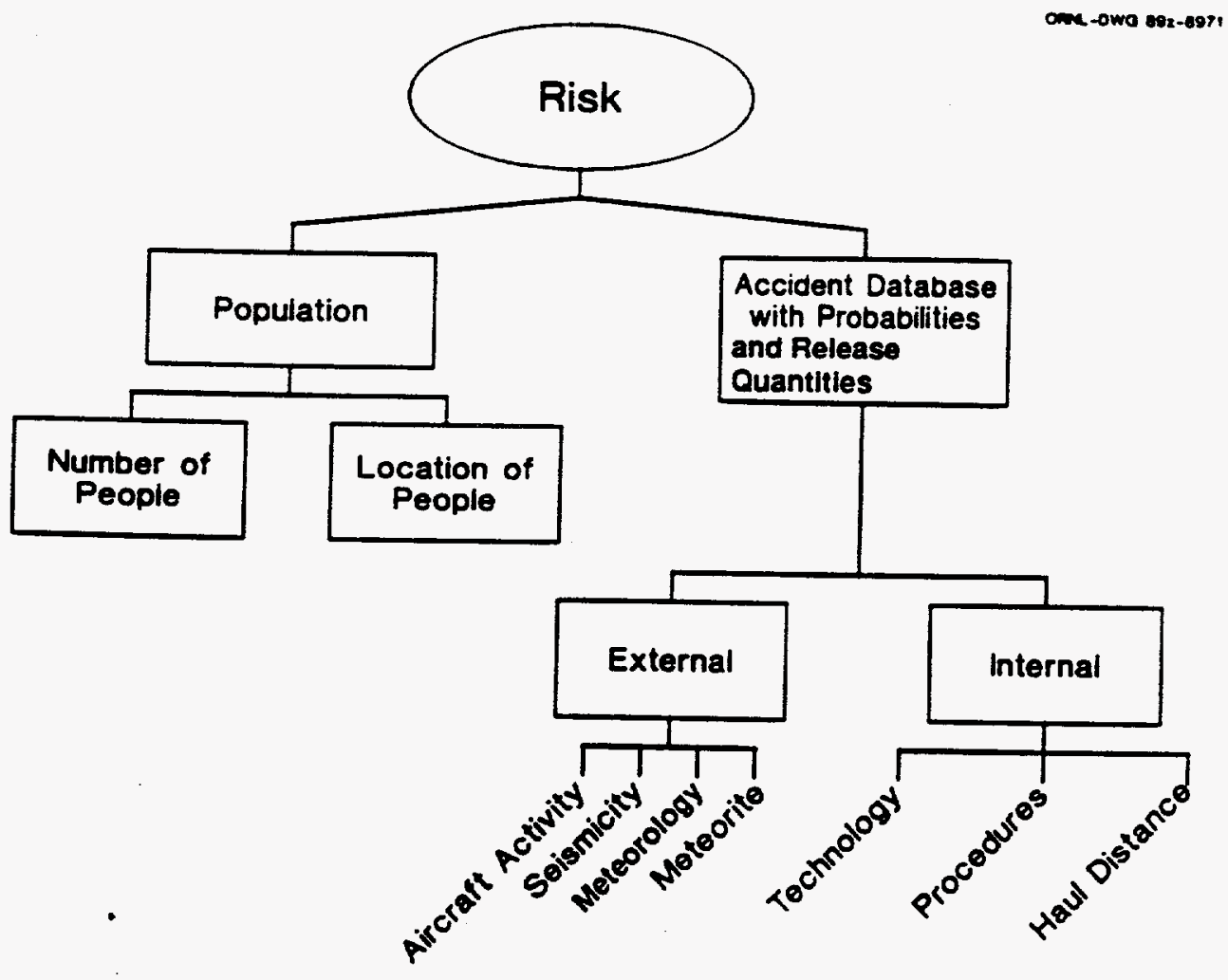

Fig. 22. Conceptual overview of data types on which the programmatic environmentally preferred alternative is based. 
Each shading pattern represents a factor-of-10 difference in the numerical risk value. The decision was made to designate a difference of at least two pictogram shading patterns as the FPEIS criterion against which a "significance difference" could be determined (Appendix A). A one-shading difference in the pictograms could not be used to guarantee the factor of ten difference, because the numerical range assigned to each pictogram shading pattern spanned a factor of ten from its lower limit to its upper one. Accepting or rejecting alternatives at a given tier was therefore based upon the fact that a difference between risk measures of at least two pictogram shading patterns represents a significant difference. At a given tier, an alternative could be selected as the environmentally preferred alternative, provided the value for at least one risk measure is significantly lower than the values of the same risk measure for the other alternatives.

As shown in Fig. 2.1, all five programmatic alternatives were examined at the first tier (human health) of the process using the first four measures of risk. The FPEIS rejects partial relocation by air, continued storage, and national disposal to be based on the first four risk measures, leaving regional disposal and on-site disposal for consideration in the second tier. Examining the regional and on-site disposal alternatives in light of ecosystem and environmental impacts showed that these two alternatives are indistinguishable.

In the third tier (emergency planning and preparedness), regional disposal was rejected because of the greater difficulties in providing adequate emergency response along transportation corridors as compared to the region around each depot. On-site disposal thus survived the three tiers to become the preferred alternative.

Using the above process and the FPEIS data collected for each site, the FPEIS goes one step further, examining the preferred programmatic alternative to show that the risks from on-site disposal are no greater than the risks from the other alternatives considered (Fig. 2.1). For PUDA, the FPEIS (see U. S. Army 1988, Vol. 1, Sect. 2.6.3.3.6) also concludes that the programmatic alternative of on-site disposal is valid.

Note that the method for identifying the environmentally preferred alternative was never used to identify on-site disposal as the site-specific alternative at any installation. Rather, it was used to identify a programmatic alternative and was then used to show that the alternative identified is not incorrect for any given installation. This completed the analyses that served as input into the decision process for identifying on-site disposal as the programmatic environmentally preferred alternative.

\subsection{Phase I CONCEPTUAL FRAMEWORK}

An overview of the approach used in this closer examination at PUDA is shown in Fig. 2.3. The Phase I report also serves the secondary function of collecting and cataloging data on site-specific resources for use in the assessment of impacts in the site-specific EIS.

As noted in Sect. 1, four broad categories of information dominate the Phase I analyses: (1) maturity of the chosen disposal technology; (2) the movement of the chemical stockpile from the FRG; (3) detailed, site-specific information; and (4) emergency preparedness. Since each category has possible findings that could cast doubt on the 


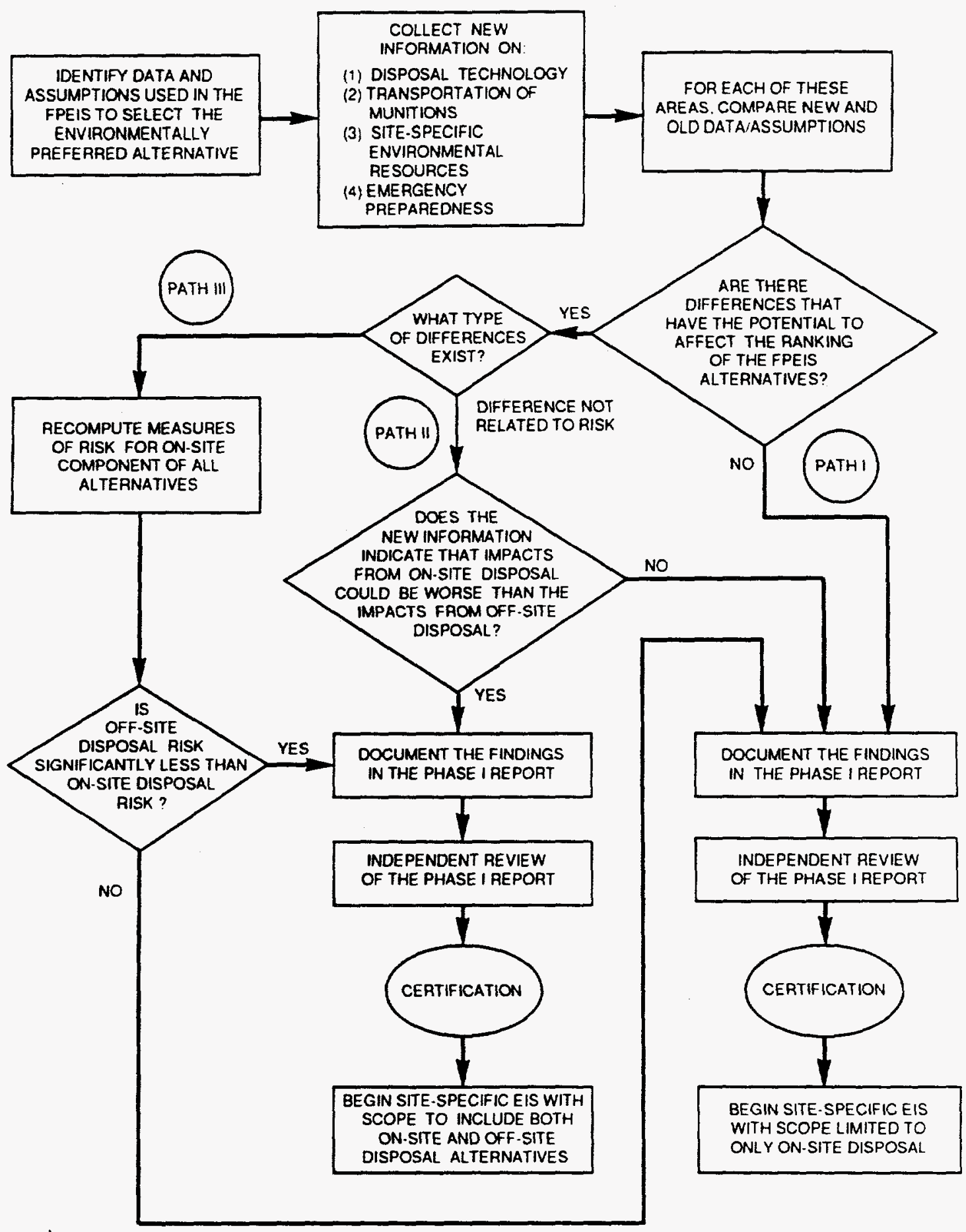

Fig. 2.3. Flowchart illustrating the Phase I concept. 
continuing validity of on-site disposal, the categories are considered separately, as shown in Fig. 2.3.

First, the data and assumptions used in the FPEIS that have the potential to change the relative ranking of alternatives are identified. Next, the new information is examined to determine if the key assumptions in the FPEIS are still valid and if there are any major differences between the new and old data. If there are no changes that cast doubt on the implementation of on-site disposal (Path I in Fig. 2.3), then the conclusion for that category of information is that on-site disposal is still environmentally preferred. If such changes are found, then subsequent consideration would take one of two paths: (1) Path III, recalculation of the measures of risk (discussed below), if the new information is amenable to such quantification, or (2) Path II, recommendation to conduct a detailed assessment of environmental impact. For example, if the new information included a potentially affected endangered species not previously considered, then the environmental impact of the various disposal alternatives on the endangered species would be examined for its potential to affect the determination of the environmentally preferred alternative at PUDA. Alternatively, if the new information included population data, it would be factored into recalculation of the measures of risk. In either case, the objective of the analysis is to determine if on-site disposal is still environmentally preferred.

Detailed, site-specific information is addressed in Sect. 5. Examination of new information for this category could follow one of the three paths shown in Fig. 2.3. For example, if new population data affect all alternatives equally, it could follow Path I and not require further assessment. It could also follow Path III, indicating a difference between the alternatives and requiring recalculation of the measures of risk. As noted above, information about endangered species could follow Path II, requiring assessment of the environmental impact of all alternatives (including off-site disposal) in the site-specific EIS, if it is found that on-site disposal is no longer the environmentally preferred alternative.

Section 7 addresses recent developments related to emergency preparedness. If changes that have occurred affect all alternatives equally, then the Phase I approach would follow Path I, and the changes would not require further assessment. However, changes that affect the alternatives differently would require assessment in the site-specific EIS.

\subsection{DATA COLLECTION AND AGENCIES CONTACTED}

This Phase I report is supported by data collected by the authors during a site visit on June 4-6, 1990, to the Pueblo, Colorado, area. A scoping meeting was also held on June 4, 1990 , at the Pueblo County High School (located in Pueblo, Colorado) to solicit public input to the environmental review process and to determine the significant issues relating to the proposed implementation of on-site disposal of the PUDA inventory. Several verbal comments were received during the scoping meeting. Verbal comments made at the meeting dealt with whether there are any long-term effects from mustard exposure; who is responsible for quickly terminating disposal operations; the extent of the security force to be in effect during disposal operations (given the reduction in force planned for PUDA under base closure and realignment); the potential for disposal operations to release toxic compounds to the atmosphere; the potential reuse of the proposed disposal facility after the PUDA stockpile is 
destroyed; and the physical properties of mustard agent. Two written comments have been received since the June scoping meeting. One was a request to be placed on the mailing list for the EIS. The second suggested incinerator design parameters that could help reduce potential environmental impacts from disposal operations. Each of the above comments is to be addressed in the site-specific EIS for PUDA; because the latter deals with impact assessment, it is beyond the scope of this Phase I report.

Written comments on the FPEIS received since its publication also have been reviewed. All were sent by the Pueblo Area Council of Governments (PACOG). They address PACOG support of on-site disposal, the need for assistance for emergency planning, and PACOG's interest in continuing involvement in planning for disposal of the PUDA stockpile. None of these comments deal specifically with the identification of new or overlooked environmental resources near PUDA that should be addressed in this Phase I report.

Input was also solicited from the cooperating agencies, which include the U.S. Department of Health and Human Services (DHHS); the U.S. Environmental Protection Agency (EPA); the U.S. Federal Emergency Management Agency (FEMA); and many agencies of the state of Colorado. Information obtained from these agencies was considered in conducting this analysis. Additionally, each agency reviewed the draft Phase I document before its release. Their comments and written responses are presented in Appendix E.

In addition to the documents referenced throughout this report, contact was made with the following agencies during the collection of data for the Phase I process.

Ed Aldred, Administrative Clerk, National Park Service, La Junta, Colo.

Luanne Beard, Pueblo Chamber of Commerce and Visitor's Bureau, Pueblo, Colo.

Arvin Bloom, Director, Instructional Services Division, Colorado State Department of Education, Denver, Colo.

Norm Childs, Convention and Visitor's Director, Pueblo Chamber of Commerce and Visitor's Bureau, Pueblo, Colo.

Richard Dale, Assistant to the Safety Officer, PUDA, Pueblo, Colo.

Steve Douglas, Director, and Karen Ashcraft, Emergency Operations Coordinator, Pueblo County Department of Public Safety, Pueblo, Colo.

Chuck Finley, Director, Pueblo County Department of Planning, Pueblo, Colo.

Michael French, Park Manager, and Gene Rizzy, Pueblo State Recreation Area, Pueblo, Colo.

Martin Gonzales, Director, and Marilyn Snook, Secretary, Pupil Personnel Department, District 60 Schools, Pueblo, Colo.

Dorothy Hammond, Office of Personnel, School District No. 60, Pueblo, Colo.

Marie Hobbs, Pueblo Greyhound Park, Pueblo, Colo.

Helen Kramer, Secretary for Residence Hall, University of Southern Colo., Pueblo, Colo.

Larry Kramer, Manager, Lathrop State Park, Walsenburg, Colo.

Jody Lane, Park Manager, Pueblo City Parks, Pueblo, Colo.

Glenn Matson, Sports Information Student Assistant, Athletic Department, University of Southern Colo., Pueblo, Colo.

Jonnie McFarland, Manager, Pueblo City Zoo, Pueblo, Colo. 
Jim Munch, Director, and Don Vest, Statistical Data Librarian, City of Pueblo Department of Planning, Pueblo, Colo.

John D. Musso, Superintendent of Support Services, School District No. 70, Pueblo, Colo. Curtis Phillips, Assistant Superintendent for Business, District 60 Schools, Pueblo, Colo.

Sollie Raso, Chairman, Pueblo County Commissioners, Pueblo, Colo.

Dee Renfrow, Secretary for Music Department, University of Southern Colo., Pueblo, Colo. U.S. Fish and Wildlife Service, Endangered Species Office, Denver, Colo. (Galene Buterbaugh)

Margaret Will, Coordinator of Student Activities, University of Southern Colo., Pueblo, Colo.

Harry Wenzel, Pueblo County Sheriff's Office, Pueblo, Colo.

Winnie Zeisel, Pueblo County Department of Community Services, Pueblo, Colo. 


\section{DEVELOPMENTS IN DISPOSAL TECHNOLOGY SINCE THE FPEIS}

The term "technology development" refers to the continuing Army refinement of designs and procedures for incineration. This refinement proceeds from the conceptual design stage, to the operation of the proposed disposal facility, through the destruction of the chemical stockpile. The design and procedures are further refined through state and EPA regulatory reviews. Regulatory approvals of the design and procedures are required from the state of Colorado prior to the start of construction of the PUDA facility.

The Army's recent experience in destroying chemical agents and munitions is examined in this section, including developments in both the reverse assembly of munitions and agent-munition incineration. The objective is to identify and review any recent developments in the Army's disposal technology that could have affected the conclusions reached in the FPEIS had the information been available prior to its publication. The ability of the Army to accomplish the destruction of the lethal unitary chemical stockpile in the manner set forth in the FPEIS is the principal issue addressed.

The technology-related assumptions and commitments used in the FPEIS selection of the environmentally preferred alternative are reviewed and compared to the data resulting from recent chemical agent and munitions disposal operations. Such a comparison will assist in determining whether actual experience with the disposal technology is consistent with the rationale developed in the FPEIS and the resulting ROD for the selection of the environmentally preferred alternative.

\subsection{ASSESSMENTS OF THE DISPOSAL PROCESS IN THE FPEIS}

\subsubsection{Background}

Chemical demilitarization operations have been successfully conducted in demilitarization facilities in former production facilities at Rocky Mountain Arsenal (RMA), located at Denver, and at the Chemical Agent Munitions Disposal System (CAMDS), located at TEAD, Utah. CAMDS is the pilot-scale facility for proof testing the incineration technology to be used for destruction of chemical agents and munitions. Through calendar year 1989, about 6.7 million $\mathrm{kg}$ (14.8 million $\mathrm{lb}$ ) of agent had been destroyed at RMA and at CAMDS.

Since publication of the FPEIS (U.S. Army 1988a), a demilitarization facility has been operated at PBA for the destruction of the nonlethal but incapacitating agent BZ. The facility was constructed to dispose of $1500 \mathrm{BZ}$ munitions, approximately 2000 drums of contaminated residue, and more than 200 drums of neat $\mathrm{BZ}$ (the purified form of the agent) that were stockpiled at PBA. Operations began on May 9, 1988. All neat BZ was destroyed by September 1988. All BZ munitions had been destroyed by September 1989, and all of the BZ-contaminated inventory had been destroyed by January 1990 . In total, approximately $42,600 \mathrm{~kg}(94,000 \mathrm{lb})$ of agent $\mathrm{BZ}$ were destroyed by incineration. 
JACADS was constructed on Johnston Island in the Pacific Ocean to dispose of the chemical munition stockpile that has been maintained in the Pacific region since the 1940s, and serves as the prototype plant for the eight CONUS on-site disposal facilities that are planned by the CSDP. Any design enhancements or operational lessons learned from the JACADS experience will be incorporated into the CONUS facilities.

In September 1988, Congress required the Army to successfully complete OVT of the JACADS technology before proceeding with destruction of the CONUS stockpile of munitions and agents (Pub. L. 100-456). The JACADS Test and Evaluation Master Plan (Duff et al. 1989) for the OVT program was reviewed by DHHS and the National Research Council, and on July 16,1990 , OVT began at the JACADS facility.

During these demilitarization operations, no facility emissions exceeding regulatory limits have been detected. Table 3.1 summarizes the U.S. Army's experience in industrialscale disposal of chemical agents and munitions.

\subsubsection{Technology-Related Assumptions and Commitments}

Implementation of the FPEIS decision methodology, outlined in Appendix A, for identifying the programmatic environmentally preferred alternative, required that some assumptions be incorporated into the process to help provide a basis for comparison of the various disposal alternatives. Additionally, to mitigate potential impacts and reduce the levels of risk, the Army made a number of commitments in the FPEIS. The FPEIS assumptions and commitments, as well as the design criteria subsequently developed that were related to the disposal technology, are briefly addressed in this section in order to set the stage for a comparison between the FPEIS and actual Army experience with the incineration process in the following section.

In the FPEIS, the technological aspects of the destruction of chemical agents and munitions are viewed as comprising three distinct phases: (1) construction of the disposal facility; (2) disposal operations, including on-site transportation to the facility; and (3) decommissioning of the disposal facilities. Of these, construction and decommissioning activities were not found to be significant in distinguishing between the disposal alternatives. Construction activities at each storage location for any of the alternatives have been determined to be "typical of that for any medium-scale industrial facility," and would not result in unmitigated impacts. Similariy, decommissioning impacts are determined to "not be of overriding concern at any particular site or vastly different among the sites" (U.S. Army 1988a).

The potential impacts from normal disposal operations would result from three sources: (1) plant emissions, (2) transport of agents and munitions from storage sites to the disposal facility, and (3) solid wastes generated from incineration of the chemical agents. In the FPEIS none of these is found to result in unmitigated impacts at individual sites, nor are the differences between sites found to be of overriding concern (U.S. Army 1988a).

In contrast to normal operations, abnormal or upset operations involving highconsequence accidents could have serious environmental consequences, including human fatalities and illnesses, destruction of wildlife and habitat, destruction of economic resources, and adverse impacts on the quality of life. Such high-consequence accidents would be unlikely and their impacts would depend on population distributions, the chemical agents and 
Table 3.1. Summary of U.S. Army's experience in industrial-scale chemical agent/munitions disposal

\begin{tabular}{|c|c|c|c|c|c|c|c|}
\hline \multirow[b]{2}{*}{ Operation } & \multirow[b]{2}{*}{ Description } & \multirow[b]{2}{*}{ Date } & \multirow[b]{2}{*}{ Agent } & \multirow[b]{2}{*}{ Site $^{2}$} & \multirow[b]{2}{*}{ Process ${ }^{h}$} & \multicolumn{2}{|c|}{ Quantity } \\
\hline & & & & & & $(1,000 \mathrm{~kg})$ & $(1,000 \mathrm{lbs})$ \\
\hline Project Eagle Phase I & Ton Containers & July $72-M a r .74$ & H & $\mathbf{R}$ & I & 2008.5 & $4,428.0$ \\
\hline Project Eagle Phase I & Ton Containers & July 72-Mar. 74 & HD & $\mathbf{R}$ & I & 777.5 & $1,714.0$ \\
\hline Project Eagle Phase II & M34 Cluster Bombs & Oct. 73-Nov, 76 & GB & $\mathbf{R}$ & $\mathrm{N} / \mathbf{1}$ & 1873.2 & $4,129.6$ \\
\hline $\begin{array}{l}\text { Project Eagle Phase II } \\
\text { (Expanded) }\end{array}$ & $\begin{array}{l}\text { Underground Storage } \\
\text { Tanks }\end{array}$ & Sept. 74-Nov. 74 & GB & $\mathbf{R}$ & $\mathbf{N}$ & 171.5 & 378.0 \\
\hline $\begin{array}{l}\text { Project Eagle Phase II } \\
\text { (Expanded) }\end{array}$ & Ton Containers & May 75-Nov. 75 & GB & $\mathbf{R}$ & $\mathrm{N} / \mathrm{I}$ & 1635.0 & $3,604.5$ \\
\hline $\begin{array}{l}\text { Project Eagle Phase II } \\
\text { (Expanded) }\end{array}$ & $\begin{array}{l}\text { Honest John Warhead } \\
\text { (M139) }\end{array}$ & Apr. 75 -Nov. 76 & GB & $\mathbf{R}$ & $\mathrm{N} / \mathrm{I}$ & 34.7 & 76.5 \\
\hline $\begin{array}{l}\text { Chemical Agent Indentification } \\
\text { Sets Disposal }\end{array}$ & $\begin{array}{l}\text { Chemical Agent } \\
\text { Identification Sets }\end{array}$ & May 31-Dec. 82 & (c) & $\mathbf{R}$ & I & 16.6 & 36.7 \\
\hline M55 Rocket Disposal & & Sept. 79-Apr. 81 & GB & C & $N / I$ & 58.1 & 128.0 \\
\hline $\begin{array}{l}\text { Agent Injection } \\
\text { Incineration Tests }\end{array}$ & & Apr. 81-Jan. 84 & GB & C & I & 5.1 & 11.2 \\
\hline $\begin{array}{l}\text { Agent Injection } \\
\text { Incineration Tests }\end{array}$ & Ton Containers & June 81-Aug. 84 & $\mathbf{v X}$ & C & $\mathbf{I}$ & 3.6 & 7.9 \\
\hline $\begin{array}{l}\text { 155mm Projectile } \\
\text { Disposal }\end{array}$ & & July 81-Jul. 82 & GB & C & $\mathrm{N}$ & $\begin{array}{l}27.4 \\
\mathrm{~N}\end{array}$ & 60.5 \\
\hline $\begin{array}{l}\text { 105mm Projectile } \\
\text { Disposal }\end{array}$ & & Mar. 82-July. 82 & GB & C & $\mathbf{N}$ & & \\
\hline $\begin{array}{l}\text { In-Situ Agent } \\
\text { Incineration }\end{array}$ & & Oct. 82-Dec. 83 & GB & C & I & 8.0 & 17.6 \\
\hline $\begin{array}{l}\text { M55 Rocket } \\
\text { Incineration }\end{array}$ & & Nov. 85-Nov. 86 & GB & C & I & 1.0 & 2.3 \\
\hline $\begin{array}{l}\text { Liquid Incineration } \\
\text { Test }\end{array}$ & & Aug. 85-Aug. 86 & GB & C & I & 17.2 & 37.9 \\
\hline Agent BZ Disposal & & May 88-Sept. 89 & $\mathrm{BZ}^{\mathrm{d}}$ & $\mathbf{P}$ & I & 42.6 & 94.0 \\
\hline Liquid Incinerator Test & & Sept. $89-$ Oct. 89 & VX & C & I & 18.1 & 40.0 \\
\hline Operational Verification Test & & July 90 -Feb. 91 & GB & $\mathbf{J}$ & I & 34.6 & 76.8 \\
\hline Total & & & & & & $6,732.8$ & $14,843.5$ \\
\hline
\end{tabular}

'R refers to Rocky Mountain Arsenal, C to Chemical Agent Munitions Disposal System, P to Pine Bluff Arsenal, and J to Johnston Atoll Chemical Agent Disposal System.

${ }^{\mathrm{b}} \mathrm{N}$ refers to agent neutralization only; I to incineration of agent and explosive (and/or metal parts thermal decontamination); $\mathrm{N} / \mathrm{I}$ to agent neutralization and explosive incineration (and/or metal parts thermal decontamination).

'Agents include phosgene, chloropicrin, mustard, lewisite, cyanogen chloride, nitrogen mustard, and GB.

dThe incapacitating agent $\mathrm{BZ}$ is not lethal. 
munitions involved, and natural conditions and features at the specific location. Hence, for identifying the environmentally preferred alternative, the principal thrust of the FPEIS is the examination of accident scenarios, their probabilities of occurrence, and attendant environmental impacts.

The Army is committed to destroying the CONUS stockpile of chemical agents and munitions in a safe and environmentally sound manner. The ability to carry out this commitment can be determined by evaluating two types of data resulting from the OVT at JACADS.

First, the Army must demonstrate efficient plant performance (i.e., the ability to destroy the agents and munitions as planned). One way this ability can be measured is by examining throughput rates (numbers of munitions processed per unit time of plant operation), examining agent destruction rates (amounts of the agents destroyed per unit time of plant operation) during the JACADS OVT, and comparing them to known design criteria for plant operations. Furthermore, as with any industrial process that is similar in scale to the JACADS facility, some problems are expected to be encountered during the startup and testing phases. The Army's ability to analyze and correct such problems efficiently, and the resulting decrease in facility downtime as the OVT progresses, can serve as indicators of the readiness of the technology for implementation in the planned CONUS facilities.

Second, the ability to destroy the chemical munitions in a way that prevents harm to human health and the environment is paramount to the CSDP operations. This capability can be demonstrated by comparing environmental data collected during the JACADS OVT to environmental and health protection commitments stated in the FPEIS or to existing environmental regulations. The pertinent data include stack emissions, solid wastes, environmental monitoring, worker exposure, and environmental compliance information. (In the CONUS facilities, all cooling water will be recycled and no liquid wastes will be released to the environment.) The environmental performance of the JACADS facility in the areas stated above can serve as an indicator of the ability of the technology to perform in an environmentally sound manner prior to its implementation in the CONUS facilities.

The following sections will address in detail both of the above types of information. Data resulting from the JACADS OVT, as well as any other pertinent Army experience in chemical agent-munitions disposal activities, will be used to demonstrate the capabilities of the incineration technology.

\subsection{RECENT DISPOSAL EXPERIENCE AT JACADS}

The disposal technology selected for PUDA is the same as that used at the JACADS facility (U.S. Army 1983), which became operational in June 1990. The selection of JACADS technology was based on technology maturity, the ability to perform operational proveouts in production-scale facilities at the JACADS plant, and safety and environmental conditions. None of the proposed CONUS disposal facilities will begin operation until the JACADS facility has been thoroughly tested and the disposal technology meets regulatory and design requirements. The JACADS system (Fig. 3.1) involves disassembly of the chemicalagent filled munitions and uses four separate incinerators for the destruction process. Each munition type is disassembled or cut into segments by automatic, remotely controlled 


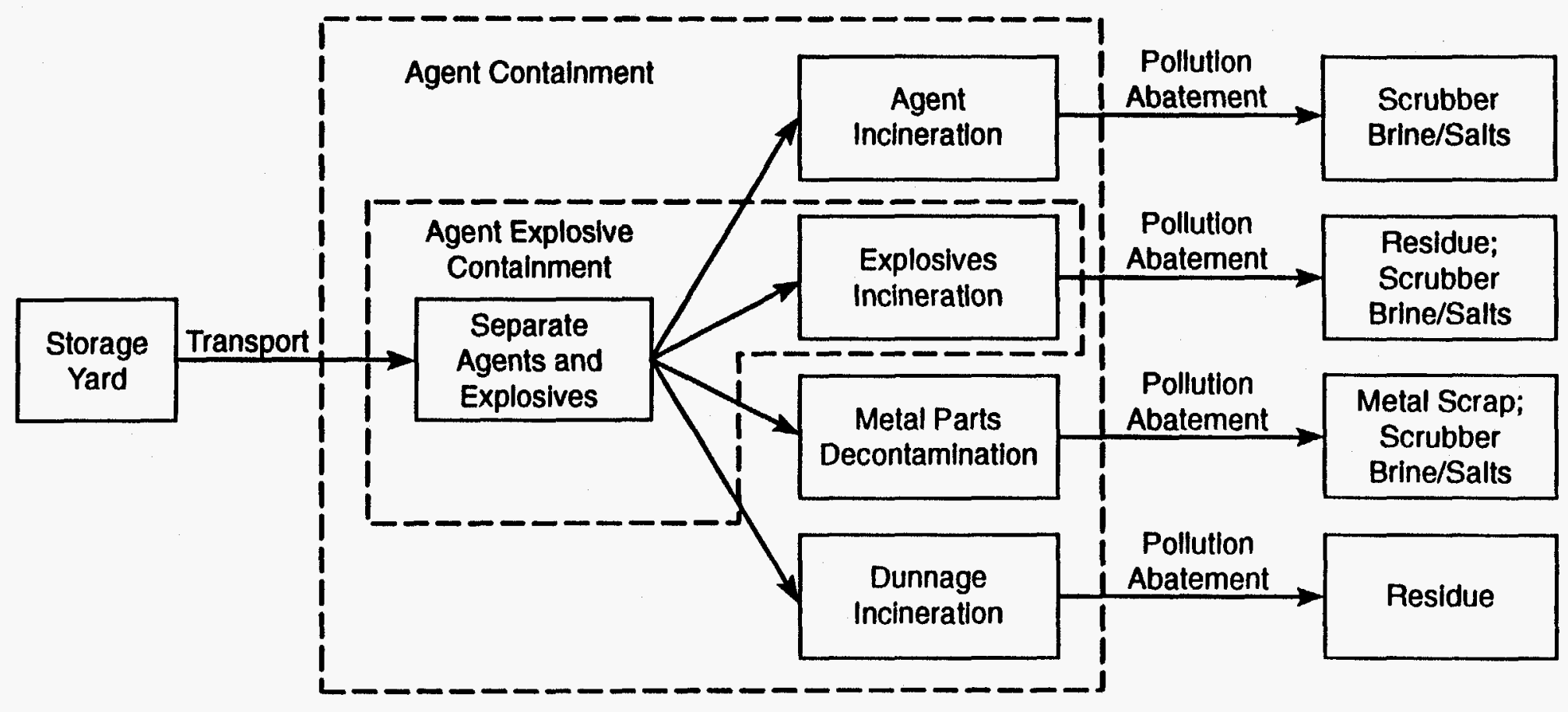

Fig. 3.1. The Johnston Atoll Chemical Agent Disposal System incineration process. 
machinery designed specifically for the munition type, and the chemical agent is drained from the munition body. The agent is then incinerated in a special furnace designed for its destruction. The furnace also incinerates spent decontamination solution. Explosives and propellants are destroyed in a separate deactivation furnace, as are certain munition hardware types from M55 rockets and M23 land mines. Metal that has been in contact with chemical agent is decontaminated in the metal parts furnace. A dunnage incinerator (DUN) is used to burn all combustible wastes. A pollution abatement system (PAS) for each furnace or incinerator is used to control atmospheric emissions. The JACADS technology is described in more detail in the FPEIS (U.S. Army 1988a, Vol. 3, Appendix C).

The OVT is being conducted during the first 21 months of JACADS operations. During this period, the overall JACADS process, and in particular the performance of the incinerator systems, are being evaluated using all three chemical agents (mustard, GB, and VX) in conjunction with the processing of rockets, projectiles, and ton containers. The general objective of the OVT is to demonstrate the operability of the entire plant, including personnel and all support systems, under toxic operating conditions. The overall JACADS system is being evaluated for environmental compliance, industrial and chemical agent safety, and system reliability.

OVT consists of four tests or campaigns. A sufficient number of munitions are to be destroyed during each test to allow refinement of the process to function effectively under normal operating conditions. Representative items in the chemical stockpile and all three agent types are being destroyed. The tests, in order of their planned occurrence, are as follows.

- M55 rockets containing nerve agent GB. Total attainment of design goals, depending on the level of success achieved, would result in the destruction of 12,000 to 16,500 rockets during OVT.

- M55 rockets containing nerve agent VX. It is intended that approximately 13,900 rockets be destroyed during OVT, if full production rates are achieved.

- One-ton containers containing blister agent HD. Each container holds about $771 \mathrm{~kg}$ $(1700 \mathrm{lb})$ of agent. Approximately 67 will be destroyed during OVT, if full production rates are achieved.

- $\quad 155-\mathrm{mm}$ projectiles containing HD. Approximately 5670 will be destroyed during OVT, if full production rates are achieved.

Each test starts at low production rates, with a carefully orchestrated rate increase to complete the test at full production rates. During periods of full production rates, trial burns will be conducted in all four incinerators as required by the permit issued under RCRA. All environmental requirements of the RCRA permit must be met during OVT to allow full operation of JACADS following OVT completion.

Test data from JACADS OVT will be evaluated for implementation into all CONUS facilities prior to construction, except the TEAD facility. Test data will be evaluated and incorporated into the TEAD facility as necessary, before the start of operations. The National Research Council is responsible for overseeing CSDP and the JACADS facility. Participation by the Council could include on-site inspections, review of data, and input for the final OVT 
reports. Much of the information in this section has been taken from the OVT report on the JACADS GB campaign (Menke et al. 1991).

Findings from the OVT will be incorporated into the PUDA design and equipment specifications before construction. A 4-month design and procurement verification period will be used to make corrections dictated from OVT and from the experience gained from the program. In addition, the OVT findings will be evaluated after each phase and immediately implemented into the PUDA design as necessary.

The JACADS experience to date has only limited applicability to the proposed facility at PUDA. That is, the JACADS tests have involved M55 rockets filled with agent GB, while PUDA stores neither rockets nor GB-filled munitions. Tests with mustard-filled munitions (of the type stored at PUDA) will not be conducted at JACADS until a later date. The discussions below, therefore, focus on the broader aspects of JACADS operation, as opposed to the munition- or agent-specific aspects.

\subsubsection{Plant Performance}

The OVT is the first time some of the new full-scale mechanical equipment has been operated for extended periods at normal operating temperatures while handling live agent and real munitions components. As expected during the preoperational period, the JACADS plant has had difficulties, mainly with the mechanical processing of rockets. Corrective measures are being taken.

\subsubsection{Processing efficiency}

Processing rates for the disposal facilities were not specified in the FPEIS; however, design goals have since been established.

From the beginning of the OVT incineration of GB-filled rockets on July 15, 1990, through February 1991 (the period of the GB campaign), a total of 7,490 M-55 rockets have been processed and approximately $75,000 \mathrm{lb}$ of agent have been destroyed. Fig. 3.2 illustrates the cumulative totals of GB rockets processed. Each rocket contains about $4.8 \mathrm{~kg}$ $(10.7 \mathrm{lb})$ of chemical agent. The goal for this time period was 12,000 to 16,000 rockets and about 55,300 to $73,800 \mathrm{~kg}(123,000$ to $164,000 \mathrm{lb})$ of agent destroyed.

While system downtimes have been higher than expected, performance of the system during periods of operation has exceeded expectations. Mechanical problem areas at JACADS have included the rocket shear machine, the demisters (which sometimes get clogged), and the heated conveyor system that carries the decontaminated rocket body scrap away from the deactivation furnace system (DFS). Modifications to correct this and other mechanical problems were made in December 1990 and January 1991, during a scheduled maintenance shutdown period. Downtimes decreased substantially during February operations. More detailed production information is presented in Appendix G.

Rockets were processed on $\mathbf{3 0}$ of the $\mathbf{8 1}$ calendar days in the period prior to the scheduled maintenance shutdown, December 20, 1990 to January 31, 1991. During the month of February, after the scheduled restart, rockets were processed on 16 of the 28 calendar 


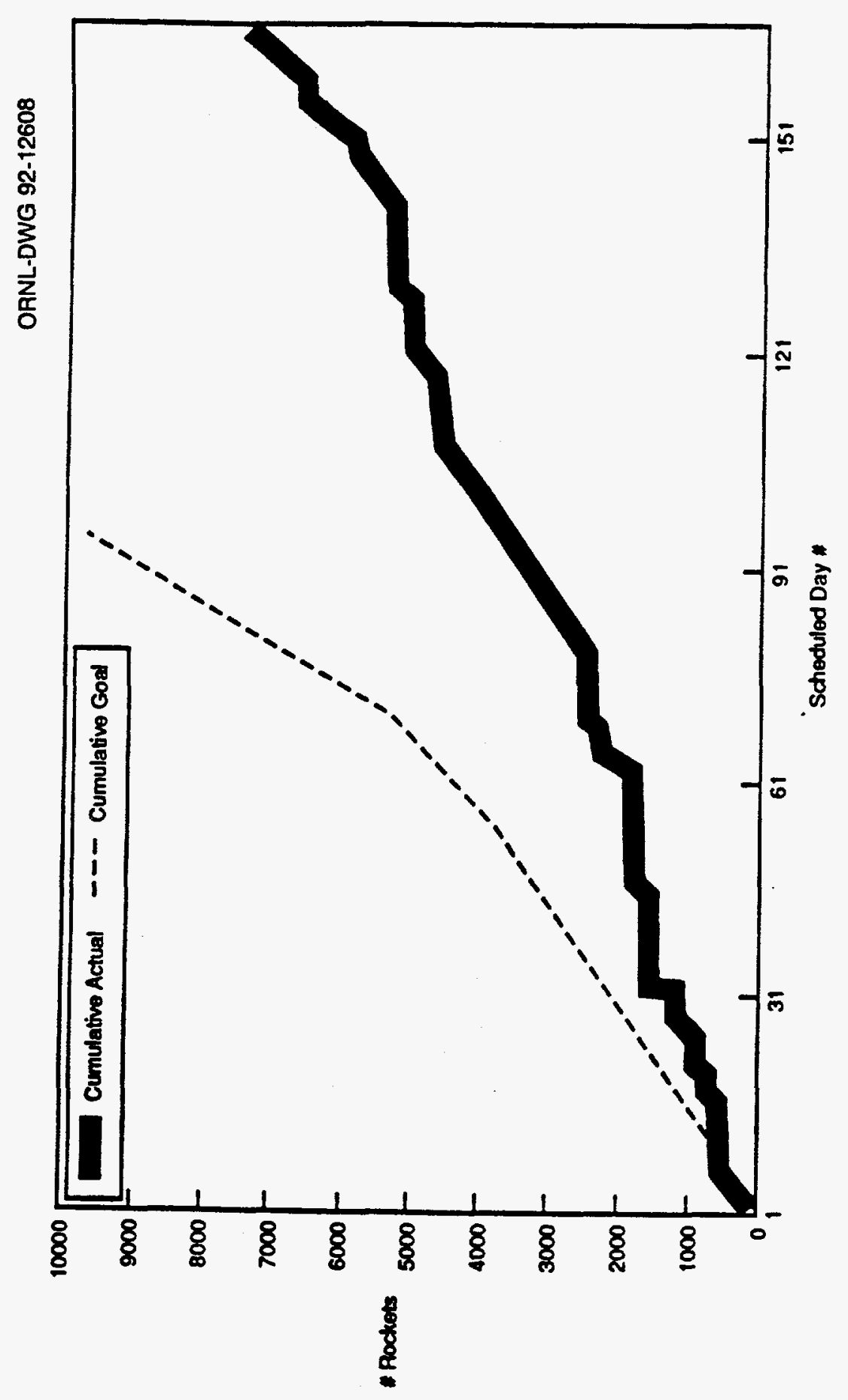


days. After scheduled maintenance, the JACADS processing rate increased from 17 rockets/hr in November and December to 23 rockets/hr in February.

For agent destruction, the daily incineration rate that is necessary to keep pace with the DFS design goal is $3120 \mathrm{lb} /$ day $(390 \mathrm{lb} / \mathrm{hr})$. However, since the publication of the FPEIS, the peak design goal for the liquid incinerator (LIC) is $1050 \mathrm{lb} / \mathrm{hr}$ or $8400 \mathrm{lb} /$ day. From October 1, 1990, to December 20, 1990, agent GB was burned on 19 of the 81 calendar days in the period. Agent was burned only on those days on which the rocket processing rate produced agent in sufficient quantities to keep the LIC in continuous operation at design capacity. Agent was stored during November to allow high capacity runs in early December. These high capacity runs supported the RCRA trial burns for the LIC. During partial days of operation the rates achieved were generally high enough to keep pace with the DFS. The peak daily rate of $698 \mathrm{lb} / \mathrm{hr}$ included a 3-hr period when the rate was $950 \mathrm{lb} / \mathrm{hr}$ (see Appendix G).

\subsubsection{On-site movement of munitions}

In Appendix $\mathrm{C}$ of the FPEIS, it is stated that munitions and bulk containers will be transported from the storage area to the Munitions Demilitarization Building (MDB) in a specially designed on-site transport container (ONC).

The FPEIS states that M55 rockets will be placed first in a specially designed overpack called the single pallet only rocket transporter (SPORT) which will then be loaded into the ONC.

Operations have proceeded safely at JACADS using the SPORT without the benefit of the ONC. The SPORT is a stainless steel box and lid that can hold one pallet of munitions (15 M55 rockets). A small vacuum pump in the SPORT maintains a partial vacuum so that any possible leak is prevented from escaping (venting is through a charcoal filter). The lid is capable of achieving an airtight seal with the box. Because PUDA does not store any rockets, the use of SPORTs will not be necessary. Munitions will be transported to the disposal facility inside an ONC.

There have been few deviations from established safety practice or standard operating procedures (SOPs) in either the loading or unloading areas during the munitions transport operation. The deviations that occurred have almost always been corrected on the spot by the Quality Assurance Specialist (Ammunition) Surveillance (QASAS).

There was a technical violation of a regulatory operational requirement (Army Materiel Command Regulation AMC-R-385-100, paragraph 16-2A) affecting the unpack area. Verbal rather than written authorization was obtained for storage of munitions in the unpack area for a period greater than three days. The extended storage was needed to accommodate day-to-day mechanical problems and associated uncertainty in restart of processing. Other conditions for storage were met, and there was no immediate threat to safety because the storage containers (SPORTs) were all under engineering controls.

The munitions transport system has been able to meet the demand for munitions from JACADS. There are many factors that affect the rate of mun however, the primary factor is the demand for munitions from the MDB. Available data show that the on-site transport 
operation at JACADS would be able to meet a much greater transport rate than has been required to date.

JACADS has halted demilitarization on only one occasion because munitions could not be delivered. On October 23, 1990, the transport operations could not be performed because the wind speed had dropped below $5 \mathrm{mph}$. The SOPs state that ammunition will not be transported when the average wind speed (measured over a 30-min period) drops below $5 \mathrm{mph}$.

In conclusion, on-site systems have been able to meet the processing demand for munitions while ensuring worker and environmental safety. There has been only one instance when on-site transport had any effect on the munitions processing rate (due to adverse weather) at JACADS. There have been no instances of personnel injury or endangerment of the environment from on-site transport activities.

\subsubsection{Personnel training}

The FPEIS states, "a training facility will be constructed for the specific purpose of providing detailed training to all participants in the program."

Construction of a training facility at Aberdeen Proving Ground (APG) has been completed. Lab training began in the summer of 1991 . The training program will be in accordance with a detailed training plan that identifies knowledge and skills required to operate the disposal plants. The training facility will be used for classroom instruction and hands-on training and will incorporate actual and mockup process equipment. A fully instrumented control room connected to a process simulation computer will provide a realistic environment for training operators in normal operating procedures as well as responses to process upset and emergency conditions. Additional training will be conducted at the CSDP sites for site-specific procedures and equipment.

Training for the JACADS personnel was conducted without the benefit of the Chemical Demilitarization Training Facility (CDTF); however, before the start of toxic operations, extensive efforts were conducted in the area of personnel training. Refresher training has continued since that time. By the start of toxic operations, operations and maintenance personnel had collectively attended more than 15,000 person-days of training.

The training program consists of approximately $60 \%$ classroom instruction and $40 \%$ field training and practical exercises. Upon completion of the classroom training, all personnel are required to take an examination for the course. Each person is required to demonstrate adequate knowledge and proficiency in the subject matter by passing a written examination for each course to become qualified and proceed to the field portion of the training program.

The field portion of the training program consists of providing instruction to the work force on the SOPs. After this period of instruction is completed, each member of the work force is required to perform the procedures in the SOPs that govern operation in his or her area of responsibility. Performance is monitored by a certifying official who can attest that the person is proficient or certified in his or her job.

To pass the field portion of the training program, the work force is required to demonstrate, without error and without access to written procedures, that they can correctly 
respond to accidents in accordance with approved contingency procedures. Demonstration of this capability is accomplished by conducting over 60 rigorous emergency exercises during which the work force is required to correctly respond to industrial-type accidents (e.g., propane or chlorine leaks and hazardous waste spills); process failures (e.g., fires in the explosive containment room, power failures, agent spills); handling accidents (e.g., detonation of a munition at the unloading dock); and low-probability catastrophic external events such as a tsunami. During each exercise, the work force is observed by contractor and Army personnel to ensure that the correct public address announcements and notification procedures are followed, appropriate corrective actions are taken to mitigate the emergency situation, equipment and facilities are shut down when appropriate, and correct cleanup procedures are implemented. The equipment's automatic response to these accident scenarios is concurrently tested (i.e., automatic shutdown of equipment transfer of critical load to the uninterrupted power supply and start-up of the emergency generator in the event of a power failure. When appropriate, the integrated response of Army and operations and maintenance contractor personnel is tested.

\subsubsection{Environmental Performance}

The U.S. Army is committed to destroying the chemical agents-munitions stockpile in a safe and environmentally sound manner. As a result, a number of commitments are made in the FPEIS specifically aimed at protection of the environmental resources (see Sect. 3.1.2). The extent to which the results of the JACADS OVT burns comply with these commitments will play a major role in determining the readiness of the JACADS disposal facility for fullscale operations.

\subsubsection{Stack emissions}

The FPEIS predicts that no violations of existing ambient air standards will result from the disposal operations.

Under both normal and abnormal conditions, the emissions from the JACADS facility have been below all applicable state and federal standards. During normal operations at both JACADS and CAMDS, no agent has been detected above the air emission limit of $0.0003 \mathrm{mg} / \mathrm{m}^{3}$. An abnormal incident occurred at CAMDS on January 28,1987 , during which liquid chemical agent (GB) leaked from the primary containment piping network inside the LIC facility. Agent was not detected outside the building (U.S. Army 1988, Vol. 3, Appendix D). Another abnormal incident occurred at JACADS on December 8, 1990, during which a very small amount of agent was released to the atmosphere. The release amounted to $8 \%$ of the permissible level and did not result in any hazards to human health or the environment (see Sect. 3.2.3.1).

Table 3.2 shows the FPEIS-predicted emissions of pollutants from the disposal facilities, the ambient-air concentrations of pollutants predicted to result from these emissions, and the corresponding air-quality standard. Estimates of pollutant concentrations in ambient air were obtained using the Industrial Source Complex (ISC) atmospheric dispersion model (EPA 1979), which assumes a Gaussian distribution in the vertical and cross-wind directions. 
Table 3.2. Emissions and annual average ground-level concentrations of industrial-type pollutants from disposal facilities

\begin{tabular}{|c|c|c|c|}
\hline Pollutant & $\begin{array}{c}\text { Emission } \\
(\mathrm{g} / \mathrm{s})^{a}\end{array}$ & $\begin{array}{c}\text { Maximum } \\
\text { predicted } \\
\text { concentration } \\
\left.\mu \mathrm{g} / \mathrm{m}^{3}\right) \\
\end{array}$ & $\begin{array}{l}\text { Ambient } \\
\text { standard } \\
\left(\mu \mathrm{g} / \mathrm{m}^{3}\right)^{b}\end{array}$ \\
\hline \multicolumn{4}{|c|}{ Agent GB } \\
\hline $\mathrm{NO}_{\mathrm{x}}$ & 20 & 5 & 100 \\
\hline Particulates & $<1$ & $<1$ & 75 \\
\hline HF & $<1$ & $\ll 1$ & -1 \\
\hline $\mathrm{HCl}$ & $<1$ & $\ll 1$ & none \\
\hline $\mathrm{P}_{2} \mathrm{O}_{5}$ & $<1$ & $\ll 1$ & none \\
\hline \multicolumn{4}{|c|}{ Agent $V X$} \\
\hline $\mathrm{NO}_{x}$ & 13 & 3 & 100 \\
\hline Particulates & $<1$ & $<1$ & 75 \\
\hline $\mathrm{SO}_{2}$ & $<1$ & $<1$ & 80 \\
\hline HF & $<1$ & $\ll 1$ & -1 \\
\hline $\mathrm{HCI}$ & $<1$ & $\ll 1$ & none \\
\hline $\mathrm{P}_{2} \mathrm{O}_{5}$ & $<1$ & $\ll 1$ & none \\
\hline \multicolumn{4}{|c|}{ Mustard } \\
\hline $\mathrm{NO}_{\mathrm{x}}$ & 5 & 1 & 100 \\
\hline Particulates & $<1$ & $<1$ & 75 \\
\hline $\mathrm{SO}_{2}$ & 1 & $<1$ & 80 \\
\hline HF & $<1$ & $\ll 1$ & -1 \\
\hline $\mathrm{HCI}$ & $<1$ & $\ll 1$ & none \\
\hline
\end{tabular}

${ }^{\sigma}$ Emissions do not include contributions from fuel.

National ambient air quality standards and appropriate state standards.

Source: U.S. Army 1988a. Chemical Stockpile Disposal Program Final Programmatic Environmental Impact Statement, Program Executive Officer-Program Manager for Chemical Demilitarization, Aberdeen Proving Ground, Md., pp.4-9.

These estimates apply to maximum controlled emissions. More recently, test burns have been conducted at CAMDS, and Toxic Substances Control Act of 1976 (TSCA) and RCRA trial burns have been conducted during the JACADS OVT. During test burns at CAMDS, emissions of the pollutants listed in Table 3.2 were found to be within regulatory limits.

Three RCRA trial burns on the LIC occurred at JACADS on December 5 and 6 , 1990. Resulting RCRA test results can be summarized for particulate matter, $\mathrm{HCl}$, and $\mathrm{HF}$. 
Particulate stack concentrations in the three trial burns of agent GB were $3.74 \mathrm{mg} / \mathrm{dscm}$, $4.23 \mathrm{mg} / \mathrm{dscm}$, and $3.89 \mathrm{mg} / \mathrm{dscm}$ corrected to $7 \% \mathrm{O}_{2}$. The particulate stack concentration limit is $180 \mathrm{mg} / \mathrm{dscm}$; thus, the limit was not exceeded (SRI 1991). Use of a simplified EPA screening model for air dispersion (SCREEN) with the $4.23 \mathrm{mg} / \mathrm{dscm}$ stack concentration and worst case (WC) 1-hr meteorological conditions resulted in a highest predicted 1-hr groundlevel concentration of less than $2 \mu \mathrm{g} / \mathrm{m}^{3}$, at $200 \mathrm{~m}(660 \mathrm{ft})$ from the JACADS stack. Because the annual average pollutant concentrations at any single point will be much less than $1 / 2$ of the maximum hourly concentrations (EPA 1977), the FPEIS prediction of less than $1 \mu \mathrm{g} / \mathrm{m}^{3}$ is confirmed. This result is well within the previous annual standard of $75 \mu \mathrm{g} / \mathrm{m}^{3}$ for total suspended particulate matter (TSP), and is also well within the more recent standard of $50 \mu \mathrm{g} / \mathrm{m}^{3}$ for particulate matter less than 10 microns in diameter (inhalable particles).

$\mathrm{HCl}$ emission rates for the three burns were $0.000023 \mathrm{lb} / \mathrm{hr}, 0.035 \mathrm{lb} / \mathrm{hr}$, and $0.087 \mathrm{lb} / \mathrm{hr}$. The allowable limit for $\mathrm{HCl}$ emissions is $4 \mathrm{lb} / \mathrm{hr}$. The measured $\mathrm{HCl}$ emission rate for each run was well under the limit, and the highest $(0.087 \mathrm{lb} / \mathrm{hr})$ was equivalent to about $0.01 \mathrm{~g} / \mathrm{s}$. This value is well within the FPEIS-predicted emission rate of less than $1 \mathrm{~g} / \mathrm{s}$. The HF emission rates were $0.11 \mathrm{lb} / \mathrm{hr}, 0.24 \mathrm{lb} / \mathrm{hr}$, and $0.20 \mathrm{lb} / \mathrm{hr}$ for the three burns. No limit was set; however, the highest HF emissions rate $(0.24 \mathrm{lb} / \mathrm{hr})$ converts to about $0.03 \mathrm{~g} / \mathrm{s}$, which agrees with the FPEIS-predicted rate of less than $1 \mathrm{~g} / \mathrm{s}$ (Table 3.2).

Initial polychlorinated biphenyl (PCB) incineration tests at CAMDS indicated that no significant levels of PCB emissions should result from the disposal process. Subsequently, three TSCA research and development (R\&D) trial burns were conducted in the DFS at JACADS in February 1990. These trial burns are required due to the presence of PCBs in the rocket shipping and firing tubes. R\&D trial burns followed by demonstration burns are required by the EPA prior to granting an operating permit to incinerate PCBs. The R\&D trial burns consisted of feeding PCB-contaminated shipping and firing tubes and the complete rocket motor section into the DFS. Chemical agents were not present in the M55 rockets during these tests. Representatives from EPA witnessed these test burns. Results have been received from the first $R \& D$ burn, which was conducted at a feed rate of 30 rockets $/ \mathrm{hr}$. These analyses were conducted and results obtained by a contractor under the direction of EPA. As previous testing at CAMDS had indicated, dioxins and furans were not detected in the stack effluent at JACADS, with the exception of tetrachlorodibenzo-p-dioxin, which was found at near ambient levels. As shown in Table 3.3, the particulate concentration in R\&D 1 was $23.9 \mathrm{mg} / \mathrm{m}^{3}$ and in $R \& D 2$ was $33.9 \mathrm{mg} / \mathrm{m}^{3}$ corrected to $7 \% \mathrm{O}_{2}$. The required particulate standard was a concentration limit of $180 \mathrm{mg} / \mathrm{cm}^{3}$ when corrected to an oxygen content of $7 \%$. Thus the limit was met in both burns. A PCB destruction and removal efficiency of $99.9999 \%$, as required by the TSCA regulations, was achieved. The highest monitored concentration of PCBs in the JACADS stack gas from the DFS test burn was $5.6 \times 10^{-4} \mathrm{~g} / \mathrm{hr}\left(2 \times 10^{-5}\right.$ ounces $\left./ \mathrm{hr}\right)$. This low concentration is achieved due to the low concentration of PCB in the feedstock (average concentration of $2700 \mathrm{ppm}$ ) and the attainment of the required $99.9999 \%$ PCB destruction and removal efficiency. Table 3.4 provides a comparison of these PCB emissions with three of the largest commercial EPA-permitted PCB incinerators located within the United States. The lowest emissions values from the PCB incinerators and the highest value measured from the JACADS DFS unit are presented. The PCB emissions monitored from the JACADS DFS were significantly lower than permitted commercial CONUS units. It should also be noted that an even higher destruction and 
Table 3.3. Summary of Toxic Substances Control Act burn results at Johnston Atoll Chemical Agent Disposal System

\begin{tabular}{|c|c|c|c|c|c|c|}
\hline \multirow[b]{2}{*}{ Parameter } & \multirow[b]{2}{*}{ Units } & \multicolumn{3}{|c|}{ Run Number } & \multirow[b]{2}{*}{ Requirement } & \multirow[b]{2}{*}{ Status } \\
\hline & & $\mathrm{R} \& \mathrm{D} 1^{a}$ & R\&D 2 & R\&D 3 & & \\
\hline DRE-PCBs ${ }^{b}$ & $\%$ & 99.999976 & 99.999946 & 99.99991 & 99.9999 & Pass \\
\hline $\begin{array}{l}\text { Particulate } \\
\text { Matter } \\
\text { corrected } \\
\text { to } 7 \% \mathrm{O}_{2}\end{array}$ & $\begin{array}{l}\mathrm{lb} / \mathrm{hr} \\
\mathrm{mg} / \mathrm{m}^{3}\end{array}$ & $\begin{array}{l}0.393 \\
23.9\end{array}$ & $\begin{array}{l}0.650 \\
33.9\end{array}$ & $\begin{array}{l}0.28 \\
12.0\end{array}$ & 180.0 & Pass \\
\hline $\begin{array}{l}\mathrm{HCl} \\
\text { Emissions }\end{array}$ & $\mathrm{lb} / \mathrm{hr}$ & 0.015 & 0.006 & 0.012 & 4.0 & Pass \\
\hline
\end{tabular}

${ }^{\mathrm{a}} \mathrm{R} \& \mathrm{D}=$ research and development.

'DRE = Destruction and Removal Efficiency; PCBs = polychlorinated biphenyls.

Table 3.4. Comparison of polychlorinated biphenyl (PCB) emissions from the Johnston Atoll Chemical Agent Disposal System (JACADS) with PCB emissions from three commercial PCB incinerators permitted by the U.S. Environmental Protection Agency

\begin{tabular}{ll}
\hline Incinerator & PCB emission rate (g/hr) \\
\hline Rollins & 0.0181 (calculated-low value) \\
ENSCO $^{a}$ & 0.0548 (calculated-low value) \\
SCA $^{b}$ & 0.0630 (measured-low value) \\
JACADS DFS $^{c}$ & 0.00056 (measured-high value) \\
\hline
\end{tabular}

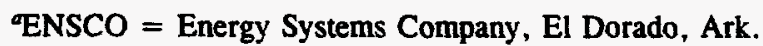

bSCA = SCA Chemical Services, Inc., South Chicago, Ill.

DFS = deactivation furnace system. 
removal efficiency is expected at the CONUS facilities due to the higher temperatures and longer residence times. The DFS afterburners for the CONUS CSDP facilities are being designed to operate at $1204^{\circ} \mathrm{C}\left(2200^{\circ} \mathrm{F}\right)$ with a $2.0-\mathrm{s}$ residence time; the JACADS DFS afterburner operates at $1093^{\circ} \mathrm{C}\left(2000^{\circ} \mathrm{F}\right)$ with a 0.5 -s residence time.

\subsubsection{Solid waste management}

The FPEIS states that solid wastes will be recycled where feasible, and disposed of according to RCRA.

The solid wastes resulting from the destruction of chemical agents and munitions at JACADS and the CONUS facilities include PAS brines (shipped for land disposal as dried salts), ash, and scrap metal. Table 3.5 presents the amounts of these wastes that were estimated for JACADS and for each CONUS disposal facility. Disposal of the European stockpile at JACADS will increase the quantity of scrap metal by $85 \%$ to about 13,000 tons and the quantity of salts by about $15 \%$ to 4400 tons. The actual amounts of the various wastes produced by the JACADS operations will serve as indicators of the accuracy of the estimates for the CONUS disposal facilities.

The JACADS destruction process generates various types of waste, including brines from the wet scrubbers in the PAS for the incinerators and furnaces. The brines consist mainly of water with suspended inorganic salts and may contain detectable levels of heavy metals such as arsenic, barium, cadmium, chromium, lead, mercury, selenium, and silver. The exact composition varies with the type of agent and munition being incinerated. The brines are analyzed for the 24 organic and 8 metallic substances specified in the EPA toxicity characteristics leaching procedure (40 CFR Pt. 261.24). If the concentration of heavy metals in the brine salts is sufficiently high, the salts will be classified as hazardous waste under RCRA.

The Army planned to store the brines temporarily at JACADS for eventual processing through a brines reduction area (BRA). The dry salts from the BRA would then be shipped to the U.S. mainland for disposal in a regulated landfill in accordance with their hazardous characteristics.

During the systemization tests at JACADS, the brine dryer was found to emit higher levels of particulate material than previously thought and required controls. Addition of a PAS with baghouse filters has been accomplished and will be fully tested during the VX rocket campaign. In the meantime, the BRA is inoperable.

As a result of the inability of the BRA to reduce the brines into salts during the GB campaign, the brines were stored on Johnston Island in liquid form in accordance with their RCRA classification. That is, brines classified as nonhazardous were stored in bladders; brines classified as RCRA hazardous waste were stored in lined, stainless steel tanks. The tanks were periodically shipped from Johnston Island to the U.S. mainland via Hawaii. At Los Angeles, the tanks were unloaded from the ships. While in Los Angeles, either the tanks were loaded onto trucks or the brine was transferred from the tanks to tank trucks. In both cases, the brine was transported to Texas where it was injected into deep wells. All handling and transport of the brines was conducted in accordance with RCRA and with the regulations of the U.S. Department of Transportation (DOT). 
Table 3.5. Solid wastes expected from on-site disposal facilities ${ }^{a, b}$ and acreage required for disposal of ash and salts ${ }^{c}$

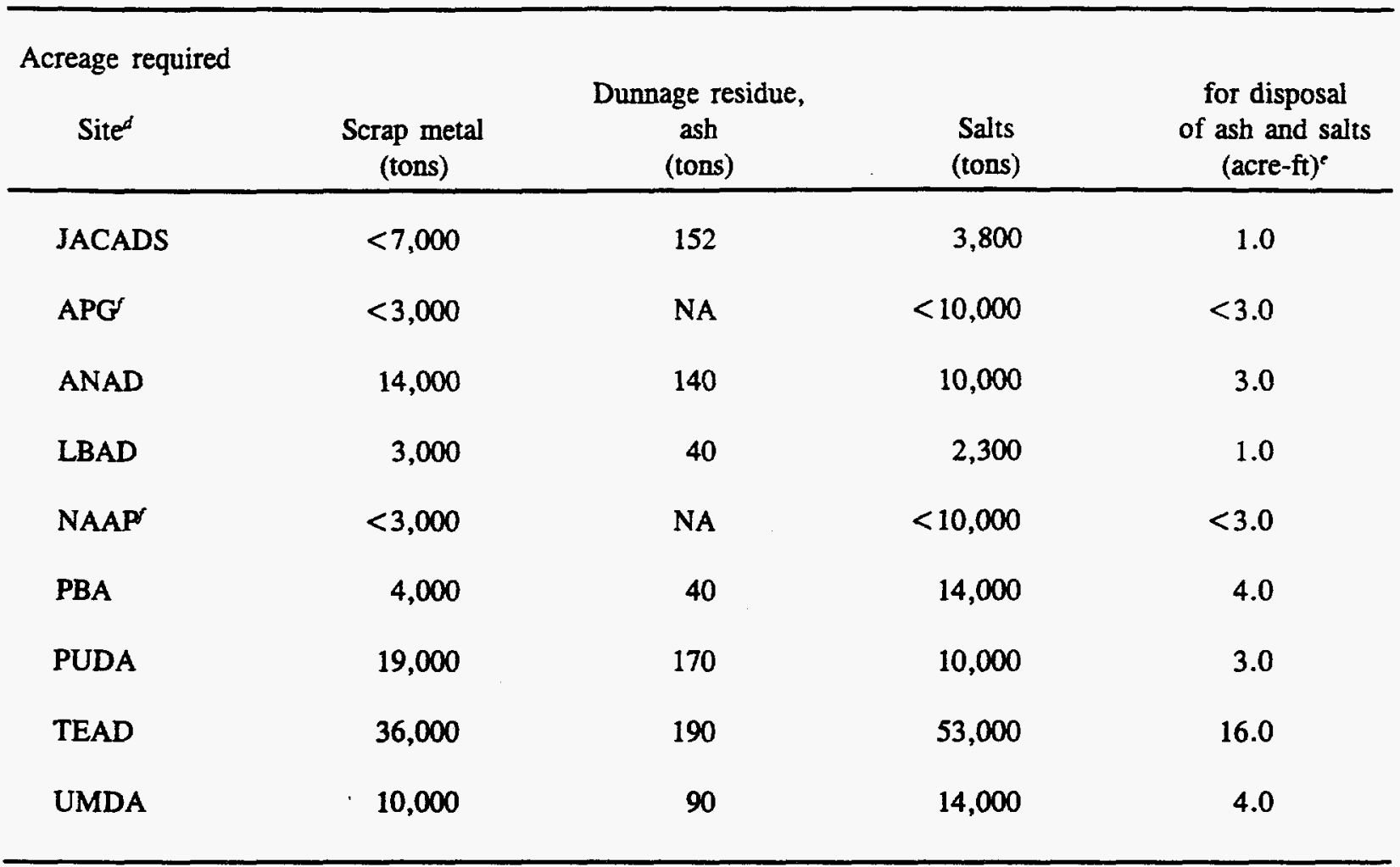

a JACADS, Vol. 1. Final design analysis narrative by Parsons.

'JACADS, FPEIS by the U.S. Army Corps of Engineers.

Density of ash $=45 \mathrm{lb} / \mathrm{ft}^{3}$; density of salts $=150 \mathrm{lb} / \mathrm{ft}^{3} ;$ an acre-ft $=43,560 \mathrm{ft}^{3} ; 2,000 \mathrm{lb} / \mathrm{ton}$; therefore, there are 980 tons of ash/acre-ft and 3,267 tons of salts/acre-ft.

JACADS = Johnston Atoll Chemical Agent Disposal System; APG = Aberdeen Proving Ground; ANAD = Anniston Army Depot; LBAD = Lexington-Blue Grass Army Depot; NAAP = Newport Army Ammunition Plant; PBA = Pine Bluff Arsenal; PUDA = Pueblo Depot Activity; TEAD = Tooele Army Depot; UMDA = Umatilla Depot Activity.

The volume that would cover 1 acre to a depth of $1 \mathrm{ft}$.

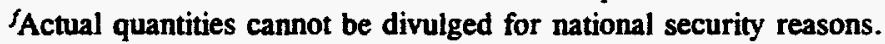

The disposal of liquid brines from the JACADS facility is only temporary and should be eliminated by the modifications accomplished for the brine dryer. Future disposal of wastes from the JACADS pollution abatement scrubbers should involve only dried salts.

The solid waste streams in the disposal process include dunnage and other materials associated with packaging of munitions, the residue from each of the furnaces, and the brines from the associated PASs. A major consideration at JACADS is the segregation of wastes that may have been contaminated with agent from other wastes, both hazardous and 
nonhazardous. Materials that are known through available information to be uncontaminated are classified as " 0 " (never contaminated). Materials that have been contaminated, and are surface decontaminated according to previously approved procedures, are classified as $3 \mathrm{X}$ and must remain under governmental control. The $3 \mathrm{X}$ materials can usually be handled as nonhazardous wastes under RCRA. Materials that have been contaminated, including materials previously surface decontaminated $(3 \mathrm{X})$, which undergo a temperature-time treatment $\left(1000^{\circ} \mathrm{F}\right.$ for $\left.15 \mathrm{~min}\right)$ that is known to destroy agent are classified as $5 \mathrm{X}$. These $5 \mathrm{X}$ materials may leave governmental control.

Dunnage incinerator (DUN). During the GB rocket campaign portion of the OVT, the major source of dunnage was wood pallets from processing M55 rockets. Since the DUN was not in operation for most of the campaign, the empty pallets, strapping, and any other wastes were stored on the site pending disposition. During tests, no preservatives or other contamination were identified in the pallets that would require them to be classified as hazardous wastes. The DUN did undergo some test burns using simulated wood pallets. The ash and other furnace residue from this testing were all found to be nonhazardous and were stored on Johnston Island or shipped to a CONUS landfill.

Liquid agent incinerator (LIC). The LIC burns agent in combination with fuel oil (JP-5). The agent itself provides most of the heating value for the incineration process and is supplemented with a small amount of fuel oil to maintain a stable flame pattern. Waste decontamination liquid is treated in the LIC where it is injected into the secondary furnace. Decontamination liquid is mostly water and weak caustic (1\% sodium hydroxide); therefore, it has no heat value. A variety of high-temperature reactions take place among the injected materials, as well as reactions between some of the components and the surface of the refractory brick in the kiln. Some of these reactions result in the formation of a mix of glassy substances that coat the inner surface of the LIC secondary furnace, and for the most part pool at the bottom. It appears that this material results primarily from the salts in the spent decontamination solutions disposed of in the LIC. It causes no problems, unless it builds up to a level that significantly reduces the volume (affecting residence time) of the furnace or impedes the flow of combustion gases. Following an industry search and consultation with major refractory manufacturers, it was concluded that Ruby SR ( $90 \%$ alumina-10\% chromia) brick had the properties to best withstand the conditions (high temperature, high phosphorus and alkali content) in the LIC secondary chamber. A new refractory has been installed in the JACADS LIC.

It is believed that less slag will be formed when the secondary chamber refractory is replaced with Ruby SR; however, because of the presence of phosphorus in the LIC feed, some slag formation will still occur. A slag removal system is being designed to facilitate maintenance operations at the JACADS facility. The proposed system will consist of a removable cart on tracks with a hydraulic mechanism to seal the cart to a port at the base of the secondary chamber.

A manhole has been installed in the JACADS LIC secondary chamber to facilitate inspections. In addition, the more toxic primary chamber will be physically divided from the secondary chamber by a wall. Maintenance operations and the removal of the slag will be facilitated by this measure.

Deactivation furnace system (DFS). Punch and drain devices remove $95 \%$ of the agent from the rockets. The rocket and its fiberglass shipping-firing tube are then sheared 
into eight sections and fed to the DFS. The burster and rocket fuel quickly ignite and burn without significant oxygen consumption. The residual agent, the fiberglass resins, and the other materials burn more slowly and consume oxygen. The residue consists primarily of aluminum, steel from the rocket motor, and fiberglass. These materials are dumped into a closed bin which, after 50 to 60 rockets are processed, is set aside to cool and a new bin is put in place. During the campaign, three samples of the waste materials were tested, and all showed the presence of lead at sufficient levels to cause its characterization as hazardous waste. No agent was found in the samples. The wastes are accumulated for up to 90 days, a limit set by RCRA, and then are shipped to a CONUS landfill.

An additional minor source of DFS residue is the cyclone used to remove particulates from the flue gas. This material was tested and shown to be nonhazardous.

Metal parts furnace (MPF). The MPF was not in service during the campaign; thus, no residue was generated.

Solid materials from all the furnaces must be shown to be free of agent and handled and disposed of properly, including proper tracking and accounting. Aside from problems with paperwork and accounting early in the campaign, and storing of some residues for more than the 90-day RCRA limit, these responsibilities were carried out correctly. All violations that have been identified to date have been procedural. They have not had any technical implications, and have not resulted in any known environmental effects.

\subsubsection{Environmental monitoring}

The FPEIS indicates that no detectable levels of chemical agent would occur at the facility perimeter.

The Army has been joined by EPA, DHHS, and the U.S. Fish and Wildlife Service (FWS) to provide an extensive safety and environmental monitoring system. The Army uses two types of monitors at JACADS to detect the presence of chemical agent. The automatic continuous air monitoring system (ACAMS) can be used to quickly detect low concentrations of agent (i.e., concentrations in the parts per trillion range). The depot area air monitoring system (DAAMS) can be used to obtain historical documentation of time-averaged agent concentrations.

The ACAMS is an automated gas chromatograph that can be configured to detect down to the 8-hr time-weighted average of GB, VX, or mustard agent. The JACADS facility has approximately 10 high-level ACAMS alarms, 4 very high-level ACAMS alarms, 51 lowlevel alarms, and 56 samplers deployed throughout the plant. Response time for the highlevel detectors is $2 \mathrm{~min}$. ACAMS low-level detectors have response times of 3-5 min and provide early warning of any agent present before any health effects would occur.

Monitoring by ACAMS is continuous in the plant toxic areas, the plant work areas, stacks from each of the furnaces, between beds of the charcoal air filter, and the exhaust of the charcoal air filters.

Perimeter monitoring is exclusively by DAAMS samplers. The samplers consist of a solid sorbent tube, through which a sample is drawn for a predetermined period of time. Samplers are used to obtain time-dependent average concentrations at low detection levels for 
historical documentation. The DAAMS uses a gas chromatograph, which has the sensitivity to detect the general population limit (GPL).

About 29,000 monitor readings are taken daily from automated detectors in the worker areas of the JACADS facility. Another 1500 readings are taken from on-line stack monitors with 48 stack samples analyzed in the laboratory each shift. Twenty-four perimeter monitor samples are analyzed daily in the laboratory. To date, no chemical agent has been detected outside of the main JACADS demilitarization building.

Based on a National Research Council recommendation, the perimeter monitoring system implemented at Johnston Island is the system currently in use at TEAD for the CAMDS facility. The JACADS perimeter system is an integral part of the demilitarization technology validation testing. The purpose of the system is not to control disposal activities or to provide an early warning of an accidental release but to provide a historical record in the unlikely event of a major release of agent. The perimeter monitoring system consists of 12 agent sampling stations around the perimeter of the JACADS facility and chemical storage area. In addition, four meteorological stations are used to collect data to model a potential agent release.

No concentrations of chemical agent above the detection limit have been measured by the perimeter monitoring system. Data for certain criteria pollutants, for which ambient standards have been established under the Clean Air Act, are also being collected at four of the perimeter stations. The criteria pollutants being measured are ozone, $\mathrm{SO}_{2}, \mathrm{NO}_{x}$, and TSP. This additional monitoring is not required by regulation but is a voluntary commitment by the Army to provide a general check on the ambient air quality impact of JACADS emissions. This perimeter monitoring system became operational in early October 1990.

In addition to the atmospheric monitoring for chemical agent, the Army has initiated a program to monitor the marine environment around Johnston Island. The program has been instituted with the cooperation of the National Marine Fisheries Service and will begin with a study of the natural variation of fish populations near the island. Because the emissions from the JACADS facility have been hypothesized to contain small amounts of toxic substances, such as dioxins or furans, there will also be studies of dioxin and furan concentrations in the marine microlayer, the thin layer on the surface of the ocean where the marine photosynthetic food chain begins. The marine monitoring program is intended to provide the earliest possible indications in the event that the JACADS process damages the marine environment.

\subsubsection{Worker exposure}

The FPEIS indicates that the Surgeon General's chemical agent exposure limits will be adhered to.

Hazards to the environment and to the safety and health of workers, and the general public represent the most important criteria by which the management of the disposal program is judged. Congress mandated that the project be conducted so as to provide maximum protection for the environment, the workers, and the general public. The Army has stated that safety is more important than schedule. Workers are protected by the full range of protective equipment including agent monitor alarms, masks, special clothing, and a ventilation system in the MDB designed to ensure air flow from the normally occupied areas 
Table 3.6. Agent release values and maximum predicted ground-level concentrations from routine operations of the proposed disposal facility

\begin{tabular}{lcccc}
\hline Agent & $\begin{array}{c}\text { Averaging } \\
\text { time }\end{array}$ & $\begin{array}{c}\text { Agent release } \\
\text { value }(\mathrm{g} / \mathrm{sec})^{a, b}\end{array}$ & $\begin{array}{c}\text { Maximum predicted } \\
\text { concentration } \\
\left(\mu \mathrm{g} / \mathrm{m}^{3}\right)^{c}\end{array}$ & $\begin{array}{c}\text { General population } \\
\text { exposure level } \\
\left(\mu \mathrm{g} / \mathrm{m}^{3}\right)\end{array}$ \\
\hline GB & $72-\mathrm{hr}$ & 0.000025 & 0.00022 & 0.003 \\
VX & $72-\mathrm{hr}$ & 0.000025 & 0.00022 & 0.003 \\
Mustard & $72-\mathrm{hr}$ & 0.00206 & 0.020 & 0.1 \\
(H, HD, HT) & & & & \\
\hline
\end{tabular}

${ }^{a}$ Agent release values are based on the allowable stack concentrations for agent as recommended by the U.S. Department of Health and Human Services, Centers for Disease Control [Fed. Regist. 53 (Pt. 50)].

'Source: Anniston Army Depot 1990. Revised Permit Application for the Department of Army Anniston Army Depot Chemical Stockpile Disposal System Rev. No. 4, Anniston, Ala., June.

Results based on the screening model approved by the U.S. Environmental Protection Agency as described in footnote "b" above. The model calculates $24-\mathrm{hr}$ averages that are used in this column as conservative estimates of the 72 -hr average values specified in the allowable stack concentrations. 
of the building to the areas potentially exposed to agent. Building ventilation exhaust is pulled through multiple charcoal air filters before being discharged to a stack.

Airborne exposure limits for GB, VX, and H/HD/HT are presented in Table 3.6. These are the same as the control limits recommended by DHHS and serve as the basis for interpreting the results of air monitoring within the chemical demilitarization plant, the holding areas, transport activities, and on the perimeter of the installation. The airborne exposure limits are set to provide a safety margin for protection of both workers and the general population.

Because the JACADS OVT is taking place on Johnston Island, where there is limited potential for exposure of the public, the principal concern is the safety of the workers during JACADS operations. During the course of the campaign, there has been no injury to workers due to munitions processing. However, seven incidents were identified in which there might have been some potential for worker exposure to agent. As a result, in accordance with established procedures, a total of approximately 12 workers were directed to undergo testing. Cholinesterase monitoring of the JACADS staff showed that in no case has any worker received a dose large enough to cause physiological symptoms.

Four lost-time accidents have occurred during the campaign, resulting in 243 lost work days. There were no cases of permanent injury or disability. The result is an industrial safety record of 1.2 lost workday cases per 200,000 hrs worked, much better than the goal of 4.1 per $200,000 \mathrm{hrs}$. In addition, there were no munitions or industrial-related events that presented a seriously increased risk of injury to the workers.

\subsubsection{Environmental compliance}

The FPEIS indicates that the disposal technology would comply with all environmental regulations.

National Pollutant Discharge Elimination System (NPDES). At JACADS water is provided for cooling via a once-through system that draws seawater from the environment, passes it through a continuous series of pipes that are completely separate from the chemical agent processes, and discharges it back to the environment at a somewhat elevated temperature. The EIS prepared as part of the permitting process for JACADS noted that the heated discharge water of the plant might adversely affect the biota in the area around Johnston Island. As a result of the EIS and pursuant to NPDES, limits were placed on the flow and discharge temperature of the cooling water used by the plant, and on the temperature rise permitted in the receiving water.

The NPDES permit for the JACADS facility was issued on August 12, 1985. The permit specified the location of the JACADS discharge outfall, and specified limits for both the quantity and quality (including temperature) of the discharge. Although there were some variances from the procedural requirements of the NPDES permit, daily monitoring showed that the seawater discharge was within both quantity and temperature limits of the NPDES permit.

Unlike JACADS, all process water at the CONUS disposal plants will be contained within a closed loop system and will be recycled. No effluents will be released to the 


\section{$3-22$}

environment by plant operations, and sanitary wastes will be treated. Thus, no impacts will occur to surface water resources (U.S. Army 1988a).

RCRA. DOD submitted an application for a RCRA permit for JACADS in 1984. After a review by EPA and a public hearing in Hawaii, a final permit was issued by EPA in 1985. This permit specifies the conditions under which JACADS must be operated and includes sections on record-keeping, waste analysis, inspections, personnel training, emergency planning, waste storage, incinerator operations, and monitoring requirements.

The cornerstone of EPA's hazardous waste incinerator regulations is the trial burn, an extensive test of the actual operating incinerator, including detailed monitoring and sampling of the stack gases. The trial burns must be successfully passed before EPA will grant an operating permit. During the trial burns for the JACADS LIC, the Army was required to demonstrate the following:

- destruction of at least $99.99 \%$ of agent GB fed into the incinerator, and concentrations of GB in the stack gas below the time-weighted average of (TWA) $0.0003 \mathrm{mg} / \mathrm{m}^{3}$;

- particulate emissions less than $180 \mathrm{mg} / \mathrm{m}^{3}$ (dry standard volume) or 0.08 grains $/ \mathrm{ft}^{3}$, when corrected for $7 \%$ oxygen content in the stack gas;

- the removal of at least $99 \%$ of the $\mathrm{HCl}$ from the incinerator exhaust gas, or $\mathrm{HCl}$ emission rates in the stack gas less than $1.8 \mathrm{~kg} / \mathrm{hr}(4 \mathrm{lb} / \mathrm{hr})$; and

- steady-state operation with the primary chamber exhaust gas temperature in excess of $1400^{\circ} \mathrm{C}\left(2550^{\circ} \mathrm{F}\right)$ and secondary chamber exhaust gas temperatures in the range of 1010 to $1175^{\circ} \mathrm{C}\left(1850\right.$ to $\left.2150^{\circ} \mathrm{F}\right)$.

In addition to the operational limits specified above, the trial burns also included the monitoring of stack emissions for oxygen, carbon monoxide, carbon dioxide, nitrogen oxides, hydrogen chloride, volatile and semivolatile products of incomplete combustion, total particulate matter, and heavy metals. The residues from the LIC were analyzed for semivolatile products of incomplete combustion, as well as for the 24 organic and eight metallic substances specified in the EPA toxicity characteristics leaching procedure (40 CFR Pt. 261.24).

The three RCRA trial burns were conducted at the JACADS LIC in early December 1990. Approximately $340 \mathrm{~kg} / \mathrm{hr}(750 \mathrm{lb} / \mathrm{hr})$ of agent GB were fed into the LIC during each test. The LIC demonstrated its ability to meet the above requirements and passed all emission tests. Results of these trial burns (see Table 3.7) showed the following:

- in all tests, the destruction of agent GB was above $99.999998 \%$, and the concentration of agent GB in the stack was below $0.0003 \mathrm{mg} / \mathrm{m}^{3}$;

- emissions of particulate matter were never greater than $4.2 \mathrm{mg} / \mathrm{m}^{3}$ when corrected to 7\% oxygen concentration;

- the $\mathrm{HCl}$ emission rates were never more than $0.04 \mathrm{~kg} / \mathrm{hr}(0.087 \mathrm{lb} / \mathrm{hr})$; and

- steady-state temperatures of the primary chamber exhaust gas averaged $1482^{\circ} \mathrm{C}$ $\left(2700^{\circ} \mathrm{F}\right)$ [range: 1480 to $1489^{\circ} \mathrm{C}\left(2696\right.$ to $\left.2712^{\circ} \mathrm{F}\right)$ ]; the average secondary chamber exhaust gas temperature was $1093^{\circ} \mathrm{C}\left(2000^{\circ} \mathrm{F}\right)$ [range: 1089 to $1133^{\circ} \mathrm{C}(1992$ to $\left.\left.2072^{\circ} \mathrm{F}\right)\right]$. 
Table 3.7. Summary of system test conditions and results

\begin{tabular}{|c|c|c|c|c|c|}
\hline \multirow[b]{2}{*}{ Parameter } & \multirow[b]{2}{*}{ Units } & \multicolumn{3}{|c|}{ Burn } & \multirow[b]{2}{*}{ Requirement } \\
\hline & & LIC 1 & LIC 2 & LIC 3 & \\
\hline GB feed rate & $\mathrm{lb} / \mathrm{hr}$ & 750 & 750 & 750 & \\
\hline GB concentration & $\mathrm{mg} / \mathrm{m}^{3}$ & $<0.0003$ & $<0.0003$ & $<0.0003$ & $<0.0003$ \\
\hline $\begin{array}{l}\text { Incinerator } \\
\text { Primary exhaust } \\
\text { Secondary exhaust }\end{array}$ & $F^{\mathbf{a}}$ & $\begin{array}{l}2701 \\
2001\end{array}$ & $\begin{array}{l}2701 \\
2000\end{array}$ & $\begin{array}{l}2699 \\
1998\end{array}$ & $\begin{array}{l}2700 \pm 150 \\
2000 \pm 150\end{array}$ \\
\hline $\begin{array}{l}\text { Destruction and removal } \\
\text { efficiency }\end{array}$ & $\%$ & $>99.999998$ & $>99.999998$ & 99.999998 & $\geq 99.99$ \\
\hline $\begin{array}{l}\text { Particulate matter } \\
\text { corrected to } 7 \% \mathrm{O}_{2}\end{array}$ & $\mathrm{mg} / \mathrm{m}^{3}$ & 3.7 & 4.2 & 3.9 & $<180$ \\
\hline HCI emissions & $\mathrm{lb} / \mathrm{hr}$ & $\leq 0.0023$ & $\leq 0.0035$ & $\leq 0.013$ & $<4$ \\
\hline Stack dry gas flow & $\mathrm{lb} / \mathrm{hr}$ & 31,500 & 30,800 & 29,100 & \\
\hline Oxygen & $\%$ & 14.6 & 14.4 & 14.6 & \\
\hline Carbon dioxide & $\%$ & 4.5 & 4.6 & 4.5 & \\
\hline $\begin{array}{l}\text { Carbon Monoxide } \\
\text { corrected to } 7 \%, \mathrm{O}_{2}\end{array}$ & $\mathrm{ppm}$ & 19 & 26 & 18 & $<100$ \\
\hline
\end{tabular}

Orsat values; to convert to degrees Celsius, subtract 32 and multiply by 0.556 . 
Combustion efficiency during the tests ranged from 99.94 to $99.99 \%$. Carbon dioxide accounted for about $4.5 \%$ of the stack gas emissions. Emissions of HF were never greater than $0.11 \mathrm{~kg} / \mathrm{hr}(0.24 \mathrm{lb} / \mathrm{hr})$; removal efficiencies for $\mathrm{HF}$ were determined to be greater than $99.78 \%$, although there is no removal efficiency requirement for $\mathrm{HF}$.

All process samples were analyzed for heavy metals: arsenic, barium, cadmium, chromium, lead, selenium, silver, and mercury. Three samples from the scrubber brine contained lead in quantities that require that the brine be disposed of as hazardous waste. All process brine that has sufficient amounts of lead to be classified as a hazardous waste will be disposed in accordance with RCRA regulations. All other samples were below regulatory limits for all parameters tested.

Potential modifications to the RCRA permit are planned. The Army has forwarded a list of such modifications to the EPA. The list includes the following:

- $\quad$ Rebricking of the secondary chamber of the LIC. Tests at CAMDS have indicated that the bricks are destroyed at an accelerated rate during the burning of decontamination solutions. The rebricking is currently under way.

- $\quad$ Addition of a PAS for the brine reduction area. Systemization testing at JACADS indicated that the brine dryer had a high level of particulate coming out the stack. A baghouse filter has been added to the system.

- Determination of the final operating conditions after the completion of trial burns. The current RCRA permit authorizes the Army to conduct trial burns, but not fullscale disposal operations. The results of the trial burns will be used to determine the actual JACADS operating rates.

As noted in Sect. 3.2.2.2, some procedural RCRA problems arose, especially during the early stages of JACADS operations. These included such items as failure to permanently record and store all required data pertaining to emissions and operating measurements, improper tracking and accounting for some containers of nonprocessed solid wastes, and storage of some wastes in excess of the 90-day RCRA limit. The Army is actively working to eliminate all such problems in future operations. While these do constitute violations of RCRA procedural regulations, no known effects to human health or the environment resulted, nor do they have any technical implications for the operation of the JACADS facility.

TSCA. During the manufacture of M55 rockets, some of the fiberglass shipping tubes were contaminated with polychlorinated biphenyls (PCBs). Because PCBs are regulated by EPA under TSCA, a permit will be required to incinerate these shipping tubes at the JACADS facility. The TSCA regulations for PCBs are similar to the RCRA regulations for hazardous wastes.

As shown in the discussion of stack emissions (Sect. 3.2.2.1), the required PCB destruction and removal efficiency (DRE) of $99.9999 \%$ was achieved. The three TSCA R\&D burns resulted in PCB DREs of $99.999976 \%, 99.999946 \%$, and $99.99991 \%$, respectively. Furthermore, PCB emissions from JACADS $(0.00056 \mathrm{~g} / \mathrm{hr})$ were much lower than permitted CONUS levels. The CONUS disposal facilities are being designed with DFS afterburners that operate at higher temperatures and longer residence times than JACADS; $1204^{\circ} \mathrm{C}\left(2200^{\circ} \mathrm{F}\right)$ for $2.0 \mathrm{~s}$, as opposed to $1093^{\circ} \mathrm{C}\left(2000^{\circ} \mathrm{F}\right)$ for $0.5 \mathrm{~s}$. Thus, even higher PCB DREs should be possible. 


\subsubsection{Accidents and Other Nonroutine Events}

This section describes the causes, consequences, and actions taken related to specific nonroutine events that have occurred at JACADS.

The FPEIS risk assessment identified the risks associated with on-site transportation activities as being dominant for on-site disposal alternatives at PUDA. However, there is little relevance between JACADS accidents and nonroutine events and the operation of the proposed PUDA facility, since GB-filled rockets are processed at JACADS, while mustardfilled projectiles only are to be processed at PUDA. Nevertheless, the discussions below focus on the types of incidents that have occurred to date during the JACADS OVT in an attempt to identify how repetitions can be prevented.

\subsubsection{Stack release}

Since the JACADS facility became operational, there has been only one confirmed emission in which agent GB was released to the atmosphere. During this event, emissions from the JACADS facility remained well below all applicable federal and state emission standards. The confirmed emission of agent GB occurred on December 8, 1990. The cause of the release has been attributed to operator error and an inadequately programmed purge cycle of the agent feed line to the LIC.

During the week of December 3, 1990, the JACADS facility conducted tests of the LIC to demonstrate compliance with RCRA requirements. The test burns were completed on December 6, and the chemical agent line to the primary chamber of the LIC was purged before the entire system was placed into a cool-down mode for preventative maintenance. The agent gun (atomizer) and a section of the agent line leading to it were inadequately purged, thereby trapping a very small amount of agent GB.

While still in the cool-down mode on December 8, chemical agent was detected by monitoring equipment in the duct leading from the LIC's PAS to the stack. The monitor in the stack indicated that no chemical agent was present; however, upon further investigation, the probe to the monitor was found to be clogged.

A stack sample was taken from the backup system that also monitors the stack gas. Laboratory results showed that, for up to $45 \mathrm{~min}$, the chemical agent concentration in the stack gases was $8 \%$ of the permissible emission standard. Gases in the stack must be discharged into the atmosphere with agent concentrations less than the stack emission limit of $0.0003 \mathrm{mg} / \mathrm{m}^{3}$ (or 52.5 parts per trillion by volume); this is also the emission limit permitted under RCRA.

When the problem had been identified, the LIC feed line was subsequently purged and an additional quantity of agent GB was released into the LIC; consequently, GB entered the furnace room. Through air pressure differential, the room air was directed into the carbon filters, and the room was swept clean of agent over the next $2.5 \mathrm{hr}$. Chemical agent monitors in the carbon filters and filter stack indicated that the agent was completely contained by the safety and absorption features designed into the ventilation and filtration system.

The low concentration of agent GB released was significantly below the stack emission limit and did not result in any hazard to human health or to the environment. To 
prevent similar accidents of this type, additional controls and procedures have been implemented to ensure adequate line purging. Stack gas sampling procedures have been modified to ensure better detection of chemical agent in the ducts and in the stack, and a redundant layer of monitoring equipment has been installed.

\subsubsection{In-plant release}

Operational problems that occurred during the early stages of the JACADS OVT did result in some in-plant releases of agent. These included the following:

- $\quad$ shutdown of the LIC during a test run,

- malfunction of a pump while transferring agent from the rocket drain station,

- disconnection of the agent line from the LIC for maintenance, and

- movement of the agent burner assembly which contained some residual in the LIC room.

None of these incidents resulted in exposures to workers. Corrective measures have been taken in each case to prevent future occurrences.

\subsubsection{Nonroutine incidents not involving chemical agent}

Fire. A fire occurred during nonagent testing of the DFS at JACADS prior to the start of toxic operations. During this test, the slide gates used to feed the furnace were not working effectively and were periodically binding from thermal expansion. In order to continue the tests while a new feed gate was being designed, the existing gates were machined down so that they would not bind. The machining of the gates introduced an opening in the feed system that enabled hot gases to exit the furnace system and resulted in a small strip of furnace insulation catching fire. The fire quickly burned out and the burned insulation was replaced. It was never the Army's intention to utilize these modified gates once operations with actual chemical agents were initiated. The slide gates have been replaced with a tipping valve which has been thoroughly tested in subsequent operations. This system will continue to be tested, and, if it continues to perform satisfactorily, will be used in the design of the CONUS disposal facilities.

Heated discharge conveyor. One mechanical breakdown which has caused much of the operational problem associated with JACADS is the heated discharge conveyor system. When the molten aluminum and fiberglass of the M55 rockets leave the deactivation furnace, the debris is carried up an inclined $\left(45^{\circ}\right)$ conveyor belt where it is discharged into a hopper. Despite the fact that the conveyor is heated, the aluminum is adhering to the conveyor or falling off the conveyor and into the housing. Correcting the jamming of the conveyor system has accounted for a significant portion of the total downtime for the JACADS facility.

During the scheduled maintenance period in mid-December 1990 through January 1991, modifications were made to the heated discharge conveyor system. Buckets were added to the discharge belt; these buckets were intended to catch the molten aluminum debris and prevent it from jamming the conveyor system. Testing with the bucket system in February produced encouraging results and demonstrated that the bucket system could be incorporated 
into future CSDP incinerator designs. Additional proof tests of the buckets, along with other modifications to the conveyor system, are planned during the VX rocket test campaign.

Monitoring system failure. On July 23, 1990, a local agent monitor sounded indicating chemical agent presence in the MPF, although no indication of the alarm had been received by the control room. Investigation revealed that the transmission of measurements from several agent monitors had been disconnected from the control room for about 3 weeks, and alarms from the units had been disconnected for about a week. The monitors had continued local data recording and alarm functions. Systems and procedures were modified to prevent a repetition of the event; however, a similar event did occur in December 1990 . In neither case was there a risk to the public, and there were no exposures and no injuries to workers, though the potential for increased risk to workers was present.

DUN Pressure Excursion. On June 26, 1991, the JACADS DUN shut down when the quench tower exhaust gas temperature exceeded the normal operating range of $325-475^{\circ} \mathrm{F}$. The quench tower was unable to control the temperature because a valve on the upper spray nozzles had been closed during maintenance. During the system upset, volatiles from smoldering dunnage in the primary chamber migrated into the DUN elevator shaft through leaks in the charge door (the charge door is not designed to be air tight). An explosion apparently resulted from the accumulation of combustible gases in the elevator shaft, the presence of oxygen, and the high temperatures in the furnace. Outside personnel in the area reported hearing a "pop" and noted that the wall panels in the DUN furnace room were out of place. This event did not result in injuries or exposure of workers to agent or the release of any agent to the environment. Several DUN system design changes are being evaluated to prevent future pressure excursions.

Collapse of MDB walls. On July 23, 1991, a series of electrical malfunctions resulted in power loss to the MDB air supply fans, while some exhaust fans remained in operation. Personnel working inside the MDB experienced popping of their ears and heard a loud metallic bang which may have been the sound of the MDB walls collapsing slightly inward. The elevator doors in the MDB were abnormally shaped by the negative pressure. The event did not resuit in the release of any agent to the environment, exposure of workers to agent, or damage to the munition disassembly or incineration equipment. To prevent recurrence of this event, an automatic trip has been installed to shut down all but one of the exhaust fans if shutdown of the air supply fans should occur again. The control room will take manual control of the one exhaust fan and modulate it to maintain necessary negative pressure in the MDB.

\subsection{OTHER RECENT DEVELOPMENTS AND DISPOSAL EXPERIENCE}

Alternate technologies for destruction and disposal of the U.S. chemical stockpile have been proposed or reviewed by many organizations (see, for example, NRC 1984 and Greenpeace 1991). Table 3.8 presents the type of processes that are in current use to destroy or eliminate other forms of hazardous waste. As indicated in the table, the various processes can be placed into six broad categories: (1) biological processes, (2) chemical processes, (3) electrochemical processes, (4) neutralization, (5) photochemical processes, and (6) thermal processes. 
Table 3.8. Alternate technologies for destruction of the chemical weapons stockpile

\begin{tabular}{|c|c|c|}
\hline Type of Process & $\begin{array}{l}\text { Representative Industrial } \\
\text { Applications }\end{array}$ & $\begin{array}{l}\text { Comments, applicability to } \\
\text { the Chemical Stockpile } \\
\text { Disposal Program (CSDP) }\end{array}$ \\
\hline Biological & $\begin{array}{l}\text { - Wastewater treatment } \\
\text { - Bioreactors/biodegradation } \\
\text { - Enzymes/microorganisms }\end{array}$ & $\begin{array}{l}\text { Generally employed with dilute aqueous solutions. Cheaper than } \\
\text { incineration, if feed stream has no heating value. Biological } \\
\text { processing of wastewater is a very mature technology, but } \\
\text { biological disposal of chemical agents is in an embryonic state of } \\
\text { development. Enzymes have been developed to "digest" nerve } \\
\text { agents. Mustard agent presents difficulties with respect to forming } \\
\text { aqueous solutions. Biological processes may also have application } \\
\text { to disposal of explosive materials. Waste streams from biological } \\
\text { disposal of chemical agents and explosives have not been fully } \\
\text { studied to identify toxic characteristics. }\end{array}$ \\
\hline Chemical & $\begin{array}{l}\text { - Stream gasification } \\
\text { - Molten salt reactors } \\
\text { - Supercritical water oxidation }\end{array}$ & $\begin{array}{l}\text { Generally involve extremely high temperatures and/or pressures. } \\
\text { Physically similar processes can be tailored to specific feed } \\
\text { materials (e.g., nerve agents, mustard agent, explosives). } \\
\text { Chemical processing is a mature technology, but application to } \\
\text { chemical agents is unexplored. Waste streams from chemical } \\
\text { processes for disposal of chemical agents and explosives have not } \\
\text { been fully studied to identify toxic characteristics. }\end{array}$ \\
\hline Electrochemical & $\begin{array}{l}\text { - Electrodialysis } \\
\text { - Electorchemical oxidation }\end{array}$ & $\begin{array}{l}\text { Generally involve either ionization and separation of the feed } \\
\text { stream or direct oxidation reactions induced by electric current. } \\
\text { Electrodialysis is more applicable to separation of metals than to } \\
\text { chemical agents; electrochemical oxidation may require the } \\
\text { addition of an oxidizing agent. Appears to have only limited } \\
\text { applicability to CSDP. Waste streams from electrochemical } \\
\text { disposal of chemical agents and explosives have not been fully } \\
\text { studied to identify toxic characteristics. }\end{array}$ \\
\hline
\end{tabular}


Table 3.8. (continued)

\begin{tabular}{|c|c|c|}
\hline Type of Process & $\begin{array}{l}\text { Representative Industrial } \\
\text { Applications }\end{array}$ & $\begin{array}{l}\text { Comments, applicability to } \\
\text { the Chemical Stockpile } \\
\text { Disposal Program (CSDP) }\end{array}$ \\
\hline Neutralization & $\begin{array}{l}\text { - Chemical reagents } \\
\text { - Hydrolysis } \\
\text { - Oxidation }\end{array}$ & Electrochemical \\
\hline Photochemical & $\begin{array}{l}\text { - Ultraviolet irradiation } \\
\text { - Lasers } \\
\text { - Ozone oxidation }\end{array}$ & $\begin{array}{l}\text { Similar to natural photodegradation processes. Some processes } \\
\text { employ catalysts or elevated temperatures. Generally have been } \\
\text { somewhat successful with the treatment of dilute feed streams; no } \\
\text { commercial processes currently in use. The need for direct } \\
\text { sunlight in some processes may limit their utility. Appears to } \\
\text { have only limited applicability to CSDP. }\end{array}$ \\
\hline Thermal & $\begin{array}{l}\text { - Municipal and hazardous waste } \\
\text { incinerators } \\
\text { - Plasma arc } \\
\text { - Infrared heating } \\
\text { - Radio frequency heating } \\
\text { - Cryofracture }\end{array}$ & $\begin{array}{l}\text { Involve high temperature combustion processes. Thermal } \\
\text { processes are the most mature of the technologies reviewed. } \\
\text { Army has extensive experience with incineration of chemical } \\
\text { agents. With the proper treatment, gaseous waste streams appear } \\
\text { to be capable of achieving environmental acceptability. Solid } \\
\text { wastes can be characterized for their hazardous nature and } \\
\text { disposed of accordingly. The incineration processes provide a } \\
\text { system capable of destroying chemical agents, as well as } \\
\text { explosives. }\end{array}$ \\
\hline
\end{tabular}


Regardless of which process (or which combination of processes) is used for the CSDP, destruction of the U.S. stockpile must entail the elimination of not only the hazards of the various chemical agents themselves, but also the energetic or explosive components of the munitions. In addition, metal components and casing materials that have been in direct contact with the chemical agents must be acceptably decontaminated. These requirements can therefore be used to assess the potential use of the technologies in Table 3.8, as discussed below.

This section provides the status of developments in the proposed disposal technology. The status of possible alternative technologies is discussed along with the experience gained with the BZ facility at PBA, Arkansas, and the related topics of training, contract awards, and individual equipment advances. New information gained since the FPEIS is examined to determine the extent to which technological experience continues to support on-site incineration.

\subsubsection{Alternative Technologies}

Alternatives discussed in the following sections are those considered in the FPEIS or alternatives that are considered technologically mature. Those techniques that are experimental or have not been proven by a pilot plant are rejected and not considered further because the technology could not be implemented in the time frame required by law to destroy the U.S. chemical weapon stockpile. Chemical agent disposal alternatives considered in the FPEIS include placement in deep ocean and the use of nuclear explosions. In fact, between World War I and 1969, chemical agents and munitions were disposed of by ocean dumping. However, in June of 1969 the National Academy of Sciences (NAS) recommended that ocean dumping be abandoned as a disposal method. National and international law now prohibit ocean dumping as a viable method of chemical weapon disposal. The use of the intense heat from the detonation of nuclear devices also proved to be infeasible for many reasons including public acceptance, identifying a site, securing approvals, and uncertain costs.

\subsubsection{Chemical neutralization}

The term "chemical neutralization" implies that a chemical reaction takes place that counteracts a toxic agent, yielding innocuous residues. Thus, it sounds like an attractive alternative for chemical munitions destruction. Intuitively it would appear that weapons that have been produced by the combinations of certain chemicals could be deactivated by reversing those reactions. However, the experience with chemical munitions has proven to be extremely complex.

In response to comments received during the public scoping process for the FPEIS, the Army considered the option of neutralizing the chemical agents prior to their ultimate destruction by incineration. The Army had previous extensive experience with neutralization of nerve agent GB at RMA in the mid-1970s and also tested a neutralization process (without incineration) for GB at CAMDS (NRC 1984). More than 8.4 million lb of agent GB were neutralized with caustic sodium hydroxide. The results of those programs were not encouraging for several reasons: (1) the process resulted in extremely slow reaction times (days as opposed to the expected hours); (2) the reaction was very complex and required large 


\section{3-31}

quantities of caustic solution (sodium hydroxide); (3) the process is not irreversible, at least for GB (i.e., process wastes are primarily organic salts that could, during spray-drying, revert to $\mathrm{GB}$ ); and (4) extremely large quantities of organic process wastes were produced by caustic neutralization ( $5 \mathrm{lb}$ of wastes for each pound of agent versus approximately 1.5 of inorganic wastes produced by incineration).

Neutralization also does not destroy the energetic materials such as bursters and M-55 rocket motors. These munition parts would require a separate method of disposal such as incineration.

Neutralization is complex and costly because each chemical agent requires a different method. To date GB is the only chemical agent with which the Army has industrial scale neutralization experience. Mustard can be neutralized by hydrolysis or by reacting with an excess of monoethanolamine. Neutralization of mustard agent is complicated by high amounts of impurities and the fact that the mustard agent may not neutralize completely. Also, wastes may be more voluminous and chemical reactions slower than expected, requiring more neutralizing agent, time, and reactor capacity than originally expected. Neutralization of the mustard agent yields a toxic organic liquid waste which is best disposed of by incineration.

VX agent can be neutralized by chlorinalysis. However this process uses chlorinebased reagents which create toxic residues. Neutralization by chlorinalysis has not been demonstrated on an industrial scale.

Each of the above neutralization processes requires the additional step of incineration of chemical process wastes.

\subsubsection{Plasma arc}

Plasma arc is a thermal destruction technology that would involve the flow of a gas stream of chemical agent through an electric arc increasing the ionization of the gas and raising its effective temperature to several thousand degrees, thus destroying the chemical agent. A device based on this principal has been used for destroying hazardous waste and is marketed commercially. In field trials, this device has reduced the toxic content in hazardous waste to less than $10^{-7}$ of the original concentration. However, plasma arc technology has not been successful when demonstrated in large disposal projects such as the Superfund program cleanup of the Love Canal area.

Problems associated with this process include production of carbon monoxide, nitrogen oxides and cyanogen which must be decomposed in a secondary combustion chamber or scrubbed out in a PAS. This process is much more expensive to operate than incineration and would be difficult to adapt to decontaminating projectile bodies and parts.

\subsubsection{Enzyme-catalyzed hydrolysis}

Enzyme catalyzed hydrolysis is a biological process that uses an enzyme (produced by a species of bacteria) to catalyze the hydrolysis of organophosphate compounds, including chemical agent. The enzyme has been shown to accelerate the hydrolysis of GB by a factor of $2 \times 10^{7}$ in pure water ( $\mathrm{pH} \mathrm{7.0)}$ ) to the point at which the half-life of GB in solution is $0.1 \mathrm{~s}$. 
However, the concentration of the enzyme in a tissue culture containing this particular enzyme is only $0.03 \%$ by weight. The production of sufficient enzyme to hydrolyze the stockpile of organophosphorus agent would, therefore, be prohibitively expensive and extremely time consuming. Additionally, the process has not been shown to completely hydrolyze all of the chemical agent introduced into the process which is a mandatory requirement of the chemical munition destruction process.

\subsubsection{Supercritical water oxidation}

The supercritical water oxidation process oxidizes organic wastes in the presence of large amounts of water by adding oxygen and heating the mixture under pressure (to $375-600^{\circ} \mathrm{C}$ at $3200-5000 \mathrm{psig}$ ). This process has been demonstrated in laboratory and small-scale facilities. It is theoretically ideal for detoxifying dilute aqueous solutions or suspensions of highly hazardous organic waste. It destroys toxic organics to the limits of detection. This process has been found to destroy more heat-resistant organic compounds at higher temperatures and pressures. At relatively low temperatures this process produces no oxides of nitrogen.

Because conditions in this process include high oxygen pressure, high temperature, low $\mathrm{pH}$, supercritical water, and chloride, corrosion is a major problem with supercritical water oxidation. It is believed that subcritical water $\left(260-350^{\circ} \mathrm{C}\right)$ may be even more corrosive to some materials than supercritical water due to the former's higher polarity and ability to keep ions in solution. The corrosion potential in combination with the extremely high temperatures and pressures employed by the technology may pose unique safety concerns. Furthermore, tests have shown the development of "hot spots" inside the reactor vessel during supercritical oxidation. These hot spots may weaken the reactor wall. Significant research into supercritical water oxidation is still under way, led by Sandia National Laboratories and funded by the Defense Advanced Research Projects Agency.

Solid waste handling has yet to be demonstrated on a full scale for this process. Supercritical water oxidation also cannot handle contaminated solid munition parts or energetic materials. Therefore, these munition components would have to be disposed of by a separate process.

\subsubsection{Summary}

While many of the technologies discussed above are capable of destroying specific components of the chemical stockpile (e.g., chemical agents or energetic materials) only the incineration processes can destroy all of the agents and munitions components and accomplish the acceptable decontamination of the remaining metal scrap. Some of the biological and chemical processes (including neutralization) have shown promise for chemical agent disposal, but the previous use of these technologies has left unexplored the issues of energetic material disposal and decontamination of metal parts.

With respect to the destruction of the chemical stockpile, the maturity of these alternate disposal technologies is obviously not so far advanced as that of the JACADS-type reverse assembly and incineration process. Technological advances in the above areas are such that, given sufficient time, alternatives to the JACADS process can be found. However, 
during that same time, the JACADS process can itself be refined and improved to complete the destruction of the U.S. chemical stockpile. For now, the JACADS process is the only disposal system that can accomplish the total CSDP mission in a reasonable time frame.

\subsubsection{Cryofracture}

The FPEIS included a discussion of the cryofracture technology in the section on disposal alternatives (see U.S. Army 1988a, Vol. 1, Sect. 2.3.6.3). The cryofracture disposal process employs a thermal destruction technology that differs from the JACADS-type reverse assembly and incineration process primarily by the manner in which the munitions are handled prior to incineration. As shown schematically in Fig. 3.3, cryofracture involves completely submerging the chemical munitions in a liquid nitrogen bath [at about $-210^{\circ} \mathrm{C}$ $\left.\left(-350^{\circ} \mathrm{F}\right)\right]$ until they are embrittled, then crushing them in a mechanical press before feeding them into a rotary kiln for incineration. A series of industrial robots would handle and position the munitions in each of the steps prior to incineration.

Because the munitions would be directly immersed in the nitrogen bath without being disassembled and/or removed from their current storage configurations (e.g., boxes), the cryofracture process has the advantage of fewer handling steps than the JACADS process. In place of the four separate furnaces used by the JACADS process (see Fig. 3.1), two furnaces would be used in the cryofracture process. The fractured pieces from the mechanical press consisting of frozen chemical agent, explosives, and metal and wooden fragments would be simultaneously processed in the kiln to destroy the agent and energetic compounds, decontaminate the metal fragments, and destroy the combustibles. A dunnage incinerator is also included in the design to accept non-explosive materials; this provides backup to the kiln.

While projectiles, mortars, mines, and rockets appear to be ideal candidates for cryofracture, it offers no advantage to the baseline process for bulk items. For bulk items, the cryofracture methodology drains the liquid from the container, incinerates the liquid, and shears the room temperature containers in the press for feed to the rotary kiln.

The Army is working toward the development of a prototype cryofracture facility. The Army is actively testing the cryofracture process as an alternative to the mechanical disassembly and rocket shear processes used in the JACADS technology. The results of these tests are being incorporated into the design of a cryofracture facility at PUDA.

\subsubsection{The BZ Facility}

As discussed in Sect. 3.1.1, a demilitarization facility has been operated at PBA for the destruction of the nonlethal but incapacitating agent BZ. Two chemical occurrences were reported during toxic operations at the $\mathrm{BZ}$ demilitarization facility. The first chemical occurrence, in November 1988, involved an operations worker who demonstrated partial symptoms of BZ exposure. A technical investigation of the first chemical occurrence revealed inconclusive evidence of worker exposure to agent BZ; however, enhancements were made to existing personnel entry and egress procedures for access to contaminated plant areas during demilitarization operations. The second chemical occurrence, in April 1989, involved a maintenance worker who demonstrated more pronounced symptoms of BZ exposure. A technical investigation of the second chemical occurrence could not determine the mechanism 
ORNL-DWG 93M-12576

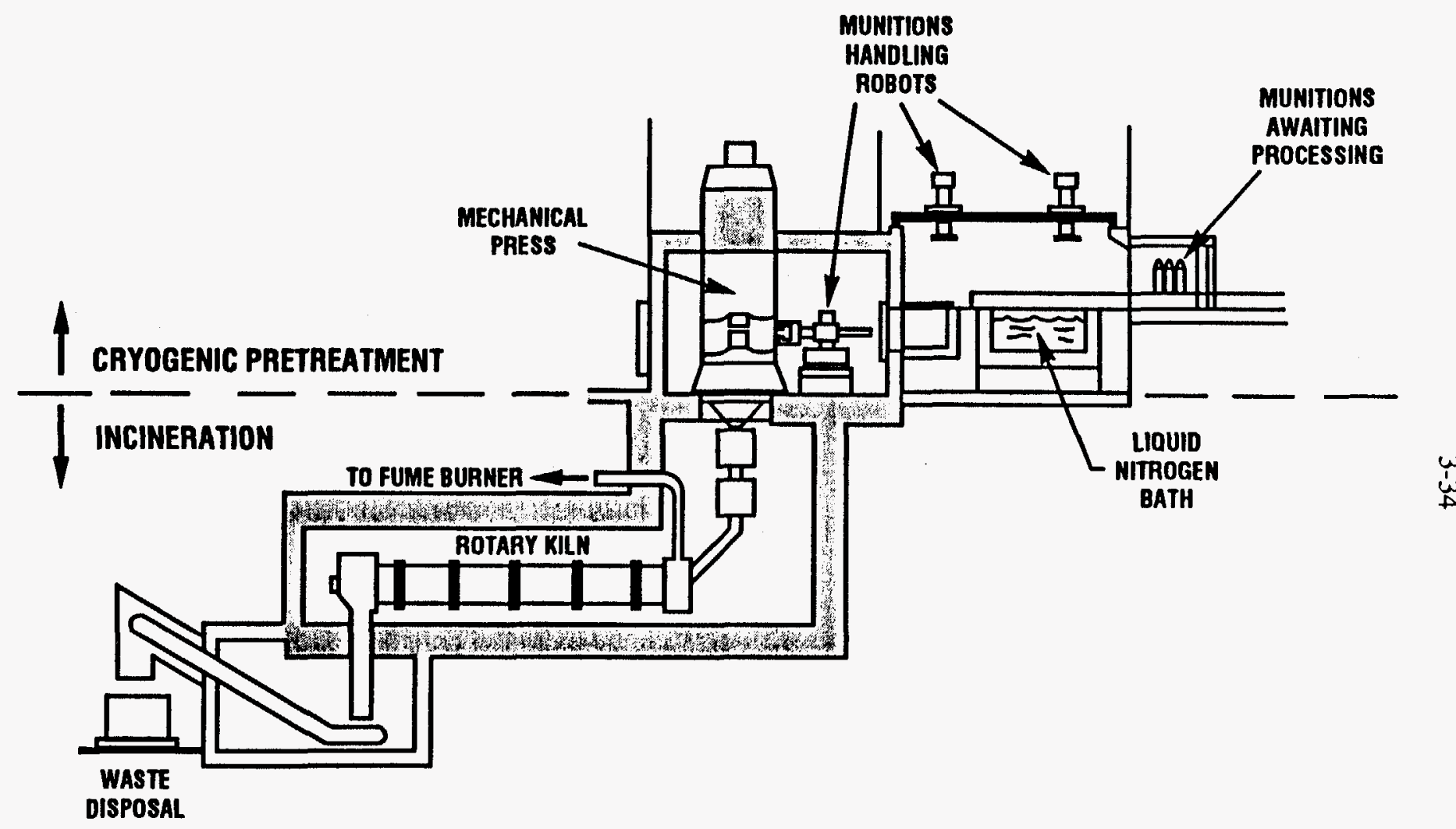

Fig. 3.3. Schematic process diagram for a cryofracture disposal facility. 
for agent $\mathrm{BZ}$ exposure; nevertheless, further enhancements were made to personnel entryegress procedures, quality control, and medical monitoring procedures. Both workers returned to duty after the conclusion of each technical investigation.

The $\mathrm{BZ}$ disposal process was developed based on knowledge gained from disposal operations at CAMDS and RMA. Selected BZ equipment, including the DFS and heated discharge conveyor, was purchased based on equipment technical data packages from CAMDS. Because the disposal procedures for $\mathrm{BZ}$ and the lethal unitary agents and munitions are based on a common technology, much of what was learned from disposal of the $\mathrm{BZ}$ has been applicable to the CSDP. In addition, although $\mathrm{BZ}$ is a nonlethal agent, the $\mathrm{BZ}$ disposal plant was operated in terms of safety, surety inspections, and guidelines as if it were disposing of lethal agents. The BZ facility and the CSDP facilities have been designed for maximum agent containment and destruction as well as maximum protection of both workers and the public from agent exposure. Specific contributions from the BZ disposal operations to the CSDP technology are listed below.

- $\quad$ The BZ training program included extensive (and successful) hands-on training that is being implemented at JACADS and will be implemented at the CDTF (see Sect. 3.3.3) to support the CSDP.

- $\quad$ At the end of systemization and before startup of the BZ disposal operations, a preoperational survey was conducted by a team of experts (U.S. Army and DHHS) to ensure that the BZ disposal system conformed to all applicable safety, environmental, quality assurance, security, and safety standards and that an acceptable level of performance could be maintained during the $\mathrm{BZ}$ disposal operations. All findings essential to the safe and efficient operation of the BZ facility required correction prior to start of operations. Many of the problems identified during the BZ preoperational survey could have been resolved much earlier in the systemization period. For this reason, operational and readiness evaluations were conducted at JACADS and are planned at the CONUS CSDP facilities before the formal preoperational survey. These evaluations will be conducted periodically during the plant systemization periods to inspect designated systems and subsystems for compliance with regulatory requirements; to assess the progress of the facility toward achieving an operational status in accordance with the schedule; and to identify and resolve problems before the formal preoperational survey, thereby minimizing schedule impacts.

- The BZ disposal facility was the first government-owned, contractor-operated facility managed by the Program Manager for Chemical Demilitarization (PMCD). Experience has been gained regarding schedule durations and potential problems associated with hiring contractor personnel under the Chemical Personnel Reliability Program. This program ensures that personnel assigned to positions involving access to chemical surety material are emotionally stable, loyal to the United States, trustworthy, and physically fit to perform assigned duties. This program has been instituted at JACADS and will be instituted at the CONUS CSDP facilities.

From January to June 1990 , cleanup and closure operations at the BZ facility were completed in accordance with all state, RCRA, and Army regulations. During the final closure ceremony on June 29,1990 , the facility was opened to the press and general public for inspection. 


\subsubsection{The Chemical Demilitarization Training Facility}

In July 1989, the systems contract for the construction and operation of a CDTF was awarded to General Physics Corporation of Columbia, Maryland. This facility, which is located at APG, Maryland, will be used to ensure uniform and consistent training is provided to workers who will operate the eight demilitarization facilities planned for construction. The CDTF began limited training operations in mid-1991.

The CDTF will provide basic and prerequisite instruction in chemical agent and munition destruction for both government and contractor personnel involved in operation of the CONUS facilities. The CDTF will provide classroom instruction, hands-on equipment operation, and continuation-refresher courses. Through computer simulation, students will be trained in realistic problem-solving and accident response scenarios as well as normal operations. A centralized training facility will enable workers to obtain training in a nonhazardous environment and will facilitate standardization of operations and maintenance procedures between the eight CONUS facilities. A single contractor is being used to train workers at the CDTF to facilitate incorporation of lessons learned and to centralize the training expertise, increasing overall training effectiveness.

\subsubsection{The Tooele Facility}

In September 1989, the systems contract for the Tooele chemical agent disposal facility was awarded to EG\&G, Inc., of Falls Church, Virginia. EG\&G, Inc., is responsible for the construction, operation, and decommissioning of the first full-scale CONUS chemical agent and munitions disposal facility. This facility is being constructed at TEAD in Utah. Operation of the Tooele facility is scheduled to begin in 1993.

\subsubsection{Contract Awards}

In November 1988, an equipment acquisition contract was awarded to Bechtel National, Inc. Bechtel is responsible for the acquisition of process equipment to be standardized among the eight CONUS demilitarization facilities. Examples of equipment to be purchased by Bechtel include the demilitarization equipment used to disassemble the munitions prior to incineration, the blast doors for the explosive containment room, and the brine reduction equipment.

Major process equipment critical to the safe operation of the facilities (e.g., furnaces, control systems, and PASs) are being purchased by United Engineers and Constructors, the JACADS equipment acquisition and operations contractor. The JACADS equipment acquisition contract contains options to purchase major equipment systems for the eight CONUS demilitarization facilities from the JACADS equipment vendors. This acquisition strategy will result in purchasing systems, critical to the safe operation of the facility, that are essentially identical to those purchased for JACADS. As a result, safety and environmental compliance aspects of this equipment will be demonstrable during JACADS OVT.

Equipment acquisition for all sites through a single equipment acquisition contractor (either Bechtel or United Engineers and Constructors) will result in uniformity and 
standardization of equipment among the CONUS sites and will facilitate the incorporation of lessons learned.

\subsubsection{Individual Equipment Advances}

In addition to experience gained from ongoing demilitarization programs, separate test programs and R\&D efforts are under way to improve the performance of individual equipment systems and ensure that state-of-the-art technology is continually incorporated into the CSDP facilities. For example, since the FPEIS was written, major improvements have been made to the ACAMS and ventilation filtration system.

During 1988, a research and development program was initiated to modify the ACAMS so that it could detect TWA concentrations of the agents HD, GB, and VX within a 3-5 min cycle. This response time was an improvement over the response time cited in the FPEIS, in which high-level detection was possible within $5 \mathrm{~min}$, but detection to the TWA level could only be achieved within 8-22 min. These reduced response times were successfully achieved during demonstration tests in mid-1988, and the JACADS ACAMS were modified to include this new technology prior to the start of operations.

Dugway Proving Ground is currently conducting adsorption tests on carbon to determine the effects of agent GB concentration, relative humidity, and temperature on adsorption and desorption performance of carbon filters. Test conditions were selected based on an experimental design chosen to provide a response surface at carbon bed depths of 5,10 , and $20 \mathrm{~cm}(2,4$, and 8 in.). The results should indicate the optimal operating conditions for the carbon and will enable the Army to assess the optimal carbon depth and the optimal operating conditions for the filters.

The FPEIS makes a public commitment to transport munitions from the storage area to the disposal facility in an ONC that would meet certain puncture, drop, fire, and crush performance criteria. The ONC is necessary to mitigate the risk of chemical munition transportation accidents during demilitarization operations. Since the publication of the FPEIS, the Army has pursued the development of this container. To date, the ONC design has been completed, puncture and fire tests have been successfully completed on a full-scale mockup ONC, and projectile penetration tests and rocket drop tests have been conducted. In June 1990, a contract was awarded to Gregory Enterprises in Carlsbad, New Mexico, to fabricate and test a prototype ONC. Following prototype testing, acquisition of the ONCs for the eight CONUS installations begins. The first production ONC is scheduled to be delivered in fiscal year 1993.

\subsection{FUTURE PLANS FOR SITE-SPECIFIC OPERATIONAL TESTING}

Under the current CSDP schedule for carrying out the destruction of the CONUS stockpile (Table 3.9), each of the new on-site disposal facilities is to undergo a period of systemization, including operational testing, prior to beginning full-scale operations. The last six of the disposal facilities scheduled to begin operations in 1998 [APG, Lexington-Blue Grass Army Depot (LBAD), Newport Army Ammunition Plant (NAAP), PBA, PUDA, and 
Table 3.9. Projected chemical agent stockpile destruction schedule

\begin{tabular}{ccc}
\hline Year & Sites starting operations $^{a}$ & Sites ending operations \\
\hline 1993 & JACADS & - \\
1994 & - & - \\
1995 & TEAD & - \\
1996 & - & JACADS (36) \\
1997 & ANAD & - \\
1998 & APG, LBAD, NAAP, PBA, & - \\
& PUDA, UMDA & \\
1999 & - & APG (12), NAAP (10) \\
2000 & - & TEAD (63), ANAD (38), \\
& & UMDA (32), PBA (33), \\
& & PUDA (21), LBAD (18) \\
\hline
\end{tabular}

aJACADS = Johnston Atoll Chemical Agent Disposal System; TEAD = Tooele Army Depot; ANAD = Anniston Army Depot; UMDA = Umatilla Depot Activity; PBA = Pine Bluff Arsenal; APG = Aberdeen proving Ground; NAAP = Newport Army Ammunition Plant; LBAD = Lexington-Blue Grass Army Depot; PUDA $=$ Pueblo Depot Activity.

Months of incinerator operations.

UMDA] will benefit from the testing and full-scale operations at ANAD, JACADS and TEAD.

PUDA will be the seventh of the chemical agent disposal facilities to begin systemization and testing. The extensive experience that will have been gained from the previously operational facilities should minimize uncertainties for the PUDA facility. Testing at PUDA will be carried out principally for purposes of permitting and check-out of individual pieces of equipment.

Prior to any operations at PUDA, the work force will have undergone the rigorous training and testing described in Sect. 3.2.1.3. Furthermore, all personnel will undergo detailed on-site training with the PUDA equipment prior to startup.

\subsection{FINDINGS AND CONCLUSIONS}

This section summarizes the major findings concerning new technology developments and states explicitly the potential of these findings to affect the re-examination of the environmentally preferred alternative in Sect. 6. Table 3.10 compares technology-related assumptions and commitments made in the FPEIS to JACADS experience. 
Table 3.10. Comparison of Final Programmatic Environmental Impact Statement (FPEIS) assumptions and commitments with disposal technology experience at Johnston Atoll Chemical Agent Destruction System (JACADS)

Processing Efficiency: Processing rates are not specified in the FPEIS, but design goals have since been established.

On-Site Transportation: On-site movement would be accomplished with agent-munitions inside an on-site container (ONC).

Personnel Training: A training facility would be constructed for detailed training of all program participants.

Stack Emissions: No violations of existing ambient air standards would result from disposal operations.

Solid Waste Management: Solid wastes would be recycled where feasible or disposed of according to RCRA requirements.

Environmental Monitoring: No detectable levels of agent would be identified by the perimeter monitoring system.

Worker Exposure: The U.S. Department of Defense airborne agent exposure limits, the same as the Surgeon General's recommended control limits, would be adhered to.

Environmental Compliance: The disposal technology would comply with all applicable environmental regulations.
Mechanical problems limited production early on. After scheduled maintenance, JACADS operated at a steady feed rate which satisfied the requirements of the Resource Conservation and Recovery Act of 1976 (RCRA) permit.

The ONC is under development. JACADS operational verification testing (OVT) is proceeding without it.

Intensive training of JACADS personnel was conducted without the training facility which is nearing completion at Aberdeen Proving Ground.

Disposal operations have complied with ambient air standards.

JACADS wastes have been managed and disposed of in accordance with RCRA.

No detectable agent concentrations have been measured at the perimeter monitoring stations.

No workers have received a measurable dose of agent.

Some procedural violations of RCRA have occurred and are being corrected. The technical requirements of RCRA and the Toxic Substances Control Act have been met. 


\subsubsection{Lessons Learned}

Since the initiation of the OVT in July of 1991 , JACADS has proven its ability to effectively dispose of GB-filled rockets. However, it has experienced significant downtimes because of mechanical problems. As is normally expected with the startup of any industrial facility of the size and complexity of JACADS, some malfunctions have occurred that have decreased production efficiency. The Army is committed to thoroughly evaluating the problems that arise during the JACADS testing, correcting them before full-scale operations begin, and incorporating these lessons into the technology to be used for the future construction and operation of the eight CONUS disposal facilities. This section summarizes OVT and systemization findings that may result in the modification of future chemical agent disposal technology.

- In the period between June 30, 1990 and December 12, 1990, there have been approximately $2882 \mathrm{~kg}(6355 \mathrm{lb})$ of slag removed from the JACADS LIC secondary chamber. During this period, $20,984 \mathrm{~kg}(46,262 \mathrm{lb})$ of $\mathrm{GB}$ and $139.9 \mathrm{~m}^{3}(36,969 \mathrm{gal})$ of spent decontamination solution were incinerated. Although the refractory in the secondary chamber is experiencing degradation, the LIC was capable of completing GB operations. Based on the recommendations of various manufacturers and consultants, the refractory in the LIC secondary chamber is being changed from a BHA brick to a RUBY SR brick during the present $s$ shutdown. It is anticipated that this will provide a longer refractory life and will generate less slag. This lesson learned has been incorporated into the CSDP.

- Demisters, by their very nature, eventually clog and require replacement; unfortunately JACADS experienced processing downtime associated with this action due to a lack of spares. The problems associated with demister plugging resulted in a very simple lesson learned: to ensure that the warehouse min-max system is allinclusive and that reorder levels allow for order, fabrication, and shipment. This issue is simply one of proper operations and maintenance.

- Upon the initiation of BRA testing, excessive amounts of particulate, in the form of a plume, were observed from the BRA stack. Particulate loading was measured and it was concluded that control of the particulate emissions was required. After an investigation of the alternative methods for particulate control, a baghouse was selected as the most appropriate technology. The baghouse has been installed at JACADS, the RCRA permit modifications have been made, and SOPs are being prepared. The baghouse is undergoing testing. This modification has been incorporated into the CSDP design. The shear spray was changed to $1 \%$ caustic and the punch cycle was changed so that the rear bottom hole is punched first, providing a direct drain when the vent is punched.

- Molten aluminum and fiberglass are GB M55 rocket process wastes. This mixture began to collect in and drip through the mesh belt of the heated discharge conveyor (HDC), ultimately solidifying on the belt at various places along the HDC housing, and on the discharge gates, causing them to jam. The mitigation for the problem will be twofold: the mixture will be conveyed to the collection hopper with the aluminum still molten, and the gates will only be cycled when it is time to change the hopper. 
This will be accomplished by replacing the existing mesh belt of the HDC with a bucket conveyor and by enclosing the collection hopper with an enclosure capable of sustaining a blast from an explosion in the kiln. There are no safety or environmental impacts due to this change; its intent is to allow the attainment of processing goals. Upon successful demonstration of this concept it will be incorporated into the CSDP design.

- The sliding gates originally installed in the DFS feed chute began to bind upon the initiation of processing expansion, but the binding was also due to particles becoming lodged in the channel of the sliding gate. This was resolved by replacing the gate with a tipping valve similar to that used at CAMDS. Since this is not an environmentally regulated item, the only potential for environmental or safety problems would be as a result of an action caused by this piece of equipment.

- $\quad$ Temperatures in the LIC room have been consistently above the temperature limits set by Occupational Safety and Health Administration to allow personnel entries. JACADS furnace rooms receive their input air from the outside; therefore, room temperatures could be lowered by first cooling the air prior to introduction into the room. A chiller and the associated air handling system has been designed and is currently being installed for JACADS. CSDP plants have been designed so that furnace room air is chilled prior to introduction into the room.

- The only confirmed agent release to the environment was on December 8, 1990. This release was below the allowable stack concentration. There have been no positive confirmed, agent perimeter monitoring readings. Changes in procedures due to the agent release have been developed.

- The DUN is currently undergoing systemization. It has not processed hazardous material to date. The data base continues to expand as we conduct systemization and as, in the nature of this test, issues that were once problems are resolved and new ones are discovered. Problems have arisen with the lift and the throughput rate of the feed system. The throughput rate, however, is improving as systemization continues. In summary, it would be premature to comment on this system until systemization is completed.

- Changes to the rocket shear machine are as follows. The fuse segregator was widened to be able to store 12 rocket fuses at one time on the belt with the associated rocket debris resulting from shearing. The underside and, correspondingly, the drive roller were changed from a smooth to a toothed surface to eliminate slippage when wet with water and decontamination liquid, and the texture of the top surface of the belt was changed from a smooth to a ribbed surface to provide more positive traction. Additionally, wipes were installed on the sides of the segregator conveyor to prevent debris from wrapping under the belt and wedging between the drive and idler drums.

\subsubsection{Conclusions}

The Army's recent experience with the incineration of chemical agents and munitions has involved a technology and process virtually identical to that incorporated into the FPEIS assessment of on-site disposal. The existing JACADS facility employs a design that contains no significant deviations from the basic concepts of reverse assembly and incineration as 
presented in the FPEIS. In addition, the Army's recent incineration experience includes no negative findings or developments that would indicate either the safety or environmental acceptability of the incineration process are questionable. Through compliance with applicable regulatory emission limits, the JACADS facility has, so far, demonstrated that it can be routinely operated with maximum protection to the workers, to the public, and to the environment.

Although there have been accidental releases of chemical agent within the JACADS facility, all emissions from the JACADS facility have been well under the applicable federal and state standards. In particular, no outside release greater than $8 \%$ of the allowable stack concentrations has been observed. The containment and filtration systems are, therefore, working as designed to protect the public.

Some mechanical problems associated with munition disassembly or the feeding of munition parts into the incinerators at JACADS were anticipated. However, the number, frequency, and complexity of such mechanical failures were not anticipated. It is expected that these mechanical problems will be resolved before the JACADS facility completes the OVT campaigns and long before full-scale disposal operations begin.

The FPEIS concludes and confirms that on-site disposal of chemical agents and munitions could be performed in a safe and environmentally acceptable manner. The Army's recent experience at CAMDS and JACADS with chemical agent-munition disposal supports that conclusion. There is no new information related to the Army's recent disposal experience that suggests the FPEIS conclusions would have been different if this new experience had been gained prior to the ROD for the CSDP. 


\section{TRANSPORTATION DEVELOPMENTS SINCE THE FPEIS}

The primary purpose of this section is to provide perspective on the Army's recent success in moving chemical munitions from Europe to Johnston Island (i.e., Operation Retrograde; see Appendix $\mathrm{H}$ for additional details) by comparing this experience with the pertinent assumptions and commitments of the FPEIS risk assessment. Another objective of this section is to review recent developments in munition transportation that could have affected the conclusions reached in the FPEIS if this new information had been available prior to issuance of the FPEIS in January 1988.

The ability of the Army to successfully move chemical stocks is not in question. The Army's record of chemical munition movements is a successful one (see, for example, U.S. Army 1987a). In the many years since World War II, the Army has moved large quantities of chemical agents and munitions with relatively few problems. There has never been a chemical agent fatality associated with such a move. Although there have been problems during the movement of chemical agents and munitions, the majority of incidents occurring during those moves did not result in injuries due to chemical agents. The relevant aspects of that previous experience have been summarized by the Army (U.S. Army 1987a) and are included in the assessments in the FPEIS.

The recent movement of munitions from Europe to Johnston Island represents only a small fraction of the Army's total experience in moving chemical munitions. As such, Operation Retrograde offers only a limited amount of information by which the Army's total experience can be updated. Nevertheless, this section identifies, discusses, and compares the similarities and differences between Operation Retrograde and the off-site movement of chemical munitions from PUDA.

As stated in Sect. 2, the FPEIS does not conclude that off-site movement of chemical agents and munitions is impractical, infeasible, or unsafe. In fact, the FPEIS determined that the regional disposal alternative (involving the off-site movement of all inventories to destruction facilities at either TEAD or ANAD) was no different than the on-site disposal alternative with respect to human health risks or risks to the ecosystem. It was the relative difficulty of implementing enhancements to existing emergency response capabilities along the transportation routes compared to enhancements at one (storage) location that resulted in the identification of on-site disposal as the programmatic environmentally preferred alternative. Emergency preparedness is discussed in Sect. 7. However, with respect to the disposal alternatives studied in the FPEIS for PUDA, on-site disposal was found to be a clear winner, possessing at least two orders of magnitude less risk than either the regional or national disposal alternative.

\subsection{TRANSPORTATION ANALYSES IN THE FPEIS}

Three alternatives involving the off-site, cross-country transportation of chemical agents and munitions are considered in the FPEIS: (1) relocation of the stocks to two 
regional disposal centers for destruction, (2) relocation of the stocks to a single national disposal center for destruction, and (3) partial relocation of the inventories of some depots to other depots for destruction. The regional and national disposal alternatives would involve transportation by rail, while the partial relocation alternative would involve transport by air.

Regional disposal. Under the regional disposal alternative, the inventories of six depots would be shipped by rail to disposal centers located at ANAD in Alabama and TEAD in Utah (as shown in Fig. 4.1). About 50 to 55 rail shipments involving $44 \%$ of the total CONUS inventory would be required. Each shipment would consist of a rail convoy of up to 140 rail cars. These shipments, carrying $21.5 \%$ of the stockpile by agent weight, would involve route lengths of up to $2010 \mathrm{~km}$ ( 1250 miles) and would pass through five western states. In the eastern United States, $22.5 \%$ of the stockpile would be transported to ANAD through as many as 11 states with route lengths of up to $2900 \mathrm{~km}$ (1800 miles).

The PUDA inventory would be moved to TEAD through Colorado and directly into Utah; no other states would be involved in the rail shipment route. The route length from PUDA to TEAD would be $1180 \mathrm{~km}$ ( 730 miles). The inventory at PUDA contains mustardfilled 105-mm projectiles that do not currently exist in the inventory stored at TEAD.

The FPEIS risk assessment found that persons within $5 \mathrm{~km}$ ( 3 miles) of the proposed rail route would be at risk if the alternative to dispose of the PUDA inventory at TEAD (regional disposal) were implemented. Along the rail route, up to 900 fatalities could occur as the result of a WC rail transportation accident. As measured by expected fatalities (see Appendix A), the risk to persons along the rail route to TEAD would be approximately 100 times higher than the risk applicable to those persons near PUDA during on-site disposal.

National disposal. Under the national disposal alternative, the inventories of seven depots would be shipped by rail to a single disposal center located at TEAD (as shown in Fig. 4.2). About 70 to 75 rail shipments would be required; $51.1 \%$ of the CONUS stockpile would be shipped to TEAD through as many as 20 states with route lengths up to $4300 \mathrm{~km}$ (2670 miles).

Under the national disposal alternative, the PUDA inventory would be moved to TEAD, as was the case under the regional disposal alternative. The details of the rail movement under these two alternatives would be identical.

Partial relocation. Under the partial relocation alternative, the Army considered relocating the inventory from APG in Maryland and LBAD in Kentucky by aircraft to TEAD for disposal. The relocation would be by C-141 aircraft. From 900 to 1200 flights would be required for shipment of the APG inventory and from 1200 to 1500 flights for shipment of the LBAD inventory. The estimated air distance is about $3320 \mathrm{~km}$ (2060 miles) from APG to TEAD and about $2400 \mathrm{~km}$ (1500 miles) from LBAD to TEAD.

The partial relocation alternative would not apply to the stockpile stored at PUDA.

\subsubsection{Recommendations of the Panel of Transportation Experts}

In order to establish a basis for the assessment of potential environmental impacts from transportation activities, the Army and its subcontractors assembled a panel of four experts knowledgeable in the safe transportation of hazardous materials. These transportation experts were drawn from industry, academia, and members of the private consulting community (see Table 4.1). 
4-3

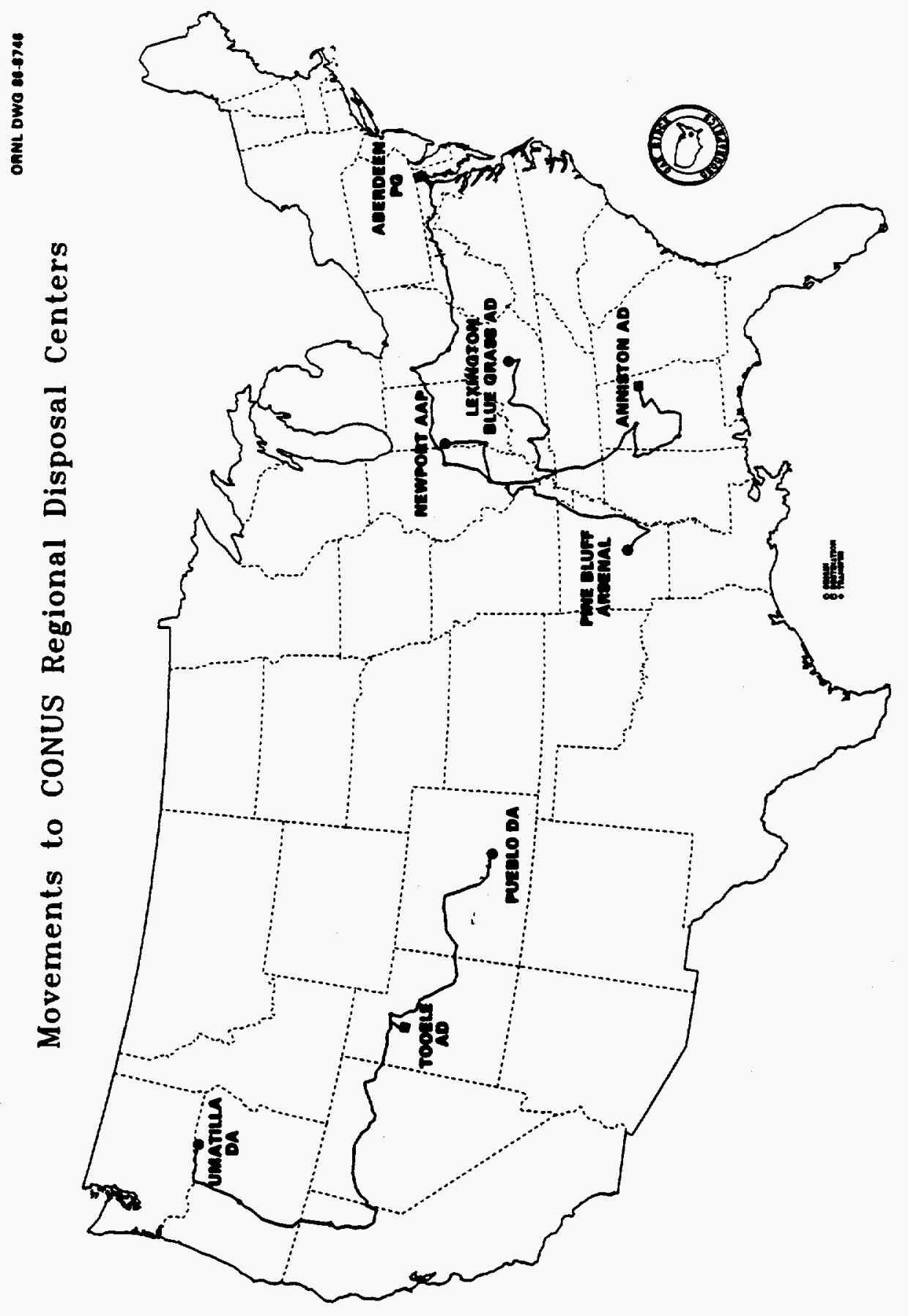

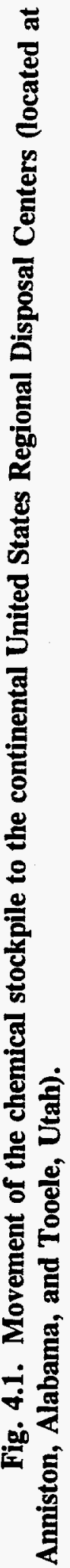


4-4
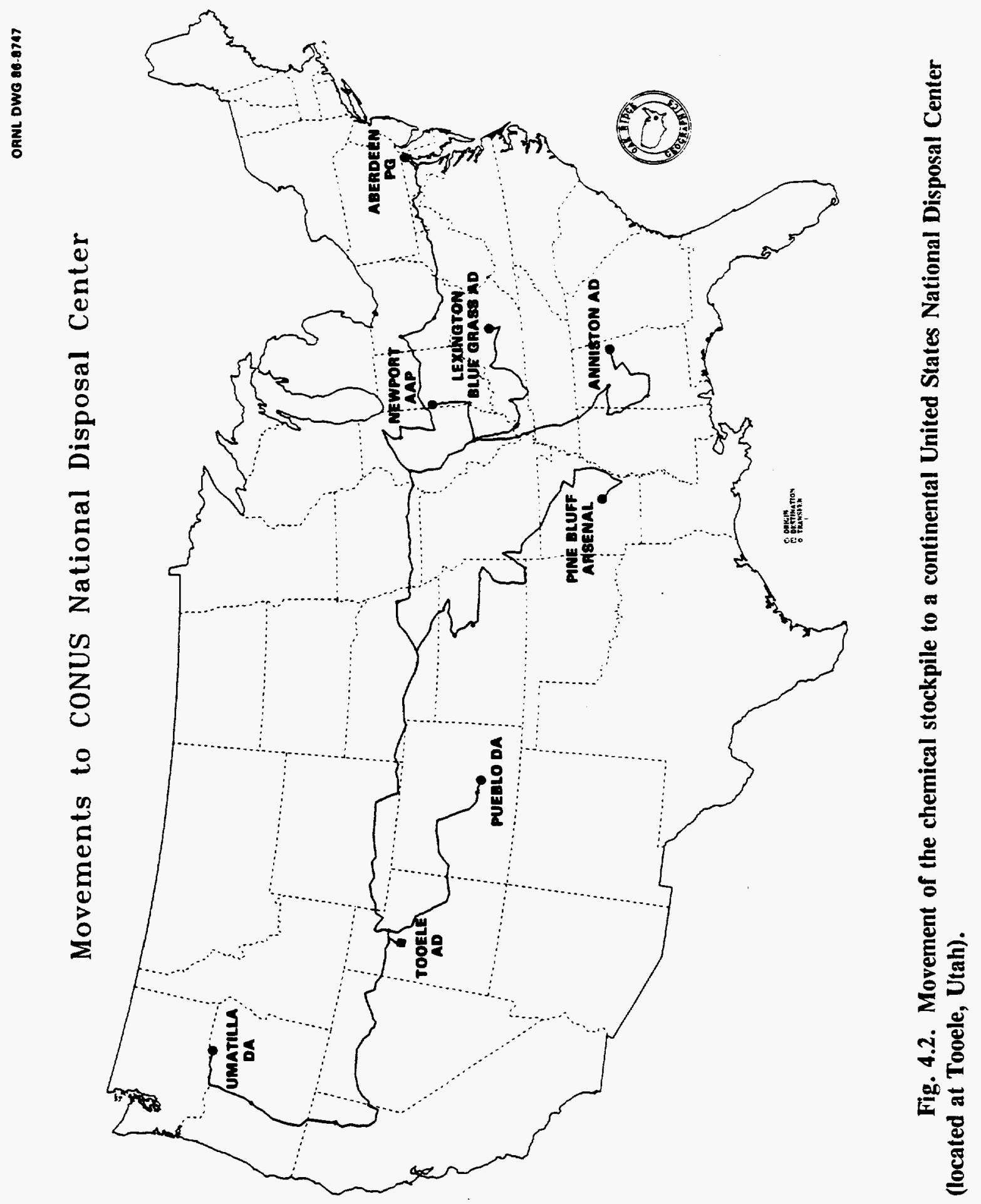
Table 4.1. Members of the expert panel on transportation concepts for chemical munitions

Michael S. Bronzini

Professor and Head

Department of Civil Engineering

Pennsylvania State University

\author{
Charles E. Dettmann \\ Vice President, Transportation \\ Union Pacific Railroad \\ Charles O. Miller \\ President \\ System Safety, Inc. \\ Bruce J. Williams \\ Manager, Land Transportation \\ Dow Chemical Company
}

Freight transportation, with emphasis

on marine transportation

Rail transportation of hazardous materials

System safety, with emphasis in aviation and human factors

Shipping of hazardous materials

The inner compartment of each OFC would have one or two removable floors onto which the munitions-agents would be secured for transportation. Up to 15 pallets of munitions could be packaged into each OFC. The OFC would be designed to meet or exceed the following performance criteria.

- Impact resistance: $12.2-\mathrm{m}(40-\mathrm{ft})$ drop [equivalent to $16 \mathrm{~m} / \mathrm{s}(35 \mathrm{mph})$ ]; container must withstand a deceleration of $340 \mathrm{~m} / \mathrm{s}^{2}\left(1130 \mathrm{ft} / \mathrm{s}^{2}\right.$ or $\left.35 \mathrm{~g}\right)$.

- $\quad$ Puncture resistance: probe velocity divided by probe radius equals $200 \mathrm{~s}^{-1}$.

- Crush resistance: $236,000-\mathrm{kg}(520,000-\mathrm{lb})$ maximum static load.

- $\quad$ Fire resistance: must keep inner wall surface temperature of OFC below $120^{\circ} \mathrm{C}$ $\left(250^{\circ} \mathrm{F}\right)$ during exposure to an all-engulfing $1010^{\circ} \mathrm{C}\left(1850^{\circ} \mathrm{F}\right)$ fire for $2 \mathrm{hr}$.

- Water immersion: $30.5 \mathrm{~m}$ (100 ft); $0.3 \mathrm{MPa}$ (43 psig).

The transportation panel was charged with developing criteria and requirements that would render the transportation of chemical agents and munitions as safe as possible should 
these munitions have to be moved. The panel was to consider safety as the primary factor of concern. Within this context, the panel was invited to study the particular difficulties of moving chemical munitions; to develop criteria and guidance; and generally, to give advice to the Army in the preparation of a transportation concept plan covering off-site transportation by rail, air, and water, as well as on-site transportation of chemical agents and munitions. The Army developed a plan (U.S. Army 1987b) that is, therefore, a description of modal transportation options based on standard U.S. Army operating procedures and proposed actions that conforms to the advice of the expert transportation panel. The detail contained in this transportation concept plan provides the basis for much of the FPEIS risk assessment.

Although the panel was not asked to make recommendations as to which transport mode was preferable, the experts concluded that "[U]nless transportation can be shown as the safest alternative, the panel prefers that the munitions not be moved off-site."

\subsubsection{Transport Containers}

The panel of transportation experts believed packaging to be the crucial component in the entire transportation system. Packaging includes the outermost transportation container, the inner containers, and possibly the munition casings themselves. The most important role for the packaging system would be the containment of the chemical agent, both during normal transportation activities and during an accident. The primary containment criteria for packaging were that these should be redundant protection against agent release during normal transport and prevention of agent release during accidents. Two additional criteria were compatibility with standard commercial handling and carrier equipment, and the capability for automated monitoring of agent presence and temperature within the transport container.

The Army initiated the conceptual design of an off-site transportation container (OFC) that would incorporate the recommendations of the panel of transportation experts. The suggested design characteristics for the OFC are described in MITRE 1987. The OFC would consist of a doubled-walled cylindrical inner chamber and a steel outer structure for rigidity and strength during handling and shipping (see Fig. 4.3). The overall dimensions of the frame for the OFC would be $2.4 \times 2.6 \times 6.1 \mathrm{~m}(8 \times 8.5 \times 20 \mathrm{ft})$, the same as standardized ISO shipping containers.

Off-site movement of the stocks from any depot would require specialized handling and packaging activities necessary to prepare the munitions and bulk agents for movement. These activities would include preparation of the nonleaking munitions for movement and loading of munitions into off-site transportation containers (OFCs). All leaking munitions would be overpacked, repalletized, and segregated before shipment to the off-site disposal facility. Loading of each OFC would occur on or adjacent to the concrete pad in front of the storage igloo.

Loaded OFCs would be placed onto a flatbed truck and moved via convoys to a temporary holding area near the railhead loading facility at the storage depot. When a sufficient quantity of OFCs became available, they would be loaded onto munition railcars and secured for off-site movement. The trains would be loaded and unloaded at facilities inside the chemical exclusion areas at the shipping and receiving sites. 


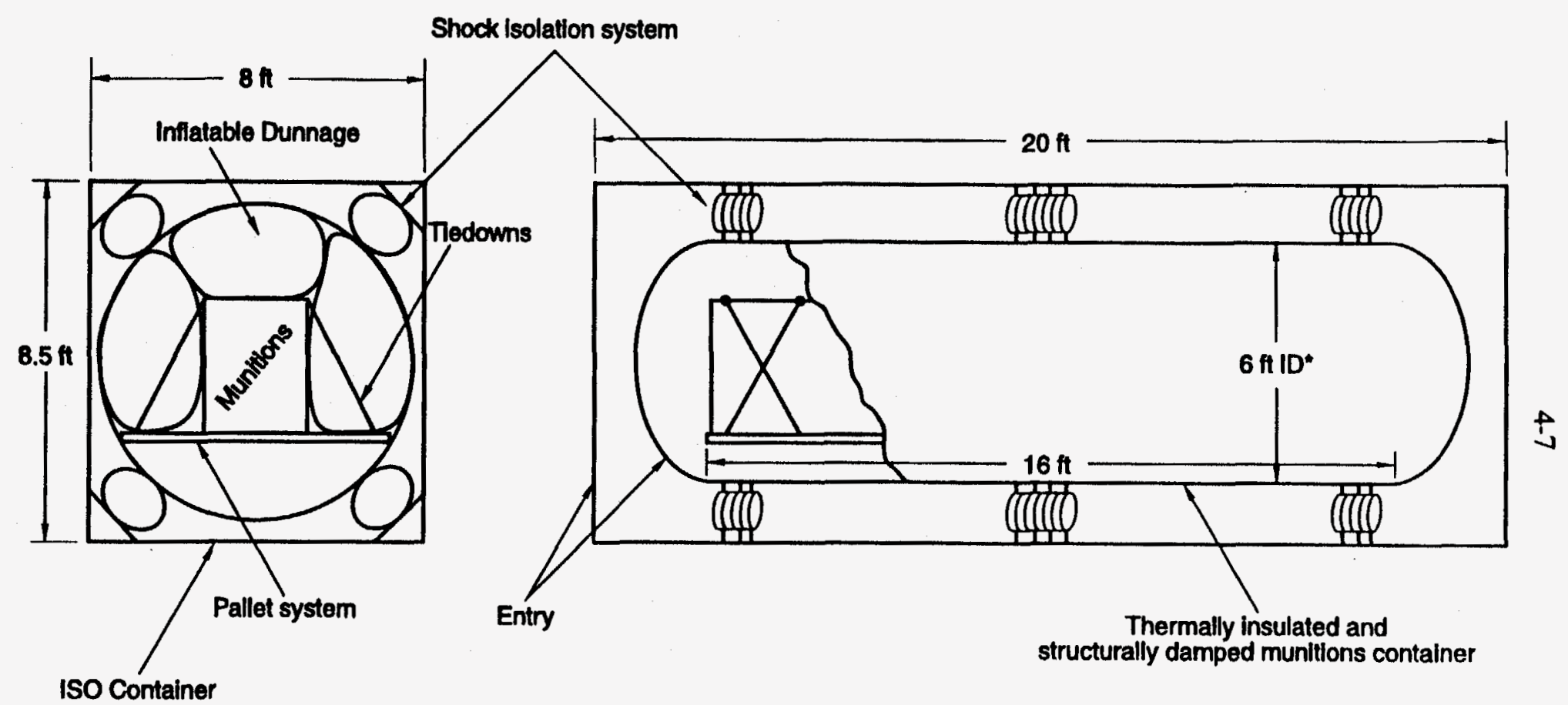

"ID refers to inside diameter

Fig. 4.3. Schematic diagram of the off-site transportation container (OFC). 


\subsubsection{Transport Vehicles}

\subsubsection{Trucks}

Standard flatbed trucks were envisioned for use during on-site transport to the railhead. A single OFC vehicle would be accompanied by four other vehicles in each convoy to the railhead area. The other vehicles would provide security, emergency response and decontamination capabilities. A $32 \mathrm{~km} / \mathrm{hr}(20 \mathrm{mph})$ speed limit would be enforced during the trip.

\subsubsection{Trains and railcars}

The concept of off-site rail transport involves dedicated rail convoys which would consist of two separate trains: a pilot (or escort) train and the munitions train. The escort train would precede the munitions train. The munitions train, in addition to munition containers, would also carry the convoy commander, security forces, other support personnel, and support equipment. The equipment required for a rail convoy would include locomotives, munitions container cars, and passenger or other standard railcars for security, other support personnel and support equipment. One possible makeup for the rail convoy would include 20 railcars in the escort train and 114 railcars (including 70 cars with OFCs) in the munitions train. The munitions trains would be restricted to a maximum length of $2440 \mathrm{~m}(8000 \mathrm{ft})$.

The escort train would precede the munitions train and carry support and emergency response equipment and personnel. To guard against potential rail track sabotage, at least one car in the escort train would have a wheel loading greater than any car on the munition train. There would also be a car as wide, low, and tall as cars on the munition train. Standard passenger and freight cars were to be used.

All railcars used for explosives would be certified for Class A explosive material. Buffer cars (standard freight cars) would separate the personnel cars from the munitions cars and carry either convoy-support equipment or an inert material. Sufficient personnel and equipment would be available on the munitions train to provide security for the cargo, to control accidental agent release, provide medical first-aid treatment for on-board personnel, and to allow quick emergency response while waiting for the arrival of personnel from the escort train at the scene.

The rail convoy would be subject to stringent inspections and operating procedures both before departure and while en route. For example, selection of the rail routing would be based on the criteria that the highest quality track should be used consistent with minimizing population exposure along the route. This implies that Federal Railroad Administration Class 4 track or better should be used as much as possible. For the existing rail network in the United States, routes with the highest quality often go through highly populated, metropolitan areas. Consequently, consideration would be given to selecting a route that would have minimized population exposure by avoiding high-population densities to the extent possible using the track class criteria. In any event, train speed would be limited to $16 \mathrm{~km} / \mathrm{hr}$ (10 mph) below the speed determined by the rail track classification for additional safety, but never greater than $80 \mathrm{~km} / \mathrm{hr}(50 \mathrm{mph})$. 
Predeparture inspections and tests of all equipment would be conducted under the supervision of railroad management representatives. Continuous nonstop operation (24-hr per day) would be maintained except for scheduled stops at intervals of not more than $1610 \mathrm{~km}$ (1000) for railroad operating crew changes, for normal train inspection, and for container monitoring. All stops would be at locations selected to minimize population exposure.

\subsubsection{Monitoring}

The air monitors proposed for use during the off-site transport of chemical agents and munitions included high-level and low-level rapid response detectors, as well as delayed-response samplers. ACAMS, an automated gas chromatograph, was proposed for use as a rapid response ( $3 \mathrm{~min}$ or less) detector for chemical agent.

The proposed samplers consist of an agent collecting device (i.e., a solid sorbent tube or a liquid-filled impinger). The stream to be sampled would be drawn through the sampler for a predetermined period of time before analysis. The sample would then be subsequently analyzed in the laboratory via gas chromatography for the solid sorbent in the DAAMS and via calorimetric analysis for the bubbler absorption system. Samplers can be used to obtain time-dependent average concentrations at low detection levels for historical documentation. However, their typical response time is greater than $1 \mathrm{hr}$.

Monitoring would be conducted during the handling and packaging activities necessary to prepare the agents and munitions for off-site shipment. Monitors would be placed around each holding area. The munition-filled cavity of the OFC would be sampled for agent in the holding area and after loading onto the transport vehicle to ensure that no leaking munitions are present at the start of the trip. During rail transport, the outermost air space of the container would be monitored for agent when planned stops were made.

\subsubsection{Safety and Security}

Safety during predeparture operations would be implemented by following established Army procedures: (1) OFCs would be loaded onto the munition railcars within the chemical exclusion area during daylight hours only and as restricted by weather conditions; (2) standard Army chemical agent monitors and alarms would be operational in the holding-loading area during loading operations; (3) workers would be required to wear work gloves and protective boots and to carry a gas mask during loading operations; and (4) the two-man rule would be used for loading operations.

During transport by rail, medical and other support personnel would maintain safety by responding to any emergency situations. To minimize the chance of these personnel being disabled in a munition-train accident, most of them would ride on the escort train, with a minimum number on the munition train to provide immediate first aid to the munition train personnel and to respond to any agent monitor alarm.

During train loading and prior to departure, security would be provided by the installation security forces. These forces would be augmented by the guards that accompany the convoy. Guards and other support personnel would be required to be on-post $48 \mathrm{hr}$ prior to train departure. 
Guard personnel would be responsible for providing train security. They would ride in guard cars dispersed among the munition cars (20 per guard car) and would work 12-hr shifts. The Command and Control Team would be in radio contact with the central Army Command and Control Office as well as with all units of the transport convoy.

\subsubsection{Public Response}

During the process leading to publication of the FPEIS, public response to the possibility of moving the CONUS chemical munitions stockpile from eight sites to a national or regional disposal facility was expressed through public scoping meetings and public hearings following publication of the CSDP DPEIS. Following DPEIS publication and before release of the FPEIS, a series of independent community group studies at five of the eight CONUS sites, funded by the Army, also reported on public response to off-site CONUS stockpile movement (Blackwell 1987, Demecs 1987, Umatilla County Soil and Water Conservation District 1987, Morekas 1987, and Concerned Citizens 1987).

There were three sets of public responses to stockpile movement. At some sites (APG, Maryland, and LBAD, Kentucky), public support for off-site stockpile movement to a national or regional disposal site was expressed. Some citizens asserted that because prior Army experience with the movement of chemical munitions transportation had been free of accident or mishap, this option was viable given the relatively small percentage (by weight) of the national stockpile stored at these sites (CSDP 1986f). At a third site (NAAP, Indiana), public response was mixed. While some claimed that transportation system improvements associated with upgrading rail facilities could be an economic boon to the local community, others expressed concern with the risk of off-site transport (Concerned Citizens 1987, CSDP 1986a).

A second set of public responses was exhibited principally at ANAD, Alabama, a possible regional disposal site. Strong, vocal public opposition to the transport of chemical munitions from other sites to Anniston was expressed (CSDP 1986g). In this instance, most claimed that the risks from on-site destruction of existing stockpiles were far less than those associated with the import of munitions from other sites.

A third set of public responses was manifested at the remaining sites (PBA, Ark.; TEAD, Utah; PUDA, Colorado; and UMDA, Oregon). Many expressed the view that off-site transportation would entail greater risk than on-site disposal, would be logistically more difficult to undertake, and would probably be opposed by communities along transportation corridors (CSDP 1986c, CSDP 1986d, CSDP 1986e, CSDP 1986b). At some of these sites, independent community group studies reflected these same concerns (Umatilla County Soil and Water Conservation District 1987).

The FPEIS discusses the need for public affairs plans to encompass these concerns in the event off-site transportation of the chemical munitions stockpile to a regional or national facility was selected. Two types of public affairs plans would be developed. The first would be special plans for originating and destination installation communities. These would be implemented prior to stockpile movement. Second, a generic public affairs plan would be established for communities along transportation corridors from all eight CONUS sites to a regional or national disposal center (U.S. Army 1988b). Each of these plans would provide 
information on details of stockpile movement to the media and the public and would provide means for responding to public inquiries.

\subsubsection{Institutional Factors}

An elaborate consultation and coordination process is envisioned in the FPEIS for off-site transportation of the CONUS stockpile. This consultation and coordination process would be necessary to encompass the jurisdictional complexity of off-site transportation. It would take place at two levels: (1) between the Army and other federal agencies with authority for health, safety, and environmental issues associated with the interstate transportation of hazardous materials, and (2) between the Army and state and local governments along transportation corridors to ensure optimal traffic control, security, adequate public notification of shipments, and a high level of emergency preparedness.

At the federal agency level, consultation with DOT, EPA, CEQ, DHHS, and the U.S. Department of the Interior (DOI) was anticipated (U.S. Army 1988a). The Defense Appropriations Act of 1986 requires the Military Traffic Management Command (MTMC), which would be invested with overall authority for stockpile movement, to permit DHHS, DOT, and DOI to review and approve operations plans, procedures, and equipment used for chemical munitions transport. Consultation with DOT, EPA, and CEQ are also required for inspection of rail or other transportation equipment, for the planning of all surface movements, and for approval of route selection to minimize adverse environmental impact in the event of mishap.

Consultation and coordination with affected states is required by the Defense Authorization Act of 1986, RCRA, Hazardous Materials Transportation Act, and Title III of the Superfund Amendments and Reauthorization Act (Pub. L. 99-145, Pub. L. 93-633, Pub. L. 99-499, and Pub. L. 94-580, respectively). The principal areas of consultation include notification of state governors prior to shipments of chemical munitions through states, the right of states to inspect and monitor stockpile movement, and prior notification of chemical munitions shipments to State Emergency Response Commissions, Local Emergency Planning Committees, and local governments adjacent to transport corridors.

\subsubsection{Command, Control, and Security}

During transportation of chemical munitions and agents to an alternate site for disposal, the transport operations would be subject to significant management controls. MTMC would provide significant assistance in surface transport by contracting with commercial rail carriers to implement the rail transport option and by executing the initial planning of all surface movements. A central command and control office would be established to provide a centralized point of contact during munition and agent movement operations.

During off-site rail transport of the stockpile, DOT would work with the Army and MTMC. DOT would also be involved with inspection of railroad equipment and rail route selection. Review and permitting might be required by individual states, depending on local laws. In addition, DHHS would review and comment on the specifics of the transportation procedures. These actions could result in additional requirements or conditions affecting 
movement. The Army would also coordinate with and obtain any necessary approvals from non-DOD federal agencies prior to the full acceptance of the OFCs.

Centralized command and control is foreseen in the FPEIS for off-site transportation of the CONUS stockpile to a single national or to two regional disposal centers.

Responsibility for all munition movements would be placed in a centralized military command office established to provide a focal point of contact for munition movement operations. This central command office would (1) function as a primary communication link during munitions movement; (2) receive constant updates on the status of stockpile movement along transport corridors; (3) relay information to participating and supporting organizations, including state and local governments; and (4) provide information on normal operations and accidents (U.S. Army 1988a). This Army command would coordinate its operations with the MTMC which would have oversight of all operations.

All military personnel involved in loading and unloading of munitions; packing, vehicle maintenance; vehicle and convoy security; emergency medical response; and other activities would be investigated, screened, and certified according to rigorous criteria established by the Army Chemical Personnel Reliability Program (U.S. Army 1988b).

After selection, military personnel would be specially trained and further certified as required by Army Material Command Regulation 350-9 for performance of individual tasks associated with the loading and unloading of chemical munitions.

While primary responsibility for security would lie with the Army, which would provide 24-hr security at all chemical munitions holding areas and security support on all rail convoys to prevent sabotage or terrorist acts (U.S. Army 1988a), this responsibility would be shared among several military units. Installation forces would provide security during handling, loading, and unloading operations, while dedicated military police and tactical units would protect chemical munitions once in transit. The dedicated military police and tactical units would serve under a unified technical escort unit (TEU), which would guard trains, rail crossings, and areas adjacent to scheduled and nonscheduled stops.

\subsubsection{Logistics}

Previous shipments of chemical agents and munitions to the eight CONUS sites provide some guidance as to the complexity of shipping chemical munitions long distances. However, the simpler regulatory environment at the time these movements took place makes it difficult to use them as a blueprint for FPEIS transportation planning.

Both air and rail transport to national and regional disposal centers are evaluated in the FPEIS. After selection of rail transport as the safest and most viable mode from the standpoint of emergency preparedness, two major logistical concerns are addressed. The first is route selection, which is based on the shortest and simplest rail routes available from origination to destination installations. The second logistical concern is the adequacy of packaging.

A special study conducted by The MITRE Corporation on behalf of the FPEIS determined that, from a risk perspective, packaging of the munitions is the most crucial component of the entire transportation system (U.S. Army 1988b). Considerable attention was given to the generic features of packaging design, including: the ability to provide redundant protection; compatibility with standard transportation and handling equipment; the 
ability to minimize munitions handling; and, finally, the ability to comply with all regulations pertaining to munitions transport, safety, and performance. Actual procurement of such packaging was beyond the scope of this study.

Safety concerns place institutional demands on rail corridors. Only the highest quality commercial grade trackage would be used, potential routes were selected to minimize population exposure in the event of an accident causing a release of chemical agent, and trains would be limited to a speed of $10 \mathrm{mph}$ below that normally permitted on a particular route, but not more than $50 \mathrm{mph}$ (U.S. Army 1986a). It was anticipated that a total of 70 to 75 rail shipments from all eight CONUS sites to a national disposal facility at TEAD would be required while 50 to 55 rail shipments to the two regional disposal facilities at TEAD and ANAD would take place.

In the event of rail transport, monitoring of the stockpile in temporary holding areas would take place, and containers would be constantly monitored by security forces once loaded onto trains (U.S. Army 1988a). This monitoring system would continue when the shipment reached its terminus and was safely unloaded and stored in special holding facilities.

\subsubsection{Transportation Alternatives Eliminated from Detailed Consideration in the FPEIS}

Implementation of either the regional or the national disposal alternative would require the shipment of extremely large quantities of lethal chemical agents from six or seven of the eight storage depots to the destruction sites. This movement would be on a scale unprecedented since the munitions were originally deployed within CONUS by rail over a period of many years (U.S. Army 1987a). Implementation of the partial relocation alternative would require the movement of relatively small inventories from selected storage locations.

Disposal alternatives involving off-site transport could include the use of munition trains, truck convoys, military airlift, and barge transport. For movements of the total chemical stockpile within the United States, the Army selected rail transport over the other transportation modes for a number of reasons, including the fact that large-scale movement must take place within the constraints of the (1) plant operating schedules and the Congressionally mandated deadline for disposal, (2) logistical limitations of transport operations, and (3) availability of storage capacity at the designated disposal locations. The Army determined that the disposal program schedule for the entire U.S. stockpile could not be met by use of the truck or air mode of transportation due to the very large number of truck convoys or airlifts that would be required. Approximately 610 truck convoys would be required for the regional disposal alternative and approximately 820 for the national disposal alternative; several thousand airlifts (using the C-141 aircraft) would be required for the same two alternatives.

The Army eliminated detailed consideration of marine transport from APG in Maryland to Johnston Atoll (see U.S. Army 1988a, Vol. 1, Sect. 2.4.1.2.3 and Vol. 3, Appendix $S$ ) because (1) lengthy studies would have been required for assessing potential impacts to Chesapeake Bay and other waterways, (2) adequate transportation alternatives were provided by the rail and air alternatives, and (3) the programmatic decision did not foreclose subsequent consideration of site-specific alternatives. Movement of the inventory of ton containers of mustard agent from APG to Johnston Island would have been accomplished using the lighter aboard ship (LASH) shipping system. In this system, barges (called lighters) 
are loaded with cargo at shore facilities and towed through shallow waters to a large, oceangoing LASH vessel anchored nearby in deeper waters. The loaded lighters are lifted aboard the LASH vessel with a shipboard crane and stored in the hold. The LASH vessel would then sail for Johnston Island. At Johnston Island, the lighters would be lifted from the hold and placed in the water using the LASH vessel crane and towed to an onshore facility where the cargo would be unloaded. The proposed route of the LASH vessel would be down the Chesapeake Bay, southward through the Atlantic Ocean along the coast of South America, and around Cape Horn to Johnston Island.

\subsection{REMOVAL OF THE U.S. CHEMICAL STOCKPILE FROM EUROPE}

At the Tokyo Economic Summit in May 1986, U.S. President Ronald Reagan and FRG Chancellor Helmut Kohl agreed to the removal of U.S.-owned chemical munitions (also called the European stockpile) from the FRG by 1992. However, in a speech in Vienna in March 1989, U.S. Secretary of State James Baker announced that the United States would explore ways of expediting the removal of these munitions, and a removal goal of late 1990 was subsequently established.

The U.S. chemical stockpile in West Germany consisted of approximately 100,000 rounds of $155-\mathrm{mm}$ and 8 -in projectiles filled with about 435 tons of nerve agents GB or VX. These projectiles were stored at a secure site near Clausen, West Germany, near the French-FRG border. Palletized munitions in the European stockpile were packed in two containers for shipment. The inner secondary steel container (SSC) was vapor tight and had a sampling port to allow for monitoring of agent before opening. Ten SSCs were subsequently packaged inside standard military ammunition shipping containers (MILVANs) $(20 \times 8 \times 8$ or $8.5 \mathrm{ft}$ shipping containers). The combined packaging of the SSCs and MILVANs did not provide the same level of protection to the munitions as would the proposed OFC (see Sect. 4.1.2).

None of the projectiles in the European stockpile were leaking chemical agent. However, the Army had previously determined that some of the projectiles were unserviceable and that some of these had the potential to leak. All the unserviceable projectiles were enclosed in steel, vapor-proof single-round containers. These were placed in separate SSCs and MILVANs for the move. No chemical agents leaked during the move.

More detailed information on specific parameters of the movement of the European stockpile (e.g., munitions containers, monitoring, security, and public response) is contained in Appendix H. The U.S. General Accounting Office (GAO 1991) finds that the transfer of munitions was conducted successfully, safely, and in accordance with DOD's overall schedule. The Army's After Action Report (U.S. Army 1991b) summarizes the detailed planning and execution actions taken prior to and during the program which is summarized below. 


\subsubsection{Execution of Operation Retrograde}

The movement of the European stockpile (Operation Retrograde) involved transport by truck, train, and ship (see Fig. 4.4). Fig. 4.5 illustrates the overall schedule for Operation Retrograde.

Between July 26, 1990, and September 1, the projectiles were removed from their storage locations and placed into SSCs. In total, 5520 SSCs were used; 10 of these were subsequently packaged inside each MILVAN. The 552 MILVANs were moved into a holding area to await movement to the railhead at Miesau Army Depot. More than 500 U.S. and 300 German military personnel and 200 German state and local police were involved in this phase.

Twenty MILVANs were transported to the Miesau Army Depot in each road convoy of approximately 80 vehicles beginning on July 26,1990 . A total of 28 convoys were conducted during daylight hours and excluded weekends, except for the final convoy, which arrived on Saturday, September 1. The MILVANs were moved by truck over a distance of $50 \mathrm{~km}$ ( 31 miles) between the storage location near Clausen to the Miesau Army Depot. The majority of the 2.5-hr trip was on a stretch of newly constructed autobahn dedicated solely for the use of the munitions convoys. It should be noted that the FPEIS assessment includes the assumption that transportation by truck to the railhead would average only $1.6 \mathrm{~km}$ (1 mile) with speeds of no more than $32 \mathrm{~km} / \mathrm{hr}(20 \mathrm{mph})$.

In addition to the MILVAN trailers, each convoy contained decontamination and firefighting equipment, German police escort personnel, maintenance equipment and U.S. TEU personnel. At the railhead at the Miesau Army Depot, the MILVANs were unloaded from the trucks and were placed into a temporary holding area. More than 500 U.S. and 500 German military personnel and 1200 German state and local police were involved in this phase. All SSC MILVAN loading operations and truck transport operations were accidentand incident-free. Over 3 million munition-miles were accumulated during this phase.

The rail portion of the movement began on September 12,1990, with the loading and departure of the first munition transport train for the 1000-km (620-mile), 13-hr trip to the port of Nordenham. Twenty MILVAN cars were included in each train with two MILVANs aboard each car. In addition to the MILVAN cars, each train carried emergency response equipment and personnel; there were approximately 30 cars in each munitions train. It should be noted that these trains contained fewer total cars and fewer munition cars than were assumed in the FPEIS analysis.

Convoys of two munitions trains and one escort train were dispatched each night for seven consecutive nights. Each escort train carried additional communications, fire, and decontamination equipment, as well as security and medical assets. German security and emergency response forces were placed on standby at strategic points along the rail routes. Over 500 U.S. and 8,000 German military personnel and 14,000 German state and local police were involved in this phase. All rail operations were conducted without accident or incident. Over 60 million munition-miles were accumulated during this phase.

Both cargo vessels departed Nordenham on September 22, 1990. The voyage lasted 44 days and covered $30,400 \mathrm{~km}(18,900$ or 16,430 nautical), along a route that took the ships north of the United Kingdom, southward through the Atlantic Ocean, and then around Cape 


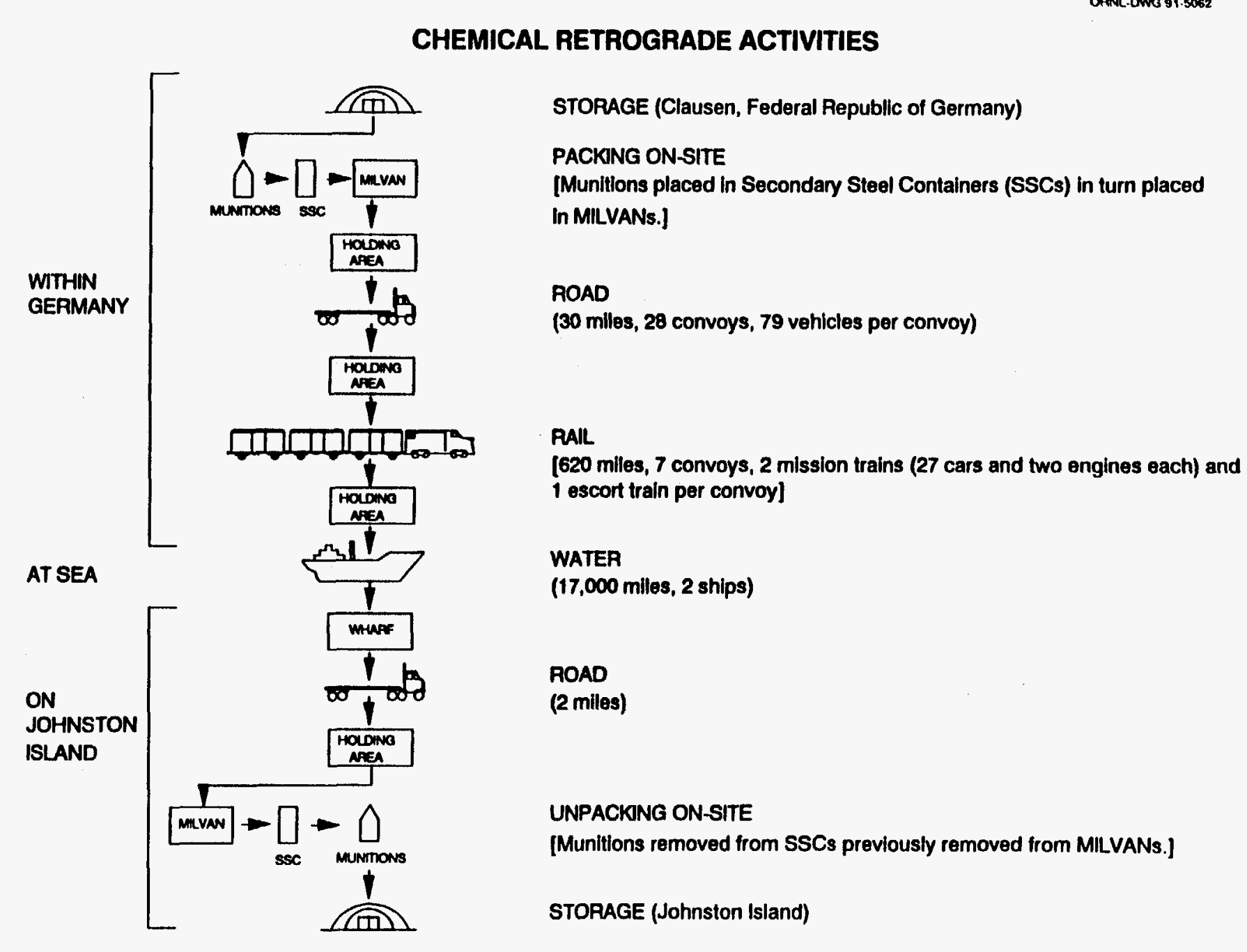

$\stackrel{+}{a}$

Fig. 4.4. Activities associated with Operation Retrograde (the removal of the U.S.owned chemical stockpile from Europe). 
ORNL-DWG 912.7116

MOVEMENT OF THE EUROPEAN STOCKPILE OF CHEMICAL MUNITIONS

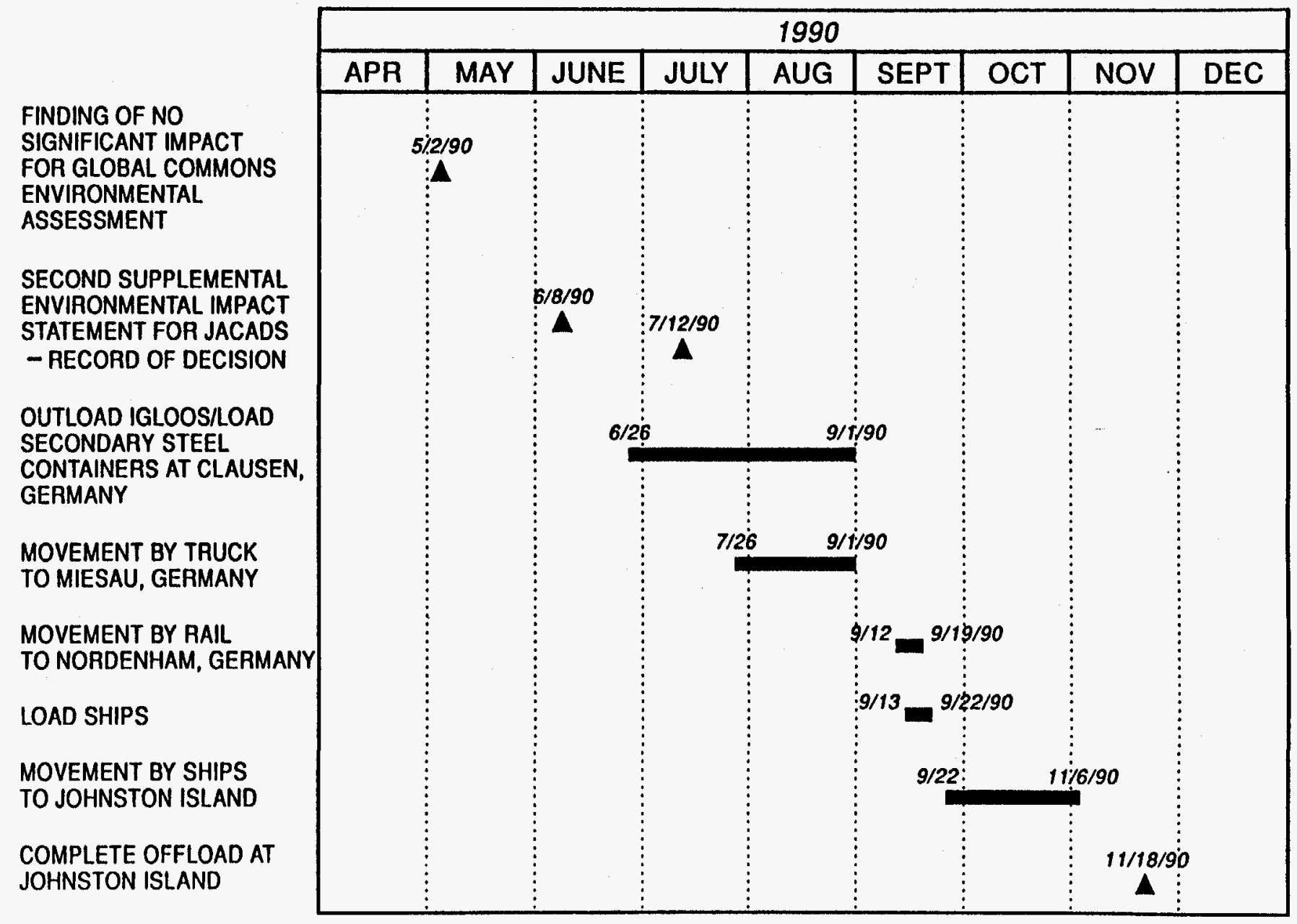

Fig. 4.5. Scheduling of the movement of the European stockpile of chemical munitions. 
Horn at the southern tip of South America (see Fig. 4.6). The first ship arrived at Johnston Island on November 6 . Continuous escort was provided during the voyage by U.S. Navy nuclear-powered guided missile cruisers. The ships were refueled three times during the voyage; the first refuelling was conducted 15 days into the voyage. During that refuelling, the fuel hose became disengaged from one of the ships; however, the problem was quickly remedied and operations concluded without further incident. The remainder of the voyage was uneventful; no other accidents or incidents occurred. Almost 2 billion munition-miles were accumulated during this phase.

Offloading operations were conducted at Johnston Island between November 8 and 18. Throughout the offloading of the ships, all MILVANs removed from the ship's hold on a single day were transported to the secure chemical storage area on Johnston Island. No MILVANs were stored overnight on the wharf or at any location other than the existing chemical storage area on the island. Unpacking of the MILVANs and the SSCs and the placement of the munitions into igloos began immediately after the MILVANs arrived in the chemical storage area. All munitions were unpacked and placed in storage igloos on Johnston Island by the end of December 1990.

\subsubsection{Differences and Similarities between the European Move and the Movement of the PUDA Stockpile}

Because the transportation of the European stockpile involved chemical agents and munition types that are different than those stored at PUDA, there is limited direct applicability of this experience to the off-site disposal alternative for the PUDA inventory. Therefore, no direct comparison of FPEIS assumptions in regard to the PUDA inventory can be made to the Army's recent transportation experience. There are, however, several broader aspects, including similarities and differences to the European movement, that should be mentioned. These aspects relate to the FPEIS analysis methods for off-site transportation risks.

The distances for rail transport of the two stockpiles are similar: $1180 \mathrm{~km}(730)$ for moving the PUDA inventory to TEAD and $1000 \mathrm{~km} \mathrm{(620)}$ for the European rail route. While the PUDA stockpile and the European stockpile both consist of explosively configured projectiles, they pose two different hazards. The PUDA munitions are filled with only mustard agent; the European stockpile contained only nerve agents (agents GB or VX). The European stockpile consisted of 8-in. and $155-\mathrm{mm}$ projectiles. The 8-in. projectiles contain the largest agent fill and the largest explosive burster of any projectile in the U.S. stockpile. There are no 8-in. projectiles in the PUDA inventory; PUDA stores only 4.2-in. mortar rounds and $105-$ and $155-\mathrm{mm}$ projectiles.

The inventory size of the two sites is also different; therefore, the time of exposure and the total hazard to which potentially affected persons would be subject are different for the two moves. The European stockpile consisted of over 100,000 projectiles (U.S. Army 1990c) containing approximately $1.4 \%$ of the total U.S. stockpile; the European rail movement involved 7 days of moves with 2 munitions trains (each composed of 40 MILVANS, 27 cars, and 2 engines) and 1 escort train (composed of 14 cars and 2 engines) (U.S. Army 1990c). More than 500 U.S. military troops, 8,000 German military troops, and 14,000 German state and local police were involved in the European rail 


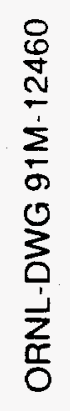

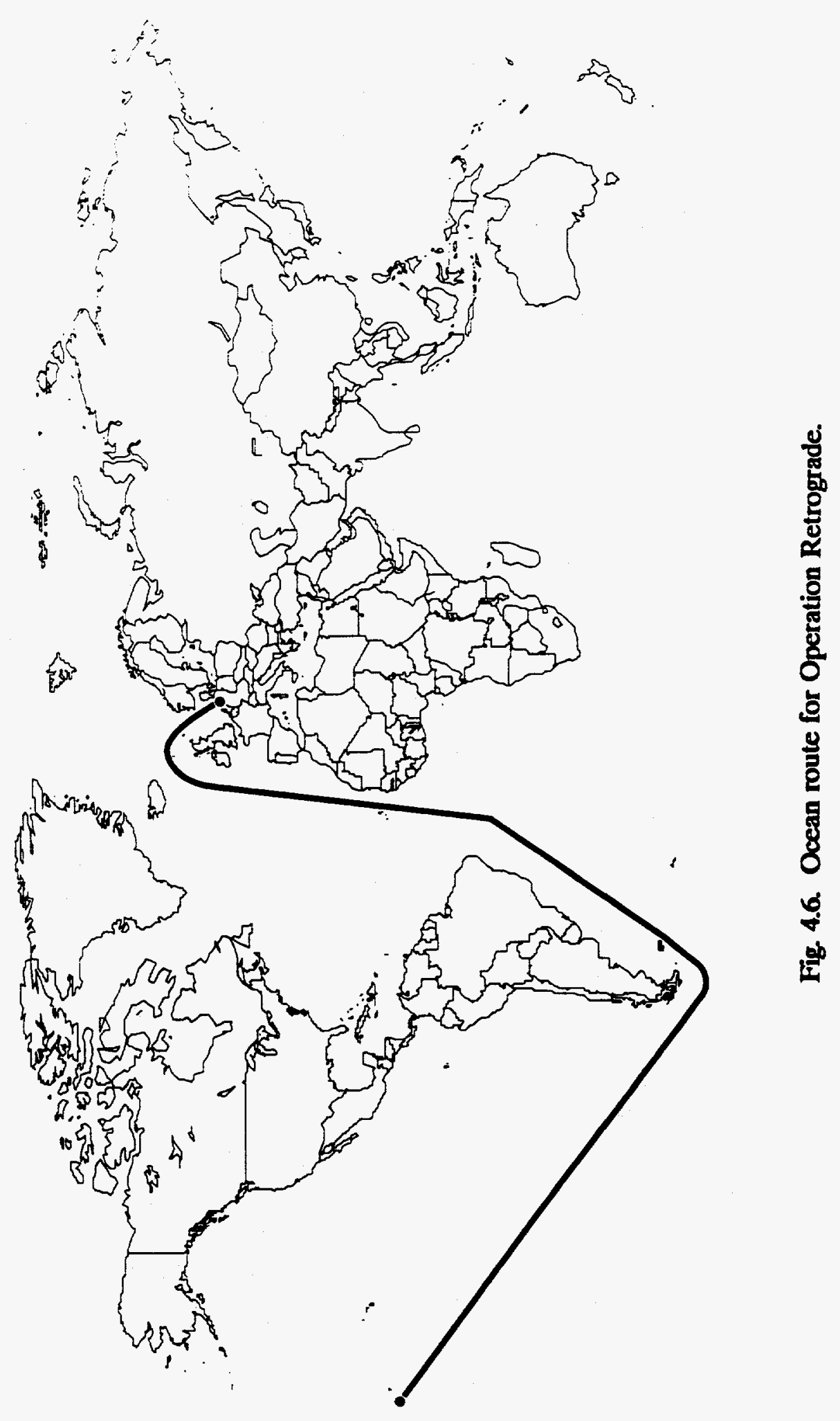


movement (U.S. Army 1991b). Although the number of munitions in the PUDA stockpile is classified, the PUDA inventory amounts to approximately $10 \%$ of the total U.S. stockpile, or approximately 7 times the size of the inventory that was stored in the FRG. If the loading capacity of a PUDA-to-TEAD rail movement replicated the European rail movement, it would require approximately 50 days of rail movements.

In addition, the planning basis accidents for the two movements are different. For the European rail movement, the WC accident was determined to be the detonation of one 8-in. GB projectile (U.S. Army 1990c). Using the D2PC atmospheric dispersion code (Whitacre et al. 1986), this release was determined to have a lethal downwind distance of approximately $2.1 \mathrm{~km}$ (1.3) under WC weather conditions. For the rail movement of the PUDA stockpile, two relevant accidents are identified in the FPEIS - an accident during interim storage pending movement of the train off-site, and an off-site train accident. For interim storage, the downwind lethal distance (under WC weather conditions) of the most severe accident (aircraft crash into transportation containers while in the holding area) is greater than $50 \mathrm{~km}$ (31) (U.S. Army 1988a). For the off-site accident (severe train accident with fire of sufficient duration to cause failure of the OFC and the munitions inside), the comparable value is approximately $4 \mathrm{~km}$ (2.5) (U.S. Army 1988a).

Even though the above differences and similarities exist, there has been no attempt in this Phase I report to suggest that the transportation of the PUDA stockpile would be either more or less risky than the transportation of the European stockpile along rail routes in the FRG. No such risk calculations exist for the European move; therefore, no direct comparison can be made.

\subsubsection{Comparison of FPEIS Assumptions and Commitments to the Recent Transportation Experience}

Table 4.2 compares the transportation-related assumptions from the FPEIS with the Army's recent experience in moving the European stockpile. As can be seen from the table, the safety and operational procedures and other details employed during Operation Retrograde were very similar to the assumptions and concepts incorporated into the FPEIS assessment of off-site transportation. The notable exception is the use of SSCs and MLVANs, which did not provide the same degree of protection to the munitions as would the stringent requirements for the shipping container (i.e., the OFC) assumed in the FPEIS assessment. One unanticipated aspect of Operation Retrograde was the high level of public opposition (see Appendix H). This topic is not included in the FPEIS assessment of off-site transportation. It can therefore be concluded that the assessments in the FPEIS incorporate the proper level of detail and that there is no new information that would have affected the FPEIS assessment of off-site transportation.

\subsection{OTHER RELATED DEVELOPMENTS IN THE TRANSPORTATION OF HAZARDOUS WASTES}

This section provides a brief overview of recent movements of high-level radioactive wastes (HLW) and transuranic (TRU) wastes from CONUS sites to other sites since the 
Table 4.2. Comparison of Final Programmatic Environmental Impact Statement (FPEIS) assumptions and commitments with actual experience in transporting chemical munitions from Europe to Johnston Island

\begin{tabular}{l} 
FPEIS \\
\hline Redundancy; double containment \\
Accident protection-withstand \\
dynamic impact, static load, fire and \\
immersion in water \\
Compatibility with standard commercia \\
handling and carrier equipment; \\
standard overall exterior dimensions \\
$(8.5 \times 8 \times 20$ ft) \\
Truck transport for on-site movement \\
only; convoys of 5 vehicles including \\
one vehicle carrying munitions inside \\
off-site transportation containers
\end{tabular}

Maximum speed limit of $32 \mathrm{~km} / \mathrm{hr}$ (20 mph)
Operation Retrograde

\section{Packaging}

Secondary steel containers (SSCs) with military ammunition shipping containers (MILVANs)

SSCs subjected to drop-transportation, explosive propagation and fire tests

Standard size $(8.5 \times 8 \times 20 \mathrm{ft})$ MILVANs 
Table 4.2. (continued)

\begin{tabular}{|c|c|}
\hline FPEIS & Retrograde \\
\hline $\begin{array}{l}\text { Maximum train length of } 2440 \mathrm{~m} \\
(8000 \mathrm{ft})\end{array}$ & $\begin{array}{l}\text { Approximately } 27 \text { cars and two engines } \\
\text { in each munition train for overall length } \\
\text { of about } 750 \mathrm{~m}(2600 \mathrm{ft})\end{array}$ \\
\hline $\begin{array}{l}\text { Containers may be stacked in } 2 \text { layers } \\
\text { or in a single layer }\end{array}$ & $\begin{array}{l}\text { MILVANs in single layer, two per rail } \\
\text { car }\end{array}$ \\
\hline Equipment of current technology & $\begin{array}{l}\text { General condition of German Railroad } \\
\text { equipment was good; Bundesbahn } \\
\text { considered best in Europe }\end{array}$ \\
\hline Maximum speed $80 \mathrm{~km} / \mathrm{hr}(50 \mathrm{mph})$ & Maximum speed $80 \mathrm{~km} / \mathrm{hr}$ (50 mph) \\
\hline $\begin{array}{l}\text { Route chosen principally on basis of } \\
\text { track quality }\end{array}$ & $\begin{array}{l}\text { Routes chosen by German government; } \\
\text { security and logistics were important } \\
\text { factors }\end{array}$ \\
\hline \multicolumn{2}{|c|}{ Logistics } \\
\hline Centralized command and control & $\begin{array}{l}\text { Task force commander was } \\
\text { commanding General, } 50 \text { th Ordnance } \\
\text { Brigade, U.S. authority limited to } \\
\text { custody of chemical munitions; } \\
\text { Germans retained control of German } \\
\text { military and civilian forces and property }\end{array}$ \\
\hline \multicolumn{2}{|c|}{ Monitoring } \\
\hline $\begin{array}{l}\text { Containers must have automatic } \\
\text { monitoring for leakage of chemical } \\
\text { agent or test points for sampling air } \\
\text { within the containers }\end{array}$ & $\begin{array}{l}\text { State-of-the-art monitoring equipment } \\
\text { used during all phases of the } \\
\text { retrogrades; MILVANs equipped with } 2 \\
\text { monitoring ports and sampled before } \\
\text { and after each handling operation }\end{array}$ \\
\hline $\begin{array}{l}\text { Standard Army chemical agent } \\
\text { monitors and alarms to be operational in } \\
\text { holding and loading area during loading } \\
\text { operations }\end{array}$ & $\begin{array}{l}\text { Area monitoring conducted using } \\
\text { Automatic Chemical Agent Monitoring } \\
\text { System as primary method with Depot } \\
\text { Area Air Monitoring System as backup } \\
\text { or confirmation method }\end{array}$ \\
\hline
\end{tabular}


preparation of the FPEIS. These issues are provided as theoretical bounding cases to exemplify the types of public concerns and issues, emergency preparedness, and the logistics of route selection and associated activities likely to be encountered if off-site transport of the CONUS stockpile is undertaken.

Recent plans for the movement of HLW and TRU wastes exemplify issues of public response analogous to those that might occur with chemical munitions stockpile movement. These plans involve the proposed defense TRU waste shipments from DOE facilities throughout the continental United States to the Waste Isolation Pilot Plant (WIPP) near Carlsbad, New Mexico, and actual movement of HLW resulting from the accident at the Three Mile Island unit 2 (TMI-2) nuclear plant in Pennsylvania to Idaho National Engineering Laboratory (INEL), near Idaho Falls.

In the case of TMI-2, there was considerable apprehension that shipment by commercial rail carrier could spark public concern. While some states expressed such concern, most did not, taking a position similar to that of Ohio, which argued that casks containing the waste would provide adequate protection of public health and safety (State Part of Path 1986). The only vocal opposition occurred during an early transit through Nebraska as discussed below.

One reason public concerns may have been allayed is due to early, consistent efforts to negotiate with railroads for services and contracts and the establishment of a single point of contact for the dissemination of information to the media, public, and interested local officials during shipments of TMI-2 core shipments (Ball et al. 1990).

In the case of WIPP, consultation and coordination between DOE and New Mexico has been detailed and elaborate. Independent studies of the viability of route selection, waste containment, and inspection procedures have been conducted by New Mexico. In 1989, New Mexico, after an independent assessment of DOE route selection criteria, decided to designate its own routes to minimize risks from accident. Extensive health monitoring criteria for drivers were also established (Gallegos and Channell 1989). In 1986, a similar state assessment was undertaken for review of DOE TRU waste packaging designs. These early designs did not meet DOT standards, according to New Mexico's review (Channell, Rodgers, and Neill 1986).

In the case of TMI-2 waste, consultation and coordination have been more sporadic, with sometimes contentious results. On July 23, 1986, the governor of Nebraska halted a TMI-2 waste shipment at the border of his state for $4 \mathrm{hr}$ because, he claimed, he had not been notified of the timetable for the shipment as required by federal law. The Governor was particularly upset because every other state along the route from Pennsylvania to Idaho had been notified in advance ("Nebraska Halts TMI Shipment," 1986).

States that were consulted generally did not oppose DOE plans for TMI-2 waste. Ohio's Disaster Services Agency, for example, announced that residents would be adequately protected by packaging design ("State Part of Path" 1986).

Centralized command and control has been the case for TMI-2 waste and for the anticipated TRU waste shipments to WIPP. In the former case, a special TMI office in DOE has jurisdiction over security and communications. For WIPP, while plans are still evolving, a centralized DOE command and control system, coordinated with states en route, is expected to result. 
As a precaution during movements of HLW from the TMI-2 accident, the media was not told the exact route the trains would take, nor the exact time when they would begin movement (Siegel 1986).

As testimony of the success of emergency preparedness plans for TMI shipment of spent fuel and core components, only two incidents of note took place. The first, in March 1987, involved a collision between a TMI train and a stalled car on a grade crossing in St. Louis, Missouri, injuring the driver of the car. The casks were unaffected by the collision. The second occurred in February 1988. It involved the display of a hazardous materials placard in error on an empty, covered hopper car being used as a buffer in a dedicated train used for shipment (SAIC 1990).

Emergency preparedness in shipments of HLW and TRU waste relies chiefly upon prevention of spills or leaks to the environment. The principal means of prevention is through special packaging that is designed to prevent possible radiation exposure of transport workers and the general public along transportation routes from normal, permissible exposures from radiation emitted.

Radiation exposure to the environment, the public, and workers may occur through accidents along transportation corridors. An elaborate system of state and federal coordination has arisen to permit the development of rail and truck transport options on a corridor-by-corridor basis, to respond to such mishaps. The basic components of this process include construction of support facilities (shipping container maintenance and operations control centers); integrated transportation systems; and continued interaction with states, communities, and tribal nations in development of warning, notification and other measures and state vehicle inspection and manifesting (DOE 1989a, b, c, d; U.S. Congress 1985; NRC 1977).

In the WIPP program, considerable effort has been spent to mitigate the expense associated with emergency response along highways and rail carrier routes. In the case of TMI-2 wastes, consultation with states took place prior to waste shipments with DOE's TMI office functioning as a central radiological response team in the event of an accident. HLW and TRU waste shipments are lengthy operations, much like the chemical munitions operation in Germany. In the case of TMI-2 waste, DOE established a special TMI office that was put in charge of the shipments of the damaged core of TMI-2 to INEL. The operation was conducted over a 2-year period (1986-1988) and transported the wastes across seven states-a distance of more than 2300 miles (Siegel 1986). Two specially designed rail cars for TMI-2 waste made 16 round trips during this 2-year period (Siegel 1986).

While WIPP TRU waste shipments have not yet been undertaken, they are likely to be lengthy operations and, as seen above will require elaborate coordination procedures with all transportation corridor states (Gallegos and Channell 1989).

\subsection{FINDINGS AND CONCLUSIONS}

\subsubsection{Lessons Learned}

The movement of chemical munitions from West Germany to Johnston Island was an unqualified success (GAO 1991). The operation experienced no chemical accident, incident, 
or event that could have contributed to the release of chemical agent into the environment. In addition, there were no incidents that threatened the security of the munitions during transport. The success of the entire operation is directly attributable to the thorough planning and coordination conducted by thousands of individuals prior to the start of the mission. The Retrograde program focused attention on detail and resulted in complete accomplishment of the operational objectives in a safe and secure manner, with complete protection to the environment.

The Army's After Action Report (U.S. Army 1991b) documents the lessons learned from the movement of the European stockpile, which are included here.

- $\quad$ Congress should be briefed early in the planning process.

- Clear, specific missions should be assigned to a single individual within each responsible organization.

- Emphasis should be placed on early and thorough planning.

- $\quad$ Planning should be conducted in an overt mode, as opposed to a covert mode, whenever possible.

- $\quad$ Cost estimates should be determined as accurately and realistically as possible.

- A comprehensive coordination process should be established between responsible organizations.

- $\quad$ Routine procedures, as opposed to new or non-routine methods, should be used.

- Joint training should be conducted prior to execution of the program.

- Organizations and individuals should remain flexible in regard to options necessary to accomplish the mission and should avoid the blind application of a rule.

- $\quad$ Political concerns should be included in operational planning.

- The control of public affairs activities should be centralized.

- $\quad$ Ships should be equipped with bilge keels.

- Ship communications capabilities should be augmented with secure communication equipment.

- Safety and environmental protection should be emphasized throughout the program.

\subsubsection{Conclusions}

The Army's recent experience in the transport of chemical munitions has involved technical and nontechnical aspects that are similar to those incorporated into the FPEIS assessment of off-site transportation risks. There have been no significant developments in either the technical or the nontechnical aspects of munition transport that would have made an impact on the conclusions in the FPEIS; although, it should be noted that along potential transportation corridors there is an increasing public opposition to the movement of chemical munitions and other hazardous materials, as well as public opposition in those locations that have been proposed as national or regional disposal centers for the CSDP.

Even though the U.S.-owned European stockpile was safely moved half-way around the world, the feasibility and safety of conducting that movement would probably have been predicted using FPEIS transportation data and analysis techniques. That is, the FPEIS concludes that off-site movement of chemical agents and munitions could be performed in a safe and environmentally acceptable manner. However, the on-site disposal alternative 


\section{4-26}

presents less risk and offers the promise of a more manageable emergency preparedness program. There is no new information related to the Army's recent transportation experience that suggests the FPEIS conclusions would have been different if this new experience had been gained prior to its date of issue.

It is concluded, therefore, that none of the new information about the transportation of chemical munitions is sufficiently different from that included in the FPEIS to warrant the reexamination of the environmentally preferred alternative (i.e., on-site disposal). Based upon transportation-related information, there is no need for additional study of the off-site disposal alternatives. The conclusions reached in the FPEIS are still valid. 


\section{NEW INFORMATION AFFECTING IMPLEMENTATION OF ON-SITE DISPOSAL AT PUEBLO DEPOT ACTIVITY}

This section presents data collected during Phase I for site-specific resources that could be affected by construction and operation of a disposal facility at PUDA. For some resources, only the highlights of the newly collected data are given in this section, with a more complete presentation of data being given in appendices to this report.

Differences in population were previously identified in Sect. 2 as a principal factor with potential to affect the risk levels calculated for the chemical munitions disposal alternatives using the FPEIS methodology. Therefore, population changes are discussed in Sect. 6, along with new information related to the accident database and design changes which also require assessment for potential affects on the risk calculations.

\subsection{METEOROLOGY, AIR QUALITY}

Some local weather data are available from a meteorological measurements tower in the northwest part of the depot, near the open burn area. These measurements were begun December 4, 1988. The on-site meteorological data were analyzed (see Appendix I) but were not used in this analysis because both the completeness and quality of these data are incomplete for adequate modeling purposes, and the accuracy of the data cannot be validated. Other on-site meteorological measurements have been made from time to time for various purposes, but records of those measurements have not been preserved.

Surface data from Pueblo Memorial Airport (1960-64) are available along with mixing heights for the same period obtained from upper-air data at Denver (Stapleton Airport). However, the height of the anemometer at the Pueblo Memorial Airport was

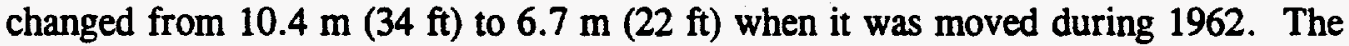
anemometer has since been at the lower height. To be consistent with the current position of the anemometer, the figures in this report are based on data for the years 1963 and 1964. Pueblo Memorial Airport stopped taking 24-hr per day observations at the end of 1964 . The terrain is flat or gently rolling throughout the region around PUDA, including the airport, so the airport data would be representative of conditions at PUDA. Mixing height, atmospheric stability and wind speed are features that are largely determined by the time of day and the large-scale weather pattern in the region; therefore, measurements of these features at the Pueblo Memorial Airport are generally representative of conditions at PUDA.

The wind roses from the Pueblo Memorial Airport summarize the joint frequency of wind speed and direction for the periods 1963-64 and 1960-64 (Fig. 5.1). The wind rose for 
Wind Rose for Pueblo Memorial Airport, 1960-64

(a)

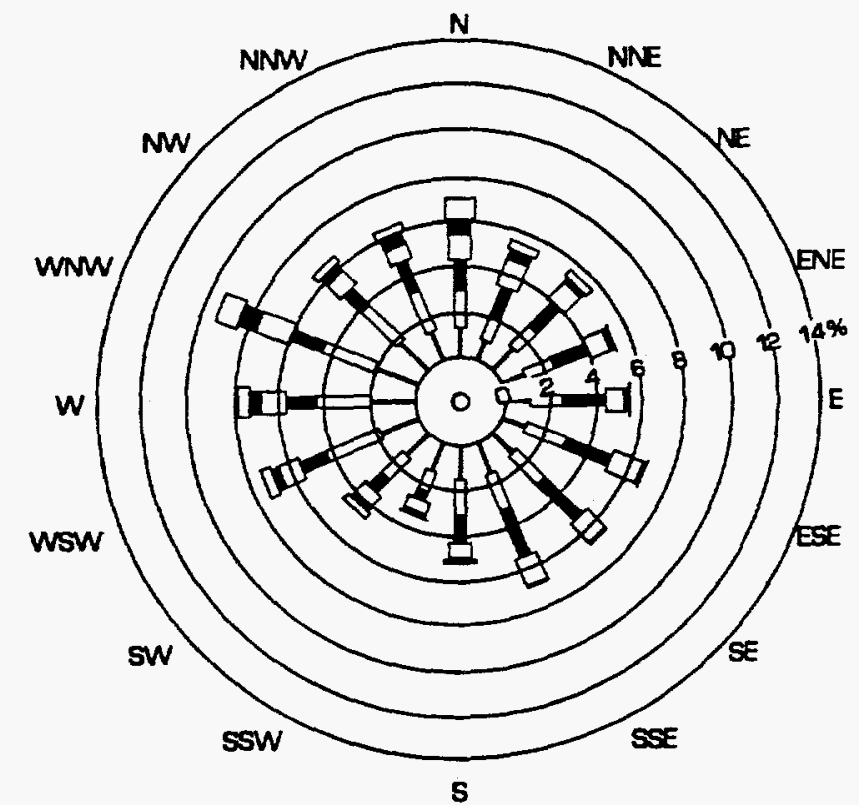

(b)

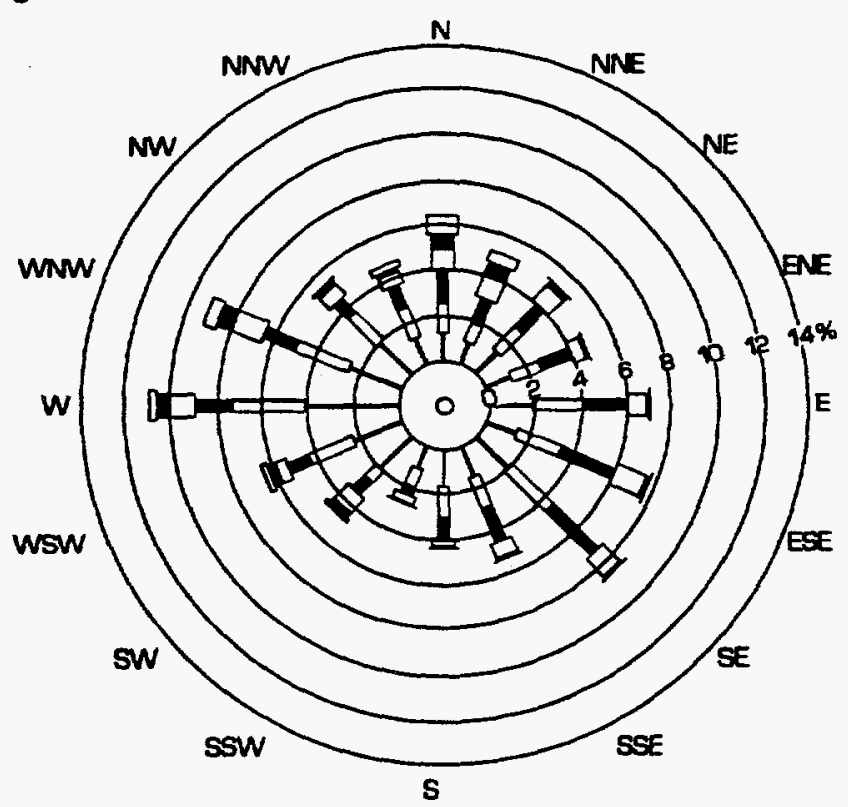

Fig. 5.1. Wind roses for Pueblo Memorial Airport covering the periods from 1963-64 (a) and 1960-64 (b). [The first period only includes data from the present location while the latter period includes data from two locations. The anemometer was moved on March 19, 1962, and was placed $6.7 \mathrm{~m} \mathrm{(22} \mathrm{ft)} \mathrm{above} \mathrm{the} \mathrm{ground} \mathrm{surface.} \mathrm{Prior}$

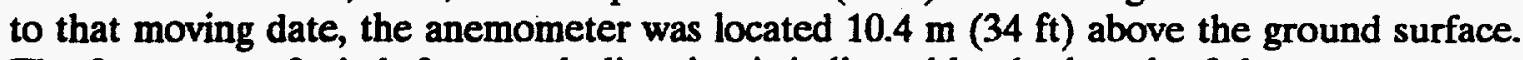
The frequency of winds from each direction is indicated by the length of the corresponding bar. Note that the points on the wind rose represent directions from which the winds originate.] 
the 5-year period (1960-64) is shown in Fig. 3.2.18 of the FPEIS (U.S. Army 1988a) and includes data from two locations. In each of these graphs, winds blowing from a particular direction are plotted as individual bars that extend from the center of the circular diagram. Wind speed classes are indicated by bar widths and shading. The frequency of winds within each speed class and wind direction is indicated by the length of the corresponding bar segment. Note that the points on the wind rose represent the directions from which the winds come. The frequencies are expressed as percentages of the total number of measurements.

The two wind roses are quite similar, as would be expected. The longer record indicated westerly winds about $11 \%$ of the time and southeasterly winds about $9 \%$ of the time, while the wind rose representing the shorter record indicated westerly winds about $8 \%$ of the time and southeasterly winds about $7 \%$ of the time. The visual effect is that the wind rose for the shorter record appears to be rotated clockwise by $22.5^{\circ}$ from the wind rose for the longer record. This effect probably reflects slightly different physiographic influences at the different locations.

Colorado has adopted both the National Ambient Air Quality Standards and a visibility standard (to become effective January 1,1993 ). The visibility standard will limit light extinction to less than $0.076 / \mathrm{km}$ for any $4-\mathrm{hr}$ period between 8:00 a.m. and 4:00 p.m. during hours when the relative humidity is below $70 \%$ but would not affect the proposed disposal facility because the Depot is outside the area affected by the new standard. The nearest affected area begins about $24 \mathrm{~km}$ (15 miles) due north of PUDA, at the El Paso County line.

The site of the proposed disposal facility is located within the South Central Air Quality Region of Colorado. The region was in attainment for all criteria pollutants in 1988 (Colorado Air Pollution Control Division 1989). Fugitive dust is a major factor affecting air quality in the region. Sources of this dust include travel on unpaved roads, agricultural activities, and mining (Colorado Air Pollution Control Division 1989).

Particulate matter less than 10 microns in diameter $\left(\mathrm{PM}_{10}\right)$ and aluminum (from rocket destruction and rocket fuel) are monitored at PUDA. In addition, TSP and lead are monitored in the city of Pueblo.

The nearest Class I Prevention of Significant Deterioration (PSD) area, designated to greatly restrict the degradation of ambient air quality, is the Great Sand Dunes National Monument located $115 \mathrm{~km}$ ( 71 miles) west-southwest of the proposed disposal facility. This is not in a direction of prevailing winds (which are from the west and southeast at PUDA) from the proposed disposal facility. Further, the Sangre de Cristo Mountains, just to the east of this Class I PSD area, would provide a partial barrier to the transport of emissions under many meteorological conditions.

Several existing emissions sources at PUDA are currently permitted by the Colorado Department of Health. These include the following:

- a hot water boiler, located in Building 485, burning No. 2 fuel oil with a sulfur content of equal to or less than $0.27 \%$ (Permit C-12.445),

- $\quad$ three oil-fired boilers in buildings 593 and 594 (Permit 86PB034), 
- $\quad$ open demolition up to 10 tons per blast and 1291 tons per year of explosives (Permit C-11 641), and

- $\quad$ static firing of Pershing rocket motors (Permit 88PB110). (This activity has been completed.)

An air quality permit application for the disposal of chemical agents and munitions has been submitted (U.S. Army 1986b).

There are 27 on-site sources of air pollutant emissions that were constructed or installed before CY 1977 and thus are not subject to current new source permitting requirements. The sources involved are coal- and oil-fired boilers regulated by the Colorado Air Pollution Control Division.

Mercury stored in buildings F101, F102, and F103 may be leaking some vapor (USATHAMA 1990 , p. 4-6). Removal of this mercury is now in the planning stage (USATHAMA 1990, p. 3-33).

Consideration of cumulative impacts (of nearby emissions sources together with impacts of the proposed disposal facility), requires knowledge of major emissions sources located within $50 \mathrm{~km}$ (31 miles) of PUDA. These sources are listed below:

- $\quad$ Comanche Power Plant, 29 km (18 miles) southwest of PUDA;

- $\quad$ Colorado State Hospital, $31 \mathrm{~km}$ (19 miles) west of PUDA;

- $\quad$ Southern Colorado Power Corporation, $30 \mathrm{~km}$ (19 miles) west of PUDA;

- $\quad$ CF\&I Steel Corporation, $30 \mathrm{~km}$ (19 miles) west-southwest of PUDA; and

- $\quad$ Ray Nixon Power Plant, 48 km (30 miles) northwest of PUDA.

The Colorado State Hospital, Southern Colorado Power Corporation, and CF\&I Steel Corporation are all in the city of Pueblo. The CF\&I steel mill has changed to electricity for smelting, which has reduced substantially its emissions of air pollutants. These sources will be considered in assessing potential ambient air quality impacts in the EIS for the proposed disposal facility.

\subsection{WATER RESOURCES}

Appendix $\mathrm{C}$ describes site-specific surface water and groundwater regimes at PUDA as well as additional data collected since publication of the FPEIS. The FPEIS provides a similar, less detailed description of PUDA surface water and groundwater regimes (U.S. Army 1988a, Vol. 1, Sect. 3.2.6.4). No modification to the conclusions reached in the FPEIS is warranted based on the additional data contained in Appendix C. Comparison of Appendix $C$ with the FPEIS has not revealed any differences-based on a thorough, in-depth inspection of site-specific data-that would contradict FPEIS statements and conclusions. Information derived from the Phase I process is summarized below.

PUDA is located on a gently rolling, upland terrace within the Arkansas River watershed. The reservation is drained by Chico, Haynes, and Boone creeks which empty into the Arkansas River. Chico and Haynes creeks are ephemeral, while Boone Creek is a spring-fed perennial stream. Linda Ann Reservoir is formed by a small dam across Boone 
Creek. The site of the proposed disposal facility is located on higher ground north of the spring feeding Boone Creek and west of Haynes Creek.

The Arkansas River is the primary public water supply for Pueblo County. Much of this water is obtained from Pueblo Reservoir located upstream from PUDA and the city of Pueblo on the Arkansas River. Using the EPA STORET data base (EPA 1982), 28 public water supply intakes have been identified that withdraw surface water downstream from PUDA (Chico, Boone, and Haynes creeks, 0; Arkansas River, 6; and Mississippi River, 22).

Process water for the proposed disposal facility would be supplied by the city of Pueblo, which obtains water from Pueblo Reservoir on the Arkansas River. Present allocations to the city of Pueblo exceed current demand by a factor of 2 or 3 . The nearest water main is located at Pueblo Memorial Airport west of PUDA. A pipeline approximately $16 \mathrm{~km}$ (24 km maximum) [10 miles (15 miles maximum)] in length, and possibly an intermediate pumping station, would be built to supply process water to the proposed disposal facility.

The quality of surface water at PUDA is generally good although Linda Ann Reservoir has a tendency to be fairly turbid. Boone Creek receives effluent from the PUDA sewage treatment plant. This waste water disposal system is in compliance with EPA discharge limitations specified in a State of Colorado National Pollutant Discharge Eliminating System (NPDES) permit.

The site of the proposed disposal facility at PUDA is located outside the 100-year floodplain.

An extensive storm sewer system collects precipitation-induced runoff at PUDA. The system discharges into Chico and Boone creeks. Oil and grease, phosphates, and nitrates sometimes are present in runoff discharged from the storm sewer system.

The erosional remnant on which PUDA is situated is composed of permeable, weathered gravel and windblown sand. The bedrock beneath these alluvial deposits is thick, relatively impermeable shale. The alluvial deposits are host to an unconfined aquifer that supplies all water currently used at PUDA. Discharges from the surficial aquifer occur from seeps and springs located along the eastern, southern, and western edges of the terrace. The quality of groundwater in the alluvial aquifer is generally good (U.S. Army 1984b, Hearne et al. 1988). Concentrations of dissolved, naturally occurring selenium sometimes exceed drinking water standards. The shale bedrock isolates a deeper Dakota sandstone aquifer, which is important on a regional basis, from the topmost, unconfined alluvial aquifer.

Excessive pumping from the PUDA well field has caused water-table declines, reduced yield, and groundwater quality degradation in the alluvial aquifer. These conditions have been stabilized by installation of two new supply wells located approximately $2 \mathrm{~km}$ ( 1 mile) west of the original well field, and by reduction in mission workload accompanied by reduced water requirements at PUDA.

An existing Colorado Water Permit allows a maximum pumpage of groundwater from the water-table aquifer beneath PUDA of 3,398,180 L/day $(897,120$ gal/day). The culinary or process water requirements of the proposed disposal facility have been estimated to average $2000 \mathrm{~m}^{3} /$ day $(0.5 \mathrm{Mgd})$, with a peak demand of $5700 \mathrm{~m}^{3} /$ day $(1.5 \mathrm{Mgd}$ ) (Forsgren-Perkins Engineering 1988). While it may be possible to supply the average demand of the proposed disposal facility from the existing PUDA well field, the peak water requirements would have 
to be met by other resources. Additional groundwater allocations are not available from the Pueblo Water Conservancy. PUDA is not a member of this organization.

The valley-fill deposits extending along the Arkansas River east of the city of Pueblo to the Colorado-Kansas state line are host to a major regional aquifer that serves as both an agricultural and municipal water supply (Cain 1987, Hearne et al. 1988). The groundwater regime in the Arkansas River alluvium is not hydraulically connected to subsurface flows in the upland alluvial deposits beneath PUDA (Watts and Ortiz 1990, USATHAMA 1990).

Spring flows originating as terrace alluvial groundwater discharge and sustained creek flows (which are ephemeral) may, however, recharge the Arkansas River alluvial aquifer.

Water resources in the vicinity of PUDA could be impacted by accidental releases of chemical agent through two environmental pathways: (1) surface water could be directly impacted by atmospheric dispersion and subsequent deposition of chemical agent, and (2) groundwater could be directly impacted by spills of chemical agent. The assessment of surface water and groundwater impacts, which considers the fate of downwind and downgradient receptors of chemical agent, is beyond the scope of this Phase I report. However, the size of downwind areas that could be affected by atmospheric dispersion and subsequent deposition of agent, as well as the mass or volume of agent that could be spilled onto the ground and then seep into the groundwater, can be used to quantify potential impacts to water resources at and near PUDA.

The size of the largest hypothetical accident for each alternative at PUDA is representative of the size of the potential area for surface water impacts (i.e., for atmospheric dispersion and deposition impacts). Regardless of the location of the surface water resource, higher concentrations of chemical agent could potentially be deposited onto surface water bodies during large accidents than during small ones. On-site disposal has a 5-km (3-mile) accident as its WC scenario; the other applicable alternatives (continued storage and national disposal) fall into the $100 \mathrm{~km}$ (62 miles) downwind accident category (U.S. Army 1988a, Vol. 1, Sect. 4.3.6.2). Based on the relative size of the wc accident for each of the alternatives, there is a greater potential for surface water impacts to occur for the continued storage and national disposal alternatives. The on-site disposal alternative presents the least potential for surface water impact.

The potential for impact to groundwater resources can be represented by the quantity of chemical agent spilled during a hypothetical, credible accident. The wc spill quantities can be obtained from the FPEIS accident data base (U.S. Army 1988a, Vol. 1, Sect. .3.6.4). For the national alternative, the largest credible spill is $62,468 \mathrm{~kg}(137,720 \mathrm{lb}$, or $13,009 \mathrm{gal})$ of mustard which would occur if an aircraft crashed into the transportation containers in the holding area, with no fire. The maximum credible spill for the on-site disposal alternative, which also would occur as a result of an aircraft crash with no fire, has been estimated to involve $184 \mathrm{~kg}$ ( $406 \mathrm{lb}$ or $38 \mathrm{gal}$ ) of mustard. Clearly, on-site disposal has the smallest accidental spill size relative to the national alternative.

For the continued storage alternative, no credible spill accidents were identified having probabilities exceeding $10^{-8}$, the criterion used in the FPEIS for credible catastrophic accidents (U.S. Army 1988a, Vol. 1, Sects. 4.2.3 and 4.3.6.4). Hence, a spill of chemical agent onto the ground during continued storage probably would not occur. This statement should not be interpreted to mean that spills are impossible, just highly unlikely. Since all munitions are stored in igloos at PUDA, the maximum spill size during continued storage 
would be some integral multiple of the contents of one igloo. Because the contents of a single igloo exceeds the quantity of chemical agent stored at the disposal facility at any given time, the conclusion presented in the FPEIS remain unchanged. On-site disposal has a smaller accidental spill size than the continued storage alternative. The on-site disposal alternative presents the least potential for environmental impact to groundwater.

The Army has made a firm commitment to a program of rapid response so that impacts from an accidental spill do not occur or, in a wc scenario, are minimized. A Spill Prevention and Countermeasures plan as well as a Contingency Plan already have been implemented at PUDA to minimize impacts caused by accidental releases of hazardous chemicals (U.S. Army 1984a, 1986a).

The design of the proposed disposal facility at PUDA, which has not been finalized, would include a system of curbs, berms, and sumps to contain, control, and collect accidental spills of chemical agent. The final design of the proposed disposal facility, which would include the system of curbs, berms, and sumps, would be submitted to EPA and the National Research Council for review. The final responsibility for the facility design would, however, remain with the Army.

\subsection{LAND USE}

PUDA is located $23 \mathrm{~km}$ (14 miles) east of Pueblo, the only major city in Pueblo County. Colorado Springs is located $74 \mathrm{~km}$ (46 miles) northwest and Canon City is located $77 \mathrm{~km}$ (48 miles) west of the PUDA site. These are the only major urban areas in the $100-\mathrm{km}$ (62-mile) impact zone. Grazing (predominantly cattle with some sheep ranching) is the major land use in the $100-\mathrm{km}(62-\mathrm{mile})$ zone. Cultivated cropland and pastureland is found along the Arkansas River, with hay or grass, wheat, corn, sorghum, dried beans, and barley being the most important crops, based on the number of hectares planted (DOC 1989). Other information on land use is found in Sects. 5.4 and 5.5 and in Appendices B and D.

\subsection{ECOLOGICAL RESOURCES}

The FPEIS concludes that "ecosystems and environmental resources" are secondary to human health in determining the environmentally preferred alternative (U.S. Army 1988a, Sect. 2.6). These resources are important because they provide support for the human population, including employment (e.g., farm- or ranch-related industries) and recreational (e.g., fishing, hunting, outdoor sports) opportunities. In the overall programmatic analysis, identification and enumeration of ecological resources within the expected plume areas (both on-site and off-site) did not provide significant differentiation among alternatives (i.e., on-site, national disposal, and partial relocation). However, there would be potentially less risk associated with the on-site alternative because of the overall smaller expected plume area than the alternatives involving transportation (U.S. Army 1988a, Table 2.6.2). Comparison of the expected plume areas associated only with the on-site portion of each alternative shows that for ecological resources there is no difference in risk among the on-site, regional, national, or 


\section{$5-8$}

continued storage alternatives. The risk associated with the continued storage of chemical agents during any of the disposal options is not included in the FPEIS.

Additional information on ecological resources obtained since the FPEIS is shown in Tables 5.1 and 5.2. The locations of these resources are shown in Fig. 5.2. Information on ecological resources included in the FPEIS is based on data from the GEOECOLOGY data base at Oak Ridge National Laboratory (ORNL). Use of a standardized data base allowed the same level of coverage for all sites and transportation options and reduced potential bias in determination of the ecologically preferred alternative. Information obtained during preparation of the Phase I report has verified the federal-level data obtained for Colorado during preparation of the FPEIS. Additional information has been obtained on national forests, parks and recreational areas, and state wildlife areas (SWAs) (see Table 5.2 and Fig. 5.2). Additional information on ecologically sensitive areas has been requested from the Colorado Natural Heritage Program and from the Nature Conservancy.

Comparison of information about threatened and endangered species between the FPEIS and the Phase I Report shows that the information obtained for the FPEIS is still valid. The Eskimo curlew, least tern, piping plover, and Pawnee montane skipper (butterfly) have been identified as endangered and threatened species (50 CFR Pt. 17) that could occur in the PUDA vicinity (L. W. Carlson, FWS, Golden, Colo., letter to V. R. Tolbert, ORNL, Oak Ridge, Tenn., July 30, 1992) since information was obtained in 1986 from FWS for the FPEIS. In addition to identifying threatened and endangered species that could occur within the 100-km (62-mile) zone, the FWS identified 35 candidate species (two of which are proposed threatened species) for listing as either threatened or endangered. Table 5.3 shows those federally listed species identified in 1986 as occurring within the 100-km (62-mile) zone compared to those identified in 1992 . The lesser prairie chicken was identified as a statelisted threatened species occurring within the study area ( $R$. Desilet, Colorado Division of Wildlife, Denver, Colo., letter to V. R. Tolbert, ORNL, Oak Ridge, Tenn., May 11, 1992). A large population of prairie dogs occurs on the PUDA site. Because areas inhabited by prairie dogs may also provide suitable habitat for the black-footed ferret, as well as the prairie dogs providing a food source for the ferret, the FWS and the Army are cooperating in a recovery project for the black-footed ferret on the PUDA site (U.S. Army 1991a). The timeframe for the reintroduction of the black-footed ferret and the implementation of the chemical agent incineration operations will be addressed in the site-specific EIS. Further consultation will be initiated with the FWS Endangered Species Office in Denver for the 100-km (62-mile) zone around PUDA during preparation of the site-specific EIS and resulting information will be included.

Endangered and threatened species could be affected by a release of chemical agent. There are several peregrine falcon eyries, bald eagle foraging and roosting areas, and nesting areas for the least tern and piping plover within the 100-km (62-mile) zone. Bald eagles and peregrine falcon also migrate through the area. The threatened greenback cutthroat trout is confined to small headwater streams of the Arkansas River and South Platte River basins, several of which occur within the study area. Potential impacts to threatened and endangered species from an accidental release will be discussed in detail in the site-specific EIS.

Arctic peregrine falcons have been identified as using the area within the vicinity of PUDA for feeding during migration, wintering bald eagles have been identified as using the Arkansas River and associated reservoirs for foraging and roosting, and least terns and piping 
Table 5.1. Number of protected ecological resources within the no-deaths ${ }^{a}$ distance for the most serious on-site accidents under worst case meteorological conditions at Pueblo Army Depot Activity

Resource

National Park Units

Wilderness Areas

National Forests

Threatened and Endangered Species ${ }^{c}$

Wild and Scenic Rivers

Nature Conservancy Areas

National Wildlife Refuges

Parks and Recreational Areas

State Wildlife Areas

Fish Hatcheries

Bureau of Land Management Areas
Number of Resources

\footnotetext{
a No-effects distances for mustard are unknown; thus, analysis is based on accidents with a no-deaths distance of $5 \mathrm{~km}$ ( 3 miles) for the on-site disposal alternative.

${ }^{b}$ Managed by the National Park Service.

'Does not include candidate species.
}

plovers have been documented as nesting at a reservoir within the study area. A total of six federally listed threatened and endangered species and nineteen candidate species and a statelisted threatened species that could occur within the 100-km (62-mile) impact zone have been identified in preparation of the site-specific EIS for PUDA. This list may be revised and expanded during preparation of the site-specific EIS as further consultation occurs with the FWS.

The identification of additional threatened and endangered species listed since data collection for the FPEIS and the addition of state parks, wildlife management areas, and important natural areas do not alter the conclusions of the FPEIS; the additional information will help to better estimate the extent of effects to important ecological resources. Information on wind direction and other meteorological conditions, the quantities of agent that could be released under WC accident scenarios, and the location and densities (where information can be obtained) of ecological resources potentially at risk will be used to estimate the extent of impacts that could occur to ecological resources in the site-specific EIS. 
Table 5.2. Ecological resources within the $100-\mathrm{km}$ (62-mile) impact zone around Pueblo Depot Activity (PUDA) as identified during the Phase I process

\begin{tabular}{|c|c|c|c|}
\hline Area & County & $\begin{array}{l}\text { Distance and direction } \\
\text { from site }(\mathrm{km})\end{array}$ & $\begin{array}{c}\text { Area } \\
\text { (acres) }\end{array}$ \\
\hline \multicolumn{4}{|c|}{ National Forests (NFs) } \\
\hline Pikes Peak NF & El Paso, Teller & $>80 \mathrm{NW}$ & 225,910 \\
\hline San Isabel NF & $\begin{array}{l}\text { Fremont, Custer, } \\
\text { Pueblo, Huerfano }\end{array}$ & 70 WSW & 437,175 \\
\hline $\begin{array}{l}\text { Comanche National } \\
\text { Grassland }\end{array}$ & Otero & $60 \mathrm{SE}$ & 19,360 \\
\hline \multicolumn{4}{|c|}{ National Historical Sites } \\
\hline $\begin{array}{l}\text { Bents Old Fort } \\
\text { Cripple Creek }\end{array}$ & $\begin{array}{l}\text { Otero } \\
\text { Teller }\end{array}$ & $\begin{array}{l}90 \mathrm{SSe} \\
95 \mathrm{NW}\end{array}$ & 799 \\
\hline \multicolumn{4}{|c|}{ State Wildlife Areas (SWAs) } \\
\hline Karval SWA & Lincoln & $90 \mathrm{NE}$ & 235 \\
\hline $\begin{array}{l}\text { Rocky Ford SWA } \\
\text { Colorado }\end{array}$ & Otero & $65 \mathrm{ESE}$ & 550 \\
\hline Springs SWA & El Paso & $35 \mathrm{NW}$ & 3,900 \\
\hline Huerfano SWA & Huerfano & 98 SSW & 544 \\
\hline Beaver Creek SWA & Telier & $80 \mathrm{WNW}$ & 2,740 \\
\hline Dome Rock SWA & Teller & $90 \mathrm{NNW}$ & 4,982 \\
\hline Macrea Reservoir & El Paso & $60 \mathrm{NW}$ & 15 \\
\hline Pikes Peak SWA & Teller & $90 \mathrm{NW}$ & 635 \\
\hline \multicolumn{4}{|l|}{ Skaguay } \\
\hline Reservoir SWA & Teller & $60 \mathrm{NW}$ & 174 \\
\hline \multicolumn{4}{|l|}{ Rosemont } \\
\hline Reservoir SWA & Teller & $60 \mathrm{NNW}$ & 20 \\
\hline Brush Hollow SWA & Fremont & $55 \mathrm{NW}$ & 461 \\
\hline De Weese SWA & Custer & $98 \mathrm{~W}$ & 780 \\
\hline Pueblo SWA & Pueblo & $22 \mathrm{~W}$ & 4,100 \\
\hline Runyon Lake Area & Pueblo & $18 \mathrm{~W}$ & 40 \\
\hline Wahatoya SWA & Huerfano & $98 \mathrm{SSW}$ & 203 \\
\hline Apishapa SWA & Huerfano & $75 \mathrm{~S}$ & 7,935 \\
\hline Olney Springs SWA & Crowley & $40 \mathrm{E}$ & 8 \\
\hline Ordway SWA & Crowley & $50 \mathrm{E}$ & 12 \\
\hline \multicolumn{4}{|l|}{ Meredith } \\
\hline Reservoir SWA & Otero & $55 \mathrm{E}$ & 3,220 \\
\hline Lake Henry SWA & Otero & $55 \mathrm{E}$ & 1,350 \\
\hline McClelland SWA & Otero & $65 \mathrm{E}$ & 662 \\
\hline \multicolumn{4}{|l|}{ Holbrook } \\
\hline Reservoir & Otero & $68 \mathrm{E}$ & 670 \\
\hline
\end{tabular}




\section{5-11}

Table 5.2. (continued)

\begin{tabular}{|c|c|c|c|}
\hline Area & County & $\begin{array}{l}\text { Distance and direction } \\
\text { from site }(\mathrm{km})\end{array}$ & $\begin{array}{c}\text { Area } \\
\text { (acres) }\end{array}$ \\
\hline \multicolumn{4}{|l|}{ Rocky Ford } \\
\hline $\begin{array}{l}\text { West SWA } \\
\text { Adobe Creek }\end{array}$ & Otero & $55 \mathrm{E}$ & 350 \\
\hline Reservoir SWA & Bent & $95 \mathrm{E}$ & 5,147 \\
\hline Timpas Creek SWA & Otero & $62 \mathrm{ESE}$ & 141 \\
\hline Setchfield SWA & Bent & $98 \mathrm{ESE}$ & 2,438 \\
\hline Purgatoire & & & \\
\hline $\begin{array}{c}\text { River SWA } \\
\text { Horse Creek } \\
\text { (Timber Lake) }\end{array}$ & Bent & $95 \mathrm{E}$ & 960 \\
\hline SWA & Bent & $90 \mathrm{E}$ & 2,603 \\
\hline \multicolumn{4}{|c|}{ State Fish Hatchery } \\
\hline $\begin{array}{l}\text { Las Animas State } \\
\text { Fish Hatchery } \\
\text { Pueblo State }\end{array}$ & Bent & 95 ESE & \\
\hline Fish Hatchery & Pueblo & $20 \mathrm{~W}$ & \\
\hline \multicolumn{4}{|c|}{ State Parks (SPs) } \\
\hline $\begin{array}{l}\text { Lathrop (Martin } \\
\text { Lake) SP }\end{array}$ & Huerfano & $85 \mathrm{SSW}$ & $\begin{array}{r}1,434 \\
320 \text { (water) }\end{array}$ \\
\hline \multicolumn{4}{|c|}{ Parks and Recreational Areas } \\
\hline $\begin{array}{l}\text { Red Canon Park } \\
\text { Temple Can Park } \\
\text { Royal Gorge Park } \\
\text { Pueblo Mountain }\end{array}$ & $\begin{array}{l}\text { Teller } \\
\text { Fremont } \\
\text { Fremont }\end{array}$ & $\begin{array}{l}75 \mathrm{~W} \\
80 \mathrm{~W} \\
90 \mathrm{WNW}\end{array}$ & \\
\hline $\begin{array}{l}\text { Park } \\
\text { Pueblo State }\end{array}$ & Huerfano & $60 \mathrm{WSW}$ & \\
\hline $\begin{array}{l}\text { Recreation Area } \\
\text { Ramah State }\end{array}$ & Pueblo & $22 \mathrm{w}$ & \\
\hline Recreation Area El Paso & $90 \mathrm{~km} \mathrm{~N}$ & & \\
\hline \multicolumn{4}{|c|}{ Bureau of Land Management Areas } \\
\hline $\begin{array}{l}\text { McIntyre Hills \& } \\
\text { Grape Creek }\end{array}$ & Fremont & $80 \mathrm{~W}$ & 38,700 \\
\hline Beaver Creek & Teller & $70 \mathrm{~W}$ & 26,150 \\
\hline \multicolumn{4}{|c|}{ Nature Conservancy Areas } \\
\hline $\begin{array}{l}\text { Garden of the Gods } \\
\text { Mueller Ranch }\end{array}$ & $\begin{array}{l}\text { El Paso } \\
\text { Teller }\end{array}$ & $\begin{array}{l}85 \mathrm{NW} \\
95 \mathrm{NW}\end{array}$ & $\begin{array}{r}5 \\
11,961\end{array}$ \\
\hline
\end{tabular}




\section{$5-12$}

OANL-DWG 90M-13421

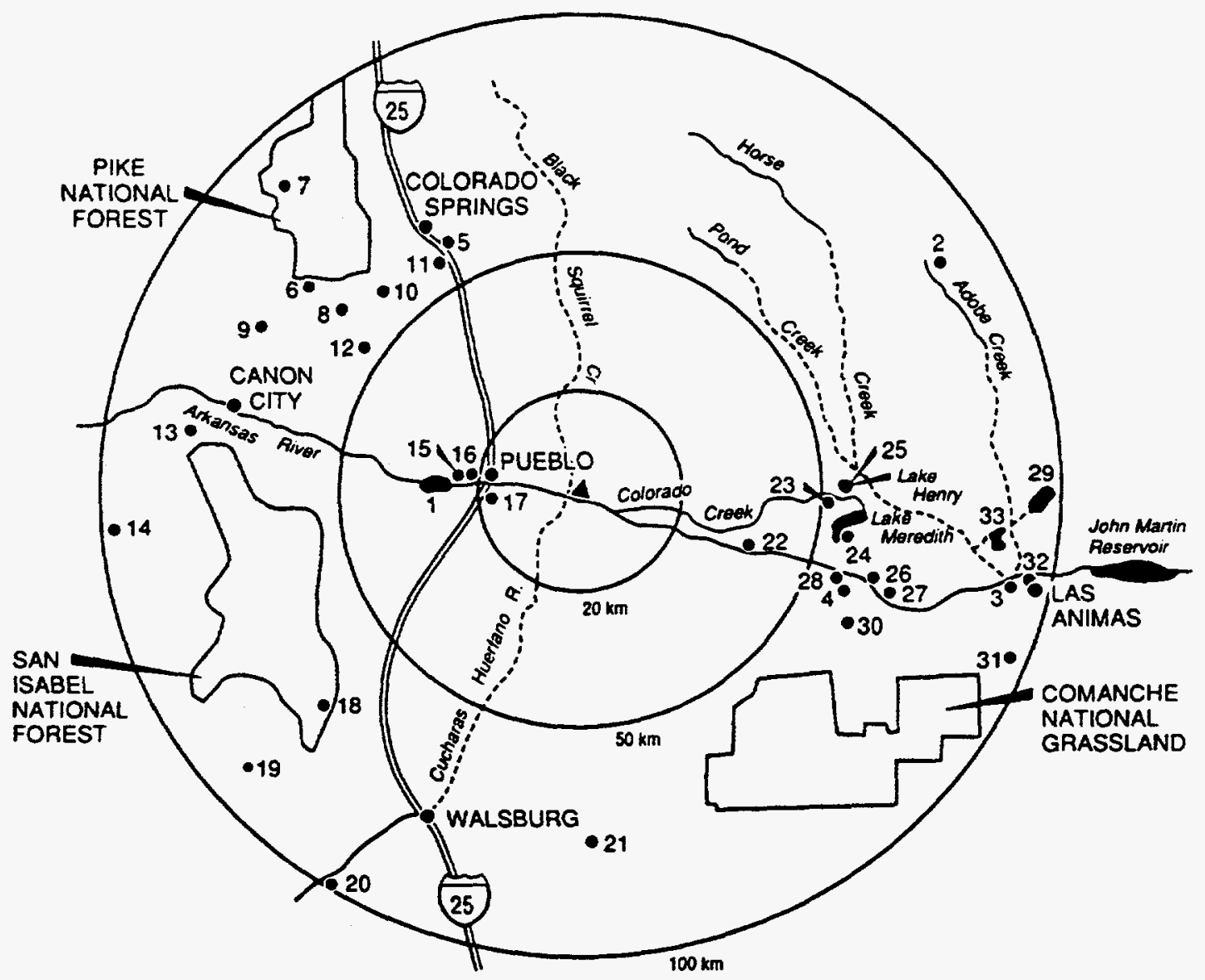

1. PUEBLO RESERVOIR
2. KARVAL SWA
3. LAS ANIMAS STATE FISH HATCHEAY
4. ROCKY FORO SWA
5. MACREA RESERVOIR SWA
6. BEAVER CREEK SWA
7. PIKES PEAK SWA
8. SKAGUAY RESERVOIR SWA
9. RED CANON PARK
10. ROSEMONT RESERVOIR SWA
11. COLORADO SPRINGS SWA
12. BRUSH HOLLOW SWA
13. TEMPLE CAN PARK
14. DE WEESE SWA
15. PUEBLO SWA
16. PUEBLO HATCHERY
17. RUNYON LAKE AREA

1. PUEBLO RESERVOIR

2. KARVAL SWA

3. LAS ANIMAS STATE FISH HATCHERY

ROCKY FORO SWA

6. BEAVER CREEK SWA

7. PIKES PEAK SWA

9. RED CANON PARK

12. BRUSH HOLLOW SWA

13. TEMPLE CAN PARK

15. PUEBLO SWA

17. RUNYON LAKE AREA
18. PUEBLO MOUNTAIN PARK
19. HUERFANO SWA
20. WAHATOGA SWA
21. APISHAPA SWA
22. OLNEY SPRINGS SWA
23. ORDWAY SWA
24. MEREDITH RESERVOIR SWA
25. LAKE HENAY SWA
26. MC CLELLAND SWA
27. HOLBAOOK RESERVOIR SWA
28. ROCKY FORD WEST SWA
29. ADOBE CREEK RESERVOIR SWA
30. TIMPAS CREEK SWA
31. SETCHFIELD SWA
32. PURGATOIRE RIVER SWA
33. HORSE CREEK (TIMBER LAKE) SWA

Fig. 5.2 Location of important ecological resources within the 100-km (62-mile) zone around Pueblo Depot Activity. 


\section{$5-13$}

Table 5.3. Threatened and Endangered Species identified within the 100-km (62-mile) zone and Pueblo Depot Activity (PUDA) during preparation of the Final Programmatic Environmental Impact Statement (FPEIS) and Phase I Report.

\section{FPEIS $^{a}$}

\section{Phase I Report}

\section{Threatened and Endangered}

$\underline{\text { Fish }}$

Greenback cutthroat trout

Birds

Arctic Peregrine falcon

Bald eagle

Whooping crane

Mammals

Black-footed ferret

Invertebrates

None

Plants

Clay-loving wild buckwheat

Spineless hedgehog cactus

Uinta Basin hookless cactus
Fish

Greenback cutthroat trout

Birds

Arctic Peregrine falcon

Bald eagle

Eskimo curlew

Least tern

Piping plover

Whooping crane

Mammals

Black-footed ferret

Invertebrates

Pawnee montane skipper (butterfly)

Plants

None

Candidate Species

Fish

Arkansas darter

Plains topminnow

Speckled chub

Reptile

Boreal western toad

Texas Horned lizard 
Table 5.3. (cont.)

\section{Birds}

Baird's sparrow

Black tern

Ferruginous hawk

Harlequin duck

Loggerhead shrike

Mexican spotted owl (proposed

threatened)

Mountain Plover

Northern goshawk

Western snowy plover

White-faced ibis

Mammals

Colorado hog-nosed skunk

Fringed-tailed myotis

North American lynx

North American wolverine

Preble's meadow jumping mouse

Swift fox

Invertebrates

Regal fritillary butterfly

\section{Plants}

Arkansas River feverfew

Bell's twinpod

Brandegee wild buckwheat

Colorado green gentian

Degener beardtongue

Pale blue-eyed grass

Penland eutrema (proposed

threatened)

Porter's feathergrass

Roundleaf four-o'clock

Royal Gorge stickleaf

Single-head goldenweed

Streaked ragweed

Weber monkey-flower 
With the wind primarily from the west or west-northwest (see Sect. 5.1), the ecological resources to the east and south-southeast of the site would be subject to the greatest potential for impact from aerosolization and deposition (see Table 5.2). There could be effects on warm-water fisheries in the Arkansas River as the result of a spill and transport of agent into the river. Impacts of a spill as well as aerosolization and subsequent deposition on the Arkansas River will be addressed in the site-specific EIS.

Data collection during preparation of the Phase I Report does not alter the conclusions of the ecological resources section of the FPEIS that in the event of an accidental release of chemical agent impacts to ecological resources would occur. The addition of state parks, wildlife management areas, and important natural areas to the list of resources within the $100-\mathrm{km}$ zone does not alter the conclusions of the FPEIS. These resources are distributed primarily in the western portion of the impact zone and are not concentrated in the general downwind direction from the site. This additional information will help to better estimate the extent of effects on important ecological resources.

\subsection{SOCIAL, ECONOMIC, AND CULTURAL RESOURCES}

Since the completion of the FPEIS, updated and additional data on community resources surrounding PUDA have been collected. Data on community resources are relevant for two purposes: (1) to identify populations and community resources that may be affected by a release of chemical agent and (2) to provide a baseline for estimating the socioeconomic impacts from population growth and other activities associated with the construction and incident-free operation of the disposal facility. The relevant study area for socioeconomic data collection during the Phase I process varies according to whether the resource potentially could be affected by an accident or by normal activities during construction and operation of the disposal facility.

Site-specific populations that have been characterized in greater detail since the FPEIS include the following: worker and resident populations located both on-post at PUDA and off-post; potentially sensitive populations (i.e., children and the elderly) by county of residence; transient populations, defined as concentrations of people visiting or gathering in the vicinity on an intermittent or irregular basis (e.g., crowds at recreational events and agrarian workers [see p. B-23]); and special and institutional populations, which include dayto-day concentrations of people with special needs who are dependent or require special attention in an emergency. There are no Indian reservations or settlements within $100 \mathrm{~km}$ (62 miles) of PUDA (EPA 1988). The FPEIS considers residential population to $100 \mathrm{~km}$ (62 miles) to estimate human fatalities. It does not consider daytime population, nonresidential data, or on-post population on a site-specific basis. Comprehensive data on daytime (i.e., place-of-work) population for the area surrounding PUDA are presently unavailable. In lieu of more detailed place-of-work data, large employers by county are identified in Appendix B. Large nearby concentrations of off-post daytime work population would consist of approximately 3000 people at the Pueblo Airport Industrial Park and 340 people at the Transportation Test Center due north of the depot. Four people who work as firefighters and guards are the only employees at the Transportation Test Center during the night shift. 
Figure 5.3 shows on-post work and residential population on PUDA. Normal working hours for PUDA employees are from 7:30 a.m. to 4:00 p.m. Nighttime on-post population consists of 35 security guards located over the entire installation, 8 firefighters located in the administrative area, 3 guard supervisors located in Building 54, and 60 military dependents located in the family housing area. Off-post guests or visitors are not quartered on-post. It is estimated that approximately 40 visitors and nonpermanently badged contractors or vendors enter the depot daily. Of the 60 on-post dependents residing in family housing, approximately 20 are at home during the day. Because data in the FPEIS consider human fatalities in the resident population to $100 \mathrm{~km}(62$ miles) for the continued storage alternative, the Phase I process has included data for off-post human resources for the region within $100-\mathrm{km}$ (62-mile) zone. Figure 1.3 shows the 15 counties that lie wholly or partially within $100-\mathrm{km}(62-\mathrm{mile})$ zone and the larger cities and towns in that area. The 5-km (3-mile) nodeaths distance determined for the on-site disposal alternative includes only one residence, located on a large ranch adjoining PUDA to the north, approximately 1.75 miles from the proposed disposal facility. The emergency planning zone, however, has been expanded to encompass an area of approximately $35 \mathrm{~km}$ ( 22 miles), which includes the city of Pueblo to the west and its northern and southern suburbs. A description of community resources potentially affected by an accidental release of chemical agent is provided in Appendix B. These resources include resident populations, potentially sensitive age groups, institutional and special populations, transient populations, and agricultural activities. Agricultural activities have been characterized with a focus on the economic value of land and products that might be affected as a result of a release of chemical agent. Because a continued storage accident could affect an area of $100 \mathrm{~km}$ (62 miles), data on agricultural activities and commodities are shown for the 100-km (62-mile) zone. These data are presented in Appendix B.

Appendix B also presents data on socioeconomic resources that are important for assessing potential impacts resulting from construction and incident-free operations. Project-induced population growth and the increased use of resources during the construction and operations phases of the project could affect employment, infrastructure, and the provision of public services in the immediate vicinity of PUDA. Based on the current locations of the residences of civilian employees at PUDA, the following approximate distribution of in-migrating population associated with the proposed disposal facility could be expected: Pueblo County, 90.0\%; Otero County, 3.0\%; Huerfano County, 1.5\%; Fremont County, 1.0\%; and other counties, $4.5 \%$. Collection of data related to construction and incident-free operations has focused primarily on Pueblo County because $90 \%$ of the potential workforce could be expected to locate there. These data, presented in Appendix B, include cultural, archaeological, and historic resources; employment and income; housing; transportation; and public services (schools, police and fire protection, and utilities). With the exception of the larger data base that extends beyond the $10-\mathrm{km}$ (6-mile) zone considered in the FPEIS, no unique resources were identified.

The cumulative social, economic, and cultural impacts from other projects in the PUDA area are not discussed in the FPEIS. Other than the realignment of PUDA, planned to be completed in June 1995 (U.S. Army 1991a), no other projects have been identified that would result in cumulative impacts. This issue will be addressed further in the site-specific EIS for PUDA. 


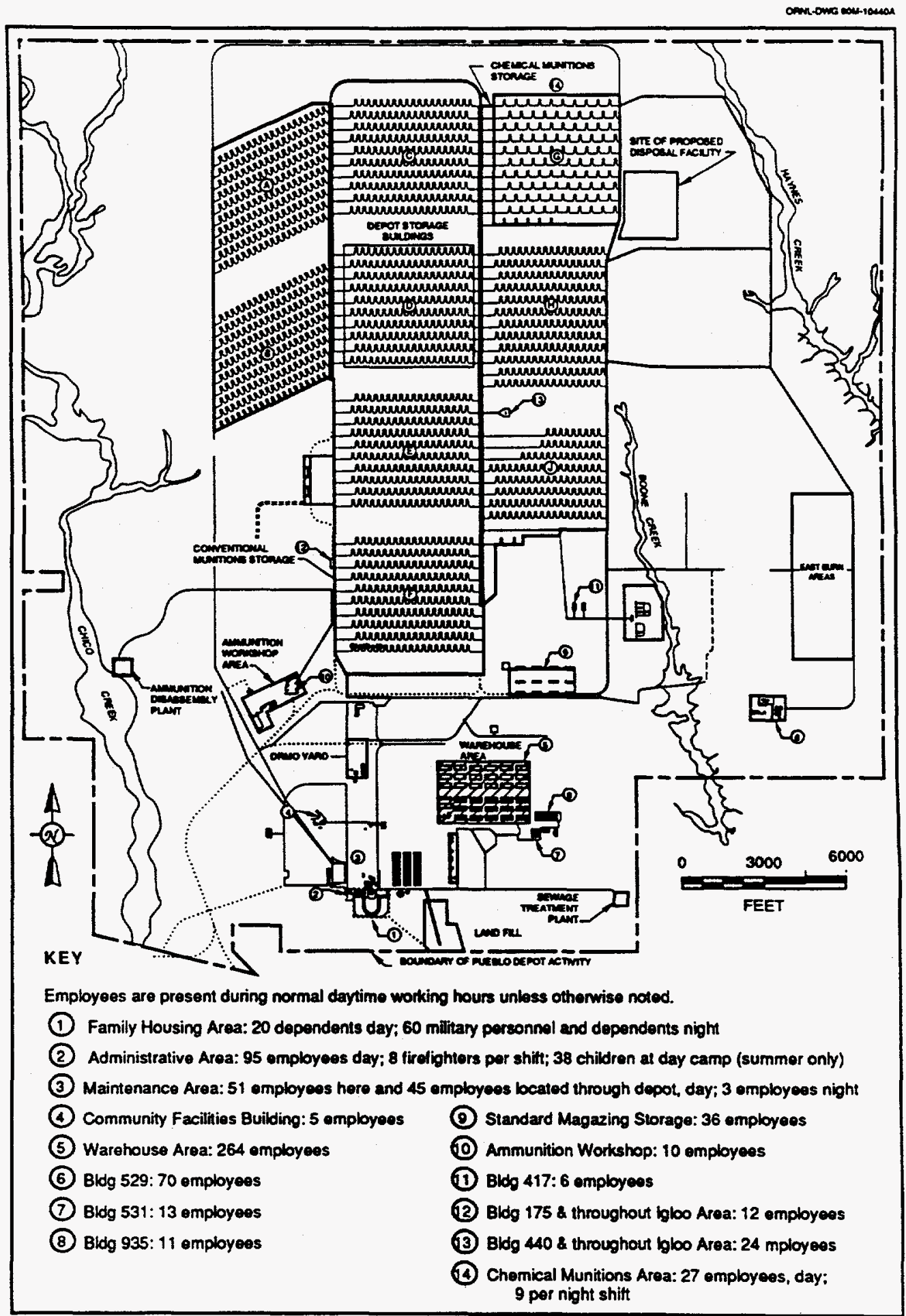

Fig. 53. On-post work and residential populations at Pueblo Depot Activity (PUDA). 


\subsection{AIRCRAFT ACTIVITY}

Information about aircraft activity in the FPEIS was taken from risk analyses by GA Technologies, Inc. (1987), judged against criteria set up by the NRC for risks to the nuclear industry from aircraft crashes. The NRC criteria for low probability of aircraft accidents at a site are met when the following conditions apply.

- The site-to-airport distance is between 5 and 10 statute miles, and the annual number of air operations is less than $\mathbf{5 0 0}$ times this distance (in miles) squared, or the site-to-airport distance is greater than 10 statute miles and the projected annual number of operations is less than 1000 times this distance (in miles) squared.

- The site is at least 5 statute miles from the edge of military training routes.

- The site is at least 2 statute miles from the nearest edge of a federal airway, holding pattern, or approach pattern.

A survey of a recent Flight Information Publication (NOS 1990) for the area around PUDA found low altitude federal airways V10-244, V81, V19-83-593, and V389 passing within a few kilometers of the installation. The addition of V593, which is concurrent with airways V19 and V83 is the only difference in low altitude federal airways noted between the data presented in the FPEIS and the present report. All of these airways pass through the Pueblo Memorial Airport airspace. In addition, high altitude jet routes J17 and J28 (noted in the FPEIS) pass through the airport airspace.

Military training route IR415/VR412 passes southwest of the installation at a distance of about $30 \mathrm{~km}$ ( 19 miles). There is no other military training route, military operations area, or restricted area nearby. The closest is restricted area $R-2601$, about $40 \mathrm{~km}$ ( 25 miles) distant.

A comparison of 1986 and 1988 air traffic activity at the Pueblo Memorial Airport shows a somewhat downward trend in air activity, as is evident from Table 5.4. 
Table 5.4. Comparison of 1986 and 1988 air traffic activity at Pueblo Memorial Airport

\begin{tabular}{|c|c|c|c|}
\hline Activity & 1986 & 1988 & $\%$ change \\
\hline \multicolumn{4}{|c|}{ Local operations } \\
\hline General aviation & 28,837 & 23,227 & \\
\hline Military & 17.414 & 16,780 & \\
\hline Total & $\overline{45,251}$ & 40,007 & -13.5 \\
\hline \multicolumn{4}{|c|}{ Primary operations } \\
\hline Air carrier & 1,728 & 2,331 & \\
\hline Air taxi & 1,335 & 1,365 & \\
\hline General aviation & 12,516 & 13,850 & \\
\hline Military & 7,891 & 7,688 & \\
\hline Total & 23,470 & 25,234 & +7.5 \\
\hline \multicolumn{4}{|c|}{ Instrument approaches } \\
\hline Air carrier & 45 & 64 & \\
\hline Air taxi & 131 & 83 & \\
\hline General aviation & 454 & 273 & \\
\hline Military & 192 & 223 & \\
\hline Total & 822 & 643 & -21.8 \\
\hline
\end{tabular}

Source: Federal Aviation Administration (FAA) 1986. FAA Air Traffic Activity, Fiscal Year 1986, U.S. Government Printing Office, Washington, D.C., FAA 1988. FAA Air Traffic Activity, Fiscal Year 1988, U.S. Government Printing Office, Washington, D.C. 


\section{RE-EXAMINING ON-SITE DISPOSAL AS THE ENVIRONMENTALLY PREFERRED ALTERNATIVE}

This section deals with reexamining on-site disposal as the environmentally preferred alternative at PUDA using recent and more detailed data than those used in the FPEIS to identify the environmentally preferred alternative. Identification of the environmentally preferred alternative was based on a risk analysis for accident conditions. As discussed in Section 2, the two types of data germane to the selection process are population and the accident database. Population data are concerned with the number and location of people in the vicinity of PUDA. The accident data are concerned with the probabilities and agent release quantities of various hypothetical accidents associated with each alternative; the probabilities and release quantities can in turn be thought of as being affected by external factors (e.g., meteorology, earthquakes, meteorites, etc.) and internal factors (technology, procedures, and facility location). This section examines accident database and population information collected during Phase I for its potential to affect on-site disposal at PUDA. Using those data that have appreciable potential to preferentially affect a given risk measure for a given alternative, this section then reevaluates the risk measures with the new data for the three alternatives applicable to Phase I. Last, the new risk measures are used in the FPEIS method for identifying the environmentally preferred alternative to determine if on-site disposal is still preferred for PUDA.

\subsection{NEW VALUES FOR PROGRAMMATIC DATA AND ASSUMPTIONS AND THEIR SIGNIFICANCE}

\subsubsection{Accident Database}

As discussed in Sect. 2, of the two major types of data that affect the accident database (internal and external), most of the focus in this Phase I report is directed toward the external data because they represent factors over which the Army has little or no control. Internal data, however, reflect factors over which the Army does have control. This section discusses those factors that could have changed from the assumptions in the FPEIS: on-site transportation (as determined from the location of the proposed on-site disposal facility as compared to the location of the existing storage area), meteorological factors, earthquakes (seismicity), aircraft activity, tornadoes, and meteorite strikes, as discussed below.

\subsubsection{On-site transportation}

As discussed in the FPEIS, the risks of on-site transport of agents and munitions are related to accidents that could occur during movement of agents and munitions from storage to the designated disposal facility (whether it is an on-site facility or an off-site facility). The potential risk from an on-site transportation accident is dependent upon a number of factors, 
including road conditions, vehicle speed on the roads, distance travelled, the types and numbers of agents and munitions to be transported, and whether or not the on-site transportation is associated with on-site or off-site disposal. For this Phase I Report, on-site transportation is relevant to the on-site disposal and national disposal alternatives; the risks from continued storage would be unaffected by any changes in parameters affecting transportation risk. The FPEIS risks to the population near PUDA for the regional disposal alternative were identical to those from national disposal.

The FPEIS assumed that all on-site transportation (for on-site, as well as off-site, disposal) at all sites involved a distance of $1.6 \mathrm{~km}$ (1 mile). On-site transportation was assumed to be restricted to a maximum speed limit of $32 \mathrm{~km} / \mathrm{hr}(20 \mathrm{mph})$ during daylight hours and was assumed to occur only under suitable weather conditions (see Section 2.3.2.2.1 of the FPEIS). The condition of the existing roads at PUDA, subsequent to proposed upgrades, are comparable to the road conditions assumed in the FPEIS risk analysis. Factors, other than on-site travel distances, that can be controlled by the Army are incorporated into the standard operating procedures for on-site movement of agents and munitions and, thus, will not be addressed further in this report. Thus, the key factor of interest with respect to transportation risks at PUDA is the on-site transport distances.

Transportation distances are dependent on the actual roads to be used in moving agents and munitions during on-site disposal and during on-site activities associated with offsite disposal (i.e., national or regional disposal). As shown in Fig. 5.3, the site of the proposed disposal facility is located about $1.6 \mathrm{~km}$ (1 mile) south of the northern PUDA installation boundary and is adjacent to the eastern border of the chemical agent storage area. The actual road distance from the storage area to the site of the proposed disposal facility ranges from $0.2 \mathrm{~km}$ to $2.6 \mathrm{~km}$ ( 0.1 mile to 1.6 miles), based upon the locations of the storage igloos located the closest and the most distant from the site. The average road distance using these two values is $1.4 \mathrm{~km}(0.9$ mile $)$-slightly less than the distance assumed in the FPEIS.

For the off-site disposal alternatives assumed in the FPEIS for PUDA, the chemical agents and munitions would be removed from storage and transported to a central, on-site loading area where they would be prepared for off-site transport. The site of such an area for PUDA has not been identified. However, many of the siting criteria used to locate the proposed disposal facility would also be used to locate the central loading area. Consequently, it is concluded that if off-site disposal were selected for the PUDA stockpile, the central loading facility would be located either at the site of the proposed disposal facility or at a location whose distance from the storage area would not appreciably differ from the distance between the storage area and the proposed disposal facility.

It is therefore concluded that there is no potential for on-site transportation differences between the FPEIS and Phase I to preferentially affect risk for the alternatives under consideration. The recomputation of on-site transportation risk is unwarranted, and this area will not be addressed further in this report.

\subsubsection{Meteorology}

The principal type of meteorological data of interest to the identification of the environmentally preferred alternative is the applicability of the meteorological conditions assumed in the FPEIS. The parameters involved are wind speed, atmospheric stability, and 
height of the mixed layer, or mixing height. Tornadoes are discussed in a separate section in conjunction with meteorites.

Meteorological data for PUDA were examined to evaluate the appropriateness of the "conservative most likely" (CML) and "worst case" (WC) meteorological conditions chosen in the FPEIS. The CML scenario represents a frequently occurring meteorological condition that results in relatively large doses compared with other frequently occurring conditions. Specifically, neutral atmospheric stability (Class D) with a wind speed of $3 \mathrm{~m} / \mathrm{s}(6.6 \mathrm{mph})$ (also referred to as the $D, 3$ scenario) was selected for the CML condition. The WC scenario represents a credible condition that results in near-maximum doses. Specifically, a stable atmosphere (Class E) with a wind speed of $1 \mathrm{~m} / \mathrm{s}(2.2 \mathrm{mph})$ was chosen for the WC condition.

To evaluate the appropriateness of these two meteorological conditions for PUDA, it is necessary to obtain accurate measurements of wind velocity and to derive accurate stabilities. On-site meteorological data were not used in this analysis because the quality of those data has not been established. Mixing height, atmospheric stability and wind speed are features that are largely determined by the time of day and the large scale weather pattern in the region; therefore, measurements of these features at the Pueblo Memorial Airport are generally representative of conditions at PUDA.

Digitized surface data from Pueblo Memorial Airport are available for the 5-year

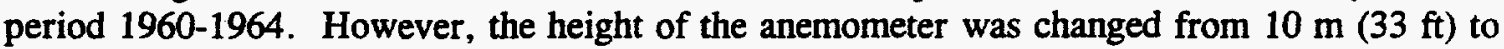
$6.7 \mathrm{~m}$ (22 ft) during 1962. The anemometer has since been at the lower height. To be consistent with the current position of the anemometer, data from the period 1963-64 were used. These data should be representative of current conditions because the surrounding area has been relatively free of large construction projects, urban encroachment, etc. that would have changed the microclimate since the mid-1960s. Even if there had been major changes in the microenvironment since 1965 , it would be logical to use the earlier data set because it would be more likely to describe natural background conditions in the area, which are similar to those around PUDA.

The joint frequency distribution of stabilities and wind speed classes (Table 6.1) was constructed to determine the applicability to PUDA of the CML and WC meteorological conditions selected in the FPEIS. This particular distribution was examined because it depicts the frequency of occurrence of conditions that are nearly identical to the selected CML and WC conditions, as well as to other stability and wind speed conditions. This distribution indicated that neutral stability (class D) occurs more often ( $44 \%$ of the time) than any of the other classes, and the subcategory of D stability with winds between 2.1 and $3.6 \mathrm{~m} / \mathrm{s}(4.7$ and $8.1 \mathrm{miles} / \mathrm{hr}$ ) occurs more than $6 \%$ of the time. Two categories of higher wind speeds occur more frequently with $D$ stability. However, the $D, 3$ scenario is more conservative than the other D categories that would occur with comparable frequency. Furthermore, after rescaling to account for the unequal width of the wind speed classes, the category including the $D, 3$ scenario occurs at least $80 \%$ as frequently as any of the less conservative D categories.

With regard to WC conditions, although maximum predicted doses result from class F stability with low wind speeds and F stability occurs about $14 \%$ of the time at PUDA, F stability was intentionally not used for the WC scenario because predicted doses are greater than doses realistically expected in a credible scenario. During F stability, a puff or plume follows a meandering path rather than moving downwind in a straight line; therefore, actual 
Table 6.1. Joint frequency distribution (in percent) of stability and wind speed for the Pueblo Depot Activity

\begin{tabular}{|c|c|c|c|c|c|c|c|}
\hline \multirow{2}{*}{$\begin{array}{l}\text { Stability } \\
\text { class }\end{array}$} & \multicolumn{7}{|c|}{ Wind speed $(\mathrm{m} / \mathrm{s})^{2}$} \\
\hline & 0 to 2.1 & 2.1 to 3.6 & 3.6 to 5.7 & 5.7 to 8.7 & 8.7 to 10.8 & above 10.8 & Total \\
\hline A & 0.6 & 0.2 & 0.0 & 0.0 & 0.0 & 0.0 & 0.8 \\
\hline $\mathbf{B}$ & 3.5 & 3.5 & 0.9 & 0.1 & 0.0 & 0.0 & 8.0 \\
\hline C & 2.9 & 3.8 & 5.8 & 1.5 & 0.3 & 0.2 & 14.5 \\
\hline D & 3.2 & 6.3 & 10.1 & 14.6 & 5.2 & 4.7 & 44.1 \\
\hline $\mathrm{E}$ & 2.8 & 7.3 & 7.9 & 0.3 & 0.1 & 0.0 & 18.4 \\
\hline $\mathrm{F}$ & 5.8 & 8.0 & 0.3 & 0.1 & 0.0 & 0.0 & 14.2 \\
\hline Total & 18.8 & 29.1 & 25.0 & 16.6 & 5.6 & 4.9 & 100.0 \\
\hline
\end{tabular}

"Multiply by 2.237 to convert to miles per hour.

Source: Wind data measured at the Pueblo Memorial Airport, located $16 \mathrm{~km}$ (10 miles) west-southwest of the existing storage area, $6.7 \mathrm{~m}$ ( $22 \mathrm{ft}$ ) above ground level; January 1 , 1963 through December 31, 1964. 
maximum doses at given locations would be reduced compared with predicted doses that assume continuous exposure along a centerline downwind axis. Class E stability with low wind speeds produces the next highest predicted doses, and the meandering of the plume is less pronounced for $E$ stability. Therefore, E stability with low wind speeds was selected as the WC scenario. Class E stability with winds less than $2.1 \mathrm{~m} / \mathrm{s}(4.7 \mathrm{miles} / \mathrm{hr})$ occurs approximately $3 \%$ of the time. Based on these results it is concluded that the CML and WC meteorological conditions used in the FPEIS are appropriate to PUDA.

The height of the mixed layer is another important meteorological factor affecting dispersion. Lowering of that height tends to decrease the volume of atmosphere available for dispersion of pollutants, thereby potentially increasing the concentrations of pollutant in the atmosphere. Data on the height of the mixed layer at the PUDA site are not available because of lack of upper air data specifically at that site. The best available estimates of mixing heights are calculated using a combination of National Weather Service surface data from Pueblo Memorial Airport, about $16 \mathrm{~km}$ (10 miles) west-southwest of PUDA, and upper-air data collected at Stapleton Airport at Denver, Colorado, about $165 \mathrm{~km}$ (103 miles) north-northwest of PUDA. Stapleton Airport is the nearest station to PUDA with the necessary upper-air data. Because Denver and Pueblo are both located at the western edge of the high plains and are about the same distance from the mountain ranges to the west, the height of the mixed layer at Denver should be representative of PUDA.

The FPEIS used a value of $750 \mathrm{~m}(2,461 \mathrm{ft})$ for accidental-release scenarios. An examination of morning and afternoon mixing heights by season (Holzworth 1972) for Denver reveals that mean morning mixing heights range from $174 \mathrm{~m}(571 \mathrm{ft})$ in the autumn to $423 \mathrm{~m}$ $(1,388 \mathrm{ft})$ in the spring, and mean afternoon mixing heights range from $1,482 \mathrm{~m}(4,862 \mathrm{ft})$ in the winter to $3,458 \mathrm{~m}(11,346 \mathrm{ft})$ in the summer. It should be noted that the mean morning mixing heights are lowered considerably by ground-level inversions during stable conditions and usually would be higher for the CML scenario of neutral atmospheric stability. For the WC scenario, the height of the mixed layer is not of concern because it is unlikely that more intense stable conditions would occur above the surface inversion that causes the stable conditions. Therefore, based on mean values reported by Holzworth, the selection of a height of $750 \mathrm{~m}(2641 \mathrm{ft})$ is appropriate for PUDA.

However, simulations have now been run using mixing heights down to $150 \mathrm{~m}$ (495 ft). Changes in results producing the largest percentage increases were about $70 \%$ in the distance to $1 \%$ lethality for a large release and in the distance to no effects for an intermediate

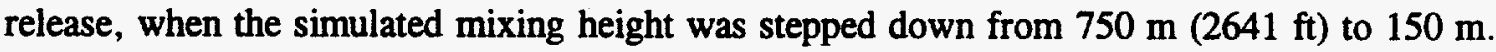
An increase of about $60 \%$ in the distance to no deaths resulted for a similar decrease in simulated mixing height. All other results changed by less than $10 \%$ when the simulated mixing height was lowered to $150 \mathrm{~m}(495 \mathrm{ft})$. When the mixing height was lowered from $750 \mathrm{~m}(2461 \mathrm{ft})$ to $350 \mathrm{~m}(1148 \mathrm{ft})$, the changes in results were always less than $25 \%$. Therefore, the results of these more conservative calculations would not appreciably change any of the conclusions or risk factors arrived at in the FPEIS.

\subsubsection{Seismicity}

Seismic information played a role in the FPEIS risk assessment through the consideration and evaluation of accidents initiated by seismic activity. This section presents 
the highlights of any new seismic information germane to the risk assessment conducted for the FPEIS. Additional detailed seismic information on the potential for surface rupture, deterministic risk analysis, the potential for liquefaction, and the potential for ground motion magnification is presented in Appendix F of this Phase I Report.

Seismic risk analysis in the FPEIS was based on probabilistic earthquake data provided by the Applied Technology Council (ATC 1978) and the assumption that important structures would be clones of facilities at TEAD. According to ATC, an effective peak ground acceleration (EPGA) equal to $0.05 \mathrm{~g}$ [corresponding to modified Mercalli intensity $\left(\mathrm{I}_{\mathrm{mm}}\right)$ of $\mathrm{V}$ to VI has a $10 \%$ probability of exceeding at least once in 50 years at PUDA. Probabilities of exceeding larger design EPGAs [0.20g and $0.81 \mathrm{~g}$ for the munitions demilitarization building (MDB) and toxic cubicle (TOX), respectively], were extrapolated from data provided by ATC and used in the FPEIS risk assessment (see Appendix F). The annual probabilities of exceeding an EPGA of $0.20 \mathrm{~g}$ and $0.81 \mathrm{~g}$ at PUDA are $7 \times 10^{-5}$ and $1 \times 10^{-6}$ such events per year for the MDB and TOX, respectively. Accidents involving the TOX were screened out of the FPEIS risk analysis on the basis of a very low probability of severe earthquake occurrence combined with failure of the TOX (less than one chance in one billion, annually).

Based on currently available data, the seismic risk for MDB and TOX at PUDA remain unchanged from the FPEIS. FEMA's 1988 seismic risk map is identical to that of ATC 1978 (which was used for the FPEIS). Both are based on a seismic risk analysis conducted by Algermissen and Perkins (1976), which provided ground motion estimates for sites on rock foundations. More recent analyses by Algermissen et al. (1982 and 1990) show no significant differences in seismic risk for PUDA. A site-specific seismic risk analysis has not been done for PUDA, and no nearby site-specific data are available for use as a surrogate for PUDA based on data provided by EPRI (1988) and Bernreuter et al. (1989).

Both the 1985 and 1988 Uniform Building Code (UBC) seismic zone maps are presented in Appendix F. PUDA is located in seismic zone 1 of both the 1985 and 1988 UBCs that predict the minor earthquake damage (corresponding to $\mathrm{I}_{\operatorname{mm}}=\mathrm{V}$ or VI; $0.05 \mathrm{~g}<\mathrm{PGA}<0.10 \mathrm{~g}$ ) with a $10 \%$ probability of exceedance at least once in 50 years. Based on current information, all but one of the most important structures at PUDA are cloned from facilities at TEAD. The majority of both TEAD and PUDA facilities are designed to meet 1985 UBC standards for seismic zone 3 (despite PUDA's location in seismic zone 1 of the 1985 UBC). The 1985 UBC standards are more stringent than those of the 1988 UBC for seismic zone 3 (Appendix F). The TOX at PUDA is also a clone of the TOX at TEAD, which is designed to shutdown safely during a maximum expected earthquake at TEAD. The maximum expected earthquake at TEAD is larger than the maximum expected earthquake at PUDA (Appendix F). The seismic design standard for the TOX at TEAD is similar to Nuclear Regulatory Commission (NRC) design standards for nuclear power reactors, and the TOX at PUDA exceeds NRC standards.

The container handling building (CHB) at PUDA is not cloned from the CHB at TEAD. The CHB at PUDA is designed to meet 1988 UBC standards for seismic zone 2B rather than seismic zone 3 as at TEAD. The 1988 UBC standards for seismic zone $2 B$ are more stringent than the 1985 UBC standards for seismic zone 2 (Appendix F). 


\subsubsection{Aircraft activity}

A review of current aircraft activities near PUDA compared with the information reported in the FPEIS indicates that:

- The airspace at PUDA is now restricted.

- A private airport, Youtsey, still exists less than $5 \mathrm{~km}$ south of the depot.

- The closest public airport is Pueblo Memorial Airport, located about $10 \mathrm{~km}$ west of the depot boundary.

- Low-altitude federal airways V10-244, V81, V19-83-593, and V389 pass within a few kilometers of the installation. V593, which is concurrent with V19 and V83, has been added since issuance of the FPEIS.

- High-altitude jet routes J17 and J28 still pass through the Pueblo airport airspace.

- No military training routes, military operations areas, or restricted airspace have been added in the vicinity.

V593 has been added and the annual number of aircraft operations at the Pueblo Memorial Airport (Section 5.6) has changed since the FPEIS. These are the only differences noted between the FPEIS and the present conditions. Neither of these changes would warrant reevaluation of risk.

\subsubsection{Meteorites/tornadoes}

Data used in the FPEIS for expected frequencies of meteorite strikes in the PUDA vicinity are contained in Appendix A (Table A.1). These data were examined and found to be reasonable. No more recent or detailed data on meteorite strikes beyond those in the FPEIS were located.

Tornado data used in the FPEIS were taken from Thom (1963). More recent data reported by Kelly et al. (1978) were examined during Phase I. No significant differences in tornado probabilities used in the FPEIS for PUDA (see Appendix A) were identified. Note that Kelly et al. (1978) is based on 27 years of data, whereas Thom (1963) is based on 10 years of data.

\subsubsection{Population}

The FPEIS presented residential population as of the 1980 census by radial sector and distance out to $100 \mathrm{~km}$ (62 miles), as shown in Table 6.2 (U.S. Army 1988a). The FPEIS method for identifying the environmentally preferred alternative is based on residential population only, and does not include place-of-work or on-post populations. Because the 1980 census data will be over 10 years old by the time construction and operation of the proposed disposal facility begin at PUDA, the latest population estimates (i.e., for 1986) have been used to adjust the 1980 census data. Population estimates in noncensus years are limited to estimates of county populations and populations within incorporated areas. A two-step process was used in this assessment for each potentially impacted county to estimate the 
Table 6.2. Residential population distribution around the proposed disposal facility site at the Pueblo Depot Activity as given in the Final

Programmatic Environmental Impact Statement

\begin{tabular}{|c|c|c|c|c|c|c|c|c|}
\hline \multirow{2}{*}{ Direction } & \multicolumn{8}{|c|}{ Incremental population data at specified distances $(\mathrm{km})^{a}$} \\
\hline & $0-1$ & $1-2$ & $2-5$ & $5-10$ & $10-20$ & $20-35$ & $35-50$ & $50-100$ \\
\hline $\mathbf{N}$ & 0 & 0 & 0 & 0 & 7 & 60 & 432 & 2,299 \\
\hline NNE & 0 & 0 & 0 & 0 & 5 & 35 & 55 & 1,087 \\
\hline NE & 0 & 0 & 0 & 0 & 5 & 34 & 80 & 413 \\
\hline ENE & 0 & 0 & 0 & 0 & 12 & 21 & 30 & 235 \\
\hline $\mathrm{E}$ & 0 & 0 & 1 & 5 & 28 & 41 & 394 & 391 \\
\hline ESE & 0 & 0 & 2 & 14 & 78 & 242 & 1,672 & 20,544 \\
\hline SE & 0 & 0 & 2 & 21 & 110 & 641 & 1,857 & 1,933 \\
\hline SSE & 0 & 0 & 2 & 15 & 76 & 140 & 439 & 159 \\
\hline$S$ & 0 & 0 & 2 & 2 & 89 & 27 & 51 & 99 \\
\hline SSW & 0 & 1 & 4 & 18 & 1,076 & 170 & 13 & 4,361 \\
\hline SW & 0 & 1 & 8 & 66 & 1,187 & 1,771 & 1,189 & 2,669 \\
\hline WSW & 0 & 1 & 11 & 69 & 2,142 & 97,158 & 2,017 & 1,844 \\
\hline W & 0 & 1 & 15 & 63 & 349 & 10,147 & 1,657 & 24,839 \\
\hline WNW & 0 & 1 & 10 & 56 & 51 & 33 & 89 & 3,516 \\
\hline NW & 0 & 1 & 4 & 17 & 24 & 17 & 1,695 & 223,994 \\
\hline NNW & 0 & 0 & 1 & 0 & 7 & 37 & 251 & 77,999 \\
\hline Incremental Total & $\overline{0}$ & $\overline{6}$ & $\overline{62}$ & $\overline{346}$ & $\overline{5,246}$ & $\overline{110,574}$ & $\overline{11,921}$ & 366,382 \\
\hline Cumulative Total & 0 & 6 & 68 & 414 & 5,660 & 116,234 & 128,155 & 494,537 \\
\hline
\end{tabular}

Multiply by 0.6214 to obtain miles.

Source: U.S. Department of Commerce, Bureau of the Census, County and City Data Book; U.S. Government Printing Office, Washington, D.C., 1983.

Note: The location used for the center of the above population is at $38^{\circ}, 20 \mathrm{~min}, 34 \mathrm{~s}$ north latitude and $104^{\circ}, 18 \mathrm{~min}$, $2 \mathrm{~s}$ west longitude.

population change at the enumeration district level. First, the estimated population changes for incorporated areas were equally apportioned among enumeration districts comprising the named area. Second, the unaccounted-for change in county population was equally apportioned among enumeration districts comprising the unincorporated areas.

As in the FPEIS, these population estimates were assigned to a grid. Whereas the estimates used in the FPEIS considered only population and enumeration district location in creating the grid-based population, the Phase I method excludes population from areas that are clearly not residential (e.g., within the PUDA installation boundary and in the Arkansas River).

The effect of using this exclusion information is to create population distributions with larger concentrations of population than were in the FPEIS. However, these concentrated 
population areas are now accompanied by completely unpopulated areas that had small, but nonzero, populations in the FPEIS.

The revised residential population data are presented in Table 6.3 in the same format used in the FPEIS. The effect of including the 1986 population estimates is to increase the total population within the $100-\mathrm{km}$ ( 62 mile) zone by $2 \%$. It is estimated that 10,182 additional people are located in the potentially impacted $100-\mathrm{km}$ zone around PUDA compared with the population in that zone as described in the FPEIS. The data collected during Phase I show that no off-post residents are located within about $2.8 \mathrm{~km}$ (1.8 miles) of the proposed disposal facilities at PUDA. This is reflected in Table 6.3 under the $0-$ to $1-\mathrm{km}$ and $1-$ to $2-\mathrm{km}$ headings. The FPEIS assumed persons lived as close as $500 \mathrm{~m}(1500 \mathrm{ft})$ to the proposed PUDA disposal facility.

Even though the relative change in residential population is not large, it does warrant reexamination of the FPEIS measures of risk for two reasons: (1) the absolute number of people affected is important, regardless of percentages, when dealing with potential fatalities, and (2) the relocation of the population resulting from use of the actual boundary of PUDA could affect the FPEIS measures of risk in a beneficial way because the number of accident scenarios may decrease.

An examination of the accident database for PUDA shows that at least $70 \%$ of the total number of accidents at PUDA would cause no fatalities beyond distances of $3.1 \mathrm{~km}$ ( 2 miles) from the point of release. Accurately excluding off-post, residential population within this distance could thus have a significant effect on reducing the magnitudes of some of the FPEIS measures of risk for PUDA. Also, the effects of the new population data on the risk measures for the three alternatives being addressed are not clear and warrant closer examination.

\subsubsection{Summary}

Evaluation of data collected during Phase I for PUDA indicates that in terms of information used to develop the five FPEIS measures of risk, only the new residential population data recalculation of risk. The accident database did not undergo sufficient change to be factored into computation of risk and thus is not further considered in this Phase I

Environmental Report. The use of actual on-site transportation distances at PUDA has little, if any, potential to increase the probability of a transportation-related accident above that presented in the FPEIS. Thus, on-site transport is not examined further in this report. Similarly, because no new aircraft activity data for the region near PUDA were located during Phase I, aircraft activity is not examined further in this report.

\subsection{EVALUATING MEASURES OF RISK WITH DATA COLLECTED DURING PHASE I}

As discussed in Section 2, comparison of FPEIS and Phase I data is used as a screening tool to identify those factors that should be incorporated into a recalculation of the 
Table 6.3. Residential population distribution around the proposed disposal facility site at the Pueblo Depot

Activity using data collected during Phase I

\begin{tabular}{|c|c|c|c|c|c|c|c|c|}
\hline \multirow{2}{*}{ Direction } & \multicolumn{8}{|c|}{ Incremental population data at specified distances $(\mathrm{km})^{a}$} \\
\hline & $0-1$ & $1-2$ & $2-5$ & $5-10$ & $10-20$ & $20-35$ & $35-50$ & $50-100$ \\
\hline $\mathbf{N}$ & 0 & 0 & 2 & 0 & 2 & 76 & 394 & 2,414 \\
\hline NNE & 0 & 0 & 1 & 3 & 23 & 47 & 60 & 1,182 \\
\hline $\mathrm{NE}$ & 0 & 0 & 1 & 6 & 24 & 47 & 87 & 427 \\
\hline ENE & 0 & 0 & 1 & 6 & 29 & 18 & 30 & 231 \\
\hline E & 0 & 0 & 2 & 10 & 45 & 34 & 926 & 689 \\
\hline ESE & 0 & 0 & 5 & 32 & 86 & 278 & 2,094 & 20,821 \\
\hline SE & $\mathbf{0}$ & 0 & 4 & 31 & 106 & 691 & 1,889 & 1,957 \\
\hline SSE & 0 & 0 & 0 & 16 & 82 & 162 & 503 & 166 \\
\hline $\mathbf{S}$ & 0 & $\mathbf{0}$ & 0 & 5 & 80 & 34 & 63 & 69 \\
\hline SSW & 0 & 0 & 0 & 8 & 1,049 & 172 & 78 & 4,699 \\
\hline sW & 0 & 0 & 0 & 36 & 1,564 & 1,450 & 208 & 2,954 \\
\hline wSW & 0 & 0 & 0 & 49 & 468 & 100,876 & 2,232 & 2,011 \\
\hline w & $\mathbf{0}$ & 0 & 0 & 127 & 688 & 15,214 & 1,910 & 25,237 \\
\hline WNW & 0 & 0 & 0 & 12 & 8 & 35 & 60 & 4,144 \\
\hline NW & 0 & 0 & 1 & 4 & 20 & 27 & 1,165 & 229,057 \\
\hline NNW & 0 & $\underline{0}$ & 2 & 0 & 11 & 46 & 276 & 72,830 \\
\hline Incremental Total & 0 & 0 & 19 & 345 & 4,285 & 119,208 & 11,975 & 368,890 \\
\hline Cumulative Total & 0 & 0 & 19 & 364 & 4,649 & 123,857 & 135,832 & 504,722 \\
\hline
\end{tabular}

"Multiply by 0.6214 to obtain miles.

Source: U.S. Department of Commerce, U.S. Bureau of the Census, Current Population Reports, Series T-26, 86-No. 86-NW, 1986 and 1985 Per Capita Income Estimates for Counties and Incorporated Places, U.S. Government Printing Office, Washington, D.C., 1988.

Note: The location used for the center of the above population is at $38^{\circ}, 20 \mathrm{~min}, 34 \mathrm{~s}$ north latitude and $104^{\circ}, 18 \mathrm{~min}^{\circ}$ 29 s west longitude.

FPEIS measures of risk. Recomputing the five measures of risk with the data collected during Phase I and evaluating the results using the FPEIS decision method allow an evaluation of the suitability of on-site disposal at PUDA.

As discussed in Section 6.1.3, changes in population data were found to be large enough to warrant reestimation of fatalities and recomputation of the five measures of risk. To maintain consistency with the FPEIS, only residential population is considered. On-post population data have been gathered for use in the PUDA EIS and are presented in Section 5.5. All population data will be considered in estimating potential fatalities for the sitespecific EIS.

\subsubsection{Approach}

As discussed in Section 2, the reexamination of the FPEIS environmentally preferred alternative in this Phase I Report is largely based on the evaluation and comparison of human 
health risks. Two major components of this comparative analysis are population data and atmospheric dispersion modeling.

The choice of an atmospheric dispersion model in the FPEIS was limited by the nature of the accidentally released chemical agents and the complexity of the disposal program. One requirement of the model or models selected for use in estimating environmental impacts was to calculate the downwind doses from agents emitted to the atmosphere from accidents (e.g., spills of liquid agent, detonation of munitions, and vapor releases from fires). In addition, the model was required to analyze the effects of thousands of potential releases under various meteorological conditions.

The atmospheric dispersion model D2PC, developed by the U.S. Army's Chemical Research, Development and Engineering Center (Whitacre et al. 1986), was used to assess the potential impacts of the proposed action and alternatives in the FPEIS. The D2PC model assumes a Gaussian distribution of agent in the vertical and cross-wind directions as the agent disperses downwind. This assumption has been documented extensively in the literature and is used by a multitude of current models. Although more sophisticated dispersion codes are available, the assumption of straight-line downwind transport of chemical agent with unvarying meteorological conditions results in conservative estimates (i.e., overpredictions) of the effects of releases. A specific point of release was not identified in the D2PC analyses, but instead a generic location was used. This assumption was made due to the number of potential release sites at each facility as well as the potential for release during the transportation alternatives analyzed. Therefore, identical downwind distances were obtained for identical accidents for all alternatives. This simple approach, while inappropriate for estimating the impacts of any given release under real-time conditions, is appropriate for analyzing and comparing the potential effects of the many postulated accidental releases.

To ensure consistency between the FPEIS and the site-specific environmental impact statements (EISs), and to allow direct risk comparisons among the site-specific and programmatic documents, the same model (D2PC) is used in this Phase I report. Use of a model other than D2PC could result in a risk estimate different than that in the FPEIS solely because of the new model and not because of any significant changes in facility design or the incorporation of site-specific data into the assessment.

The first step in evaluating the measures of risk is to compute the estimated maximum fatalities, as well as the average fatalities, for a finite set of accidental releases. These accidental releases have been placed into distance categories, as used in the FPEIS, corresponding to downwind no-deaths distances of $1,2,5,10,20,50$, and $100 \mathrm{~km}$, respectively (see Appendix A for a more detailed discussion). For each distance category, average fatalities are computed by calculating the mean number of fatalities among 360 plumes of chemical agent atmospherically dispersed by an accidental release. The "maximum number of fatalities" measure of risk is taken to be the largest number of fatalities from among all of these 360 plumes. Each plume is directed radially away from the site of the proposed disposal facility and is aimed at a particular point of the compass-beginning at due east. Thus, for each distance category there are 360 such plumes with each plume directed one compass degree differently from the next. Overlaying the updated population with plumes resulting from the same assumed meteorological conditions (i.e., CML and WC) used in the FPEIS (see Appendix A, Fig. A.3) gives new fatality estimates for accidental releases of agent. 


\subsubsection{Results}

The revised fatality estimates for PUDA are presented in Table 6.4. For comparison, Table 6.4 repeats the original PUDA fatality estimates from the FPEIS (U.S. Army 1988a, Vol. 1, Table 4.3.27). One major difference between the revised estimates and the FPEIS fatality estimates is that the number of fatalities for accident distance categories of $2 \mathrm{~km}$ (1.2 miles) or less drops to zero because, contrary to what was assumed in the FPEIS, there is actually no off-post residential population closer than about $2.8 \mathrm{~km}$ (1.8 miles) to the site of the proposed disposal facility. The data in Table 6.4 indicate that for distance categories larger than $20 \mathrm{~km}$ (12 miles), the fatality estimates based on the new residential population data are larger than those in the FPEIS. This increase is due to the increased population since the 1980 census and to the consideration of the population exclusion areas (e.g., the PUDA installation boundary and the Arkansas River).

The greatest percentage increase in estimated potential maximum fatalities is in the 50-km (31-mile) category, in which the estimate increases $11 \%$ (from 6300 in the FPEIS to 7020 in Phase I). The largest numerical increase is 720 persons, also in the $50-\mathrm{km}$ (31-mile) category.

The fatality estimates given in Table 6.4 were then used to compute each of the five measures of risk for on-site disposal, continued storage, and on-site activities associated with off-site transport. Fig. 6.1 shows the revised risk pictogram (part B) along with values from the original FPEIS pictogram (part A) (U.S. Army 1988a, Vol. 1, Fig. 4.3.8) for comparison. Because this Phase I report is concerned with differences in site-specific data from those in the FPEIS, the only alternatives included in Fig. 6.1 are continued storage, onsite disposal, and national disposal (the original FPEIS pictogram for PUDA also contains data for regional disposal). On-site activities associated with off-site transport are represented by national disposal in the pictogram. The risks to the residential population near PUDA for the national disposal alternative are the same as those for off-site transport of the PUDA stockpile under the regional disposal alternative.

\subsubsection{Comparison of FPEIS and Phase I Risk Values}

Fig. 6.1 presents pictograms depicting the five measures of risk for appropriate alternatives at PUDA using FPEIS and Phase I population data, respectively. Details on the computation of the five measures of risk presented in Fig. 6.1 are discussed in Appendix A. The summary discussion below is limited to the differences between the FPEIS risks and the risks computed with the FPEIS meteorological conditions and the new population data collected during Phase I. Site-specific conclusions are presented in Section 6.3.

Probability of one or more fatalities. As discussed above, there are no off-post residents within $2.8 \mathrm{~km}$ (1.8 miles) of the proposed disposal site at PUDA. This is reflected in Table 6.3, which shows no off-post residents in the $0-1 \mathrm{~km}$ and $1-2 \mathrm{~km}$ distance categories. The value of zero residents should be compared to the six residents specified in the FPEIS for the same region (Table 6.2). As explained in Section 6.1.2, the difference is due to the use of the actual PUDA installation boundary and the distance to the nearest off-site resident. The FPEIS generically assumed that this distance was $500 \mathrm{~m}(1640 \mathrm{ft})$. The significance of this difference in population is directly reflected in the Phase I fatality estimates (Table 6.4). As a 
Table 6.4. Comparison of Phase I and Final Programmatic Environmental Impact Statement (FPEIS) fatality estimates for an accidental release of mustard agent during on-site disposal at Pueblo Depot Activity

\begin{tabular}{|c|c|c|c|c|c|c|c|c|c|c|c|c|}
\hline \multirow{3}{*}{$\begin{array}{l}\text { Downwind } \\
\text { distance } \\
\text { (km) }\end{array}$} & \multicolumn{6}{|c|}{$\begin{array}{l}\text { Conservative most likely (CML) } \\
\text { meteorological conditions }\end{array}$} & \multicolumn{6}{|c|}{$\begin{array}{l}\text { Worst Case (WC) meteorological } \\
\text { conditions }^{2}\end{array}$} \\
\hline & \multicolumn{3}{|c|}{ Average fatalities ${ }^{b, c}$} & \multicolumn{3}{|c|}{ Maximum fatalities $s^{b, d}$} & \multicolumn{3}{|c|}{ Average fatalities $s^{b, c}$} & \multicolumn{3}{|c|}{ Maximum fatalities ${ }^{\text {hdd }}$} \\
\hline & FPEIS ${ }^{e}$ & $\begin{array}{c}\text { Phase } \\
\text { I }\end{array}$ & $\begin{array}{c}\% \\
\text { change }\end{array}$ & FPEIS & $\begin{array}{l}\text { Phase } \\
\text { I }\end{array}$ & $\begin{array}{c}\% \\
\text { change }\end{array}$ & FPEIS $^{e}$ & $\begin{array}{c}\text { Phase } \\
\text { I }\end{array}$ & $\begin{array}{c}\% \\
\text { change }\end{array}$ & FPEIS ${ }^{e}$ & $\begin{array}{l}\text { Phase } \\
\text { I }\end{array}$ & $\begin{array}{c}\% \\
\text { change }\end{array}$ \\
\hline 1.0 & 0 . & 0 & 0 & 0 & 0 & 0 & 0 & 0 & 0 & 0 & 0 & 0 \\
\hline 2.0 & 0 & 0 & 0 & 0 & 0 & 0 & 0 & 0 & 0 & 0 & 0 & 0 \\
\hline 5.0 & 1 & 1 & 0 & 1 & 1 & 0 & 1 & 1 & 0 & 1 & 1 & 0 \\
\hline 10.0 & 2 & 1 & -5 & 6 & 4 & -33 & 1 & 1 & $\mathbf{0}$ & 3 & 2 & -33 \\
\hline 20.0 & $\mathbf{N A}^{\mathbf{f}}$ & $\mathbf{N A}^{\mathrm{f}}$ & - & $\mathbf{N A}^{\mathbf{f}}$ & $N^{\prime}$ & - & 9 & 5 & -44 & 30 & 30 & 0 \\
\hline 50.0 & $\mathbf{N A} \mathbf{A}^{\mathbf{f}}$ & $N A^{f}$ & - & $N A^{f}$ & $\mathrm{NA}^{t}$ & - & 335 & 320 & -4 & 6,300 & 7,020 & 11 \\
\hline 100.0 & $\mathbf{N A}^{f}$ & $N^{f}$ & - & $\mathbf{N A}^{f}$ & $\mathrm{NA}^{\mathbf{r}}$ & - & 1,500 & 1,220 & -19 & 16,500 & 16,800 & 2 \\
\hline
\end{tabular}

'CML meteorological conditions are D stability and a wind speed of $3 \mathrm{~m} / \mathrm{s}$. WC conditions are E stability and a wind speed of $1 \mathrm{~m} / \mathrm{s}$. Note that the data in this table are organized by downwind distance and not by the quantity of chemical agent released. Within the same downwind distance category, estimates of potential fatalities are larger for an accident under CML conditions than WC conditions because the CML plume is larger and hence has a greater area. However, for a given quantity of chemical agent that might be accidentally released, the WC conditions would produce a larger downwind distance than would CML conditions and would, therefore, produce a larger value for the number of potential fatalities.

The number of potential deaths is rounded. The fatality estimates are cumulative in that the data entries for a particular downwind distance category include fatalities at all smaller distances.

'The average number of potential fatalities equals the arithmetic mean of fatalities computed from 360 possible plumes centered on the location of the proposed disposal facility, each differing in direction by $1^{\circ}$ compass increments, beginning at due north.

'The maximum number of potential fatalities equals the largest number of fatalities among the set of data computed from the 360 plumes described above.

eSource: Table 4.3.9 in Vol. 1 of U.S. Army, Final Programmatic Environmental Impact Statement (FPEIS) for the Chemical Stockpile Disposal Program, Program Executive Officer-Program Manager for Chemical Demilitarization, Aberdeen Proving Ground, Md., January 1988.

NA = not applicable, because the largest credible accident does not travel this distance under CML conditions. 
A. ORIGINAL RISK PICTOGRAM (FROM THE FPEIS)

\begin{tabular}{|c|c|c|c|c|c|}
\hline Alternatives & $\begin{array}{c}\text { Probability } \\
\text { of one } \\
\text { or more } \\
\text { fatalities }\end{array}$ & $\begin{array}{c}\text { Maximum } \\
\text { number of } \\
\text { fatalities }\end{array}$ & $\begin{array}{c}\text { Expected } \\
\text { fatalities }\end{array}$ & $\begin{array}{c}\text { Person- } \\
\text { years } \\
\text { at risk }\end{array}$ & $\begin{array}{c}\text { Expected } \\
\text { plume } \\
\text { area } \\
\left(\mathbf{k m}^{2}\right)\end{array}$ \\
$\begin{array}{c}\text { Continued Storage } \\
25 \text { Years (STR) } \\
\begin{array}{c}\text { On-Site Disposal } \\
\text { (ONS) } \\
\text { National Disposal } \\
\text { (NAT) }\end{array}\end{array}$ & & & & & \\
\hline
\end{tabular}

\section{B. REVISED RISK PICTOGRAM (USING PHASE 1 FATALTY DATA)}

\begin{tabular}{|c|c|c|c|c|c|}
\hline Alternatives & $\begin{array}{c}\text { Probability } \\
\text { of one } \\
\text { or more } \\
\text { fatalities }\end{array}$ & $\begin{array}{c}\text { Maximum } \\
\text { number of } \\
\text { fatalities }\end{array}$ & $\begin{array}{c}\text { Expected } \\
\text { fatalities }\end{array}$ & $\begin{array}{c}\text { Person- } \\
\text { years } \\
\text { at risk }\end{array}$ & $\begin{array}{c}\text { Expected } \\
\text { plume } \\
\text { area } \\
\left(\mathrm{km}^{2}\right)\end{array}$ \\
\cline { 2 - 6 } $\begin{array}{c}\text { Continued Storage } \\
25 \text { Years (STR) } \\
\text { On-Site Disposal } \\
\text { (ONS) } \\
\begin{array}{c}\text { National Disposal } \\
\text { (NAT) }\end{array}\end{array}$ & & & & & \\
\hline
\end{tabular}

\begin{tabular}{|c|c|c|c|c|c|c|}
\hline $\begin{array}{l}\text { Legend: } \\
\text { Relative }\end{array}$ & Shading & $\begin{array}{c}\text { Probability } \\
\text { of one } \\
\text { or more } \\
\text { fatalities }\end{array}$ & $\begin{array}{l}\text { Maximum } \\
\text { number of } \\
\text { fatalities }\end{array}$ & $\begin{array}{l}\text { Expected } \\
\text { fatalities }\end{array}$ & $\begin{array}{l}\text { Person- } \\
\text { years } \\
\text { at risk }\end{array}$ & $\begin{array}{c}\text { Expected } \\
\text { plume } \\
\text { area } \\
\left(\mathrm{km}^{2}\right)\end{array}$ \\
\hline \multirow{3}{*}{ Higher } & & $>10^{-3}$ & $>10.000$ & $>10^{-2}$ & $>10^{6}$ & $>10^{-2}$ \\
\hline & & $10^{-4}-10^{-3}$ & $\begin{array}{l}5.000 \\
10,000\end{array}$ & $10^{-3} \cdot 10^{-2}$ & $10^{5} \cdot 10^{6}$ & $10^{-3} \cdot 10^{-2}$ \\
\hline & EOIA & $10^{-5}-10^{-4}$ & $\begin{array}{c}1.000 \\
5,000\end{array}$ & $10^{-4}-10^{-3}$ & $10^{4}-10^{5}$ & $10^{-4} \cdot 10^{-3}$ \\
\hline Lower & & $<10^{-5}$ & $<1,000$ & $<10^{-4}$ & $<10^{4}$ & $<10^{-4}$ \\
\hline
\end{tabular}

Fig. 6.1. Risk with mitigation in the vicinity of the Pueblo Depot Activity (PUDA) for programmatic alternatives. (Risk along transportation corridors or at a national destruction site is not included. For the on-site and national disposal alternatives, this diagram does not include the risk associated with approximately 3 years of stockpile storage at PUDA.) 
result of fewer people living close to the PUDA installation boundary, small accidental releases of chemical agent-now produce no fatalities. Many accidents are therefore eliminated from consideration in the accident database. Thus, the "probability of one or more fatalities," which is the sum of probabilities for all accidents causing at least one fatality, decreases for all alternatives (for continued storage, the decrease was large enough to change shading patterns-see Fig. 6.1).

Maximum number of fatalities. Based upon newly collected population data, the "maximum number of fatalities" for a 5-km accident under WC meteorological conditions at PUDA would be 1 (Table 6.4). For a 100-km (62-mile) accident the number would be 16,800. These numbers compare to 1 and 16,500 respectively as presented in the FPEIS (Table 6.4). The Phase I PUDA pictogram shadings for the "maximum number of fatalities" under all alternatives remain unchanged from those in the FPEIS (Fig. 6.1).

Expected fatalities. The Phase I PUDA pictogram shadings for the "expected fatalities" measure of risk do not change from those presented in the FPEIS for any of the PUDA alternatives. Person-years at risk. The total population within the $100-\mathrm{km}$ (62-mile) potential impact zone increased by only $2 \%$ over the population data presented in the FPEIS for the PUDA area. For the 5-km (3.1-mile) potential impact zone, the population actually decreased by about $70 \%$ over the period 1980-1986 (from 62 persons to 19 persons). Therefore, the Phase 1 PUDA risk values for "person-years at risk" actually decrease from those given in the FPEIS, but the change is not large enough to be reflected in the pictogram shading patterns. The Phase I pictogram thus shows no change from that presented in the FPEIS.

Expected plume area. Because neither the probability of an accident nor the resulting plume area were changed by the new data collected during Phase $I$, the "expected plume area" measure of risk for PUDA did not change from that presented in the FPEIS.

In summary, the pictogram developed with the Phase I data is identical to that developed with the FPEIS data, except for the decreased value of the risk measure of "probability of one or more fatalities" for continued storage.

\subsubsection{Effect of Various Meteorological Conditions upon Measures of Risk}

As discussed in Sect. 6.1.1.2, high wind speeds are associated with a more effective atmospheric dispersion of chemical agent and would produce a lower estimated dose than would low wind speeds. It is therefore not necessary to study the effect of atmospheric dispersion of chemical agent under meteorological conditions in stability class $D$ with wind speeds higher than $3 \mathrm{~m} / \mathrm{s}$ (the FPEIS choice for CML conditions) or in stability class $\mathrm{E}$ with wind speeds higher than $1 \mathrm{~m} / \mathrm{s}$ (the choice for WC conditions). Based on the meteorological data in Table 6.1, it does appear that D stability and wind speeds below $3 \mathrm{~m} / \mathrm{s}$ warrant further investigation for use as a potential CML condition in regard to atmospherically dispersed doses of chemical agent and the recomputation of risk. The results of such a study are presented in this section.

A new site-specific CML meteorological condition (defined as D stability with a $1 \mathrm{~m} / \mathrm{s}$ wind speed) was selected for study. The use of the new CML condition provides very conservative results (i.e., high fatality estimates) compared to the FPEIS choice for the CML 
condition. The FPEIS choice is closer to the weighted average of the meteorological conditions provided in Table 6.1.

When the new CML condition was used as input to the D2PC dispersion model, it produced higher doses of chemical agent at larger downwind distances than were reported in the FPEIS. New plume dose-contours and new downwind accident distance categories (see Appendix A for a discussion of the concepts involved) were generated from the D2PC atmospheric dispersion model with the new CML condition as input. The FPEIS methodology of computing estimated fatalities and then computing the five measures of risk was used to study the implications of the new CML meteorological condition at PUDA.

New risk values were computed for the on-site disposal alternative at PUDA, using the new CML condition. These new values were intended for direct comparison to those in Fig. 6.1; however, there was no difference in the on-site disposal risks when the new CML results were compared to the values in Fig. 6.1. It is therefore concluded that the choice of meteorological conditions for the purpose of computing measures of risk at PUDA is inconsequential; it has no potential to change the FPEIS ranking of the alternatives. The risks of the on-site disposal alternative as computed with the FPEIS CML condition (see Fig. 6.1) did not change when a new site-specific CML condition was used at PUDA.

\subsection{DESIGN CHANGES REQUIRING REEXAMINATION OF RISK AT THE PUEBLO DEPOT ACTIVITY}

\subsubsection{Container Handling Building (CHB)}

The FPEIS assumed that agents and munitions would be removed from their existing storage, placed inside on-site transportation containers, and transported to a munitions holding igloo (MHI). The MHI provided temporary storage of sufficient munition quantities to operate the plant during nondaylight hours (i.e., when on-site transport from existing storage directly to the plant could not occur). The MHI concept involved storing packaged munitions in a standard earth-covered magazine (igloo), handling the packages with forklifts inside the igloo, and moving the packages by forklift across an open area to the demilitarization building.

The MHI concept was subsequently found to be inadequate because its capacity was insufficient and there were too many handling steps to support the throughput and processing rates required by the demilitarization plant. The new PUDA design incorporates a CHB which eliminates these inadequacies of the MHI concept; however, the CHB introduces new design features that warrant a reexamination of risk. Because the $\mathrm{CHB}$ has a larger capacity than the MHI and is not as well protected from external events as was the MHI (i.e., the MHI was to have been an earth-covered concrete structure), there exists a potential for more agent to be involved in an accidental release. In addition, there are fewer handling steps-and a reduced probability of accidents-for the CHB than for the MHI. While these may appear to be offsetting factors, their relative contribution to risk is unclear. Thus, a reexamination of risk was required to define the overall risks associated with the replacement of the MHI by the CHB design.

The result of examining the risks of this new design indicates that all of the five FPEIS measures of risk for PUDA are higher with the CHB than with the MHI. The risks 
(primarily those risks from munitions handling) associated with the $\mathrm{MHI}$ were eliminated from the FPEIS accident database, and new risks were developed for the $\mathrm{CHB}$ and added back into the database. The net result was that there was an increase in the three probability-related measures of risk (i.e., the probability of one or more fatalities, the expected fatalities, and the expected plume area), but the FPEIS values were so infinitesimally low that the increase does not affect the pictogram. There is a substantial increase in the non-probabilistic risk measures because the single most severe accident increased from the $5-\mathrm{km}$ (3-mile) accident distance category (in the original analysis) to the $50-\mathrm{km}(31-\mathrm{mile})$ category (in the revised analysis). In the revised analysis, the most severe accident is the result of an aircraft crash into the CHB. In the original (FPEIS) analysis an accident involving a plane crash into temporary storage (MHI) was screened out because the probability of such an accident was below $10^{-8}$. The size of the CHB is sufficiently larger than that of the MHI to increase the probability of the plane crash just over the $10^{-8}$ threshold. Moreover, the relatively large inventory in the CHB results in a severe accident. Design modifications (e.g., utilizing ONC for storage inside the $\mathrm{CHB}$ ) are currently being developed and evaluated for PUDA to reduce risk values to levels that are equal to or less than those presented in the FPEIS. This evaluation will be completed and published prior to the distribution of the PUDA DEIS for public review.

\subsubsection{Redesigned On-Site Container}

The FPEIS assumed that pallets or boxes of munitions would be removed from existing storage, placed individually inside an ONC for protection during on-site movement, and transported to the disposal facility (either directly to the plant or to the MHI). During onsite movement, four ONCs would be loaded onto a munitions vehicle, and only one munitions vehicle would be in the convoy as it moved between the existing storage area and the disposal facility.

Resolving the inadequacies of the MHI, as described above, by using the new CHB also required redesigning the ONC. The redesigned ONC will now carry more than one pallet or box of munitions (e.g., up to nine pallets of projectiles can be simultaneously transported inside the new ONC). Two of the new ONCs will be loaded onto a munitions vehicle for transport between the storage area and the disposal facility.

Because the new ONC has a larger capacity than the ONC concept assumed in the FPEIS risk analysis, there exists a potential for a transport accident to release larger quantities of chemical agent than in the FPEIS. Furthermore, the larger capacity of the new ONC will require fewer trips between the storage area and the disposal facility. Fewer vehicle miles will be travelled, and the probability of an accident during transport will therefore decrease. The potential offsetting effects of these two factors (larger capacity and fewer vehicle miles) makes the impact on the FPEIS risk values for PUDA unclear. Therefore, a reexamination of ONC risks is warranted.

The result of reexamining the risks of the new ONC design, and its accompanying transportation procedures, indicates that none of the five FPEIS measures of risk for PUDA are higher than with the old ONC conceptual design. There was a decrease in the three probability-related measures of risk (i.e., the probability of one or more fatalities, the expected fatalities, and the expected plume area). The decrease in risk was up to $100 \%$ less than the FPEIS values for these three measures of risk. Because the size (i.e., downwind no deaths 
distance) of the largest $\mathrm{ONC}$ accident with the new design was no larger than other dominant accidents at PUDA (i.e., the largest accident would still be placed into the 5-km (3-mile) accident distance category), the maximum number of fatalities and the person-years at risk measures of risk did not change. The risks associated with the new ONC design are therefore less than or equal to the risks associated with the ONC concept in the FPEIS for PUDA.

\subsubsection{Addition of a Mustard Thaw Capability}

The FPEIS assumed that the agents inside the bulk containers and munitions would be drained into a TOX and eventually fed into a LIC for destruction. This requires that the agent be in liquid form prior to being processed. Among the types of chemical agents to be destroyed at PUDA, HD has the unique physical property that it is a solid at temperatures below $14^{\circ} \mathrm{C}\left(58^{\circ} \mathrm{F}\right)$. HD is present at PUDA in $155-\mathrm{mm}$ projectiles, 42 in. mortar rounds and 105-mm projectiles, all of which are stored in concrete, earth-covered igloos. Because of the existing mustard storage configuration, the mustard agent at PUDA cannot be guaranteed to be in a liquid form during cold weather months.

The additional handling steps required to thaw the mustard, as well as the heating process itself, were not included in the FPEIS risk analysis. The Army is currently evaluating alternative mustard thaw configurations for PUDA that would reduce risks to levels at or below those computed for the FPEIS. These alternative mustard thaw configurations include thawing mustard in storage igloos and storing the thawed mustard in ONCs in the CHB. This evaluation will be completed and published prior to the distribution of the PUDA DEIS for public review.

\subsection{EXAMINATION OF RISKS FOR A CRYOFRACTURE DISPOSAL FACILITY AT THE PUEBLO DEPOT ACTIVITY}

Section 3.3.2 describes a disposal technology known as cryofracture that is being pursued by the Army to augment or replace the JACADS-type technology evaluated in this Phase I report. As discussed in Sect. 3.3.2, the chemical agent and munition inventory at PUDA is a candidate for application of the cryofracture technology.

An assessment of risks for a cryofracture facility at PUDA was conducted by the MITRE Corporation (Perry 1993). MITRE's methodology is consistent with the one used for risk assessments in support of the FPEIS. The cryofracture process subject to MITRE's risk assessment includes all activities from transfer of munitions from their storage igloos, through transport to the cryofracture disposal facility, and on to final demilitarization. The same five measures of risk that were used in the FPEIS risk assessment are incorporated into the MITRE study of cryofracture risks.

If a comparison of risks is made between the pictogram in Fig. 6.1 and MITRE's cryofracture assessment, there is a significant increase in all measures of risk. This is due to the inclusion of a container handling building (CHB) in the cryofracture facility design, which is not present in the baseline analysis that produced Fig. 6.1. However, if the baseline risk assessment in Fig. 6.1 were updated to include the $\mathrm{CHB}$ (see the discussion of CHB risks for the baseline facility in Sect. 6.3.1.), it is likely, since the CHB makes up such a large portion 
of the total risk, that there would be no significant difference in any risk measure between the baseline and the cryofracture facilities (Perry 1993).

\subsection{DENTIFYING THE SITE-SPECIFIC ENVIRONMENTALLY PREFERRED ALTERNATIVE}

Part B of Fig. 6.1 presents the revised, site-specific measures of risk from the perspective of the population residing near PUDA. The on-site risks of the national disposal alternative serve as a surrogate for the risks of off-site transport from PUDA. Cross-country transportation risks for an off-site disposal alternative are not shown, but would be the same as presented in the FPEIS for a regional or national disposal option (U.S. Army 1988, Vol. 1, Figs. 4.4.1 and 4.4.2). Results for the five measures of risk are summarized in Table 6.5. The application of these risk results to the FPEIS method for identifying the environmentally preferred alternative is discussed below.

Applying the newly computed risk measures for PUDA (Fig. 6.1 part B) to the programmatic method for identifying the environmentally preferred alternative (Fig. 6.1 part A) indicates that on-site disposal is the environmentally preferred alternative for PUDA. At the first tier of the evaluation (human health), on-site disposal was found to be significantly better than continued storage and national disposal for two measures of risk (see Fig. 6.1, part B and Table 6.5); consequently, in accordance with the FPEIS method (Section 2.1), onsite disposal is selected as the environmentally preferred alternative, and continued storage and national disposal are rejected as clearly inferior alternatives. Thus, on-site disposal remains valid as the environmentally preferred alternative for PUDA. The second and third tiers of the FPEIS method (ecosystem/environmental effects and emergency planning/preparedness, respectively) were not needed to identify the environmentally preferred alternative for PUDA. As indicated in Fig. 6.1, part B and Table 6.5, use of the second tier would have been inconclusive for PUDA because all alternatives are indistinguishable for the risk measure of expected plume area, a surrogate for ecological and socioeconomic impacts. Consideration of emergency planning and preparedness (in the third tier) would have given further evidence for the selection of on-site disposal. If one adds the off-site transportation risks-the on-site alternative is clearly preferable given the opportunity for risk reductions associated with emergency planning and preparedness activities that are under way at PUDA. 
Table 6.5. Results of comparing the recomputed measures of risk for alternatives at the Pueblo Depot Activity (Note: Risks of design change are not included.)

\begin{tabular}{ll}
\hline \multicolumn{1}{c}{ Measure of risk } & $\begin{array}{c}\text { Comparison among } \\
\text { alternatives }\end{array}$ \\
\hline Probability of one or more fatalities & $\begin{array}{l}\text { Alternatives are indistinguishable (i.e., their } \\
\text { risks differ by no more than one pictogram } \\
\text { shading pattern) }\end{array}$ \\
Maximum number of fatalities & $\begin{array}{l}\text { On-site disposal is better than any other } \\
\text { alternative (i.e., its risk is lower by two } \\
\text { pictogram shading patterns than either } \\
\text { continued storage or national disposal) }\end{array}$ \\
Expected fatalities & $\begin{array}{l}\text { Alternatives are indistinguishable } \\
\text { person-years at risk }\end{array}$ \\
On-site disposal is better than any other \\
alternative \\
Ecosystem, environmental risks \\
Alternatives are indistinguishable
\end{tabular}




\section{DEVELOPMENTS IN EMERGENCY PREPAREDNESS}

The potential of emergency preparedness improvements to reduce the impacts of an accidental release of chemical agent differs for each programmatic alternative, including continued storage. That differing potential was a major factor in identifying on-site disposal as the environmentally preferred alternative and in the subsequent programmatic ROD endorsing on-site disposal. This section (1) summarizes emergency preparedness mitigation measures for the proposed disposal sites as discussed in the FPEIS; (2) describes and summarizes the status of emergency preparedness enhancements made at the storage and proposed disposal sites since the FPEIS, including those for PUDA and its surrounding jurisdictions; (3) summarizes the emergency preparedness mitigation measures for rail transport corridors (the only off-site transport alternative considered for the PUDA stockpile) as discussed in the FPEIS; and (4) identifies relevant new information regarding emergency preparedness for rail transport, specifically those measures implemented during the European portion of the movement of munitions from the Federal Republic of Germany (FRG). Finally, this section assesses whether developments in emergency preparedness since publication of the FPEIS would have affected the selection of on-site disposal as the environmentally preferred alternative for the PUDA stockpile. FPEIS assumptions and commitments regarding emergency preparedness enhancements for the proposed disposal sites and rail transport corridors are compared with emergency preparedness developments since the FPEIS.

\subsection{EMERGENCY PREPAREDNESS MITIGATION FOR FIXED SITES IN THE FPEIS ENVIRONMENTALLY PREFERRED ALTERNATIVE}

In the FPEIS, the Army recommended that enhancements to emergency preparedness should be made and noted that it would seek necessary funds for implementation of such enhancements, regardless of the disposal alternative that was selected for implementation (U.S. Army 1988a). These enhancements would mitigate adverse consequences of the selected alternative in two ways-they would reduce the impacts of an accidental release of agent, and federally funded enhancements would offset the cost impacts that would normally be borne by state and local governments for protecting public health and safety.

It was determined that improvements were necessary for each installation regardless of the disposal alternative selected and that additional requirements would be needed if an alternative involving off-site transport were chosen. Based on a generic emergency response concept plan developed in support of the FPEIS (Jacobs Engineering, Inc., and Schneider EC Planning and Management Services 1987), improvements were estimated at that time to cost approximately $\$ 80$ million on a life-cycle basis for all of the eight CONUS sites; enhancements for off-site transportation were estimated to result in additional costs of approximately $\$ 10$ million for the regional disposal alternative and $\$ 11.5$ million for the national disposal alternative. The plan would include various activities, such as funding for 
state and local planning efforts; improvements to emergency operations centers; procurement, implementation, and maintenance of effective communication and public alert systems; procurement, implementation, and maintenance of protective action measures; public education and emergency worker training; and exercises.

\subsection{DEVELOPMENTS IN ON-SITE EMERGENCY PREPAREDNESS}

On August 31,1987 , prior to the programmatic record of decision for the CSDP, the then Under Secretary of the Army, J. R. Ambrose, initiated a series of steps to improve both on-site and off-site emergency response capabilities at the eight CONUS installations. This decision was based, in part, on preliminary findings in the FPEIS and the emergency response concept plan. These steps included the following:

- initial upgrading of emergency plans and procedures;

- improving the technical basis of emergency planning, including analysis of site-specific hazards and establishing appropriate emergency planning standards and review criteria;

- coordinating the emergency planning improvements with FEMA, DHHS, and other appropriate federal and state organizations;

- $\quad$ establishing an oversight and review board to coordinate emergency planning among the eight CONUS sites and to ensure that guidelines specified in the Emergency Response Concept Plan (ERCP) (Jacobs Engineering Group, Inc., and Schneider EC Planning and Management Services 1987) would be implemented on schedule; and

- pursuing means to reduce the costs of emergency preparedness enhancements to local governments.

Following the FPEIS for the CSDP and using the steps initiated by the Under Secretary as a blueprint, the Army initiated the development of the Chemical Stockpile Emergency Preparedness Program (CSEPP) with the active assistance of FEMA, DHHS, EPA, and affected state and local officials.

To complement its expertise in the safe handling and on-post destruction of chemical weapons, the Army sought assistance in assessing and improving off-post emergency preparedness by entering into a Memorandum of Understanding (MOU) with FEMA on August 10, 1988 (Department of the Army and Federal Emergency Management Agency 1988). The stated purpose of the MOU is to:

... establish a framework of coordination between FEMA and Department of the Army to identify their respective roles and responsibilities for emergency preparedness involving the storage and ultimate disposal of chemical weapons and to establish joint program efforts in emergency preparedness planning, training, and information exchange. 
The areas of cooperation between the two agencies include: (1) facilitating the Army's requests for funding needed to develop and implement emergency preparedness programs; (2) developing and implementing program initiatives to integrate the planning and preparedness functions of FEMA and establishing a joint FEMA/DA CSEPP Steering Committee to review the status of joint programs, discuss and resolve issues, consult on major policy issues, and provide the necessary direction to meet the Army's overall CSDP goals; (4) determining exercise requirements for storage locations and State and local governments and jointly developing and evaluating such exercises; (5) developing and implementing a community relations program that will bring together FEMA and Army personnel and local public officials and interest groups; and (6) encouraging private-sector initiatives beneficial to the State and local governmental units responsible for emergency preparedness.

The principal purpose of the CSEPP is to mitigate the adverse human health effects of an unintentional release of chemical agent during storage pending disposal of the stockpile and during implementation of the CSDP. Three program objectives are loss reduction, community participation, and functional equivalency. Loss reduction, as measured primarily by avoidance of fatalities given an accidental chemical agent release, is the most important objective. Community participation means that the citizens affected by the emergency preparedness mitigation need to become part of the planning process to enhance its acceptability and workability. Finally, although the eight CONUS storage/disposal sites may have different emergency preparedness needs (e.g., based on differences in stockpile hazard, population distribution, and topography and meteorology that may affect agent dispersion) and may opt for different approaches, it is important that each site receive enhancements that are more or less equivalent from a functional perspective.

The CSEPP is implemented by the states so that protection of the public may be accomplished in accordance with state law. The governor of the state has the responsibility to protect the citizens of the state, and the local governments have the authority as prescribed by state law. In the case of Colorado, the Pueblo County Office of Emergency Preparedness (OEP) has assumed all CSEPP planning responsibilities, because the immediate response zone (IRZ) and protective action zone (PAZ) are both within the county. Pueblo County has been actively involved in planning on a day-to-day basis. The local government is typically able to respond most effectively and efficiently to major emergencies, particularly those that develop suddenly. Therefore, planning and preparation by state and local governments are key elements in off-post emergency preparedness.

The hazardous materials emergency planning infrastructure has been established by Colorado under the authority of Title III of the Superfund Amendment and Reauthorization Act of 1986, also known as the Emergency Planning and Community Right-to-Know Act (EPCRA). It includes both a State Emergency Response Commission (SERC) (in Colorado called the Colorado Emergency Planning Commission to emphasize its planning versus response character) and a Local Emergency Planning Committee (LEPC) in each county or community of over 25,000 population, in Colorado, within the emergency planning district (Feldman 1989). The LEPCs consist of a broad spectrum of community representatives including elected local officials, law enforcement, fire fighting, health, environmental, and transportation agencies; emergency medical services and hospitals; broadcast and print media; community groups; and representatives of facilities subject to EPCRA requirements. The LEPC's primary task is to develop a planning process to prepare for and respond to chemical 
emergencies, particularly those involving extremely hazardous substances. In addition to this planning responsibility, the LEPC (through the Pueblo County OEP) serves as a focal point in the community for information and discussions about chemical hazards, emergency planning, and health and environmental risks. The LEPC can also provide a forum for communicating information to the community on the ongoing activities related to CSDP and PUDA.

Under CSEPP, FEMA and the Army are providing and will continue to provide financial and technical assistance for emergency preparedness, but ultimate responsibility for developing and implementing these programs lies with the state and local governments that have established close working relationships with the Army installations within their jurisdictions.

\subsubsection{National CSEPP Activities}

CSEPP activities fall generally into four categories or phases. Although there is a temporal sequence to many of the activities, others are implemented simultaneously. Phase I of the program, provided an interim upgrade of off-post emergency planning using existing community resources and the development and presentation of chemical accident medical training courses for emergency workers; Phase I also included studies analyzing equipment needs for communications and public alerting, and an initial analysis of program training needs. Phase II of the program, includes the preparation of various technical studies to support local decision making. Those studies form the basis for program guidance and the definition of standards and criteria to be used to determine the adequacy of comprehensive emergency plans and preparedness for the program. Phase III of the program, constitutes the implementation of the program. It includes the preparation of site-specific concept plans; the determination of planning, equipment and training needs required to satisfy the standards and criteria established during Phase II; the acquisition, installation and testing of equipment and training of emergency response organizations and personnel in its use; and the implementation of comprehensive planning, training, and exercise programs. Phase IV, composed of maintenance and support of the major preparedness programs, will last until the chemical agent stockpile is eliminated.

\subsubsection{PUDA Emergency Preparedness Enhancements}

At the time of the FPEIS, on-site emergency preparedness was based on the installation's current Chemical Accident/Incident Control Plan (U.S. Army 1985), which was an annex to the Tooele Army Depot (TEAD) Disaster Control Plan (chemical stockpile activities at PUDA report through TEAD).

Off-site emergency services for jurisdictions surrounding PUDA were based on the state-approved Pueblo County Department of Public Safety and Operations' Emergency Operations Plan, which contained an Annex P devoted to Hazardous Materials, Emergency Procedures in the Event of Chemical Accidents (Schneider Engineers 1988). Both of these plans were under revision at the time of the FPEIS publication. The County Public Safety Department's prior experience with actual emergencies includes one natural disaster and two major hazardous material transport accidents. A 1965 flood of Fountain Creek affected the southeastern portion of the City of Pueblo and caused injuries. Additionally, in 1985, a train 
struck a tank truck carrying ammonium nitrate, which resulted in fatalities. In 1987, a leaking liquid oxygen truck resulted in a spill at the Pueblo Reservoir, and county emergency officials responded by placing containment booms to control the spill. Approximately one to two hazardous material transport accidents occur each year (S. Douglas, Pueblo County Department of Public Safety and Operations, Pueblo, Colo., personal communication with S. Schexnayder, Oak Ridge National Laboratory, Oak Ridge, Tenn., June 8, 1990).

CSEPP activities relevant to the interim storage and disposal of the PUDA stockpile are summarized below according to the first three phases of the CSEPP. As explained above, the fourth phase of the CSEPP at all sites, including PUDA, will involve the maintenance of all essential program equipment, plans, training and exercises, and public affairs for the duration of the disposal program.

\subsubsection{PUDA CSEPP Phase I activities}

Principal among the Phase I activities for the PUDA stockpile were (1) draft revisions to the chemical accident-specific emergency response plans for Pueblo County, including hazard-specific appendices, and implementing procedures for those plans; (2) special facility plans developed for facilities within the PUDA IRZ, including the Pueblo Community Health Center, the Avondale Elementary School, and Pueblo School District 70 (Schneider Engineers 1989); (3) a number of technical reports, and (4) proposed revisions for the PUDA Disaster Control Plan's Annex C-Chemical Accident/Incident Response and Assistance (CAIRA) Plan.

In addition, meetings were convened with state, county, installation, and contractor representatives to address issues such as IRZ and PAZ boundaries, the adequacy of the existing off-site EOC (extant plans called for the use of the Pueblo Fire Department conference room), and the emergency notification and alerting processes. Actions recommended for subsequent phases of the CSEPP for the PUDA stockpile were also identified (Schneider 1989). These included, among other items, the development of a functional EOC (to replace the emergency use of the Fire Department facility) and the acquisition of protective equipment and training for emergency workers; the expeditious installation of an improved notification and communications system between PUDA and off-site jurisdictions; the conduct of a series of emergency drills and exercises; the development of an emergency public information and education program; and the identification of special needs populations and resources necessary to support them.

\subsubsection{PUDA CSEPP Phase II activities}

Phase II activities encompass analytical efforts that provide a technical basis for subsequent program activities. Consequently, they constitute technical assistance for planning and preparedness enhancement efforts for all of the installations and their environs. They include (1) technical support studies, (2) planning guidance, and (3) revisions to the Chemical Accident/Incident Response and Assistance (CAIRA) Operations manual (U.S. Army 1991c), which will lead to ongoing installation-specific revisions.

The technical studies that were initiated included evaluations of protective action effectiveness, public information and education, accident classification, dispersion modeling, 
emergency management decision making, re-entry, exercise design and implementation, emergency worker training, and other technical areas determined by the Army and FEMA.

Guidance is being promulgated by the Army and FEMA on specific aspects of emergency planning related to a chemical event (e.g., properties of chemical agents, the CAIRA Plan, EPZs, accident assessment and off-post notification, and protective action decision making). Planning standards have been approved by the CSEPP Joint Steering Committee for alert and notification, communications, EOCs, and public information and education.

\subsubsection{PUDA CSEPP Phase III activities}

Phase III activities for the PUDA stockpile have included (1) the preparation of an emergency response concept plan for PUDA and vicinity (comparable plans were prepared for the other seven storage/disposal sites as well); (2) technical assistance and planning support for the IRZ; (3) the initiation of planning support for the PAZ; (4) technical assistance to the Colorado DODES; (5) preparation and implementation of a CSEPP appendix to the state Emergency Operations Plan; and (6) development of a training and exercise program.

The two major decisions addressed in the concept plan (Carnes et al. 1989) are the determination of the boundaries of the IRZ, PAZ, and PZ, and the selection of protective action strategies to protect human health and safety. Recommendations from this report are being considered in decision making. Revisions to a county-wide ERP and Implementing Procedures for Chemical Accidents at Pueblo Depot Activity for the IRZ have been promulgated.

Technical assistance and planning support have continued during this phase of the program. For example, the outdoor public warning needs in the PUDA area and the adequacy of the existing EOC in Pueblo have been evaluated. It was determined that IRZ outdoor warning can be accomplished by six PUDA on-site sirens in addition to nine omni-directional electronic sirens in the IRZ and four sirens in the more populous areas of the PAZ (near and south of the Pueblo Memorial Airport).

Following the recommendations of the study, the EOC is located in the basement of the Judicial Building in downtown Pueblo, approximately $23 \mathrm{~km}$ (14 miles) from the installation and outside the IRZ. Renovation of this location began in early 1990; official occupancy of the new EOC began in July 1992.

Additional activities that are under way related to implementation of CSEPP for the PUDA stockpile include, among other items:

- assistance to the Colorado Division of Disaster Emergency Services (DODES) in the redesign, layout, and automation of the state EOC;

- assistance in the development of reception center and mass-care facility procedures; and

- technical assistance to state and local CSEPP staff in the design, evaluation, and implementation of public alert and communications systems. 
The CSEPP calls for an ongoing 2-year exercise cycle (involving state and local jurisdictions) to continue until disposal is completed. For PUDA, full-scale exercises are scheduled for the third quarter of CY 1994 and the fourth quarter of CY 1996 with remedial exercises as required.

Other Phase III activities (e.g., determination of site requirements; finalization of equipment requirements; procurement, installation, and testing of equipment; final development and implementation of exercise and training programs, and development and implementation of public affairs programs) will follow as the technical studies supporting them are completed. Some planning activities, such as those related to emergency worker protection, re-entry and recovery, and chemical agent detection, have not yet been addressed in the county plans due to a lack of detailed program guidance; as indicated earlier, technical studies supporting these issues are currently under way.

\subsubsection{Summary of PUDA emergency preparedness developments since the FPEIS}

Implementation of the preliminary and longer term upgrades to on- and off-site emergency preparedness associated with the storage and disposal of the stockpile at PUDA has followed the framework initially outlined in the FPEIS and the ERCP. Changes to those upgrades have occurred as the CSEPP has evolved and as additional technical information has become available. Moreover, further changes can be anticipated as new issues arise that require resolution. The Army and FEMA have made financial and technical assistance available to relevant agencies in Colorado and Pueblo County, and this assistance will continue until the PUDA stockpile is eliminated.

\subsection{EMERGENCY PREPAREDNESS MITIGATION FOR RAIL TRANSPORT CORRIDORS IN THE FPEIS}

Although it is not considered feasible to plan and implement an emergency preparedness capability for transportation corridors that is as detailed as that around each installation, the Army remains committed to providing those planning and preparedness capabilities that would be required to provide maximum safety to its personnel and the

potentially affected public. Regardless of how detailed an emergency response capability might be for a transit corridor, the absence of any buffer zone around the moving stockpile limits its effectiveness in the event of an accidental release. This section summarizes the transportation corridor emergency response concepts identified in the FPEIS (U.S. Army 1988). Only those aspects relevant to rail transport of stockpile items, as would be the case for movement of the PUDA stockpile to TEAD under either the regional or national disposal center alternative, are considered.

The initial ERCP identified the basic elements of enhancements for transportation corridors as well as for the storage and potential disposal sites (U.S. Army 1988). Due to the impracticality of developing and implementing detailed emergency response plans for lengthy transportation corridors, the emergency management concepts for accidental chemical agent releases in transit are of a more general nature than for fixed sites. They were to be based either on transporting the appropriate emergency response capability with the stockpile or 
establishing a broad-area response capability organized at the state level or regionally for the various corridors (U.S. Army 1988). For rail transport of stockpile items, it was envisioned that a mobile emergency response capability, much of which would be located on an escort train, would accompany the munition train(s). Moreover, a state-level and regional coordination system would be established to support the mobile capability, but this state/regional coordination would essentially provide a secondary emergency response capability.

The mobile escort capability would consist of Army personnel and resources for implementing the primary public protective measures that are conducted by community officials in the fixed-site emergency response program. These activities would include public alert and notification, traffic and access control, assistance to affected populations, and initial medical intervention and care. The escort emergency response organization would coordinate its activities with local officials and emergency response personnel at the site of an accident. However, the mobile unit should be prepared to conduct all immediate response measures necessary, since no substantial detailed local planning or training for chemical agent accidents would be conducted for the transportation corridors.

The mobile organization would include sufficient personnel to manage the emergency response, coordinate with civilian emergency response personnel, and conduct public warnings and other immediate public protective actions in the vicinity of the accident. It would be equipped with computerized dispersion modeling and accident assessment capabilities, radio communications, public alerting devices, appropriate transportation capabilities (e.g., allterrain vehicles), and sufficient protective equipment and medical supplies for escort and local civilian emergency response personnel. The transportation emergency response plan would also include medical support plans providing for evacuation of chemically injured victims, preparation of hospitals and emergency medical facilities to handle injured, and assurance of fully stocked medical facilities. A training program for medical personnel along transport corridors would also be provided. Each medical support plan would be jointly approved by the Army Health Service Command and DHHS (U.S. Army 1988).

The state-level emergency response planning would focus on providing expedient resource support to the site of a rail transportation accident from state or nearby local government resources. However, such support was considered likely to require up to several hours to mobilize and deploy to an accident location. State-coordinated support would be effective for secondary activities (e.g., medical and evacuee care, security, etc.) but would not likely be effective for the principal response activities needed immediately following an accident.

The limitations associated with deploying all or most of the emergency response resources from a mobile escort capability restrict the potential effectiveness of such a response. Under certain accident scenarios and conditions, this capability could be effective in reducing civilian casualties. However, for accident conditions that do not involve easy access to affected populations, or that involve a densely populated area with little or no buffer between the accident location and the affected public, the mobile emergency response capability may not be effective in preventing civilian casualties. 


\subsection{EMERGENCY PREPAREDNESS FOR THE EUROPEAN PORTION OF THE MOVEMENT OF CHEMICAL MUNITIONS FROM THE FEDERAL REPUBLIC OF GERMANY}

Although the specific language regarding the overall operating philosophy of the movement of stockpile items from the Federal Republic of Germany (FRG) was slightly different from that assumed in the FPEIS, the thrust of the two are similar. The former noted that all operations should be designed so as to expose the minimum number of people for the minimum amount of time to the minimum hazard consistent with safe and efficient operations (U.S. Army 1990d), while the latter was based on providing maximum protection of the environment, the general public, and the personnel involved in the movement [based on the statutory mandate of Pub. L. 99-145 (1986)].

In the unlikely event of a chemical agent release during the European rail movement, extensive operations plans were developed and would have been implemented to minimize casualties. With respect to the rail movement of stockpile items from Miesau Army Depot to the port at Nordenham, these plans included extensive training and exercises; prepositioning of emergency response equipment, personnel, and infrastructure; coordination of mobile emergency response capabilities with corridor capabilities; and command and control concepts. However, even with extensive planning it is unlikely that all casualties could have been avoided if an accidental release had occurred, particularly if it had occurred in a densely populated area.

The safety, medical, and emergency preparedness aspects of the rail movement portion of the overall operations plan, known as OPLAN-4332 (U.S. Army 1990d), included the development and deployment of mobile capabilities (i.e., on the munitions and escort trains) coordinated with commensurate transport corridor capabilities. Elements of the U.S. Army were responsible for emergency preparedness while still on U.S. Army installations (and for U.S. Army personnel accompanying the munitions and escort trains), while the FRG was responsible for emergency response at all other times. The specific elements of these capabilities are outlined below.

\subsubsection{Mobile Emergency Response Capabilities}

The safety annex to the operations plan for the movement of the European stockpile established personnel protection criteria, contamination control requirements, downwind hazard prediction methodology, and service support requirements. Monitoring was to be accomplished only if there were a chemical accident or incident (U.S. Army 1990d), although monitoring, decontamination, and leak sealing equipment were available with the munition and escort trains. American and German emergency preparedness personnel assigned to the mission and escort trains included 7 members of the Technical Escort Unit, 6 communications staff, 24 fire fighters, 52 police or police liaison, and 136 medics (U.S. Army 1990d). Support equipment for each rail move included five Chemical Agent Monitors (CAMs), other chemical detectors, decontaminant, protective clothing for train personnel, and antidote kits (applicable for nerve agent only) (U.S. Army 1990d). In addition, medical support was provided for all U.S. personnel through a number of U.S. Army medical commands, detachments, and facilities (U.S. Army 1990d). Aeromedical (helicopter) evacuation 
capabilities were provided by a variety of crews stationed at various FRG military installations (U.S. Army 1990d).

Command and control in the event of an accidental release followed basic CAIRA principles. The mission was to prevent and control the release of chemical agent, conduct emergency medical response to save lives, coordinate release of information to the public, and conduct decontamination and restoration activities. The 59th Ordnance Brigade was responsible for CAIRA on U.S. installations, and the FRG was responsible for accident response off U.S. installations (U.S. Army 1990d).

\subsubsection{Prepositioned Emergency Response Capabilities}

The FRG deployed Bundeswehr emergency response forces on standby at specified locations along the rail transportation routes, with the capability to respond in less than $2 \mathrm{hrs}$ (U.S. Army 1990d). FRG forces came from the Ministry of Defense and Ministry of Interior, various military commands, and numerous civilian forces, including Federal Border Police, state and local police, and fire fighters. Although many of these workers' primary mission was security, they were also available to support emergency response in the event of an accident. The FRG also prepositioned disaster relief workers during the rail movement (U.S. Army 1990c).

\subsubsection{Conclusions}

The rail movement of unitary chemical weapons in Europe was accomplished without incident and, thus, did not require the actual use of either the mobile or prepositioned emergency response capabilities. Even though the development and implementation of emergency response capabilities were extensive, it would have been unlikely that casualties could have been avoided in the event of an accidental chemical agent release. The actual effectiveness of those capabilities would depend on the location of the release (i.e., the proximity of the release to persons in the downwind hazard area), which cannot be controlled, as well as on the capabilities themselves, which could be and were controlled. It should be noted that no new data on the effectiveness of emergency response were obtained. There were no accidents, so no new data were collected.

\subsection{COMPARISON OF FPEIS COMMITMENTS AND RECENT DEVELOPMENTS IN EMERGENCY PREPAREDNESS}

This section assesses whether developments in emergency preparedness since publication of the FPEIS would affect the selection of on-site disposal as the environmentally preferred alternative for the PUDA stockpile. This is accomplished by comparing the assumptions and commitments made in the FPEIS regarding enhancements to emergency preparedness for fixed sites and rail transport corridors with emergency preparedness developments since the FPEIS. 


\subsubsection{Emergency Preparedness for Installations and Surrounding Communities}

As noted in Section 7.1, the Army identified substantial enhancements to emergency preparedness for the CONUS storage and proposed disposal site installations, regardless of the disposal alternative selected for implementation. These enhancements were to be based on a generic emergency response concept plan (Jacobs Engineering, Inc., and Schneider EC Planning and Management Services 1987) and included funding for state and local planning efforts; improvements to emergency operations centers; procurement, implementation, and maintenance of effective communications and public alert systems; procurement, implementation, and maintenance of protective action measures; public education and emergency worker training; and exercises.

The Army, in coordination with FEMA, other Federal agencies, and state and local agencies, initiated implementation of the CSEPP in 1988. As described in Section 7.2, this program for fixed-site emergency preparedness corresponds closely to the elements identified in the FPEIS and the emergency response concept plan. Differences between the two are of a kind that are to be expected as one moves from a conceptual stage to actual implementation (e.g., the development and promulgation of some emergency preparedness standards take longer than originally planned due to the necessity of additional technical study and analysis; site-specific EPZ boundary definition is an iterative process involving technical study and analysis followed by local and state civilian decision making).

In summary, the assumptions and commitments made in the FPEIS for fixed-site emergency preparedness are consistent with actual developments during the implementation of the CSEPP. This conclusion is valid for the program as a whole, as well as for the PUDA stockpile.

\subsubsection{Emergency Preparedness for Rail Movement}

The generic emergency response concepts for rail movements identified in the FPEIS (U.S. Army 1988) are reasonably similar to those implemented in the rail movement portion of the Retrograde Operation transferring chemical munitions out of the FRG. In both cases, a mobile emergency response capability accompanies the munitions train(s), and certain capabilities are prepositioned at various locations along the transport route during the move. As would be expected, the emergency preparedness concepts presented in the FPEIS were not as detailed as those detailed operations plans for the European movement. For comparison purposes, the principal elements of the FPEIS and European movement emergency preparedness concepts are summarized in Table 7.1.

It should be noted that there are some significant differences between the European rail movement and a rail movement of the PUDA stockpile. The risk-related differences are discussed in Section 4.2.2; this section discusses the differences from the perspective of emergency preparedness planning. The European rail movement involved considerable coordination between American and FRG personnel, some of the information provided below is useful in the context of analyzing the functions and actual experience of the movement, but is only marginally useful as it applies specifically to any such move within the continental United States. Although the rail transport distances involved with the movement of the stockpile in the FRG and the PUDA stockpile are similar (each approximately $1000 \mathrm{~km}$, or 
Table 7.1. Rail transport corridor emergency preparedness components in the Final Programmatic Environmental Impact Statement (FPEIS) and in the European movement

\begin{tabular}{|c|c|c|c|c|}
\hline Capabilities & Mobile & Prepositioned & Mobile & Prepositioned \\
\hline $\begin{array}{l}\text { Accident } \\
\text { assessment }\end{array}$ & $\begin{array}{l}\text { Accident assessment, } \\
\text { computerized dispersion } \\
\text { modeling }\end{array}$ & & $\begin{array}{l}\text { Monitoring equipment; agent detection, } \\
\text { downwind hazard } \\
\text { prediction, and decontamination } \\
\text { personnel and equipment (German } \\
\text { decontamination teams respond } \\
\text { within } 15 \mathrm{~min} \text { ) }\end{array}$ & \\
\hline Communications & Radio communications & & $\begin{array}{l}\text { Three communications personnel } \\
\text { and equipment }\end{array}$ & \\
\hline Warnings & $\begin{array}{l}\text { Public alert and } \\
\text { notification }\end{array}$ & & Loudspeaker vehicle & $\begin{array}{l}\text { Public alert and } \\
\text { notification by local } \\
\text { polizei (police) }\end{array}$ \\
\hline Emergency relief & $\begin{array}{l}\text { Protective equipment and } \\
\text { supplies for escort and } \\
\text { local civilian emergency } \\
\text { response personnel, } \\
\text { transportation } \\
\text { capabilities (e.g., } \\
\text { forklifts and ramps) }\end{array}$ & $\begin{array}{l}\text { Preparation of hospitals } \\
\text { and emergency medical } \\
\text { facilities to handle } \\
\text { injured, fully stocked } \\
\text { medical facilities, } \\
\text { expedient resource } \\
\text { support from state and } \\
\text { nearby local } \\
\text { government resources } \\
\text { (e.g., medical and } \\
\text { evacuee care, security, } \\
\text { etc.) }\end{array}$ & $\begin{array}{l}\text { Protective equipment, clothing } \\
\text { and supplies for movement } \\
\text { personnel; emergency Personnel } \\
\text { Decontamination Station equipment; } 24 \\
\text { fire-fighting personnel and equipment; } \\
\text { transportation } \\
\text { capabilities (e.g., forklifts } \\
\text { and ramps); decontaminant }\end{array}$ & $\begin{array}{l}\text { Equipment (to include } \\
\text { cranes and } \\
\text { decontamination } \\
\text { equipment), air or } \\
\text { ground evacuation of } \\
\text { chemically-injured } \\
\text { victims }\end{array}$ \\
\hline
\end{tabular}


620 miles), the institutional complexity of the two moves are qualitatively different-the European rail route crossed six FRG states or Länder (i.e., Rheinland Palatinate, Bavaria, Hesse, North Rhine Westphalia, Lower Saxony, and Bremen), each with its own disaster control force (U.S. Army 1990b), whereas moving the PUDA stockpile would involve transporting through only two states, Colorado and Utah. However, the states in the United States are empowered with more legal authority to control activities within their borders than are the German Länder.

Moreover, the populations at risk for the two moves are quite different. Although it is not feasible to estimate the civilian population along the transport corridor and within the downwind hazard distance of the European rail movement (see Section 4.2.1), Table 7.2 provides estimates of the total municipal populations for selected cities along that route. In contrast, there are few cities of comparable size for the rail movement of the PUDA stockpile (e.g., Pueblo, Colorado, and Provo and Salt Lake City, Utah). Population values for smaller cities through which the European rail movement moved (i.e., those comparable to Salida, Leadville, and Grand Junction, Colorado, and Green River and Clover, Utah, for the PUDA movement) are not available. It should also be noted that the overall population density for the six FRG Länder ranges from a low of 151 persons $/ \mathrm{km}^{2}$ for Lower Saxony to a high of 1618 persons $/ \mathrm{km}^{2}$ for Bremen (Paxton 1990). By way of contrast, the population densities in 1988 for Colorado and Utah were approximately 32 persons $/ \mathrm{mile}^{2}\left(12.5\right.$ persons $\left./ \mathrm{km}^{2}\right)$ and 20 persons $/ \mathrm{mile}^{2}$ (7.8 persons $/ \mathrm{km}^{2}$ ), respectively (Akins 1990 ).

Table 7.2. Population of cities along European rail transport route (1987)

\begin{tabular}{lr}
\hline City & Population \\
\hline Miesau & NA \\
Saarbrucken & 187,400 \\
Ludwigshafen & 156,700 \\
Darmstadt & 134,200 \\
Frankfurt & 618,500 \\
Kassel & 188,500 \\
Bremen & 533,400 \\
Nordenham & NA \\
\hline
\end{tabular}

Source: John Paxton, ed. 1990. The Statesman's Year-Book, St. Martins Press New York, p. 534.

Finally, the agent-specific hazards presented by the stockpiles are different. Although both stockpiles include explosive munitions, the European stockpile involved nerve agents GB and VX in 8-in. and 155-mm projectiles, whereas the PUDA stockpile involves mustard agent only, configured in $105-\mathrm{mm}$ and $155-\mathrm{mm}$ projectiles, and 4.2-in. mortars. The difference in 
the type of agent has implications for health effects in the event of exposure that should be reflected in protective action strategies and emergency response plans and capabilities.

For both the European rail movement and any PUDA rail movement, the effectiveness of emergency response for persons close to the accident site would likely be minimal, since the lethal plume may arrive before sufficient response capabilities could be mobilized and deployed. This would particularly be the case if the accident occurred in a densely populated area. In a sparsely populated rural area, the mobile emergency response capability may be sufficient to provide adequate protection. If the retrograde planning basis of a maximum of $2 \mathrm{hr}$ for prepositioned capabilities to reach an accident site is assumed to be reasonable, that would be well beyond the time in which persons at risk would be exposed to lethal and sublethal concentrations of agent. The travel time of the largest credible off-site rail movement accident ( $4 \mathrm{~km}$, or 2.5 miles, for the PUDA stockpile) is on the order of $1.1 \mathrm{hr}$ under $1 \mathrm{~m} / \mathrm{s}$ winds and $35 \mathrm{~min}$ for $3 \mathrm{~m} / \mathrm{s}$ winds. Comparable values for the European stockpile $2.1 \mathrm{~km}$ (1.3-mile) accident are $35 \mathrm{~min}$ and $12 \mathrm{~min}$, respectively. Thus, fatalities, particularly for those closer to the accident site, would not be significantly reduced even with a much quicker response time for prepositioned emergency workers.

\subsubsection{Conclusions}

In the FPEIS, emergency preparedness considerations play an important role in identifying on-site disposal as the environmentally preferred alternative. The FPEIS selects on-site disposal over regional disposal because of the relative difficulty of implementing enhancements to existing emergency response capabilities along the cross-country transportation routes compared to similar enhancements around each storage depot. (See Sect. 2 for a more detailed discussion of the FPEIS selection methodology.)

None of the information presented above on recent developments in emergency preparedness would have altered the FPEIS preference for on-site disposal. In particular, there is no evidence from the European move that would suggest that emergency preparedness for the off-site disposal alternatives would be either less complex or more effective than was assumed in the FPEIS.

As discussed in Sect. 6, on-site disposal is a clear winner at PUDA based upon an examination of the human health risk measures. The continued storage alternative and the regional or national disposal alternatives would clearly be more risky than on-site disposal at PUDA and would, therefore, be rejected from further consideration. Because of this riskrelated preference for on-site disposal, there is no need to use emergency preparedness as a "tie-breaker" in the selection process at PUDA. However, the enhancements and improvements in local emergency preparedness around PUDA provide an additional advantage for on-site disposal that would be difficult to duplicate during the transportation of the PUDA inventory to TEAD. 


\section{FINDINGS AND CONCLUSIONS}

\subsection{ENVIRONMENTALLY PREFERRED ALTERNATIVE}

Recent and more detailed data than were used in the FPEIS assessment concerning the incineration technology, transportation of chemical agents and munitions, environmental resources, population, and emergency response were gathered in the Phase I process. These new data were then evaluated and compared to the FPEIS data to determine if there are changes that would warrant reconsideration of the programmatic selection of the environmentally preferred alternative.

Technology developments since the publication of the FPEIS were examined and compared to the technology-related assumptions and commitments stated in the FPEIS. The assessment focused on the experience recently gained through OVT at JACADS, but also included the CAMDS and BZ operations, as well as other technology-related developments. The purpose was to identify any problems or changes concerning the disposal technology that could cast doubt on the ability of the disposal facilities to function as predicted in the FPEIS.

CAMDS, the Army's pilot plant for testing the chemical agent-munition disposal technology, has provided very useful experience for the design, construction, and testing for the full-scale JACADS facility. The BZ disposal process was also developed based on knowledge gained from disposal operations at CAMDS and the previous incineration experience at RMA. As expected, some initial problems were encountered at both CAMDS and the BZ facility; however, these were satisfactorily resolved and the plants demonstrated the ability to dispose of the agents and munitions efficiently and in an environmentally sound manner.

The JACADS plant has also experienced the mechanical problems typically associated with the startup of industrial facilities of similar size. These have been associated mainly with the mechanical handling and processing of rockets. However, during operations, the plant has effectively incinerated chemical agent to the predicted Destruction and Removal Efficiency (DRE) of $99.9999 \%$. It is expected that any existing problems will be resolved before the OVT is completed and long before full-scale disposal operations begin. No releases of chemical agent or other emissions exceeding regulatory levels have been detected at the CAMDS, BZ, or JACADS facilities.

The JACADS facility has, so far, demonstrated that it can be routinely operated with maximum protection to the workers, to the public, and to the environment. Based on the Army's recent disposal experience, there is no new information indicating that the FPEIS conclusions would have been different if this new experience had been gained prior to the ROD.

Similarly, the recent experience gained by the Army in transporting the U.S.-owned chemical agent-munition stockpile from Europe to Johnston Island in the Pacific Ocean (Operation Retrograde) has been compared to the assumptions and commitments in the FPEIS concerning off-site transportation. The FPEIS concludes that off-site movement of chemical agent and munitions could be performed in a safe and environmentally acceptable manner. 
However, the on-site disposal alternative presented less risk and offered the potential for a more effective and more manageable emergency preparedness program.

As would have been predicted using the FPEIS transportation data analysis techniques, the European stockpile was safely transported by truck and rail from storage at Clausen, FRG, over approximately $1000 \mathrm{~km}$ (620 miles), to the shipping port at Nordenham, FRG. Generally, the safety and operational procedures and other details employed during the movement in Europe were very similar to the concepts incorporated into the FPEIS, with the exception of the use of less sturdily constructed containers than are recommended in the FPEIS.

This experience, however, must be compared to a much more complex U.S. situation. Generally, the off-site disposal alternatives in the United States would involve much larger amounts of agent and munitions to be transported from several different storage locations over many more land miles to reach the disposal site(s). Thus, compared to the European movement, the logistics problems would be magnified and the possibility of an accident would be increased by the greater distances to be traveled and the greater number of trips required. Additionally, although the stockpile was transported through six German states, states within the United States are empowered with greater legal control of their boundaries and the land within them. Thus, stronger and more complex legal barriers could be implemented within the United States to slow or halt the transport of chemical agents and munitions.

A comparison of the European stockpile movement to a potential rail movement of the PUDA stockpile highlights significant differences between the two locations. First, the potential downwind hazard distance is approximately $100 \%$ greater for PUDA. The population at risk was greater for the European movement, on average, although Salt Lake City, the most densely populated area of the PUDA movement, would be comparable to the European movement. Furthermore, the different agent and munition makeups of the two stockpiles pose different hazards with different emergency response implications. Finally, the stockpile quantity, the number of train trips, and the associated duration of hazard during rail movement would be substantially greater for the PUDA stockpile than for the European movement.

The European movement was successful, and there is no new information related to the Army's recent transportation experience that suggests the FPEIS conclusions would have been different if this new experience had been gained prior to its date of issue. In fact, if the weaker shipping container (as actually used during the movement in Europe) had been included in the FPEIS risk assessment, then the off-site disposal alternatives would have resulted in even more risk than on-site disposal.

New and more recent site-specific data of the type used in the FPEIS were evaluated and, where appropriate, included in the recalculation of the measures of risk for both on-site and off-site disposal alternatives for PUDA. At the first tier of evaluation (human health), on-site disposal was found to be significantly better than continued storage and national disposal for two of the five measures of risk. Consequently, in accordance with the FPEIS method for the assessment of risk, on-site disposal remains valid as the environmentally preferred alternative for PUDA.

Finally, in the FPEIS and the subsequent ROD, emergency preparedness is an important factor in the selection of on-site disposal as the preferred alternative for the CSDP. It was determined that emergency preparedness plans could be more efficiently developed and 
more effectively applied in the case of an accidental release with on-site disposal as opposed to off-site movement. Emergency preparedness is addressed in this study to allow evaluation of new developments in the field since publication of the FPEIS, and to provide a comparison of the CONUS sites with the emergency preparedness considerations of the movement of the European stockpile from the inland storage area to the shipping port.

Significant enhancements in fixed-site emergency preparedness have been made since the FPEIS, including funding for state and local planning efforts, improvements to EOCs implementation of effective communications and public alert systems, implementation of protective action measures, public education and emergency worker training, and emergency response exercises. Off-site transport would require more extensive emergency response preparations, involving thousands of security and response personnel, along transport corridors hundreds of miles long. Such an operation would greatly increase the difficulty of emergency planning and response by introducing significant institutional and jurisdictional problems and by providing an endless variety of locations and conditions under which a potential accident could occur.

In summary, the above information supports the FPEIS conclusion that on-site incineration, with the well-developed state of the technology, logistically simpler concept, and more effective emergency response capability, is still valid for PUDA.

\subsection{PROPOSED SCOPE FOR THE SITE-SPECIFIC EIS}

During the Phase I process, data on resources that could be affected by on-site disposal at PUDA were gathered to determine if any significant new or site-specific resources are present that could be affected by (or that could affect) construction and operation of the on-site disposal facility (including both incident-free operations and accident scenarios). These resources are population (including residential, on-post, daytime, and special populations), meteorology and air quality, surface water and groundwater, land use, ecology, socioeconomics, emergency planning and preparedness, and aircraft activity. Some of these resources are examined in the FPEIS in assessing potential impacts of the programmatic alternatives, whereas others represent new information that was not appropriate for examination at the programmatic level. No assessment of potential impacts was done during the Phase I process. Rather, the data were examined to help identify potential issues to be analyzed during the preparation of the site-specific EIS for PUDA. Results for the principal resource areas are presented below.

\subsubsection{Population}

Residential population (1986 data) within the 100-km (62-mile) zone of the site of the proposed disposal facility at PUDA increased about $2 \%$ from the 1980 (FPEIS data) population of 366,382 . Using the actual PUDA boundary, no off-post residential population was found within $3.1 \mathrm{~km}$ ( 2 miles) of the proposed disposal site. The significance of these changes has been discussed in Sect. 3.3. On-post population was found to range from about 700 in the daytime to about 100 in the nights and evenings. Special populations (infrequent events) have been identified in areas at and near PUDA. All of these data will be considered, 
in conjunction with data on residential population, in estimating fatalities in the site-specific EIS for PUDA.

\subsubsection{Meteorology and Air Quality}

The CML and WC weather conditions assumed in the FPEIS were found to be appropriate for PUDA. Meteorological data identified in this report will be used as input for atmospheric dispersion models in assessing potential impacts from construction and normal, incident-free operations. The nearest Class I PSD area is located $115 \mathrm{~km}$ (71 miles) westsouthwest of PUDA. Potential impacts of air emissions from the proposed disposal facility on this area of pristine air quality will be addressed in the site-specific EIS for PUDA.

\subsubsection{Surface Water and Groundwater}

During the collection and analysis of data for Phase I, no new information was discovered that would invalidate conclusions drawn in the FPEIS. Peak water demands for the incinerator cannot be obtained from groundwater. Process water for the proposed disposal facility would be obtained from Pueblo Reservoir on the Arkansas River, from which allocations are available. Information on groundwater resources will be used in the site-specific EIS for PUDA to assess potential environmental impacts of accidental spills of agent into water resources.

\subsubsection{Land Use}

No unique resources have been identified after examining more recent and detailed data.

\subsubsection{Ecological Resources}

Since the publication of the FPEIS, Arctic peregrine falcons have been identified as using the area within the vicinity of PUDA for feeding during migration. This brings the number of threatened and endangered species that could occur within the 100-km (62-mile) impact zone to a total of eight species. This list may be revised and expanded after a response to the request for site-specific information is obtained from the FWS and will be addressed in the site-specific EIS. Candidate species that could occur in the 100-km (62-mile) zone are given in Appendix D.

The identification of additional threatened and endangered species listed since data collection for the FPEIS, and the addition of state parks, wildlife management areas, and important natural areas do not alter the conclusions of the FPEIS; the additional information will help to better estimate the extent of effects to important ecological resources.

Information on prevailing wind direction and other meteorological conditions, the quantities of agent that could be released under WC accident scenarios, and the location and densities of ecological resources potentially at risk (where information can be obtained) will be used to estimate the extent of impacts that could occur to ecological resources in the site-specific EIS. 


\subsubsection{Social, Economic, and Cultural Resources}

Additional data relevant to an accident involving off-site chemical agent exposure were collected beyond the 10-km (6.2-mile) zone used in the FPEIS. These data include worker and resident populations located both off-post and on-post at PUDA; potentially sensitive populations (i.e., children and the elderly) by county of residence within a $100-\mathrm{km}$ zone; transient populations on PUDA and in Pueblo County; institutional populations within a $100-\mathrm{km}$ (62-mile) zone; major concentrations of employment in Pueblo County; agricultural land use and production within the 100-km (62-mile) zone; and historic and archeological sites on PUDA and within the 100-km (62-mile) zone. Detailed data on employment, services, and infrastructure in Pueblo County relevant to construction and incident-free operations were collected for Pueblo County. The identification of social, economic, and cultural resources did not yield data to alter the conclusions of the FPEIS.

\subsubsection{Aircraft Activity}

There is no significant change in aircraft activity near the site of the proposed disposal facility as compared to that presented in the FPEIS.

\subsubsection{Emergency Preparedness}

Emergency preparedness and response enhancements at PUDA have been initiated since the FPEIS. The Army has begun implementing an emergency response plan at PUDA, has funded work to upgrade existing plans of local governments, and is committed to providing technical assistance and coordination to local planning efforts. Coordination between PUDA and off-post emergency planning officials, which has been limited in the past, is increasing. 


\section{REFERENCES}

Akins, I. 1990. State Yellow Book, Monitor Publishing Company, Washington, D.C. Algermissen, S. T., and Perkins, D.M. 1976. A Probabilistic Estimate of Maximum Acceleration in Rock in the Contiguous United States, U.S. Geological Survey OpenFile Report 76-416, Denver, Colo.

Algermissen, S. T., et al. 1982. Probabilistic Estimates of Maximum Acceleration and Velocity in Rock in the Contiguous United States, U.S. Geological Survey Open-File Report 82-1033, Denver, Colo.

Algermissen, S. T., et al. 1990. Probabilistic Earthquake Acceleration and Velocity Maps for the United States and Puerto Rico, U.S. Geological Survey Miscellaneous Field Studies Map MF-2120, Denver, Colo.

ANS (American Nuclear Society) 1983. American National Standard for Estimating Tornado and Extreme Wind Characteristics at Nuclear Power Sites, ANS, LaGrange Park, Ill.

ANL (Argonne National Laboratory) 1989a. Chemical Stockpile Disposal Program: Review and Comment on the Phase I Environmental Report for the Tooele Army Depot, Tooele, Utah, ANL/EES-TM-359, Argonne, Ill., January.

ANL (Argonne National Laboratory) 1989b. Chemical Stockpile Disposal Program: Review and Comment on the Phase I Environmental Report for the Anniston Army Depot, Anniston, Alabama, ANL/EAIS/TM-5, Argonne, Ill., December.

ANL (Argonne National Laboratory) 1990a. The Chemical Stockpile Emergency Preparedness Program Management Plan, prepared for the U.S. Department of the Army, Office of the Assistant Secretary for Installations, Logistics, and Environment; and for the U.S. Federal Emergency Management Agency, Office of Natural and Technological Hazards, Argonne, Ill., March.

ANL (Argonne National Laboratory) 1990b. Chemical Stockpile Disposal Program: Review and Comment on the Phase 1 Environmental Report for the Umatilla Depot Activity, Hermiston, Oregon, ANL/EAIS/TM-33, Argonne, Ill., October.

ANL (Argonne National Laboratory) 1990c. Chemical Stockpile Disposal Program: Review and Comment on the Phase 1 Environmental Report for the Pine Bluff Arsenal, Pine Bluff, Arkansas, ANL/EAIS/TM-34, Argonne, Ill., October.

ATC (Applied Technology Council) 1978. Tentative Provisions for the Development of Seismic Regulations for Buildings, National Bureau of Standards Special Publication NBS SP-510, U.S. Government Printing Office, Washington, D.C.

Ball, L. J., et al. 1990. "TMI-2 Core Shipping Preparations," unpublished manuscript supported by the U.S. Department of Energy (DOE), Assistant Secretary for Nuclear Energy, Office of Light Water Reactor Safety and Technology under DOE Contract No. DE-ACO7-76ID01570, Washington, D.C.

Bernreuter, D. L., et al. 1989. Seismic Hazard Characterization of 69 Nuclear Plant Sites East of the Rocky Mountains, prepared by Lawrence Livermore National Laboratory 
for the U.S. Nuclear Regulatory Commission, NUREG/CR-5250, Vols. 1-3, Washington, D.C.

Blackwell, O. 1987. Report of Kentucky Community Study Group, Eastern Kentucky University Contract No. DAAA15-87-C-0015, Richmond, Ky., October.

Cain, D. 1987. Relations of Specific Conductance to Streamflow and Selected Water-Quality Characteristics of the Arkansas River Basin, Colorado, Water-Resources Investigations Report 87-4041, U.S. Geological Survey, Denver, Colo.

Carnes, S. A., et al. 1989. Emergency Response Concept Plan for Pueblo Depot Activity and Vicinity, ORNL/TM-11098, Oak Ridge National Laboratory, Oak Ridge, Tenn.

Channell, J. K., Rodgers, J. C., and Neill, R. H., 1986. Adequacy of TRUPACT-I Design for Transporting Contact-Handled Transuranic Wastes to WIPP, EEG-33/DOE/AL-10752-33, Environmental Evaluation Group, Environmental Improvement Division, Health and Environment Department, State of New Mexico, Santa Fe, N.M., July.

Colorado Air Pollution Control Division 1989. Colorado Air Quality Report to the Public-1989, Colorado Air Quality Control Commission, Denver.

Concerned Citizens (of Vermillion, Parke, Vigo, Fountain, and Tippecanoe Counties) 1987. Community Review Final Report: Disposal of VX Ton Containers, prepared for the U.S. Army, Contract No. DAAA-15-87-C-0030, Newport Study Group, Newport, Ind.

CSDP (Chemical Stockpile Disposal Program) 1986a. CSDP Public Hearing: Newport Army Ammunition Plant, Clinton, Ind., August 11, Ace-Federal Reporters, Inc., Washington, D.C.

CSDP (Chemical Stockpile Disposal Program) 1986b. CSDP Public Hearing: Tooele Army Depot, Tooele, Utah, August 14, Ace-Federal Reporters, Inc., Washington, D.C.

CSDP (Chemical Stockpile Disposal Program) 1986c. CSDP Public Hearing: Umatilla Depot Activity, Hermiston, Oreg., August 18, Bridges, Kennedy, and Felshaw Professional Reporters, Pendleton, Oreg.

CSDP (Chemical Stockpile Disposal Program) 1986d. CSDP Public Hearing: Pueblo Depot Activity, Pueblo, Colo., August 21, Ace-Federal Reporters, Inc., Washington, D.C.

CSDP (Chemical Stockpile Disposal Program) 1986e. CSDP Public Hearing: Pine Bluff Arsenal, Pine Bluff, Ark., August 25, Ace-Federal Reporters, Inc., Washington, D.C.

CSDP (Chemical Stockpile Disposal Program) 1986f. CSDP Public Hearing: Lexington-Blue Grass Army Depot, Eastern Kentucky University, Richmond, Ky., August 28, S. C. Wilder, transcriptionist.

CSDP (Chemical Stockpile Disposal Program) 1986g. CSDP Public Scoping Meeting: Anniston Army Depot, Anniston, Ala., September 3, Ace-Federal Reporters, Inc., Washington, D.C.

DOC (U.S. Department of Commerce) 1989. 1987 Census of Agriculture, Vol. 1, "Geographic Area Series, Pt. 6," Colorado State and County Data, U.S. Bureau of the Census, Washington, D.C.

DOD (U.S. Department of Defense) 1988, Base Realignments and Closures, Report of the Defense Secretary's Commission, December. 
DOE (U.S. Department of Energy) 1989. Integrated Data Base for 1989: Spent Fuel and Radioactive Waste Inventories, Projections, and Characteristics, DOE, Washington, D.C., November.

DOE (U.S. Department of Energy) 1989a. Final Version, Dry Cask Storage Study, DOE/RW-0220, DOE, Office of Civilian Radioactive Waste Management, Washington, D.C., February.

DOE (U.S. Department of Energy) 1989b. Annual Report to Congress, DOE/RW-0216, DOE, Office of Civilian Radioactive Waste Management, Washington, D.C., December.

DOE (U.S. Department of Energy) 1989c. Transporting Radioactive Material: Answers to Your Questions, DOE/DP-0064, DOE, Office of Civilian Radioactive Waste Management, Washington, D.C., August.

DOE (U.S. Department of Energy) 1989d. Federal Agencies Involved in the Implementation of the Nuclear Waste Policy Act of 1982, DOE/RW-0241, DOE, Office of Civilian Radioactive Waste Management, Washington, D.C., June.

DOE (U.S. Department of Energy) 1986. Transporting Spent Nuclear Fuel: An Overview, DOE, Office of Civilian Radioactive Waste Management, DOE/RW-0065, Washington, D.C., March.

Duff, W., et al. 1989. Operational Verification Test and Evaluation Master Plan for the Johnston Atoll Chemical Agent Disposal System (JACADS), The MITRE Corporation, McLean, Va., January.

EA Engineering, Science, and Technology, Inc. 1987. Community Review Support Study: Aberdeen Area, prepared for the Program Manager for Chemical Demilitarization, Sparks, Md.

Eggleston, H. C., 1989. Requirements Document for Secondary Steel Container, U.S. Department of the Army, Office of Deputy Chief of Staff for Operations and Plans, May 17.

EPA (U.S. Environmental Protection Agency) 1977. Guidelines for Air Quality Maintenance Planning and Analysis Volume 10 (Rev.): Procedures for Evaluating Air Quality Impact of New Stationary Sources, EPA, Research Triangle Park, N.C.

EPA (U.S. Environmental Protection Agency) 1982. STORET User Handbook, Water Quality Control Information System, Washington, D.C.

EPA (U.S. Environmental Protection Agency) 1988. U.S. Indian Tribes, Alaskan Native Villages and Related Indian Files, EPA, Office of Federal Activities, Washington, D.C.

EPRI (Electric Power Research Institute) 1988. Seismic Hazard Methodology for the Central and Eastern United States, EPRI NP-4726-A, Rev. 1, Vol. 1, Pts. 1 and 2, EPRI, Palo Alto, Calif.

Fisher, 1990. "Village Cheers as U.S. Chemical Weapons Depart," Associated Press, September 1.

Forsgren-Perkins Engineering 1988. Tooele Army Depot CSDP Facility Culinary Water and Wastewater Treatment Study, 1849 West North Temple, Suite C, Salt Lake City, Utah. 
GAO (U.S. General Accounting Office) 1991. Chemical Warfare: DOD's Successful Effort to Remove U.S. Chemical Weapons From Germany, GAO/NSAID-91-105, GAO, Washington, D.C., February.

GA Technologies, Inc. 1987. Risk Analysis of the Continued Storage of Chemical Munitions, Reports GAC-18564 and SAPEO-CDE-IS-87009, prepared for Program Executive Officer-Program Manager for Chemical Demilitarization by GA Technologies, Inc., La Jolla, Calif.

Gallegos, A. F., and Channell, J. K. 1990. Risk Analysis of the Transport of Contact Handled Transuranic (CH-TRU) Wastes to WIPP Along Selected Highway Routes in New Mexico Using Radtran IV, EEG-46/DOE/AL/58309-46, Environmental Evaluation Group, Albuquerque, N.M., August.

Hearing on CSDP, Edgewood, Md. Aug. 7, 1986. Ace-Federal Reporters.

Hearne, G. A., et al. 1988. "Colorado Ground-Water Quality," pp. 181-90 in National Water Summary 1986-Hydrologic Events and Ground-Water Quality, U.S. Geological Survey Water-Supply Paper 2325, compiled by D. W. Moody et al., U.S. Government Printing Office, Washington, D.C.

Holzworth, G. C. 1972. Mixing Heights, Wind Speeds, and Potential for Urban Air Pollution Throughout the Contiguous United States, U.S. Environmental Protection Agency, Office of Air Programs, Research Triangle Park, N.C.

Jacobs Engineering Group, Inc., and Schneider EC Planning and Management Services 1987. Emergency Response Concept Plan, Report SAPEO-CDE-IS-87007, Program Manager for Chemical Demilitarization, Aberdeen Proving Ground, Md.

Jacobs Engineering Group, Inc. 1989. Training Needs Analysis for the Chemical Emergency Response Program for Pueblo Depot Activity, Pasadena, Calif., prepared for the Chemical Emergency Response Program for Pueblo Depot Activity, Chemical Demilitarization Program Office, Aberdeen Proving Ground, Md.

Kelly, D. L., et al. 1978. "An Augmented Tornado Climatology," Monthly Weather Review 106, 1172-83.

Menke, J. L., et al. June 1991. Evaluation of the GB Rocket Campaign: Johnston Atoll Chemical Agent Disposal System Operational Verification Testing, MTR-91W00039 prepared for the Program Manager for Chemical Demilitarization, Aberdeen Proving Ground, Md., by The MITRE Corporation, McLean, Va.

Miller, L. 1989. "Environmental Policy: Federal Republic of Germany," pp. 207-34 in International Public Policy Sourcebook, Vol. 2, Education and Environment, ed. F. N. Bolotin, Greenwood Press, Westport, Conn.

The MITRE Corporation 1987. Conceptual Design of a Chemical Munitions Transport Packaging System, Report WP-8700347, The MITRE Corporation, McLean, Va.

"Nebraska Halts TMI Shipment for Four Hours," Los Angeles Times, 19, July 24, 1986.

NOS (National Oceanic Service) 1990. Flight Information Publication, NOS, Riverdale, Md. NRC (U.S. Nuclear Regulatory Commission) 1977. Final Environmental Impact Statement on the Transportation of Radioactive Material by Air or Other Modes, Vol. 1, Docket No. PR-71, 73, NUREG-0170, NRC, Office of Standards Development, December. 
OES (Office of Emergency Services) 1990. Draft Emergency Response Plan and Implementing Procedures for Chemical Accidents at Pueblo Depot Activity, Pueblo County, Pueblo, Colo.

Owen, J., 1990. "Plan Draws Cheers, Jeers," Stars and Stripes 24, March 8.

Owen, J., and Davidson, P., 1990. "Nerve Gas Safety Plan Explained," Stars and Stripes, 1-28, March 9.

Paxton, John, ed. 1990. The Statesman's Year-Book, St. Martins Press New York, p. 534.

Perry, J., and G. Nelson, 1993. Cryofracture/Incineration Demonstration Plant (CIDP): Risk Assessment for Pueblo Depot Activity (PUDA), The MITRE Corporation, McLean, VA, March 26.

Rogers, G.O., et al. 1990. Evaluating Protective Actions for Chemical Agent Emergencies, ORNL/TM-6615, Oak Ridge National Laboratory, Oak Ridge, Tenn.

Schneider Engineers 1988. "Updated Site Assessment for Pueblo Depot Activity and Adjacent Jurisdictions," in Emergency Response Site Assessments for the Chemical Stockpile Disposal Program, prepared under subcontract to Jacobs Engineering Group, Inc., for the Program Manager for Chemical Demilitarization, Aberdeen Proving Ground, Md.

Schneider Engineers 1989. Final Report, Phase I Emergency Program Development, Pueblo Depot Activity, prepared under subcontract to Jacobs Engineering Group, Inc., for the Program Manager for Chemical Demilitarization, Aberdeen Proving Ground, Md., May.

SAIC (Science Applications International Corporation, Inc.) 1990. Historical Overview of Domestic Spent Fuel Shipments-Update, prepared for Oak Ridge National Laboratory and the Office of Civilian Radioactive Waste Management Transportation Operations Office under Subcontract No. 88-17B-997962V/1, Oak Ridge, Tenn., July.

Siegel, J., 1986. "Trains Carrying Damaged TMI Fuel Planned," Associated Press, February 13.

"State Part of Path for TMI Waste," Akron Beacon Journal, July 2, 1986.

Southwest Research Institute 1990. Report of Results from the Incineration of Agent VX at the CAMDS in Tooele, Utah, San Antonio, Tex., June.

Southern Research Institute 1990. Results of the RCRA Trial Burn for the Liquid Incinerator at the Johnston Atoll Chemical Agent Disposal System, prepared for the Program Manager for Chemical Demilitarization, Aberdeen Proving Ground, Md. by Southwest Research Institute, Birmingham, Ala., June.

Thom, H. C. S., 1963. "Tornado Probabilities," Monthly Weather Review 91(10-12) 730-36.

Umatilla County Soil and Water Conservation District 1987. Final Report for U.S. Army, Evaluation of the DPEIS for the Destruction of Chemical Munitions Stored at Umatilla Army Depot and Other Army Facilities, Contract No. DAAA-15-87-Q-0086, Pendleton, Oreg., September 30.

U.S. Army 1983. Final Environment Impact Statement, Johnston Atoll Chemical Agent Disposal System (JACADS), U.S. Army Toxic and Hazardous Materials Agency, Aberdeen Proving Ground, Md. 
U.S. Army 1984a. Final Report RCRA Part B Permit Application, Selected Facilities, Pueblo Depot Activity, Pueblo, Colorado 81001, EPA ID No. CO 8213820725, prepared for Tooele Army Depot Complex, Pueblo Depot Activity, Pueblo, Colo., under contract with Department of the Army, Huntsville Division, Corps of Engineers, Huntsville, Ala., for submittal to U.S. Environmental Protection Agency, Region VIII, Denver.

U.S. Army 1984b. Installation Environmental Assessment, Pueblo Depot Activity, Pueblo, Colorado, Revision of the December 1982 Draft, Headquarters, U.S. Army Depot System Command, Tooele, Utah, November.

U.S. Army 1985. Annex C (Chemical Accident/Incident Control Plan) to Pueblo Depot Activity Disaster Control Plan, Pueblo Depot Activity, Pueblo, Colo.

U.S. Army 1986a. Pueblo Depot Activity Hazardous Waste Management Plan, prepared by B. Rossi, Chemical Engineer, August 4.

U.S. Army 1986b. Air Pollution Emission Permit Application for the Department of the Army Pueblo Depot Activity Chemical Stockpile Disposal System, draft, submitted to the Colorado Department of Health Air Pollution Control Division, Denver, prepared for Program Manager for Chemical Munitions, Aberdeen Proving Ground, Md.

U.S. Army 1987a. Chemical Stockpile Disposal Program-Chemical Weapons Movement History Compilation, SAPEO-CDE-IS-87001, Program Executive Officer-Program Manager for Chemical Demilitarization, Aberdeen Proving Ground, Md.

U.S. Army 1987b. Chemical Stockpile Disposal Program-Transportation of Chemical Agents and Munitions: A Concept Plan, SAPEO-CDE-IS-87003, Program Executive Officer-Program Manager for Chemical Demilitarization, Aberdeen Proving Ground, Md.

U.S. Army 1988a. Chemical Stockpile Disposal Program Final Programmatic Environmental Impact Statement, Vols. 1-3, Program Executive Officer-Program Manager for Chemical Demilitarization, Aberdeen Proving Ground, Md., January.

U.S. Army 1988b. Record of Decision for the Chemical Stockpile Disposal Program, Office of the Under Secretary of the Army, Washington, D.C., February 23.

U.S. Army 1988c. Chemical Stockpile Disposal Program-Final Phase I Environmental Report for Tooele Army Depot, Tooele, Utah, Program Executive Officer-Program Manager for Chemical Demilitarization, Aberdeen Proving Ground, Md., September.

U.S. Army 1988d. System Safety Management Plan for the Chemical Stockpile Disposal Program, Program Manager for Chemical Demilitarization, Aberdeen Proving Ground, Md.

U.S. Army 1989a. Disposal of Chemical Agents and Munitions Stored at Tooele Army Depot, Tooele, Utah-Final Environmental Impact Statement, Program Manager for Chemical Demilitarization, Aberdeen Proving Ground, Md.

U.S. Army 1989b. Disposal of Chemical Agents and Munitions Stored at Anniston Army Depot, Anniston, Alabama-Final Phase I Environmental Report, Office of the Program Manager for Chemical Demilitarization, Aberdeen Proving Ground, Md., July.

U.S. Army 1990a. Disposal of Chemical Agents and Munitions Stored at Umatilla Depot Activity, Hermiston, Oregon-Final Phase I Environmental Report, Office of the 
Program Manager for Chemical Demilitarization, Aberdeen Proving Ground, Md., February.

U.S. Army 1990b. Disposal of Chemical Agents and Munitions Stored at Pine Bluff Arsenal, Pine Bluff, Arkansas-Final Phase I Environmental Report, Office of the Program Manager for Chemical Demilitarization, Aberdeen Proving Ground, Md., May.

U.S. Army 1990c. Chemical Accident/Incident Response and Assistance (CAIRA) Operations, Pamphlet 50-6, Headquarters, U.S. Army, Washington, D.C.

U.S. Army 1990d. 59th Ordinance Brigade OPLAN-4332 (Retrograde of Chemical Munitions from Federal Republic of Germany), Headquarters 59th Ordinance Brigade, APO, New York, N.Y.

U.S. Army 1990e. Steel Box European After Action Report, Headquarters, U.S. Army, Europe and Seventh Army, APO, New York, N.Y.

U.S. Army 1991a. Realignment of Pueblo Depot Activity, Colorado with Transfers to Tooele Army Depot, Utah and Red River Army Depot, Texas-Final Environmental Impact Statement, U.S. Army Corp of Engineers, Omaha, Neb., August.

U.S. Army 1991b. After Action Report for the Chemical Retrograde Operation, draft, Office of the Deputy Chief of Staff for Operations and Plans, Washington, D.C. January 9.

U.S. Army 1991c. Chemical Accident/Incident Response and Assistance (CAIRA) Operations, Pamphlet 50-6, Headquarters, U.S. Department of the Army, Washington, D.C.

U.S. Army 1991d. Final Environmental Impact Statement for Disposal of Chemical Agents and Munitions Stored at Anniston Army Depot, Anniston, Alabama, Program Manager for Chemical Demilitarization, Aberdeen Proving Ground, Md.

U.S. Army and FEMA (U.S. Federal Emergency Management Agency) 1988. Memorandum of Understanding, "Chemical Stockpile Disposal Program," U.S. Department of the Army, Washington, D.C.

USATHAMA (U.S. Army Toxic and Hazardous Materials Agency) 1990. Enhanced Preliminary Assessment Report: Pueblo Depot Activity, Pueblo, Colorado, CETHA-BC-CR-90045, prepared for USATHAMA, Aberdeen Proving Ground, Md., by Ebasco Environmental, Lakewood, Colo., under the supervision of Environmental Assessment and Information Sciences Division, Argonne National Laboratory, Argonne, Ill.

U.S. Congress 1985. Managing the Nation's High Level Radioactive Waste, Office of Technology Assessment, Washington, D.C.

U.S. Congress 1986. Transportation of Hazardous Materials, OTA-SET-304, Office of Technology Assessment, Washington, D.C., July.

Watts, K. R., and Ortiz, R. F. 1990. Geohydrology and Ground-Water Quality at the Pueblo Depot Activity Landfill near Pueblo, Colorado, Water-Resources Investigations Report 89-4143, U.S. Geological Survey, Denver, Colo.

Whitacre, G. C., et al. 1986. Personal Computer Program for Chemical Hazard Prediction (D2PC), U.S. Army Chemical Research and Development Centers, Aberdeen Proving Ground, Md. 


\section{APPENDIX A \\ IMPACT ANALYSES IN THE FINAL PROGRAMMATIC ENVIRONMENTAL IMPACT STATEMENT}

This appendix provides a summary of the impact analyses conducted in the Final Programmatic Environmental Impact Statement (FPEIS), including the method and data used to identify the programmatic environmentally preferred alternative, the examination of the acceptability of the alternative for Pueblo Depot Activity (PUDA), and nonrisk impact analyses conducted for the stockpile at PUDA. Because the Army's stockpile of chemical agents contains some of the most toxic materials in the world, and because some of the present storage installations are located near highly populated areas, public concern about the safety of the proposed disposal alternatives was the key issue addressed in the FPEIS. Specifically, concerns about the safety of incineration operations and about impacts to human health from both incident-free operations and accidental releases of chemical agent became the primary focus of the FPEIS impact analyses.

\section{A.1 IDENTIFYING THE ENVIRONMENTALLY PREFERRED ALTERNATIVE}

\section{A.1.1 Approach Taken in the Programmatic Assessment}

To categorize the environmental impacts of the programmatic disposal alternatives, the FPEIS identified three distinct activities required for the destruction of the continental United States (CONUS) stockpile: (1) construction (or modification) of disposal facilities (incinerators and shipping and receiving facilities); (2) disposal operations, including transportation (offsite, as well as on-site); and (3) decommissioning of all disposal facilities upon completion of the program. These activity categories existed for each programmatic disposal alternative, although the applicability and phasing of these activities at each storage installation were dependent on each particular alternative.

Early on, the construction and decommissioning activities were determined to be rather insignificant in regard to the ability to use impacts from these activities in distinguishing among the various programmatic disposal alternatives. Construction activity at each storage location (regardless of the alternative) would be typical of that for any medium-scale industrial facility.

In contrast, the nature and significance of the environmental impact of disposal operations depend upon whether or not the operations would be incident free. Therefore, incident-free disposal operations were defined as those occurring without any intentional release of chemical agent above prescribed emission levels. Abnormal operations were defined as those involving major accidents with off-site consequences. It is obvious that accidents could have major environmental consequences. These consequences could include 
human fatalities and chronic illnesses, destruction of wildlife and wildlife habitat, destruction of economic resources, and adverse impacts on the quality of life in the affected areas.

Fortunately, such high-consequence accidents would be unlikely. This low likelihood would be ensured principally through plant design, munition packaging, and well-conceived and well-implemented transportation and operating procedures. The area affected by (and the potential severity of) accidents would be specific both to the storage site and the point of occurrence along the transportation corridor. The impacts from potential accidents would be largely dependent upon population distributions, the chemical agents and munitions involved, and natural conditions and features at the accident location. Hence, the principal thrust of the FPEIS was directed toward the examination of accident scenarios, their probabilities of occurrence, and attendant environmental impacts.

\section{A.1.2 Approach to the Analysis of Accidents}

In support of the FPEIS, a comprehensive study was performed to identify the credible accidents and the expected effects on human health, ecological systems, water resources, and socioeconomic resources. Such accidents were identified in risk analyses (GA Technologies 1987a, 1987b, and 1987c) and integrated by MITRE Corporation and Oak Ridge National Laboratory (ORNL) (U.S. Army 1988).

Each programmatic disposal alternative was included in the study. The principal areas of focus were plant operations; off-site transportation (for national, regional, and partial relocation options); on-site transportation via truck; and munition-handling operations. Accident initiators that were considered included equipment failures and human error, as well as external events (seismic events, meteorites, tornadoes, high winds, lightning, and air crashes). In addition, crashes (truck, train, and airplane) and train derailment were considered as initiators for the transportation accidents. Except for the inventory differences among storage installations and certain site-specific events, such as earthquakes and tornadoes, the hazards associated with plant operations are the same for all sites and all disposal alternatives.

Some 3000 potential accidents were identified and included in the programmatic analysis. Each potential accident was characterized by its probability (i.e., its expected frequency); its source size (i.e., the size of the release as expressed by weight of specific chemical agent); the type of agent released; its mode of release (e.g., spill, detonation, fire); the possible accident location (e.g., storage area, disposal plant, along a transportation corridor); and the duration of time during which that accident could occur (i.e., the total time during which agent could be released, from the onset of the disposal program until the completion of that particular activity). A computerized atmospheric dispersion method was used to characterize each accident involving agent release in terms of its plume geometry and its lethal downwind distance; fatalities were estimated for these accidents using 1980 census data (DOC, Bureau of the Census 1980) around the appropriate site of release.

Because it is impossible to develop a "no-risk" alternative for the disposal of the chemical agent stockpile, the possibilities of an accident and the resulting adverse impacts were included in a hazards analysis to determine the relative importance of each accident. The selected measure of the hazard was the "risk." The risks associated with the numerous activities of the programmatic disposal alternatives were quantified and were then used to 
compare the hazards associated with each programmatic alternative. Risk analyses have been widely used in the nuclear and chemical industries to evaluate related hazards and to communicate these results to both the public and decision makers.

To assess the impacts of accidents on human health and environmental and socioeconomic resources, various probabilistic measures of risk were developed and applied to each programmatic alternative for comparison among alternatives. Five measures of risk were chosen:

1. Probability of one or more fatalities. The chance that there will be at least one fatality at a given site or along a transportation corridor, or for the nation as a whole, during implementation of a given programmatic alternative. This measure was computed mathematically as the sum of probabilities for only those credible accidents that result in one or more fatalities under conservative most likely meteorological conditions; this measure of risk was expressed as a probability or frequency per stockpile (e.g., $2 \times 10^{-5}$ ).

2. Maximum number of fatalities. The maximum human health consequences among all credible accidents at a site or along a transportation corridor, or for the nation as a whole, for a given programmatic alternative. This measure was computed as equal to the largest number of fatalities associated with that single credible accident that has the greatest lethal downwind distance under worst case meteorological conditions; this measure of risk was expressed as fatalities (e.g., 2100 people).

3. Expected fatalities. A statistical measure equal to the sum of the risk contribution of all credible accidents at a site or along a transportation corridor, or for the nation as a whole, for a given programmatic alternative. This measure was computed mathematically as the summed product of probabilities for all credible accidents and the fatalities for those same accidents under most likely meteorological conditions. This measure of risk was expressed as fatalities (e.g., $9 \times 10^{-4}$ ). This risk measure is widely used in the nuclear and chemical industries to evaluate the hazards associated with these industries. It is regarded to be the best measure for representing the integrated hazards associated with numerous activities for a particular action.

4. Person-years at risk. A statistical measure equal to the product of the number of persons near a site or along a transportation corridor who are at risk from the credible accident (that has the greatest lethad downwind distance for a given programmatic alternative) and the length of time during which that accident could occur. This measure of risk was expressed in person-years (e.g., $5 \times 10^{6}$ person-years).

5. Expected plume area. A statistical measure expressing the cumulative risk contribution of all potential plume areas from all credible accidental agent releases for a given programmatic alternative. This measure was computed mathematically as the summed product of all accident probabilities and the resulting plume areas; it is analogous to expected fatalities and is computed in an identical manner except that the plume area is used instead of the number of fatalities. This measure of risk, expressed in units of area (e.g., $3 \times 10^{-3} \mathrm{~km}^{2}$ ), is sensitive not only to the size of the areas potentially affected by releases, but also to the probabilities of those releases. This risk measure was used as the surrogate for (or indicator of) impacts to environmental, cultural, and socioeconomic resources. 
Pictograms (as shown in Figs. A.1 and A.2) were developed to present the results of this risk analysis in a format that could be easily comprehended by the public and would not reveal classified details (such as agent or munition quantities) for the site-specific stockpiles. Pictograms display a pictorial indicator (the darkness of the shading) of the relative magnitude of each of the preceding measures of risk. This array of data allows direct comparison of risk at all sites for a given programmatic disposal alternative or, alternatively, comparison among all alternatives for a given site. Both sets of pictograms are employed and presented in the FPEIS (U.S. Army 1988). These risk pictograms provide a visual impression of the relative magnitude of public risk for all combinations of alternatives and locations; they contain the data used in the method for the selection of the environmentally preferred alternative.

\section{A.1.3 Method for Identifying the Environmentally Preferred Alternative}

The Army and its subcontractors developed a method (U.S. Army 1988) for systematically comparing the programmatic alternatives to select an environmentally preferred alternative. That method was based on a comparison of alternatives in terms of the activities associated with implementing each alternative and the impacts of those activities under both normal operations and accident scenarios. Although the principal purpose of the method was to facilitate the selection of the environmentally preferred alternative, the method as presented in the FPEIS also allowed other interested and affected groups to compare the public health and environmental impacts of the various alternatives and identify the public health and environmental trade-offs associated with each programmatic alternative.

The method used to identify the environmentally preferred alternative consisted of a sequential consideration and comparison of the factors embracing the programmatic objectives of no fatalities and minimal or no environmental impact. This comparison involved three consecutive tiers of examination for each programmatic alternative: (1) the comparisons were first made for human health impacts using the previously defined measures of risk; (2) the "expected plume area" was then used for comparison of ecosystem and environmental impacts; and, finally, (3) the feasibility and potential effectiveness for emergency planning and preparedness were used as a basis for comparison.

These three tiers of comparison were applied sequentially; if an alternative proved to be significantly worse than others on the basis of human health impacts, it was removed from further consideration. Similarly, if a single alternative was significantly superior to all others on the basis of human health impacts, it was to be selected as the environmentally preferred alternative. If two or more alternatives proved to be relatively equivalent (but superior to the other, rejected alternatives) during this first tier of comparison, then these alternatives were selected for inclusion in the next tier of comparison (i.e., ecosystem and environmental impacts). 

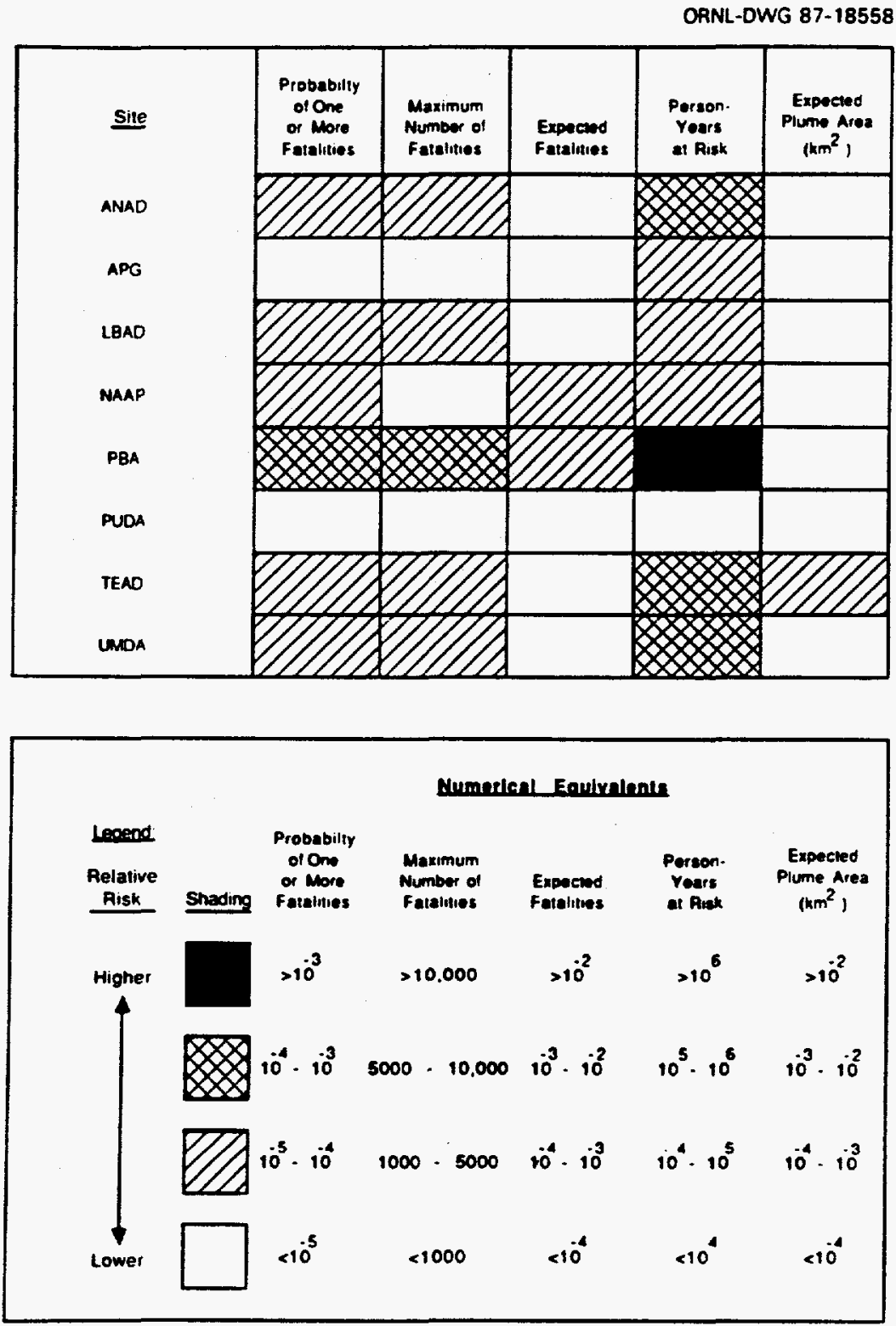

Fig. A.1. Risk with mitigation: site-specific comparison for on-site disposal (Risk along transportation corridors is not included. This diagram also does not include the risk associated with approximately 3 years of stockpile storage at the existing storage sites.) 
ORNL-DWG 87-18566

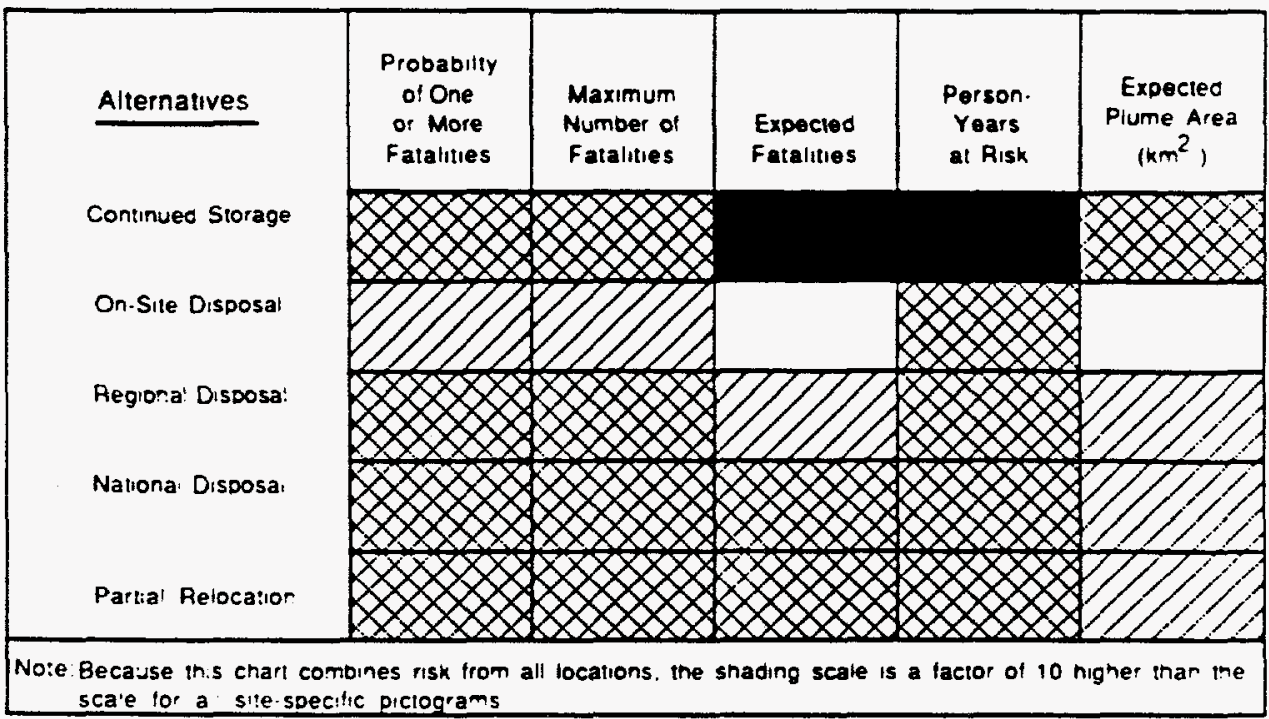

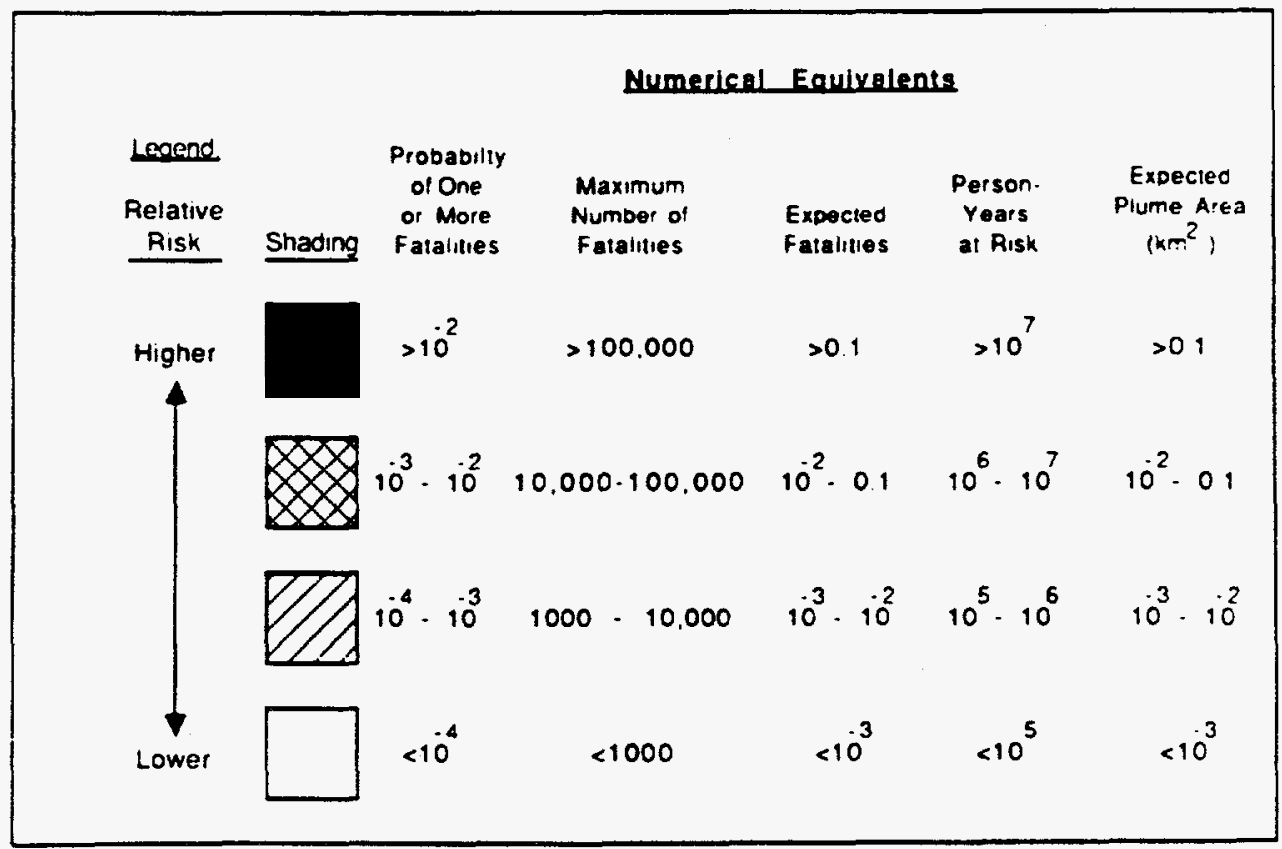

Fig. A2 Risk with mitigation: comparison for programmatic alternatives, all locations combined. (For the disposal alternatives, this diagram does not include the risk associated with approximately 3 years of stockpile storage at the existing storage sites.) 
The same technique was used in the second tier of comparison to compare only those alternatives that survived the first tier; this second tier of comparison considered the potential for ecosystem and environmental impacts. If there were still alternatives that were judged to be relatively equivalent following this comparison, they were compared on the basis of the feasibility and potential effectiveness for emergency planning and preparedness (i.e., the third and final tier of the selection method).

Improved emergency response planning and preparedness can significantly reduce both the maximum number of fatalities and the expected fatalities in the unlikely event of catastrophic agent release. However, no proven or acceptable method exists to quantify this potential for reduction in impacts. Nevertheless, implementation of an emergency response program yielding comparable reductions would be more difficult, if not impossible, along the transportation routes as compared with implementation at any or all of the eight existing storage installations.

Finally, if no clear choice could be made after three levels of comparison, then no single environmentally preferred alternative exists. In any event, at whichever tier a final choice was made, the environmentally preferred alternative would then be examined with respect to the stockpile at each installation to ensure that the selection method had indeed identified an alternative that was correct for each stockpile.

For the purpose of accepting or rejecting alternatives at each tier, a determination of the relative significance of the risk measures was made. The accident and risk analyses attempted to ensure that uncertainties about the values for the five measures of risk were treated consistently and systematically for all alternatives. It was acknowledged that the values for the probability of one or more fatalities, the expected fatalities, and the expected plume area might be in error by as much as a factor of 10 in either direction. However, the maximum number of fatalities did not depend on accident probabilities or frequencies and therefore had no expressed uncertainty. At each tier in the selection method, a comparison was made between those risk values shown in the pictograms for each alternative. Because actual numerical values for the five measures of risk were classified and could not be released for public review and because the pictograms used shadings and patterns to depict the range of each measure of risk, it was determined that a difference of two shading patterns (i.e., a difference of two orders of magnitude or a factor of 100 ) would be used as the criterion to define the significance of differences between alternatives.

In view of the preceding criterion, it is important not to emphasize the absolute values of the risk measures; rather, differences between the risk measures become the key to the comparisons. Significant (i.e., valid) differences in one or more measures of risk depict a definite risk difference and are sufficient to reject the alternatives with greater risks.

Furthermore, if there are consistent differences in the measures of risk between alternatives (even at one order of magnitude of difference in the pictograms), this consistent difference is an indication that significant differences between alternatives may exist from an overall perspective. However, such consistent differences were never used in the selection method to either select or reject an alternative. 


\section{A.1.4 Data Used in the Programmatic Assessment}

Data needed for the FPEIS assessment were drawn from several support studies, each of which was separately published and incorporated by reference into the FPEIS. Key support studies addressed (1) packaging, (2) transportation, (3) safety improvements, (4) hazards, (5) risk, (6) monitoring, and (7) emergency response. Of these, the analysis and results of the risk study were the most important in the selection of the environmentally preferred alternative.

The data used in the FPEIS risk analysis were of two broad types: (1) historical data derived from records of a large number of actual events that are related to specific types of accidents or events leading to accidents, and (2) hypothesized data derived from largely subjective modeling of assumed accident sequences with the aid of fault and event trees. The use of fault and event trees is a standard procedure to investigate sequences of occurrences in a complex system.

GA Technologies (GA Technologies 1987a, 1987b, 1987c), with technical assistance from H\&R Technical Associates, JBF Associates, and Battelle-Columbus Laboratories, conducted the comprehensive assessment of accident probabilities for all munition types. The event and fault tree analyses, together with information on mechanical and thermal threshold conditions for each munition type, were used to estimate the probability of agent release and the quantity of agent released. Some accidents were postulated to be caused by external initiating events (i.e., those outside U.S. Army control). Table A.1 summarizes the assumed frequencies of these accidents for PUDA.

The human health impact at downwind locations following an accidental release of agent would depend on meteorological conditions that dictate the extent of atmospheric dispersion. The FPEIS used the D2PC atmospheric dispersion model (Whitacre et al.1986) to predict downwind transport of agent. The D2PC computer program (or code) is an air dispersion model that assumes a Gaussian distribution of agent in the vertical and cross-wind directions as the agent disperses downwind. This assumption has been documented extensively in the literature and is used by a multitude of current models (EPRI 1985). Although more sophisticated dispersion codes are available, the assumption of straight-line transport with unvarying meteorological conditions results in conservative estimates of the effects of releases because the major parameter used in subsequent analyses was the distance to a given dose rate. This simple, conservative approach, while inappropriate for estimating the impacts of any given release under real-time conditions, is appropriate for analyzing and comparing the potential effects of postulated accidental releases. A particular location was not specified in the D2PC model runs; rather, a generic location was used because of the number of potential release sites at each facility as well as the potential for release during transportation. Therefore, identical downwind distances were obtained for identical accidents for all alternatives.

In the FPEIS, results from the D2PC model were obtained for two generic meteorological conditions: conservative most likely and worst case. The conservative most likely scenario represents a frequently occurring meteorological condition that results in relatively large doses compared with other frequently occurring conditions. Specifically, the neutral atmospheric stability (Class D) with a wind speed of $3 \mathrm{~m} / \mathrm{s}(6.7 \mathrm{mph}$ ) was 
Table A.1. Site-specific frequencies of external initiating events for Pueblo Depot Activity

\begin{tabular}{ll}
\hline \multicolumn{1}{c}{ Event } & Frequency \\
\hline & \\
Large aircraft crash & $5.9 \times 10^{-5}$ \\
(events/year/mile $)^{2}$ & \\
& \\
Small aircraft crash & $1.0 \times 10^{-4}$ \\
(events/year/mile $\left.{ }^{2}\right)$ & \\
& \\
Meteorite $(>1.0 \mathrm{lb}$ ) & \\
strikes (events/year/ft $\left.{ }^{2}\right)$ & $6.4 \times 10^{-13}$ \\
& \\
Earthquakes (events/year) & \\
$0.15 \mathrm{~g}$ & \\
$0.2 \mathrm{~g}$ & $1.5 \times 10^{-4}$ \\
$0.25 \mathrm{~g}$ & $7.0 \times 10^{-5}$ \\
$0.3 \mathrm{~g}$ & $4.0 \times 10^{-5}$ \\
$0.4 \mathrm{~g}$ & $2.5 \times 10^{-5}$ \\
$0.5 \mathrm{~g}$ & $1.2 \times 10^{-5}$ \\
$0.6 \mathrm{~g}$ & $6.0 \times 10^{-6}$ \\
$0.7 \mathrm{~g}$ & $3.5 \times 10^{-6}$ \\
& $2.5 \times 10^{-6}$ \\
Tornadoes (events/year) & \\
$150 \mathrm{mph}$ windspeed & $1.0 \times 10^{-5}$ \\
$200 \mathrm{mph}$ windspeed & $1.0 \times 10^{-6}$ \\
$250 \mathrm{mph}$ windspeed & $1.0 \times 10^{-7}$ \\
\hline
\end{tabular}

Sources: American Nuclear Society 1983. American National Standard for Estimating Tornado and Extreme Wind Characteristics at Nuclear Power Sites, American Nuclear Society, LaGrange Park, Ill.; GA Technologies, Inc. 1987. Risk Analysis of the On-Site Disposal of Chemical Munitions, Reports GAC - 18562 and SAPEO-CDE-IS-87020, prepared for Program Executive Officer-Program Manager for Chemical Demilitarization by GA Technologies, Inc., La Jolla, Calif.

selected as the conservative most likely condition. The worst case scenario represents a credible condition that results in near-maximum doses. Specifically, a stable atmosphere (Class E) with a wind speed of $1 \mathrm{~m} / \mathrm{s}(2.2 \mathrm{mph})$ was chosen for the worst case condition. Other atmospheric conditions were kept constant for the two meteorological scenarios. Wind direction was not specified but was assumed to remain constant throughout individual runs of the D2PC model. Downwind distances and areas that were predicted by the model were 
subsequently rotated about the point of release to evaluate all directions of interest. The height of the mixed layer of the atmosphere was assumed to be $750 \mathrm{~m}$ ( $2460 \mathrm{ft}$ ).

The D2PC code predicts the dose of agent (defined as the mathematical product of agent concentration and the duration of exposure) expected at locations downwind of the release point. Within each downwind dispersion plume were three dose-response contours, representing fatality rates of $0 \%, 1 \%$, and $50 \%$. The dose corresponding to the $0 \%$ rate (also called the "no-deaths" dose in the FPEIS) is the largest dose that would result in no fatalities to healthy adults. Figure A.3 illustrates the plume geometries and dose-response contours under the two meteorological conditions used in the FPEIS.

To simplify the analysis of the many accidents identified in the FPEIS risk analysis, the accidents were grouped into categories defined by their downwind no-deaths distance. These downwind no-deaths distance categories were used generically in the FPEIS to (1) define all accidents by category and (2) estimate fatalities by category. The distance categories used in the FPEIS are shown in Table A.2. Every accidental release was assigned a distance category, and the maximum downwind boundary of that category was used to represent the entire class of similar releases. For example, an accidental release that was predicted by the D2PC code to result in a downwind no-deaths distance of $11 \mathrm{~km}$ ( 7 miles) was placed into the 10- to 20-km (6- to 12-mile) accident category, and a distance of $20 \mathrm{~km}$ (12 miles) was used to characterize that particular accident in the FPEIS. Human health impacts, as defined by potential fatalities, were based upon the generic plumes described by these distance categories.

In the FPEIS, the distribution of population around each Army installation was taken from 1980 Bureau of the Census data. The coordinates of the census enumeration district centroids were first used to estimate the boundaries and areas of each district. Next, a population density was estimated within these areas. Finally, a predefined grid of very small cells [roughly $370 \times 370 \mathrm{~m}(1200 \times 1200 \mathrm{ft})$ ] was overlaid on the distributed population, and the number of people per cell was determined. This grid-based population was used in the estimation of fatalities from accidental releases of agent.

Fatality estimates were developed by overlaying the plume geometries [including the three dose-response contours (50\% lethal dose, $1 \%$ lethal dose, and no deaths)] on the population grid. First, the number of people between each dose-response contour was counted. Then "fatality multipliers" were applied to the populations in each zone as follows: of the people inside the $50 \%$ dose-response contour, $75 \%$ were assumed to die; $25 \%$ of the people in the region between the $50 \%$ and the $1 \%$ dose-response contours were assumed to die; and $0.5 \%$ of the people in the region between the $1 \%$ dose-response and the no-deaths contours were assumed to die.

This fatality estimation process was repeated 360 times for each downwind no-deaths distance category and for each of the two meteorological conditions. That is, each plume was rotated in increments of one compass degree around the point of release, and fatality estimates were computed for each of these increments. Among all 360 computations, the absolute largest number of fatalities was identified in the FPEIS as the "maximum number of fatalities" associated with that particular downwind no-deaths distance category. This computational technique does not take wind direction into 
ORNL DWG $87-1246 R$

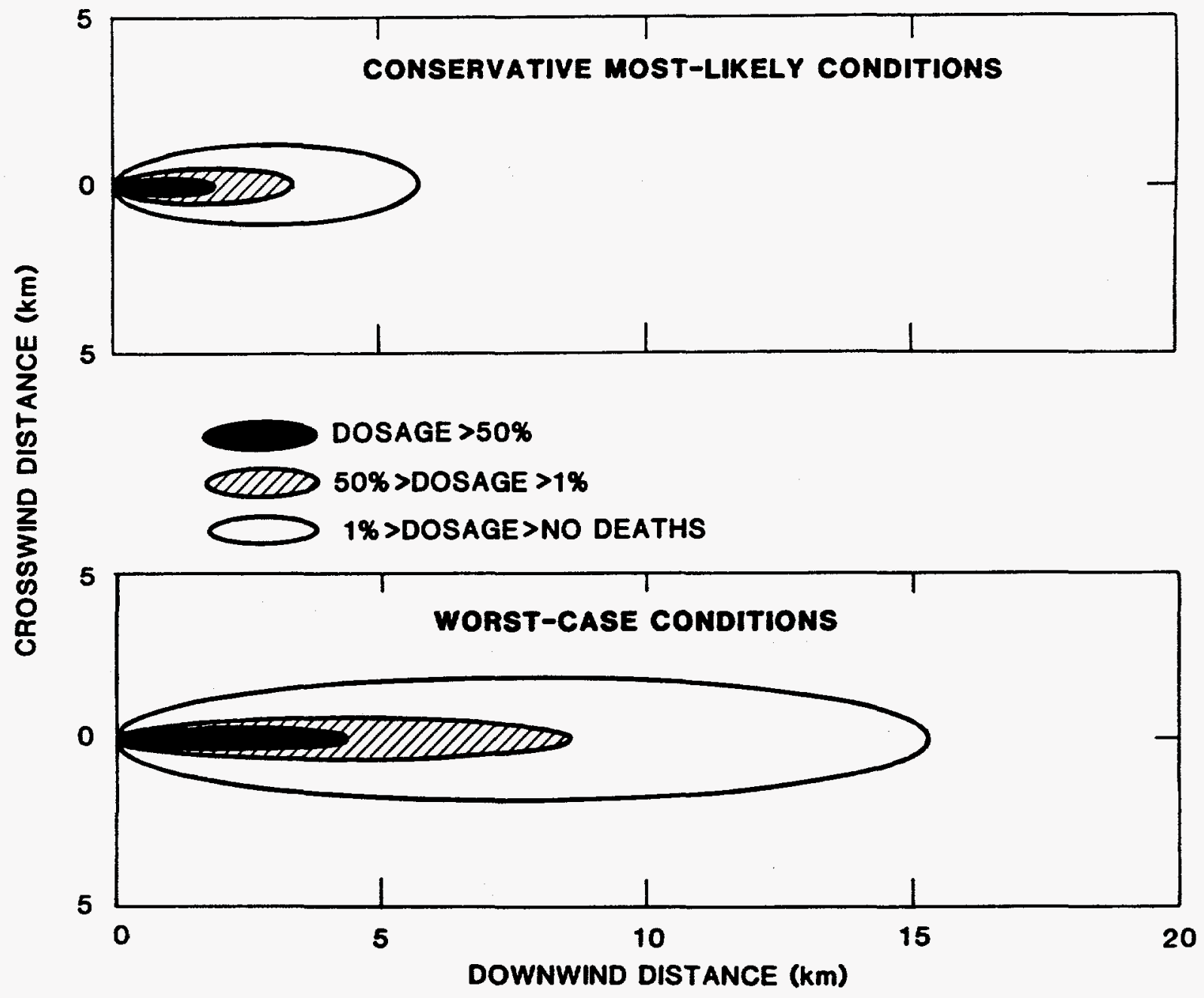

Fig. A.3. A hypothetical scenario illustrating plume distances and shapes for the same accident under different meteorological conditions. 
Table A.2. Downwind no-deaths distance categories used to characterize chemical agent releases

\begin{tabular}{cccc}
\multicolumn{2}{c}{$\begin{array}{c}\text { Predicted accident } \\
\text { downwind distance }(\mathrm{km})^{a}\end{array}$} & \multicolumn{2}{c}{ Associated plume area $\left(\mathrm{km}^{2}\right)$} \\
\hline $\begin{array}{c}\text { Greater than } \\
\text { or equal to }\end{array}$ & But less than & $\begin{array}{c}\text { Conservative most likely } \\
\text { meteorological conditions }\end{array}$ & $\begin{array}{c}\text { Worst case } \\
\text { meteorological conditions }{ }^{c}\end{array}$ \\
\hline $0.5^{d}$ & 1 & 0.07 & 0.03 \\
1 & 2 & 0.28 & 0.14 \\
2 & 5 & 1.76 & 0.85 \\
5 & 10 & 7.03 & 3.40 \\
10 & 20 & 28.11 & 13.61 \\
20 & 50 & 175.66 & 85.07 \\
50 & 100 & 702.65 & 340.30 \\
\hline
\end{tabular}

aDistance to the no-deaths contour as predicted from the D2PC atmospheric dispersion model. To convert to English units, $1 \mathrm{~km}=0.6214$ miles.

${ }^{b}$ Atmospheric stability of Class D with a wind speed of $3 \mathrm{~m} / \mathrm{s}$.

cAtmospheric stability of Class $E$ with a wind speed of $1 \mathrm{~m} / \mathrm{s}$.

${ }^{d}$ Accidents with downwind distances less than $500 \mathrm{~m}$ will not produce plumes which go beyond the installation boundary and, thus, were eliminated from the risk analysis. 


\section{A-13}

account; instead, it assumes conservatively that the wind has some nonzero probability of blowing in the direction that would cause the most fatalities in the event of a release.

The following assumptions and qualifications of the fatality estimation process were enumerated in the FPEIS (U.S. Army 1988):

1. The assumed values of the fatality multipliers were based on linear variations of agent doses within each dose-response contour. In actuality, the doses decrease with distance from the release point at a greater than linear rate; thus, the FPEIS estimates of maximum fatalities are conservatively high.

2. The D2PC atmospheric dispersion model was originally developed as a planning tool for estimating the magnitude of battlefield casualties under war-game scenarios. The model predicts dose-response contours based on the expected response of healthy aduit males to battlefield agent concentrations. The variation of dose response among age classes (e.g., infants, children, and the elderly) was not included in the estimation of fatalities in the FPEIS. It was assumed that the dose response of healthy adult males would closely approximate the response of an average member of the general public.

3. Downwind no-deaths distance estimates from D2PC are accurate to within only $\pm 50 \%$. This limitation of the atmospheric dispersion model resulted in a systematic uncertainty that applied equally to all fatality estimates for all alternatives.

4. Variations in wind direction, atmospheric stability, and terrain during a release would cause the plume to have a much more complex geometry than the simplistic ellipsoidal shape used in the FPEIS. The longer the time period over which the plume develops, the greater the likelihood that changes in the wind conditions will affect the plume geometry.

5. The same variations in wind direction, atmospheric stability, and terrain make it impossible to reliably predict the shape of a very large plume contour. For this reason, fatality counts for accidents with extremely large downwind no-deaths distances were truncated at $100 \mathrm{~km}$ (62 miles) in the FPEIS.

6. The census data used to develop the distribution of population around each site are representative of the place of residence; thus, these data more closely depict nighttime populations than daytime populations. Furthermore, transient populations (such as people in shopping centers or at major sporting events) and on-post employees were not included in the population data in the FPEIS.

7. The grid-based population allowed all grid cells beyond this zone to be filled with a distributed population even though, in reality, no such population existed for certain cells. Likewise, other known uninhabited regions (such as lakes, forested areas, federally restricted areas, as well as the actual site boundaries) were not accounted for in the FPEIS grid-based population; all such zones were filled with population according to the method described previously.

8. The locations used in the FPEIS for the source of every chemical agent release were assumed to be the proposed location of the Chemical Stockpile Disposal Program (CSDP) disposal facilities as estimated from a 1:250,000-scale map. All plumes used this release point for estimating fatalities. In the accident analyses, where storage area accidents or on-site transportation accidents resulted in agent release, the release point may not be exact in the FPEIS; however, the implication of this assumption would be 
more significant for small releases of agent than for large releases. That is, for large releases, the downwind distances predicted by the atmospheric dispersion model are significantly larger than the distance between any possible points of release at a particular site.

The probability data and agent release data from GA Technologies, meteorological data from ORNL, and fatality estimates from ORNL were integrated by the MITRE Corporation (MITRE 1987) to develop the five measures of risk previously described.

\section{A.1.5 Summary of Results}

For accidental agent releases, the five measures of risk were used to distinguish among alternatives. Implementation of the three-tiered selection method resulted in the following conclusions:

1. The continued storage, national relocation, and partial relocation alternatives were rejected from further consideration based on the method's first tier of comparing human health impacts.

2. The on-site disposal and regional alternatives stood the test of the first tier of comparison and were then subjected to the second tier. Of note, however, was that the on-site disposal alternative was consistently less risky in all areas (except person-years at risk) than the regional alternative, but not at a significant level.

3. In the comparison of on-site and regional alternatives at the second tier (ecosystem and environmental impacts), again the on-site disposal alternative was better than the regional alternative, but not to a significant level. Therefore, both alternatives were allowed to pass to the third tier of comparison.

4. Considering the greater degree and extent of mitigation (potential for saving lives) afforded by emergency response for the on-site alternative as compared with the regional alternative, the on-site alternative was determined to be better than the regional alternative. The validity of this conclusion is strengthened by the consistently better ranking of the on-site alternative at the first and second tiers of comparison.

The key findings of the FPEIS have resulted in the Army's selecting the on-site disposal alternative as its environmentally preferred alternative. The CONUS stockpile of chemical agents and munitions can be destroyed in a safe, environmentally acceptable manner. The environmental impacts of construction and incident-free disposal operations would be minimal. The risk of catastrophic accidents is relatively low for all programmatic alternatives; however, on-site disposal poses less risk than those alternatives involving off-site movement of the stockpile and is therefore the best choice from public health and environmental perspectives. 


\section{A.2 SITE-SPECIFIC ACCEPTABILITY OF PROGRAMMATIC PREFERENCE}

After the environmentally preferred alternative was identified, the final step in the analysis was to examine this alternative (on-site disposal) against each installation inventory to ensure that the method did not identify an alternative that was incorrect for inventories of one or more installations. The following discussion examines the selected alternative for PUDA, comparing the selected alternative against the site- and corridor-specific risk pictograms.

The two-risk-shadings decision rule discussed previously was used to help identify the likely site preference (where possible) and to compare it with the programmatic preference for on-site disposal. Because the Army would implement enhanced emergency planning and preparedness at the installation regardless of the alternative selected, the benefits or risk reductions attributable to emergency planning and preparedness, although more relevant to the maximum fatalities and expected fatalities measures, should not affect site preference and have not been considered.

The preliminary selection of the on-site disposal alternative as the environmentally preferred alternative from a programmatic viewpoint was verified for each storage site to ensure that this alternative did not present an unusual problem or risk based on its inventories, population, geography, or any other feature unique to the site. Therefore, the purpose of this exercise was not to depict that on-site destruction is significantly better than other alternatives but rather to demonstrate that on-site disposal was at least equal.

From the perspective of the population near PUDA, on-site disposal was found to be at least equivalent to all other options in terms of human health effects measures; there was no clear choice among programmatic alternatives for PUDA. However, with the addition of the transportation risks, the on-site alternative has the advantage, given the opportunity of risk reductions associated with emergency planning and preparedness that was not afforded off-site transportation alternatives.

\section{A.3 FPEIS IMPACT ASSESSMENT FOR PUEBLO DEPOT ACTIVITY}

In addition to the risk-based impact assessment used to select the environmentally preferred alternative, the FPEIS also presented potential environmental impacts from implementing the programmatic alternatives at each of the sites (as appropriate). Potential effects from construction and incident-free operations are described. This section summarizes this part of the FPEIS as applicable to PUDA.

Disposal activities can be viewed as a three-phased set of activities. Construction involves activities to procure and build the disposal plant(s) and support functions. Operations activities involve disposal of the chemical munitions. This includes activities at the site of existing storage, movement of stockpiles from those storage sites to disposal plants, and disposal plant operations. Movement is defined to include on-site handling and transport, as

well as off-site transport. Decommissioning involves closure and dismantling of disposal facilities. 


\section{A.3.1 Construction Impacts}

Minor impacts from increased spending, the creation of new employment, and the ecological disruption at the plant site are expected. No significant impacts to human health, air quality, or water quality are expected.

The construction of a disposal facility would produce an average of 150 new jobs during the time required for construction. The construction will also probably result in increased sales in construction-related industries in the region. Additional tax revenues will be produced. The total economic impact of the creation of jobs and increased spending at each site under on-site disposal would be minor. The direct and indirect employment would not result in significant in-migration, and impacts to local economic infrastructures are unlikely.

Minor impacts were expected on ecological resources from construction of the disposal facilities. Construction at PUDA under the on-site disposal alternative was estimated to require about 4 ha (11 acres) of land. Best available technologies for sediment control during construction were estimated to minimize any potential effects to surface waters.

\section{A.3.2 Incident-Free Operations Impacts}

Overall, the impacts of disposal are quite limited in scope and significance. Construction impacts include the socioeconomic impacts of increased spending, the creation of new employment, and the ecological disruption at the plant site. By definition, incident-free operations are characterized by no releases of agent above emission criteria. Operations impacts of concern include possible exposure to low (below detectable), but permitted, levels of chemical agent, air quality impacts, socioeconomic impacts to community resources and well-being, solid waste disposal, and water use. Impacts to socioeconomic resources come primarily from the need for local communities to upgrade emergency response planning for an accidental release of agent. Finally, decommissioning impacts of concern include the socioeconomic impacts of plant closure and disposal of hazardous wastes.

\section{A.3.3 Accident Impacts}

To assess the environmental impacts of accidents, it is necessary to identify the credible accidents that could occur and ways that agent released in those accidents is dispersed in the environment. The identification of an accident also involves an understanding of the amount of agent released, which is frequently referred to as an agent source term. Identification also requires a knowledge of how the agent is released. It can be spilled, vaporized by an explosion, or released by a fire or some combination of release modes. Furthermore, information on the duration of release is required.

The ways in which the agent is dispersed after a release are called environmental pathways. The basic paths include the movement of small droplets of agent in the air; the movement of vapor in the air; the deposition of agent from air movement onto underlying lands, vegetation, or water; the movement of agent into bodies of water through runoff or deposition; and the movement into groundwater. 
When agent is released into the environment, it may have effects on human health, ecological systems, water use, and socioeconomic resources. Any effects would be estimated by the dispersion processes that give information about the form and level of the agent in the environment and the response of various ecological systems to the agent.

It is important to realize that each of the three stages of the analysis is associated with uncertainties and error bounds. These uncertainties are largely a function of imperfect knowledge. The application of these methods to the specific areas of concern (i.e., the installations and their environs, and the transportation corridors) provides assessments of impacts.

The pictogram in Fig. A.4 summarizes the risks for accidents at PUDA as presented in the FPEIS. PUDA has a large inventory comprising $10 \%$ (by weight) of the national stockpile. The PUDA inventory consists solely of mustard-filled projectiles and mortar rounds. The "probability of one or more fatalities" is small at PUDA for all alternatives, primarily because of the remoteness of the site. The "maximum fatalities" are large for both the continued storage and the national and regional (off-site movement) alternatives; however, the very small values shown for "expected fatalities" for these latter alternatives indicate that the accidents leading to large consequences for the off-site movement are very infrequent. The "person-years at risk" are large for all alternatives at PUDA because of the size of the PUDA inventory.

For the continued storage alternative at PUDA, the "expected fatalities" risk is dominated by accidents resulting from air crashes into the storage area with a subsequent fire (100\% of the total risk). The continued storage alternative is assumed to continue for 25 years. For the on-site disposal alternative at PUDA, the risk is dominated by on-site transport accidents resulting in a fire and subsequent detonation (100\%). For the national and regional disposal alternatives at PUDA, the dominant risks are from air crashes into the off-site transport holding area with a subsequent fire $(100 \%)$.

The on-site disposal alternative is the least risky alternative for persons residing near PUDA (Fig. A.4). It is one shading pattern better than continued storage on the "probability of one or more fatalities" measure, and two or more shading patterns better than continued storage and regional and national disposal centers alternatives on the "maximum fatalities" measure and the "person-years at risk" measure. Although the risk pictogram for PUDA shows no difference for "expected fatalities," "probability of one or more fatalities," and "expected plume area" among any of the disposal alternatives, on-site disposal is clearly the preferred alternative in terms of "maximum fatalities" and "person-years at risk." On-site disposal at PUDA also avoids the incremental risks for the cross-country transport corridor and the destination installation. The selection of on-site disposal is valid for PUDA.

\section{A.3.4 Decommissioning Impacts}

Based on the information available on the procedures for decommissioning (dismantling and disposing) disposal facilities, minor but insignificant impacts would occur to socioeconomics and solid waste. Before implementing decommissioning, further 
ORNL DWG 87-19237

\begin{tabular}{|c|c|c|c|c|c|}
\hline Alternatives & $\begin{array}{l}\text { Probabilty } \\
\text { of One } \\
\text { or More } \\
\text { Fatalities }\end{array}$ & $\begin{array}{l}\text { Maximum } \\
\text { Number of } \\
\text { Fatalities }\end{array}$ & $\begin{array}{l}\text { Expected } \\
\text { Fatalities }\end{array}$ & $\begin{array}{l}\text { Person- } \\
\text { Years } \\
\text { at Risk }\end{array}$ & $\begin{array}{c}\text { Expected } \\
\text { Plume Area } \\
\left(\mathrm{km}^{2}\right)\end{array}$ \\
\hline \multicolumn{6}{|l|}{ Continued Storage } \\
\hline \multicolumn{6}{|l|}{ On-Site Disposal } \\
\hline \multicolumn{6}{|l|}{ Regional Disposal } \\
\hline \multicolumn{6}{|l|}{ Nanonal Disposal } \\
\hline Partial Relocation & & & & & \\
\hline
\end{tabular}

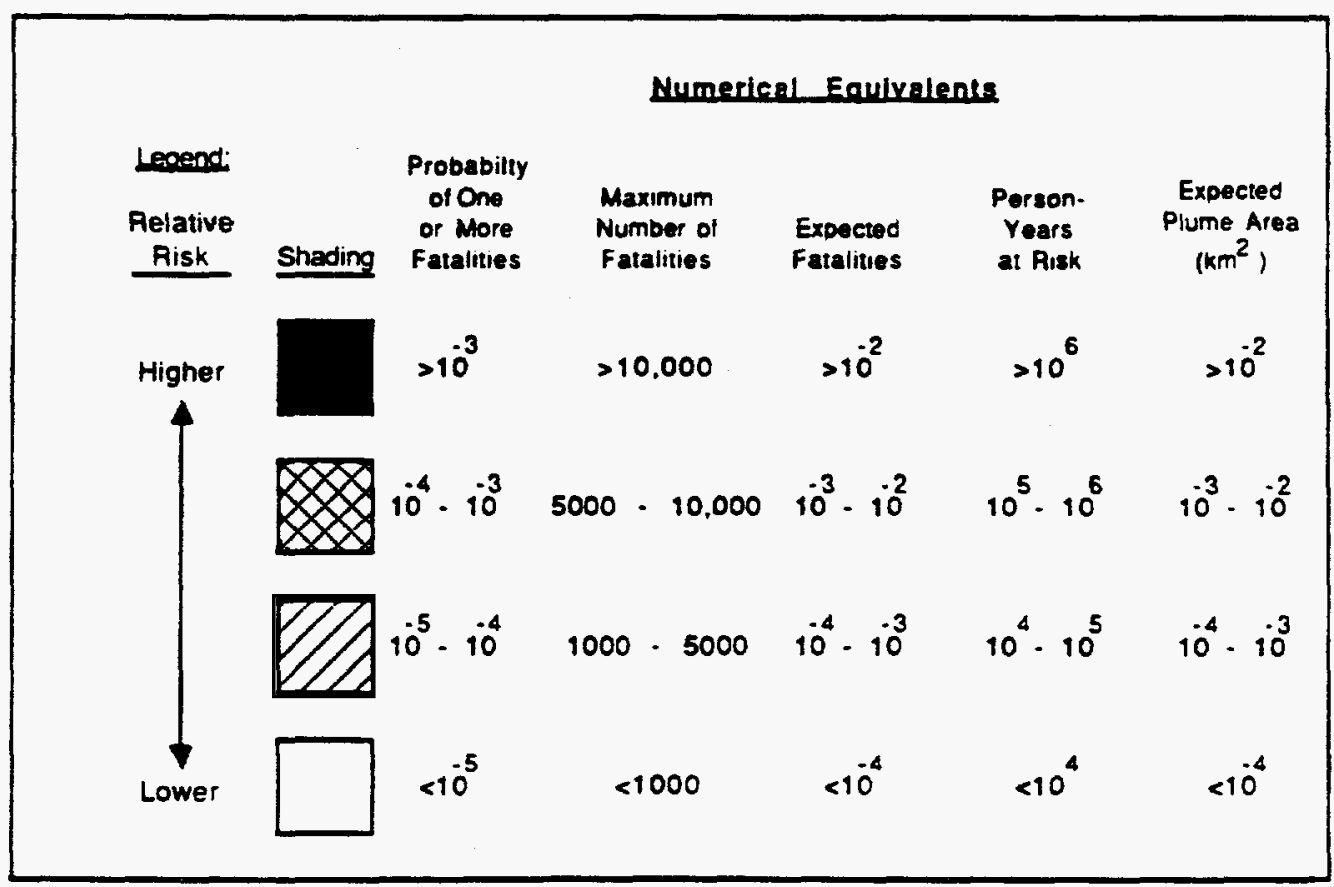

Fig. A4. Risk with mitigation in the vicinity of Pueblo Depot Activity (PUDA) for programmatic alternatives. (Risk along transportation corridors or at destination sites not included. For the disposal alternatives, this diagram does not include the risk associated with approximately 3 years of stockpile storage at PUDA) 
A-19

National Environmental Policy Act of 1969 documentation is required, and more detailed impact assessments will be conducted.

On completion of a disposal program at a site, the decommissioning of a facility would involve the employment of both construction- and industrial-type work forces. When decommissioning ends, local economic impacts from the increased jobs from construction, operations, and decommissioning would no longer be experienced. When operation ends, the risk of an accident and the potential for any associated impacts also end. Overall, no significant impacts are expected from decommissioning.

Final closure activities for the chemical stockpile disposal facilities would result in removal or decontamination of all process equipment, structures, soils, or other materials containing or contaminated with hazardous waste or hazardous constituents. Amounts of containerized wastes that would be shipped to off-site permitted waste facilities are unknown; projected types of these wastes are (1) brine salt generated during closure, (2) incinerator ash, (3) baghouse dust and cyclone residue, and (4) miscellaneous nonagent-related wastes generated during facility closure. The metal parts of agent tanks, furnaces, and incinerators would be disassembled and decontaminated to $5 \mathrm{X}$ level $\left(1000^{\circ} \mathrm{F}\right.$ for $15 \mathrm{~min}$ ), which means that an item is clean and may be released from government control. Closure plans for the sites are described in Sect. I of Part B of the RCRA permit applications for each site.

\section{A.4 REFERENCES}

EPRI (Electric Power Research Institute) 1985. Operational Validation of Gaussian and First-Order Closure Plume Models at a Moderately Complex Terrain Site, EA-3759, Project 1616-9, Palo Alto, Calif.

GA Technologies, Inc. 1987a. Risk Analysis of the On-Site Disposal of Chemical Munitions, Reports GAC-18562 and SAPEO-CDE-IS-87010, prepared for Program Executive Officer-Program Manager for Chemical Demilitarization by GA Technologies, Inc., La Jolla, Calif.

GA Technologies, Inc. 1987b. Risk Analysis of the Disposal of Chemical Munitions at National or Regional Sites, Reports GAC-18563 and SAPEO-CDE-IS-87008, prepared for Program Executive Officer-Program Manager for Chemical Demilitarization by GA Technologies, Inc., La Jolla, Calif.

GA Technologies, Inc. 1987c. Risk Analysis of the Continued Storage of Chemical Munitions, Reports GAC-18564 and SAPEO-CDE-IS-87009, prepared for Program Executive Officer-Program Manager for Chemical Demilitarization by GA Technologies, Inc., La Jolla, Calif.

MITRE Corporation 1987. Risk Analysis Supporting the Chemical Stockpile Disposal Program, SAPEO-CDE-IS-87014, McLean Va., for Program Executive Officer-Program Manager for Chemical Demilitarization, Aberdeen Proving Ground, Md. 
U.S. Army 1988. Chemical Stockpile Disposal Program Final Programmatic

Environmental Impact Statement, Vols. 1, 2, and 3, Program Manager for Chemical Demilitarization, Aberdeen Proving Ground, Md., January.

U.S. Department of Commerce, Bureau of the Census 1980. Census of Population, Vol. 1, Characteristics of the Population, U.S. Government Printing Office, Washington, D.C.

Whitacre, G. C., et al. 1986. Personal Computer Program for Chemical Hazard Prediction (D2PC), U.S. Army Chemical Research and Development Centers, Aberdeen Proving Ground, Md. 


\section{APPENDIX B \\ DESCRIPTION OF SITE-SPECIFIC COMMUNITY RESOURCES}

Pueblo County is assumed to be the region of impact for construction and incidentfree operations at the proposed disposal facility. Pueblo County, in which Pueblo Depot Activity (PUDA) is located, contains a large infrastructure, is easily within commuting distance of the installation, and has the potential for absorbing impacts resulting from the proposed action. For accidental releases of agent during storage, the $100-\mathrm{km}$ (62-mile) zone surrounding PUDA is assumed to be the region of potential impacts. For accidental releases during disposal operations, Pueblo County is assumed to be the region of impact. This appendix presents community resource information germane to incident-free operations (Sect. B.1) and accidental releases (Sect. B.2).

\section{B.1 RESOURCES POTENTIALLY AFFECTED BY CONSTRUCTION AND INCIDENT-FREE OPERATIONS}

\section{B.1.1 Labor Force and Infrastructure}

Data on resources included in this section are relevant to assess socioeconomic impacts associated with construction and incident-free operations. These data primarily concern the economic base and the public service infrastructure in Pueblo County.

\section{B.1.1.1 Employment and income}

Employment trends in Pueblo County are shown in Table B.1. The civilian labor force totalled 49,670 in 1989 , and the unemployment rate was $8.2 \%$. Most of the nonagricultural employment is concentrated in the services, government, and wholesale and retail sectors (Colorado Division of Employment 1990). Personal income and earnings in counties located within the $100-\mathrm{km}$ (62-mile) zone are shown in Table B.2.Pueblo has experienced significant changes in employment during the 1980s. The county's single largest employer, CF\&I Steel Corporation, laid off approximately 4000 workers in 1982, reducing its work force to its current level of 1750 (J. Munch and D. Vest, City of Pueblo Planning Department, Pueblo, Colo., personal communication to S. Schexnayder, Oak Ridge National Laboratory (ORNL), Oak Ridge, Tenn., June 7, 1990). A realignment at PUDA in the late 1970s compounded the loss of jobs in the area (S. Rasso, Chairman, Pueblo County Commissioners, Pueblo, Colo., personal communication to S. Schexnayder, ORNL, Oak Ridge, Tenn., June 8, 1990). In response to the local economic impacts due to the layoffs, the city of Pueblo formed an Economic Development Corporation to recruit new businesses. This effort resulted in the addition of approximately 2500 new jobs in the Airport Industrial 
Table B.1. Employment trends, Pueblo County, Colo., 1981-1989 (annual average)

\begin{tabular}{|c|c|c|c|c|c|c|c|c|c|}
\hline Type of employment & 1981 & 1982 & 1983 & 1984 & 1985 & 1986 & 1987 & 1988 & 1989 \\
\hline Total employment & 44,931 & 41,732 & 43,239 & 44,395 & 44,761 & 44,556 & 44,342 & 45,200 & 45,598 \\
\hline Agricultural & 782 & 772 & 790 & 780 & 770 & 697 & 770 & 800 & 690 \\
\hline Non-agricultural & 44,149 & 40,960 & 42,449 & 43,615 & 43,991 & 43,859 & 43,572 & 44,400 & 44,908 \\
\hline Unemployment & 4,982 & 8,296 & 7,047 & 5,241 & 5,230 & 6,053 & 5,340 & 4,434 & 4,072 \\
\hline Unemployment rate & $10.0 \%$ & $16.6 \%$ & $14.0 \%$ & $10.6 \%$ & $10.5 \%$ & $12.0 \%$ & $10.7 \%$ & $8.9 \%$ & $8.2 \%$ \\
\hline Total labor force & 49,913 & 50,028 & 50,286 & 49,636 & 49,991 & 50,609 & 49,682 & 49,634 & 49,670 \\
\hline
\end{tabular}

Source: City of Pueblo Department of Planning 1990. City of Pueblo Data Book, Pueblo, Colo. 
B-3

Table B.2. Personal income and earnings within $100 \mathrm{~km}$ (62 miles) of Pueblo Depot Activity

\begin{tabular}{|c|c|c|c|c|}
\hline County & $\begin{array}{c}\text { Personal } \\
\text { income } \\
1984 \\
\text { (\$ million) }\end{array}$ & $\begin{array}{c}\text { Personal } \\
\text { income } \\
\% \text { change } \\
1980-84 \\
\text { (\$ million) }\end{array}$ & $\begin{array}{c}\text { Personal } \\
\text { income } \\
\text { per } \\
\text { capita } \\
(1984 \$)\end{array}$ & $\begin{array}{c}\text { Personal } \\
\text { income } \\
\text { earnings } \\
1984 \\
\text { (\$ million) }\end{array}$ \\
\hline Bent & 59.4 & 36.9 & 10,023 & 39.1 \\
\hline Crowley & 38.9 & 39.1 & 12,053 & 21.6 \\
\hline Custer & 16.1 & 43.0 & 8,617 & 5.1 \\
\hline Douglas & 595.2 & 79.4 & 17,650 & 152.8 \\
\hline Elbert & 109.0 & 51.5 & 13,338 & 28.4 \\
\hline El Paso & $4,301.4$ & 60.7 & 12,323 & $3,214.3$ \\
\hline Fremont & 315.1 & 44.9 & 10,186 & 148.4 \\
\hline Huerfano & 63.2 & 43.0 & 8,964 & 15.8 \\
\hline Kiowa & 32.6 & 65.1 & 16,745 & 23.8 \\
\hline Las Animas & 128.5 & 19.5 & 8,675 & 60.2 \\
\hline Lincoln & 62.4 & 42.3 & 13,627 & 38.1 \\
\hline Otero & 23.7 & 42.6 & 10,874 & 8.0 \\
\hline Park & 76.5 & 53.9 & 11,197 & 18.0 \\
\hline Pueblo & $1,267.0$ & 19.9 & 10,149 & 767.3 \\
\hline Teller & 121.8 & 75.8 & 11,556 & 29.9 \\
\hline
\end{tabular}

Source: U.S. Bureau of the Census 1988. County and City Dasa Book 1988, U.S. Government Printing Office, Washington, D.C.

Park (J. Munch and D. Vest, City of Pueblo Planning Department, Pueblo, Colo., personal communication with S. Schexnayder, ORNL, Oak Ridge, Tenn., June 7, 1990). The unemployment rate dropped from $16.2 \%$ in 1982 to $8.2 \%$ in 1989 (City of Pueblo Department of Planning 1990).

The realignment of PUDA, planned for completion in June 1995, is expected to result in a decrease of 467 employees at PUDA ( 464 civilian and 3 military) before demilitarization. The Army's assessment of the secondary effects of the closure indicates an expected decrease of 1300 persons in the regional population. Estimates predict a total decrease in regional population of $1 \%$ of the estimated 1989 total regional population. An annual decrease of $\$ 13.6$ million in total regional wages and salaries and of $\$ 18.9$ million in regional personal income also are predicted by the Army. An annual decrease of $\$ 35.3$ million in regional sales volume, including secondary effects, is expected as a result of the realignment (U.S. Army 1991). 


\section{B.1.1.2 Housing}

Recent housing studies in Pueblo indicate that the housing market has experienced substantial change within the last two decades. From 1970 to 1980 , growth in the local housing inventory greatly exceeded population growth in Pueblo. Within the Pueblo Metropolitan Statistical Area, the population grew by only $6.5 \%$ from 1970 to 1980, while the growth in available housing was $30.4 \%$. The percentage of owner-occupied housing in Pueblo is high relative to other cities of similar size in Colorado, approximately $69.5 \%$. There were 996 new single-family units and 741 new apartment and duplex units constructed from January 1, 1980, through December 31, 1989 (City of Pueblo Department of Planning 1990). Table B.3 shows housing trends and characteristics since 1980.

Recent residential building trends indicate that an increasing amount of new residential construction is occurring outside the Pueblo city limits in Pueblo County. Only a very few areas within the city limits have experienced notable growth in recent years. Housing costs in Pueblo are relatively low. In 1989, the median price for a three-bedroom home in Pueblo was $\$ 50,515$. Rental prices also are low; average rent for a one-bedroom apartment ranges from $\$ 238$ to $\$ 313$. The city's housing stock is old, however, relative to other Colorado cities; a high proportion of it was constructed prior to 1940 (City of Pueblo Department of Planning 1990).

A preliminary estimate of the effect of the planned PUDA realignment on housing indicates that approximately 140 owner-occupied and 324 rented units may become vacant (U.S. Army 1991).

\section{B.1.1.3 Transportation}

Transportation in the area is provided by highway, rail, and air. Interstate 25 runs north and south through the city of Pueblo. U.S. Route 50 provides four-lane access between PUDA and the city of Pueblo, where it intersects I-25. State Route 96 provides access to North Avondale and Boone.

U.S. 50 provides access to PUDA from the southwest boundary and provides access to the Pueblo Memorial Airport. U.S. 50 has an average traffic flow of 10,600 vehicles daily (P.J. Steranka, Safety Manager, PUDA, letter to S. Schexnayder, ORNL, Oak Ridge, Tenn., June 13, 1990). Developments in recent years at the Pueblo Airport Industrial Park have begun to cause traffic congestion and delays on U.S. 50, particularly during the afternoon peak hour traffic (4:00-5:00 p.m.) at the westbound on-ramp to U.S. 50 and during morning peak hour traffic (6:00-7:00 a.m.) at the eastbound off-ramp (City of Pueblo Department of Planning 1988). Traffic counts in August of 1989 indicated that approximately 4500 vehicles enter the industrial park daily (Pueblo Area Council of Governments 1989). Studies are under way to plan for alternative access corridors to the industrial park.

The scheduled realignment of PUDA is expected to result in the elimination of virtually all traffic on the depot.

Rail transport is provided by Denver and Rio Grande, Santa Fe, Burlington Northern, and Missouri Pacific railroads. Rail access to PUDA is provided along the depot's southwestern boundary, east of the highway entrance. 
B-5

Table B.3. Housing characteristics for Pueblo, Colorado

\begin{tabular}{|c|c|c|c|c|}
\hline & $\begin{array}{c}\text { Total } \\
1980 \text { census }\end{array}$ & $\begin{array}{c}\text { Total } \\
\text { December } \\
1989\end{array}$ & $\begin{array}{c}\text { Percent } \\
\text { increase } \\
1980-89\end{array}$ & $\begin{array}{c}1989 \\
\text { Vacancy } \\
\text { rate }\end{array}$ \\
\hline \multicolumn{5}{|c|}{ Total housing units } \\
\hline Pueblo County & 49,095 & 52,247 & 6.4 & 8.0 \\
\hline City of Pueblo & 40,012 & 41,640 & 4.1 & $\mathrm{NA}^{a}$ \\
\hline \multicolumn{5}{|c|}{ Occupancy (Pueblo County) } \\
\hline Owner-occupied & 32,359 & 34,651 & 7.1 & 5.7 \\
\hline Renter-occupied & 12,736 & 13,397 & 5.2 & 8.5 \\
\hline \multicolumn{5}{|c|}{$\begin{array}{l}\text { Year-round units by type } \\
\text { (Pueblo County) }\end{array}$} \\
\hline Single-family & 36,819 & 38,540 & 4.7 & NA \\
\hline $2-4$ units & 3,934 & 4,403 & 11.9 & NA \\
\hline 5 or more units & 5,654 & 5,907 & 4.5 & NA \\
\hline Mobile homes & 2,240 & 2,949 & 31.7 & NA \\
\hline Total & 48,647 & 51,799 & 6.5 & NA \\
\hline
\end{tabular}

NA $=$ not available.

Sources: City of Pueblo Department of Planning 1990. City of Pueblo Data Book 1990, Pueblo, Colo.;

Federal Home Loan Bank Board, Housing Survey, Pueblo SMSA 1989.

Nearby air transport is available at the Pueblo Memorial Airport, which is located approximately $11.3 \mathrm{~km}$ (7 miles) west of PUDA off U.S. 50 and is served by three scheduled commercial airlines (Division of Local Government's Airport System Plan 1987). The closest major airport is in Denver, approximately $177 \mathrm{~km}$ (110 miles) north of PUDA. In addition to the importance of potential effects of accident-free construction and operations on transportation, transportation facilities are important to emergency planning for an accidental release of agent.

\section{B.1.1.4 Public services}

The public services potentially affected by accident-free construction and operations at PUDA are limited primarily to schools, public safety/fire protection, and public utilities. 
Schools

Public education in the Pueblo vicinity is provided by city and county jurisdictions. The state of Colorado Education Department recommends that student-to-teacher ratios not exceed 25 to 1 . School accreditation is based on a student-to-teacher ratio of 28 to 1 , however (A. Bloom, Instructional Services Division, Colorado State Department of Education, Denver, Colo., personal communication with S. Schexnayder, ORNL, Oak Ridge, Tenn., August 13, 1990).

School District No. 60 and School District No. 70 serve the majority of children of PUDA employees. A total of 351 students whose parents are employed at PUDA attended District 60 as of May 1990. Of these, 138 are in elementary grades, 90 are in middle school, and 123 are in high school. District 60 officials project that this number will be reduced to approximately 160 by the 1995-1996 school year because of job losses associated with the PUDA realignment. Total District 60 enrollment for 1989-1990 was 18,202. The projected enrollment in 1995-1996, assuming no PUDA job losses and no new hirings, is 17,329 (Martin E. Gonzales, Office of Pupil Personnel, School District 60, Pueblo, Colo., correspondence to Dr. Vallejo, Superintendent, Pueblo, Colo., May 21, 1990). The present student/teacher ratio in District 60 is 17.4 to 1 (M. Snook, Pupil-Personnel Secretary, School District No. 60, Pueblo, Colo., personal communication with S. Schexnayder, ORNL, Oak Ridge, Tenn., June 7, 1990). District No. 60 recently applied for and received funds through the Colorado Association of School Boards Blind Pool Lease/Purchase Financing Program. The $\$ 26$ million financing proceeds will be used for 22 building projects and for acquiring instructional technology equipment through 1992 (Pueblo School District No. 60 1990).

District 70 had a total enrollment of 4068 in the 1989-1990 school year. In this district, there are 128 children whose parents work at PUDA (J. D. Musso, Superintendent of Support Services, School District No. 70, Pueblo, Colo., letter to S. Schexnayder, ORNL, August 8, 1990). The student/teacher ratio in District 70 is 15.5 to 1 (Pueblo School District No. 70 1989; Pueblo School District No. 70 1990).

\section{Police and fire protection}

The city of Pueblo employs 171 uniformed police officers and 132 uniformed fire department personnel (City of Pueblo Department of Planning 1990). The Pueblo City Fire Department also provides emergency medical services for the county. All fire fighters have emergency medical technician training and the 12 pumper trucks serve as emergency medical service vehicles. The fire department also has a hazardous materials unit to respond to hazardous materials emergencies. The Pueblo County Sheriff's Office maintains a patrol and investigative force of 77 officers (full-time equivalents) and provides search and rescue capability for the county. The sheriff's department serves areas of Pueblo County outside the city of Pueblo, including the incorporated cities of Boone and Rye. Limited service is provided within the city of Pueblo (Capt. H. Wenzel, Pueblo County Sheriff's Office, Pueblo, Colo., personal communication with S. Schexnayder, ORNL, Oak Ridge, Tenn., Sept. 27, 1990). Fire protection in Pueblo County outside the city of Pueblo is provided by the following volunteer fire departments: Avondale, Beulah, Boone, Pueblo Rural (Stations 1 and 2), Pueblo West, Rye, and West Park. 
There are 105 security officers currently employed at PUDA (R. Dale, Assistant to the Safety Officer, PUDA, Pueblo, Colo., personal communication to S. Schexnayder, ORNL, Oak Ridge, Tenn., June 13, 1990). Current plans are for approximately 75 security officers to remain at PUDA after realignment for the demilitarization phase; however a final determination of the number of personnel to remain at the depot after realignment has not yet been made (J. Provost, Realignment Officer, PUDA, Pueblo, Colo., personal communication to S. Schexnayder, ORNL, Oak Ridge, Tenn., June 6, 1990).

\section{Utilities}

Utilities in Pueblo include municipal water and wastewater services, natural gas, and electricity. Five rural water districts and two metropolitan districts (areas in which three or more public services are available) supply water to county residents. The Arkansas River is the source of drinking water for the city. The Pueblo Board of Water Works has a pumping capacity of $80 \mathrm{Mgd}$; average demand is $23 \mathrm{Mgd}$, and peak demand is $58.6 \mathrm{Mgd}$ (Pueblo Chamber of Commerce 1989a).

The municipal sewage treatment facility has a capacity of $19 \mathrm{Mgd}$, with an average demand of $13.5 \mathrm{Mgd}$ and peak demand of $15.4 \mathrm{Mgd}$ (Pueblo County Department of Planning and Development 1987). This system is expected to provide adequate treatment capacity beyond the year 2004 .

Natural gas is supplied to Pueblo residents by the Pueblo Gas and Fuel Division of the Public Service Company of Colorado. Demand averages $291,000 \mathrm{ft}^{3} / \mathrm{hr}$. Electric power is supplied by Centel Electric, San Isabel Electric Association, Inc., and Colorado Ute Electric Services, Inc. Centel Electric has an agreement with the Public Service Company of Colorado to meet excess demand.

The primary provider of electrical power to PUDA is the Western Area Power Administration (WAPA). WAPA allotments to PUDA range from approximately $800,000 \mathrm{kWh}$ to $1,080,000 \mathrm{kWh}$, depending on the time of year. PUDA usually requires the maximum allotment. A supplemental contract with Centel Electric exists to provide additional power. Monthly electricity usage at PUDA in 1990 has ranged from $862,000 \mathrm{kWh}$ to $1,520,000 \mathrm{kWh}$. PUDA also holds a lease on Public Service Commission lines that pass south of the depot (R. Henderer, Energy Conservation Officer, PUDA, Pueblo, Colo., personal communication to S. Schexnayder, ORNL, Oak Ridge, Tenn., June 6, 1990).

Natural gas is provided to PUDA by Colorado Public Service Company, but service is available only in the family housing area approximately 4 miles south of the proposed disposal site (E. St. Clair, Facilities Engineer, PUDA, Pueblo, Colo., personal communication to S. Schexnayder, ORNL, Oak Ridge, Tenn., June 6, 1990).

Water is provided by wells on the depot, and the supply currently is adequate to meet demand. Additional demand, however, would require a new water source, such as a city water line run from the airport to the depot (E. St. Clair, Facilities Engineer, PUDA, Pueblo, Colo., personal communication to S. Schexnayder, ORNL, Oak Ridge, Tenn., June 6, 1990). 


\section{B.1.2 Cultural, Archeological, and Historic Resources}

Cultural, archeological, and historic resources located on PUDA could be affected by excavation during construction. Additionally, resources within $100 \mathrm{~km}$ (62 miles) could be affected by an accidental release of agent. Resources relevant to both scenarios are discussed in this section. There are no presently recorded prehistoric or historic archeological resources on PUDA, but no cultural resource surveys have been undertaken on the property (Nickens and Associates 1984). There are at least ten potential prehistoric archeological resource locations now known within the facility boundaries. Local informants maintain that one of these sites, located south of the proposed disposal facility, contains Indian burial grounds, but a 1984 archeological overview and management plan for PUDA indicates that these features are more likely to be hearths (Nickens and Associates 1984). Except for one location in the northwestern portion of the depot, all of the prehistoric archeological resource locations are reported to be lithic scatter sites containing lithic manufacturing debris as well as finished and broken lithic tools. The remaining site can be classified as a Folsom Paleo-Indian site location. The location of the potential archeological resources suggests that archeological sites tend to occur on high ridges overlooking drainages and on low ridges along the minor creeks draining the Arkansas River. Fig. B.1 shows the location of the ten potential archeological resources relative to the proposed disposal facility. However, the cultural history of the surrounding area suggests that additional archeological resources could occur in the undisturbed portions of the facility (Nickens and Associates 1984).

Many characteristics of the archeological resources are incompletely known or understood, as so few archeological research or management studies have been completed in the PUDA area. Nickens and Associates (1984) concluded that any archeological sites with physical integrity that might be found on PUDA probably would be of important scientific research value and sociocultural value. High research value is associated with the strong potential for materials crucial to determining early human adaptations to the region and for materials that represent an episode of significant subsistence change within a relatively short period of time. Sociocultural significance is associated with potential prehistoric archeological resources that may be significant to Native American groups, and historic Euroamerican archeological resources would be important to the many living descendants of early settlers in the area. The study concluded that, while it is relatively unlikely that historic archeological resources would be found on PUDA, the discovery of historical resources may provide significant information that could add substantially to the region's history as presently known (Nickens and Associates 1984).

A 1984 Historic Properties Report concluded that there are no Category I (properties of major importance), Category II (properties of importance), or Category III (properties of minor importance) sites located on the installation (MacDonald and Mack Partnership 1984). Table B.4 lists by county historic sites that lie within $100 \mathrm{~km}$ (62 miles) of PUDA. 


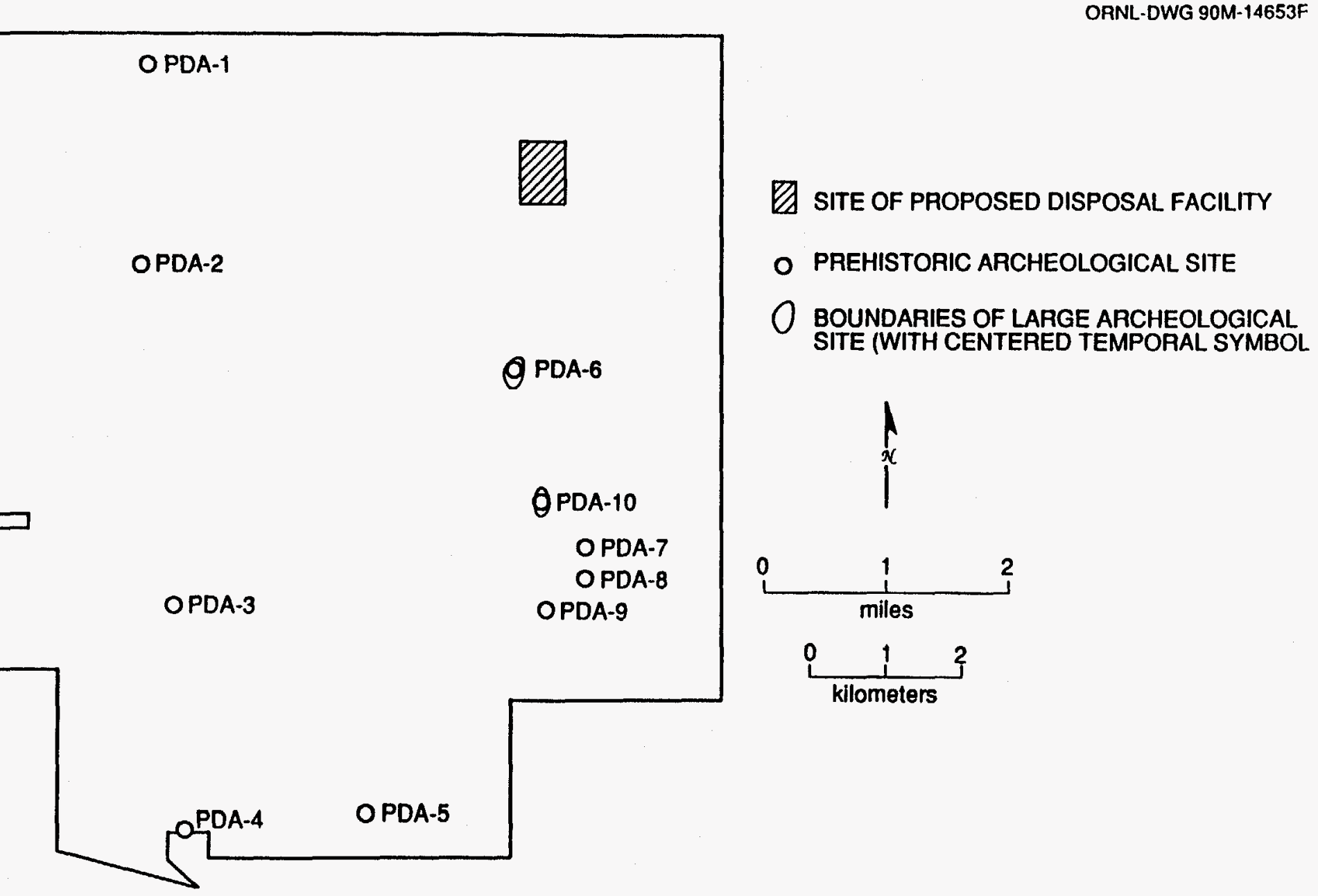

Fig. B.1. Map of potential archaeological resources on the Pueblo Depot Activity. Source: Nickens and Associates, 1984. An Archaeological Overview and Management Plan for the Pueblo Depot Activity, Pueblo County, Colorado under Contract CX-5000-3-0771 with the National Park Service, U.S. Department of the Interior, Montrose, California. 
Table B.4. Historic sites located within $100 \mathrm{~km}$ (62 miles) of Pueblo Depot Activity (PUDA)

\begin{tabular}{|c|c|c|c|}
\hline Site name & Site address & City & $\begin{array}{c}\text { Distance } \\
\text { from } \\
\text { PUDA }(\mathrm{km})^{a}\end{array}$ \\
\hline \multicolumn{4}{|c|}{ Pueblo County } \\
\hline Rosemount & 419 W. 14th St. & Pueblo & 27 \\
\hline Beaumont, Allen, J., House & 425 W. 15th St. & Pueblo & 27 \\
\hline King, Dr. Alexander T., House and Carriage & 229 Quincy St. and $215 \mathrm{~W}$ & Pueblo & 28 \\
\hline McCarthy, T. G., House & 817 N. Grand Ave. & Pueblo & 27 \\
\hline Mechanics Building/Masonic Building & 207-211 N. Main St. & Pueblo & 27 \\
\hline Butler House & 6916 Broadacre Rd. & Pueblo & 38 \\
\hline \multicolumn{4}{|l|}{ Henkel-Duke Mercantile Company } \\
\hline Warehouse & 212-222 W. 3rd Ave. & Pueblo & 27 \\
\hline Rood Candy Company Building & $408-416$ W. 7th St. & Pueblo & 27 \\
\hline Star Journal Model Home & 2920 High St. & Pueblo & 27 \\
\hline White, Asbury, House & 417 W. 11 th St. & Pueblo & 27 \\
\hline Colo. State Hospital Superintendent's House & 13th \& Francisco Sts. & Pueblo & 28 \\
\hline Black, Dr. John A., House Complex & 102 W. Pitkin Ave. & Pueblo & 28 \\
\hline Barndollar-Gann House & 1906 Court St. & Pueblo & 26 \\
\hline Rice, Ward, House & 1825 Grand Ave. & Pueblo & 26 \\
\hline Tooke-Nuckolls House & 38 Carlile Pl. & Pueblo & 28 \\
\hline Woodcroft Sanatorium & $1300 \mathrm{~W}$. Abriendo Ave. & Pueblo & 29 \\
\hline Farris Hotel & 315 N. Union Ave. & Pueblo & 27 \\
\hline Huerfano Bridge & U.S. Hwy 50 & Boone & 14 \\
\hline Nepesta Bridge & Cty. Rd. 613 & Boone & 24 \\
\hline Avondale Bridge & Cty. Rd. 327 & Avondale & 11 \\
\hline St. Charles Bridge & Cty. Rd. 65 & Pueblo & 25 \\
\hline Duke, Nathaniel W., House & 1409 Craig St. & Pueblo & 27 \\
\hline First Congregational Church & $225 \mathrm{~W}$. Evans & Pueblo & 29 \\
\hline Pryor, Frank, House & 1325 Greenwood St. & Pueblo & 27 \\
\hline Stickney, Charles H., House & 101 E. Orman Ave. & Pueblo & 29 \\
\hline Frazier, R. T., House & 2121 N. Elizabeth St. & Pueblo & 27 \\
\hline Edison School & 900 W. Mesa & Pueblo & 27 \\
\hline Streit, J. L., House & 2201 Grand Ave. & Pueblo & 32 \\
\hline Walter, Martin, House & 300 W. Abriendo Ave. & Pueblo & 28 \\
\hline Tutt Building & 421 Central Plaza & Pueblo & 27 \\
\hline Central High School & 431 E. Pitkin Ave. & Pueblo & 28 \\
\hline First Methodist Episcopal Church & 400 Broadway St. & Pueblo & 28 \\
\hline Sacred Heart Church & 1025 N. Grand Ave. & Pueblo & 27 \\
\hline Sacred Heart Orphanage & 2316 Sprague St. & Pueblo & 30 \\
\hline Fitch Terrace & $401,403,405,407,409$ & Pueblo & 27 \\
\hline Baxter House & 325 W. 15th St. & Pueblo & 27 \\
\hline Bowen Mansion & 229 W. 12th St. & Pueblo & 26 \\
\hline Young Women's Christian Association & 801 N. Santa Fe Ave. & Pueblo & 26 \\
\hline Doyle Settlement & SE of Pueblo on Doyle Rd & Pueblo & 32 \\
\hline Union Avenue Historic Commercial District & Roughly bounded by RR tr & Pueblo & 27 \\
\hline Galligan House & 501 Colorado Ave. & Pueblo & 29 \\
\hline Gast Mansion & 1801 Greenwood St. & Pueblo & 27 \\
\hline City Park Carousel & City Park & Pueblo & 31 \\
\hline Glass, J. S., Clothing Store & 308 S. Union Ave. & Pueblo & 27 \\
\hline Hazelhurst & 905 Berkley Ave. & Pueblo & 29 \\
\hline
\end{tabular}


Table B.4. (continued)

\begin{tabular}{|c|c|c|c|}
\hline Site name & Site address & City & $\begin{array}{c}\text { Distance } \\
\text { from } \\
\text { PUDA }(\mathrm{km})^{\sigma}\end{array}$ \\
\hline Pitkin Place Historic District & $S$ side of 300 block W. P & Pueblo & 29 \\
\hline Pueblo Federal Building & 421 N. Main St. & Pueblo & 27 \\
\hline Vail Hotel & 217 S. Grand Ave. & Pueblo & 28 \\
\hline Orman-Adams House & 102 W. Orman Ave. & Pueblo & 29 \\
\hline Quaker Flour Mill & 102 S. Oneida St. & Pueblo & 27 \\
\hline Goodnight Barn & W of Pueblo at $\mathrm{CO} 96 \mathrm{~W}$ & Pueblo & 34 \\
\hline Pueblo County Courthouse & 10th and Main Sts. & Pueblo & 26 \\
\hline Union Depot & Victoria and B Sts. & Pueblo & 28 \\
\hline \multirow[t]{2}{*}{ Indian Petroglyphs and Pictographs } & Address Restricted & Penrose & 47 \\
\hline & Bent County & & \\
\hline Boggsville & S of Las Animas on CO 10 & Las Animas & 102 \\
\hline \multirow[t]{2}{*}{ Bent County Courthouse } & Bounded by Carson and Bent & Las Animas & 100 \\
\hline & Crowley County & & \\
\hline \multirow[t]{2}{*}{ Manzanola Bridge } & CO Hwy. 207 & Manzanola & 46 \\
\hline & Custer County & & \\
\hline Hope Lutheran Church & 310 S. 3rd St. & Westcliffe & 103 \\
\hline National Hotel-Wolff Building & 201 Second St. & Westcliffe & 103 \\
\hline \multirow[t]{2}{*}{ Westcliffe School } & 304 4th St. & Westcliffe & 103 \\
\hline & Douglas County & & \\
\hline Spring Valley School & E of Larkspur at Spring & Larkspur & 97 \\
\hline \multirow[t]{2}{*}{ Glen Grove School } & $\mathrm{N}$ of Palmer Lake & Palmer Lake & 98 \\
\hline & Elbert County & & \\
\hline \multirow{2}{*}{ St. Mark United Presbyterian Church } & 225 Main St. & Elbert & 98 \\
\hline & El Paso County & & \\
\hline Pikes Peak & $15 \mathrm{mi}$. W of Colorado Spr & Colorado Spgs & 83 \\
\hline Pikes Peak & $15 \mathrm{mi} . \mathrm{W}$ of Colorado Spr & Colorado Spgs & 83 \\
\hline Alamo Hotel & $128 \mathrm{~S}$. Tejon St. & Colorado Spgs & 69 \\
\hline Cutler Hall & 912 N. Cascade Ave. & Colorado Spgs & 71 \\
\hline Palmer Hall & 116 E. San Rafael & Colorado Spgs & 71 \\
\hline Colorado Springs Fine Arts Center & 30 W. Dale St. & Colorado Spgs & 71 \\
\hline Claremont & 21 Broadmoor Ave. & Colorado Spgs & 67 \\
\hline Miramont & 9 Capitol Hill & Manitou Spgs & 77 \\
\hline Second Midland School & 815 S. 25th St. & Colorado Spgs & 72 \\
\hline \multicolumn{4}{|l|}{ US Post Office and Federal } \\
\hline Courthouse-Colo & 210 Pikes Peak Ave. & Colorado Spgs & 69 \\
\hline US Post Office-Manitou Springs Main & 307 Canon Ave. & Manitou Spgs & 77 \\
\hline Gwynne-Love House & 730 N. Cascade Ave. & Colorado Spgs & 71 \\
\hline Stockbridge House & 2801 W. Colorado Ave. & Colorado Spgs & 73 \\
\hline Cliff House & 306 Canon Ave. & Manitou Spgs & 77 \\
\hline DeGraff Building & 116-118 N. Tejon & Colorado Spgs & 70 \\
\hline Emmanuel Presbyterian Church & 9 Mesa Rd. & Colorado Spgs & 71 \\
\hline Hagerman Mansion & 610 N. Cascade Ave. & Colorado Spgs & 70 \\
\hline
\end{tabular}


Table B.4. (continued)

\begin{tabular}{|c|c|c|c|}
\hline Site name & Site address & City & $\begin{array}{l}\text { istance } \\
\text { from } \\
\text { A }(\mathrm{km})^{a}\end{array}$ \\
\hline Plaza Hotel & 830 N. Tejon St. & Colorado Spgs & 46 \\
\hline Manitou Springs Bridges (2) & Park Ave. and Cannon Ave & Manitou Spgs & 77 \\
\hline Giddings Building & $101 \mathrm{~N}$. Tejon St. & Colorado Spgs & 70 \\
\hline City Hall of Colorado City & 2902 W. Colorado Ave. & Colorado Spgs & 74 \\
\hline St. Mary's Catholic Church & 26 W. Kiowa St. & Colorado Spgs & 70 \\
\hline Wheeler Bank & 717-719 Manitou Ave. & Manitou Spgs & 77 \\
\hline \multicolumn{4}{|l|}{ Atchison, Topeka and Santa Fe } \\
\hline Passenger Dep & 555 E. Pikes Peak Ave. & Colorado Spgs & 69 \\
\hline Boulder Crescent Place Historic District & 9 and 11 W. Boulder St. & Colorado Spgs & 70 \\
\hline First Presbyterian Church of Ramah & 113 S. Commercial St. & Ramah & 86 \\
\hline Lewis, Inez Johnson, School & 146 Jefferson St. & Monument & 95 \\
\hline Crystal Valley Cemetery & Plainview Ave. & Manitou Spgs & 75 \\
\hline Manitou Springs Historic District & Roughly bounded by $\mathrm{El} \mathrm{Pa}$ & Manitou Spgs & 76 \\
\hline Keithley Log Cabin Development District & Roughly bounded by Santa & Manitou Spgs & 75 \\
\hline North End Historic District & Roughly bounded by Monum & Colorado Spgs & 71 \\
\hline \multicolumn{4}{|l|}{ Old Colorado City Historic } \\
\hline Commercial Distr & N side of Colorado Ave. & Colorado Spgs & 73 \\
\hline Bemis, Judson Moss, House & 506 N. Cascade Ave. & Colorado Spgs & 70 \\
\hline Chambers Ranch & 3202 Chambers Way & Colorado Spgs & 75 \\
\hline Midland Terminal Railroad Roundhouse & 600 S. $21 \mathrm{st}$ St. & Colorado Spgs & 72 \\
\hline Rio Grande Engine No. 168 & 9 S. Sierra Madre & Colorado Spgs & 70 \\
\hline Y.W.C.A. & 130 E. Kiowa St. & Colorado Spgs & 70 \\
\hline \multicolumn{4}{|l|}{ North Weber Street-Wahsatch } \\
\hline Avenue Historic & N. Weber St. & Colorado Spgs & 70 \\
\hline Bridge over Fountain Creek & Rt. 24 & Manitou Spgs & 78 \\
\hline Old Livery Stable & 217 W. Missouri & Fountain & 50 \\
\hline Barker House & 819 Manitou & Manitou Spgs & 77 \\
\hline First Congregational Church & 101 Pawnee Ave. & Manitou Spgs & 77 \\
\hline Manitou Bathhouse & 934 Manitou Ave. & Manitou Spgs & 77 \\
\hline Glen Eyrie & 3280 N. 30th St. & Colorado Spgs & 78 \\
\hline Pioneer Cabin & $11 \mathrm{mi}$. $\mathrm{N}$ of Colorado Spr & Colorado Spgs & 85 \\
\hline El Paso County Courthouse & 215 S. Tejon St. & Colorado Spgs & 69 \\
\hline McAllister House & 423 N. Cascade Ave. & Colorado Spgs & 70 \\
\hline Briarhurst & 404 Manitou Ave. & Manitou Spgs & 76 \\
\hline Burgess House & 730 N. Nevada Ave. & Colorado Spgs & 73 \\
\hline Montgomery Hall, Colorado College & 103 N. Cascade Ave. & Colorado Spgs & 70 \\
\hline Carlton House & U.S. Air Force Academy & Colorado Spgs & 83 \\
\hline Colorado Springs Day Nursery & 104 E. Rio Grande St. & Colorado Spgs & 72 \\
\hline Colorado Springs Airport & Ent. Ave. and Peterson Blvd. & Colorado Spgs & 70 \\
\hline \multirow[t]{2}{*}{ Navajo Hogan } & 2817 N. Nevada Ave. & Colorado Spgs & 73 \\
\hline & Fremont County & & \\
\hline Royal Gorge Bridge and Incline Railway & NW of Canon City & Canon City & 89 \\
\hline McClure House & 323-331 Main St. & Canon City & 81 \\
\hline Canon City Downtown Historic District & Roughly Main St. from 3rd & Canon City & 81 \\
\hline Fourth Street Bridge & 4th St. & Canon City & 80 \\
\hline US Post Office-Florence Main & 121 N. Pikes Peak St. & Florence & 70 \\
\hline Bridge No. 10/Adelaide Bridge & Fremont Cty. Rd. & Florence & 71 \\
\hline
\end{tabular}


Table B.4. (continued)

\begin{tabular}{|c|c|c|c|}
\hline Site name & Site address & \multicolumn{2}{|c|}{$\begin{array}{c}\begin{array}{c}\text { Distance } \\
\text { from }\end{array} \\
\text { PUDA }(\mathrm{km})^{\circ}\end{array}$} \\
\hline Portland Bridge & SR 120 & Portland & 61 \\
\hline Robison Mansion & 12 Riverside Dr. & Canon City & 81 \\
\hline Canon City Municipal Building & 612 Royal Gorge Blvd. & Canon City & 81 \\
\hline $\begin{array}{l}\text { US Post Office and Federal Building-Canon } \\
\text { Canon City Downtown Historic District }\end{array}$ & Fifth St. and Macon Ave. & Canon City & 81 \\
\hline (Boun & 602 Macon Ave. & Canon City & 81 \\
\hline Holy Cross Abbey & US 50 & Canon City & 78 \\
\hline First Presbyterian Church & Macon and 7th Sts. & Canon City & 81 \\
\hline \multicolumn{4}{|c|}{ Huerfano County } \\
\hline \multicolumn{4}{|c|}{ Las Animas County } \\
\hline Arnet, Adam \& Bessie, Homestead & Address Restricted & La Junta vicinity & 75 \\
\hline Cross, John Sanders, Homestead & Address Restricted & La Junta vicinity & 75 \\
\hline Doyle, Mary, Claim & Address Restricted & La Junta vicinity & 75 \\
\hline Haines, Asa T., Homestead & Address Restricted & La Junta vicinity & 75 \\
\hline PCMS Historic Archeological Dist. & Address Restricted & La Junta vicinity & 75 \\
\hline PCMS Prehistoric Archeological Dist. & Address Restricted & La Junta vicinity & 75 \\
\hline Rourke, Eugene Ranch & Address Restricted & La Junta vicinity & 75 \\
\hline Samuel Taylor Brown's Sheep Camp & Address Restricted & La Junta vicinity & 75 \\
\hline Stevens, Moses B., Homestead & Address Restricted & La Junta vicinity & 75 \\
\hline \multicolumn{4}{|c|}{ Otero County } \\
\hline Bent's Old Fort National Historic Site & CO 194 & La Junta & 83 \\
\hline Lincoln School & 300 block W. 3rd St. & La Junta & 78 \\
\hline Finney, Dr. Frank, House & 608 Belleview Ave. & La Junta & 78 \\
\hline Sciumbato, Daniel, Grocery Store & 706 2nd St. & La Junta & 77 \\
\hline U.S. Post Office & 4th and Colorado Ave. & La Junta & 78 \\
\hline Rourke, Eugene, House & 619 Carson St. & La Junta & 78 \\
\hline San Juan Avenue Historic District & San Juan Ave. & La Junta & 78 \\
\hline Hart, Wilson A., House & 802 Raton Ave. & La Junta & 78 \\
\hline \multicolumn{4}{|c|}{ Teller County } \\
\hline Victor Hotel & 4th St. and Victor Ave. & Victor & 82 \\
\hline Cripple Creek Historic District & Rt. 67 & Cripple Creek & 85 \\
\hline Goldfield City Hall and Fire Station & Victor Ave. and 9th St. & Goldfield & 81 \\
\hline Victor Downtown Historic District & Roughly bounded by Diamo & Victor & 82 \\
\hline Midland Terminal Railroad Depot & 230 N. 4th St. & Victor & 82 \\
\hline Florissant School & 2009 Co. Rd. 31 & Florissant & 100 \\
\hline
\end{tabular}

Multiply km by 0.6214 to obtain miles.

Source: National Park Service, National Register of Historic Sites, p. c. diskettes. 
B-14

\section{B.2 RESOURCES POTENTIALLY AFFECTED BY ACCIDENTS}

\section{B.2.1 General Population Surrounding PUDA}

Table B.5 identifies the population distributions within $100 \mathrm{~km}$ (62 miles) of PUDA by distance intervals and 22.5 degree radial sectors. These data are essential to the impact analysis of an accidental agent release and for pollutants associated with normal operations. These data indicate that (1) a large concentration of people reside approximately $30 \mathrm{~km}$ (19 miles) from the installation (in the city of Pueblo) and (2) other smaller concentrations of people reside in smaller settlements and towns closer to the installation.

\section{B.2.2 Nearby Counties}

Table B. 6 lists the counties that lie wholly or partially within a $100-\mathrm{km}(62-\mathrm{mile})$ zone of PUDA and indicates the population trends from 1980 through 1986. The 100-km (62-mile) impact area is considered here because the accident analysis presented in the Final Programmatic Environmental Impact Statement (FPEIS) indicates that resources as far away as $100 \mathrm{~km}$ ( 62 miles) could be impacted by low-probability but high-consequence events associated with continued storage of agents and munitions. The potential impact area for an accidental release during operations activities is significantly smaller, $5 \mathrm{~km}$ ( 3.1 miles), and is entirely within Pueblo County; it includes only one residence approximately $1.75 \mathrm{~km}$ (1.1 miles) north of the installation boundary. The emergency planning zone for PUDA, however, has been expanded to encompass an area of approximately $35 \mathrm{~km}$ ( 21.7 miles), which includes the city of Pueblo to the west and its northern and southern suburbs.

\section{B.2.3 Sensitive Populations}

Table B.7 presents the distribution of residential populations by potentially sensitive age groups. The most potentially sensitive age groups include infants to 4 years; children 5-14 years; and the elderly, aged 65 years or more.

\section{B.2.4 Daytime Population Distribution}

Detailed daytime population data are unavailable. A reasonable approximation for daytime population, however, may be considered to be persons at their normal daytime locations, including places of work, schools, hospitals, and shopping areas. Table B.8 lists places of employment in Pueblo that have more than 100 employees at a single location. A large number of these businesses are concentrated in the Airport Industrial Park, approximately $13 \mathrm{~km}$ (8 miles) west of PUDA. The largest single employer in the area is CF\&I Steel Corporation. Data regarding populations in other daytime locations are discussed in Sect. B.2.6 (see Tables B.12 through B.17). 
Table B.5. Residential population distribution around the proposed disposal facility site at the Pueblo Depot Activity using data collected during Phase I

\begin{tabular}{|c|c|c|c|c|c|c|c|c|}
\hline \multirow{2}{*}{ Direction } & \multicolumn{8}{|c|}{ Incremental population data at specified distances $(\mathrm{km})^{a}$} \\
\hline & $0-1$ & $1-2$ & $2-5$ & $5-10$ & $10-20$ & $20-35$ & $35-50$ & $50-100$ \\
\hline $\mathbf{N}$ & 0 & 0 & 2 & 0 & 2 & 76 & 394 & 2,414 \\
\hline NNE & 0 & 0 & 1 & 3 & 23 & 47 & 60 & 1,182 \\
\hline $\mathrm{NE}$ & 0 & 0 & 1 & 6 & 24 & 47 & 87 & 427 \\
\hline ENE & 0 & 0 & 1 & 6 & 29 & 18 & 30 & 231 \\
\hline $\mathrm{E}$ & 0 & 0 & 2 & 10 & 45 & 34 & 926 & 689 \\
\hline ESE & 0 & 0 & 5 & 32 & 86 & 278 & 2,094 & 20,821 \\
\hline SE & 0 & 0 & 4 & 31 & 106 & 691 & 1,889 & 1,957 \\
\hline SSE & 0 & 0 & 0 & 16 & 82 & 162 & 503 & 166 \\
\hline$S$ & 0 & 0 & 0 & 5 & 80 & 34 & 63 & 69 \\
\hline SSW & 0 & 0 & 0 & 8 & 1,049 & 172 & 78 & 4,699 \\
\hline SW & 0 & 0 & 0 & 36 & 1,564 & 1,450 & 208 & 2,954 \\
\hline WSW & 0 & 0 & 0 & 49 & 468 & 100,876 & 2,232 & 2,011 \\
\hline W & 0 & 0 & 0 & 127 & 688 & 15,214 & 1,910 & 25,237 \\
\hline WNW & 0 & 0 & 0 & 12 & 8 & 35 & 60 & 4,144 \\
\hline NW & 0 & 0 & 1 & 4 & 20 & 27 & 1,165 & 229,057 \\
\hline NNW & 0 & 0 & 2 & 0 & 11 & 46 & 276 & 72,830 \\
\hline Total & 0 & 0 & 19 & 345 & $\overline{4,285}$ & 119,208 & 11,975 & $\overline{368,890}$ \\
\hline
\end{tabular}

"Multiply by 0.6214 to obtain miles.

Source: U.S. Department of Commerce, U.S. Bureau of the Census 1988. Current Population Reports, Series T-26, No. 86-NW, 1986 and 1985 Per Capita Income Estimates for Counties and Incorporated Places, U.S. Government Printing Office, Washington, D.C.

Note: The location used for the center of the above population is at $38^{\circ}, 20 \mathrm{~min}, 34 \mathrm{~s}$ north latitude and $104^{\circ}$, $18 \mathrm{~min}, 29 \mathrm{~s}$ west longitude.

\section{B.2.5 Transient Populations}

Transient populations are composed of people who are not regular inhabitants of the area, but are visiting the base or vicinity for some common event or purpose. They include people attending special events and training exercises held on-post, special events held offpost, public areas, convention and meeting centers, and recreation areas, as well as migrant workers in the area. Transient populations are especially problematic from an emergency planning standpoint; they can be either widely distributed in sparse concentrations, or they may be large and concentrated in one place. 
Table B.6. Population trends in counties located within $100 \mathrm{~km}$ (62 miles) of Pueblo Depot Activity

\begin{tabular}{|c|c|c|c|c|}
\hline & $\begin{array}{c}\text { Land area } \\
1980 \\
\left(\mathrm{mi}^{2}\right)\end{array}$ & $\begin{array}{c}\text { Population } \\
1986\end{array}$ & $\begin{array}{c}\text { Population } \\
\text { change } \\
1980-86\end{array}$ & $\begin{array}{c}\text { Population } \\
\text { percent change } \\
1980-86\end{array}$ \\
\hline Bent & 1,517 & 5,800 & -100 & -2.3 \\
\hline Crowley & 790 & 3,200 & 200 & 6.7 \\
\hline Custer & 740 & 1,900 & 300 & 21.9 \\
\hline Douglas & 841 & 38,800 & 13,600 & 54.2 \\
\hline Elbert & 1,851 & 8,600 & 1,800 & 25.9 \\
\hline El Paso & 2,129 & 380,400 & 71,000 & 22.9 \\
\hline Fremont & 1,538 & 31,800 & 3,200 & 11.0 \\
\hline Huerfano & 1,584 & 6,900 & 500 & 7.4 \\
\hline Kiowa & 1,758 & 1,900 & -100 & -2.8 \\
\hline Las Animas & 4,771 & 14,200 & -700 & -4.9 \\
\hline Lincoln & 2,586 & 4,700 & 0 & 0.1 \\
\hline Otero & 1,247 & 21,900 & -700 & -3.0 \\
\hline Park & 2,192 & 7,000 & 1,700 & 31.1 \\
\hline Pueblo & 2,377 & 127,100 & 1,100 & 0.9 \\
\hline Teller & 559 & 11,600 & 3,600 & 44.8 \\
\hline
\end{tabular}

Source: U.S. Bureau of the Census 1986. County and City Data Book, computer data file, Washington, D.C.

Transient populations on-post at PUDA include visitors, contractors, participants in day camp and special functions, and military trainees. The number of visitors registered at PUDA (not including contractors, military trainees and families, or visitors to depot functions) during 1989 ranged from 74 during the fourth quarter to 340 during the second quarter (L. Massey and J. Westfall, PUDA Public Affairs, Pueblo, Colo., personal communication with S. Schexnayder, ORNL, Oak Ridge, Tenn., June 11, 1990). PUDA hosts a day camp from June 7 to August 24 that is attended by 30 children and 6 to 8 teen counselors. Military training is conducted for 4 to 6 weeks each summer involving 400 to 500 Army Reserve troops. Also, the Colorado National Guard brings in 20 people for 20 people for one weekend every month, and 10 active-duty soldiers from Ft. Carson visit the depot quarterly (P. J. Steranka, Safety Manager, PUDA, letter to S. Schexnayder, ORNL, Oak Ridge, Tenn., June 13, 1990).

Transient populations in Pueblo County were identified during the Phase I process. A number of meeting and convention facilities are located in Pueblo. Those facilities with a total capacity of 300 or more are listed in Table B.9. In 1990, approximately 30 conventions, hosting an estimated 39,000 delegates, were held or were to be held (L. Beard, Pueblo 
Table B.7. Sensitive populations within $100 \mathrm{~km}(62 \mathrm{miles})$ of Pueblo Depot Activity-1990 estimates (\% of total county population)

\begin{tabular}{lcccc}
\hline County & $\begin{array}{c}\text { Persons } \\
<5 \text { years }\end{array}$ & $\begin{array}{c}\text { Persons 5-14 } \\
\text { years }\end{array}$ & $\begin{array}{c}\text { Persons 65-74 } \\
\text { years }\end{array}$ & $\begin{array}{c}\text { Persons } \geq 75 \\
\text { years }\end{array}$ \\
\hline Bent & & & & \\
Crowley & 5.4 & 15.4 & 9.7 & 7.2 \\
Custer & 6.0 & 13.3 & 6.9 & 6.5 \\
Douglas & 5.4 & 18.5 & 3.5 & 5.5 \\
Elbert & 9.8 & 15.5 & 2.7 & 1.4 \\
El Paso & 7.4 & 16.5 & 4.1 & 3.1 \\
Fremont & 11.2 & 16.4 & 4.8 & 3.0 \\
Huerfano & 6.5 & 12.1 & 8.9 & 10.3 \\
Kiowa & 5.3 & 16.0 & 8.9 & 9.0 \\
Las Animas & 6.4 & 16.8 & 14.8 & 5.2 \\
Lincoln & 5.8 & 15.4 & 9.5 & 9.6 \\
Otero & 8.6 & 14.9 & 9.6 & 8.1 \\
Park & NA & NA & NA & NA \\
Pueblo & 8.7 & 15.8 & 5.0 & 2.2 \\
Teller & 7.0 & 14.1 & 8.0 & 6.0 \\
\hline
\end{tabular}

Source: Colorado Division of Local Government 1990. Colorado Population Projections, computer data files, Denver.

Chamber of Commerce, Pueblo, Colo., personal communication with J. Morrissey, Science Applications International Corp. (SAIC), Oak Ridge, Tenn., Sept. 20, 1990).

Local recreation areas and estimated visitation are presented in Table B.10. Pueblo Reservoir, a popular park for boating, swimming, camping and other activities, is located $32 \mathrm{~km}$ (20 miles) west of PUDA. Visitation at the reservoir has totalled 1.3 million to 1.4 million per year from FY 1987-1988 through FY 1989-1990. Monthly visitation may range from approximately 22,000 in the winter to 275,000 in the summer (Michael French, Park Manager, Lake Pueblo State Recreation Area, Pueblo, Colo., personal communication to J. Morrissey, SAIC, Oak Ridge, Tenn., Aug. 21, 1990). State and federal public areas located within $100 \mathrm{~km}$ (62 miles) are shown in Table B.11.

Crowd-drawing events in Pueblo that take place annually are shown in Table B.12. The largest annual event in Pueblo is the Colorado State Fair. A 17-day event that closes on Labor Day each year, the Colorado State Fair drew over 1,014,000 people in 1991. During the off season, approximately 316,000 people are attracted to the Colorado State Fairgrounds (M. Marsh, Pueblo Chamber of Commerce, personal communication with J. Terry, ORNL, 
Table B.8. Employers in Pueblo County with more than 100 employees at one location

\begin{tabular}{llr}
\hline \multicolumn{1}{c}{ Employer } & \multicolumn{1}{c}{ Location } & Number of employees \\
\hline Atlas-Pacific & AIP & 120 \\
B.F. Goodrich & AIP & 128 \\
Candy's Tortilla Factory & Pueblo & 380 \\
CF\&I Steel Corporation & Pueblo & 1900 \\
Colorado National Bank & Pueblo & $100+$ \\
Colorado State Hospital & Pueblo & 1375 \\
Dana Corporation & AIP & 250 \\
Government Printing Office & & \\
Distribution Center & AIP & 100 \\
Kaiser Aerotech & AIP & 150 \\
Kurt Manufacturing & AIP & 101 \\
McDonnell-Douglas & AIP & 295 \\
Parkview Hospital & Pueblo & 1130 \\
Pueblo Chieftain & Pueblo & 210 \\
Rainbo Bakery & Pueblo & 100 \\
St. Mary Corwin Hospital & Pueblo & 1565 \\
Target & AIP & 300 \\
Trane Company & AIP & 170 \\
Transportation Test Center & NE Pueblo County & 340 \\
Unisys & AIP & 775 \\
University of Southern Colorado & Pueblo & 500 \\
WATS Telemarketing & Pueblo & 740 \\
\hline
\end{tabular}

${ }^{\circ}$ AIP $=$ the Pueblo Memorial Airport Industrial Park

Sources: Pueblo Chamber of Commerce March 1989. Major Industries/Employment, Pueblo, Colo.

Pueblo City Department of Planning and Development May 1988. Business Located at Pueblo Memorial Airport Industrial Park Since, and Including, Unisys, Pueblo, Colo.; Chuck Finley, Director, Pueblo County Department of Planning and Development, Pueblo, Colo., personal communication to S. Schexnayder, Oak Ridge National Laboratory, Oak Ridge, Tenn., Aug. 10, 1990.

Oak Ridge, Tenn., Jan. 16, 1992). The fairgrounds are located approximately $27.3 \mathrm{~km}$ (17 miles) WSW of PUDA.

Other frequent events occurring on a seasonal basis include games played by the Ratliff Ravens, a semi-professional hockey team, and college basketball. The Ratliff Ravens play at the Pueblo Plaza Ice Arena from October through March, and between 200 and 400people attend the games (Jody Lane, Park Manager, Pueblo City Parks, Pueblo, Colo., personal communication with S. Schexnayder, ORNL, Oak Ridge, Tenn., Sept. 28, 1990).

The University of Southern Colorado, located approximately $16 \mathrm{~km}$ (10 miles) west of PUDA, is the site of a number of crowd-drawing events, such as basketball games, concerts, theater performances, and the annual Town and Gown Series for the performing arts. Men's 
Table B.9. Meeting and convention centers in Pueblo with total seating capacity of at least 300

\begin{tabular}{lcc}
\hline \multicolumn{1}{c}{ Facility } & $\begin{array}{c}\text { Number of } \\
\text { meeting rooms }\end{array}$ & $\begin{array}{c}\text { Total } \\
\text { seating capacity }\end{array}$ \\
\hline Colorado State Fairgrounds & 4 & 7300 \\
Memorial Auditorium & 1 & 1500 \\
Minnequa Club & 2 & 790 \\
Pueblo Community College & 1 & 500 \\
Pueblo Policeman's Benevolent & 1 & 850 \\
Association, Inc. & 4 & 500 \\
Hotel Pueblo & 3 & 1600 \\
Sangre de Cristo Arts and \\
Conference Center
\end{tabular}

Source: L. Beard, Pueblo Chamber of Commerce, Pueblo, Colo., personal communication with J. Morrissey, SAIC, Oak Ridge, Tenn., Sept. 20, 1990.4

and women's basketball games are the most popular sporting event, attracting approximately 1000 people per game. The basketball games are played at the University Sporting Complex,which has a capacity of 5000 , from November through the first week in March (Glenn Matson, Sports Information Student Assistant, University of Southern Colorado Athletic Department, Pueblo, Colo., personal communication with J. Morrissey, SAIC, Oak Ridge, Tenn., Aug. 13, 1990). The Hoag Recital Hall, which has a seating capacity of 603, is the location of music department concerts, theater performances, and the Town and GownSeries held from December through early March. The Occhiato University Center held from December through early March. The Occhiato University Center Ballroom is used for dances, which are more frequent in the fall and which attract 350 to 400 people (Margaret Will, Coordinator of Student Activities, University of Southern Colorado, Pueblo, Colo., personal communication with J. Morrissey, SAIC, Oak Ridge, Tenn., Aug. 13, 1990). In addition to concerts held in Hoag Recital Hall, large concerts may be held in the University Sporting Complex (D. Renfrow, Secretary, Music Department, University of Southern 
Table B.10. Visitor use of recreational areas and facilities in Pueblo, Colorado

\begin{tabular}{lcc}
\hline \multicolumn{1}{c}{ Recreational facility } & Peak periods & Annual visitors \\
\hline $\begin{array}{l}\text { Pueblo city parks } \\
\text { City Park }\end{array}$ & Summer & $a$ \\
Mineral Palace Park & & \\
Mountain Park & & \\
Pueblo City Zoo & & \\
& Summer; weekends in & 60,000 \\
Pueblo Plaza Ice Arena & spring and fall & \\
Greenway and Nature Center & Winter months & 29,000 \\
Pueblo Greyhound Park & NA & 213,000 \\
Aircraft and B-24 Museum & August-March & NA \\
Beacon Hill Speedway & NA & NA \\
Pueblo Motorsports Park & NA & NA \\
Rosemount Victorian House & Christmas season & 12,000 \\
Museum & year-round & \\
El Pueblo Museum & September-January & 5,375 \\
Dutch Clark Stadium & year-round & NA \\
Colorado State Fairgrounds & & 305,000 \\
(off-season) & NA & 60,000 \\
Sangre de Cristo Arts and & & \\
Conference Center & &
\end{tabular}

aCity Park is the most heavily used of Pueblo's city parks. On a summertime weekend day, between 1000 and 1500 persons may visit City Park, which has 18 tennis courts, a swimming pool, and picnic areas. At Mineral Palace Park, two or three large swim meets held each summer attract 500 to 700 people in addition to its regular users. Mountain Park is now being used as a biology field school for local students.

'Approximately 80 children per day, 3 days a week, attend educational programs during winter months.

Total attendance includes spectators of the Ratliff Ravens games; mid-winter regionals, a figure skating event that attracts 800 to 1000 people over a 4-day period; youth hockey matches; and open recreational skating.

Not available.

Sources: Luanne Beard, Pueblo Chamber of Commerce, Pueblo, Colo., personal communication with J. Morrissey, SAIC, Oak Ridge, Tenn.; Jonnie McFarland, Pueblo City Zoo, Pueblo, Colo., personal communication with S. Schexnayder, ORNL, Oak Ridge, Tenn., Sept. 27, 1990; Marie Hobbs, Pueblo Greyhound Park, Pueblo, Colo., personal communication with S. Schexnayder, ORNL, Oak Ridge, Tenn., Sept. 27, 1990; Jody Lane, Park Manager, Pueblo City Parks, Pueblo, Colo., personal communication with S. Schexnayder, ORNL, Oak Ridge, Tenn., Sept. 28, 1990.

Colorado, Pueblo, Colo., personal communication with J. Morrissey, SAIC, Oak Ridge, Tenn., Aug. 13, 1990). 
Table B.11. State and federal public areas within $100 \mathrm{~km}$ (62 miles) of Pueblo Depot Activity

\begin{tabular}{|c|c|c|c|}
\hline Area & County & $\begin{array}{l}\text { Distance } \\
\text { from site }\end{array}$ & $\begin{array}{l}\text { Annual visitors } \\
\text { (in } 1000 \text { s) }\end{array}$ \\
\hline \multicolumn{4}{|c|}{ National forests (NFs) } \\
\hline Pikes Peak NF & El Paso, Teller & $80 \mathrm{~km} \mathrm{NW}$ & 4223.0 \\
\hline San Isabel NF & $\begin{array}{l}\text { Fremont, Custer, } \\
\text { Pueblo, Huerfano }\end{array}$ & $70 \mathrm{~km}$ WSW & NA \\
\hline Comanche Nat'l Grassland & Otero & $60 \mathrm{~km} \mathrm{SE}$ & NA \\
\hline \multicolumn{4}{|c|}{ National historic sites (NHSs) } \\
\hline Bents Old Fort NHS & Otero & $90 \mathrm{~km} \mathrm{SSE}$ & 45.5 \\
\hline Cripple Creek NHS & Teller & $95 \mathrm{~km} \mathrm{NW}$ & NA \\
\hline \multicolumn{4}{|c|}{ State parks (SPs) } \\
\hline Lathrop SP & Huerfano & $85 \mathrm{~km}$ SSW & 221.8 \\
\hline \multicolumn{4}{|c|}{ State wildlife areas (SWAs) } \\
\hline Karval SWA & Lincoln & $90 \mathrm{~km} \mathrm{NE}$ & NA \\
\hline Rocky Ford SWA & Otero & $65 \mathrm{~km}$ ESE & NA \\
\hline Sheep Rock SWA & Teller & $98 \mathrm{~km} \mathrm{NW}$ & NA \\
\hline Beaver Creek SWA & Teller, Fremont & $80 \mathrm{~km} \mathrm{WNW}$ & NA \\
\hline Dome Rock SWA & Teller & $90 \mathrm{~km} \mathrm{NNW}$ & NA \\
\hline Colorado Springs SWA & El Paso & $35 \mathrm{~km} \mathrm{~N}$ & NA \\
\hline Huerfano SWA & Huerfano & $98 \mathrm{~km} \mathrm{SW}$ & NA \\
\hline \multicolumn{4}{|c|}{ State recreational areas (SRAs) } \\
\hline Ramah SRA & El Paso & $90 \mathrm{~km} \mathrm{~N}$ & NA \\
\hline $\begin{array}{l}\text { Pueblo SRA } \\
\text { (Pueblo Reservoir) }\end{array}$ & Pueblo & $32 \mathrm{~km} \mathrm{~W}$ & 1500.0 \\
\hline
\end{tabular}

NA = not available; multiply $\mathrm{km}$ by 0.6214 to obtain miles.

Sources: L. Kramer, Manager, Lathrop State Park, Walsenburg, Colo., personal communication to

J. Morrissey, SAIC, Oak Ridge, Tenn., Aug. 16, 1990; E. Aldred, Administrative Clerk, National Park Service, La Junta, Colo., personal communication to J. Morrissey, SAIC, Oak Ridge, Tenn., Aug. 16, 1990; U.S. Forest Service, A Summary of Recreation Use (M/RVDS) for FY 1986 by Activity, Washington, D.C., 1987.

Michael French, Park Manager, Pueblo State Recreation Area, Pueblo, Colo., personal communication to J. Morrissey, SAIC, Oak Ridge, Tenin., Aug. 21, 1990. 


\section{B-22}

Table B.12. Annual event and attendance in Pueblo

\begin{tabular}{lccc}
\hline \multicolumn{1}{c}{ Event } & Location & Time/duration & $\begin{array}{c}\text { Approximate } \\
\text { attendance }\end{array}$ \\
\hline Governor's Cup Regatta & Pueblo Reservoir & $\begin{array}{c}\text { Memorial Day } \\
\text { weekend }\end{array}$ & 12,790 \\
Rolling River Raft Race & Arkansas River & & 10,000 \\
Stomp-On & Rosemount & Late August & 7,000 \\
Colorado State Fair & Fairgrounds & 17 days ending & $1,014,000+$ \\
Labor Day & \\
$\begin{array}{l}\text { Christmas Posada } \\
\begin{array}{l}\text { Parade of Lights } \\
\text { Rosemount Victorian }\end{array}\end{array}$ & NA & Christmas season & NA \\
Christmas Tour & NA & Christmas season & 25,000 \\
$\begin{array}{l}\text { Olympia Cup Stock Car } \\
\text { Championship }\end{array}$ & Neacon Hill & Christmas season & 12,300 \\
$\begin{array}{l}\text { Pueblo County Fair } \\
\text { Cinco de Mayo }\end{array}$ & Fpeedway & NA & NA \\
\hline
\end{tabular}

Source: L. Beard, Pueblo Chamber of Commerce, Pueblo, Colo., personal communication with J. Morrissey, SAIC, Oak Ridge, Tenn., Aug. 13, 1990.

Additional transient populations in the Pueblo vicinity are composed of migrant farm workers. Workers are present in the area from May through September. The number of workers peaks in late July, August, and early September when crops are being harvested. The workers and their families are concentrated in housing primarily in the communities of Boone and Avondale, located south to southeast of the depot. They work in fields located along the Arkansas River Valley, where the primary crops are onions, chili peppers, sweet corn, tomatoes, cantaloupe, lettuce, cauliflower, and sod. Based on records of the Pueblo County's surplus food program, which distributes food to $90 \%$ of the migrant workers, there were approximately 1200 individuals in about 450 migrant households in 1989 (W. Zeisel, Pueblo County Department of Community Services, Pueblo, Colo., personal communication with S. Schexnayder, ORNL, Oak Ridge, Tenn., June 8, 1990). 


\section{B.2.6 Institutional Populations}

Concentrations of people who would require special assistance in the event of an emergency occur primarily in institutional settings. Examples of institutionalized populations with special needs include schools, day care centers, hospitals, nursing homes, and correctional facilities. The Phase I process has attempted to identify and characterize such populations within the $100-\mathrm{km}$ zone. Noninstitutionalized special populations (e.g., the blind, hearing impaired, homeless, and bedfast) may need special assistance as well, although no effort has been made in Phase I to identify these.

Table B.13 presents enrollment and staffing data for individual schools in Pueblo City and Pueblo County and for counties outside Pueblo County. Avondale Elementary School is the nearest school to PUDA, approximately $3.2 \mathrm{~km}$ ( 2 miles) south, and has an enrollment of about 280 children. Table B.14 presents the total capacity of day care facilities for each county within $100 \mathrm{~km}$ (62 miles).

Table B.15 presents recent enrollments for institutions of higher education within the 100-km (62-mile) zone. The University of Southern Colorado, with an enroliment of 4000, is located in Pueblo approximately $16 \mathrm{~km}$ (10 miles) west of PUDA. Its residence hall has a capacity of 450 (College Blue Book 1989).

Table B.16 shows total nursing home capacity in each of the counties within the 100 $\mathrm{km}$ (62-mile) zone. Table B.17 presents hospitals within the $100-\mathrm{km}(62-\mathrm{mile})$ zone. Hospitals could be affected by an accidental release of agent in two ways: (1) they house patients with special needs who would require carefully planned protective measures and (2) they would be needed to administer services to persons in the general population who were affected by chemical agent. Three hospitals are located in Pueblo: Colorado State Hospital, a psychiatric institution with a capacity of 698; Parkview Episcopal Medical Center, with a capacity of 239 beds; and St. Mary-Corwin Regional Medical and Health Center, with 307 beds.

PUDA operates an Occupational Health Clinic that responds to minor medical emergencies on-site. A mutual assistance agreement with Ft. Carson Medical Department Activity (MEDDAC) exists. Rapid response is made possible by MEDDAC's helicoptertransported medical teams. MEDDAC is the approving authority for the transfer of injured personnel to civilian hospitals, although PUDA is authorized to act in the event of a lifethreatening situation. The Army has provided protective equipment to a local hospital, which was used to establish a decontamination and treatment center. It has been suggested that these plans and agreements be extended and procedures be developed to deal with civilian casualties.

Table B.18 shows state correctional facilities within $100 \mathrm{~km}$ (62 miles) of PUDA. One facility, with a capacity of 966 , is located in Crowley, which is approximately $40.2 \mathrm{~km}$ (25 miles) east of PUDA. Nine facilities, with a total capacity of over 3200 , are located in Canon City, about $64.4 \mathrm{~km}$ (40 miles) west of PUDA. 
B-24

Table B.13. Schools within $100 \mathrm{~km}$ (62 miles) of Pueblo Depot Activity

\begin{tabular}{|c|c|c|c|c|}
\hline Facility & Grade & Enrollment & $\begin{array}{l}\text { Total faculty } \\
\text { and staff }\end{array}$ & $\begin{array}{c}\text { Number of } \\
\text { teachers }\end{array}$ \\
\hline
\end{tabular}

Pueblo County schools, District $\mathbf{7 0}^{\circ}$

$\begin{array}{lllll}\text { Avondale Elem. } & \text { K-5 } & 276 & 24 & 15 \\ \text { Beulah Elem. } & \text { K-5 } & 103 & 17 & 12 \\ \text { North Mesa } & \text { K-5 } & 311 & 28 & 16 \\ \text { Pueblo West Elem. } & \text { K-5 } & 320 & 26 & 17 \\ \text { Rye Elem. } & \text { K-5 } & 234 & 23 & 15 \\ \text { South Mesa } & \text { K-5 } & 420 & 39 & 24 \\ \text { Vineland Elem. } & \text { K-5 } & 277 & 27 & 18 \\ \text { Beulah School } & \text { K-8 } & 144 & 17 & 12 \\ \text { Craver } & 6-8 & 128 & 17 & 12 \\ \text { Pleasant View } & 6-8 & 381 & 30 & 20 \\ \text { Pueblo West Middle } & 6-8 & 159 & 17 & 11 \\ \text { Vineland Middle } & 6-8 & 308 & 25 & 63 \\ \text { County High } & 9-12 & 952 & 85 & 20 \\ \text { Rye High } & 9-12 & 178 & 28 & \end{array}$

Pueblo city schools, District $60^{b}$

$\begin{array}{llllr}\text { Belmont } & \text { P-5 } & 457 & 38 & 21 \\ \text { Bessemer } & \text { P-5 } & 374 & 34 & 20 \\ \text { Beulah H. } & \text { K-5 } & 391 & 39 & 23 \\ \text { Bradford } & \text { P-5 } & 312 & 33 & 14 \\ \text { Carlile } & \text { K-5 } & 392 & 34 & 19 \\ \text { Columbian } & \text { P-5 } & 565 & 53 & 29 \\ \text { Eastwood } & \text { P-5 } & 182 & 21 & 8 \\ \text { Fountain } & \text { P-5 } & 323 & 38 & 20 \\ \text { Franklin } & \text { K-5 } & 479 & 34 & 22 \\ \text { Goodnight } & \text { K-5 } & 374 & 34 & 19 \\ \text { Haaff } & \text { K-5 } & 366 & 30 & 17 \\ \text { Hellbeck } & \text { K-5 } & 413 & 38 & 19 \\ \text { Highland Park } & \text { K-5 } & 567 & 47 & 27 \\ \text { Hyde Park } & \text { P-5 } & 217 & 31 & 15 \\ \text { Irving } & \text { K-5 } & 289 & 39 & 18 \\ \text { Jefferson } & \text { K-5 } & 356 & 29 & 27 \\ \text { Minnequa } & \text { K-5 } & 471 & 41 & 26 \\ \text { Morton } & \text { K-5 } & 542 & 42 & 24 \\ \text { Park View } & \text { K-5 } & 407 & 42 & 20 \\ \text { Somerlid } & \text { K-5 } & 396 & 36 & 17 \\ \text { South Park } & \text { P-5 } & 396 & 36 & 16 \\ \text { Spann } & \text { P-5 } & 366 & 33 & 23 \\ \text { Sunset Park } & \text { P-5 } & 481 & 39 & 38 \\ \text { Corwin } & \mathbf{4 - 8} & \mathbf{5 8 8} & 72 & 40 \\ \text { Freed } & \mathbf{6 - 8} & 706 & 73 & \end{array}$




\section{B-25}

Table B.13. (continued)

\begin{tabular}{lcccc}
\hline Facility & Grade & Enrollment & $\begin{array}{c}\text { Total faculty } \\
\text { and staff }\end{array}$ & $\begin{array}{c}\text { Number of } \\
\text { teachers }\end{array}$ \\
\hline Heaton & $6-8$ & 679 & 66 & 40 \\
Pitts & $6-8$ & 830 & 90 & 45 \\
Risley & $6-8$ & 517 & 55 & 33 \\
Roncalli & $6-8$ & 629 & 65 & 33 \\
Keating Extension & $6-12$ & 111 & 37 & 15 \\
Centennial & $9-12$ & 1124 & 127 & 67 \\
Central & $9-12$ & 1229 & 130 & 72 \\
East & $9-12$ & 1132 & 139 & 68 \\
South & $9-12$ & 1415 & 140 & 76
\end{tabular}

Public school enrollment 1987

County

$\begin{array}{lr}\text { Bent } & 1,072 \\ \text { Crowley } & 523 \\ \text { Custer } & 309 \\ \text { Douglas } & 9,693 \\ \text { Elbert } & 1,869 \\ \text { El Paso } & 69,625 \\ \text { Fremont } & 5,694 \\ \text { Huerfano } & 1,076 \\ \text { Kiowa } & 366 \\ \text { Las Animas } & 2,447 \\ \text { Lincoln } & 722 \\ \text { Park } & 1,434 \\ \text { Pueblo } & 23,143 \\ \text { Teller } & 2,445\end{array}$

Teachers include classroom teachers only and exclude counselors, principals, and teacher aides.

'In addition to teachers and staff reported per school, there are 320 employees [i.e., music teachers, child study (special education services) teams, food service workers, and maintenance staff] that serve all schools in District 60.

Sources: Pueblo School District No. 70, 1989-1990 Directory, Administrative Services Center, Pueblo, Colo., 1989; Pueblo School District No. 70, Principal's Periodic Report-April 2 - June 6, 1990, Pueblo, Colo., 1990; Pueblo School District No. 60, Membership by Grade and School, Deparment of Pupil Personnel, Pueblo, Colo., June 6, 1990; D. Hammond, Office of Personnel, School District No. 60, Pueblo, Colo., personal communication to S. Schexnayder, ORNL, Oak Ridge, Tenn., June $7,1990$.

\section{B.2.7 Indian Entities}

There are no Indian reservations or settlements within $100 \mathrm{~km}$ (62 miles) of PUDA (EPA, Office of Federal Activities 1988). 
Table B.14. Day care facilities and capacity within 100 km (62 miles) of Pueblo Depot Activity

\begin{tabular}{|c|c|c|c|}
\hline County & City or town & $\begin{array}{l}\text { Number of } \\
\text { facilities }\end{array}$ & Total capacity \\
\hline Pueblo & $\begin{array}{l}\text { Pueblo } \\
\text { Woodland Park }\end{array}$ & $\begin{array}{c}24 \\
1\end{array}$ & $\begin{array}{c}1392 \\
49\end{array}$ \\
\hline Crowley & Fowler & 1 & 30 \\
\hline Custer & Westcliffe & 1 & 10 \\
\hline Douglas & $\begin{array}{l}\text { Castle Rock } \\
\text { Sedalia }\end{array}$ & $\begin{array}{l}5 \\
2\end{array}$ & $\begin{array}{l}221 \\
150\end{array}$ \\
\hline El Paso & $\begin{array}{l}\text { Black Forest } \\
\text { Colorado Springs } \\
\text { Green Mtn. Falls } \\
\text { Monument } \\
\text { Security } \\
\text { Vista Grande }\end{array}$ & $\begin{array}{c}1 \\
85 \\
1 \\
3 \\
3 \\
1\end{array}$ & $\begin{array}{c}24 \\
5950 \\
38 \\
79 \\
188 \\
22\end{array}$ \\
\hline Fremont & $\begin{array}{l}\text { Canon City } \\
\text { Florence } \\
\text { Salida }\end{array}$ & $\begin{array}{c}10 \\
1 \\
2\end{array}$ & $\begin{array}{c}252 \\
30 \\
75\end{array}$ \\
\hline Huerfano & $\begin{array}{l}\text { Trinidad } \\
\text { Walsenburg }\end{array}$ & $\begin{array}{l}1 \\
4\end{array}$ & $\begin{array}{l}12 \\
82\end{array}$ \\
\hline Kiowa & Eads & 1 & 20 \\
\hline Otera & $\begin{array}{l}\text { La Junta } \\
\text { Rocky Ford } \\
\text { Swink }\end{array}$ & $\begin{array}{l}3 \\
2 \\
1\end{array}$ & $\begin{array}{l}114 \\
42 \\
10\end{array}$ \\
\hline
\end{tabular}

Source: Colorado Department of Social Services 1990. Day Care List by Provider Type, Denver.

\section{B.2.8 Agricultural Activities}

Because agriculture is an important economic activity in the region surrounding PUDA, a release of chemical agent could affect yields and sales of agricultural products. The extent of agricultural activity in the area within $100 \mathrm{~km}$ (62 miles) is depicted in Table B.19. Pueblo County has over 892,000 acres of farmland, most of which is pastureland. Agricultural production returned approximately $\$ 38.3$ million to Pueblo County in 1987. 


\section{B-27}

Table B.20 shows livestock inventory and sales for each county within $100 \mathrm{~km}$ (62 miles). Crowley County, which adjoins Pueblo County's eastern boundary, is a major producer of cattle and calves, with sales of $\$ 83.4$ million in 1987 . Otero County, which neighbors Pueblo County to the southeast, also is a major cattle producer, with $\$ 74$ million in sales.

Table B.15. Institutions of higher education within $100 \mathrm{~km}$ (62 miles) of Pueblo Depot Activity

\begin{tabular}{llr}
\hline \multicolumn{1}{c}{ Institution } & Location & Enrollment \\
\hline Univ. of Southern Colorado & Pueblo & 3953 \\
Pueblo Community College & Pueblo & 2600 \\
U.S. Air Force Academy & Colorado Springs & 4600 \\
Bethel College of Nursing & Colorado Springs & NA \\
Blair Junior College & Colorado Springs & 1322 \\
University of Colorado & Colorado Springs & 5853 \\
Colorado College & Colorado Springs & 1940 \\
Colorado Technical College & Colorado Springs & 1300 \\
Nazarene Bible College & Colorado Springs & 400 \\
Pikes Peak Community College & Colorado Springs & 3475 \\
Otero Junior College & LaJunta & 801 \\
& & \\
\hline
\end{tabular}

NA $=$ not available

Source: The College Blue Book: Tabular Data, 22nd edition, Macmillan, New York, 1989.

Table B.21 shows the market value and production of various crops in each county within $100 \mathrm{~km}$ (62 miles). Crop production is relatively low in economic importance with the exception of hay in Bent and Otero counties and wheat in Lincoln and Kiowa counties.

\section{B.2.9 Cultural, Archeological, and Historical Resources}

Cultural and historic properties within $100 \mathrm{~km}$ (62 miles) could be affected by an accidental release of chemical agent. Because these resources also are relevant to accidentfree activities related to construction and operations, they are described in Sect. B.1.2. 
Table B.16. Number and capacity of nursing homes within $100 \mathrm{~km}$ (62 miles) of Pueblo Depot Activity

\begin{tabular}{lcc}
\hline County & $\begin{array}{c}\text { Nursing } \\
\text { homes } \\
(1986)\end{array}$ & $\begin{array}{c}\text { Nursing } \\
\text { home } \\
\text { beds (1986) }\end{array}$ \\
\hline Bent & 1 & 10 \\
Crowley & 1 & 59 \\
Custer & 0 & 0 \\
Douglas & 1 & 80 \\
Elbert & 1 & 32 \\
El Paso & 26 & 1636 \\
Fremont & 11 & 672 \\
Huerfano & 1 & 50 \\
Kiowa & 2 & 49 \\
Las Animas & 1 & 226 \\
Lincoln & 4 & 131 \\
Otero & 5 & 305 \\
Park & 0 & 0 \\
Pueblo & 26 & 1037 \\
Teller & 1 & 59 \\
& & \\
\hline
\end{tabular}

Source: U.S. Bureau of the Census 1986. County and City Data Book, computer data file, Washington, D.C. 
Table B.17. Hospitals within $100 \mathrm{~km}$ (62 miles) of the Pueblo Depot Activity site

\begin{tabular}{llrr}
\hline \multicolumn{1}{c}{ Facility name } & \multicolumn{1}{c}{ Ciry } & $\begin{array}{c}\text { Number } \\
\text { of beds }\end{array}$ & $\begin{array}{c}\text { Occupancy } \\
\text { rate }(\%)\end{array}$ \\
\hline Colorado State Hospital & Pueblo & 698 & $90.5 \%$ \\
Parkview Episcopal Med. Ctr. & Pueblo & 239 & 51.9 \\
St. Mary-Corwin Hosp. \& Health Ctr. & Pueblo & 307 & 58.6 \\
Cedar Springs Psychiatric Hosp. & Colorado Springs & 100 & 64.0 \\
Doctors Hosp. Medical Center & Colorado Springs & 122 & 25.4 \\
Memorial Hospital & Colorado Springs & 367 & 45.6 \\
Penrose Hospitals & Colorado Springs & 460 & 63.3 \\
St. Francis Hospital Systems & Colorado Springs & 204 & 53.9 \\
Evan's U.S. Army Commty Hosp. & Fort Carson & 108 & 60.3 \\
U.S. Air Force Academy Hosp. & USAF Academy & 70 & 74.3 \\
St. Thomas More Hosp. \& Care Ctr. & Canon City & 201 & 59.7 \\
St. Joseph Hospital & Florence & 77 & 61.0 \\
Weisbrod Memorial Hospital & Eads & 42 & 66.7 \\
Veteran's Admin. Medical Ctr. & Fort Lyon & 372 & 93.8 \\
Lincoln Commty Hosp. \& Nursing Home & Hugo & 56 & 71.4 \\
Arkansas Valley Reg. Med. Ctr. & La Junta & 218 & $\mathbf{8 5}$ \\
Mount San Rafael Hospital & Trinidad & 38 & 25.8 \\
Huerfano Memorial Hospital & Walsenbury & NA \\
\hline
\end{tabular}

NA $=$ not available.

Source: American Hospital Association 1988 American Hospital Association Guide to the Health Care Field, Chicago, Ill.

Table B.18. State correctional institutions within $100 \mathrm{~km}$ (62 miles) of Pueblo Depot Activity

\begin{tabular}{lll}
\hline \multicolumn{1}{c}{ Facility } & Location & Capacity \\
\hline Arkansas Valley Correctional Facility & Crowley & 966 \\
Arrowhead Correctional Center & Canon City & 360 \\
Centennial Correctional Facility & Canon City & 336 \\
Colorado Territorial Correctional Facility & Canon City & 554 \\
Colorado Women's Correctional Facility & Canon City & 300 \\
Four Mile Correctional Center & Canon City & 300 \\
Fremont Correctional Facility & Canon City & 656 \\
Pre-Release Unit & Canon City & 164 \\
Shadow Mountain Correctional Facility & Canon City & 384 \\
Skyline Correctional Center & Canon City & 200 \\
\hline
\end{tabular}

Source: Colorado Department of Corrections 1990. Facilities Directory, Colorado Springs, Colo., June. 
Table B.19. Agricultural population and land use within $100 \mathrm{~km}$ (62 miles) of Pueblo Depot Activity

\begin{tabular}{|c|c|c|c|c|c|c|c|c|c|}
\hline County & $\begin{array}{c}\text { Number } \\
\text { of farms } \\
1987\end{array}$ & $\begin{array}{c}\text { Land } \\
\text { in farms (acres) }\end{array}$ & $\begin{array}{c}\% \text { with } \\
<50 \text { acres }\end{array}$ & $\begin{array}{c}\% \text { with } \\
>500 \text { acres }\end{array}$ & $\begin{array}{l}\text { Average size } \\
\text { (acres) }\end{array}$ & $\begin{array}{c}\text { Total } \\
\text { cropland (acres) }\end{array}$ & $\begin{array}{c}\text { Pastureland } \\
\text { (all types } \\
\text { acres) }\end{array}$ & $\begin{array}{c}\% \text { of operators } \\
\text { with farming as } \\
\text { principal } \\
\text { occupation }\end{array}$ & $\begin{array}{l}\text { Market value of } \\
\text { agricultural product } \\
\text { sold }(\$ 1000)\end{array}$ \\
\hline Bent & 292 & 855,503 & $14.4 \%$ & $50.3 \%$ & 2,930 & 102,814 & 754,777 & $71.9 \%$ & 36,977 \\
\hline Crowley & 187 & 408,649 & 19.2 & 47.0 & 1,156 & 58,979 & 349,171 & 69.5 & 87,708 \\
\hline Custer & 130 & 150,334 & 11.5 & 46.9 & 1,156 & 28,675 & 126,040 & 61.5 & 5,064 \\
\hline Douglas & 454 & 212,011 & 41.4 & 21.6 & 467 & 31,696 & 186,434 & 38.1 & 8,859 \\
\hline Elbert & 679 & $1,015,333$ & 17.8 & 46.7 & 1,495 & 196,912 & 827,063 & 53.6 & 38,654 \\
\hline El Paso & 711 & 917,824 & 26.6 & 39.5 & 1,291 & 90,348 & 852,430 & 46.8 & 23,557 \\
\hline Fremont & 412 & 305,137 & 57.8 & 22.3 & 741 & 20,443 & 283,974 & 43.7 & 9,924 \\
\hline Huerfano & 243 & 643,050 & 10.7 & 58.0 & 2,646 & 35,464 & 610,139 & 62.1 & 7,702 \\
\hline Kiowa & 328 & 996,785 & 6.1 & 73.2 & 3,039 & 500,782 & 492,969 & 72.9 & 21,313 \\
\hline Las Animas & 481 & $2,149,828$ & 12.3 & 59.9 & 4,469 & 31,710 & $2,058,208$ & 56.2 & 20,846 \\
\hline Lincoln & 489 & $1,081,703$ & 13.1 & 77.9 & 3,303 & 473,084 & $1,110,898$ & 78.9 & 57,069 \\
\hline Otero & 491 & 731,609 & 27.9 & 25.7 & 1,490 & D & 650,704 & 60.3 & 79,261 \\
\hline Park & 162 & 400,090 & 16.0 & 44.4 & 2,470 & 22,049 & 376,847 & 50.0 & 3,594 \\
\hline Pueblo & 615 & 892,183 & 33.0 & 32.3 & 1,451 & 102,747 & 801,701 & 50.4 & 38,389 \\
\hline Teller & 67 & 83,281 & 28.4 & 37.3 & 1,243 & 3,463 & 73,891 & 37.3 & 1,114 \\
\hline Colorado State & 27,284 & $34,048,433$ & 25.9 & 25.2 & 1,248 & $10,988,853$ & $23,269,684$ & 60.5 & $3,143,131$ \\
\hline
\end{tabular}

$\mathrm{D}=$ witheld to avoid disclosing data for individual farms

Source: U.S. Bureau of the Census 1987. 1987 Census of Agriculture, Vol.1: Geographic Area Series, Part 6: Colorado, Government Printing Office, Washington, D.C 
Table B.20. Livestock inventory and sales in counties within $100 \mathrm{~km}$ of Pueblo Deport Activity

\begin{tabular}{|c|c|c|c|c|c|c|c|c|c|}
\hline \multirow[b]{2}{*}{ Counties } & \multicolumn{3}{|c|}{ Cattle and calves } & \multicolumn{2}{|c|}{ Hogs and pigs } & \multicolumn{2}{|c|}{ Sheep and lambs } & \multicolumn{2}{|c|}{ Horses and ponies } \\
\hline & Inventory & $\begin{array}{c}\text { Dairy } \\
\text { products sold } \\
(\$ 1000)\end{array}$ & $\begin{array}{c}\text { Cattle and } \\
\text { calves sold } \\
(\$ 1000)\end{array}$ & Inventory & $\begin{array}{c}\text { Sold } \\
(\$ 1000)\end{array}$ & Inventory & $\begin{array}{l}\text { Sheep, lambs, } \\
\text { and wool sold } \\
(\$ 1000)\end{array}$ & Inventory & $\begin{array}{c}\text { Sold } \\
(\$ 1000)\end{array}$ \\
\hline Bent & 62,018 & 308 & 54,307 & 2,733 & 490 & 1,495 & 99 & 605 & 64 \\
\hline Crowley & 86,024 & 1,066 & 83,483 & 1,952 & 369 & 187 & 9 & 415 & D \\
\hline Custer & 12,059 & - & 3,929 & D & $\mathbf{D}$ & D & D & 630 & 19 \\
\hline Douglas & 10,797 & D & 5,726 & 226 & D & 706 & 34 & 3,060 & 713 \\
\hline Elbert & 55,176 & 1,248 & 20,532 & 988 & 195 & 713 & D & 1,984 & 356 \\
\hline El Paso & 46,344 & 3,762 & 12,967 & 354 & 87 & 302 & 22 & 2,656 & 477 \\
\hline Fremont & 16,017 & 1,643 & 5,441 & 939 & 125 & 446 & 23 & 1,413 & 262 \\
\hline Huerfano & 27,452 & 604 & 6,666 & 256 & 41 & 222 & 10 & 657 & 29 \\
\hline Kiowa & 34,854 & D & 10,660 & 337 & 80 & 155 & 15 & 449 & $\mathrm{D}$ \\
\hline Las Animas & 65,380 & 470 & 18,068 & 282 & 26 & 695 & 27 & 1,340 & 43 \\
\hline Lincoln & 72,239 & - & 42,261 & 4,092 & 701 & 404 & 249 & 623 & 33 \\
\hline Otero & 74,096 & 648 & 64,361 & 6,590 & 1,276 & 9,953 & 363 & 906 & 56 \\
\hline Park & 10,074 & - & 3,078 & 37 & 7 & 837 & 30 & 1,014 & 80 \\
\hline Pueblo & 63,688 & 2,270 & 26,177 & 3,426 & 513 & 826 & $\mathbf{D}$ & 2,034 & 131 \\
\hline Teller & 2,863 & - & 1,033 & 8 & D & 57 & $\mathbf{D}$ & 430 & D \\
\hline Total & 639,081 & 12,019 & 357,656 & 22,220 & 3,903 & 16,968 & 880 & 18,216 & 2,263 \\
\hline Colorado State & $2,946,334$ & 136,818 & $1,964,765$ & 258,725 & 46,495 & 708,070 & 108,883 & 78,848 & 8,192 \\
\hline
\end{tabular}

$\mathrm{D}=$ withheld to avoid disclosing data for individual farms. Washinton, D.C.

Source: U.S. Bureau of the Census 1987. 1987 Census of Agriculture, Vol. 1: Geographic Area Series, Part 6: Colorado, U.S. Government Printing Office, 
Table B.21. Value of crop production, by county within $100 \mathrm{~km}$ of Pueblo Depot Activity (\$1000)

\begin{tabular}{|c|c|c|c|c|c|c|c|c|}
\hline \multirow[b]{2}{*}{ Counties } & \multirow[b]{2}{*}{ Wheat } & \multicolumn{2}{|c|}{ Corn } & \multirow[b]{2}{*}{ Barley } & \multirow[b]{2}{*}{ Sorghum } & \multirow[b]{2}{*}{ Dry beans } & \multirow[b]{2}{*}{ Hay } & \multirow{2}{*}{$\begin{array}{r}\text { Vegetables } \\
\text { sweet corn } \\
\& \text { melon } \\
\end{array}$} \\
\hline & & Grain & Silage & & & & & \\
\hline Bent & 1,893 & 2,111 & 788 & 167 & 1,236 & 110 & 11,930 & D \\
\hline Crowley & 565 & 1,474 & 400 & 0 & 220 & 104 & 3,959 & 263 \\
\hline Custer & 0 & 0 & 0 & 0 & 0 & 0 & 3,712 & D \\
\hline Douglas & 405 & 64 & 0 & 44 & 0 & 0 & 1,661 & D \\
\hline Elbert & 4,280 & 0 & 48 & 86 & 0 & 0 & 4.187 & 0 \\
\hline El Paso & 415 & 58 & 144 & 8 & 14 & 12 & 2,914 & D \\
\hline Fremont & 44 & 0 & 72 & 0 & 0 & 0 & 2,576 & 181 \\
\hline Huerfano & 15 & 0 & 0 & 0 & 0 & 0 & 3,433 & D \\
\hline Kiowa & 13,700 & 127 & 0 & 217 & 1,622 & 0 & 768 & D \\
\hline Las Animas & 1,465 & 189 & 192 & 11 & 38 & 0 & 3,945 & 0 \\
\hline Lincoln & 15,580 & 211 & 0 & 117 & 259 & 0 & 2,717 & 0 \\
\hline Otero & 778 & 5,559 & 1,326 & 24 & 218 & 683 & 10,744 & 4,602 \\
\hline Park & 0 & 0 & 0 & 0 & 0 & 0 & 1,778 & \\
\hline Pueblo & 368 & 4,010 & 1,000 & 11 & 135 & 1,436 & 5,112 & 3,020 \\
\hline Teller & 0 & 0 & 0 & 0 & 0 & 0 & 336 & 0 \\
\hline Total & 39,507 & 13,803 & 3,970 & 685 & 3,742 & 2,345 & 59,772 & 8,066 \\
\hline Colorado State & 290,867 & 339,200 & 53,613 & 36,348 & 19,458 & 77,507 & 338,324 & 60,731 \\
\hline
\end{tabular}




\section{B.3. REFERENCES}

American Hospital Association 1988. American Hospital Association Guide to the Health Care Field, Chicago, Ill.

City of Pueblo Department of Planning 1990. City of Pueblo Data Book. Pueblo, Colo.

City of Pueblo Department of Planning 1988. Businesses Located at Pueblo Memorial Airport Industrial Park Since, and Including, Unisys, Pueblo, Colo.

City of Pueblo Department of Planning and Development 1988. Pueblo Airport Industrial Park Access Alternatives Study, Pueblo, Colo., July.

The College Blue Book 1989. Second edition, Macmillan, New York.

Colorado Agricultural Statistics Service 1989. Colorado Agricultural Statistics, Colorado

Department of Agriculture, Denver, Colo., July.

Colorado Blue Book: Tabular Data 1989. 22nd ed., Macmillan, New York.

Colorado Department of Corrections 1990. Facilities Directory, Colorado Springs, Colo., June.

Colorado Department of Social Services 1990. Day Care List by Provider Type, Denver.

Colorado Division of Employment 1990. Employment Trends, Pueblo County, Colorado 1981-1989, cited in City of Pueblo Data Book 1990, City of Pueblo Planning Department, Pueblo, Colo.

Division of Local Governments Airport System Plan 1987.

EPA, Office of Federal Activities 1988. U.S. Indian Tribes, Alaskan Native Villages and Related Indian Files, Washington, D.C.

Federal Home Loan Bank Board 1989. Housing Survey, Pueblo SMSA.

Local Government Survey 1987. Received from City of Pueblo Department of Planning, Pueblo, Colo.

MacDonald and Mack Partnership 1984. Historic Properties Report, Pueblo Depot Activity,

Pueblo, Colorado. Final Report, Prepared under contract CX-0001-2-0033 between

Building Technology Inc., Silver Spring, Md., and the Historic American Buildings

Survey/Historic American Engineering Record, National Park Service, U.S.

Department of the Interior, Minneapolis.

National Park Service, National Register of Historic Sites, p.c. diskettes.

Nickens and Associates 1984. An Archeological Overview and Management Plan for the

Pueblo Depot Activity, Pueblo, Colorado, Prepared under contract CX-5000-3-0771

with the National Park Service, U.S. Department of the Interior, Atlanta, Montrose, Colo.

Pueblo Chamber of Commerce 1989. Major Industries/Employment, Pueblo, Colo., March.

Pueblo Chamber of Commerce 1989a. Housing and Utilities. Pueblo, Colo.

Pueblo Area Council of Governments 1989. Airport Industrial Park/CF\&I Trip Generation Study, Pueblo, Colo., December.

Pueblo County Department of Planning and Development 1987. 208 Plan Update, Vol. VI, Pueblo, Colo.

Pueblo School District No. 70, 1990. Principal's Periodic Report-April 2-June 6, 1990, Pueblo, Colo. 
Pueblo School District No. 70, 1989. 1989-1990 Directory, Administrative Services Center, Pueblo, Colo.

Pueblo School District No. 60 1990. Membership by Grade and School, Department of Pupil Personnel, Pueblo, Colo., June 6.

Pueblo School District No. 60 1990. CASB Lease/Purchase Financing Program. Pueblo, Colo.

U. S. Army 1991. Final Environmental Impact Statement for Realignment of Pueblo Depot Activity, Colorado with Transfers to Tooele Army Depot, Utah, and Red River Army Depot, Texas, U.S. Army Corps of Engineers, Omaha, Neb., August.

U.S. Army 1988. Chemical Stockpile Disposal Program Final Programmatic Environmental Impact Statement, Vols. 1-3, Program Manager for Chemical Demilitarization, Aberdeen Proving Ground, Md., January.

U.S. Bureau of the Census 1988. County and City Data Book 1988, U.S. Government Printing Office, Washington, D.C.

U.S. Bureau of the Census 1987. 1987 Census of Agriculture, Vol. 1 Geographic Area Series, Part 6 Colorado, U.S. Government Printing Office, Washington, D.C.

U.S. Bureau of the Census 1986. County and City Data Book, computer data file, Washington, D.C.

U.S. Forest Service 1987. A Summary of Recreation Use (M/RVDS) for FY 1986 by Activity, Washington, D.C. 


\section{APPENDIX C \\ DESCRIPTION OF SITE-SPECIFIC SURFACE WATER AND GROUNDWATER RESOURCES}

This appendix describes site-specific surface water and groundwater regimes in the vicinity of Pueblo Depot Activity (PUDA) and the proposed disposal facility site. Pathways are identified along which contaminants could migrate if discharged into the hydrosphere. Water resources that could be affected by the contaminants are identified. Surface water pathways are determined by a consideration of topography, while groundwater pathways require an evaluation of geologic structure, lithology, stratigraphy, and geohydrologic conditions. Water quality, river and creek flowrates, well locations, consumption, and potential yield determine which water resources are important. Evaluation of the proposed disposal facility site requires an identification of both on-site and off-site pathways and of resources that could be affected during accidental upset conditions when spills of chemical agent might occur. No liquid discharges enter the hydrosphere during incident-free operation of the disposal facility.

\section{C.1 SURFACE WATER}

PUDA is located in the drainage basin of the Arkansas River on a flat to gently rolling upland terrace remnant east of the Rocky Mountains. Elevations on this mesa range from $1364 \mathrm{~m}(4474 \mathrm{ft})$ to $1468 \mathrm{~m}(4814 \mathrm{ft})$ above mean sea level, sloping downward at less than $1 \%$ from the northwestern to the southeastern corner of the reservation (U.S. Army 1984). Relatively steep slopes, averaging $15 \%$, occur along drainageways traversing the eastern and western reservation boundaries. Erosion has created local relief of approximately $30 \mathrm{~m}(100 \mathrm{ft})$ (U.S. Army 1989).

Three creeks drain the PUDA reservation (see Fig. C.1). Chico and Haynes Creeks, which are ephemeral, flow along the western and eastern installation boundaries, respectively, while Boone Creek, a spring-fed perennial stream, drains the central portion of the reservation. A small dam across Boone Creek forms Linda Ann Reservoir, a 6.9-ha (17-acre) impoundment that is used primarily for on-site runoff control. The maximum height of the

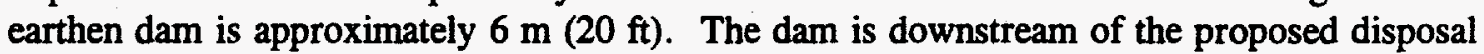
facility site. Sustained flows in Chico Creek, Haynes Creek, and the lower reaches of Boone Creek beneath the dam occur only during periods of heavy rainfall or rapid snowmelt when runoff proceeds overland into these local drainageways, flowing southward-to-southeastward into the Arkansas River, and then eastward toward the Mississippi River.

The primary source of drinking water for Pueblo County, as well as for the cities of Pueblo and Colorado Springs, is provided by the Arkansas River (Cain 1987). Pueblo Reservoir, located on the Arkansas River upstream from Pueblo, provides water for 
C-2

ORNL-DWG SON-13185

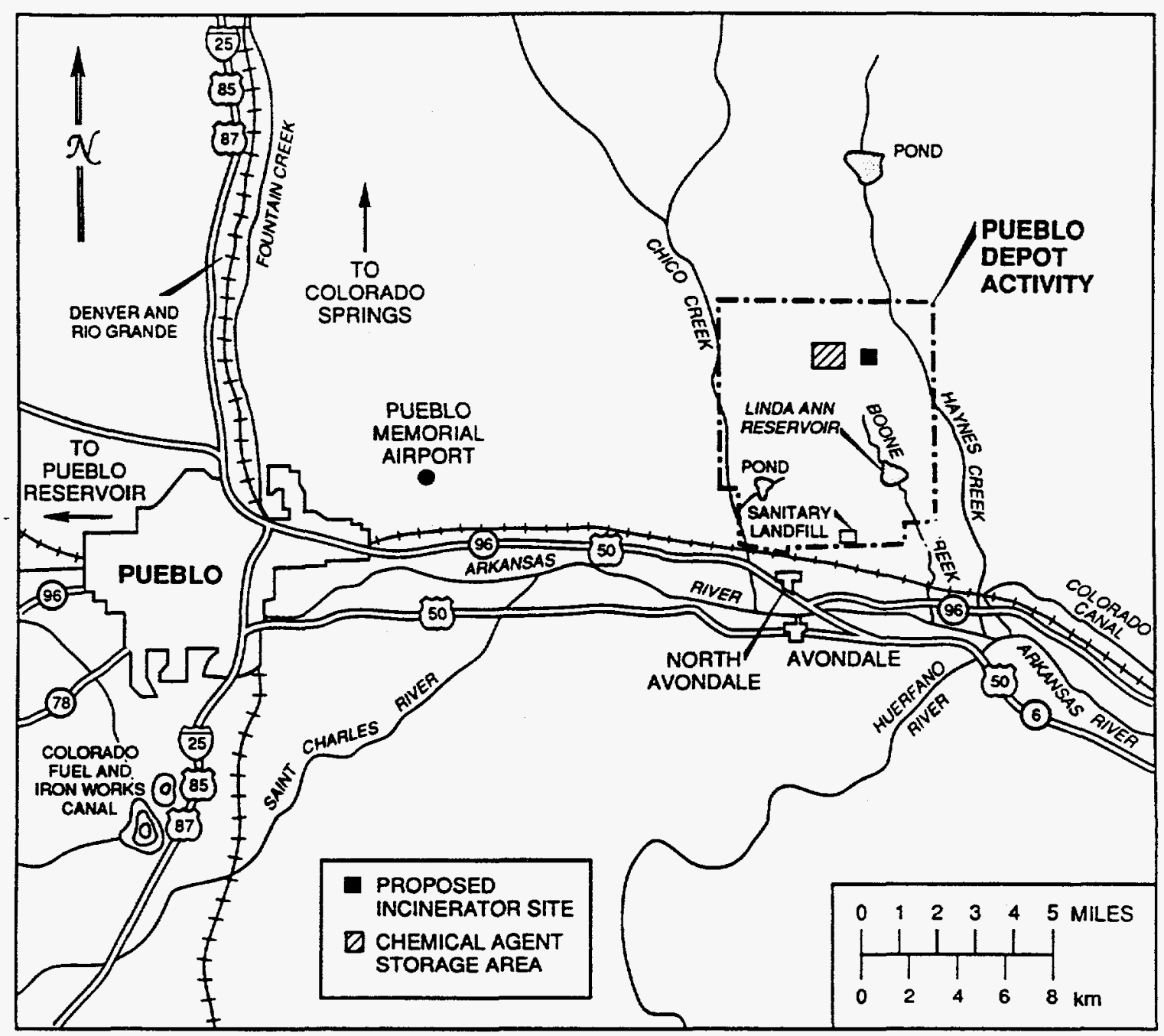

Fig. C.1. Surface water regime in the vicinity of Pueblo Depot Activity and the proposed site for the disposal facility. Source: U.S. Department of the Army 1984. Installation Environmental Assessment, Pueblo Depot Activity, Pueblo, Colorado, November 1984 Revision of December 1982 Draft, Headquarters, U.S. Army Depot System Command, Tooele, Utah. Adapted from map, p. 3. 
municipal, recreational, and agricultural use. Major tributaries emptying into the Arkansas River near PUDA includeFountain Creek and the Saint Charles and Huerfano Rivers (see Fig. C.1). Numerous canals divert water from the Arkansas River drainage basin for industrial and agricultural use. Using the U.S. EPA STORET data base (EPA 1982), 28 public water supply intakes that use surface water have been identified downstream from PUDA (Chico, Boone, and Haynes creeks, 0; Arkansas River, 6; and Mississippi River, 22).

Two ponds are located near PUDA. The on-site pond is in the southwestern portion of the installation, near the Ammunition Workshop, and within the drainage basin of Chico Creek. The second pond is offsite to the north on the Thatcher Ranch along Haynes Creek.

Three industrial waste lagoons are located in the southeastern part of PUDA. The smallest lagoon has an area of 0.57 ha $(1.4$ acres), while the other two each have an area of 3.0 ha (7.5 acres) (U.S. Army 1988, Vol. 1, p. 3-91). All 3 lagoons are lined with 760 micron (0.030 in. [30 mil]) polyvinyl chloride (PVC) and are used for the storage and evaporation of industrial effluents generated by vehicle wash racks, plating and stripping processes, and ammunition maintenance facilities.

The quality of surface waters on the PUDA installation is generally good, as evidenced by biological evaluation (U.S. Army 1984, p. 35). Both Linda Ann Reservoir and the small pond to the southwest are fairly turbid. The small pond is clearer than the reservoir (U.S. Army 1988 Vol. 1, p. 3-91). Some fish reproduce naturally in both bodies of water.

The proposed disposal facility site is located on higher ground between Boone and Haynes creeks outside the 100-year floodplain.

Boone Creek receives discharge water from the PUDA sewage treatment plant. This wastewater disposal system is in compliance with EPA discharge limitations specified in State of Colorado NPDES permit C0-0000931. The capacity of the sewage treatment plant is 632 $\mathrm{m}^{3} /$ day $(167,000$ gal/day) (U.S. Army 1984 , p. 19). Wastewater discharged into Boone Creek in 1981 measured $210 \mathrm{~m}^{3} /$ day $\left(55,000\right.$ gal/day), with a maximum flow of $300 \mathrm{~m}^{3} /$ day (80,000 gal/day) (U.S. Army 1984 , p. 91 ).

Storm drainage at PUDA is accommodated by an extensive storm sewer piping system throughout the administration and warehouse areas and open drainage ditches and culverts throughout the ammunition area. The system is composed of approximately 15,622 linear $\mathrm{m}$ $(51,240$ linear $\mathrm{ft})$ of reinforced concrete pipe. This system discharges into Chico and Boone Creeks during periods of heavy precipitation and rapid snowmelt. Storm water runoff from this system sometimes contains oil and grease, phosphates, and nitrates (U.S. Army 1984).

The igloo blocks within the chemical munitions storage area are drained by an east-to-west trending system of ditches, culverts, and bridges. The drainage system empties into Chico and Haynes creeks. A continuous earthen barrier or berm less than $1 \mathrm{~m}(3 \mathrm{ft})$ high surrounds the entire storage facility. The primary purpose of the barrier is to slow vehicles attempting to penetrate the facility. The barrier also provides for spill containment.

The culinary or process water requirements of the disposal facility have been estimated to average $2000 \mathrm{~m}^{3} /$ day $(0.5 \mathrm{Mgd})$, with a peak demand of $5700 \mathrm{~m}^{3} /$ day $(1.5 \mathrm{Mgd})$ (Forsgren-Perkins Engineering 1988). Process water will be supplied by the city of Pueblo, which obtains water from Pueblo Reservoir on the Arkansas River. Present allocations to the city of Pueblo exceed current demand by a factor of two or three. The nearest water main is located at Pueblo Memorial Airport west of PUDA. A pipeline approximately $16 \mathrm{~km}(24 \mathrm{~km}$ 


\section{C-4}

maximum) [10 miles (15 miles maximum)] in length, and possibly an intermediate pumping station, will be built to supply the process water requirements of the disposal facility.

All process-generated liquid effluents generated on-site by the PUDA disposal facility will be disposed of internally by incineration (Parsons 1988). No process-generated liquid effluents discharged by the disposal facilities enter the hydrologic cycle during incident-free operations. The only liquid effluents exiting the facilities will be the sanitary sewage discharge. Sewage treatment facilities for each of the eight sites in the Chemical Stockpile Disposal Program (CSDP) will be established by a site-adapted architect engineer or the U.S. Army Corps of Engineers for the appropriate district.

Similar sanitary wastewater processing methodology and capacity are expected for the proposed disposal facility at PUDA as for the one being constructed at Tooele Army Depot, Tooele, Utah, which is the first of the eight CONUS sites in the CSDP. The liquid effluent from the Tooele sewage treatment facility will be returned to the disposal facility as process makeup water. The expected quantity of wastewater discharged from the Tooele disposal facilities that must be treated is $114 \mathrm{~m}^{3} /$ day $(30,100 \mathrm{gal} /$ day), consisting of effluent from bathroom, shower, and laundry facilities, as well as from laboratory cleaning and monitoring devices (Forsgren-Perkins Engineering 1988).

\section{C.2 GEOHYDROLOGY}

\section{C.2.1 Geology}

PUDA is situated in the western part of the Colorado Piedmont Sect. of the Great Plains Physiographic Province (USATHAMA 1990). The Colorado Piedmont is a broad, shallow basin formed approximately 28 million years ago when pre-Tertiary sediments were eroded by the ancestral Arkansas River and its tributaries. The depot resides on an erosional remnant of a once extensive alluvial terrace deposit.

The stratigraphic column for PUDA is summarized in Table C.1. Most of the reservation is underlain by Verdos alluvium consisting of weathered gravel, residing on cut (erosional) surfaces 60 to $75 \mathrm{~m}$ ( 200 to $250 \mathrm{ft}$ ) above modern streams, deposited during the Kansan glaciation or subsequent Yarmouthian interglaciation of the Pleistocene Epoch (Scott et al. 1978; Jacobs Engineering Group 1987). The northeastern corner of the reservation, including the proposed site for the disposal facility, has surficial deposits consisting of late Pleistocene and Holocene, fine to coarse eolian (windblown) sand. The alluvial and eolian deposits beneath PUDA extend to a depth of approximately $23 \mathrm{~m}$ (75 ft), averaging from 15 to $17 \mathrm{~m}$ (50 to $55 \mathrm{ft}$ ) (U.S. Army 1984).

The bedrock surface beneath the alluvial and eolian deposits is the Upper Cretaceous Pierre shale composed of gray, marine, clayey shale and sandy shale (USATHAMA 1990). The Pierre shale is exposed in portions of the stream valleys of Chico, Boone, and Haynes creeks; along the edges of the mesa; and along bluffs on the north side of the Arkansas River.

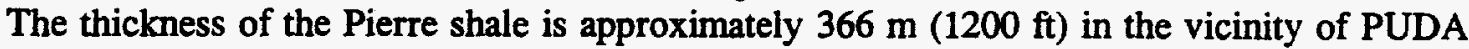
(Watts and Ortiz 1990).

A sequence of shale and limestone deposits underlies the Pierre shale, followed by the Lower Cretaceous Dakota sandstone (Welder and Hurr 1971). The Dakota sandstone is 


\section{C-5}

Table C.1. Stratigraphic column for Pueblo Depot Activity

ORNL-DWG DOM-13186

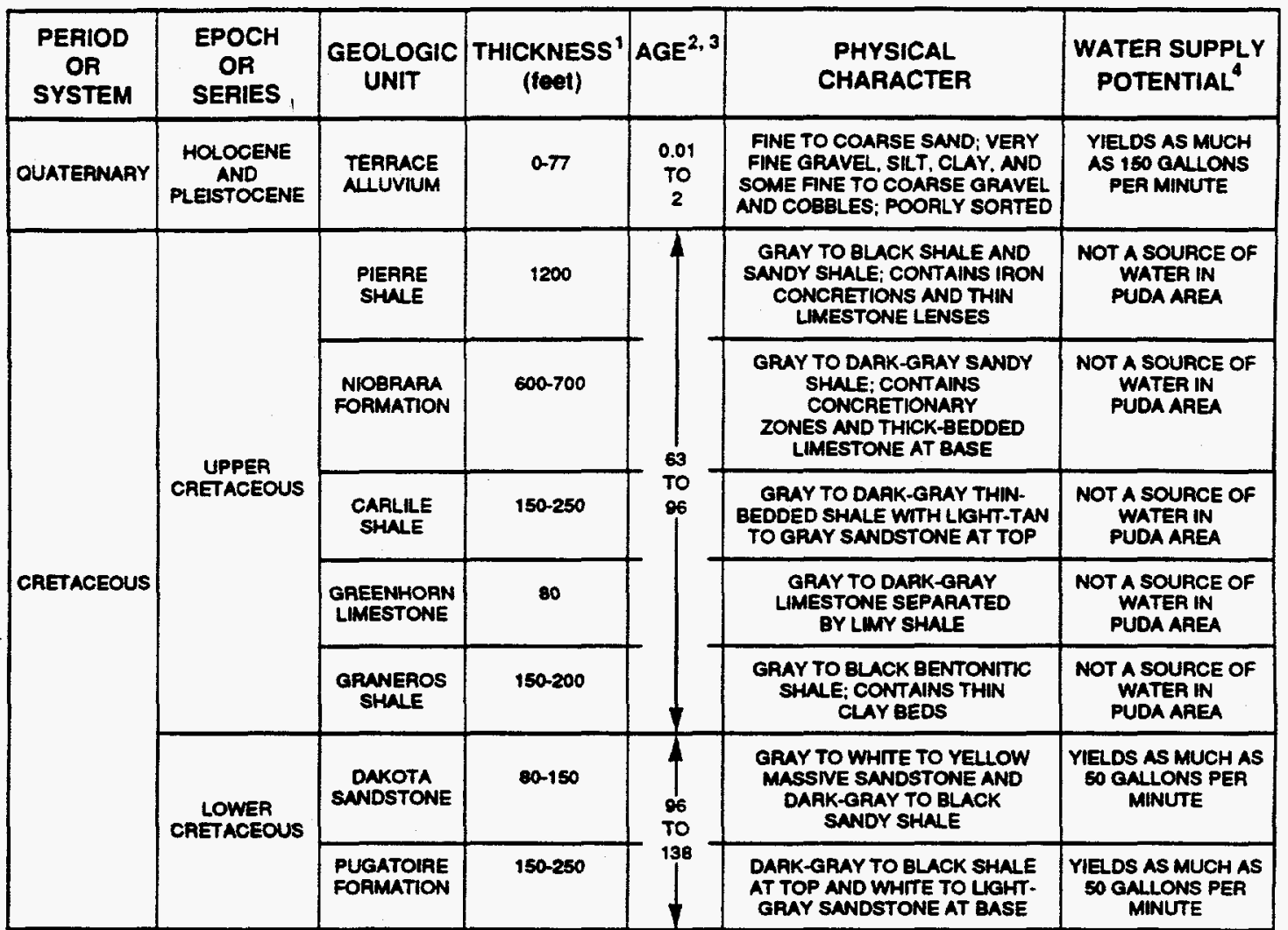

NOTES:

13.28 feet $=1$ meter

2 Expressed in millions of years betore present

${ }^{3}$ The time interval or uncontormity between the end of the Upper Cretaceous Epoch and the beginning of the Pleistocene Epoch is a period of erosion of nondeposition

4264 gellons $=1000$ liters
SOURCES:

F. A. Welder and R. T. Hurr, 1971. Appraisal of Shallow Ground-Water Resources, Pueblo Army Depot, Colorado. Open-File Report 71006. Water Resources Division, Colorado District, Denver, Colorado. Also, K. R. Watts and R. F. Ortiz, 1990. Geohydrology and Ground-Water Quality at the Pueblo Depot Activity Landfill Near Pueblo. Colorado. Water-Resources Investigations Report 89-4143, U. S. Geological Survey, Denver, Colorado. 
approximately $671 \mathrm{~m}(2200 \mathrm{ft})$ below the surface at PUDA and consists of gray to yellow massive sandstone and dark-gray to black sandy shale.

\section{C.2.2 Soils}

Soils over the central portion of the PUDA reservation, which accounts for almost one-half of the total area occupied by the depot, are deep, well-drained clay, silty clay, and sandy loams formed in alluvium (U.S. Department of Agriculture 1979; U.S. Army 1984). Alkalinity is mild to moderate, permeabilities are moderate, water-holding capacity is high, and runoff is slow to medium.

Near the western boundary and the northeastern and southeastern corners of the installation, which includes the proposed disposal facility site, the alluvial soils grade into sands, sandy loams, and loamy sands formed in eolian deposits. Alkalinity is neutral to mild, permeabilities are rapid, water-holding capacity is low, and runoff is slow. These soils are highly susceptible to water erosion during thunderstorms and to wind erosion where vegetative cover is absent.

\section{C.2.3 Groundwater}

The near surface, moderately permeable Verdos alluvium and eolian sands are host to an unconfined aquifer that supplies all water currently used at PUDA. Significant quantities of groundwater are not available from the deeper, underlying, relatively impermeable Pierre shale. The water-table aquifer is recharged by an underflow from the north whose magnitude is approximately $110 \mathrm{ha}-\mathrm{m} /$ year (900 acre-ft/year). Rainfall, which averages $30 \mathrm{~cm} /$ year (12 in./year), is insufficient to maintain the aquifer. The arid climate, in which the potential for evaporation is high, also reduces recharge.

The flow of groundwater in the Verdos alluvium parallels the surficial topography, the downgradient direction being southeastward. Near wells where groundwater pumping occurs, cones of depression cause deviations from the overall flow direction. Discharges from the aquifer occur from seeps and springs located along the eastern, southern, and western edges of the terrace. Many of these springs have been developed by private individuals for domestic and stock use.

Groundwater in the Verdos alluvium is of the sodium bicarbonate type and of generally good quality (U.S. Army 1984). This groundwater has a median total dissolved solids concentration of $230 \mathrm{mg} / \mathrm{L}$, is moderately hard (61 to $120 \mathrm{mg} / \mathrm{L}$ of calcium carbonate), and usually has sulfate concentrations that do not exceed the national secondary drinking water standard (40 CFR Pt. 143) of $250 \mathrm{mg} / \mathrm{L}$ (Hearne et al. 1988). Iron concentrations are sufficiently low (less than $0.3 \mathrm{mg} / \mathrm{L}$ ) that staining does not occur. Selenium concentrations (Table C.2) border the national primary drinking water standard (40 CFR Pt. 141) of 0.01 $\mathrm{mg} / \mathrm{L}$, and sometimes exceed it by a factor of two. The selenium in the groundwater is natural in origin. Pueblo County has commercial deposits of uranium ore, with which selenium is associated (Hem 1989).

An elaborate system of wells tapping the Verdos alluvial aquifer provides the PUDA water supply. The wells feed into a common distribution system that mixes the groundwater into a fairly homogeneous solution with respect to mineral constituent concentrations. An 
Table C.2 Selenium concentrations measured in groundwater supply wells at Pueblo Depot Activity, Colorado

\begin{tabular}{|c|c|}
\hline Well & $\begin{array}{c}\text { Selenium }^{a} \text { concentration }(\mathrm{mg} / \mathrm{L}) \\
\text { (Selenium drinking water standard }{ }^{\mathrm{b}} \text { is } 0.01 \mathrm{md} / \mathrm{L} \text { ) }\end{array}$ \\
\hline 1 & 0.015 \\
\hline 2 & 0.012 \\
\hline 3 & 0.008 \\
\hline 4 & 0.010 \\
\hline 5 & 0.011 \\
\hline 8 & 0.010 \\
\hline 12 & 0.010 \\
\hline 13 & 0.012 \\
\hline 15 & 0.02 \\
\hline 16 & 0.02 \\
\hline 17 & 0.010 \\
\hline
\end{tabular}

Source: U.S. Army 1984. Installation Environmental Assessment, Pueblo Depot Activity, Pueblo, Colorado, November 1984 Revision of December 1982 Draft, Headquarters, U.S. Army Depot System Command, Tooele, Utah, Table 22, p. 34.

The species present in most wells was tetravalent $(+4)$ selenium, although some wells also contained hexavalent $(+6)$ selenium. No bivalent $(+2)$ selenium was found in these wells.

'Taken from 40 CFR Part 141, National Interim Primary Drinking Water Regulations, July 1, 1985, edition, p. 523.

existing Colorado Water Permit allows a maximum pumpage of groundwater at PUDA of $3,398,180 \mathrm{~L} /$ day $(897,120 \mathrm{gal} /$ day) (U.S. Army 1984).

Twenty wells at PUDA have been issued permits by the Colorado State Engineer's Office (USATHAMA 1990). Each well for consumptive use must have a valid, unexpired permit. Seventeen wells discharge into the common distribution system, and the remaining three were constructed as stock supply wells. Thirteen wells have current, active permits. Twelve of these wells are presently being used, while one (well 6) is inactive because of the presence of elevated levels of selenium.

Three elevated tanks provide potable water storage at PUDA. Two of the tanks have a capacity of $380 \mathrm{~m}^{3}$ (100,000 gal) each, and the third can hold $285 \mathrm{~m}^{3}(75,000 \mathrm{gal})$. The three tanks are filled with groundwater pumped from the Verdos alluvium.

Withdrawal of groundwater at PUDA has caused a decline of the water table. Water levels near the center of the well field declined $8.2 \mathrm{~m}(27 \mathrm{ft})$ between 1943 and 1970. Since

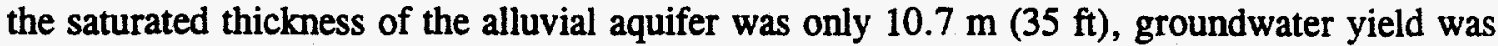
substantially reduced. In 1971, two additional wells were drilled $2 \mathrm{~km}$ (1 mile) west of the original well field. Increased groundwater production at these new wells reduced demand from the original well field. Reduction in mission workload at PUDA with the associated 


\section{C-8}

reduced water requirements, coupled with the installation of the new wells, stabilized and to some extent slightly reversed the declining water table trend.

Table C.3 depicts measured, progressive deterioration of groundwater quality associated with the water table decline in the surficial aquifer. Calcium carbonate hardness increased from $70 \mathrm{mg} / \mathrm{L}$ (moderately hard) in 1952 to $138 \mathrm{mg} / \mathrm{L}$ (hard) in 1967, and the concentration of total dissolved solids increased from $252 \mathrm{mg} / \mathrm{L}$ to $381 \mathrm{mg} / \mathrm{L}$. Measurements reported for 1981 exhibited a small decrease in hardness and a slight increase in total dissolved solids. Installation of the wells east of the well field, coupled with decreased groundwater demand at the depot, slowed the historical trend of water quality degradation. Even though the current, reduced demand for water at PUDA can be met by pumping only 3 days per week, localized drawdown continues to cause some water quality problems. The existing groundwater system at PUDA may be able to meet the average process water requirements of the disposal facility because of the relatively recent reduced load on the system. However, the peak requirements of the facility exceed the entire underflow from the north that sustains the aquifer. The present groundwater system cannot maintain an adequate supply of process water to operate the disposal plant.

Expansion of the groundwater system at PUDA would require additional allocations, which are governed by the Pueblo Water Conservancy District. Expansion of the existing groundwater system to meet the demands of the disposal facility is not likely to occur. PUDA is not a member of the Pueblo Water Conservancy District.

The Dakota sandstone is the first significant water-bearing formation beneath the Verdos alluvium (USATHAMA 1990). The Dakota sandstone aquifer has been developed extensively west of Pueblo. The relatively impermeable, thick, intervening layer of shale and limestone isolates the deeper aquifer from activities at PUDA. The Dakota sandstone aquifer is not hydraulically connected to the Verdos alluvial aquifer. Wells in the Dakota sandstone aquifer beneath PUDA would be costly to construct and operate due to extreme depths. Yields would be low. Water quality would be poor because of high concentrations of dissolved solids and the presence of radioactive isotopes (Felmlee and Cadigan 1979). The valley-fill deposits extending along the Arkansas River east of the city of Pueblo to the Colorado-Kansas state line are host to a major regional aquifer (Cain 1987;Hearne et al. 1988). This extensive alluvial aquifer is as much as $91 \mathrm{~m}$ (300 ft) thick and 2 to $22 \mathrm{~km}$ (1 to 14 miles) wide, with an average width of 5 to $8 \mathrm{~km}$ ( 3 to 5 miles). This alluvial aquifer supplies many large irrigation wells and serves as the municipal water supply for several cities downstream from PUDA. The groundwater regime in the Arkansas River alluvium is not hydraulically connected to subsurface flows in the upland Verdos alluvial deposits beneath PUDA (Watts and Ortiz 1990; USATHAMA 1990). However, spring flows originating as terrace alluvial groundwater discharge or as sustained creek flows may recharge the Arkansas River alluvial aquifer.

\section{C.3 PREEXISTING CONTAMINATION}

Past and present missions at PUDA have required the storage, handling, use, and disposal of hazardous chemicals. The storage, operation, and disposal practices associated with these activities have resulted in known and suspected areas of environmental 
Table C.3. Groundwater quality from selected wells measured between 1952 and 1981 at Pueblo Depot Activity, Colorado (expressed in $\mathrm{mg} / \mathrm{L}$ except for conductance in micro-mhos) ${ }^{a}$

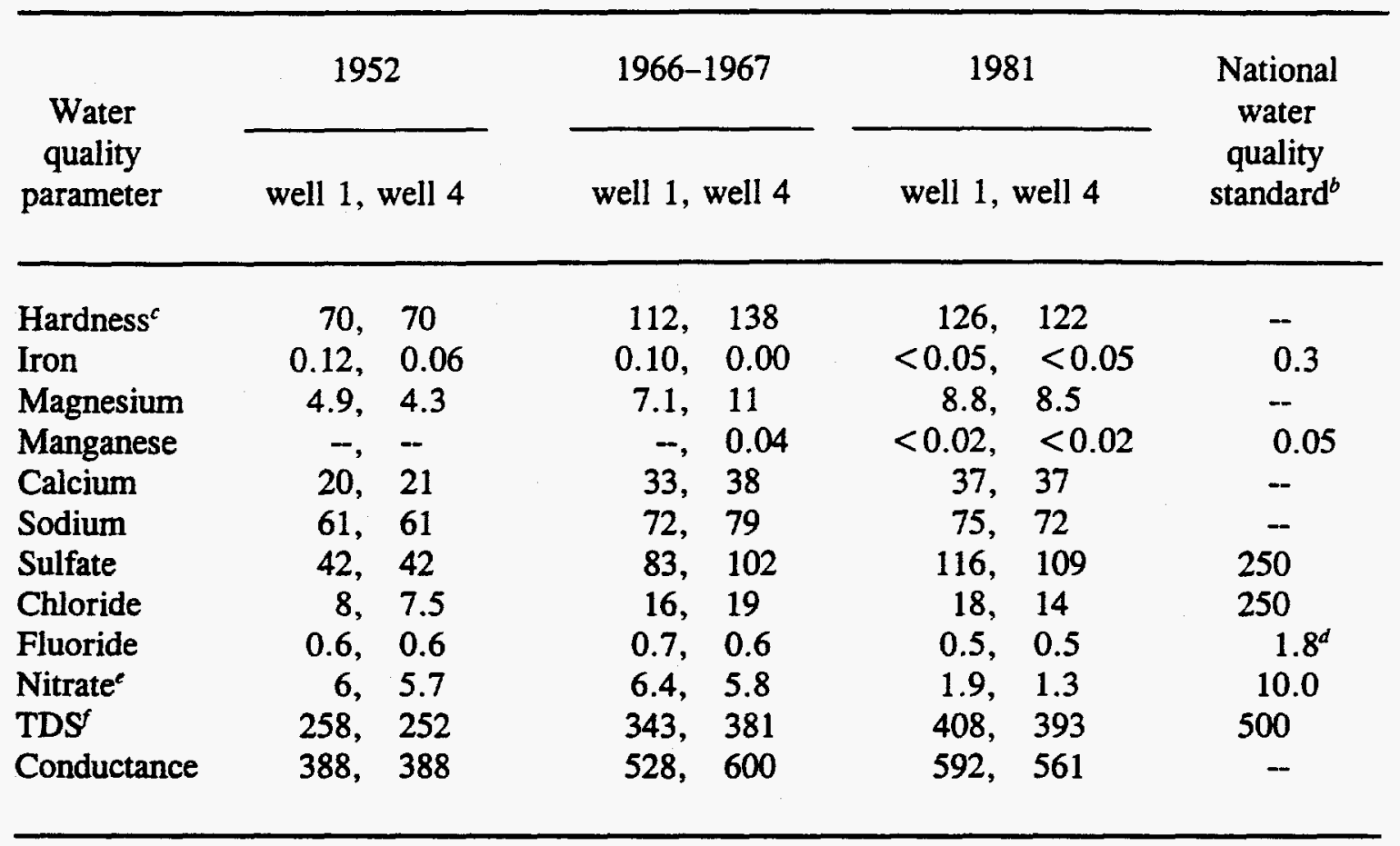

aSource: U.S. Army 1984. Installation Environmental Assessment, Pueblo Depot Activity, Pueblo, Colorado, November 1984 Revision of December 1982 Draft, Headquarters, U.S. Army Depot System Command, Tooele, Utah, Table 66, p. 90.

Taken from 40 CFR Pt. 141 July 1, 1985 edition. National Interim Primary Drinking Water Regulations, pp. 520-565; 40 CFR Pt. 143 July 1, 1985 edition. National Secondary Drinking Water Regulations, .pp. 58-585.

'As $\mathrm{mg} / \mathrm{L}$ of calcium carbonate $\left(\mathrm{CaCO}_{3}\right)$.

Based on an average annual maximum air temperature of $67.9 \mathrm{~F}$ obtained from p. 29 of U.S. Army 1984.

(U.S. 1984).

'As $\mathrm{mg} / \mathrm{L}$ of nitrogen (N).

Total dissolved solids $(\mathrm{mg} / \mathrm{L})$.

contamination, including soils, groundwater, surface water, and structures. A recent study has identified 53 areas at PUDA requiring environmental evaluation (USATHAMA 1990). The report makes specific recommendations for each area regarding any investigations or actions necessary to resolve identified environmental concerns. A corrective action program has been issued for many of these contaminated areas in accordance with the Resource Conservation 
and Recovery Act (RCRA) and Sect. 3004 (u) of the RCRA Hazardous and Solid Waste Amendments of 1984 (U.S. Army 1989).

Unmapped burial sites possibly containing unexploded munitions exist at PUDA. Geophysical surveys would be required at the proposed site for the disposal facility before construction of the facility.

Pershing missiles were destroyed at PUDA as part of the Intermediate-Range Nuclear Forces Treaty (U.S. Army 1988b). The site for these activities was in the northwest corner of the reservation within the Demolition Area. Analyses concluded that these missiles could be neutralized in a manner that would avoid significant impacts to the environment.

A sanitary landfill is operated at PUDA occupying approximately 14 ha (35 acres) (U.S. Army 1984). Refuse, garbage, debris, and dunnage are compacted and covered with soil in accordance with standard operating procedures. Past operations at the landfill, which are no longer performed, have included disposal of semiliquid, industrial sludge containing heavy metals, phosphorus, and organics. Contamination from the landfill has the potential to affect North Avondale Spring, which serves as a public water supply; an intermittent stream east of the landfill that provides drinking water for livestock at a nearby cattle farm; and the Arkansas River alluvial aquifer. Recent measurements (Watts and Ortiz 1990) confirm the presence of trichloroethylene and trans-1,2-dichloroethylene at five monitor wells, a seep discharge, and an off-site stock tank. Additional monitoring indicates that these organic compounds have not migrated into the nearby Arkansas River alluvial aquifer.

\section{C.4 REFERENCES}

Cain, D. 1987. Relations of Specific Conductance to Streamflow and Selected Water-Quality Characteristics of the Arkansas River Basin, Colorado, Water-Resources Investigations Report 87-4041, U.S. Geological Survey, Denver, Colo.

EPA (U.S. Environmental Protection Agency) 1982. STORET User Handbook, Water Quality Control Information System, Washington, D.C.

Felmlee, J. K. and Cadigan, R. A. 1979. Radium and Uranium Concentrations and Associated Hydrogeochemistry in Ground Water in Southwestern Pueblo County, Colorado, Open-File Report 79-974, U.S. Geological Survey, Denver, Colo.

Forsgren-Perkins Engineering 1988. Tooele Army Depot CSDP Facility Culinary Water and Wastewater Treatment Study, Salt Lake City, Utah.

Hearne, G. A. et al. 1988. "Colorado Ground-Water Quality," pp. 181-90 in National Water Summary 1986-Hydrologic Events and Ground-Water Quality, U.S. Geological Survey Water-Supply Paper 2325, compiled by D. W. Moody, J. Carr, E. B. Chase, and R. W. Paulson, U.S. Government Printing Office, Washington, D.C.

Hem, J. D. 1989. Study and Interpretation of the Chemical Characteristics of Natural Water, 3rd ed., U.S. Geological Survey Water-Supply Paper 2254, U.S. Government Printing Office, Washington, D.C.

Jacobs Engineering Group 1987. Geological-Seismological Investigation of Earthquake Hazards for a Chemical Stockpile Facility at the Pueblo Depot Activity, Colorado, Contractor report to the U.S. Army Engineer Division, Huntsville, Ala., prepared by 


\section{C-11}

the Jacobs Engineering Group, Inc., and URS/John A. Blume \& Associates, Engineers under contract No. DACA87-86-D-0085, Delivery Order 0004, October.

Parsons, R. M. 1988. Chemical Stockpile Disposal Program Waste Management Study, Rev. 1, prepared for Program Executive Officer-Program Manager for Chemical Demilitarization under contract No. DACA87-86-C0084 with U.S. Army Engineer Division, Huntsville, by the Ralph M. Parsons Company (Task B-11F1), Huntsville, Ala.

Scott, G. R., et al. 1978. Geologic Map of the Pueblo $1 \times 2$ Quadrangle, South-Central Colorado, U.S. Geological Survey Miscellaneous Investigations Map I-1022, scale $1: 250,000,2$ sheets.

USATHAMA (U.S. Army Toxic and Hazardous Materials Agency) 1990. Enhanced Preliminary Assessment Report: Pueblo Depot Activity, Pueblo, Colorado, CETHA-BC-CR-90045. Prepared for USATHAMA, Aberdeen Proving Ground, Maryland, by Ebasco Environmental, Lakewood, Colo., under the supervision of Environmental Assessment and Information Sciences Division, Argonne National Laboratory, Argonne, Ill.

U.S. Department of Agriculture 1979. Soil Survey of Pueblo Area, Colorado: Parts of Pueblo and Custer Counties, Soil Conservation Service in cooperation with Colorado Agricultural Experiment Station.

U.S. Army 1984. Installation Environmental Assessment, Pueblo Depot Activity, Pueblo, Colorado, November 1984 Revision of December 1982 Draft, Headquarters, U.S. Army Depot System Command, Tooele, Utah.

U.S. Army 1988a. Chemical Stockpile Disposal Program Final Programmatic Environmental Impact Statement, Vols. 1, 2, and 3, Program Executive Officer-Program Manager for Chemical Demilitarization, Aberdeen Proving Ground, Md.

U.S. Army 1988b. Environmental Assessment for the Proposed Elimination of Intermediate-Range and Shorter-Range Missiles Pursuant to the INF Treaty.

U.S. Army 1989. Final Pueblo Depot Activity RCRA Facility Investigation and Corrective Measures Study Work Plan, Prepared for U.S. Army Corps of Engineers, Huntsville Division, Huntsville, Ala., by Engineering-Science, Inc., Denver, Colo.

Watts, K. R. and Ortiz, R. F. 1990. Geohydrology and Ground-Water Quality at the Pueblo Depot Activity Landfill near Pueblo, Colorado, Water-Resources Investigations Report 89-4143, U.S. Geological Survey, Denver, Colo.

Welder, F. A. and Hurr, R. T. 1971. Appraisal of Shallow Ground-Water Resources, Pueblo Army Depot, Colorado, Open-File Report 71006, Water Resources Division, Colorado District, Denver, Colo. 


\section{APPENDIX D \\ DESCRIPTION OF SITE-SPECIFIC ECOLOGICAL RESOURCES}

The operational definition of ecological resources for the Final Programmatic Environmental Impact Statement (FPEIS) for the U.S. Army's Chemical Stockpile Disposal Program (U.S. Army 1988) and this Phase I report includes all living organisms (except humans) and their associated habitats, as well as areas containing important terrestrial or aquatic resources (e.g., parklands, wilderness areas, Nature Conservancy areas, and wetlands). Terrestrial and aquatic species protected by the Endangered Species Act are identified in this appendix for the 20-, 50-, and 100-km (12.4-, 31-, and 62-mile) zones around Pueblo Depot Activity (PUDA). Aspects of land use related to ecological resources are described in this appendix.

The maximum no-effects radius (100 km [62 miles]) considered for mustard agents in preparation of the FPEIS and this Phase I report includes 14 counties or parts of counties in Colorado. The potential no-deaths distance determined for the worst case potential accident involving storage of mustard agents is $56 \mathrm{~km}$ (35 miles). Mustard agents are carcinogenic and therefore do not have a no-effects distance. Ecological resources of special concern within this 100-km (62-mile) radius are summarized in Sect. 5.4, Table 5.1. Additional site-specific information is found in the Installation Assessment of Pueblo Depot Activity (U.S. Army 1984).

\section{D.1 TERRESTRIAL RESOURCES}

The principle native vegetation is shortgrass prairie, with grass species of blue gramma, western wheatgrass, buffalo grass, sand dropseed, galleta, and alkali sacaton. Forbs include coppermallow, sunflower, Russian thistle, and yucca. Cattle grazing is the primary land use in the surrounding area; about 2000 ha of the PUDA site is currently leased for grazing (USATHAMA 1990).

Mule and white-tailed deer frequent the area. Populations are small due to the lack of suitable habitat and food sources. A population of about 25 pronghorn antelope is located on the PUDA site. Upland game birds such as scaled quail and small game mammals such as cottontail rabbits, jackrabbits, and prairie dogs are common to the site and the 100-km (62mile) zone. Coyotes are the only common fur-bearers in the vicinity. Small mammals such as mice and voles and small birds are abundant and serve as prey for raptors that may use the area. Nesting sites for both game birds and small birds in the vicinity of PUDA are scarce because of the lack of suitable vegetation and bodies of water. Wildlife refuges containing suitable habitat for raptors and large mammals are located some distance away (Sect. 4.4, Table 4.9). No sport shooting or trapping is permitted on the PUDA site. 


\section{D.2 AQUATIC RESOURCES}

The major body of water within the 100-km (62-mile) zone around PUDA is the Arkansas River. Under the proposed action of on-site disposal, the only transportation of agent would be from the storage area to the site of the proposed disposal facility; therefore, the only bodies of water in which aquatic resources could be adversely impacted directly by a spill would be the ephemeral tributaries to the Arkansas River and the river itself. Additional bodies of water (Fig. D.1) within the impact zone could be affected by atmospheric deposition from aerosolization of agent. Potential impacts to aquatic biota within these water bodies will be discussed in the site-specific environmental impact statement (EIS).

As discussed in Appendix C, drainage at the site of the proposed disposal facility is ultimately to the Arkansas River. Specific information on the aquatic resources of the Arkansas River and the calculated concentrations of agent that could occur following an accidental spill or deposition onto the river will be used in preparation of the site-specific EIS to calculate the expected mortalities of fish that could occur both at the site and downstream in the event of an accidental release.

Several small creeks occur adjacent to the PUDA site. Information on the aquatic resources and the effects of an accidental release on these resources will be addressed in the site-specific EIS.

Information on wetlands has been requested from the Federal Emergency Management Agency and the U.S. Fish and Wildlife Service. Wetlands information obtained from these and other agencies will be included in the appropriate EIS sections.

\section{D.3 THREATENED AND ENDANGERED SPECIES}

Eight federally-listed endangered species were listed in the FPEIS (U.S. Army 1988) as occurring within the $100-\mathrm{km}$ (62-mile) zone: bald eagle, Arctic peregrine falcon, whooping crane, greenback cutthroat trout, black-footed ferret, clay-loving wild buckwheat, spineless hedgehog cactus, and Uinta Basin hookless cactus. The 1984 environmental assessment (U.S. Army 1984) reported that the white pelican was also present in the area.

According to a July 1992 communication, nine federally-listed threatened and endangered species might be found within the 100-km zone around PUDA: bald eagle (Haliaeetus leucocephalus), black-footed ferret (Mustela nigripes), Eskimo curlew (Numenius borealis), greenback cutthroat trout (Salmo clarki stomias), least tern (Sterna antillarum), Pawnee montane skipper (Hesperia leonardus montana), Arctic peregrine falcon (Falco peregrinus), piping plover (Charadrius melodus), and whooping crane (Grus americana) (FWS 1992).

Candidate species listed as of July 1992 include three fish: Arkansas darter (Etheostoma cragini), plains topminnow (Fundulus sciadicus), and speckled chub (Extrarius aestivalis); two reptiles: boreal western toad (Bufo boreas boreas) and Texas horned lizard (Phrynosoma cornutum); ten birds: Baird's sparrow (Ammodramus bairdii), black tern (Chlidonias niger), ferruginous hawk (Buteo regalis), harlequin duck (Histrionicus histrionicus), loggerhead shrike (Lanius ludovicianus), Mexican spotted owl (Strix occidentalis lucida) (proposed threatened), mountain plover (Charadrius montanus), northern goshawk (Accipiter gentilis), western snowy plover (Charadrius alexandrinus nivosus), and white-faced ibis (Plegadis chihi); six mammals: Colorado hog-nosed skunk (Conepatus mesoleucus 
D-3

ORNL-DWG $90 \mathrm{M}-13422$

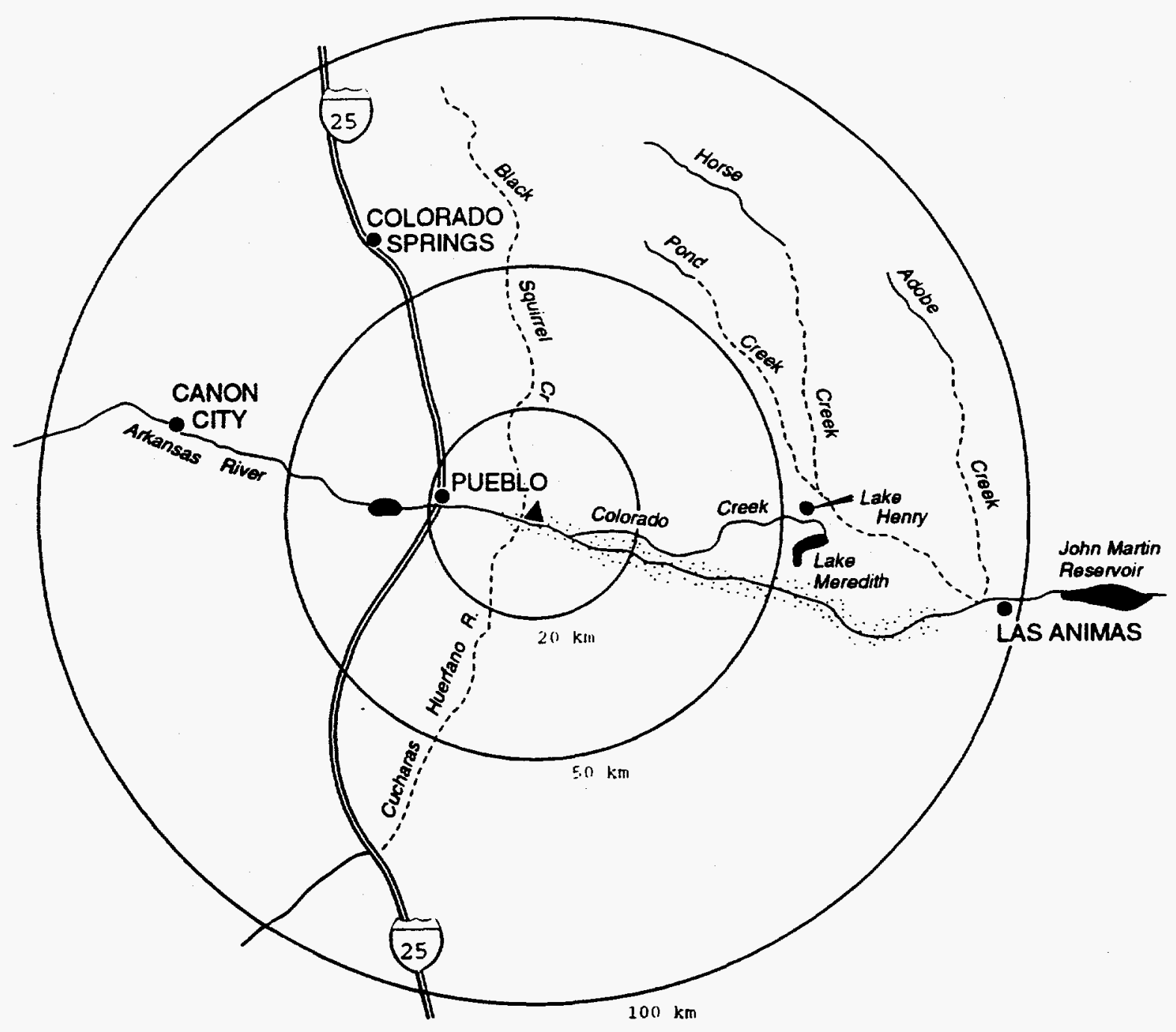

Fig. D.1. Surface waters within $100 \mathrm{~km}$ of Pueblo Army Depot Activity. Stippled areas along the Arkansas River are those areas subject to inundation (U.S. Geological Survey 1981, 1982). 
figginsi), fringed-tailed myotis (Myotis thysanodes pahasapensis), North American lynx (Felis lynx canadensis), North American wolverine (Gulo gulo luscus), Preble's meadow jumping mouse (Zapus hudsonius preblei), and swift fox (Vulpes velox); one invertebrate: regal fritillary butterfly (Speyeria idalia); and 13 plants: Arkansas River feverfew (Parthenium tetraneuris); Bell's twinpod (Physaria bellii); brandegee wild buckwheat (Eriogonum brandegei); Colorado green gentian (Frasera coloradensis); degener beardtongue (Penstemon degeneri); pale blue-eyed grass (Sisyrinchium pallidum); Penland eutrema (Eutrema penlandii) (proposed threatened); Porter's feathergrass (Ptilagrostis porteri); roundleaf four-o'clock (Oxybaphus [Mirabilis] rotundifolius); Royal Gorge stickleaf (Mentzelia densa); single-head goldenweed (Haplopappus fremontii ssp. monocephalus); streaked ragweed (Ambrosia linearis); and Weber monkey-flower (Mimulus gemmiparus) (FWS 1992).

One Colorado state threatened species, the southern redbelly dace (Phoxinus erythrogaster), was introduced into the pond in the southwest portion of PUDA on Chico Creek in 1987. The Arkansas darter (Etheostoma cragini) may be introduced into the Linda Ann Reservoir in the near future (FWS 1987).

The greenback cutthroat trout may occur in the Arkansas River to the south and west of PUDA. Because the wind direction at PUDA is primarily from the west and west-northwest, the potential for impacts to this species from an accidental release is fairly remote. This will be addressed in greater detail in the site-specific EIS.

\section{D.4 REFERENCES}

FWS (U.S. Fish and Wildife Service) 1987. Fish and Wildlife Management Plan, U.S. Army Pueblo Deport Activity, Pueblo, Colorado, U.S. Fish and Wildlife Service, Colorado Fish and Wildlife Assistance Office, Golden, Colo.

FWS (U.S. Fish and Wildlife Service) 1992. LeRoy W. Carlson, FWS, letter to R. V. Tolbert, ORNL, Oak Ridge, Tenn., July 30, 1992.

U.S. Army 1984. Installation Environmental Assessment, Pueblo Depot Activity, Pueblo, Colorado, November 1984 Revision of December 1982 Draft, Headquarters, U.S. Army Depot System Command, Tooele, Utah.

U.S. Army 1988. Chemical Stockpile Disposal Program Final Programmatic Environmental Impact Statement, Vols. 1, 2, and 3, Program Executive Officer-Program Manager for Chemical Demilitarization, Aberdeen Proving Ground, Md., January.

USATHAMA (U.S. Army Toxic and Hazardous Materials Agency) 1990. Enhanced Preliminary Assessment Report: Pueblo Depot Activity, Pueblo, Colorado, CETHA-BC-CR-90045, Ebasco Environmental, Lakewood, Colo. 


\section{APPENDIX E \\ RESPONSES TO COMMENTS FROM STATE \\ AND FEDERAL AGENCIES}

A draft of this document was circulated among the following relevant state and federal agencies, and their comments were solicited:

- Pueblo County, Office of Public Safety and Operations;

- State of Colorado, Department of Health;

- State of Colorado, Department of Public Safety;

- U.S. Department of Health and Human Services;

- U.S. Environmental Protection Agency; and

- U.S. Federal Emergency Management Agency.

Written comments were received from the State of Colorado, Department of Public Safety, the U.S. Federal Emergency Management Agency, and the Pueblo County, Office of Public Safety and Operations. This appendix presents copies of the letters received (Sect. E.1) and offers responses to the comments contained therein (Sec. E.2).

\section{E.1 WRITTEN COMMENTS RECEIVED FROM STATE AND FEDERAL AGENCIES}

Note that the specific page numbers referenced in the following letters are related to the draft version of this document and therefore may not exactly match the corresponding page or line in this Final Phase I Report. 


\section{E-2}

COLORADO

DEPARTMENT OF

PUBLIC SAFETY hichano E. matten, DIRECTOP.

DIVISLN OP DISASTER

EMERCENCY SERYICES

Camp Corom Weat

Goven Coloreso 40401

$13003273 \cdot 1622$

October 7, 1991

Brigadier General Walter L. Busbee

Program Menager for Chemical Demillizarization

ATIN: SAII - PMM

Aberdeen Proving Ground, MD 21010-5401

Dear General Busbee:

Thank you for providing an opportunity to review the Cooperating Agency Review Draft Phase 1 Eovironmental Impact Strement (EIS) for the proposed Pueblo Chemical Agent Disposai Facility. We want to emphasita our desire to work with you in all aspects of the Chearical Demilitarization Program; however, we need adoquate time to do a comprebersive review of drat documents. The time allocated to review the ErS dratt was insufficient. The document should have been avaiiable at least thirty days prior to the auspense date.

Endosed are commenes and we hope they will assist you. If we may provide further assistanee. Ted Medley (303-273-1859) is my designated contact for your staff.

Sincerdy, 
The following comments to your Cooperating Agency Review Draft Phase I Environmental Impset Statemenu for the proposed Pueblo Chemical Agency Disposal Facility, September 1991, are provided:

1. Section 3.3.1.3 Cryofracture, discusses alternative procens to the present incineration tectunolor:Recommend the section be expanded to include an explanation of what is the intended use of 6 :is proceas if the prototype cryofracture facility proves to be fensible. Wal th replace or augment the current process for destroying chemical ageass and munitions?

2. Section 7.2.2.3-PUDA CSEPP Phase In activities. The following CSEPP activities have been developed, coondinated with PUDA, and implemented.
a. A CSEPP appendix to the State Emergency Operations Plan.
b. A ĆSEPP training and exercise program.

3. Section 7.5.2 Emergency Preparedness for Rail Movement, p8 7-15, line 17 stres that the PUDA stockplie has ton comainers of mustard. Delere ton containers becusse there are none in the PUDA stockpile. There are $105-\mathrm{mm}$ and $155-\mathrm{mra}$ projectiles in eddition to 4.2 -in mortar rounds in the inventory.

4. There are two small segments of the local population who oppose current incineration concepts and their level of public opposition is expected to increase. One is Greenpeace who is distributing literanure in the Denver metropolitan area which is anci-incineration, antitransportation, and advocates researching and developing alternate technologies for destroying the stockpile. The literature stresses that incineration of chemical agents poses unacceptable risks of an Iromediate and long term nature. The risios are the result of exriesions which escape the comberstion system and threaren public health along with the ceosystem. The confirmed enission of nerve agent to the atmosphere from the JACADS facility on Decmber 8, 1990, is highlighted.

The second group. The Rosebud Comminee, comprised of Pueblo citizens, is exploring economic developmeat alternatives for PUDA atter the incineration is completed. The Army plans to close the facility upon completion of disposal operations and ceturn it to the eppropriate agency. The committee is advocating moving the stockpile so the Army can reaum the depor to the community for commercial development. Currenty, PUDA is at the end of the list for completing disposal operations. A recent editorial in the Pueblo Chieftain newspaper stated the Army should move the depot to the top of the list, or Congress sturld allow the weapons to be shipped to another site such as Tooele. The Army's recent success in moving chessical munitions from Germany to Johnston Island is expected to reiuforce their position.

Recommend development of a response wo these positions which could be included in the environmental report. 


\title{
Federal Emergency Management Agency
}

\author{
Washington, D.C. 20472
}

\section{DEC\&U1991}

Mr. Charles Baronian

Deputy Program Manager

for Chemical Demilitarization

Aberdeen Proving Ground, MD 21010-5401

Dear Mr. Baronian:

My staff have reviewed the Cooperating Agencies Review Draft: Phase 1 Environmental Report for the area surrounding the Pueblo Depot Activity in Colorado. I have enclosed our agency's comments regarding the status of emergency preparedness for this site and comments on the site specific data.

Thank you for the opportunity to review the document. We appreciate the opportunity to view such drafts in the future.

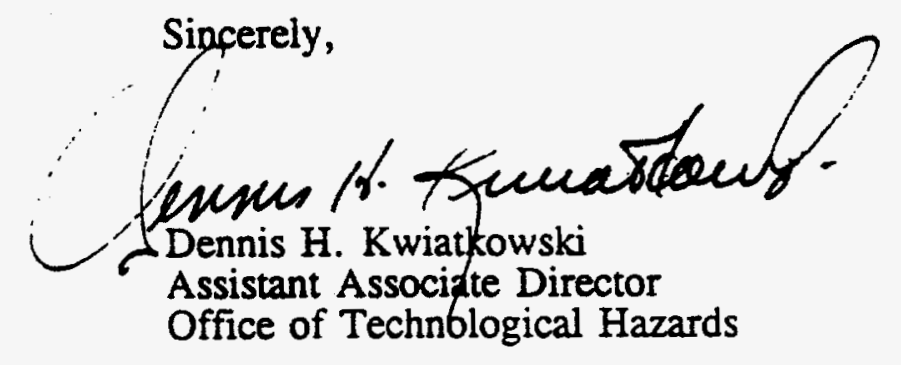

Enclosure 
Comments on Pueblo Depot Activity EIs

Page \# / Line \#

Comment

(1)

$3-17 / 26$

(2) 6-7/17 and 6-17/37

(3) $7-2 / 26$

(4) $7-2 / 28$

(5) $7-2 / 38$

(6) $7-4 / 34$
The acronym for pollution abatement system, "PAS", is used here and elsewhere but is not included in the list of abbreviations and acronyms.

If aircraft accidents constitute a substantial risk, the Army should, in consultation $w /$ the FAA (if needed) consider making the airspace over PUDA "restricted airspace."

The FEMA/Army Memorandum of Understanding (August, 1988) is conspicuously absent from this discussion of off-post preparedness. The MOU is the seminal document in the CSEPP.

The "oversight and review board" referred to here is the CSEPP Joint steering committee, which was created by the FEMA/Army MOU.

FEMA's lead role in offpost preparedness is obscured by this sentence. The meaning would be clearer if it were phrased as "the Army and Faya initiated the development..."

The Pueblo county Department of Public Safety and operations is incorrectly identified as the "Pueblo County civil Defense Agency." 
E-6

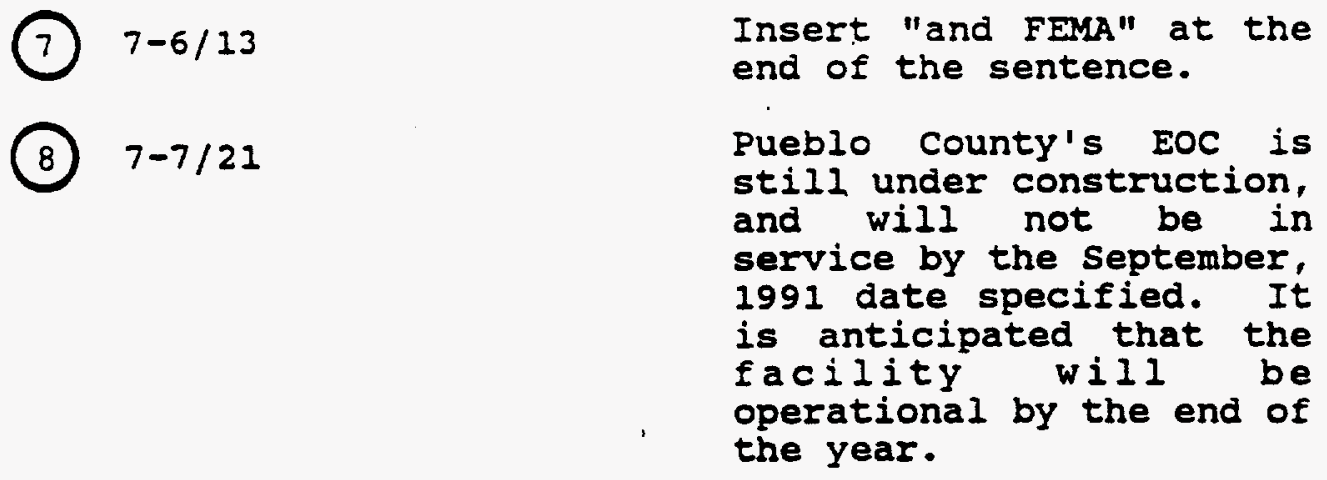

(9) $7-7 / 40$

Delete the word "functional." There will not be any "functional exercises" in CSEPP. "Direction and control exercises" will take their place, but the insertion of that terminology is unnecessary here.

(10) $7-9 / 18$
This is the first of two references to the provision of personal protective equipment to civilian emergency workers. As of this date, it appears that the M-17 mask will not be used off-post for any purpose. Because the area of personal protective equipment in CSEPP is undergoing rapid changes, the deletion of any reference to the Army providing protective equipment to civilians is recommended.

This statement regarding $t h e$ a p p a r e n impossibility of preventing civilian fatalities has broad implications, in light of the cSEPP program's Congressional mandate for "maximum protection."

(12) $A-13 / 11$

The dose response of a 
E-7

(13) $\mathrm{B}-6 / 42$

healthy adult male
exposed to chemical agent
is not necessarily
representative of how
other segments of the
population (e.g. infants,
elderly) would respond to
agent exposure.

Information regarding Pueblo County's emergency medical services resources was omitted, as was information regarding fire protection outside Pueblo's city limits. The county's search \& rescue, HAZMAT response, or other supplementary emergency response resources should have been addressed as well. This information is available through Pueblo County or the State of Colorado.

(14) $B-26 / 39$

This is the second of two references to the Army's provision of personal protective equipment to civilian emergency personnel (see. note above). 
Deanmber 26, 1991

Ms. Marilyn Iischbin

Office of the Program Manager

for Chomical Demilitarization

AtEn: SAII-BMI

Aberdeen ProvIng Ground, ND 21010

Dear Mar1lyn:

Attached are the comments on the Rhare I Fayt ronmantal Repart frow the CSPPP AOP Specialiet Richard Valdez and Btaft Aseistant stoliy DuVall of Pueblo County. The comonets have been reviewed by steve Douglas, the Dlrector of Public Bafety and Operations.

Due to the lack of time given to review the document, wo were not able to returs the comments on the deadline date.

If you have any questions portaining to the comments, please call Richard or no at (719) 546-6060.

sincerely.

Shulyth. Oulacl

Shol2y h. DuVajl

Csipp staff Aneistant, Pueblo Connty 


\title{
Interoffice Memo
}

\author{
To: Steve Douglas \\ From: Rlchard Valdez, shelly Duvall bs. If \\ Dete: December 26,1991 \\ subject: PUDA, DEIS review comments

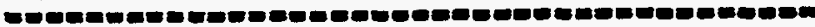

(1) P. 2-8, 14-16, only two coments were recelved regard1ng the disposal program. The sentence aysi "Each of the above comanta is to be addressed in the 81 te specillc EIS for PUDA; because many of thea deal with lmpace aseesenent..." Should renove many which is obvious bolder plate language.

(2) p. 2-9, 10-24, (epolling errors) - Soll1e Raseo (Raro), Harry Winsel (Wenzol), Glenn Matson, Ansistant Sports Information Director, Athletic Department, Univ. of Southern Colorado (Sports Information Student Assistant)

3) p. 3-5, 3-4, "None of the propoeed conus alaporal fac1lities will begin operation until the JACADS facillty has been thoroughly tested and the dssposal technology proven out." The "proven out" statement should have c comment regarding where to lind criterla, or elaborate on what "proven out" meana.

(4) p. 3-11, 3, (E1rst paragraph grammaticad error) - extra "to"

5) P. 3-11, 37-40, "All process water at the conus disposal plants will be recycled. No effluents w11l be released to the environnent by plant operations and senitary wastes w11l be treated. Mus, no lmpacts w11l occur to surface water resources." Even though the corrus sites will have a closed loop system, the JACADS Bystem didn't. This staremene seems ro glose over and exclude mention of waete serean release during oVT, dated $6 / 91$ (2-57) indleating that offluente (waste water at above amblent tomp.s) wero in lect released.

6) P. 3-20, 41-44, "Because the enisslons from the JACxDs Eac111ty have been hypothestzod to contals omild amounts of toxdc substances, such as dioxins, or lurane, there will be studies of dioxin and furan concentratione in the marine microlayer...." We recommend an implementation of a continual, program-wide analysis of pelected biota and sensitive ecogystems, before during and after program.

(7) p. $3-26,22$, (second paragraph grammatical ezrox) - are to (bo) procosed

8) P. 3-26,27, 3.2.3, Accidente and othex Norroutine Incidente/Events. This section does not elaborate sulflelently to indicate the 1mportance of a problem about a disconnected ACAks at JACrDS (OVY 
repore, 6/91, 2-24, nonltorlag syseon la1lure) which should be mantionod hero.

(9) p. 1-18, 22, (grannatical erroz third paragraph) - lued hose bocane disengaged from the one of the ships

(10) p. 4-24, 32, (grammat1cal error seventh paragraph) - extre "1s"

(11) p. 5-3,5.1 Meteorology/Air ouallty. Data gathered for only a very saall amount of time $(1960-64)$, this should be expended or defended.

(12) P. 5-13, 12-39 "Site apecifle poprlations that have been characterized in greater dotali since the FPEIs Include the following: worker and resldent populations located both on-post at PUDA and off-post:....; translent populations, defined as concentrations of people visiting or gathering in the vicinity on an intermittant or 1 rregular bas 1 s (e.g. recreational events): ..." Th1s paragraph does not seem to specilically consider agrarian workers in defining site spoetfle pops. See and allude here to B-23

(13) p. 7-7, 3-10, "The former report estimates that IRz outdoor warning can be accomplished by nine ounl-directional elrens in the IR2 and lour in the more populous PAz ... Placed at locations identifled on the basis of assurance of necesenzy aound coverage for the two zones." They seem to have forgotten 6 on-alte (DUDA), whlch is w/In IR2.

(14) P. 7-7, 20-21, The new EOC w111 not be occupied unt1l April 1992.

(15) p. B-7, 3, (spelling error) - Lt. Harry Winsel (Capt. Harry Wenzel)

(10) P. B-17, 45, The Colorado state Falr la now a 17-day event.

(17) p. B-18, 45, The Pueblo Crusaders are now defunct.

(18) P. B-18, Table B.8, does not mention Puoblo County employees.

(19) p. B-19, 45, refer to p. 2-9 comant

(20) P. B-22, Table B.12, State Falr 18 a 17-day event as of 8-91, w1en up to 1 mililon visitors in the period.

(21) P. B-22, Table B.12, puablo crusaders are now detunct.

(22) P. B-22, Table B.12, no mention of stomp-On at Rosemount kuseum, Puoblo.

(23) P. B-22, Table B.12, no mention of parade of Llghts in Pucblo. 
E-11

\section{E.2 RESPONSES TO COMMENTS}

\section{E.2.1 Responses to October 7, 1991 letter from Richard E. Hatten, State of Colorado, Department of Public Safety.}

Response to comment \#1: Intensive testing will be conducted at the prototype cryofracture facility with the results helping to determine whether the technology can be used to augment or replace incineration for chemical weapons destruction. This is now stated in the text.

Response to comment \#2: Comment incorporated into this Report.

Response to comment \#3: Comment incorporated into this Report.

Response to comment \#4: Comment is noted. These issues are addressed in Sects. 3.5.2 and 4.4.2, respectively.

E.2.2 Responses to the December 20, 1991, letter from Dennis G. Kwiatkowski, U.S. Federal Emergency Management Agency, Washington, D.C.

Response to comment \#1: Comment incorporated into this report.

Response to comment \#2: The airspace over Pueblo Depot Activity (PUDA) is now designated as "restricted." This revision has been incorporated into the text.

Response to comment \#3: A discussion of the Memorandum of Understanding between DOD and FEMA has been incorporated into Sect. 7.2 Developments in On-Site Emergency Preparedness.

Response to comment \#4: References to the oversight and review board have been changed to reflect the official title of Chemical Stockpile Emergency Preparedness Program Joint Steering Committee.

Response to comment \#5: Conment incorporated into this report.

Response to comment \#6: References to the Pueblo County Department of Public Safety have been changed to reflect the correct title, Pueblo County Civil Defense Agency.

Response to comment \#7: Comment incorporated into this report.

Response to comment \#8: Completion of the Emergency Operations Center (EOC) has now been projected by the Pueblo County Department of Public Safety and Operations for April 1992. This date has been incorporated into the text of the Phase I Report.

Response to comment \#9: Comment incorporated into this report. 
Response to comment \#10: The specific text referred to in this comment is part of a discussion of Final Programmatic Environmental Impact Statement (FPEIS) statements related to emergency preparedness for rail transport; it is not intended to describe current CSEPP plans for personal protective equipment during on-site disposal. The comment concerning the current uncertainty of the Army providing personal protective equipment for public use is accurate; however, Chemical Demilitarization Center (CDC) has formed an expert work group to study this issue and make recommendations.

Response to comment \#11: The statement in question is part of the discussion of the FPEIS emergency preparedness measures for rail transport corridors. The success of such measures for accidents that could occur anywhere along these corridors is obviously difficult to predict. The statement has been revised to better reflect the uncertainty.

Response to comment \#12: Appendix A of this Phase I Report provides a summary of the impact analyses conducted in the FPEIS, including the methods, assumptions, and data used to identify the programmatic environmentally preferred alternative for disposal of the stockpiles of all eight continental United States (CONUS) storage sites. The increased effects of chemical agent exposure on more sensitive population groups (infants and the elderly) will be thoroughly discussed in the site-specific environmental impact statement.

Response to comment \#13: The recommendation for more information concerning Pueblo County's emergency response capabilities is appreciated. This information has been added to Appendix B, Sect. B.1.1.4 Public Services.

Response to comment \#14: The statement concerning the Army's provision of personal protective equipment refers to an actual case in which the Army has provided such equipment to one hospital that had been designated as a "decontamination and treatment center." It does not imply the establishment of a general policy of provision of such equipment by the Army to the public. See also response to comment $\# 10$.

\section{E.2.3 Responses to the December 26, 1991 letter from Shelly M. DuVall, Pueblo County Department of Public Safety and Operations, Pueblo, Colorado.}

Response to comment \#1: The word "many" has been deleted from the discussion of comments received during the PUDA scoping process in Sect. 2.3. It has been replaced with more appropriate terminology.

Response to comment \#2: Comment incorporated into this report.

Response to comment \#3: The term "proven out" is not sufficiently descriptive of the requirements of the testing and approval process for the Johnston Atoll Chemical Agent Disposal System (JACADS) facility. The term has been replaced in this report with the statement that the JACADS technology must "meet regulatory and design requirements."

Response to comment \#4: Comment incorporated into this report. 
Response to comment \#5: The discussion of the disposal facility process water system that elicited this comment has been moved to Sect. 3.2.2.5 Environmental Compliance. It has been incorporated into the discussion of the JACADS National Pollutant Discharge Elimination System (NPDES) permitting process and results. As described in the operational verification testing (OVT) Report dated June 1991, and now stated in the above section, there were some variances from the procedural requirements of the NPDES permit at JACADS. However, daily monitoring showed that the seawater discharge was within both quantity and temperature limits of the NPDES permit. Although JACADS employs a once-through cooling water system, the CONUS facilities will use a closed loop system which will release no process water to the environment.

Response to comment \#6: Monitoring of the JACADS OVT operations to date have identified no detectable emissions of dioxins or furans, with the exception of tetrachlorodibenzo-p-dioxin, which was found to be near ambient levels. Longer range studies of dioxins and furans at JACADS are being conducted. The Army will continue to evaluate the need for additional monitoring efforts over and above the regulatory requirements.

Response to comment \#7: Comment incorporated into this report.

Response to comment \#8: The disconnected monitors occurrence did constitute a nonroutine event and has been included in Sect. 3.2.3 along with other events that had not previously been documented in this report.

Response to comment \#9: Comment incorporated into this report.

Response to comment \#10: Comment incorporated into this report.

Response to comment \#11: The U.S. Environmental Protection Agency recommended period for meteorological data measurements is 5 years, which was completed for Pueblo Memorial Airport at the end of 1964 . This includes over 43,000 hourly observations. Air dispersion modeling is done on an hour-by-hour basis, and the time scales of the worst pollution episodes are usually on the order of days, so this length of record assures a large number of independent replications of the meteorological phenomena of interest. As stated in Sect. 5.1, PUDA on-site measurements were begun in December 1988 and continued irregularly because of equipment downtimes. The reader is directed to Appendix I for more detailed information concerning the PUDA on-site measurements.

Response to comment \#12: Sect. 5.5 has been revised to indicate that agrarian workers are included in the figures for transient populations. The reader is directed to Appendix B for more detailed information.

Response to comment \#13: Text has been added to Sect. 7.2.2.3 to include the six PUDA on-site sirens in the outdoor warning system at PUDA. 


\section{E-14}

Response to comment \#14: The text has been revised to indicate the projected April 1992 occupation date for the EOC.

Response to comment \#15: Comment incorporated into this report.

Response to comment \#16: The text of Appendix B has been revised to state that the Colorado State Fair is now a 17-day event.

Response to comment \#17: The Pueblo Crusaders have been deleted from the discussion of public events in Appendix B.

Response to comment \#18: The caption for Table B.8 has been revised to indicate that the figures presented are for employers who have more than 100 employees at one location.

Response to comment \#19: Comment incorporated into this report.

Response to comment \#20: Table B.12 has been revised to show that the state fair is now a 17-day event with more than one million visitors.

Response to comment \#21: The Pueblo Crusaders have been deleted from Table B.12.

Response to comment \#22: The Stomp-on at Rosemont Museum has been included in Table B.12.

Response to comment \#23: The Parade of Lights has been included in Table B.12. 


\section{APPENDIX F}

\section{SEISMICITY}

Jacobs Engineering Group, Inc., and URS/John A. Blume and Associates, Engineers, were contracted by the U.S. Army Engineer Division, Huntsville, Alabama, to provide a detailed deterministic seismic risk analysis for the Pueblo Depot Activity (PUDA), Colorado. This analysis (Blume 1987) cited 110 references and used computer-stored earthquake data from the National Oceanic and Atmospheric Administration's (NOAA's) Geophysical Data Center in Boulder, Colorado. Blume's summary is reproduced verbatim here as an introduction to geology and seismicity at PUDA and adjacent regions. Salient details of Blume's seismic risk analysis and other pertinent earthquake information are presented in subsequent sections.

The site is located in the Great Plains physiographic province of eastern Colorado about $65 \mathrm{~km}$ east of the Front Range. The site is blanketed by fine to medium windblown sand of Holocene and Pleistocene age which is underlain by weathered gravels called the Verdos Alluvium of Pleistocene age. These unconsolidated materials vary from dense to moderately dense and have a combined thickness of about $15 \mathrm{~m}$. Bedrock beneath these unconsolidated materials consists of siltstone and claystone of the Upper Cretaceous age Pierre Shale. The Pierre Shale and underlying sedimentary formations of increasing age comprise an essentially conformable sequence of strata that dips very gently to the north or northeast.

Few faults are known in the Great Plains of Colorado; however, two have been identified near the PUDA site. The nearest of these, the Fowler fault, is about $20 \mathrm{~km}$ to the southeast. It is a normal fault dipping to the south, striking northwesterly, and is about $20 \mathrm{~km}$ long. The Fowler fault is considered capable according to the definition of the U.S. Nuclear Regulatory Commission and is the location of the maximum earthquake for the site. However, it trends to the south of the site and does not extend closer than within about $20 \mathrm{~km}$. Therefore there is no known or apparent hazard due to surface fault rupture at the site.

The estimated peak ground acceleration at the PUDA site would be generated by a local earthquake of $m_{b}=5.7$ on the Fowler fault at a distance of $18 \mathrm{~km}$. This event would produce an estimated peak ground acceleration of $0.21 \mathrm{~g}$, which is recommended for seismic design. A response spectrum and earthquake time history are presented in Sect. 3; the earthquake duration is estimated to be $8 \mathrm{sec}$. (Blume 1987) 


\section{F.1 PROBABILISTIC RISK ANALYSIS}

Seismic risk analysis in the Final Programmatic Environmental Impact Statement (FPEIS) was based on probabilistic earthquake data provided by the Applied Technology Council (ATC) (ATC 1978) and the assumption that important structures would be clones of like-functioning facilities at Tooele Army Depot (TEAD). According to ATC, an effective peak ground acceleration (EPGA) equal to $0.05 \mathrm{~g}$ [corresponding to modified Mercalli intensity $\left(\mathrm{I}_{\mathrm{mm}}\right) \mathrm{V}-\mathrm{VT}$ ] has a $10 \%$ probability of exceedance at least once in 50 years at PUDA. Probabilities of exceeding larger design EPGAs [0.20g and $0.81 \mathrm{~g}$ for the main munitions demilitarization building (MDB) and toxic cubicle (TOX), respectively] were extrapolated from data provided by ATC (Figs. F.1 and F.2) and used in the FPEIS risk analysis. The annual probabilities of exceedance of EPGA $=0.20 \mathrm{~g}$ and $0.81 \mathrm{~g}$ at PUDA are $7 \times 10^{-5}$ and $1 \times 10^{-6}$ such events per year for the MDB and TOX, respectively (Fig. F.2). The TOX was screened out of the risk analysis on the basis of a very low probability of occurrence (less than one chance in a million, annually).

Based on currently available data, the seismic risk for the MDB and TOX at PUDA remains unchanged. FEMA's (1988) seismic risk map is identical to that of ATC 1978, both having been based on a seismic risk analysis by Algermissen and Perkins (1976) that provided ground motion estimates for sites on rock foundations. More recent analyses by Algermissen et al. in 1982 (Plate 2) and 1990 (Sheet 1, Map A) result in no significant differences in seismic risk for PUDA. Each Algermissen study was national, rather than site-specific, in scope and may not necessarily be a good representation of seismic risk at PUDA. The foundation materials beneath PUDA are moderately deep soils, and some differences in ground response are expected. Nevertheless, the Algermissen studies are the only probabilistic risk analyses available at this time. A site-specific probabilistic risk analysis [as described by the Electric Power Research Institute (EPRI) (1988) and Bernreuter et al. (1989)] for use in nuclear power plant seismic risk analyses has not been done for PUDA. No nearby site-specific data are available for use as a surrogate for PUDA [for example, data similar to site-specific seismic hazard curves provided by Bernreuter et al. (1989) for 69 nuclear power plants in the eastern United States]. However, Staub (1991) demonstrates that the ATC seismic hazard curves (ATC 1978; the basis of the Army's seismic risk analysis at PUDA) are generally conservative with respect to Bernreuter's 50th percentile (median) seismic hazard curves.

\section{F.2 UNIFORM BUILDING CODES}

Figure F.3 is the 1988 Uniform Building Code (UBC) seismic zone map [nternational Conference of Building Officials (ICBO) 1988, p. 178]. This map is nearly identical to ATC's 1978 and FEMA's 1988 seismic risk maps (Fig. F.1); the boundaries between seismic zones are essentially the same as the peak ground acceleration (PGA) contours as presented in the risk maps. Like the risk maps, the 1988 UBC seismic zone map is based on the probabilistic risk analysis of Algermissen and Perkins 1976. PUDA is located in seismic zone 1 of Fig. F.3. Seismic zone 1 of the $1988 \mathrm{UBC}$ is a region where minor earthquake damage (corresponding to $\mathrm{I}_{\mathrm{mm}}=\mathrm{V}$ of $\mathrm{VI} ; 0.05_{\mathrm{g}}<\mathrm{PGA}<0.10_{\mathrm{g}}$ ) may be expected at least 
F-3
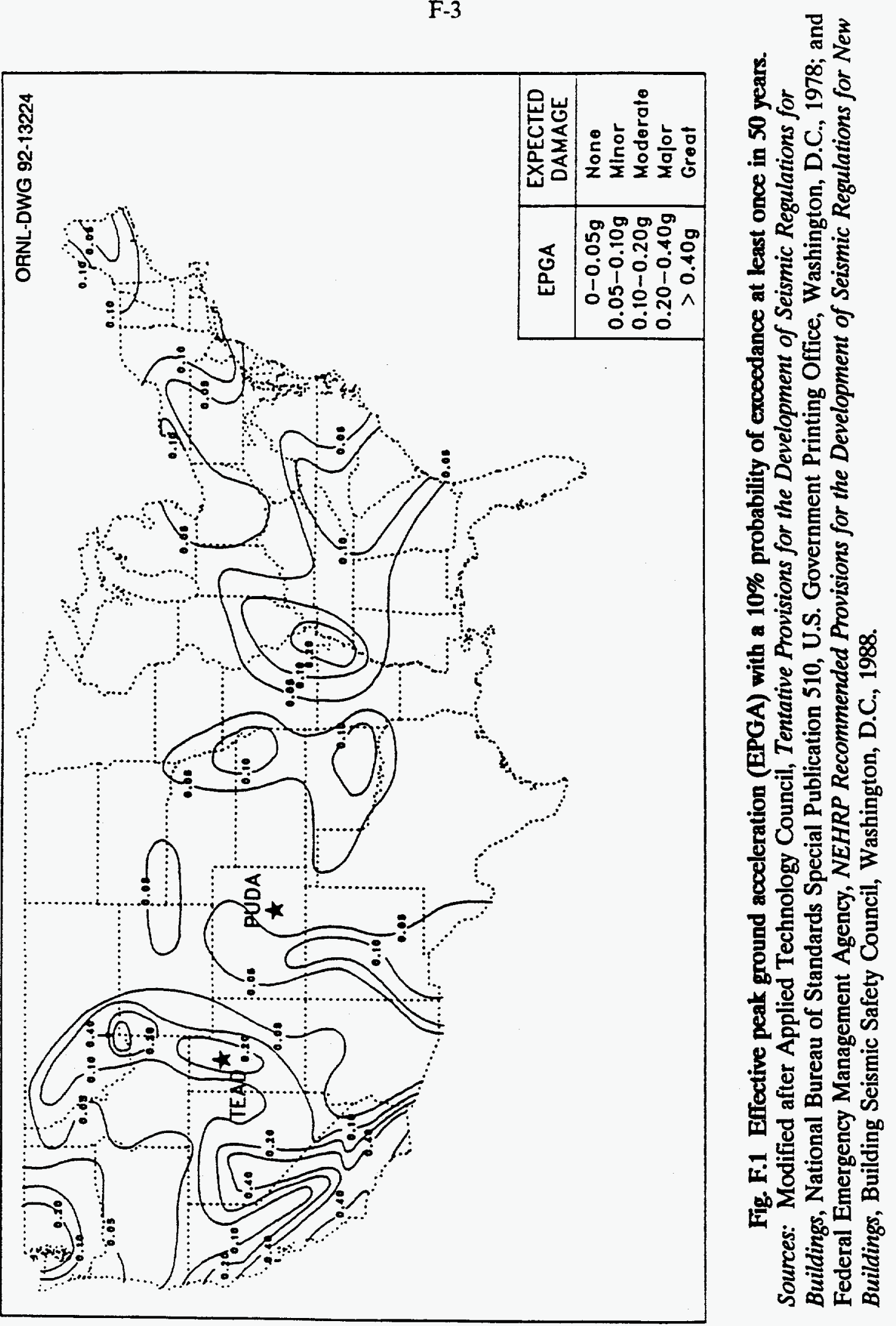
ORNL-DWG 90M-6928

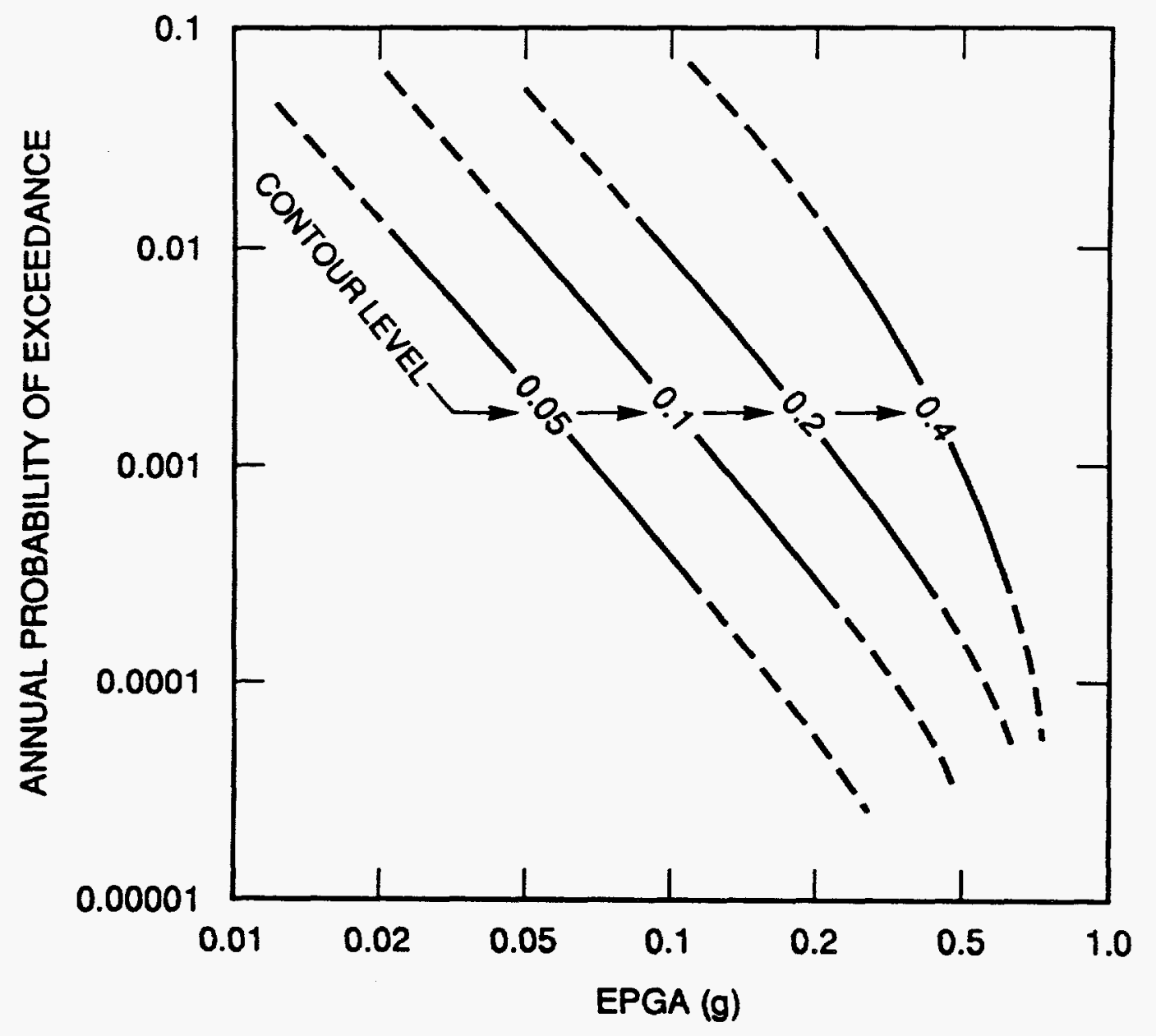

Fig. F.2 Annual risk of exceeding various effective peak ground accelerations (EPGA) for locations on the indicated contours of EPGA in Fig. F.1. Sources: Modified after ATC (Applied Technology Council), Tentative Provisions for the Development of Seismic Regulations for Buildings, National Bureau of Standards Special Publication 510, U.S. Government Printing Office, Washington, D.C., 1978; and FEMA (Federal Emergency Management Agency), NEHRP (National Earthquake Hazard Reduction Program), Recommended Provisions for the Development of Seismic Regulations for New Buildings, Building Seismic Safety Council, Washington, D.C., 1988. 


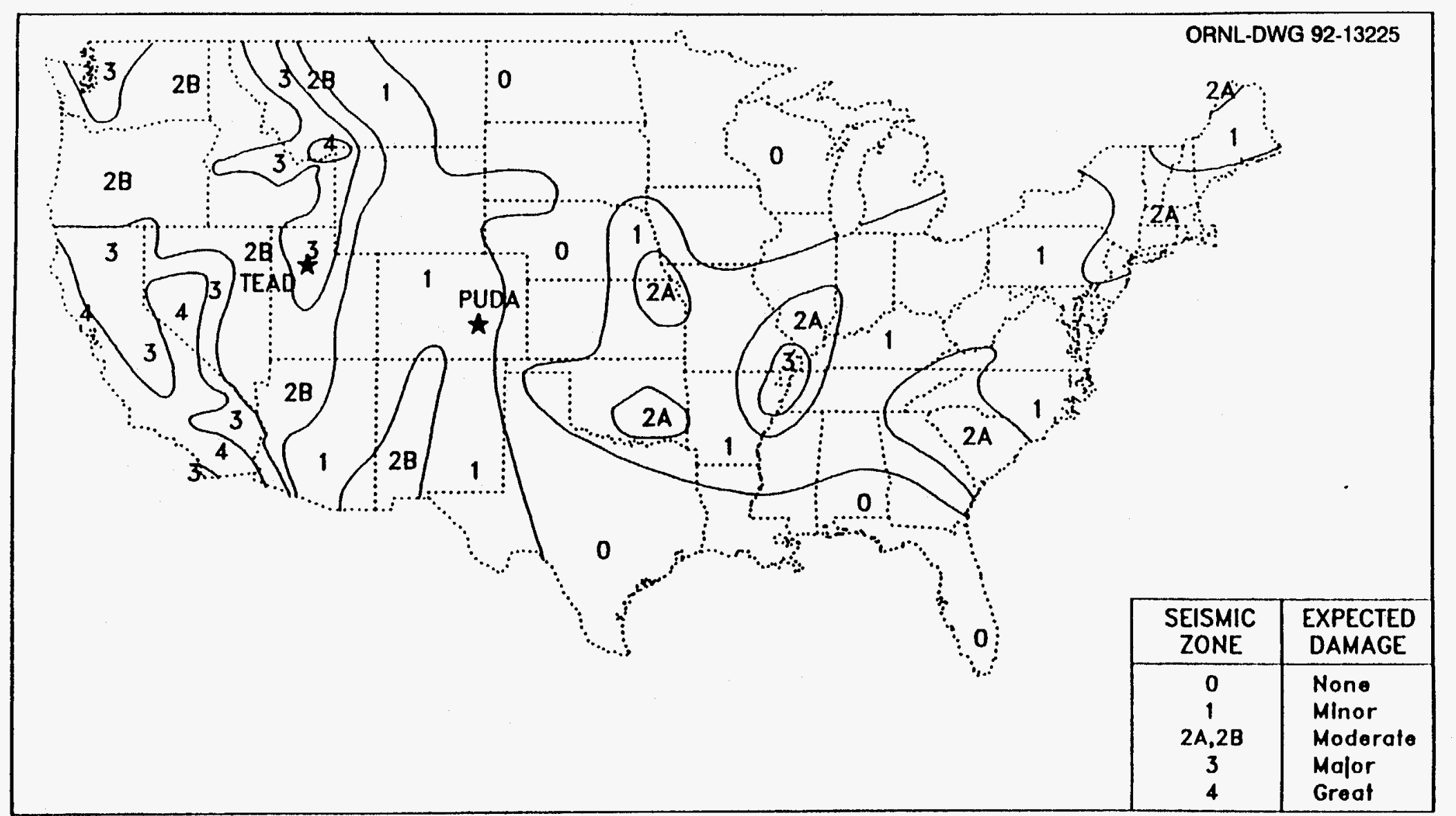

Fig. F.3. Seismic zone map of conterminous United States showing the locations of Pueblo Depot Activity and Tooele Army Depot, using 1988 data. Source: Modified after the International Conference of Building Officials, Uniform Building Code, Whittier, Calif., 1988. 
once in 500 years (or a $10 \%$ probability of occurrence in 50 years). In contrast, TEAD is located in seismic zone 3 where major earthquake damage (corresponding to $\mathrm{I}_{\mathrm{mm}}=\mathrm{VIII}$; $0.20 \mathrm{~g}<\mathrm{PGA}<0.40 \mathrm{~g}$ ) may be expected at least once in 500 years.

Fig. F.4 is the 1985 UBC seismic zone map (ICBO 1985). This map is nearly identical to Algermissen's 1969 seismic risk map. Algermissen's 1969 map is deterministic, rather than probabilistic; PGAs and their associated probabilities of occurrence were not provided. PUDA and TEAD are located in seismic zones 1 and 3, respectively, of the 1985 UBC. Earthquakes of $I_{\mathrm{mm}}=\mathrm{V}-\mathrm{VI}$ and VIII (corresponding to minor and major damage) may be expected in seismic zones 1 and 3, respectively, of the $1985 \mathrm{UBC}$.

Table F.1 presents the results of lateral shear calculations for selected structures at both TEAD and PUDA that are designed to meet the more stringent of either 1985 or 1988 UBC standards. The TOXs at TEAD and PUDA are not included in this table because they are designed according to more stringent guidelines similar to those used by the Nuclear Regulatory Commission for licensing nuclear power reactors. Most other important structures at PUDA are clones of corresponding TEAD structures and designed to meet 1985 UBC standards (ICBO 1985) for seismic zone 3 despite PUDA's location in the less seismically active zone 1. The container handling building (CHB) at PUDA is not a clone of the CHB at TEAD, as it is designed to meet 1988 UBC standards for seismic zone $2 B$ rather than 1985 UBC standards for seismic zone 3. Results in Table F.1 show that 1985 UBC standards are generally more stringent than 1988 UBC standards. The reason for this is that the "importance factor" (I) used in calculating the required resistance to lateral shear has been reduced from 1.5 to 1.25 in the $1988 \mathrm{UBC}$.

\section{F.3 POTENTIAL FOR ON-SITE SURFACE RUPTURE}

The only active faults in the Plains physiographic province (where PUDA is located) are the Fowler and Cheraw faults (Blume 1987). The locations of these two faults are shown in Fig. F.5. Only the Fowler fault is significant in terms of potential for on-site surface rupture at PUDA during a major earthquake.

At its closest approach, the surface expression of the Fowler fault is $20 \mathrm{~km}$ southeast of the site of the proposed disposal facility at PUDA. Exposed portions of this fault can be traced for a distance of $12 \mathrm{~km}$ from southeast to northwest. In places, Rocky Flats Alluvium (early Pleistocene stream deposits) is displaced by an $18 \mathrm{~m}$ fault scarp, suggesting repeated earthquake-induced surface ruptures between 1 and 3 million years ago. Piney Creek Alluvium (Holocene stream deposits) is not displaced along the Fowler fault, suggesting no major earthquakes have occurred there during the last 10,000 years. It is not known whether any Wisconsin (late Pleistocene) surface faulting has occurred. The projection of this fault passes northwest, parallel to the edge of the Denver Basin and beneath PUDA (about $4 \mathrm{~km}$ south of the site of the proposed disposal facility).

No faults have been discovered at PUDA. About $15 \mathrm{~m}$ of undisturbed early Pleistocene and Holocene alluvium rest on massive beds of Pierre Shale (upper Cretaceous). Faults of small displacement would be difficult to detect in the region surrounding PUDA.

Fault-generated surface rupture at PUDA apparently has not taken place since early Pleistocene times. 
F-7

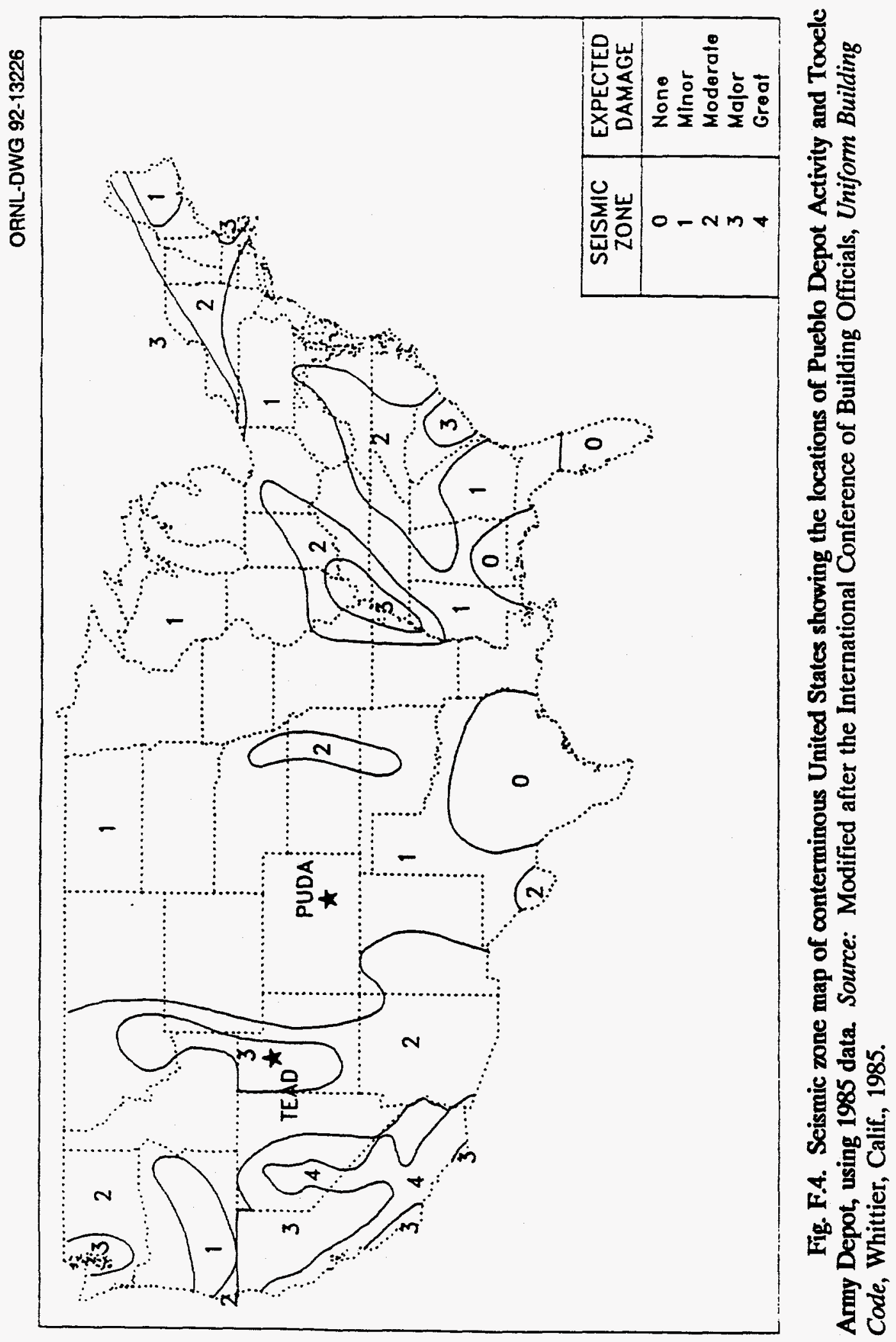


Table F.1. Chemical Stockpile Disposal Program (CSDP) design lateral shear compared with calculated lateral shear based on 1985 and 1988 Uniform Building Code (UBC)

standards for selected buildings at Tooele Army Depot (TEAD)

and Pueblo Depot Activity (PUDA)

\begin{tabular}{|c|c|c|c|c|c|c|c|}
\hline \multirow[b]{2}{*}{ Building } & \multirow[b]{2}{*}{ Construction } & \multicolumn{3}{|c|}{ Seismic zone } & \multicolumn{3}{|c|}{$\begin{array}{c}\text { Lateral shear } \\
\text { (\% of building weight) }\end{array}$} \\
\hline & & UBC 1985 & UBC 1988 & $\begin{array}{l}\text { CSDP } \\
\text { design }\end{array}$ & $\begin{array}{l}\text { UBC } 1985 \\
(I=1.50)^{a}\end{array}$ & $\begin{array}{l}\text { UBC } 1988 \\
(I=1.25)^{a}\end{array}$ & $\begin{array}{l}\text { CSDP } \\
\text { design }\end{array}$ \\
\hline \multicolumn{8}{|c|}{ TEAD } \\
\hline $\mathrm{MDB}^{b}$ & Concrete & 3 & 3 & 3 & 21 & 17.2 & 21 \\
\hline CHB & Steel $^{c}$ & 3 & 3 & 3 & 15.8 & 12.9 & 15.8 \\
\hline PAS & Steel & 3 & 3 & 3 & 30 & 25.8 & 30 \\
\hline PUB & Steel & 3 & 3 & 3 & 10.5 & 10.3 & 10.5 \\
\hline \multicolumn{8}{|c|}{ PUDA } \\
\hline MDB & Concrete & 1 & 1 & 3 & 10 & 4 & 21 \\
\hline CHB & Steel $^{c}$ & 1 & 1 & $2 B$ & 8 & 3 & 8.6 \\
\hline PAS & Steel & 1 & 1 & 3 & 15 & 6 & 30 \\
\hline PUB & Steel & 1 & 1 & 3 & 5 & 3 & 10.5 \\
\hline
\end{tabular}

'I is importance factor from appropriate Uniform Building Code.

bAcronyms: Tooele Army Depot (TEAD), Pueblo Depot Activity (PUDA), main munitions demilitarization building

(MDB), container-handling building (CHB), pollution abatement system (PAS), process utilities building (PUB),

Uniform Building Code (UBC), Chemical Stockpile Disposal Plant (CSDP).

'Pre-engineered.

Sources: U.S. Army Engineer Division, Huntsville, Alabama open-file data; ICBO (International Conference of Building Officials) Uniform Building Code 1985, pp. 125-135; ICBO Uniform Building Code 1988, pp. 168-178. 
F-9

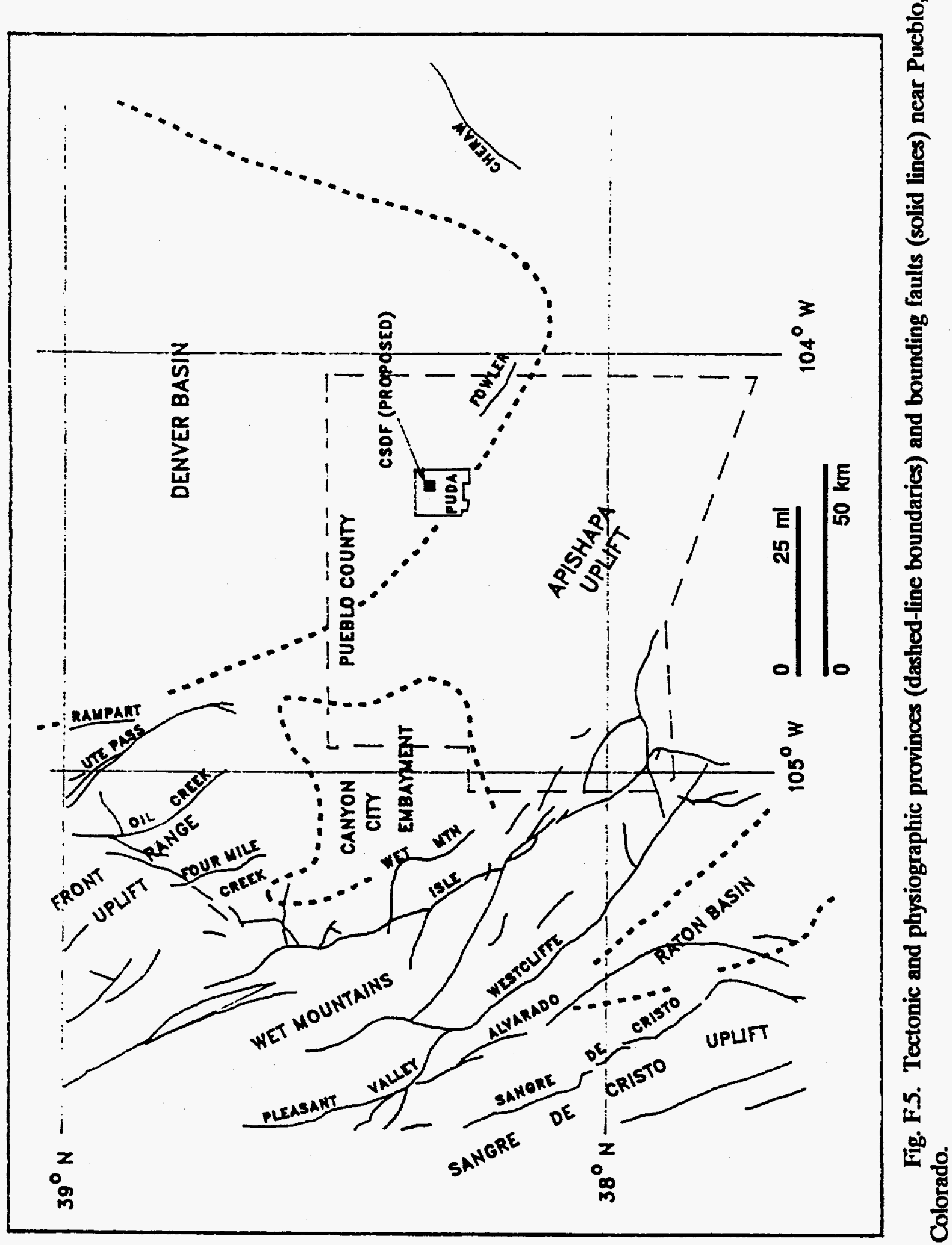




\section{F.4 DETERMINISTIC RISK ANALYSIS}

Fig. F.6 shows the locations of all historical strong-motion earthquakes [equal to or greater than body-wave magnitude $\left(\mathrm{m}_{\mathrm{b}}\right)$ equal 4.5 ; modified Mercalli intensity $\left(\mathrm{I}_{\mathrm{mm}}\right)$ VI or greater] within $320 \mathrm{~km}$ (200 miles) of PUDA. Tectonic provinces and seismic source zones are superimposed on this figure. The locations and intensities of earthquakes that occurred more than 50 years ago are not well known. The epicentral locations of older events may be off by as much as $100 \mathrm{~km}$, and their sizes may be off by one intensity unit. More recent events were recorded by modern seismic instruments; their locations and sizes are known to within $10 \mathrm{~km}$ and 0.1 to 0.2 magnitude units, respectively. The historical record of seismicity in Colorado is less than 150 years old. These data were acquired from computerstored files of the NOAA Geophysical Data Center in Boulder, Colorado.

Table F. 2 is a compilation of the maximum historical earthquakes $\left(m_{b}\right.$ or $\left.I_{b}\right)$ in the tectonic provinces of Fig. F.6. Also shown are the maximum expected earthquakes $\left(m_{b}\right)$ in each province, the minimum distance from each province to PUDA, and the predicted maximum intensities $\left(\mathrm{I}_{\mathrm{mm}}\right)$ and their corresponding PGA at PUDA. According to Blume (1987) an earthquake on the Fowler Fault (Fig. F.5) would produce the largest expected ground motions at PUDA ( $\mathrm{I}_{\mathrm{mm}}=$ VIII and PGA $=0.21 \mathrm{~g}$ ).

Four Plains earthquakes are listed in Table F.2. Maximum expected earthquakes in other provinces are too distant to produce large intensities and associated ground motions at PUDA. The Rocky Mountain Arsenal (RMA) earthquake of August 1967 was induced by injection of RMA waste liquids. Earthquakes at the arsenal have decreased in frequency and magnitude since fluid injection was terminated in 1968 (Kirkham and Rogers 1986). Thus seismicity at RMA is not a factor in predicting future ground motions at PUDA. Other large earthquakes in the Plains province are constrained to Pleistocene faults such as those described in the subsection on "Potential for On-Site Surface Rupture." The Fowler Fault is the closest of these Plains faults. Other historical earthquakes on the Plains are much smaller.

One historical earthquake deserves special consideration. According to several authors (Hadsell 1968; Dames and Moore 1981; and Kirkham and Rogers 1986), the earthquake of November 7,1882 , is the largest historical earthquake $\left(I_{\operatorname{mm}}=V I I\right)$ in Colorado with the exception of the RMA event described above. However, these authors cannot agree on its precise location. Hadsell places it in the Plains near Denver; Dames and Moore place it in western Colorado; and Kirkham and Rogers place it either in the Front Range of Colorado or in its extension into southern Wyoming (the Laramie Range). Kirkham and Rogers' locations are equivalent to Blume's Eastern Mountain Tectonic Province. If Hadsell is correct, an earthquake this size could be "floated" to PUDA. Furthermore, if the maximum expected intensity is one unit larger than the maximum historical event, the PGA $(0.25 \mathrm{~g})$ would be somewhat larger than the maximum PGA associated with an earthquake on the Fowler Fault. However, the duration of shaking would be somewhat less. The on-site (Hadsell) and Fowler Fault maximum expected earthquakes may be approximately equivalent in terms of damage potential at PUDA.

Fig. F.7 shows the locations of all the historical earthquakes in NOAA's data file within $100 \mathrm{~km}$ of PUDA. Sedimentary basins, ranges, and uplifts of Frezon and Finn (1988) are superimposed on this figure. 


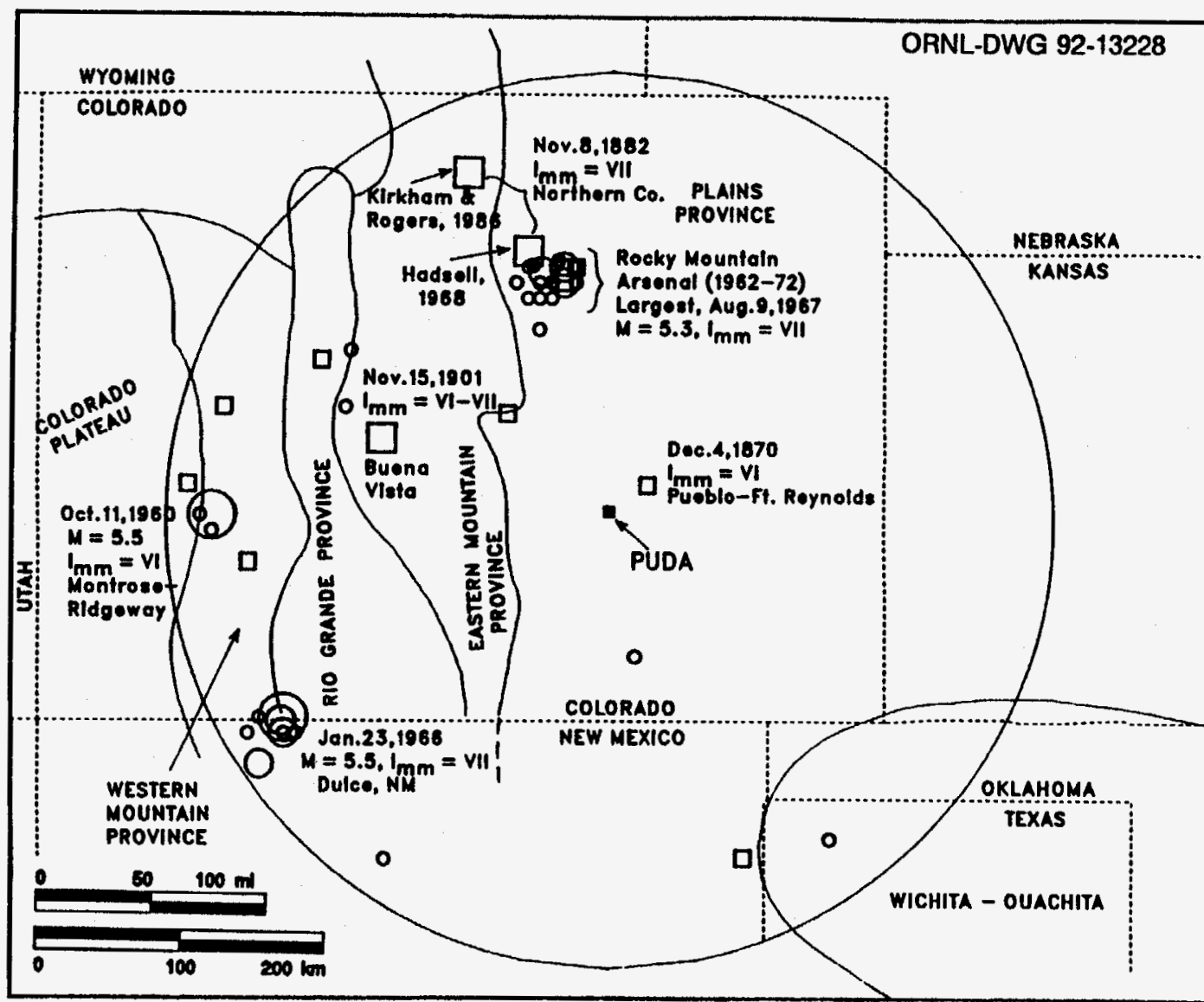

INTENSITY . I
$\square \quad$ VI
$\square$ VII

MAGNITUDE, M

$\stackrel{\circ}{\bigcirc} \quad 4.5-4.9-5.4$

Fig. F.6. Locations of all historical strong motion earthquakes [equal to or greater than body-wave magnitude $\left(\mathrm{m}^{\mathrm{b}}\right)$ of 4.5, modified Mercalli Intensity ( ${ }^{\mathrm{mm}}$ ) VI] within $320 \mathrm{~km}$ (200 miles) of Pueblo Depot Activity. Sources: National Oceanic and Atmospheric Administration, Geophysical Data Center, Boulder, Colorado; Blume (Jacobs Engineering Group, Inc. and URS/John A. Blume and Associates, Engineers), Geological-Seismological Investigation of Earthquake Hazards for a Chemical Stockpile Disposal Facility at the Pueblo Depot Activity, Colorado, prepared for the Office of the Program Manager for Chemical Munitions by U.S. Army Engineer Division, Huntsville, Ala., 1987; Kirkham, R. M., and Rogers, W. P., "An Interpretation of the November 7, 1882 Colorado Earthquake," in Rogers, W. P., and Kirkham, R. M., eds., Contributions to Colorado Seismicity and Tectonics $\rightarrow 1986$ Update, Colorado Geological Survey, special Publication 28, Denver, 1986. 
Table F.2. Maximum expected earthquakes and their associated peak ground accelerations (PGAs) at Pueblo Depot Activity (PUDA) for significant seismic source zones in the western

plains and Rocky Mountain regions (modified after Blume 1987)

\begin{tabular}{|c|c|c|c|c|c|}
\hline $\begin{array}{l}\text { Tectonic province or } \\
\text { seismic source zone }\end{array}$ & $\begin{array}{l}\text { Maximum historical } \\
\text { earthquake }\end{array}$ & $\begin{array}{l}\text { Maximum expected } \\
\text { earthquake }\left(m_{b}\right)\end{array}$ & $\begin{array}{l}\text { Minimum distance } \\
(\mathrm{km}) \text { from PUDA }\end{array}$ & $\begin{array}{l}\text { Modified Mercalli } \\
\text { intensity at PUDA }\end{array}$ & $\begin{array}{l}\text { Maximum peak } \\
\text { ground acceleration at } \\
\text { PUDA }\end{array}$ \\
\hline \multicolumn{6}{|l|}{ Plains } \\
\hline Rocky Mountain Arsenal ${ }^{a}$ & $\begin{array}{l}8 / 9 / 1967 \\
m_{b}=5.3\end{array}$ & 5.3 & 176 & $<$ III & $<0.01 \mathrm{~g}$ \\
\hline Fowler Fault ${ }^{b}$ & None & 5.7 & 18 & VIII & $0.21 \mathrm{~g}$ \\
\hline Other & $\begin{array}{c}12 / 4 / 1870 \\
I_{o}=V I\end{array}$ & -5.0 & On-site & VII & $0.18 \mathrm{~g}$ \\
\hline $\begin{array}{l}\text { Hadsell } 1968^{\circ} \\
\text { Eastern Mountain }\end{array}$ & $I_{o}=$ VII, $m_{b}=5.0$ & -- & --- & $\cdots$ & --- \\
\hline Blume 1987 & $\begin{array}{c}11 / 15 / 1901 \\
I_{0}=V I\end{array}$ & 6.0 & 60 & $\mathrm{VI}+$ & $0.08 \mathrm{~g}$ \\
\hline $\begin{array}{c}\text { Kirkham \& Rogers } 1986^{\circ} \\
\text { Rio Grande }\end{array}$ & $\begin{array}{l}11 / 7 / 1882 \\
I_{0}=V I I\end{array}$ & $\ldots$ & $\cdots$ & $\cdots$ & $\cdots$ \\
\hline $\begin{array}{l}\text { Blume } 1987 \\
\text { Western Mountain }\end{array}$ & $\begin{array}{l}1 / 23 / 1966 \\
m_{b}=5.1\end{array}$ & 6.0 & 85 & VI & $0.06 \mathrm{~g}$ \\
\hline Blume 1987 & $\begin{array}{l}10 / 11 / 60 \\
m_{b}=5.5\end{array}$ & 5.9 & 200 & IV + & $0.02 \mathrm{~g}$ \\
\hline Dames \& Moore $1981^{c}$ & $\begin{array}{l}11 / 7 / 1882 \\
I_{0}=V I I\end{array}$ & $\cdots$ & $\ldots$ & --- & --- \\
\hline
\end{tabular}

Induced seismicity from Rocky Mountain Arsenal underground injection activities.

The Fowler Fault has not been active during historic time; the last known displacement (Rocky Flats Alluvium) was early Pleistocene.

There is controversy with respect to the epicentral location of this earthquake, the largest historical earthquake in Colorado. 
ORNL-DWG $92-13229$

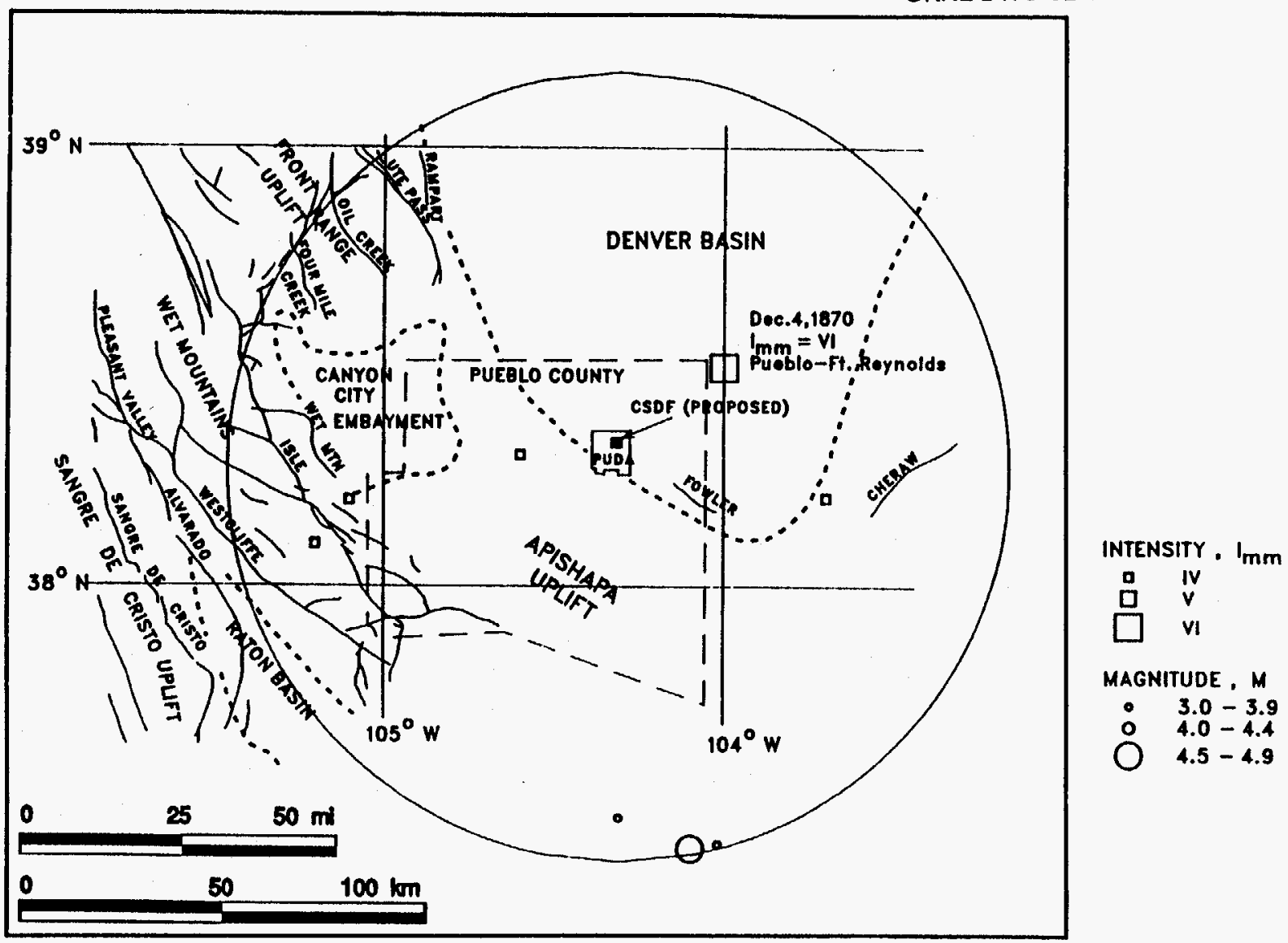

Fig. F.7. All earthquakes within $100 \mathrm{~km}$ (62 miles) of Pueblo Depot Activity. Sources: National Oceanic and Atmospheric Administration, Geophysical Data Center, Boulder, Colorado; Blume (Jacobs Engineering Group, Inc., and URS/John A. Blume and Associates, Engineers), Geological-Seismological Investigation of Earthquake Hazards for a Chemical Stockpile Disposal Facility at the Pueblo Depot Activity, Colorado, prepared for the Office of the Program Manager for Chemical Munitions by U.S. Army Engineer Division, Huntsville, Ala., 1987; and Frezon, S.E. and Finn, T.M., Map of Sedimentary Basins in the Conterminous United States, U.S. Geological Survey Oil and Gas Investigations Map OM-223, Denver, 1988. 


\section{F.5 POTENTIAL FOR LIQUEFACTION}

Thirteen test soil borings were drilled by the Army (U.S. Army Engineer Division) in October, 1986 at the site of the proposed disposal facility. Each boring was about $9 \mathrm{~m}(30 \mathrm{ft})$ deep. Generally, the material encountered consisted of 4-5.5 m (13-18 ft) of stiff to hard, lean to fat clay over medium dense to very dense silty sand. These shallow borings did not penetrate the underlying Pierre Shale. Groundwater levels varied from 3 to $4 \mathrm{~m}(9.5$ to $13 \mathrm{ft})$ below the surface. Standard penetrometer blow counts below the water table generally ranged from 25 to 60 blows per foot of penetration. At several locations, low density silty sands were encountered immediately below the water table (as indicated by blow counts ranging from 16 to 22) and one sample had an exceptionally low density (as indicated by 4 blow counts per foot of penetration). Low-density samples were the exception rather than the rule.

Shallow groundwater beneath the site exists under water table (unconfined) conditions. Confined groundwater under artesian conditions is separated from the surface by more than $300 \mathrm{~m}(1000 \mathrm{ft})$ of Pierre Shale.

Based on the above data, the potential for liquefaction during a strong motion earthquake is generally slight. Localized liquefaction may occur where unusually low-density soils lie immediately beneath the water table (one such site has been identified). The potential for liquefaction could be eliminated by removal or in-situ densification of low density soils. Sand dikes created during an earthquake are unlikely to penetrate through $300 \mathrm{~m}$ of Pierre Shale.

\section{F.6 POTENTIAL FOR GROUND MOTION MAGNIFICATION}

Based on the geotechnical data provided in the previous section, there is slight potential for ground motion magnification during an earthquake. The extent of magnification depends on the thickness of overburden above the Pierre Shale. Although the Pierre Shale was not penetrated by any of the above described test borings, data from other wells and outcrops in the vicinity suggest that soils are generally less than $15 \mathrm{~m}(50 \mathrm{ft})$ thick.

The above site conditions are typical of Soil Profile Type $\mathbf{S 1}$ as described by FEMA (1988). Such soils have relatively low ground motion magnifications (spectral accelerations) relative to other soil types at excitation periods exceeding $0.5 \mathrm{~s}$.

Blume (1987) recommends the simplified 84th percentile response spectrum for stiff soil and rock (Seed, Ugas, and Lysmer 1976) for use in design of the PUDA TOX facility. This design response spectrum is more stringent (conservative) than other spectra (FEMA 1988, AEC 1973) at earthquake excitation periods greater than $0.5 \mathrm{~s}$ and is roughly equivalent at shorter periods. Blume also provides a strong motion earthquake time-history based on several accelerograms for site conditions similar to those anticipated at PUDA. This timehistory has been modified for duration ( $8 \mathrm{~s}$ for a near-field earthquake), zero period mean PGA (0.21g), and spectral content to match Blume's recommended design response spectrum.

The Army has chosen to use the same seismic design for the TOX at PUDA as Blume's recommended seismic design for the TOX at TEAD (Blume 1988). The latter is a significantly more stringent design than Blume's recommendation for PUDA. Blume (1988) recommends the simplified 84th percentile response spectrum of Seed, Ugas, and Lysmer 


\section{F-15}

(1976) for deep, cohesionless soils (Soil Profile Type S4 of FEMA 1988) for seismic design of the TOX at TEAD. These soils have a high ratio of spectral acceleration to zero period PGA for earthquake excitation periods greater than $0.5 \mathrm{~s}$. Blume (1988) also provides a strong motion earthquake time-history based on several accelerograms for site conditions similar to those at TEAD. This accelerogram has been modified for duration (20 s), zero period mean PGA $(0.81 \mathrm{~g})$, and spectral content to match Blume's 1988 recommended design response spectrum for TEAD. The TOX at PUDA will have the same basic design as that for TEAD.

\section{F.1 REFERENCES}

AEC (Atomic Energy Commission) 1973. "Design Response Spectra for Seismic Design of Nuclear Power Plants," Regulatory Guide 1.60, Washington, D.C.

Algermissen, S. T. 1969. Seismic Risk Studies in the United States, 4th World Conference on Earthquake Engineering, Santiago, Chile.

Algermissen, S. T. and Perkins, D. M. 1976. A Probabilistic Estimate of Maximum Acceleration in Rock in the Contiguous United States, U.S. Geological Survey Openfile Report 76-416, Denver, Colo.

Algermissen, S. T., et al. 1982. Probabilistic Estimates of Maximum Acceleration and Velocity in Rock in the Contiguous United States, U.S. Geological Survey Open-File Report 82-1033, Denver, Colo.

ATC (Applied Technology Council) 1978. Tentative Provisions for the Development of Seismic Regulations for Buildings, National Bureau of Standards Special Publication 510, U.S. Government Printing Office, Washington, D.C.

Bernreuter, D. L., et al. 1989. Seismic Hazard Characterizations of 69 Nuclear Plant Sites East of the Rocky Mountains, Vols. 1-7, NUREG/CR-5250, prepared by Lawrence Livermore National Laboratory for the U.S. Nuclear Regulatory Commission, Washington, D.C.

Blume (Jacobs Engineering Group, Inc., and URS/John A. Blume and Associates, Engineers) 1987. Geological-Seismological Investigation of Earthquake Hazards for a Chemical Stockpile Disposal Facility at the Pueblo Depot Activity, Colorado, prepared for the Office of the Program Manager for Chemical Munitions by U.S. Army Engineer Division, Huntsville, Ala.

Blume (Jacobs Engineering Group, Inc., and URS/John A. Blume and Associates, Engineers) 1988. Geological-Seismological Investigation of Earthquake Hazards for a Chemical Agent Demilitarization Facility at the Tooele Army Depot, Utah, prepared for the Office of the Program Manager for Chemical Munitions by U.S. Army Engineer Division, Huntsville, Ala.

Dames and Moore 1981. Final Report, Geologic and Seismologic Investigations for Rocky Flats Plant for U.S. Department of Energy, Volumes 1, 2, and 3, Job Number 10805041-14, Department of Energy Contract Number DE-AC04-80AL10890, Dames \& Moore, Denver, Colo. 
EPRI (Electric Power Research Institute) 1988. Seismic Hazard Methodology for the Central and Eastern United States, Vols. 1-10, EPRI Final Report NP-4726, Projects P10138, -45, -46, and 2556-14, Palo Alto, Calif.

FEMA (Federal Emergency Management Agency) 1988. NEHRP (National Earthquake Hazard Reduction Program), Recommended Provisions for the Development of Seismic Regulations for New Buildings, Building Seismic Safety Council, Washington, D.C.

Frezon, S. E. and Finn, T. M. 1988. Map of Sedimentary Basins in the Conterminous United States, U.S. Geological Survey Oil and Gas Investigations Map OM-223, Denver, Colo.

Hadsell, F. A. 1968. "History of Earthquake Activity in Colorado," in Hollister, J. C., and Weimer, R. J., eds., Geophysical and Geological Studies of the Relationships Between the Denver Earthquakes and the Rocky Mountain Arsenal Well, Part A: Quarterly of the Colorado School of Mines, 63 (1), p. 57-72.

ICBO (International Conference of Building Officials) 1985. Uniform Building Code, Whittier, Calif.

ICBO (International Conference of Building Officials) 1988. Uniform Building Code, Whittier, Calif.

Kirkham, R. M., and Rogers, W. P., 1986. "An Interpretation of the November 7, 1882 Colorado Earthquake," in Rogers, W. P., and Kirkham, R. M., eds., Contributions to Colorado Seismicity and Tectonics-A 1986 Update, Colorado Geological Survey, Special Publication 28, Denver, Colo.

Seed, H. B., Ugas, C., and Lysmer, J. 1976. "Site-Dependent Spectra for Earthquake Resistant Design," Bulletin of the Seismological Society of America 66, 221-43.

Staub, W. P. 1991. "Nuclear Power Station Seismic Hazard Curves in the Eastern United States and the Uniform Building Code," Bulletin of the Association of Engineering Geologists 28 (3), 227-33.

U.S. Army Engineer Division, 1987. Geotechnical Data for the Pueblo Depot Activity, U.S. Army Corps of Engineers, Huntsville Dist., Alabama Open File, Huntsville, Ala. 


\section{APPENDIX G}

\section{JACADS PROCESSING RATES}

Processing rates for the disposal facilities were not specified in the Final Programmatic Environmental Impact Statement (FPEIS); however, design goals have since been established. Figure G.1 shows the number of GB-filled rockets processed on each day of the Johnston Atoll Chemical Agent Disposal System (JACADS) operational verification testing (OVT) from October 1, 1990, to February 28, 1991. Rockets were processed on 30 of the 81 calendar days in the period prior to the scheduled maintenance shutdown, December 20,1990 , to January 31,1991 . The total number of rockets processed in the period was 3011, or an average of 100 rockets/day over the time period. During the month of February, after the scheduled restart, 2004 rockets were processed on 16 of the 28 calendar days for an average rate of 125 rockets/day. The design goal for sustained operation is 29 rockets $/ \mathrm{hr}$ for $8 \mathrm{hrs} / \mathrm{day}$, or 232 rockets/day. Jamming of the heated discharge conveyor and feed rate limitations hindered the throughput rate during this time.

The best indication of JACADS performance is presented in Fig. G.2, which shows the average hourly processing rate for each day of rocket processing. During October 1990, JACADS achieved a peak rocket processing rate of 28 rockets/hr. The average processing rate during November and December was 17 rockets $/ \mathrm{hr}$. In February the rate increased to 23 rockets/hr. A total of $7490 \mathrm{~GB}$-filled rockets was processed during the GB campaign.

From October 1, 1990, to December 20, 1990, agent GB was burned on 19 of the 81 calendar days in the period. Figure G.3 shows the amount of agent incinerated on each day during that period of the JACADS OVT. The largest amount incinerated during a single day's processing was $5500 \mathrm{lb}$. The total amount burned over the 81-day period was 43,020 lb. During February 1991, daily operations increased and agent was burned on 13 of the 28 calendar days. Approximately $20,000 \mathrm{lb}$ of agent was destroyed at a rate of $275 \mathrm{lb} / \mathrm{hr}$. Combining the December and February totals with the amount burned during startup of the OVT (July-September) brings the total amount of agent destroyed at JACADS to approximately $75,000 \mathrm{lb}$.

Through December, the number of days during which no agent was burned resulted in part because the low rocket processing rate did not produce agent in sufficient quantities to keep the liquid incinerator (LIC) in continuous operation at its design capacity. During most of the month of November, agent was stored to allow high capacity runs in early December to support the Resource Conservation and Recovery Act trial burns for the LIC. The daily incineration rate necessary to keep pace with the deactivation furnace system (DFS) design goal of $3120 \mathrm{lb} / \mathrm{day}(390 \mathrm{lb} / \mathrm{hr})$ is indicated in Fig. G.4. The peak design goal for the LIC, established since the publication of the FPEIS, is $1050 \mathrm{lb} / \mathrm{hr}$, or $8400 \mathrm{lb} /$ day. 
G-2

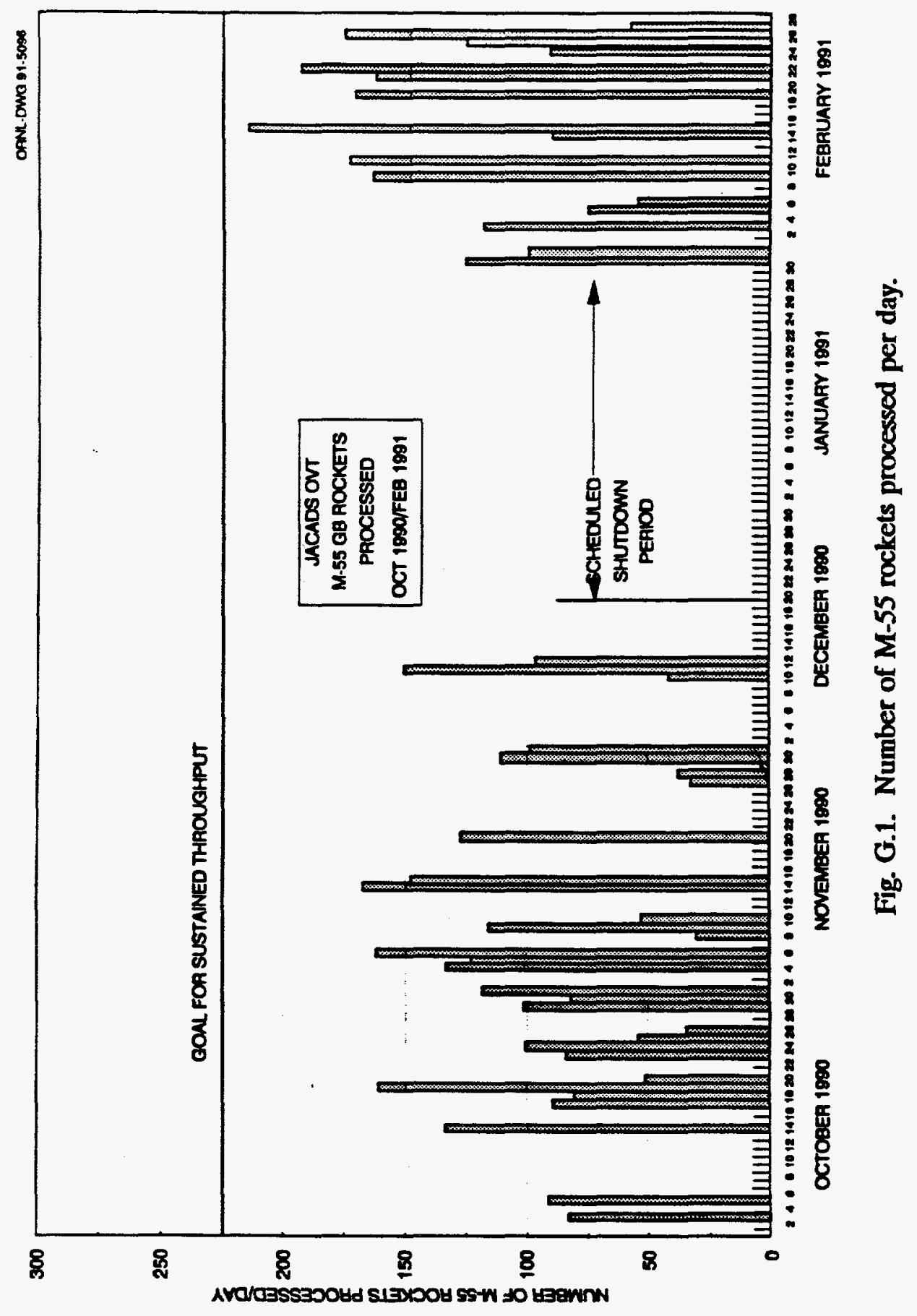


G-3

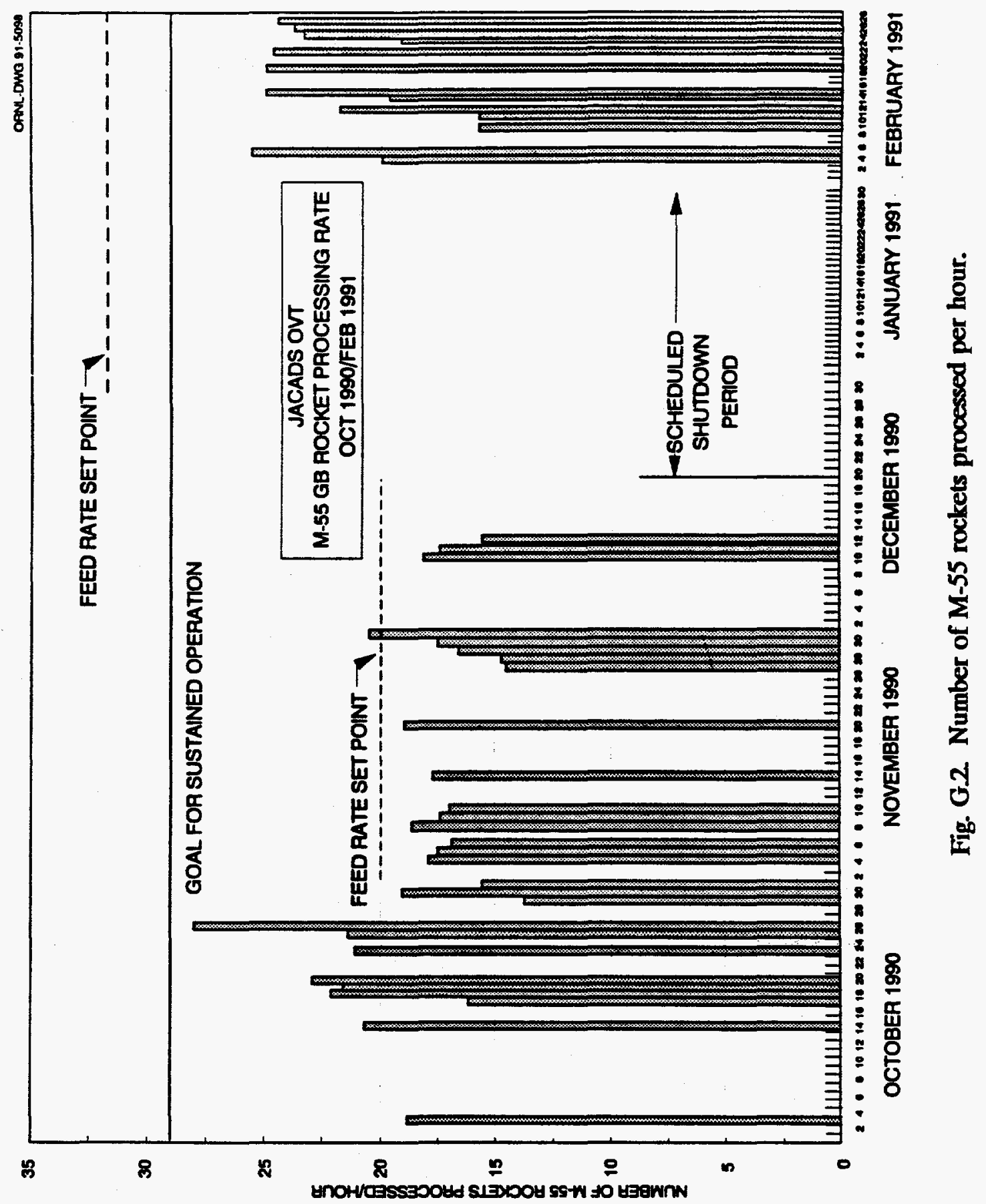


G-4

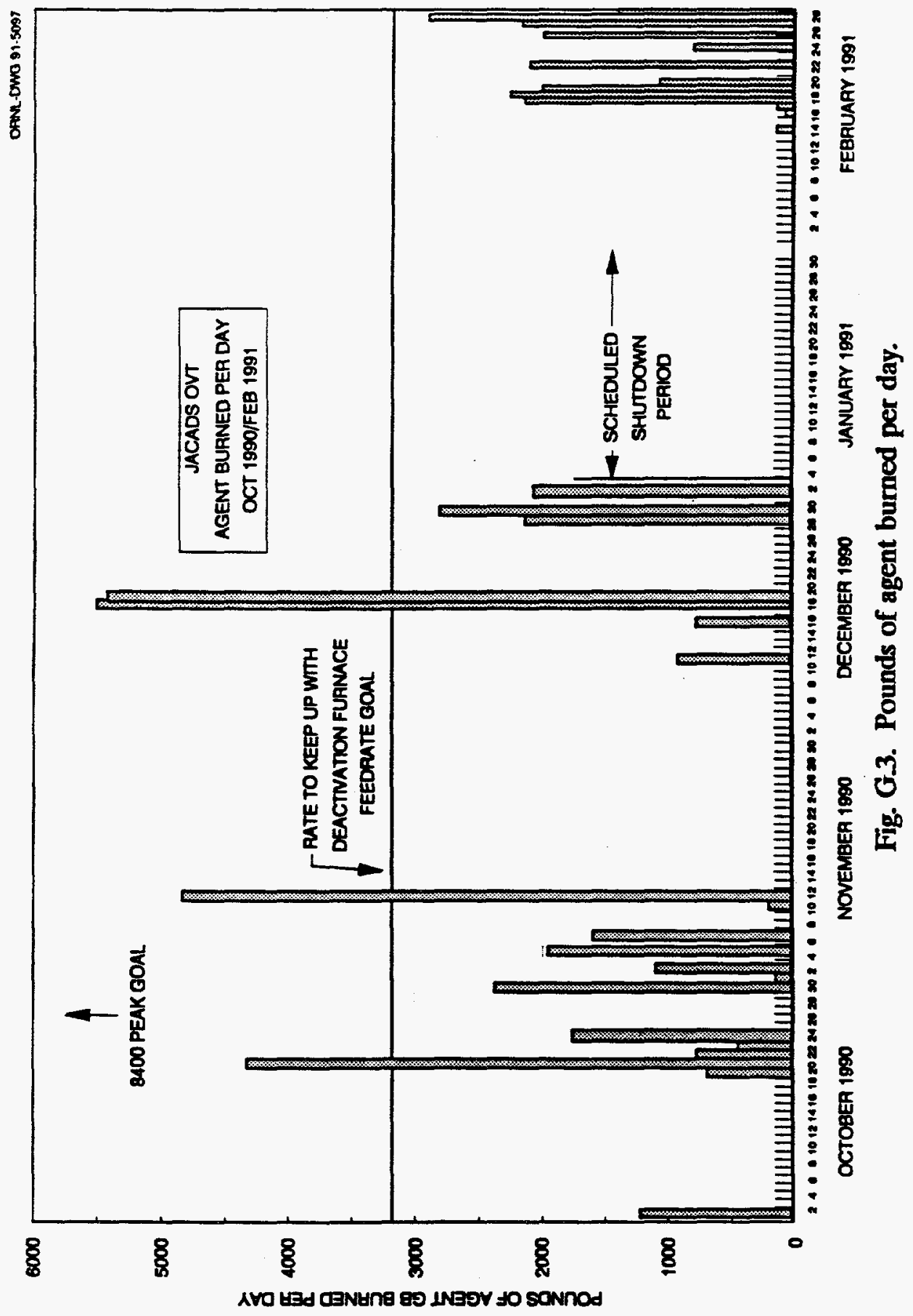




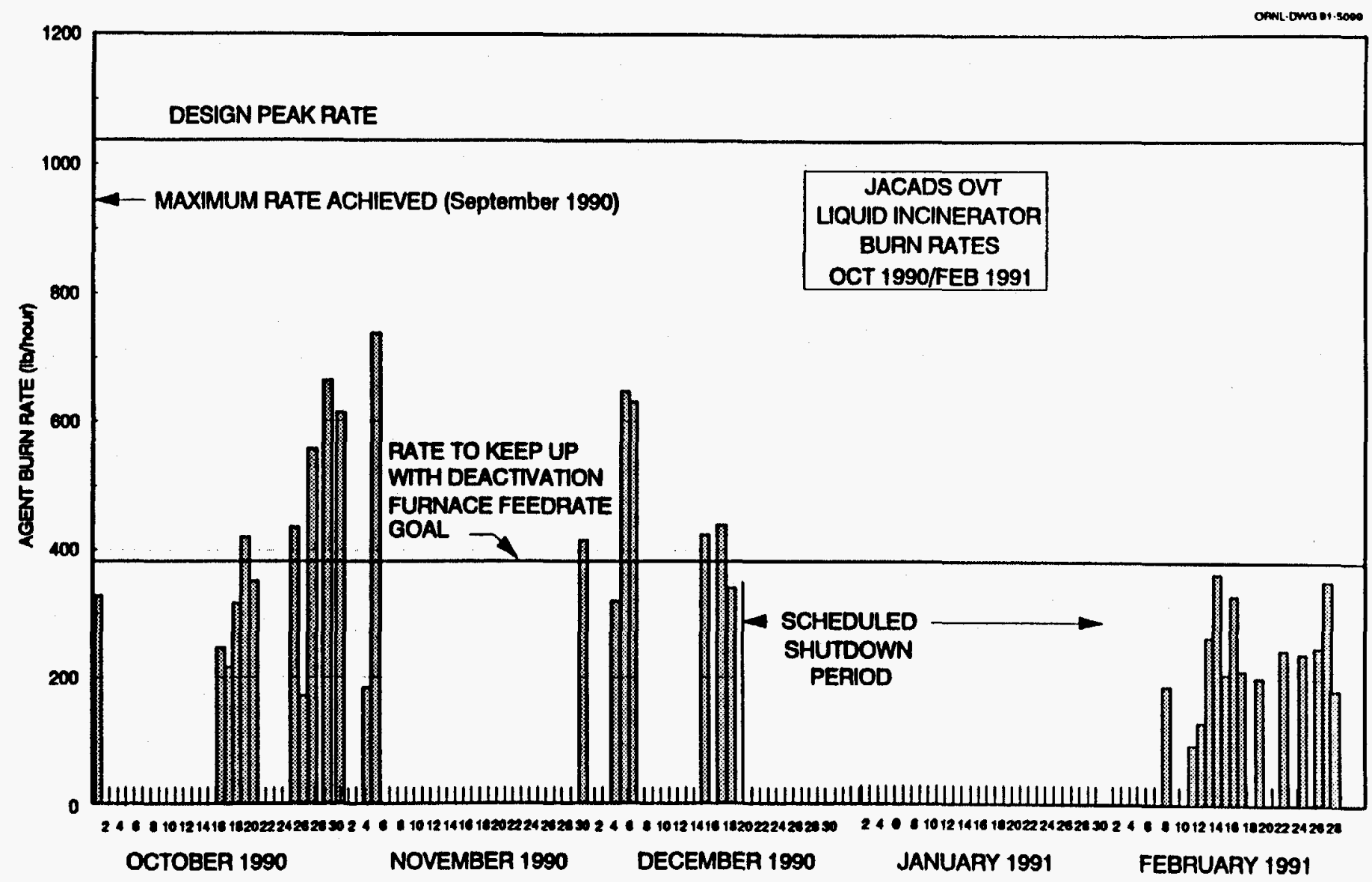

Fig. G.4. Agent burn rate (lb/hr). 


\section{G-6}

The incineration rate/hr is shown in Fig. G.4. The rates achieved during partial days of operation were generally high enough to keep pace with the DFS. The peak daily rate was $698 \mathrm{lb} / \mathrm{hr}$, which includes a 3-hr period when the rate was $950 \mathrm{lb} / \mathrm{hr}$. The maximum feed rate demonstrated was within $10 \%$ of the design peak rate. 


\section{APPENDIX H}

\section{DETAILS REGARDING THE REMOVAL OF THE U.S. CHEMICAL STOCKPILE FROM EUROPE}

\section{H.1 BACKGROUND}

At the Tokyo Economic Summit in May 1986, U.S. President Ronald Reagan and West German Chancellor Helmut Kohl agreed to the removal of U.S.-owned chemical munitions (also called the European stockpile) from the Federal Republic of Germany (FRG) (West Germany) by 1992. However, in a speech in Vienna in March 1989, U.S. Secretary of State James Baker announced that the United States would explore ways of expediting the removal of these munitions, and then established a removal goal of late 1990.

The movement of the European stockpile (Operation Retrograde) involved transport by truck, train, and ship. The loaded MILVANs were transported by truck from Clausen to a railhead at the Miesau Army Depot in Miesau, West Germany. From there, the MILVANs were shipped by rail to the port of Nordenham, West Germany. Two military sealift command ships, the SS Gopher State and SS Flickertail State, were assigned the task of moving the chemical weapons from Nordenham to Johnston Island. All munitions were unpacked and placed in storage igloos on Johnston Island by the end of December 1990.

\section{H.2 MUNITIONS CONTAINERS}

\section{H.2.1 Military Ammunition Shipping Containers (MILVANs)}

The International Maritime Organization, a United Nations organization composed of member nation representatives, sets international maritime standards and addresses international maritime issues. This organization established the International Maritime Dangerous Goods (IMDG) code, which sets safety and serviceability standards for maritime freight containers used to ship dangerous goods such as munitions. The North Atlantic Treaty Organization (NATO) has adopted safety standards affecting the use of munitions containers in host countries identical to those in the code, and West German law also requires that maritime containers used there meet these standards. Previous munitions shipments were conducted with MILVANs, in compliance with the IMDG code.

The Army planned to identify and use 600 of its best MILVANs for Operation Retrograde. However, most of the Army's MILVAN fleet did not meet minimum international safety standards. As a result, the U.S. Department of Defense (DOD) decided to repair MILVANs as needed to meet international standards, thus incurring additional costs. Six Army facilities in West Germany subsequently refurbished 315 MILVANs. 
In conjunction with the repair work to place the MILVANs in compliance with the IMDG code requirements, each MILVAN had two monitoring ports installed to allow air monitoring without the need to open the MILVAN during transit.

\section{H.2.2 Secondary Steel Containers}

During the initial operational planning stages, the munitions were originally to be packaged and transported inside MILVANs like conventional, high-explosive ammunition. Because of a remote possibility of an agent vapor leak in the event of a handling or transportation accident, a form of secondary containment was considered. The U.S. Coast Guard later indicated that compliance with Amendment 25 to the IMDG Code would be required. That amendment requires that chemical munitions transported by vessel be shipped in vapor-tight, portable steel magazines, or secondary steel containers (SSCs). An effort was therefore undertaken to design and construct an SSC.

The specifications and test requirements for the SSCs were to (1) maintain a positive internal pressure of $5.0 \mathrm{psi}( \pm 0.5 \mathrm{psi}$ ) while subjected to drop and transport tests, (2) contain either 2 pallets of 8-in. projectiles or 3 pallets of $155-\mathrm{mm}$ projectiles, and (3) permit 10 SSCs to fit inside each MILVAN. Three major series of tests were conducted on SSC prototypes: drop and transportation tests, an explosive propagation test, and a fire test. The General Accounting Office (GAO) concluded that Army testing of the SSC design was thorough and successful; the stringent fire, explosion, drop, rail impact, vertical movement, seaworthiness, and pressurization tests involving SSCs were passed.

The explosive propagation test was conducted to determine whether a single round detonating inside the SSC would initiate a mass detonation of adjacent projectiles. No mass detonations occurred during the test, and the SSC was found to reduce fragment dispersion and blast effects if a single round happened to detonate.

The fire tests were conducted to determine whether fire fighting efforts would be hindered by the imminent danger of a projectile explosion in a major fire engulfing a MILVAN. A container simulating a MILVAN loaded with SSCs and projectiles (some of which were explosively configured rounds) was suspended directly above a burning pan of diesel fuel. After $70 \mathrm{~min}$ of exposure to the engulfing fire, one of the projectiles detonated, and a second one detonated within 10 more min; however, the tests confirmed that fire fighters would have sufficient time to fight a fire before any danger of projectile detonation.

The production and funding of SSCs were more problematic. A total of 18 Army design changes, improvements, or modifications resulted in 57 production changes in Germany and various production problems, delays, and increased costs. For example, the original plans called for different materials and thicknesses of steel than were locally available in Germany. Bolts for the SSC doors were not delivered as scheduled, and the rubber gaskets intended for the doors had to be replaced. Substitute gaskets and bolts were installed until suitable ones were received. A misunderstanding between the Army and the contractor regarding door flange specifications also resulted in 1570 containers failing their acceptance tests, and many required rework because they might not have been airtight. 


\section{H.3 VESSELS USED FOR OCEAN TRANSPORT}

For the sea portion of the transfer, DOD selected two ships from the Ready Reserve Fleet and modified them to ensure crew safety, reduce the risk of an accidental release of chemical agent, and otherwise facilitate the movement of the chemical munitions to Johnston Island. DOD selected the SS Gopher State and the SS Flickertail State primarily because they (1) had self-supporting cranes that would enable them to unload their cargo at Johnston Island, (2) had sufficient cargo space below deck to accommodate the munitions and separate them by type of nerve agent, and (3) could be modified to accommodate other safety and operational equipment identified as needed for the transfer. Additional selection criteria included the ability of the required ships to (1) meet length and draft restrictions at Johnston Island, (2) be self-sustaining, and (3) meet IMDG codes.

The collective protection and containment system added to each ship was similar to that installed aboard Navy combatants; it provided a contamination-free environment for crew members and the containment of agent in the cargo holds in the event of a release. Other safety modifications included decontamination stations and upgrades to the ships' medical facilities and firefighting and damage control systems.

To monitor the cargo, the ships were equipped with three different systems for testing the atmosphere for the presence of chemical agents. These systems used special ventilation equipment, various air sampling devices, and on-board laboratories for sample analysis. The ship holds and hatch covers were modified to be airtight. Empty containers were loaded along the sides of the cargo holds, providing a buffer zone to protect the cargo in the event of a collision and to prevent the cargo from shifting during rough seas.

Operational modifications included upgraded communications equipment and facilities and the installation of fueling stations. The fueling stations enabled the two ships to refuel at sea and thus sail nonstop from Germany to Johnston Island. Their ability to stay at sea both eliminated security problems that would have accompanied the need to stop at ports en route and removed the potential for exposing densely populated areas to harmful nerve agents in the event of an accident or terrorist incident. The additional communications equipment permitted secure and nonsecure radio communication between the ships, the escort vessel, and various DOD commands in Washington, D.C., and at other locations.

Ship personnel were required to attend special training in fire fighting, damage control, chemical response, and refueling at sea. The training was specifically designed to prepare these personnel for Operation Retrograde.

Underway refueling was practiced during these tests until the crews on both ships developed proficiency at this task. However, the drills revealed design problems with the roller device installed on these ships to hoist and guide the fuel hose on deck. The rollers tended to bind and seize the fuel hose as it was being winched on deck.

\section{H.4 MONITORING}

State-of-the-art (flame photometric and gas chromatographic) monitoring equipment for detection of any chemical agent was used during all phases of Operation Retrograde activity. Detection limits of the equipment met or exceeded the Surgeon General's recommendations for an 8-hr time weighted average airborne exposure limit. In addition, 
military personnel conducted gross level monitoring with hand-held instruments during various phases of the operation.

Monitoring for chemical agent was conducted using the Automatic Chemical Agent Monitoring System (ACAMS) as the primary method and with the Depot Area Air Monitoring System (DAAMS) as the backup and confirmation method. ACAMS and DAAMS were mounted in vehicles and portable shelters to protect these laboratory-quality instruments in a field environment. For shipboard monitoring, $20-\mathrm{ft}$ sea vans were modified to house 6 ACAMS and support for continuous, 24-hr monitoring of the ships' cargo holds during ocean transit.

The monitoring conducted during Operation Retrograde included essentially the same level of detail as in the FPEIS assessment of off-site transport.

\section{H.5 SAFETY AND SECURITY}

Security throughout the entire Operation Retrograde was extensive. Security in West Germany was a joint effort between U.S. Army-Europe (USAREUR) and the West German government, involving hundreds of German police and U.S. security troops. German border and railroad police provided security for all road convoys and train movements. German harbor police provided waterborne security at the port of Nordenham. USAREUR provided custodial security for the chemical munitions at all times while in West Germany. The U.S. Army Technical Escort Unit (TEU) provided custodial security during the ocean transit. U.S. Army-Pacific troops provided custodial and physical security for all actions occurring on Johnston Island, and the U.S. Coast Guard provided waterborne security around the island during offloading operations. A U.S. Navy guided missile cruiser escorted the ships at sea. No significant security incidents occurred during the move.

The security aspects of Operation Retrograde included essentially the same level of detail as in the FPEIS assessment of off-site transportation.

\section{H.6 PUBLIC RESPONSE}

There were two occurrences of public response during Operation Retrograde movement: The first expression of concern occurred during the movement of the munitions from their storage facility near Clausen, Rheinland-Pfalz, a small community in central-western Germany near the French border, to Nordenham, a NATO military port of embarkation on the North Sea; and the second occurred during sea-borne transit of the munitions from Nordenham to Johnston Atoll. During this second occurrence, public response was manifested by concerns expressed by political leaders and stakeholder groups representing Pacific basin countries including Australia, New Zealand, Fiji, and the Marshall Islands. The state of Hawaii and a coalition of international environmental groups including Greenpeace and the Sierra Club also expressed concerns.

Within Germany, public response to stockpile movement varied by proximity to the stockpile and perceived risk of transport. At the local community level in Germany, within the towns of Clausen and Miesau (the railhead for shipment to Nordenham), there was 
considerable public support for stockpile removal. This is exemplified by rapid public endorsement of the stockpile removal plans of the government of Chancellor Helmut Kohl by Clausen's mayor and local government (Fisher 1990). It is also exemplified by open public celebration following removal of the munitions from their storage area near Clausen and along the entire autobahn route from Clausen to the railhead at Miesau Army Depot (Fisher 1990).

Along transport corridor communities between Miesau Army Depot and Nordenham, however, public displays of opposition were vocal even before transport began. Much of this opposition was orchestrated by a coalition of German environmental groups centered at the state and local level. The largest of these groups was the Freedom Coordination Group of West Pfalz, which contended that (1) stockpile transport operations were being prepared too hastily; (2) the German government had refused to permit independent studies of the operation by environmental groups or scientific researchers; and (3) emergency preparedness officials at state and local levels had been denied important information on the stockpile's size, characteristics, and plans for movement vital for drawing up adequate emergency response plans (Neth 1990a).

These contentions were mirrored by criticisms by the two principal opposition parties in the German national legislature (the Bundestag), the Social Democrats and the Green Party. These parties criticized the Kohl government for what they alleged to be a hasty decision to remove the stockpile from the Federal Republic by the end of 1990 . It was claimed that the decision to demand early removal of the stockpile by the United States was predicated on hopes of influencing the upcoming parliamentary elections in the fall of 1990 (Neth 1990a). The Greens unsuccessfully demanded that the government undertake a comparative risk analysis of the likely hazards of removing the chemical munitions, destroying them onsite at Clausen or at another incinerator facility in Germany, or continuing on-site storage at Clausen. Citing the FPEIS prepared for the continental United States (CONUS) stockpile, members of the Green Party demanded that the government explain why it was considered too risky to transport chemical munitions off-site in the United States but not in Germany (Neth 1990a).

When legislative efforts to overturn or delay the Kohl government's plans failed, German environmental groups took legal actions through the German court system to halt the retrograde movement of the stockpile (U.S. Army 1991; Removal of Chemical Agents 1989). Under German law, litigants must demonstrate that the government ignored compelling information necessary for rendering a policy decision. German courts upheld the legality of stockpile movement by charging that environmental litigants had not demonstrated that the government failed to take all necessary precautions to minimize mishap (Todt 1990).

Before and during stockpile transit from Clausen to Nordenham, a 24-hr telephone hotline was jointly established by the U.S. Army European Command (USAREUR) and German officials. The purpose of this hotline was to serve as a public affairs link between the military and the public, providing an information center to respond to questions about the chemical stockpile movement.

During sea-borne transit, public response to the retrograde movement of the stockpile was manifested by statements of national political leaders and interest groups representing Pacific Basin states. The Pacific Island Forum, a group comprising leaders from 15 South Pacific countries, expressed opposition to shipments of additional chemical munitions from outside the Pacific Basin region. However, Forum members generally supported destruction 
of those munitions currently stored at Johnston Atoll or that might be found in the Solomon or Marshall Islands ("Forum Head Criticizes" 1990).

Forum opposition to additional shipments and, in some cases, to destruction of munitions already based at Johnston Atoll centered on six issues: (1) lack of absolute assurance that chemical disposal through incineration would be safe, (2) resentment over the destruction of munitions in an area considered by these countries to be their backyard, (3) lack of high-level diplomatic consultation between U.S. leaders and the leaders of Pacific Basin states prior to the shipment of the German stockpile, (4) indifference toward the environmental concerns of predominantly nonwhite residents of Basin countries, (5) long-simmering distrust between many Pacific Forum member-states and industrialized countries (including the United States, over unrelated but important environmental issues such as the cleanup of radioactive contamination from French underground nuclear tests at Muraroa Atoll) and alleged Bush administration indifference to the possible impacts of global warming on their countries, and (6) fear that the JACADS facility might become a permanent toxic substances incinerator ("Forum Head Criticizes" 1990; Borg 1990a; Borg 1990b; Borg 1990c).

The latter view was associated with Walter Lini, the Prime Minister of Vanuatu, and Governor Waihee of Hawaii. The latter expressed his concern to the U.S. Secretary of Defense in the fall of 1990 (Waihee 1990; DoD OKs 1990). Hawaiian opposition to this option was also expressed to Senator Daniel Inouye at a series of public hearings. Inouye expressed the view that if Hawaiians were against future use of the JACADS facility, he too would be against it (Kresnak 1990).

The most serious charge of the Forum, indifference to the nonwhite population of the region, was expressed by Forum Secretary-General Henry Naisili who charged that a region inhabited largely by nonwhite people was singled out for the disposal of chemical munitions developed by white people and formerly stored in white-inhabited countries. He further claimed that the United States was treating Pacific islanders as "coconuts and guava" ("Forum Head Criticizes" 1990; Borg 1990b).

After several months of debate in the fall of 1990 , members of the Pacific Basin Forum endorsed the plan to incinerate chemical munitions already at the JACADS facility, although they continued to express concern about the effects of chemical agent releases on fish stocks in the event of an accident and remained opposed to further shipments.

Pivotal to the endorsement of incineration was the release of Australian scientific reports endorsing the method, U.S. permission granting Australia and other Pacific Basin states the right to send their own scientific missions to JACADS, and the view that destruction of the Johnston Atoll stockpile would contribute symbolically to world disarmament-a view that tended to divide some environmental groups and arms control proponents (Pekol 1990; Voisey 1990; Shulman 1990). Another compelling reason was evidence that because of the degree of corrosion of munitions stored at Johnston Atoll, their removal to the continental United States would pose greater environmental risks to the region than would destroying them at the JACADS facility. This position was endorsed by Micronesia and Western Samoa (Borg 1990b).

Finally, the U.S. Secretary of Defense offered the Forum the opportunity to suggest "what further steps the United States could take to address remaining concerns," and promised that, in the future, members would be consulted about JACADS (Hunt 1990). 
Paralleling the activities of the Pacific Basin Forum, a coalition of internationally representative environmental organizations including Greenpeace, the Sierra Club, the Institute for the Advancement of Hawaiian Affairs, and the Hawaiian chapter of the World Council of Indigenous Peoples filed suit to halt the shipment of the German stockpile to Johnston Atoll beginning on August 1,1990. This coalition based its litigation upon the claim that movement of the stockpile, and its incineration at the JACADS facility, violated the U.S. National Environmental Policy Act (NEPA) of 1970. It also alleged that the U.S. Secretary of Defense's claims that the JACADS facility would not become a permanent toxic incinerator were untrue and that chemical munitions from Aberdeen Proving Ground in Maryland would eventually be shipped to JACADS (DOD OKs 1990).

A federal district judge for the 9th U.S. Circuit, San Francisco, California, rejected the coalition's suit and refused to grant a temporary delay of the stockpile's transit, on October 8, 1990 (U.S. Army 1991). Five reasons were given for the decision: (1) the litigants had failed to demonstrate that the Army had not complied with NEPA; (2) there were greater environmental and health and safety risks associated with halting the movement of the chemical munitions stockpile once in transit; (3) United States environmental law was not applicable in Germany, especially since German courts had already upheld the legality of movement; (4) an injunction would interrupt a carefully timed operation and demonstrably endanger German welfare; and (5) an injunction would interfere with a duly enacted foreign policy decision, made by the President and concurred in by Congress, that required transoceanic movement to fulfill a legal objective (Judge Clears Way, Sept. 8, 1990; Todt 1990; Order Denying 1990). This decision was upheld by a federal appeals court.

On October 28, 1990, a few weeks before the arrival of the German stockpile at JACADS, President Bush pledged that the JACADS facility would be used only for destruction of existing stocks, those from Germany, and any others discovered in the Pacific Basin (Hunt 1990). Bush also promised that there would be no future use of JACADS for toxic materials destruction (Borg 1990c). Pub. L. 99-145 also requires the dismantling and decommissioning of each of the eight CONUS disposal facilities at the end of the disposal program.

The level of public opposition to Operation Retrograde was somewhat unanticipated. This topic was not included in the FPEIS assessment of off-site transportation.

\section{H.7 INSTITUTIONAL FACTORS}

The movement of the German stockpile required an extensive consultation and coordination process between the governments of two countries, four German states or "Länder" (Rheinland-Pfalz, Nordrein-Westfalen, Niedersachsen, and Bremen), and among many components of the armed forces of the United States and Germany.

German federalism complicated regulatory compliance and coordination of political jurisdictions for two reasons. First, under German environmental law, the federal government must clearly elucidate the risks of any federally mandated decision that could affect the health or welfare of individual states. This requires full and complete disclosure of risk-related information (Mangun 1988; Miller 1989). Second, implementation of environmental laws, particularly those regulating hazardous waste disposal or transport, is 
delegated primarily to state governments (Mangun 1988; Miller 1989; OECD 1980; "Removal of Chemical Agents" 1989).

In addition, the desire to ensure compliance with international law was an important constraint on container design and stockpile movement and was an additional institutional factor affecting stockpile movement. In particular, concern was expressed that stockpile destruction could violate the 1972 London Dumping Convention, which prohibits deliberate disposal of wastes in an environmentally unsafe manner and the IMDG code (Caldwell 1984; Borg 1990a; GAO 1991).

Many U.S. government agencies participated in Operation Retrograde. The U.S. Army served as DOD's primary executive agent for planning the move and established the Chemical Retrograde Task Force to coordinate the move. Headquarters, USAREUR, planned and implemented the move in Germany, and the U.S. Army Western Command (now renamed the U.S. Army Pacific Command) planned and managed the activities on Johnston Island. The U.S. Navy's Military Sealift Command coordinated the sealift phase of Operation Retrograde and worked with the U.S. Department of Transportation's Maritime Administration to activate and modify the two Ready Reserve Fleet ships used for the mission. In addition, the U.S. Army's Armament, Munitions and Chemical Command designed the SSCs; the Military Traffic Management Command provided and repaired the MILVANs; the Naval Surface Weapons Center designed personnel protection systems on board the ships; and the U.S. Army's Chemical Research, Development and Engineering Center designed chemical agent monitoring systems. Naval escort was provided for the ships by the U.S. Navy's Atlantic and Pacific Commands.

To coordinate U.S. Army planning efforts associated with the European stockpile movement from Germany, a Chemical Retrograde Task Force was established in July 1989. In September 1989, an Interagency Task Force composed of representatives from DOD specialized in inter-service coordination issues and international regulatory compliance was also formed (U.S. Army 1991). This task force participated in worldwide coordination meetings and served as staff advisers to U.S.-German bilateral planning discussions. These latter discussions began on a rudimentary level in May 1986, following agreement between President Reagan and Chancellor Kohl to remove the chemical munitions stockpile by 1992 . They were conducted with greater frequency beginning in March 1989, when the removal timetable was accelerated.

The U.S. Army Western Command (renamed the Pacific Command) was charged with planning and managing the movement phase from Germany to Johnston Atoll. The U.S. Navy's Military Sealift Command, working with the Federal Maritime Administration, activated two Ready Reserve Fleet ships (the SS Flickertail State and the SS Gopher State), and coordinated the sealift phase from Nordenham to Johnston Atoll in cooperation with the Army Western Command (GAO 1991).

A similar coordination process took place within the FRG. The Federal Security Council, analogous to the U.S. National Security Council, organized a multiministry coordination program through a special memorandum of understanding among agencies with jurisdiction over health, safety, environmental protection, and transportation concerns (Naumann and Kreibohm 1990; U.S. Army 1991). It was agreed by all members of this coordination program (the IMK-CM), that German laws would be the basis for all measures for chemical munitions removal and that transport of the munitions within Germany would 
comply with all German Federal Republic laws pertaining to hazardous materials transport. The U.S. Army concurred fully with this recommendation.

In compliance with Executive Order 12114, a global commons environmental assessment was undertaken in support of the ocean movement from Nordenham to Johnston Atoll. The assessment concluded that movement of the stockpile would pose no significant impact to the global commons and a finding of no significant impact subsequently was issued to that effect. The conclusions of the global commons assessment were used as planning guidance to select optimal transport routes that would minimize passage through areas most vulnerable to chemical spills in the unlikely event of an accident (U.S. Army 1990c).

\section{H.8 COMMAND, CONTROL, AND SECURITY}

Movement of the chemical munitions from Clausen to the railhead at Miesau Army Depot $50 \mathrm{~km}$ ( 31 miles) away, and then to Nordenham by rail, was under the joint command of U.S. and German forces. Actual movement of the stockpile was under the direction of the security forces of the FRG. The U.S. Army's TEU, under the command of the 59th Ordnance Brigade, was responsible for maintaining custody of the munitions themselves in all holding areas, in the truck convoys, on trains, and within the port of Nordenham (Fowler 1991).

U.S. and German armed forces units were integrated to ensure effective command and control of every phase of Operation Retrograde. The U.S. Army TEU established operations centers at Nordenham (the terminus of the rail movement) and at Pirmasens, the headquarters for the 59th Ordnance Brigade responsible for munitions custody (approximately $50 \mathrm{~km}$ from Clausen). The Nordenham forward command post was set up 1 week before rail movement began from Miesau Army Depot.

While security was coordinated by U.S. and German armed forces, direct security forces were provided by the American TEU, as noted above; German federal military police; state and local police detachments; and special federal tactical police. The retrograde movement phase from Clausen to Nordenham involved more than 10,000 German police from four states (Fowler 1991). State police performed several security duties, including hazards identification and correction before stockpile movement and prevention, prosecution, and investigation of threatened criminal acts against stockpile movement. The day stockpile movement began, one bomb threat, which proved to be a hoax, was telephoned to police.

German security measures were begun in earnest in May 1989. The interministerial coordination program (see Sect. 4.2.2.2) developed a comprehensive safety plan for movement of the stockpile, ranging from special training of state police units in traffic safety for hazardous cargos to manpower plans, including leave and vacation cancellation (Ludwig 1990). The state of Rheinland-Pfaltz was granted special responsibility for basic security matters such as traffic and crowd control (Naumann and Kreibohm 1990). No aerial combat training was permitted during convoy movement operations to Miesau. All nonessential low-level military and civilian flights around Clausen and Miesau were canceled except for search-and-rescue operations (Fowler 1991). Rheinland-Pfalz and other state police provided the outer security ring for the entire mission, standing guard at rail and road crossings and flying helicopters over the truck and train convoys (Davidson 1990). 
Prior to daily truck convoy movement from Clausen to Miesau Army Depot, Rheinland-Pfalz police selected the actual routes. These routes were not announced to the public until the day of the movement (Ludwig 1990). More than 1200 police officers were on duty in Rheinland-Pfalz each day during the movement. In the communities of Clausen and Miesau, leaflets were distributed to all residents by the police asking citizens to understand the necessity for temporary traffic delays.

Only one security concern arose before the movement. A GAO investigation declared that the sea-leg portion of the planned movement provided insufficient defense against potential heliborne terrorist attack. Despite GAO suggestions that ship security forces improve their ability to defend, DOD relied almost entirely upon the defensive capabilities of escort vessels (missile-launching cruisers) that accompanied the two transport vessels. There were no significant security incidents at sea (GAO 1991).

The level of detail about command, control, and security for Operation Retrograde is essentially identical to that included in the FPEIS assessment of off-site transportation.

\section{H.9 EMERGENCY PREPAREDNESS}

Emergency preparedness measures for Operation Retrograde were established in parallel to security measures. These measures consisted of three components: (1) special training programs for emergency medical, communications, and other personnel prior to chemical munitions stockpile movement; (2) preparation of hospitals and other emergency medical facilities along transport routes to ensure they would be able to treat chemical-accident victims; and (3) the holding of a series of quarterly emergency exercises by members of the operation's designated Emergency Response Team to ensure readiness and certification.

U.S. and German military and civilian hospitals were prepared to receive casualties through provision of chemical agent antidote stores (atropine), special isolation wards, and specialized emergency medical training. All major medical facilities along transport routes were fully equipped to deal with casualties (Fowler 1991). U.S. military air-evacuation helicopters were prepositioned along the route to expedite transfer of casualties in the event of an accident (Fowler 1991).

U.S. personnel from the 763rd Medical Detachment, 3rd Ordnance Battalion, and 7th Medical Command received specialized training in handling patients exposed to chemical agent (Fowler 1991). Each medical team prepositioned along the transport route carried atropine. These medical teams were located at each site where munitions were stored or handled. Additional medical personnel accompanied munitions convoys around the clock.

Finally, special U.S. Army chemical decontamination teams from the 98th Chemical Detachment, 84th Ordnance Battalion, as well as six U.S. Chemical Emergency Response Squads equipped with special protective gear, were deployed along the transport route to mop up spills and respond to accidents (Fowler 1991).

The emergency response measures incorporated into Operation Retrograde were essentially identical to those included in the FPEIS assessment of off-site transportation. 
H-11

\section{H.10 LOGISTICS}

An elaborate, extensive joint effort among U.S. and FRG officials was required to coordinate all facets of the transport of the German chemical munitions stockpile to Johnston Atoll. This effort required the preparation of munitions for transport, the procurement of SSCs from both German and American sources (since there were insufficient SSCs available to U.S. forces in Europe), the repair or refitting of existing SSCs to ensure their compliance with international standards (see Sect. H.3.2), and the selection of transportation routes and equipment.

Original SSC procurement plans called for different materials and thicknesses of steel than were, at first, locally available in Germany. There were also problems getting the German contractor to produce SSCs when DOD exhausted funds for this purpose in April 1990. Production resumed in May 1990, when the FRG government agreed to fund completion of the work.

In early 1990 , it was determined that at least $80 \%$ of the 4200 Army munition MILVANs available for Operation Retrograde had structural defects or inadequate repairs that prevented them from meeting international standards. Subsequent to a GAO recommendation for enhanced roof inspection and other operational changes, the Army amended its inspection procedures in February 1990 to ensure that all MILVANs used for the movement would meet international standards. Six U.S. Army facilities in Germany refurbished 315 retrograde MILVANs.

Electric forklifts were used to remove munitions from their facility near Clausen. This operation was performed by the 330th Ordnance Company, 3rd Ordnance Battalion, 59th Ordnance Brigade, and was assisted by German and U.S. civilian chemical experts. The munitions were stored temporarily in holding areas at Clausen and guarded by the 110th Military Police Company until they were loaded onto truck convoys. At every phase of this operation, U.S. and German munition surveillance experts monitored the outloading (Fowler 1991).

The stockpile was moved from Clausen via a series of autobahns and medium grade secondary routes to the railhead at Miesau Army Depot by 30 truck convoys between July 26 and Sept. 1, 1990. Each convoy had more than 80 U.S. Army, German Army, and German police vehicles. Fewer than one-third carried chemical munitions; the remainder carried security and emergency response personnel The convoy proceeded at an average speed of 29 $\mathrm{km} / \mathrm{hr}(18 \mathrm{mph})$, less than the maximum contemplated by the FPEIS for CONUS stockpile movement (Fowler 1991). The 50-km (31-mile) movement from Clausen to the Miesau Army Depot took almost $2 \mathrm{hr}$.

The convoys were driven by American drivers who received advanced training in the United States and Germany on German traffic laws and European equipment, truck maintenance, and safety and reaction procedures for handling hazardous materials (Fowler 1991). All military and civilian convoy personnel were carefully screened. If they had experienced disciplinary action or had been involved in a questionable incident such as a traffic accident, they were not allowed to participate in the operation (Fowler 1991).

Train loading and final preparations required 11 days. Movement of munitions by train from Miesau to Nordenham then took place between Sept. 12 and 19, 1990. Efforts to ship the chemical munitions stockpile on high grade track through areas designed to minimize 
population exposure in the event of mishap were constrained by population density and track availability.

There were only two rail freight routes from Miesau Army Depot to Nordenham. Both passed close to the Ruhr valley, one of the most densely populated regions in Europe. The railhead at Miesau underwent minor upgrades before the movement. These consisted of a rail switch repair in June 1990 and an upgrade of track (Denniston 1990). In addition, the holding area adjacent to the railhead was given a $12,000 \mathrm{~m}^{2}$ asphalt hardstand, security fences, lighting, and lightning protection (Fowler 1991).

At Nordenham, the loaded MILVANs were transferred to the two transport vessels by the MIDGARD Company. The U.S. Army fully indemnified MIDGARD against liability (Naumann and Kreibohm 1990). Ship berthing required a few port facility upgrades and special operational measurers at Nordenham. For example, ship loading was conducted only during daylight hours.

After the MILVANs were loaded onto the transport vessels, the ships departed Germany on September 22. There was a 2-day delay because of inclement weather in the North Sea (Fowler 1991). The vessels arrived at Johnston Atoll on November 6, 1990.

\section{H.11 COST AND SCHEDULE}

According to the GAO, the costs for Operation Retrograde totaled \$53 million, which is $\$ 11$ million higher (about $25 \%$ higher) than originally budgeted. This total does not include at least an additional $\$ 7.2$ million paid by the German government and $\$ 1.4$ million paid by DOD for container production and repair costs that were not charged to Operation Retrograde.

DOD repaired many shipping containers to meet the standards of the United Nations, NATO, and West Germany. Difficulties in manufacturing and repairing the steel shipping containers needed to transport the munitions both increased overall costs and threatened to jeopardize the mission schedule.

The SSCs were designed by the U.S. Army Defense Ammunition Center and School at Savannah, Illinois, but were manufactured by a U.S. government-owned German contractor operation at the U.S. Mainz Army Depot in Mainz, West Germany. The Army contracted for the production of 5680 containers for a total cost of about $\$ 6.7$ million. DOD, in producing the SSC, encountered several problems that increased costs by at least $\$ 7.2$ million and threatened to jeopardize the mission schedule until the West German government agreed to pay these costs. An additional \$1.4 million was required to repair MILVANs so they would meet minimum international safety and serviceability standards.

DOD and the Maritime Administration activated and modified the two ships used in the operation. Congressional funding restrictions prevented the Maritime Administration from awarding the ships' activation contracts according to plan and contributed to compressed shipyard work schedules. This and unanticipated maintenance and repairs to the ships' engines, hardware, and other mechanical equipment resulted in increased costs. Despite funding problems and various shipyard delays, shipyard modifications and other preparations were essentially completed in time for the ships' operational tests in mid-August 1990. 
$\mathrm{H}-13$

\section{H.12 REFERENCES}

Borg, J. 1990a. "Chemical Weapons Burning Plan Draws Fire," Honolulu Advertiser, A-3 March 20.

Borg, J. 1990b. "Waihee: Pacific Summit Planned too Hastily," The Honolulu Advertiser, A-5 Oct. 27.

Borg, J. 1990c. "Bush Gives Pacific Isles Assurances on Johnston," Honolulu Sunday Star-Bulletin and Advertiser, A-1, A-10 Oct. 28.

Caldwell, L. K. 1984. International Environmental Policy: Emergence and Dimensions, Duke University Press, Durham, N. C.

Davidson, P. 1990. "Security Tight for Transfer of Shells," Stars and Stripes, 1 July 6.

Deniston, J. 1990. "Technical Escort Unit Paves Way; Ensures Safety for Historic Removal," 59th Courier, 5.

"DOD OKs FRG Gas to JACADS" Aug. 1, 1990. The Washington Pacific Report 8 (21), 1-3.

Fisher, M. July 27, 1990. "U.S. Starts Pullout of Chemical Arms," Washington Post, A-1.

"Forum Head Criticizes U.S. Incineration Plans" Sept. 7, 1990. Associated Press.

Fowler, D. March-April 1991. "Removing Chemical Weapons From Europe," Army Logistician: Professional Bulletin of United States Army Logistics, 36-39.

GAO (U.S. General Accounting Office) February 1991. Chemical Warfare: DOD's Successful Effort to Remove U.S. Chemical Weapons from Germany, GAO/NSIAD-91105, report to congressional requesters prepared by U.S. General Accounting Office, Washington, D.C.

Hunt, T. Oct. 28, 1990. "Bush: U.S. Not Looking for War, But it Won't Back Down," Associated Press.

"Judge Clears Way for Chemical Weapons Shipment to Johnston Atoll" Sept. 8, 1990. Associated Press.

Kresnak, W. Aug. 17, 1990. "Inouye Meets Johnston Isle Protesters," The Honolulu Advertiser, 1.

Ludwig, H. P. Mar. 8, 1990. Briefing, Assistant Secretary, Ministry of the Interior and Sports, Rheinland-Pfalz, Pirmasens, Germany.

Mangun, W. R. 1988. "A Comparative Analysis of Hazardous Waste Management Policy in Western Europe," pp. 205-222 in Dimensions of Hazardous Waste Politics and Policy, eds. C. E. Davis and J. P. Lester, Contributions in Political Science No. 200, Greenwood Press, New York.

Miller, L. 1989. "Environmental Policy: Federal Republic of Germany," pp. 207-234 in International Public Policy Sourcebook, Vol. 2, Education and Environment, ed. F. N. Bolotin, Greenwood Press, Westport, Conn.

Naumann, K., and Kreibohm, G. Mar. 8, 1990. Summary of Federal Republic of Germany Remarks for Media Day, Pirmasens, Germany.

Neth, M. 1990a. "Secrecy Worries West German Groups," Stars and Stripes 9, July 6.

Neth, M. 1990b. "Calm Residents of Clausen Took Convoy in Stride," Stars and Stripes 3, July 27. 
OECD (Organization for Economic Cooperation and Development) 1980. "Developments in Siting Procedures and Policies in the Federal Republic of Germany," in Siting Procedures for Major Energy Facilities: Some National Cases, Paris, France.

"Order Denying Plaintiff's Motion for Preliminary Injunction" 1990. Greenpeace USA vs. Michael P. Stone, U.S. District Court for the District of Hawaii, Civil No. 90-00588, Sept. 7.

Pekol, S. 1990. "Forum Alarmed by Weapons Dump," Brisbane Courier-Mail, Australia, Aug. 2.

"Removal of Chemical Agents" 1989. Der Spiegel, 58-63, Dec. 25.

"Removal of Nerve Gas Scheduled" 1990. Stars and Stripes, 1, 24, Mar. 8.

Shulman, S. 1990 . "Bombs Burning in the Pacific," Technology Review, 18-20, October.

Todt, R. 1990. "Judge Refuses to Block Shipments of Chemical Weapons," United Press International, Sept. 8.

U.S. Army 1990. Global Commons Environmental Assessment and Finding of No Significant Impact (FONSI) for the German Retrograde Program, Office of the Assistant Secretary of the Army, Chemical Demilitarization Agency, Washington, D.C., April 30.

U.S. Army 1991. After Action Report for the Retrograde of Unitary Chemical Munitions from the Federal Republic of Germany, prepared by the Chemical Retrograde Task Force, Office of the Deputy Chief of Staff for Operations and Plans, Washington, D.C.

Voisey, M. 1990. "Seminar Backs Johnston Atoll," Brisbane Courier-Mail, Australia, Nov. 14.

Waihee, Governor J. (Hawaii), 1990. Correspondence to Dick Cheney, Secretary of Defense, Aug. 13. 


\section{APPENDIX I \\ EXAMINATION OF ON-SITE METEOROLOGICAL DATA}

Quality assurance of meteorological data is essential for making reliable estimates of pollutant concentrations that would result from a proposed action, and also for making the kinds of generalizations about weather and climate that are necessary for planning decisions. The location nearest PUDA that provides meteorological data of known quality is the Pueblo Memorial Airport, about $16 \mathrm{~km}$ (10 miles) to the west-southwest of the proposed disposal site. Airport data are constantly used by pilots and are therefore continually scrutinized for accuracy. Given the general patterns of land use and terrain in the area, the Pueblo Memorial Airport is close enough to the proposed disposal site that the data are representative of PUDA for purposes of determining large-scale features such as annual frequencies of stability and wind velocity classes.

However, on-site data are taken closer to the location of the proposed action and may therefore reflect more precisely the influences of local land use and terrain on meteorological variables. In general, on-site measurements are preferable unless the data are inaccurate or inadequate (e.g., a large percentage of the observations are missing). Instrument malfunctions often go undetected and uncorrected for long periods of time if data are not checked regularly and/or the instruments are not checked and calibrated every few months (e.g., quarterly or semi-annually).

Therefore, on-site data are examined for obvious inaccuracies or large gaps and, if the data are inaccurate or inadequate, then data from the next nearest measurement site (Pueblo Memorial Airport) are considered. Because the on-site data are sufficiently complete, the following material will focus on the examination of the data for accuracy.

\section{I.1 METEOROLOGICAL RECORDS FOR PUDA}

The meteorological instrument tower at PUDA is located in the northwest corner of the depot, about $5 \mathrm{~km}$ ( 3 miles) west of the proposed disposal site. Records of inspection, calibration, and maintenance were obtained on October 26, 1992. The records contain a few purchase orders and receipt records for parts (received under limited technical inspection), and some (bench) calibration records by White Sands Missile Range (WSMR) Atmospheric Sciences Laboratory. The WSMR records indicate results of their wind tunnel testing of the instruments and indicate nothing about the performance of the instruments as mounted at PUDA. No records have been received documenting that the instruments at PUDA were ever calibrated in situ or subjected to routine inspection and maintenance.

Signed and dated comments included in the hard-copy data strongly indicate that the meteorological instruments need to be secured and that calibration and maintenance need to be 
assured. These comments are suggestive of serious problems with data collection throughout the period of record. Some typical examples of these comments are given below.

Note dated 4/22/91:

"As of this date of 4/22/91, this MET SITE equipment is secured from all other persons access but the ENVIRONMENTAL OFFICE!

The equipment in its entirity (sic) is off limits to any AMMO and/or INFTCO personnel.

Agreed to this date by INF-TCO.

New locks applied \& keys in our custody only."

Another note, dated May 21, 1991 reads as follows:

"Due to circumstances beyond our control - recordings were not made for JDT 128-136, 7 MAY THRU 15 MAY.

Steps have been taken to secure the area computer from intrusions by those not authorized to use it.

Available records suggest that the instruments were not subject to routine calibration and maintenance procedures at the PUDA site, and were probably subject to some vandalism. This in no way reflects on the quality of the calibration of instruments as sent from the Atmospheric Sciences Laboratory at WSMR.

\section{I.2 ANALYSIS OF WIND DATA}

Wind speed and direction at PUDA are measured at 2 meters and 10 meters above ground level. Wind speed generally increases with height above ground, so the PUDA data were adjusted to represent winds at 6.7 meters, for comparison with data from Pueblo Memorial Airport which are taken at that height. Each hourly wind speed adjustment was made using the appropriate formula for the stability category recorded for the same hour (EPA, 1987). The resulting frequency distribution of wind speed for the on-site data is shown as the dashed line in Fig. I.1. The open circles represent wind data from $1990,{ }^{1}$ the dark circles represent data from 1991, and the dashed line represents the two-year sample. These wind speed distributions may be compared with that of the airport data which is shown as a solid line. Because of differences in instrument exposures (the on-site anemometers are

\footnotetext{
${ }^{1}$ The data for the last 3 months of 1990 were missing. The so-called 1990 data are actually comprised of the last 3 months of 1989 and the first 9 months of 1990.
} 


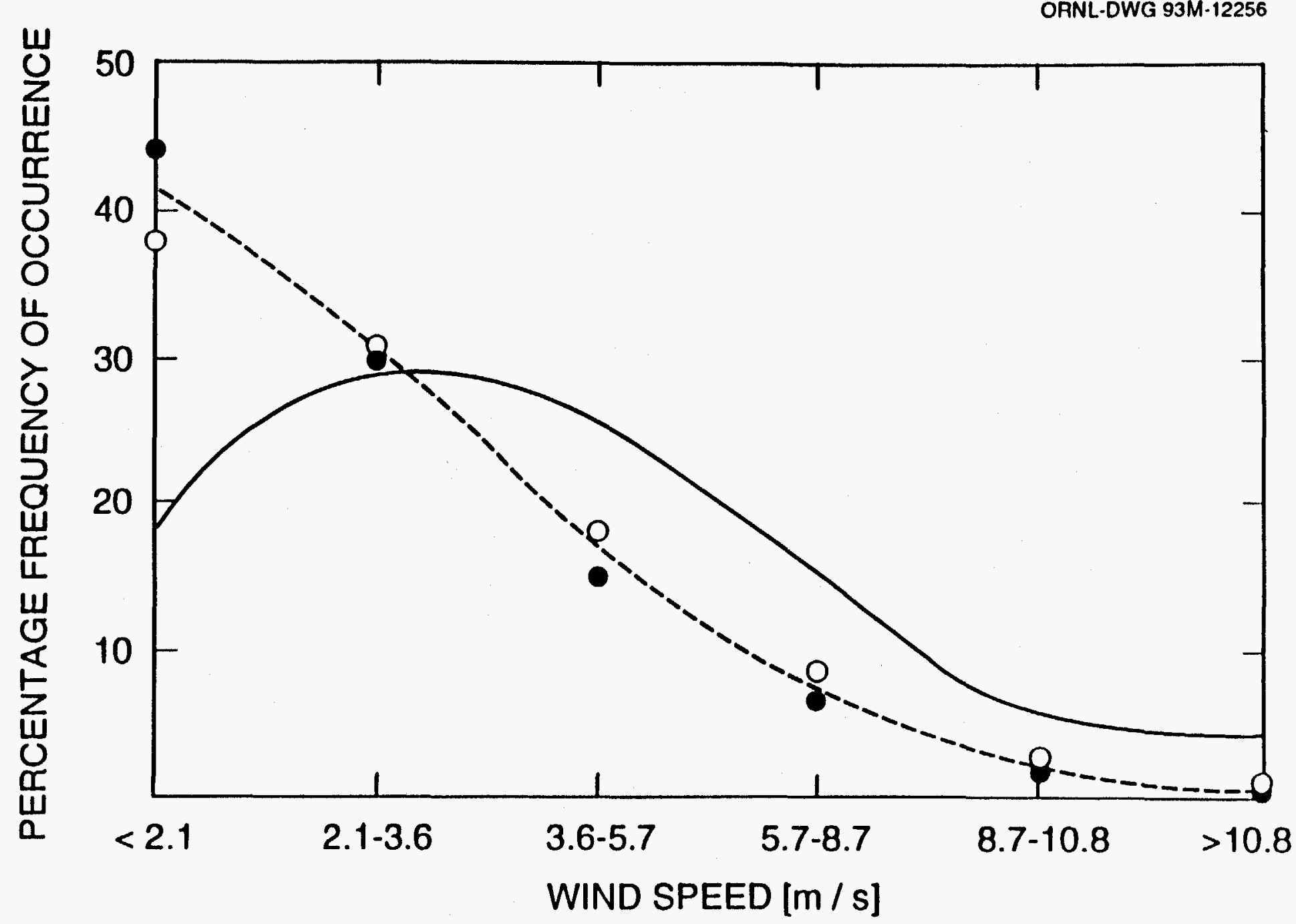

Fig. I.1. Distribution of wind speeds obtained from the anemometer 10 meters above ground level at PUDA (dashed line) and the anemometer 6.7 meters above ground level at the Pueblo Memorial Airport (solid line). The open circles represent PUDA wind data from October 1989 through September 1990, the dark circles represent PUDA data from 1991, and the dashed line represents the two-year sample at PUDA. The PUDA wind speeds were adjusted to represent winds at 6.7 meters, for comparison with the airport data. 
located in a slightly less exposed location), the on-site data would be expected to show slightly slower wind speeds in general (lower frequencies of the high wind speed classes and higher frequencies of the low wind speed classes). However, the on-site distribution of wind-speed frequencies would be expected to be of the same general shape as that of the airport data. That is, it would be expected to have the highest frequency in the $2.1-3.6 \mathrm{~m} / \mathrm{s}$ category. Instead, the highest frequencies for the on-site data are in the lowest wind speed category, suggesting a sluggish instrument. Such a condition is often due to a problem with sluggish or "frozen" bearings. Problems of this kind tend to occur when instruments are not inspected, maintained, and calibrated routinely.

Additional evidence supports the above conclusion. The wind vane tends to lock into one position, indicating only one wind direction for long periods of time. For example:

On December 6,1989, the wind vane at 10 meters above ground level became stuck in the 355-degree position, with only a few degrees variation, until April 18, 1990 when it shifted to zero degrees, with only a few minor variations (of a few degrees), until June. On June 12,1990 there is a record of a call to installation personnel to inform them that the 10meter reader was "non functional."

On Julian Day 139, (May 19), 1991, the 10-meter wind vane became stuck at 355 degrees again. This was not fixed until Julian day 255 (September 22).

Even in cases when the wind direction was not "frozen" in the "north" position, the wind instruments still seemed to be sluggish. For example, on March 5, 1992, the 10-meter wind vane became stuck again, this time at zero degrees. This appeared to have been fixed on April 14. A note in the hard-copy data for that date indicated that the new wind vane was "in place and functional." However, the wind vane still had a tendency to become stuck in one position. At the end of the day it was installed (April 14, or Julian day 105), the wind vane had been stuck at 355 degrees for 4 hours and remained at 355 degrees for the first 6 hours of the following day. For each of the next 3 days the wind vane was stuck in one position (without varying by as much as 1 degree) for at least 6 hours each day. On April 18-19, the wind vane was stuck at 16 degrees for 13 hours. Further tabulations of times when the wind vane at 10 meters was stuck in the same position (without varying as much as 1 degree) for at least 3 hours are given in Table I.1. Each day is summarized until Julian Day 120 (April 29), when it was arbitrarily decided (for the sake of brevity) to cover only every fifth day until Julian day 145 . This particular record ended on Julian day 149 . For that day, only the first 13 hours were given. The first 12 of these indicated a wind direction of 221 degrees. Thus, the wind vane at 10 meters above ground frequently appeared to become stuck in one position for several hours at a time during the first several weeks after a new vane was installed, suggesting the possibility of problems with instrument installation.

The same suspicious features of the 10-meter data also show up, although considerably reduced, in the 2-meter data. The wind roses for 1990 and 1991 (Fig. 1.2) show a tendency for the wind vane to become stuck at a position indicative of northerly winds. While a tendency for northerly flow would be expected at 2 meters, due to cold-air drainage flow at night, the tendency also shows up strongly during the daylight hours, being dominant for the $\mathrm{C}$ stability category which is predominantly a daytime category (Fig. I.3). Further, 
Table I.1 Summary of times the wind was recorded as being from precisely the same direction for three consecutive hours or more, immediately following replacement of the wind vane on April 15, 1992 (Julian day 105).

\begin{tabular}{|c|c|c|}
\hline $\begin{array}{c}\text { Julian } \\
\text { Date }\end{array}$ & $\begin{array}{l}\text { Indicated } \\
\text { wind direction } \\
\text { degrees }\end{array}$ & $\begin{array}{c}\text { Number of } \\
\text { consecutive } \\
\text { hours }\end{array}$ \\
\hline $105-106$ & 355 & 10 \\
\hline 106 & 171 & 4 \\
\hline $106-107$ & 165 & 8 \\
\hline 107 & 349 & 3 \\
\hline 107 & 259 & 3 \\
\hline 107 & 212 & 3 \\
\hline 108 & 110 & 4 \\
\hline 108 & 1 & 6 \\
\hline 109 & 31 & 7 \\
\hline $109-110$ & 16 & 13 \\
\hline $110-111$ & 51 & 14 \\
\hline 111 & 64 & 3 \\
\hline 111 & 98 & 3 \\
\hline $111-112$ & 168 & 5 \\
\hline $112-113$ & 204 & 16 \\
\hline 114 & 217 & 11 \\
\hline 114 & 29 & 3 \\
\hline 115 & 287 & 10 \\
\hline 115 & 274 & 3 \\
\hline $115-116$ & 232 & 4 \\
\hline 116 & 242 & 7 \\
\hline $116-118$ & 204 & 32 \\
\hline 118 & 245 & 3 \\
\hline $118-119$ & 198 & 5 \\
\hline 119 & 50 & 6 \\
\hline $119-120$ & 153 & 10 \\
\hline 120 & 260 & 6 \\
\hline 125 & 120 & 7 \\
\hline $125-126$ & 315 & 3 \\
\hline $130-131$ & 293 & 10 \\
\hline 135 & 166 & 5 \\
\hline 140 & 193 & 6 \\
\hline $140-141$ & 258 & 19 \\
\hline 145 & 121 & 5 \\
\hline 145 & 198 & 5 \\
\hline
\end{tabular}




\section{Wind Speed and Direction at Pueblo Army Depot} ( 2 meters above ground level)

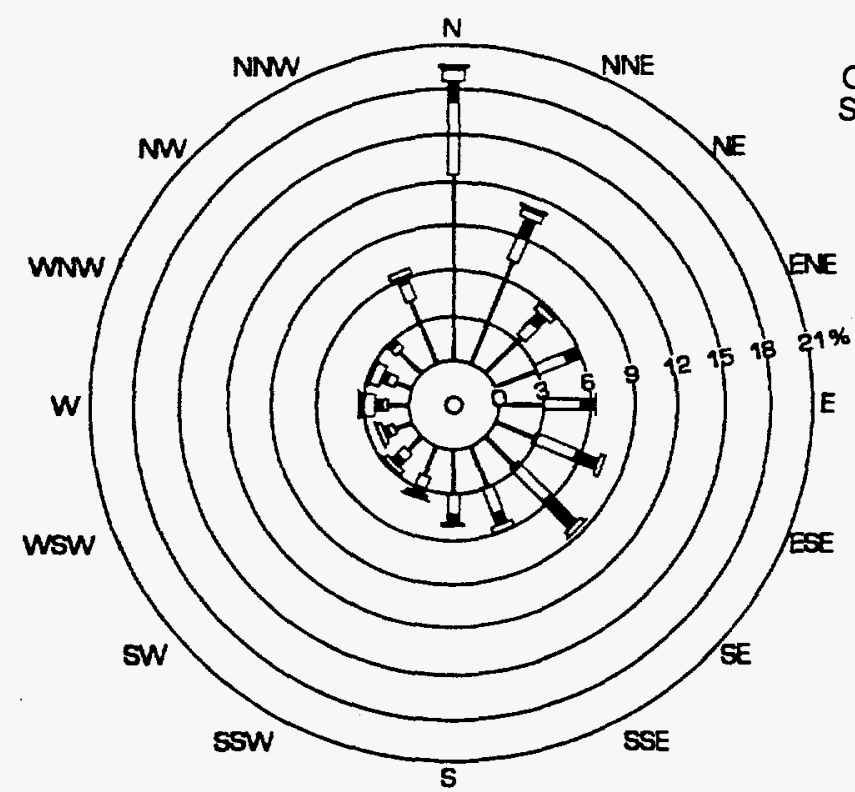

October 1989 to

September 1990

January 1991 to December 1991

Wind Speed $(\mathrm{m} / \mathrm{s})$

$\begin{array}{lllllll}0.0 & 2.1 & 3.6 & 5.7 & 8.7 & 10.8\end{array}$

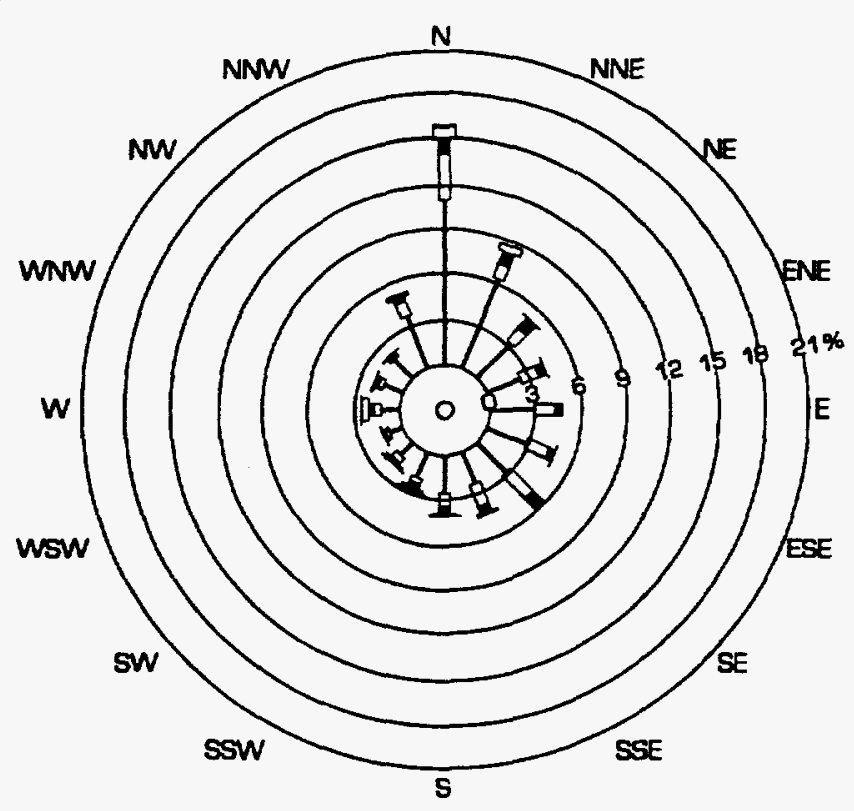

Fig. 1.2. Wind rose for PUDA at 2 meters above ground level, for the 12-month periods of October 1989 through September 1990 and January 1991 through December 1991. 
Wind Speed and Direction at Pueblo Army Depot (2 meters above ground level)

C Stability Only
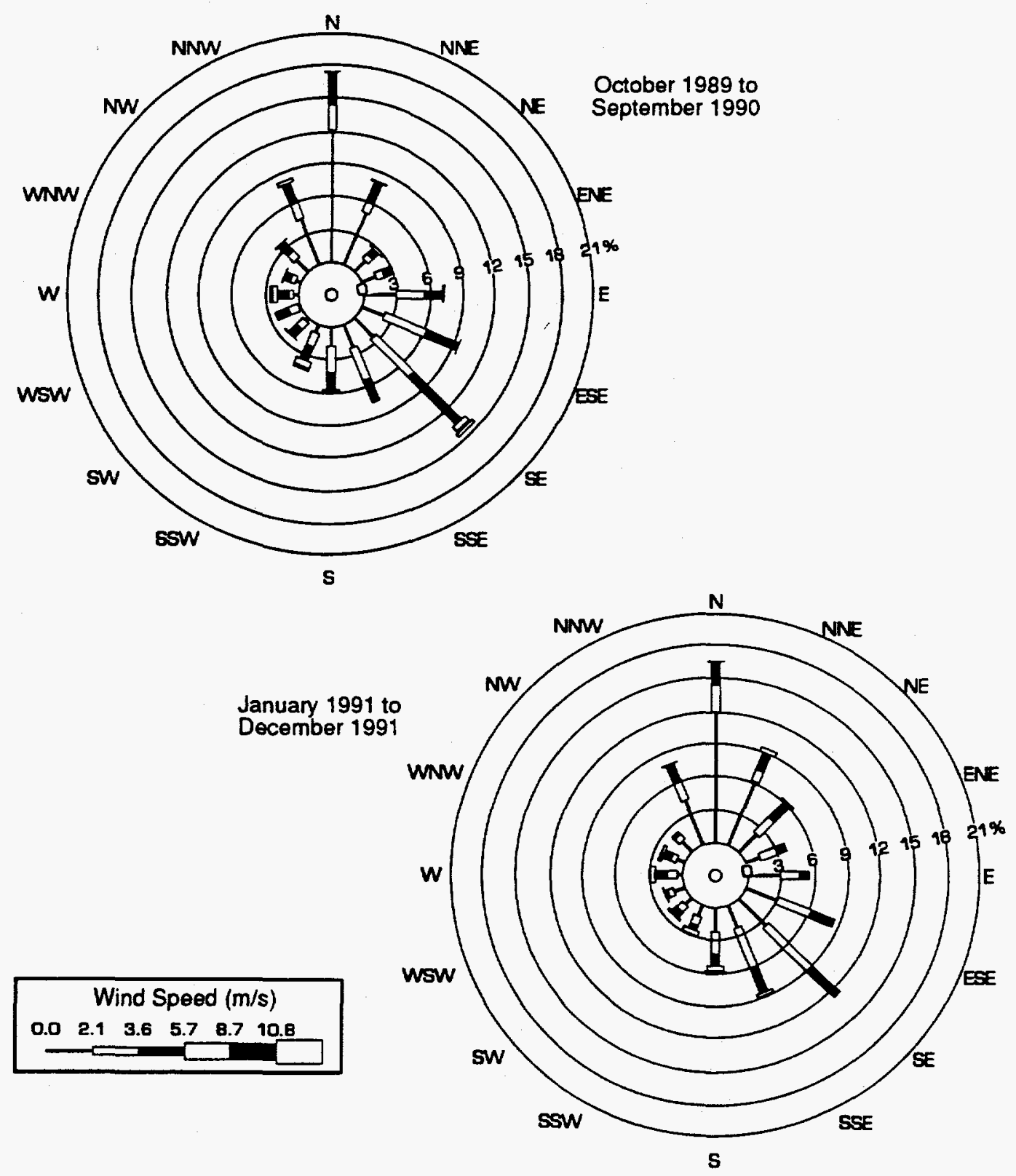

Fig. 1.3. C stability wind rose for PUDA. 


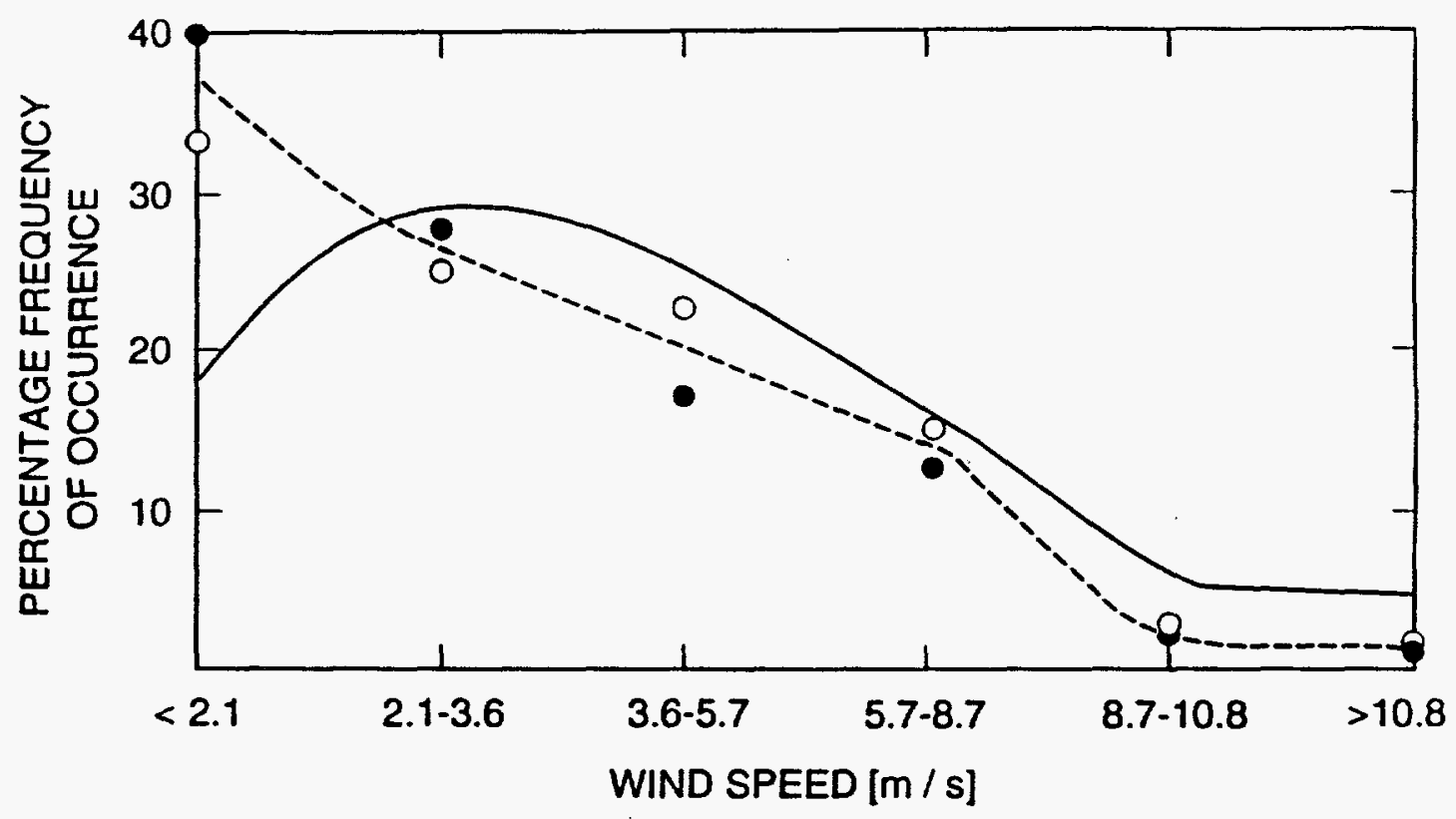

Fig. I.4. Distribution of wind speed obtained from the anemometer 2 meters above ground level at PUDA (dashed line) and the anemometer 6.7 meters above ground level at the Pueblo Memorial Airport (solid line). The open circles represent PUDA wind data from October 1989 through September 1990, the dark circles represent PUDA data from 1991, and the dashed line represents the two-year sample at PUDA. The PUDA wind speeds were adjusted to represent winds at 6.7 meters, for comparison with the airport data. 
the frequency distribution of wind speed at 2 meters (Fig. I.4) has the same shape as that of the 10 -meter distribution. ${ }^{2}$

A plot of average wind speed for each hour of the day for June - August at the Pueblo Memorial Airport is shown in Fig. 1.5 (solid line). The wind speed at the airport is greatest duringthe late afternoon, as would be expected. The wind speeds at PUDA for June August, 1991 - a period when the PUDA 10-meter wind vane was stuck in the $355^{\circ}$ position are also shown (dashed line). The winds at PUDA are slower than at the airport, which is not surprising, ${ }^{3}$ although the difference in wind speeds seems unusually large. However, the greatest wind speeds at PUDA are indicated at about 7:00 PM, about 2 hours later than at the airport. Also the curves seem to diverge about 7:00 AM and converge at about 7:00 PM. The arrows above the curves indicate the ratio of frequency of north winds to south winds at the airport during June - August. The greatest differences in the two curves occur when the wind is least likely to be from the north, as would be expected if the wind speeds were being measured by a propeller on a wind vane constantly pointing north. (A drawing of the instrument used at PUDA is shown in Fig. I.6.) The rapid convergence of the two curves at about the time the frequency of north winds tends to increase and the rapid divergence of the curves at about the time the frequency of north winds decreases is further evidence that the slower

wind speeds indicated at PUDA are at least partly due to the sluggishness of the wind vane, and a tendency for the wind vane to remain stuck in the "north" position.

As noted above, the wind vane tends to be sluggish even at times when it is not obviously stuck. Because deterioration is likely to be gradual, sluggishness would be expected to occur prior to periods when the wind vane became obviously stuck. No way of knowing when to believe the on-site data are accurate has been established. It might be surmised that the most likely times for accurate data would be immediately after a new wind vane was installed, but inspection of the data at such times (e.g., after a new wind vane was installed on April 14, 1992) clearly indicates the likelihood of serious error in making such an assumption about the on-site data at PUDA.

Stuck wind vanes and associated fictitiously slow wind speeds would lead to a fictitiously high frequency of $F$ stability for methods of stability calculation involving wind speed and/or standard deviation of the horizontal wind direction.

\footnotetext{
${ }^{2}$ Wind speeds were adjusted to 6.7 meters for comparison with airport data. This was done by taking the 2 meter wind speed, finding the appropriate exponential (using the given stability category) to calculate the increase in wind speed with height, and calculating the wind speed at $10 \mathrm{~m}$. Because the wind speed at 2 meters is often low enough that the stabilities estimated using wind speed are biased away from the categories associated with higher speeds (C and D), stabilities were then recalculated using estimated wind speed at $10 \mathrm{~m}$ and the time of day. The recalculated stability category was then used to determine the appropriate exponential for calculating the change in wind speed with height, and the original measured wind speed at 2 meters was then adjusted to 6.7 meters for comparison with airport data.
}

\footnotetext{
${ }^{3}$ Airports are located at flat terrain, where winds can build up speed. By contrast, the meteorological tower at PUDA is located in a relatively low area in very gently rolling terrain. Therefore, even though the exposure of the PUDA tower is good (no nearby buildings, terrain obstacles, etc.), the wind speeds at the airport would be expected to be about the same or somewhat higher than at the PUDA meteorological tower.
} 


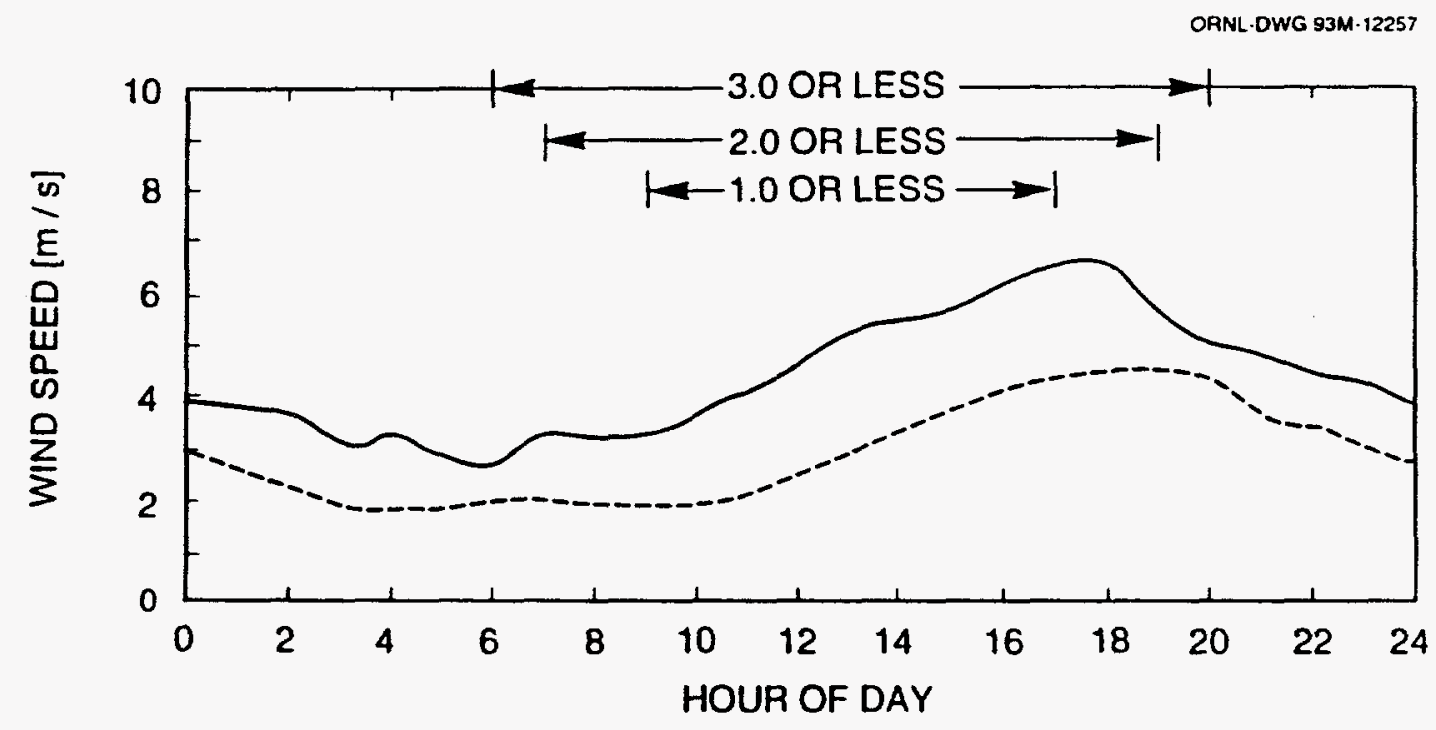

Fig. 1.5. Average wind speed for each hour of the day at Pueblo Memorial Airport (solid line) and at PUDA (dashed line). The wind speeds were taken from the 10-meter anemometer at PUDA and adjusted to represent winds at 6.7 meters, for comparison with the airport data. The arrows above the curves indicate portions of the day when the ratio of the frequency of north winds to the frequency of south winds (at the airport) is equal to or less than 3.0, 2.0. and 1.0. 


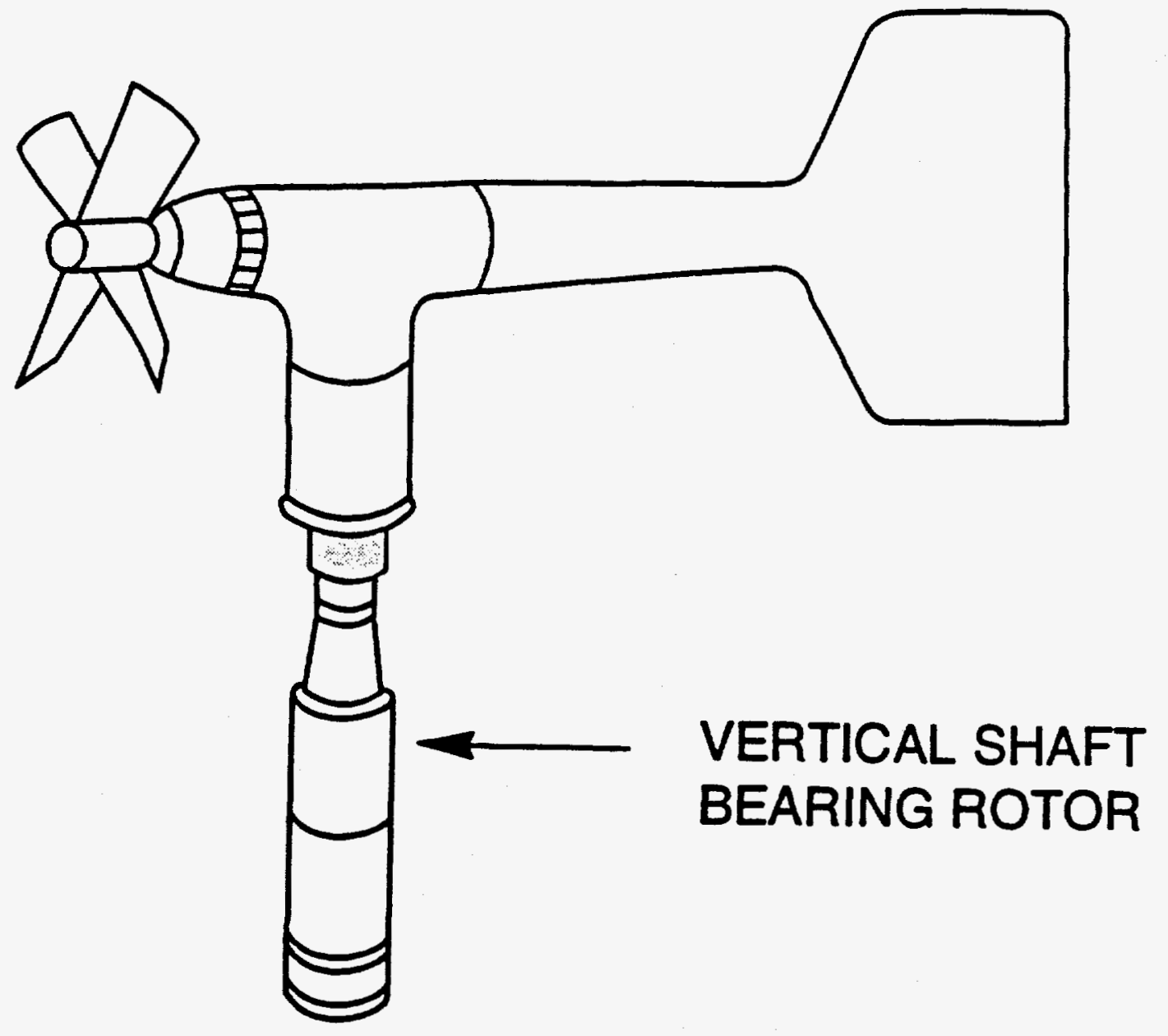

Fig. 1.6. Drawing of the anemometer mounted on the meteorological tower at Pueblo Depot Activity. 
All indications are that a lack of routine inspection and maintenance, and possibly improper installation of the instruments, have led to gross inaccuracies in the meteorological data from PUDA. The response of the instruments to changes in environmental conditions has often been sluggish or, in many cases, nonexistent. Therefore, the on-site data are not recommended for use in arriving at any statistical generalizations whatsoever, including estimates of probabilities of particular meteorological conditions, at PUDA. The worst-case and conservative-most-likely meteorological conditions are designated based on parameters that are spatially homogeneous; therefore the use of data from the Pueblo Memorial Airport, about $16 \mathrm{~km}$ (10 miles) away would be sufficient for use in determining such conditions at PUDA. In any case, meteorological conditions other than those deemed worst-case or conservative-most-likely (based on airport data) were also considered for risk assessment, as discussed in Section 6.2.4: Effect of Various Meteorological Conditions upon Measures of Risk.

\section{I.4 REFERENCE}

EPA (U.S. Environmental Protection Agency) 1987. On Site Meteorological Program Guidance for Regulatory Modeling Applications, EPA-450/4-87-013. U.S. Environmental Protection Agency, Office of Air Quality Planning and Standards, Research Triangle Park, NC. 


\section{INTERNAL DISTRIBUTION}

$\begin{array}{llll}\text { 1-5. } & \text { J. W. Terry } & 21 . & \text { R. M. Reed } \\ \text { 6-10. } & \text { G. P. Zimmerman } & 22 . & \text { S. M. Schexnayder } \\ \text { 11. } & \text { T. J. Blasing } & 23 . & \text { R. B. Shelton } \\ \text { 12. } & \text { S. A. Carnes } & 24 . & \text { J. T. Shor } \\ \text { 13. } & \text { G. E. Courville } & 25 . & \text { W. P. Staub } \\ \text { 14. } & \text { J. T. Ensminger } & 26 . & \text { R. K. Tallent } \\ \text { 15. } & \text { K. S. Gant } & 27 . & \text { V. R. Tolbert } \\ \text { 16. } & \text { F. M. Glenn } & 28 . & \text { ORNL Patent Office } \\ \text { 17. } & \text { C. W. Hagan, Jr. } & 29-30 . & \text { Central Research Library } \\ \text { 18. } & \text { R. O. Johnson } & 31 . & \text { Document Reference Section } \\ \text { 19. } & \text { D. A. Lombardi } & 32-33 . & \text { Laboratory Records } \\ \text { 20. } & \text { C. I. Moser } & 34 . & \text { Laboratory Records-RC }\end{array}$

\section{EXTERNAL DISTRIBUTION}

35. Dr. Thomas E. Drabek, Professor, Department of Sociology, University of Denver, Denver, Colorado 80208-0209

36. Dr. Stephen G. Hildebrand, Director, Environmental Sciences Division, Oak Ridge National Laboratory, Post Office Box 2008, Oak Ridge, Tennessee 37831-6037

37. Mr. George F. Sowers, P.E., Senior Vice President, Law Companies Group, Inc., 114 Townpark Drive, Suite 250, Kennesaw, Georgia 30144-5599

38. Dr. C. Michael Walton, Ernest H. Cockrell Centennial Chair in Engineering and Chairman, Department of Civil Engineering, University of Texas at Austin, Austin, Texas 78712-1076

39. Office of Assistant Manager for Energy, Research, and Development, DOE/OR, P. O. Box 2001, Oak Ridge, Tennessee 37831-8600

40. U.S. Department of the Army Chemical Demilitarization and Remediation Activity, ATTN: AMSCB-PAO (Marilyn Tischbin), Edgewood Area, Bldg. 4585, Aberdeen Proving Ground, Maryland 21010-5401

41. U.S. Department of the Army Chemical Demilitarization and Remediation Activity, ATTN: AMSCB-RAE-E (Kate Miller), Edgewood Area, Bldg. E4517, Aberdeen Proving Ground, Maryland 21010-5401 
42. U.S. Department of the Army Chemical Demilitarization and Remediation Activity, ATTN: AMSCB-RAE-E (MAJ Trent Moxley), Edgewood Area, Bldg. E4517, Aberdeen Proving Ground, Maryland 21010-5401

43-44. Office of Scientific and Technical Information (OSTI), U.S. Department of Energy, P. O. Box 62, Oak Ridge, Tennessee 37831 